Tesis Doctoral

\title{
PRÁCTICAS Y REPRESENTACIONES EN TORNO A LOS PROCESOS DE SALUD-ENFERMEDAD EN LA POBLACIÓN DE AZAMPAY
}

Autor: Georgina Strasser

Director: Dra. María Susana Ortale Co-director: Dra. Bernarda Zubrzycki

Facultad de Ciencias Naturales y Museo, Universidad Nacional de La Plata Año: 2011 
Esta tesis fue posible gracias al financiamiento otorgado por:

- Secretaría de Ciencia y Técnica de la Universidad Nacional de La Plata:

Beca de Iniciación durante el período 2005-2006, dirigida por la Dra. Marta Mercedes Maffia y co-dirigida por la Dra. María Susana Ortale

- Consejo Nacional de Investigaciones Científicas y Técnicas (CONICET):

Beca doctoral Tipo I durante el período 2006-2009, dirigida por la Dra. Susana A. Salceda y codirigida por la Dra. María Susana Ortale

Beca doctoral Tipo II durante el período 2009-2011, dirigida por la Dra. Carlota Sempé y co-dirigida por la Dra. María Susana Ortale. 
Agradecimientos:

A los azampeños, por el cariño con el que siempre me recibieron;

A Susana Ortale, Marta Maffia y Bernarda Zubrzycki, quienes guiaron mi trabajo;

A Gisel, Leticia, Natalia, Florencia, Alejandra, Gimena y Valeria por su apoyo y sostén. 
Dedicada a mis padres, Amal y Edgardo 


\section{Índice de contenido}

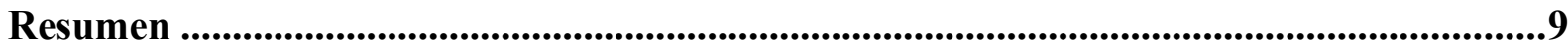

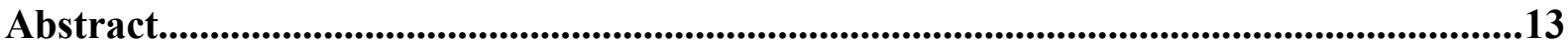

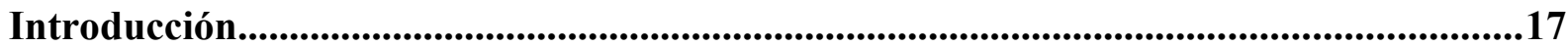

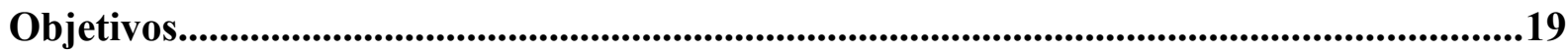

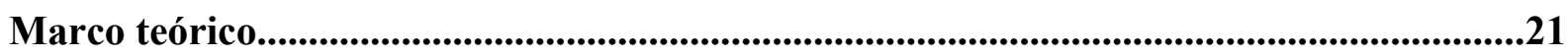

Breve reseña del desarrollo de la antropología médica.................................................21

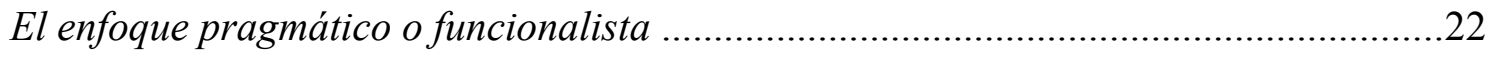

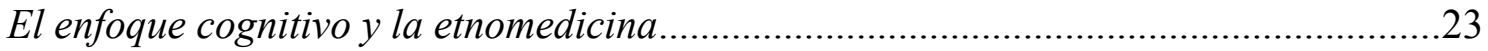

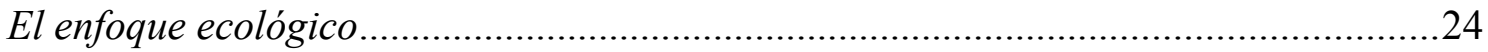

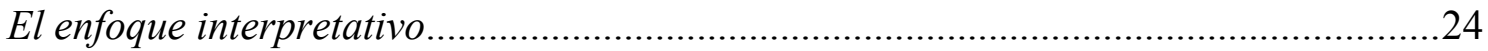

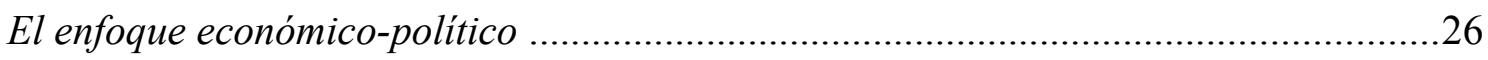

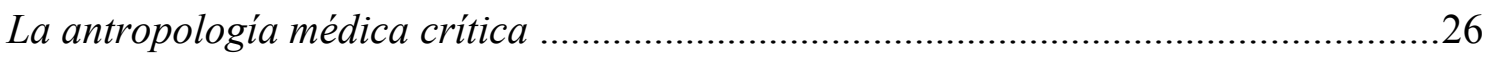

Acerca de las elecciones teóricas en función de los objetivos de la tesis..........................28

Los procesos de salud-enfermedad como construcción social, objeto de prácticas

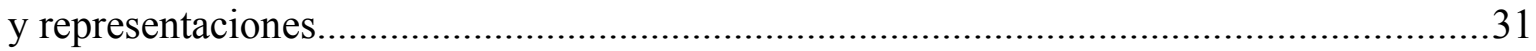

Las representaciones sociales en el cruce subjetividad-intersubjetividad-

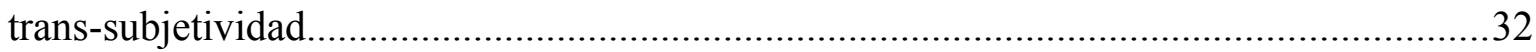

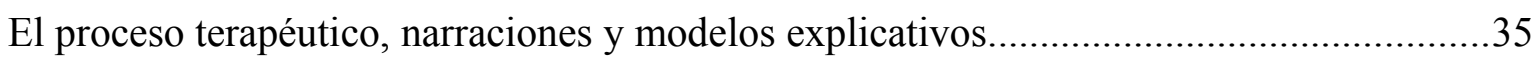

Aportes desde las Filosofías de la Existencia a la noción de experiencia ..........................37

El espectro de opciones de atención, la importancia de un enfoque relacional...................41

Navegando a través de un mar de elecciones terapéuticas .........................................45

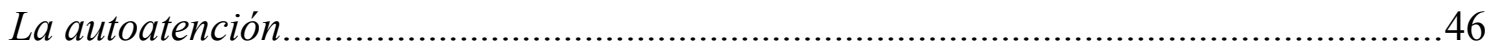

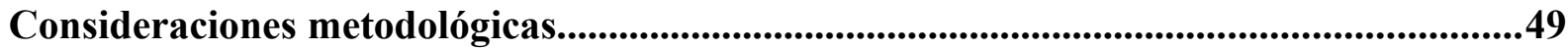

Reflexiones sobre la elección de técnicas para un abordaje cualitativo..............................49

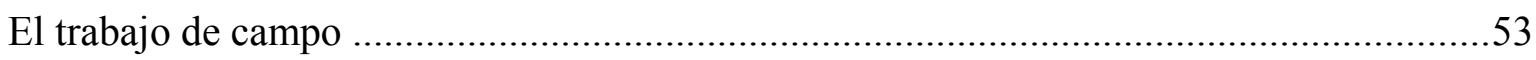

- ¿Cómo está?, - con el favor de dios y la mamá virgen, bien .......................................56

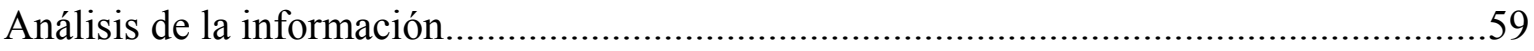

Caracterización geográfica y poblacional..................................................................................61

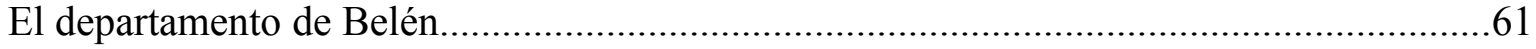

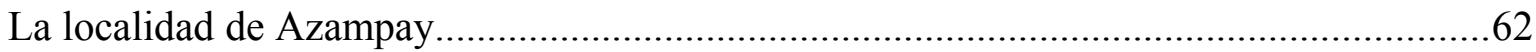

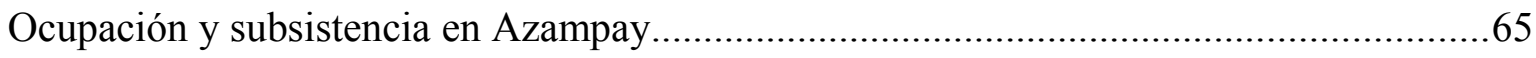


Descripción del sistema estatal de atención a la salud y del perfil epidemiológico de la

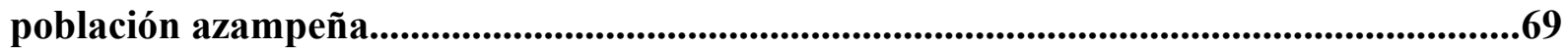

El sistema estatal de atención a la salud en la provincia de Catamarca............................69

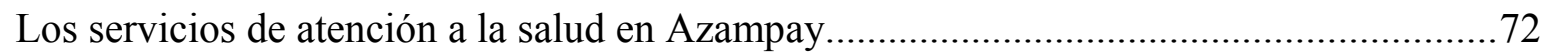

Caracterización del estado de salud de los azampeños................................................74

Las opciones terapéuticas mencionadas por los azampeños..............................................79

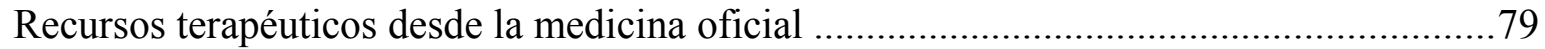

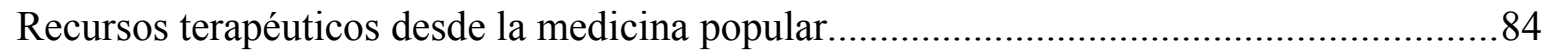

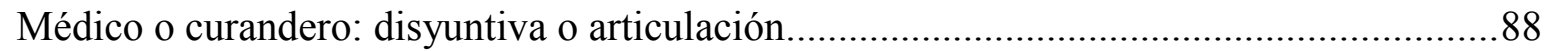

La autoatención: la medicina casera, ejercicio del cuidado y autocuidado........................93

El embarazo y parto: de la autoatención y la medicina tradicional a su medicalización.

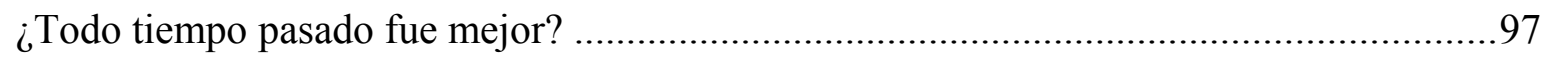

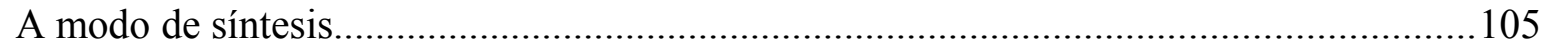

Padecimientos "para curanderos". Representaciones y prácticas en torno a taxa tradicionales. Aportes de estudios transregionales. Generalidades y singularidades del caso azampeño.

"El susto, la ojeadura, el aire, tantos males que hay, a veces no son males para los

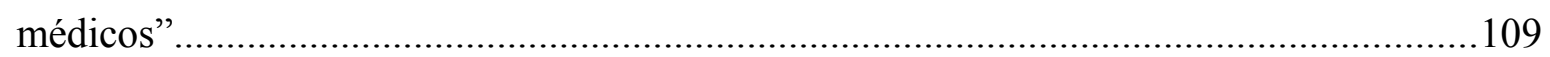

El aire como enfermedad o causa última de ciertos padecimientos...............................123

Los procedimientos terapéuticos para los casos de aire....................................................125

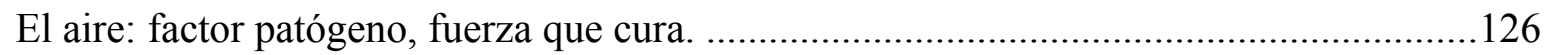

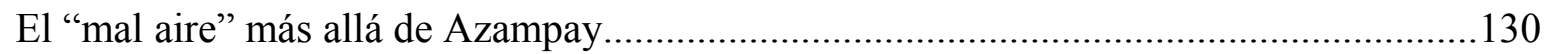

Discusión en torno a viejas dicotomías a partir de la noción de aire. Enfermedades naturales vs enfermedades sobrenaturales: etiologías empíricas vs etiologías místicas, terapéuticas empíricas vs terapéuticas mágicas...........................................................131

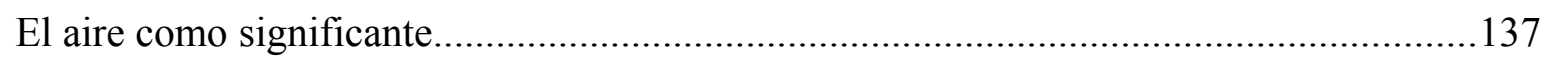

Etiologías, factores patógenos; terapéuticas, elementos de sanación..................................141

La identificación de las causas en el proceso de atribución de sentido a las experiencias de

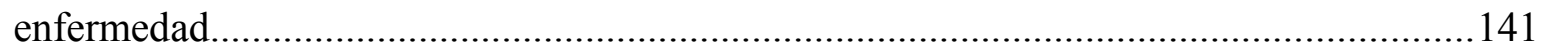

Las experiencias de enfermedades crónicas como "lugares de memoria"..................143

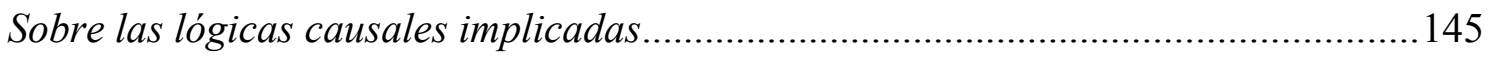

El medioambiente como responsable de padecimientos..............................................146

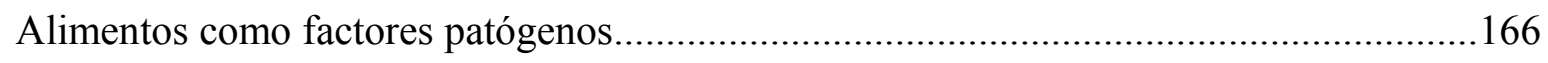

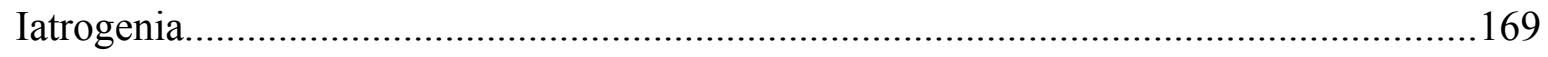


El trabajo.

Etiología psicosocial.

Transmisión de enfermedades.

“Lo que está en juego" en torno a las etiologías. Factores patógenos y vulnerabilidad corporal

Las representaciones del cuerpo a partir de las explicaciones y sentidos atribuidos a los procesos de salud-enfermedad.

La experiencia de malestar: acicate de la enunciación indirecta del cuerpo propio y de su objetivación

"Ser-para-sí": el "dolor vivido" 190

El sufrimiento como resistencia al "ser-en-el-mundo" 193

El valor de la metáfora para una etnografía de la experiencia 196

"Ser-para-otro": "el mal padecido". 205

"Ser-para-sí-como-para-otro": "la enfermedad". 207

El lenguaje como objetivación y comunicación de la experiencia de enfermedad.

La eficacia terapéutica.

Una conceptualización fluida de eficacia: entre las expectativas y los cambios percibidos

Sobre la eficacia de las terapéuticas biomédicas..

Sobre la eficacia de las terapéuticas tradicionales.

Sobre la eficacia de las terapéuticas caseras.

La eficacia simbólica desde distintas perspectivas teóricas. La especificidad de la cura religiosa.

“... con la gracia de dios...”.

Fe en la eficacia y la eficacia de la fe. 261

Evaluaciones y apreciaciones sobre los terapeutas y su relación con el paciente

“... era un doctor que tiene voluntad, el doctor tiene que ser como nosotros, conversador, éste es un respingón, dice 'andate nomás'...”. 265

“... es muy buena curanderita...". .270

El discurso médico moralizante .272

Apreciaciones sobre las relaciones sociales y connotaciones morales en torno a los procesos de salud-enfermedad-atención. 275

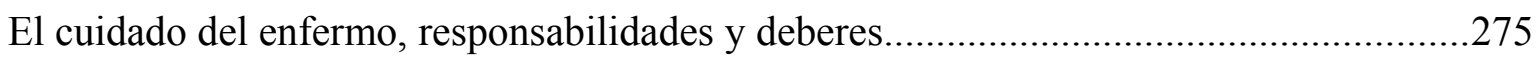

El autocuidado como "deber ser", los usos moralizadores del relato 280 
El relato de trayectorias terapéuticas como impugnación de prácticas y

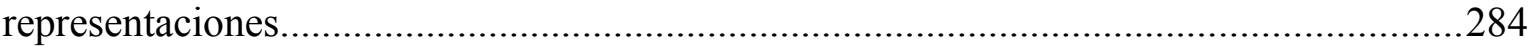

Aspectos enfermantes de las relaciones sociales...........................................................28

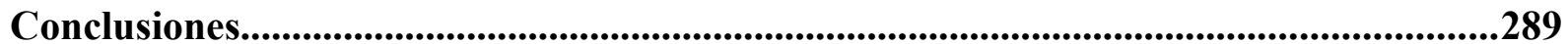

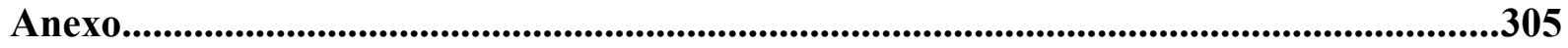

Bibliografía …...........................................................................................................................315 


\section{Resumen}

El objetivo de la tesis consiste en identificar y analizar las representaciones y prácticas vinculadas a las enfermedades predominantes en la localidad de Azampay: su denominación, clasificación y explicación causal, estrategias y recursos utilizados en el diagnóstico, prevención y atención. Se focaliza en la perspectiva de la población adulta lega pero integrándose los discursos de trabajadores de los distintos espacios de atención utilizados por los azampeños: curadores informales, enfermeros y médicos.

La localidad de Azampay se encuentra ubicada al pie de los cerros que limitan por el occidente al Valle de Hualfín, en el oeste de la provincia de Catamarca, a $50 \mathrm{~km}$ de la ciudad de Belén, a la que la une un camino de acceso medianamente transitable desde la ruta provincial No40. Desde 1995 un equipo multidisciplinario viene desarrollando sus investigaciones en dicha localidad, abordando el estudio integral de la problemática bio-sociocultural de las comunidades actuales y arqueológicas con el objetivo de caracterizar procesos de largo plazo. El tamaño reducido de la población actual (un total de 250 habitantes incluyendo los puestos vecinos Chistín y La Agüita) y su localización fuera de las principales rutas de comunicación posibilitó realizar estudios sobre población total, minimizando el sesgo potencial de un muestreo, habiéndose trabajado con profundidad analítica temas relevantes tales como ocupación, migración, organización familiar, parentesco, propiedad de la tierra y el agua, crecimiento, desarrollo y estado nutricional de la población infantil. El presente trabajo se vio motivado por la necesidad planteada por dicho equipo de incorporar el estudio concerniente a los procesos de salud-enfermedad, problemática central en la vida cotidiana, contribuyendo al conocimiento integral de la población de Azampay.

La información fue construida a partir de entrevistas y charlas casuales compartidas con los habitantes de Azampay (incluidos Chistín y La Agüita), observaciones y notas de campo durante sucesivos trabajos de campo (2004, 2005, 2006, 2007 y 2009), junto a la obtenida en anteriores trabajos del equipo (lo que facilitó una caracterización general de la población) y al aporte de reflexiones teóricas desarrolladas desde la Antropología Médica, la Sociología Médica, los enfoques Fenomenológico y Hermenéutico y las Metodologías Cualitativas. La técnica de relevamiento central fue la entrevista, mínimamente estructurada a partir de un guión temático, en la etapa de apertura se recurrió a preguntas descriptivas a los 
fines de elaborar un marco de términos y referencias, en la etapa de focalización y profundización se introdujo el uso de preguntas contrastativas y estructurales. La observación participante permitió tener en cuenta la dinámica de las relaciones construidas entre entrevistador y entrevistado y las prácticas, los gestos y el habla informal sobre lo cotidiano. El cuerpo de información (un total de 80 entrevistas) una vez transcripto fue codificado utilizando el software ATLAS.ti.

Desde la caracterización de los médicos y enfermera entrevistados, las enfermedades frecuentes en la población de Azampay son las respiratorias (angina, bronquitis, neumonía), artrosis, hipertensión, problemas digestivos y parasitosis, diferenciándose de los pacientes de la ciudad no por el tipo de problemas de salud sino porque llegan a los centros de atención con grados más avanzados de la enfermedad y porque, especialmente los niños, presentan peores condiciones en su estado nutricional.

Se relevaron los malestares predominantes mencionados por los azampeños (padecidos personalmente o por conocidos, tanto en la actualidad como en tiempos pasados), relacionándolos con las explicaciones causales y con los síntomas a partir de los cuales se los identifica y se realiza el diagnóstico; se describen y analizan las respuestas terapéuticas y las estrategias de diagnóstico y prevención frente a cada enfermedad identificando los distintos recursos o servicios disponibles y los factores que influyen en la elección y el acceso a los mismos. En Azampay se observa un uso combinado de los diferentes espacios de atención para la salud: el ámbito doméstico con sus respuestas caseras, la atención de curanderos dentro o fuera de la localidad, los servicios médicos locales (la localidad cuenta con una Posta Sanitaria donde atienden dos enfermeros y periódicamente el médico de zona) y los de las ciudades de Belén y Catamarca (públicos o privados). La elección del servicio de atención, si bien se ve influida por los factores materiales que configuran su accesibilidad (distancias, posibilidades de traslado, costo monetario, obstáculos burocráticos), depende también de cómo es identificada la enfermedad (su causalidad, las formas de enfrentarla aprendidas en anteriores experiencias personales o transmitidas por otros individuos) y de cómo se evalúe el accionar y competencia de los distintos curadores y la eficacia de sus terapéuticas.

En el nivel de la autoatención predominan las referencias al uso de hierbas pero también se menciona el consumo de medicamentos patentados (generalmente analgésicos de venta libre) para hacer frente a eventos de gripe, resfrío, fiebre, tos, dolores musculares, de huesos y articulaciones, problemas digestivos, de los riñones, presión alta, ojeadura, aire, abertura de pecho. En algunos casos se reconoce el carácter paliativo de estas respuestas junto con la necesidad de recurrir a un curador en cuanto sea posible, en otros casos es esta 
movilización la que se pretende evitar mediante soluciones momentáneas. Sin embargo, la mayoría de los casos de atención doméstica se realizan a partir del reconocimiento de poder manejar por los propios medios una situación de malestar ya conocida y de menor gravedad o de la resignación ante un padecimiento que no tiene cura. Frente a padecimientos considerados resultantes de las condiciones de trabajo, de la edad y de características ambientales (como el frío y la altitud), generalmente asociados a un desgaste corporal (reuma, dolor de huesos pero también alergias, hipertensión), los azampeños recurren tanto a la atención biomédica como a la de curanderos. Ambos recursos terapéuticos se utilizan también para tratar dolores originados en golpes o accidentes y ante malestares asociados a nervios y a problemas mentales. Por otra parte, problemas de la vista, de apéndice y vesícula, cardíacos, enfermedades respiratorias (neumonía, bronquitis, asma, tuberculosis), hepatitis, sarampión, epilepsia, se consideran casos que deben ser tratados por médicos. El término "infección" denota una enfermedad como de incumbencia médica (caries por infección, infección urinaria) y va asociado al de "antibiótico" como recurso necesario para la cura. Mientras que abertura de pecho, aire, pata de cabra, susto, culebrilla, ojeadura son competencia exclusiva de los curanderos. En estos casos se explicita una distinción entre enfermedades "para el médico" y enfermedades "para el curandero", una delimitación del ámbito de competencia de ambos trabajadores de la salud, y el pasaje de la atención de uno a otro implica la redefinición del diagnóstico. Se destaca la circularidad de la relación entre diagnóstico y tratamiento: a partir de un diagnóstico se define el accionar orientado a revertir la situación de malestar identificada y desde los resultados percibidos durante el tratamiento el diagnóstico inicial se confirma, se ajusta o se descarta por completo prosiguiendo la búsqueda por las diferentes ofertas de atención, búsqueda dirigida no sólo a un cambio de terapéutica sino también a una redefinición del diagnóstico que conlleve a un tratamiento más eficaz.

La identificación de los factores a partir de los cuales se elaboran los por qué y cómo de una enfermedad es un aspecto central dado el peso que tiene la búsqueda de eventos causales en las historias de salud, así como la variedad y complejidad de los factores que son evocados en las etiologías connotando aspectos del mundo con una carga valorativa en función de su carácter patogénico o sanador. Identificar y analizar los elementos que son considerados enfermantes conllevó al análisis de la imagen corporal implicada en la relación con el medio del cual dichos elementos provienen.

La explicitación de etiologías psicosociales para síntomas corporales, la vivencia del padecimiento afectando el "cuerpo propio" en el que no se puede escindir la carne del espíritu, categorías de enfermedad que exponen un vínculo entre el orden natural y psicosocial 
y el malestar físico, las terapéuticas que apelan en mayor grado a recursos simbólicos, todo ello exige romper con nociones de persona y cuerpo que desde un realismo ingenuo sostienen en el plano fenomenológico la artificialidad analítica de los niveles socio-cultural, psíquico y somático. Se consideran las objeciones que desde la Antropología Médica Crítica se han hecho a la aplicación de categorías que reproducen dicotomías arraigadas en la visión occidental, positivista y/o biomédica y que no reflejan las rupturas y continuidades conceptuales nativas. Desde la perspectiva de las filosofías de la existencia se entiende la experiencia como instancia preobjetiva (pero no precultural), resultado de la interacción de categorías culturales y estructuras sociales con los procesos psicológicos y físiológicos.

El acceso a las representaciones a través de las narrativas con las que el individuo comparte y objetiviza sus experiencias de enfermedad requirió reflexionar sobre los recursos lingüísticos de los que se valen los azampeños para narrar sus eventos de malestar, explorando la relación entre lenguaje y experiencia. Los individuos manejan un cuerpo de nociones para identificar sus malestares que se nutre desde distintos conjuntos de saberes: el de la ciencia médica, el de las medicinas tradicionales, y uno mucho menos delimitado conformado por información de experiencias, situaciones, vivencias que se van transmitiendo y a partir de las cuales el individuo compara, completa, o cuestiona lo que el médico o curandero le dice.

El tema de la eficacia terapéutica es abordado desde la perspectiva de los individuos que buscan solucionar y entender sus padecimientos: en qué fundamentan sus conclusiones de eficacia o fracaso, cómo se explican la eficacia, a qué cualidades o elementos la atribuyen, lo cual, frecuentemente está entretejido con los elementos identificados como patogénicos, sobre todo cuando explicitan una relación clara entre la causa del malestar y el accionar de la terapéutica correspondiente. Un apartado especial se dedica al componente religioso de las terapéuticas de los curanderos. Se analizan los aportes y limitaciones de distintos enfoques teóricos para indagar cómo trabaja la cura religiosa, y en qué consiste su eficacia terapéutica.

Se analizan las evaluaciones y apreciaciones sobre los terapeutas y su relación con el paciente dado que los individuos entrelazan con las valoraciones sobre su labor comentarios sobre el trato personal que mantienen con ellos, siendo la inclinación afectiva un factor que influye en la decisión de recurrir a sus servicios.

Finalmente se considera cómo las narrativas en torno a padecimientos dan lugar a aseveraciones morales sobre el cuidado personal e interpersonal, a la expresión de juicios sobre las relaciones sociales que contextualizan y en algunos casos explican los eventos de enfermedad y cura. 


\section{Abstract}

The objective of this thesis consists in identifying and analyzing the practices and representations linked to the predominant sicknesses among the Azampay population: their denominations, classifications and causal explanations, strategies and resources employed by diagnosis, prevention and treatment. The focus of attention is on the perspective of the lay adult population, but by integrating the discourses of workers from different healthcare sources employed by Azampay people: medicine men/women, nurses and physicians.

Azampay is located in the West of the province of Catamarca, at the foot of the mountain by which the valley of Hualfín is bounded to the West. A passable way links this town to the provincial route 40 that leads to Belen city, $50 \mathrm{~km}$ away from Azampay. Since 1995 a multidisciplinary group has been carrying out research there, dealing with an integral study of the bio-socio-cultural problematic in both present and archaeological communities, with the purpose of characterizing long-term processes. The reduced size of the present population (250 inhabitants including the neighbor hamlets of Chistín and La Agüita) and its location outside the main communication routes has allowed to make research among the total population reducing the potential slant of sampling and working by analyzing in depth important issues such as employment, migration, family organization, kinship, ownership of land and water, growth, development and nutritional state of the infant population. The subject of this thesis was motivated by the necessity viewed by this research team of incorporating the study concerning health-sickness processes, a pivotal aspect in everyday life, and in so doing contribute to the integral study of the Azampay population.

The information was obtained through interviews, observations and spontaneous conversations shared with the inhabitants of Azampay (included Chistín and La Agüita) while successive fieldworks (2004, 2005, 2006, 2007 and 2009), together with that previously obtained by the research team, which provided a general characterization of the population, and with the contribution of theoretical reflections developed in the areas of Medical Anthropology, Medical Sociology, from the Phenomenological and Hermeneutic approaches and in Qualitative Methodology. The core technique of data gathering was the interview, only structured with a thematic outline. At the stage of opening, descriptive questions were used in order to develop a frame of terms and references, at the stage of focusing and deepening, 
contrastive and structural questions were introduced. Participant observation enabled to consider the dynamic of the relationships built between interviewer and interviewee as well as the practices, gestures and the informal speech about everyday life. The corpus of information (a total of 80 interviews) has been transcribed using the software ATLAS.ti.

From the characterization made by the interviewed doctors and nurse, the prevalent diseases among the Azampay population are respiratory diseases (angina, bronchitis, pneumonia), arthritis, hypertension, digestive problems and parasites, differing from city patients not because of the sort of health problems, but because they come to the healthcare centers with higher degrees of disease severity and because they have a worse nutritional status, especially children.

The predominant sicknesses recognized by Azampay people (personally or by acquaintances suffered illnesses, both nowadays and in the past) were surveyed and related to the causal explanations and the symptoms by which they are identified and diagnosis is made; therapeutic responses and strategies of diagnosis and prevention in the face of each sickness were described and analyzed and in so doing available healthcare resources or services were identified as well as the factors that have an influence on their choice and the access to them. In Azampay different sources of healthcare are used together: the household sphere with its homemade responses, the attention of medicine men/women within or outside the town, local medical services (the village has a primary healthcare center where two nurses provide care and that is periodically attended by a traveling doctor) and public or private medical services in the cities of Belén and Catamarca. The choice of the source of healthcare, although influenced by material factors which shape its accessibility (distances, means of transport, financial cost, bureaucratic obstacles), depends principally on the way the sickness is identified (its etiology, the ways to confront it learned from previous own or other's experiences) and the way the work and ability of the different healers and the efficacy of their therapeutics are assessed.

At the level of self care, references to the use of herbs are predominant but also the intake of registered medicines is mentioned (generally analgesics which are not on prescription) to deal with flu events, colds, fever, cough, muscle, bone and joint aches, digestive problems, kidney disease, hypertension, “ojeadura" (evil eye), “aire”, "abertura de pecho". Sometimes the palliative character of homemade responses is recognized besides the need to turn to a healer as soon as possible, other times it is to avoid this mobilization what is sought by using temporary solutions. Nonetheless, the majority of the cases of household healthcare are based on the acknowledgment that some already known and less serious 
sickness episodes are able to be treated by people's own means or on the resignation to an incurable illness. In the face of illnesses caused by working conditions, age or environmental characteristics (such as cold and altitude), generally associated with body wasting (rheumatism, bone pain but also allergies and hypertension), the Azampay people make use of biomedical services as well as medicine men/women's attention. Both therapeutic resources are also used to treat pain caused by knocks or accidents and illnesses related to nerves and mental problems. On the other hand, vision problems, appendicitis, gallbladder dysfunction, heart or respiratory disease (pneumonia, bronchitis, asthma, tuberculosis), hepatitis, measles, epilepsy, are considered cases which must be treated by doctors. The term "infection" denotes a disease as medical concern (caries caused by infection, urinary tract infection) and is associated to the notion of "antibiotic" as the necessary resource for its cure. Whereas "abertura de pecho" (“opening of the chest"), "aire" ("air"), "pata de cabra", "susto" (“fright"), “culebrilla" (“shingles"), "ojeadura" (“evil eye") are the exclusive competence of medicine men/women. In those cases a distinction between diseases "for the doctor" and diseases "for medicine men/women" is explicitly stated, a limitation of the sphere of competence of both healthcare workers, and the change from medical care to a medicine man/woman or vice versa involves a redefinition of the diagnosis. The circularity of the relationship between diagnosis and treatment stands out: actions aimed at reversing a state of illness are elaborated from a diagnosis and from the results perceived during the treatment the initial diagnosis is confirmed, readjusted or completely rejected, in which case the search through different healthcare sources continues, not just a search for a change of the therapy but also for a redefinition of the diagnosis that could lead to a more effective treatment.

The identification of the factors considered by the development of the why and how about an illness is a core issue given the importance of the search for causal events in medical histories, as well as the variety and complexity of the factors that are evoked into the etiologies and that imply a value-laden view of the world depending on their pathogenic or healing character. The identification and analysis of the elements which are considered pathogenic lead to the examination of what is the body image entailed in the relationship with the environment from which these elements came.

The fact that psychosocial etiologies are attributed to embodied symptoms, the experience of illness affecting the body as his own, where it is impossible to separate flesh from spirit, some categories of sickness that show a link between the natural and psychosocial order and the embodied discomfort, therapeutics appealing to a large degree to symbolic resources, all that calls for breaking away from notions of person and body that, from a 
standpoint of naive realism, maintain the analytical artificiality of the sociocultural, psychic and somatic levels on the phenomenological one. It is taken into account the objection made by the Critical Medical Anthropology to the application of categories that reproduce dichotomies rooted in Western, positivist and/or biomedical thinking and which do not mirror the native conceptual ruptures and continuities. It is also considered the perspective of the Philosophy of Existence that regards experience as the pre-objective (but not pre-cultural) stage resulting from the interaction of cultural categories and social structures with psychological and physiological processes.

To access to the representations through the narratives by means of which people share and objectify their experiences of illness, it was necessary to reflect about the linguistic resources that Azampay people use to tell their events of sickness, analyzing the relationship between language and experience. People handle a corpus of notions to identify their ailments that draws on different sets of knowledge: that of medical science, that of traditional medicines, and a much less defined one constituted by information about experiences, undergone situations that are transmitted and with which they compare, complete, or call into question what the doctor or medicine man tells them.

The issue of therapeutic efficacy is tackled from the point of view of the subjects who are trying to solve and understand their illnesses: what do they ground on their conclusions of efficacy or failure, how do they explain efficacy, on which qualities or components do they confer it, which is frequently interwoven with the factors identified as pathogenic, above all when they explicitly assert a clear relation between the etiology of the disease and the corresponding therapeutic. A special section is devoted to the religious component of the therapeutic of medicine men/women. Contributions and limitations of different theoretical approaches to inquire into how religious healing works and in what consist its efficacy, are analyzed.

Evaluations and assessments of therapists and their relationship with patients are analyzed, given that the individuals intertwine the appraisals of their work with comments about the personal way they are treated by them, being the emotional inclination an influencing factor on the decision to use medical services.

Finally, it was important to consider how narratives about illnesses give rise to moral claims about self care and caregiving, to the expression of judgments about social relations that contextualize and in some cases explain the events of illness and healing. 


\section{Introducción}

Desde 1995 un equipo multidisciplinario viene desarrollando sus investigaciones en la localidad de Azampay y sus alrededores (Chistín, La Agüita y El Carrizal), abordando el estudio integral de la problemática bio-socio-cultural de las comunidades actuales y arqueológicas con el objetivo de caracterizar procesos de largo plazo. La elección de la localidad de Azampay se realizó en función de:

1) Su claro rol estratégico a nivel arqueológico, como proveedor de alimentos durante el Período de Desarrollos Regionales: Azampay constituye actualmente una localidad del valle de Hualfín asentada sobre un sitio arqueológico que cuenta con obras agrícolas y de regadío a gran escala.

2) El tamaño reducido de la población actual (alrededor de 250 individuos) y su localización fuera de las rutas de comunicación habituales, lo que posibilita realizar estudios sobre población total trabajando con mayor profundidad analítica y minimizando el sesgo potencial de un muestreo.

En el marco del proyecto conjunto "Estudio Antropológico Integral del valle de Hualfin (Catamarca)"1 y desde el área de antropología sociocultural se realizaron estudios en torno a temas como ocupación, migración, organización familiar, parentesco, propiedad de la tierra y el agua, enfermedad de chagas y con la incorporación de odontólogos se indagó la presencia de enfermedades periodontales y su asociación con variables culturales. Desde el enfoque antropobiológico se focalizó en el crecimiento, desarrollo y nutrición de la población infanto-adolescente ${ }^{2}$. Siendo la salud y la enfermedad problemáticas centrales de la vida cotidiana se planteó la necesidad de incorporar su estudio a los fines de lograr un conocimiento integral de la vida en Azampay.

\footnotetext{
${ }^{1}$ Dirigido por la Dra. Carlota Sempé en el área arqueológica, la Dra. Susana Salceda en el área biológica y la Dra. Marta Maffia en el área sociocultural. Acreditado por la UNLP en el marco del Programa de Incentivos del Ministerio de Educación y Tecnología de la Nación, Código 11/N365 y posteriormente Código 11/N499.

${ }^{2}$ Los resultados de estos trabajos han sido compilados en el libro "Azampay. presente y pasado de un pueblito catamarqueño" (Sempé et al., 2005).
} 


\section{Objetivos}

El objetivo general del presente trabajo de tesis consistió en identificar y analizar las representaciones y prácticas vinculadas a las enfermedades predominantes en la localidad de Azampay: su denominación, clasificación y explicación causal, estrategias y recursos terapéuticos utilizados en el diagnóstico, prevención y atención. En función del mismo se plantearon los siguientes objetivos específicos:

- Realizar un relevamiento de las enfermedades predominantes reconocidas por diversos actores (curadores ${ }^{3}$ y legos) y relacionarlas con las explicaciones causales y con los síntomas a partir de los cuales se las identifica y diagnostica;

- Identificar, describir y analizar los modelos de atención y los factores que determinan la elección y el acceso a los distintos recursos o servicios disponibles (tales como características de la enfermedad, convicciones y creencias, aspectos económicos, de transporte, etc.);

- Identificar, describir y analizar las respuestas terapéuticas frente a cada enfermedad desde los distintos modelos de atención.

Los mismos fueron desarrollándose a partir de la información obtenida mediante entrevistas, observaciones y diálogos casuales compartidos con habitantes de Azampay (incluidos Chistín y La Agüita) durante sucesivos trabajos de campo (2004, 2005, 2006, 2007 y 2009), junto a la información resultante de anteriores trabajos del equipo (lo que facilitó una caracterización general de la población) y al aporte de reflexiones teóricas desarrolladas desde la Antropología Médica, la Sociología Médica, los enfoques Fenomenológico y Hermenéutico y las Metodologías Cualitativas. Siendo la investigación un proceso recursivo, la retroalimentación constante entre trabajo de campo y análisis de datos posibilitó la dinámica entre planteos iniciales e hipótesis emergentes, enriquecida y orientada por la lectura crítica de las teorías relacionadas al tema.

\footnotetext{
${ }^{3}$ El término "curador", sin adjetivaciones que lo particularicen, es empleado para referir a la categoría general de personas que prestan servicios de atención a la salud, sean biomédicos, enfermeros o curanderos, en tanto actividad laboral (se excluyen a quienes realizan cuidados desde el ámbito de la autoatención).
} 


\section{Marco teórico}

\section{Breve reseña del desarrollo de la antropología médica}

La antropología médica es una especialidad relativamente nueva dentro de la antropología, dedicada al estudio de los procesos de salud, enfermedad y atención integrando aspectos culturales, sociales, políticos, económicos y biológicos, atendiendo a la amplia diversidad de sociedades humanas. Pioneros en la sistematización de prácticas y creencias médicas "primitivas" fueron los trabajos de W. H. R. Rivers (Medicine, Magic and Religion, 1924), F. E. Clements (Primitive Concepts of Disease, 1932), Evans-Pritchard (Witchcraft, Oracles and Magic Among the Azande, 1937), E. H. Ackernecht (Primitive Surgery, 1946) y Malinowski (Magic, Science, and Religion, 1948), destacables en un período de la disciplina en que los temas de salud-enfermedad tenían un lugar apenas marginal. Su posterior desarrollo se vio influido por diversas orientaciones dentro de la disciplina: desde el área biológica, por su atención a los procesos de evolución y adaptación humana; desde la etnografía, por su interés en sistemas médicos no occidentales (las llamadas etnomedicinas) y en estudios transculturales de psiquiatría (desde el énfasis dado por la escuela de Cultura y Personalidad); así como también por la participación de la antropología en programas internacionales de salud pública. Desde mediados de los años 80 la producción académica de este área ha proliferado notoriamente pasando a ser uno de los campos de mayor debate teórico, e incorporando ya de manera definitiva a su reflexión teórica y práctica etnográfica amplios territorios temáticos anteriormente alejados del análisis antropológico, como por ejemplo la biomedicina, y dentro de ella temas como las tecnologías médicas, la ingeniería genética, las categorías biomédicas de enfermedades, etc.

Desde un período en que los temas de salud-enfermedad eran casi ignorados (salvo las excepciones arriba citadas) o tratados sólo superficialmente dentro de temáticas más amplias, pasando por una etapa pragmática o funcionalista de aplicación de la disciplina a las necesidades del campo biomédico, la antropología médica de los años 90 en adelante ha delineado una perspectiva crítica desde la que se debaten cuestiones tales como la interacción entre super e infraestructura, biopolítica, poder, dominación y resistencia, sincretismo en la utilización de recursos médicos; y desde la que se considera a la biomedicina y a la ciencia 
como productos culturales en estrecha vinculación con la lógica económico-política del capitalismo.

A los fines de una breve reseña del devenir de la antropología médica ${ }^{4}$, se presenta una secuencia simple siguiendo el orden cronológico en el que se fueron delineando las distintas perspectivas. Aunque la emergencia de cada una de ellas implicó la crítica a limitaciones y sesgos de enfoques previos, no debe entenderse ésto en términos de superación y reemplazo de una corriente por otra, sino como coexistiendo, dialogando, confrontándose pero también influyéndose mutuamente e incidiendo en desarrollos posteriores.

\section{El enfoque pragmático o funcionalista}

Desde fines de los años 40 comenzó a incluirse una antropología aplicada en los programas de salud para los países en desarrollo y, en menor medida, en algunas problemáticas sociosanitarias del Primer Mundo. Al incorporar el estudio de las culturas nativas en lo referente al tema de salud-enfermedad se buscaba mejorar la eficiencia de las campañas de salud pública, por lo que la antropología cumplía un rol instrumental respecto a la medicina occidental, manteniendo una dependencia teórica y conceptual respecto a ésta. Así, el desarrollo de la antropología médica de este momento fue impulsado en parte por agencias internacionales como la OMS, en muchos casos con el patrocinio de fundaciones "filantrópicas" privadas, en el marco de políticas de desarrollo para los países del Tercer Mundo. Se planteaba la necesidad de conocer las prácticas y conocimientos locales para una mejor implementación de los programas de higiene y prevención, de reducción de las tasa de morbilidad y mortalidad, etc., por lo que los antropólogos fueron apelados como agentes intermediarios, traductores entre la población nativa y los profesionales, cuya función era informar cómo determinadas creencias o determinados hábitos autóctonos podían propiciar la proliferación de ciertas enfermedades, constituir barreras o formas de resistencia a tales programas obstruyendo o retardando su éxito. De esta manera se intentaba resolver los

\footnotetext{
${ }^{4}$ Los lineamientos y autores aquí recuperados son de origen norteamericano dado que Estados Unidos y Canadá fueron el núcleo de mayor desarrollo de esta subdiciplina antropológica, ejerciendo una importante influencia en la antropología médica del resto del mundo académico (Comelles y Martínez, 1997; Menéndez, 1997a). No obstante no se ignora que en esta reseña acotada quedan sin mencionar distintas líneas de desarrollo que ha tenido la especialidad en contextos regionales diferentes. Para una visión más amplia del desarrollo de la antropología médica se sugiere la lectura de Comelles, J., "La Configuración del Modelo Médico y del Modelo Antropológico", en Enfermedad, Cultura y Sociedad. Madrid, Eudema. 1993; Aguirre Beltrán, G., "Nace la Antropología Médica”, en La Antropología Médica en México, Campos Navarro, R. comp., Universidad Autónoma Metropolitana, 1992; Singer, M. y H. Baer, "Medical Anthropology and Its Transformation", en Critical Medical Anthropology, Amityville, New York, 1995; Menendez, E., "Aproximación Crítica al desarrollo de la Antropología Médica en América Latina”, en Nueva Antropología, VII (28):11-27, 1985; Martínez Hernáez, A, Antropología médica. Teorías sobre la cultura, el poder y la enfermedad, Barcelona, Anthropos, 2008; entre otros.
} 
inconvenientes derivados de la unidireccionalidad del modelo biomédico a la hora de trabajar con colectivos indígenas, enfatizando la importancia de un conocimiento de la realidad local sobre la que los profesionales de la salud querían intervenir. En estos años fueron de influencia los estudios de la escuela de Chicago y de la escuela de Cultura y Personalidad sobre problemas psiquiátricos y urbanización, así como aquellos que intentaron profundizar el enfoque etnomédico ya iniciado por Rivers y Clements (aún hoy algunos autores siguen utilizando sus clasificaciones de las concepciones sobre etiología y tratamientos de enfermedades en sistemas mágico, religioso y naturalista, según Rivers, o en las categorías etiológicas identificadas por Clements como brujería, intrusión de un objeto, intrusión de un espíritu, transgresión de un tabú y pérdida del alma). Esta funcionalidad pragmática de la antropología en la medicina (más que una antropología médica) si bien impulsó el campo de la etnomedicina, mantuvo su producción en un nivel de afinidad temática y no de un desarrollo conceptual propio debido a su dependencia teórica del modelo biomédico. Al reconocer que las medicinas "tradicionales" o "nativas" tenían su propias lógicas diagnósticas y terapéuticas, que además estaban integradas a valores y sentidos más amplios de esa cultura, pero a su vez considerar a la biomedicina como conocimiento a-cultural y a la enfermedad como una entidad biológica, la propuesta era de integración y aculturación, con el menor costo cultural posible, de los nativos a las prácticas médicas científicas (Menéndez, 1985). Se sostuvo la oposición ciencia vs creencia y medicina-racionalidad vs cultura (a pesar de que Malinowski y Evans-Pritchard sostuvieran que la relación entre magia y pensamiento racional era de complementariedad y no de exclusión y oposición), sin analizar la racionalidad del comportamiento nativo ni el peso de las creencias y de la cultura dentro de la biomedicina.

\section{El enfoque cognitivo y la etnomedicina}

Entre los años 50 y 60 la influencia del paradigma cognitivo incorporado en las etnociencias, focalizando en las estructuras del lenguaje y de la cognición, condujo a un énfasis en el análisis y categorización de las representaciones de las enfermedades. Se planteó la distinción de dos dimensiones de la enfermedad expresada a partir de dos términos que aunque sinónimos en el inglés cotidiano se utilizarán como contrastativos: "disease" e "illness". "Disease" (frecuentemente traducido como "patología") refiere a disfunciones y desequilibrios orgánicos identificados desde el criterio de la medicina occidental, es decir, constituye la perspectiva etic de la enfermedad. "Illness" (traducida como "malestar") designa 
la dimensión cultural de la enfermedad, las percepciones nativas, los tratamientos y explicaciones indígenas, es decir, la perspectiva emic, objeto de estudio del antropólogo, en tanto que la disease, siendo una categoría definida desde la biomedicina quedó al margen de los análisis comparativos de los sistemas médicos por considerarse en correspondencia directa con fenómenos naturales. Así, el enfoque cognitivo llevó a estudiar la "illness" como dominio estructurado por el lenguaje y la cultura, y ésta en tanto concepciones y creencias (aquí particularmente las que atañen a salud-enfermedad) que explican los comportamientos humanos. Mientras que las etnociencias y etnosemánticas de la enfermedad fueron objeto de estudio, el modelo biomédico fue negado como territorio etnográfico, confirmándolo como descripción "verdadera", fiel reflejo de una realidad natural.

\section{El enfoque ecológico}

La oposición ciencia vs cultura se mantuvo en el enfoque ecológico que empezó a desarrollarse a mediados de los 60, desde el que se asume que las categorías de enfermedad son universales mientras que la cultura juega un rol adaptativo en relación con las mismas. Desde una posición marcadamente empirista, la ecología médica analizó a las poblaciones como unidades biológicas y culturales, estudiando la interacción entre el sistema ecológico, salud y evolución humana, considerando a la cultura, al igual que los procesos genéticos y fisiológicos como un recurso de respuesta a problemas ambientales. El estado de salud fue tomado como medida de la adaptación mientras que la enfermedad sería un indicador de desequilibrio. Esta corriente se centró en los patrones de subsistencia, nutrición, crecimiento y desarrollo, tasas de embarazo y parto, tamaño, densidad y mobilidad de las poblaciones, enfermedades crónicas e infecciosas; se interesó particularmente por poblaciones aisladas en medioambientes extremos tales como regiones árticas, tropicales, de altitud elevada, etc. incorporando posteriormente la ecología urbana de la salud en diálogo con el enfoque económico-político de la salud.

\section{El enfoque interpretativo}

A fines de los años 70 comienza a abrirse camino la discusión teórica y conceptual a partir de las críticas al modelo funcionalista, a la ecología médica y sobre todo a la 
biomedicina. El enfoque interpretativo, el enfoque económico-político de la salud y la antropología médica crítica fueron forjándose en los años 80 y 90 desde propuestas que buscan, mediante nuevas formas de abordaje y de recorte del objeto de estudio, superar las limitaciones de los planteos previos.

La etnomedicina, originalmente dedicada a las sociedades denominadas folk $\mathrm{o}$ tradicionales, fue incorporando las sociedades complejas a su universo de estudio. Dentro de esta corriente se desarrolló el enfoque interpretativo de los procesos de salud-enfermedad como parte del paradigma interpretativo y constructivista que postula una realidad dependiente de los significados que las personas le atribuyen, una realidad social construída a través de estos significados, y que lo que la gente hace o dice es producto de cómo define su mundo. Se propuso indagar la relación entre el dominio cultural y el de la "disease", entendiendo a la cultura ya no como un medio de representación de la enfermedad (y ésta como fenómeno natural, existente en sí) sino como algo esencial en la construcción de la enfermedad como realidad humana. Así, la dualidad disease-illness es redefinida: mientras que "disease" anteriormente refería a una disfunción biológica en sí, pasa a ser considerada como la representación biomédica de algo identificado como disfunción, como una desviación respecto a la norma, pero una representación dentro de las posibles y no universal, relativizándose la carga de certeza, verdad y racionalidad de la misma. Autores como A. Kleinman (1977) y B. J. Good (1994b) señalaron el error de considerar que las categorías biomédicas de enfermedad pertenecen a la naturaleza y están por ello más allá de la cultura. La "disease", al igual que la "illness" son construcciones del conocimiento o categorías culturales suceptibles de ser analizadas etnográficamente.

Desde el enfoque interpretativo se examina cómo las prácticas interpretativas y los significados interactúan con procesos sociales, psicológicos y fisiológicos produciendo diferentes formas de enfermedad y de trayectorias terapéuticas. Un concepto clave es el de "modelo explicativo" introducido por A. Kleinman, como el conjunto de nociones sobre las causas de una enfermedad, los criterios para el diagnóstico y las opciones para el tratamiento. Al entender la enfermedad como una experiencia interpretada intersubjetivamente, esta perspectiva se vale de los aportes hechos por la fenomenología que considera la experiencia como previa a toda representación, para desde allí analizar la relación entre experiencia y formas culturales como la narración y el anclaje de la experiencia en los mundos morales locales. 


\section{El enfoque económico-político}

Se trata de una perspectiva crítica macroanalítica que indaga la distribución de las enfermedades y de los servicios de atención en relación a los sistemas económicos, particularmente al expandido sistema capitalista mundial, y la manera en que la biomedicina opera dentro de ese contexto. Se visibilizan así los intereses políticos y económicos incluidos en la administración y provisión de servicios de salud en el sistema capitalista y las lógicas concomitantes del capitalismo y la biomedicina (la orientación a las ganancias, por ejemplo, involucra a la biomedicina en metas intensivas en capital y orientadas al uso masivo de drogas, de alta tecnología, a la concentración de servicios en complejos médicos, etc.). Desde la corriente interpretativa se le criticó a este enfoque descuidar los contenidos subjetivos, particulares de la enfermedad, el sufrimiento, y la cura en tanto experiencias vividas, así como desatender a las diferencias de identidades existentes no reducibles a las relaciones de clase (de género, etnicidad, nacionalidad, etc).

\section{La antropología médica crítica}

Desde mediados de los 80 , a partir de polemizar la relación entre la antropología médica y la biomedicina, se fue demarcando la separación entre una antropología médica que se autodenominó "crítica" en oposición a la antropología médica que se venía desarrollando desde años atrás, a la que designó como "clínica" para destacar su dependencia del paradigma biomédico. Desde la antropología médica crítica se cuestionó que la antropología médica clínica (también llamada "aplicada" por tener como objetivo facilitar la intervención en el mantenimiento de la salud y la resolución de problemas clínicos), asumía acríticamente los supuestos y las problemáticas biomédicas. Esta antropología médica aportaba a la biomedicina el conocimiento acerca de las representaciones profanas de enfermedad y salud que pudieran tener consecuencias en la comunicación clínica, de manera de contribuir a superar las barreras culturales entre médicos y legos pero incrementando también el poder de penetración de la medicina moderna en otras culturas. Esta "medicalización de la antropología médica" (Singer, 1990) implicó además que el análisis, tanto de los comportamientos "no médicos" de la biomedicina como de las relaciones de clase y poder imbrincadas en el encuentro clínico no fueran objeto de estudio. 
La propuesta de integrar la mirada macro del enfoque económico-político de la salud sin perder de vista la experiencia y la capacidad de agencia del individuo fue pautando el desarrollo de la antropología médica crítica, que planteó buscar la relación entre los factores políticos y económicos con aquellos del orden fisiológico, cognitivo, inter-subjetivo y cultural. Influidos por la teoría marxista, la teoría de la dependencia y el enfoque económicopolítico de la salud, autores como S. Morsy, A. Young, H. Baer, M. Singer, M. Lock y N. Scheper-Hughes orientaron el análisis hacia la producción social de la enfermedad y de la pobreza dentro de la dinámica más amplia de las relaciones de clase y del sistema económico mundial, hacia las formas de control social a través del cuerpo (lo señalado por Foucault como anátomopolítica y biopolítica), las diferencias de poder y autoridad entretejidas en los procesos de salud-enfermedad-atención (por ejemplo en relación médico-paciente). Desde esta perspectiva se le criticó al enfoque interpretativo un excesivo énfasis en la experiencia individual sin tener en cuenta las relaciones de poder en la construcción de las realidades clínicas y las determinaciones estructurales sobre la experiencia y sus interpretaciones. Pero a la vez se consideró que reconocer la importancia de las fuerzas económicas y sociales no implicaba una pasividad de los individuos ni desconocer la capacidad de agencia y resistencia, sobre todo frente a los procesos de medicalización, por lo que era fundamental recuperar el papel de la cultura como vínculo entre las acciones individuales y los determinantes sociales y estructurales, entender la cultura en conexión con el poder, las formas de control, resistencia y desafío vinculadas a los procesos de salud-enfermedad-atención. Así mismo se profundiza el análisis en torno a la experiencia del enfermo pero no aislada de las fuerzas sociales y económicas sino como producto social constituido por categorías de sentidos y por las fuerzas económicas y políticas que forman el contexto de la vida cotidiana.

Al incorporar el saber médico y el quehacer científico como objeto de estudio, se fue conformando un modelo analítico descriptivo de los rasgos fundamentales de la biomedicina, el denominado "modelo médico hegemónico" en oposición al cual se fueron explicitando los fundamentos de la visión de la antropología médica crítica, a saber: frente a la dicotomía mente-cuerpo, independencia de lo natural respecto a lo social, individualismo epistemológico, biologicismo, mecanicismo, a-socialidad, a-historicidad, eficacia pragmática, entre otros, se plantea sostener una visión cultural y social de la enfermedad, la multicausalidad etiológica, visibilización de la relación entre normatividad social y normalidad biológica, etc. Se cuestionaron también algunas categorías del pensamiento científico (especialmente de la biomedicina, de las ciencias naturales pero también de las ciencias sociales) alertando evitar que las mismas sean un sesgo en el diálogo entre 
informante y antropólogo y que distorsionen el análisis forzando los datos mediante clasificaciones a priori. Así, por ejemplo, se propone dejar de lado dicotomías como las de mente-cuerpo, natural-supernatural, individual-colectivo, que lejos de corresponderse con la información recuperada a partir del trabajo etnográfico limita su análisis.

La influencia de la fenomenología en considerar la experiencia como inmediatez corporal y la representación de la misma no sólo como su denotación sino como su instancia constitutiva, permitió evitar también el dualismo experiencia-lenguaje, y sostener la incidencia de la cultura aún en procesos de percepción pre-objetivos. Así, se avanza el estudio de las representaciones culturales del sufrimiento (imágenes, metáforas, narraciones prototípicas, modelos) en tanto producto de patrones colectivos de experiencia que no sólo dan expresión sino también forma a las percepciones individuales a medida que son inscriptas en el campo discursivo. Es decir, entender la enfermedad como experiencia, y ésta como medio intersubjetivo, como espacio emergente a partir de la interacción de categorías culturales y estructuras sociales con los procesos psicológicos y fisiológicos, permite evitar el subjetivismo y captar la articulación entre la vivencia de enfermedad y los procesos sociales y culturales.

\section{Acerca de las elecciones teóricas en función de los objetivos de la tesis}

Los objetivos planteados en esta tesis se enmarcan parcialmente en el enfoque interpretativo, ya que se propone describir y analizar representaciones y prácticas vinculadas a las enfermedades predominantes en una localidad; identificar las denominaciones, clasificaciones y explicaciones causales así como las estrategias de atención y recursos terapéuticos utilizados. Sin embargo se consideran también los señalamientos de la antropología médica crítica respecto a que los procesos de salud-enfermedad-atención son emergentes estructurales de las condiciones históricas de vida y de trabajo en una sociedad dada a la vez que objeto de la construcción de saberes y prácticas donde se articulan procesos económico-sociales, políticos e ideológicos.

Para definir qué se entiende por representaciones y cómo éstas se articulan con las prácticas se recurre a la conceptualización de "representaciones sociales" elaborada por la escuela europea de psicología social, en tanto ésta, en concordancia con el enfoque interpretativo y constructivista, refiere a formas de construcción y reproducción social de la realidad, teorías implícitas en el sentido común que operan como guías explicativas y 
evaluativas en la resolución de problemas y en la elaboración de comportamientos, y hacen posible la comunicación mediante un código compartido para nombrar y clasificar los diversos aspectos del mundo. Así mismo, esta escuela destaca tanto el papel del sujeto situado en el mundo a través de su cuerpo, pero produciendo y reproduciendo representaciones en la esfera de la intersubjetividad a través del intercambio dialógico.

Es a través de las narraciones que los individuos elaboran para significar y compartir las experiencias de malestar que se accede a las denominaciones de los padecimientos, las connotaciones que vinculan éstos con aspectos del mundo social más amplio, los elementos a partir de los que se identifica cada malestar, las evaluaciones de los servicios de atención. Por ello se recupera el concepto de "modelo explicativo" de A. Kleinman y su definición de "proceso terapéutico" como toda actividad significativa que media entre los procedimientos y los resultados, y que se extendiende más allá del evento puntual de enfermedad.

Respecto a la descripción y análisis de los procesos de identificación, denominación y explicación de los padecimientos, la mirada constructivista que implica rechazar la pretensión de existencia de las enfermedades como entidades independientes de la actividad significante e identificadora de los individuos, conlleva a pensar los síntomas también resultantes de un proceso de recorte y atribución de sentidos a partir de un marco aprendido y compartido que estructura la percepción corporal. El proceso de enfermedad comienza en una experiencia preobjetiva (presencia sensorial, inserción y ajuste en el mundo) a partir de la cual, estructuras del lenguaje de por medio, se construye un saber objetivado de la misma. El antropólogo accede a la enfermedad a través de las narraciones que los individuos elaboran sobre ésta, por lo que se torna necesario reflexionar acerca del vínculo entre experiencia y lenguaje. Para ello, y orientada por el interés mostrado desde el enfoque interpretativo y la antropología médica crítica en incorporar reflexiones del campo de la fenomenología, se recurre a las filosofías de la existencia, desde donde se incorpora una noción de experiencia que, evitando dualismos como el de cuerpo-mente o percepción-conciencia, permite considerar la dimensión del cuerpo propio como punto de partida de las significaciones que lo trascienden y el lenguaje no como mera representación sino en tanto revelador y objetivador de la experiencia. El pasaje de la instancia subjetiva hacia una intersubjetiva se condensa en la atribución de un nombre a la experiencia, en el disponer de palabras para designar los estados vividos. Los aportes en torno al carácter pre-reflexivo de la experiencia son además recuperados en el apartado dedicado a la eficacia simbólica, desde el enfoque de Csordas que conceptualiza lo sagrado en tanto sentido de otredad atribuido a gestos espontáneos y experiencias pre- 
reflexivas, e identifica el locus de la eficacia simbólica en el self entendido como conjunción de la experiencia corporal pre-reflexiva y el medio culturalmente constituido.

De las reflexiones realizadas desde las filosofías de la existencia en torno a la experiencia de enfermedad se tienen en consideración también las nociones de "situación límite" y "misterio" para analizar los elementos de fe y religiosidad vinculados a los procesos de salud-enfermedad.

Al describir las enfermedades predominantes reconocidas por los sujetos y relacionarlas con las explicaciones causales y con los síntomas a partir de los cuales se las identifica y diagnostica, así como también con los tratamientos buscados para hacerles frente, y a la luz de las objeciones que desde la antropología médica crítica se han hecho a la aplicación de categorías que reproducen dicotomías arraigadas en la visión occidental, positivista y/o biomédica, se discuten trabajos anteriores sobre medicina tradicional del NOA cuyas clasificaciones no reflejan las rupturas y continuidades conceptuales nativas.

En lo que refiere a los objetivos de identificar y analizar los distintos recursos de atención disponibles y sus respuestas terapéuticas frente a cada enfermedad, así como los factores que influyen en la elección y el acceso a los mismos, y dado que en las sociedades actuales predomina lo que se conoce como pluralismo médico donde diversas formas de atención coexisten de manera antagónica pero a la vez complementaria, se considera importante el abordaje desde un enfoque relacional que permita aprehender el uso articulado y no excluyente de los diversos recursos de atención. Siguiendo los señalamientos de Menéndez, para evitar un cuadro polarizado de los distintos recursos para la salud éstos deben ser identificados desde la misma "carrera del enfermo" ya que son los sujetos quienes en el transcurso de sus trayectorias terapéuticas establecen la red de relaciones entre los diferentes servicios de salud. También se considera, en concordancia con lo señalado por la antropología médica crítica como limitación del enfoque interpretativo, la advertencia de este autor respecto a que un énfasis puesto en los procesos de decisión, elección y búsqueda de eficacia, lleve a no tener en cuenta los condicionamientos materiales, los factores limitantes que restringen las posibilidades de instrumentación exitosa y transforman la elección en una adecuación a lo posible.

Se toma también de Menéndez su clasificación de las distintas formas de atención, particularmente su caracterización de aquellas de tipo biomédica y las de tipo "popular" o “tradicional” por ser las que están presentes en el caso azampeño, así como su descripción del nivel de autoatención, destacado por ser el recurso de salud primero y más constante donde se sintetizan las concepciones y técnicas procedentes de diferentes servicios, desde el cual los 
sujetos generan las prácticas relacionales entre los diversos servicios de atención y que permite que las demás formas de atención puedan funcionar.

\section{Los procesos de salud-enfermedad como construcción social, objeto de prácticas y representaciones}

Partiendo del reconocimiento de que los procesos de salud-enfermedad son un hecho universal dentro de la vida de la humanidad: todos los grupos humanos conocidos desarrollan creencias, experiencias y percepciones para definir y conocer la enfermedad y la enfrentan actualizando estrategias y distribuyendo roles de acuerdo con sus recursos (Wellin en Magrassi y Radovich, 1982), se propone ir más allá de estas generalizaciones para dar cuenta de cómo, desde su pertenencia sociocultural, el hombre aprende a identificar las enfermedades que lo aquejan, elabora explicaciones sobre sus causas, define las formas de estar sano y sentirse enfermo, establece estrategias de atención y pauta las relaciones entre el enfermo y el grupo orientadas a restablecer su salud y/o a otorgarle un nuevo espacio social en tanto individuo enfermo.

Como señala Grimberg, los procesos de salud-enfermedad-atención presentan un carácter universal (el padecimiento, la incapacidad, la muerte, y las respuestas de la sociedad para enfrentarlas son fenómenos presentes en toda sociedad) a la vez que muestran variabilidad y particularidad histórico social. Es por ello que los mismos deben ser considerados emergentes estructurales de las condiciones históricas de vida y de trabajo en una sociedad dada a la vez que objeto de la construcción de saberes y prácticas no sólo por parte de los especialistas del campo médico sino del conjunto de la población. Los procesos de salud-enfermedad-atención son una construcción social en tanto son el resultado de modalidades específicas de relaciones sociales y a su vez constituyen una trama de representaciones y prácticas en las que se articulan procesos económico-sociales, políticos e ideológicos (Grimberg, 1992; 1995; 1998). "Las representaciones abarcan los modos de percibir, categorizar y significar la enfermedad; los modos globales de interpretar, de asignar sentidos en la vida social, sin plantear a priori oposiciones entre ciencia/ideología o ciencia/sentido común" [...] "Las prácticas incluyen las estrategias en relación a las mismas que no necesariamente responden a criterios explícitos de la medicina o que no se presentan como una mera reproducción de ellos. Las prácticas comprenden los modos de acción, organización y respuesta social e institucional no sólo referidas al saber desarrollado por la 
medicina sino también a las prácticas de los conjuntos sociales, vinculadas en una relación activa de apropiación, reelaboración y reinterpretación (tanto dentro del propio campo médico como entre distintos actores sociales)" (Grimberg, 1988 en Ortale, 2002: 112-113). Cabe agregar que la relación entre prácticas y representaciones no es especular, en el sentido de que las últimas sean un reflejo fiel de las primeras, o que éstas sean una impronta de las representaciones en el plano de la acción. Las representaciones conforman un sistema de expectativas, un marco de referencia que orienta la acción, siendo en la práctica donde ellas se realizan pero también se modifican, pues las prácticas no reproducen mecánicamente las representaciones sino que es posible también la discrepancia entre entre ambos niveles.

La antropología, con su metodología de producción de conocimiento a partir de la construcción de una relación social con el "otro", permite recuperar los saberes de los sujetos sociales, en tanto los considera sujetos activos de sus condiciones de vida, enfrentando opciones y desarrollando estrategias de reproducción, impugnación, etc., dentro de un campo de disputa social (Grimberg, 1995).

\section{Las representaciones sociales en el cruce subjetividad-intersubjetividad- trans-subjetividad}

El concepto de "representaciones sociales" ha sido elaborado por la escuela europea de psicología social, recuperando y operacionalizando el de "representaciones colectivas" de Durkheim, pero sustituyendo el término "colectivo" por el de "social" a fin de enfatizar el proceso de adquisición y comunicación de conocimientos y no sólo como una clase general de creencias o ideas ya dadas a los sujetos. Como señaló Moscovici, "las representaciones son al mismo tiempo generadas y adquiridas, le quitamos ese lado preestablecido, estático que ellas tenían en la visión clásica" (Moscovici en Araya Umaña, 2002: 22). Se trata de "un corpus organizado de conocimientos y una de las actividades psíquicas gracias a las cuales los hombres hacen inteligible la realidad física y social, se integran en un grupo o en una relación cotidiana de intercambios" (Moscovici en Araya Umaña, 2002: 27), "una forma de conocimiento socialmente elaborado y compartido, y orientado a la práctica, que contribuye a la construcción de una realidad común a un conjunto social” (Jodelet en Giménez, 1997: 14), “construcciones socio-cognitivas propias del pensamiento ingenuo o del 'sentido común', que pueden definirse como conjunto de informaciones, creencias, opiniones y actitudes a propósito de un objeto determinado" (Abric en Giménez, 1997: 14), "sistemas cognitivos en 
los que es posible reconocer la presencia de estereotipos, opiniones, creencias, valores y normas que suelen tener una orientación actitudinal positiva o negativa. Se constituyen, a su vez, como sistemas de códigos, valores, lógicas clasificatorias, principios interpretativos y orientadores de las prácticas" (Araya Umaña, 2002: 11).

Las representaciones son sociales por sus condiciones de producción y circulación (procesos de intercambio, interacción cara a cara, comunicación, lenguaje), y sobre todo por sus funciones: construcción y reproducción social de la realidad; construcción de 'minimodelos' o teorías implícitas, explicativas y evaluativas del entorno; construcción del conocimiento del sentido común; desarrollo de una identidad personal y social; guía operacional para la vida social, para la resolución de los problema y conflictos y para la elaboración de los comportamientos; hacer posible la comunicación proporcionando un código para el intercambio social y para nombrar y clasificar los diversos aspectos del mundo) (Araya Umaña, 2002; Páez, 1987 y Farr, 1988 en Mora 2002).

Según Banchs las representaciones sociales permiten a los sujetos sentirse dentro del ambiente social, "no quedar excluido[s] del ámbito de las conversaciones sino poder realizar inferencias rápidas, opiniones al respecto y un discurso más o menos desarrollado" (Banchs en Mora, 2002: 9), así se entiende que una de las condiciones de su emergencia sea lo que Moscovici denominó "presión a la inferencia": "socialmente se da una presión que reclama opiniones, posturas y acciones acerca de los hechos que están focalizados por el interés público: en la vida corriente, las circunstancias y las relaciones sociales exigen del individuo o del grupo social que sean capaces, en todo momento, de estar en situación de responder" (Moscovici en Mora, 2002: 9), sobre todo en momentos de crisis y conflictos, ante acontecimientos complejos y dolorosos (Tafjel en Mora, 2002: 8).

Jodelet señala que las representaciones sociales deben ser referidas a tres esferas: la de la subjetividad, la de la intersubjetividad y la de la trans-subjetividad: Atender a la subjetividad implica considerar los procesos cognitivos y emocionales a través de los cuales el sujeto se apropia de y construye tales representaciones y que dependen de la experiencia en el mundo de vida, "el sujeto situado en el mundo lo es en primer lugar por su cuerpo, como lo establece la fenomenología. La participación en el mundo y en la intersubjetividad pasa por el cuerpo: no existe pensamiento desencarnado flotando en el aire" (Jodelet 2008: 51-52).

La esfera de la intersubjetividad remite al "papel del intercambio dialógico del que resultan la transmisión de información, la construcción del saber, la expresión de acuerdos o de divergencias a propósito de objetos de interés común, la interpretación de temas pertinentes para la vida de los participantes en la interacción, y la posibilidad de creación de 
significados o de resignificaciones consensuales. [...] En estos espacios de interlocución también se ha recurrido a un universo ya construido, el plano personal o social, de representaciones. Éstas intervienen como medios de comprensión y como instrumentos de interpretación y de construcción de significados compartidos en torno de un objeto de interés común" (Jodelet, 2008: 52-53). Contra toda visión solipsista del sujeto la autora recupera los señalamientos de Merleau-Ponty acerca de que es en el encuentro intersubjetivo donde se establecen los sistemas de referencia con respecto a los cuales las experiencias tendrán sentido y se ordenarán en forma de una sucesión, de una historia (Jodelet, 2008: 48). También Moscovici, apoyándose en el Interaccionismo Simbólico de $\mathrm{Mead}^{5}$, propuso un esquema triádico sujeto-grupo-objeto, donde los otros sujetos son mediadores del proceso de construcción del conocimiento y la relación de ellos con el objeto físico, social, imaginario o real es lo que posibilita la construcción de significados (Araya Umaña, 2002: 18).

La esfera de la trans-subjetividad atraviesa los espacios de vida locales $\mathrm{y}$, superando el marco de las interacciones, conforma el contexto que permite la intercomprensión. La misma resulta "del acceso al patrimonio de recursos proporcionados por el aparato cultural para la interpretación del mundo, el cual proporciona los criterios de codificación y de clasificación de la realidad, los instrumentos mentales y los repertorios que sirven para construir significados compartidos" [...] "también del juego de coacciones o de presiones, asignables sea a las condiciones materiales de existencia, sea a imposiciones ligadas a la estructura de las relaciones sociales y de poder, sea al vigor de los sistemas de normas y valores [...] Remite, igualmente, al espacio social y público donde circulan representaciones de origen diverso: la difusión por los medios masivos de comunicación, los marcos impuestos por los funcionamientos institucionales, las hegemonías ideológicas, etc.” (Jodelet, 2008: 53-54).

Moscovici al estudiar el movimiento de incorporación del psicoanálisis en la sociedad francesa de los años 50 distingue dos procesos que explican cómo lo social transforma un conocimiento en representación colectiva: la objetivación y el anclaje. La objetivación consiste en hacer real un esquema conceptual, a partir de una selección y descontextualización de ciertos elementos (términos o conceptos) que pasarán a formar un núcleo figurativo que se naturaliza, es decir, se le otorga el carácter de evidencia válida. Combinaciones de experiencias y estructuras simbólicas junto con una carga de afectos y valores tornan los términos abstractos en "una imagen más o menos consistente en la que los aspectos metafóricos ayudan a identificarla con mayor nitidez". El anclaje implica la integración

${ }_{5}^{5}$ Desde el que se plantea la intersubjetividad como "un espacio de realidad en las mediaciones; un espacio interactivo no biológico sino social que es percibido en términos de significaciones, puesto que su materia es el símbolo” (Mora, 2002: 5). 
cognitiva, la inserción del nuevo objeto de representación dentro del sistema de pensamiento preexistente (Mora, 2002: 11-12). Estos señalamientos sobre el pasaje de un conocimiento científico al dominio público permiten entender el uso por parte de legos de términos provenientes de la biomedicina.

\section{El proceso terapéutico, narraciones y modelos explicativos}

Las denominaciones con las que se cuenta para referir los padecimientos, las connotaciones que vinculan éstos con aspectos del mundo social más amplio, los elementos que se tienen en consideración para identificar cada malestar, así como las evaluaciones de los servicios de atención, su competencia, eficacia y limitación para dar una respuesta eficaz, todo ello va emergiendo a lo largo de las narraciones que los individuos elaboran para significar y compartir las experiencias de malestar. "Kleinman (1980) llama 'modelos explicativos' a estos esquemas de referencia. Los modelos explicativos populares se encuentran impregnados por los esquemas profesionales, y podemos afirmar que son integrados, asimilados a esquemas de valores más amplios" (Prece et al., 1996: 62). Las prácticas vinculadas a los procesos de salud-enfermedad-atención están sumergidas "dentro de una realidad simbólica en el interior de la cual se producen, se curan y se sanan las dolencias y las enfermedades. Las principales funciones 'clínicas' de los sistemas médicos comprenden la construcción de la experiencia de enfermedad, el manejo cognoscitivo (denominación, explicación, tipificación, clasificación, etc.) y el manejo terapéutico" (Prece et al., 1996: 52).

Es importante entender el proceso terapéutico, siguiendo a Kleinman y Csordas, como toda actividad significativa que media entre los procedimientos y los resultados $^{6}$, pero extendiéndose, en tanto proceso, más allá del evento de enfermedad específico e involucrando aspectos del mundo social más amplio del enfermo. El proceso terapéutico abarca toda progresión o curso de un episodio de enfermedad, definido por una secuencia de decisiones dirigidas al diagnóstico y tratamiento, representando la perspectiva del individuo enfermo "navegando a través de un mar de elecciones terapéuticas" (Kleinman y Csordas, 1996: 10).

\footnotetext{
${ }^{6}$ En cuanto al procedimiento terapéutico los autores señalan que "puede ser definido en términos de quién hace qué a quién con respecto a las medicinas administradas, a las técnicas físicas u operaciones llevadas a cabo, plegarias recitadas, objetos simbólicos manipulados, estados de conciencia alterados inducidos o invocados", por resultados terapéuticos se refieren a la disposición de los participantes en un determinado punto final del proceso terapéutico, tanto respecto a su satisfacción expresada (elevada o baja) como al cambio positivo o negativo de los síntomas, la patología o el funcionamiento (Kleinman y Csordas, 1996: 8, 10).
} 
La persona va desarrollando una secuencia de observaciones, evaluaciones, decisiones y acciones que la conducirán hacia los distintos espacios de atención a la salud. Las nociones que se manejan sobre las enfermedades, sus síntomas y recetas para su cura son expresadas a través de las narraciones con las que el individuo objetiviza y comunica sus experiencias de enfermedad, a la vez que se van modificando al contrastar con las observaciones de la evolución del malestar, con las experiencias transmitidas por otros individuos y con los fragmentos de saberes que le transmiten los profesionales médicos, curanderos y demás curadores a los que recurre.

A partir de las narraciones obtenidas se intenta reconstruir los modelos explicativos, en el sentido propuesto por Kleinman, es decir, el conjunto de creencias o entendimientos que especifiquen para un episodio de enfermedad su causa, tiempo, modo de comienzo, los síntomas, el curso de la enfermedad y el tratamiento. Estos modelos emergen de un conocimiento cultural general a la vez que son siempre atributos de los individuos, y al respecto se ha señalado la dificultad de especificar en qué medida son formulaciones culturales y hasta dónde son idiosincrásicas (Rubel y Hass, 1996). Sin embargo, y teniendo en cuenta los señalamientos de Jodelet anteriormente recuperados acerca del entrecruzamiento de las esferas de subjetividad, intersubjetividad y trans-subjetividad, cada testimonio recuperado en el campo debe ser considerado, más allá de su particularidad, en tanto forma parte del “discurso social”, es decir, del "conjunto existencial de las construcciones que circulan en una sociedad, con eficacia para la efectiva producción y/o reproducción de representaciones perceptuales y de interpretaciones conceptuales o valorativas" (Magariños de Morentin, 1990: 8).

Desde el momento en que una persona comienza a percibir irregularidades en la rutina de su existencia corporal (en el sentido de cuerpo vivido, indisociable de su existencia subjetiva, que es a su vez una subjetividad encarnada), dolores, disfunciones, incomodidades no reconocidas como parte de los eventos normales de su cotidianidad son interpretadas como señales corporales de que algo anda mal constituyéndoselas en signos de una enfermedad en mayor o menor grado determinada. Como ha destacado Susan Sontag, por mucho que pese su calidad material (física, biológica), los síntomas, los signos de la enfermedad son hechos sociales. Basta recordar los significados enormemente diferentes transmitidos por síntomas como el dolor de cabeza, la visión borrosa, el mareo, la obesidad o la delgadez, en distintos momentos de la historia y en diferentes culturas, "las manifestaciones de una enfermedad son como símbolos, y el médico que hace el diagnóstico los ve y los interpreta con el ojo entrenado por las determinaciones sociales de la percepción" (Taussig, 1992: 115). La 
relación entre la percepción de procesos orgánicos (molestias, dolores, etc.) y su configuración en síntoma no es inmediata ni lineal, implica un proceso complejo de operaciones de identificación, diferenciación y significación; hacer referencia a un síntoma es atribuir sentidos (Grimberg, 1991).

Para reflexionar sobre el vínculo entre las experiencias de salud-enfermedad y las narraciones que los individuos construyen al respecto, se tuvo en cuenta el enfoque de las filosofías de la existencia, desde donde se incorporó una noción de experiencia que, evitando el dualismo conciencia-percepción, permite considerar el lenguaje no como mera representación sino en tanto revelador y objetivador de la experiencia.

\section{Aportes desde las Filosofías de la Existencia a la noción de experiencia}

Como se planteó anteriormente, recuperando la dialéctica individuo-sociedad, se considera la experiencia como medio intersubjetivo de las transacciones sociales, como el espacio emergente a partir de la interacción de categorías culturales y estructuras sociales con los procesos psicológicos y fisiológicos (Kleinman y Kleinman, 1991). Por más personal que sea la vivencia de malestar, la misma podrá incorporar sus sentidos (identificación de las causas, reacción de rechazo, resistencia o resignación, nociones orientadas a la búsqueda de soluciones y cuidados y a la movilización de estructuras de apoyo y sostén, etc.) sólo desde una posición de relaciones al interior de un grupo y a partir de modelos de experiencia culturalmente compartidos.

Por otra parte, la cualidad de inmediatez de la experiencia en tanto presencia sensorial, inserción y ajuste en el mundo remite a niveles pre-objetivos (pero no por ello pre-culturales) donde los límites entre lo biológico y lo cultural se diluyen. Considerando la experiencia como síntesis pre-objetiva vivida, corporizada, se puede analizar cómo lo social, la base cultural de la experiencia se carga como un rasgo de la existencia corporal, cómo el significado cultural es intrínseco a toda experiencia corporal (Csordas, 1992b). La experiencia de enfermedad nos remite a nuestra corporeidad en el sentido de cuerpo vivido, indisociable de nuestra subjetividad (que es a su vez una subjetividad encarnada).

Frente a dualismos como el de cuerpo-mente (experiencia-reflexión), que plantea una relación instrumental entre un cuerpo (objeto) y una mente (manipuladora del instrumento), o aquél que identifica la relación conciencia-percepción con el par cognoscente-conocido, autores como Karl Jaspers, Gabriel Marcel y Jean Paul Sartre sostienen una relación 
existencial, inmediata de ambos términos: el ser es el cuerpo propio, lo existe, toda reflexión despierta frente a la situación del ser, responde a las circunstancias en las que éste se encuentra, y no hay posibilidad de abstraerla de la condición encarnada desde la que se ejerce; la conciencia de percepción es constitutiva de la percepción, conforma la percepción misma, es el único modo de existencia de toda percepción de algo, de toda conciencia posicional. Concibiéndose al ser como una unidad cuerpo-espíritu el cuerpo no se comprende como una externalidad, como algo de lo que es posible separarse, como si pudiera existir una sensación previa a la conciencia o una conciencia ajena a la percepción. La reflexión, la conciencia son entendidas como modos del ser, modalidades de existir el cuerpo.

La existencia humana no puede entenderse como un ser en abstracto sino como un "ser en situación", un ser "encarnado", donde el dato circunstancial se reconoce íntimamente (esencialmente) ligado a la actividad reflexiva increpándola, desde su valor de obstáculo o atajo en el vivir. Para Marcel no hay experiencia que no sea reflexiva, que pueda quedar en el plano del registro pasivo de impresiones para posteriormente ser tocada por la reflexión, así como no hay reflexión sin experiencia. La reflexión se realiza frente a algo que se presenta como obstáculo a la vida, que exige un reajuste, un cambio, y es la experiencia lo que media para que cosas circunstanciales afecten a la vida y cumplan así una función constitutiva de la reflexión. "La reflexión se ejerce únicamente a propósito de lo que vale la pena", se articula con algo vivido, "es un cierto modo de vida, o más profundamente, una forma mediante la cual la vida pasa de un nivel a otro" (Marcel, 1953: 83, 86). Si bien la reflexión se presenta como una actividad libre, es interpelada y constreñida por los hechos ineludibles que forman parte de la experiencia, de manera que el yo que reflexiona pareciera un "no-alguien, ligado en condiciones fundamentalmente oscuras a alguien en particular sobre el que me interrogan y no soy libre de responder lo que me plazca" (Marcel, 1953: 89-90). De ahí que no se pueda considerar el dato circunstancial como mero conjunto de cosas existente en sí, del que es posible despojarse para dar con un "núcleo racional y trascendente". El dato circunstancial no es algo ajeno, externo a la reflexión, autónomamente significativo, sino que se trata de aquellos hechos que actúan "en relación con una actividad libre para la que constituye(n) un conjunto de simulaciones o de obstáculos" y de los cuales todo intento de abstracción en pos de una actividad reflexiva pura o todo intento de objetivación para tratarlos como datos expuestos a (blanco de) dicha actividad no deja de ser un movimiento "ilusorio y en cierta medida engañoso" de evasión hacia un "ninguna parte", "especie de olimpo espiritual”. "No hay ni puede haber abstracción global, por la profunda razón de que nuestra condición es en última instancia la de un ser itinerante que no es posible inmovilizar por completo, salvo por 
medio de una ficción que la reflexión filosófica debe rechazar decididamente.[...] ser en situación y ser en marcha constituyen los modos inseparables, los dos aspectos complementarios de nuestra condición" (Marcel, 1953: 128, 129).

Dice Mario Presas que el punto de partida de las filosofías de la existencia, como se ha denominado la orientación de estos autores, "no está dado por un dato intelectual "claro y distinto", al estilo cartesiano, sino por una experiencia vivida de la cual hay que hacerse cargo por un movimiento reflexivo. Se trata, en cierto modo, de recobrar una originaria participación en el mundo a través de la mediación de mi cuerpo" (Presas, 1971: 101). El ser es siempre en situación, es el cuerpo propio la posibilidad y fundamento de todo conocimiento y por ello inaccesible él mismo, en tanto "para-sí" a toda sistematización o saber objetivado. El cuerpo propio es el punto de vista (el punto cero), siempre trascendido, sobre el cual no se puede adoptar otro punto de vista.

Sartre recurre a la experiencia del dolor como esclarecedora e ilustrativa de la relación existencial conciencia-cuerpo. Él parte de rechazar un análisis de la conciencia como mero conocimiento, si bien toda conciencia es conciencia de algo, es intención dirigida hacia el exterior, lo que se trasciende para alcanzar un objeto, para ser conocimiento debe ser también “conciencia de sí misma como siendo ese conocimiento" (Sartre, 2006: 19). Pero considerar esta conciencia de conciencia como conocimiento de conocimiento exigiría a su vez buscar el fundamento del primer conocimiento, y aquí “o nos detenemos en un término cualquiera de la serie conocido-cognoscente conocido-cognoscente conocido por el cognoscente, etc. y entonces la totalidad del fenómeno cae en lo desconocido, es decir, nos damos siempre, como término último, contra una reflexión no consciente de sí; o bien afirma[mos] la necesidad de una regresión al infinito" (Sartre, 2006: 20). Así, para entender la conciencia reflexiva no sirve introducir la dualidad cognoscente-conocido en la conciencia, pues no se puede dar cuenta del término último que haría que el cognoscente se torne conocido a su vez. La conciencia de sí no es dualidad, no es relación cognitiva de sí a sí, es una relación inmediata, espontánea, no es posicional sino constitutiva de toda conciencia posicional de objeto. "La conciencia (de) placer es constitutiva del placer, como el modo mismo de su existencia, como la materia de que está hecho y no como una forma que se impusiera con posterioridad a una materia hedonista. [...] no hay antes una conciencia que reciba después la afección de "placer" a la manera en que se colora un agua, así como no hay antes un placer (inconsciente o psicológico) que reciba después la cualidad de consciente, a modo de un haz de luz" (Sartre, 2006: 22). Toda reflexión se realiza ya sobre la base de una conciencia no-reflexiva "hay un cogito pre-reflexivo que es la condición del cogito cartesiano" (Sartre, 2006: 21). A partir de 
identificar esta conciencia irreflexiva como constitutiva de toda percepción, de toda conciencia posicional, el análisis de la relación conciencia-cuerpo puede evitar la confusión generada al intentar unir una conciencia captada como "interioridad absoluta" a un cuerpo en tanto objeto, cosa definida desde afuera, el cuerpo "de los otros" (Sartre, 2006: 420). Sartre va a distinguir tres dimensiones del cuerpo: como ser-para-sí, como ser-para-otro y como serpara-sí-como-para-otro. El cuerpo padecido, la dimensión del ser-para-sí, es el núcleo y punto de partida de las "significaciones alienadoras que lo trascienden", el movimiento de reflexión lleva del dolor vivido hacia el mal padecido y (estructuras del ser-para-otro mediante) de este hacia "la Enfermedad". El pasaje de la instancia subjetiva hacia una intersubjetiva se condensa en la atribución de un nombre a la experiencia (de padecimiento, en este caso), en el disponer de palabras para designar los estados vividos.

La experiencia de enfermedad, el mal padecido resultan paradigmáticos para el análisis del camino vivencial que recorre la conciencia en un movimiento que va de la conciencia inmediata, pre-reflexiva a un saber objetivado (donde el lazo existencial entre conciencia y experiencia es distorsionado por modelos dualistas, que cosifican tanto el cuerpo como la mente), y, en la medida en que se reconoce que tales situaciones de sufrimiento ("situaciones límite") señalan desde su inminencia algo que está más allá del saber objetivo, la conciencia puede aprehenderlas como misterio y extraer de ellas una revelación transformadora del existir.

Que experiencias de enfermedad, de sufrimiento, la conciencia de ser mortal, de estar siempre en situación, sean inabarcables en sus múltiples manifestaciones por el conocimiento objetivo, y que además impliquen una limitación y o destrucción de las fuerzas vitales, motivó a Jaspers a denominarlas "situaciones límites" pues "referidas a nuestra concreta existencia empírica revelan el carácter de ser definitivas, últimas" (Jaspers, 1956: 203 en Presas, 1971: 102). Frente a estas situaciones el hombre puede mantenerse en una concepción instrumental de su cuerpo y ser espectador y (con suerte) manipulador de sus dolores y disfunciones negándose a la experiencia reveladora del límite que su condición encarnada le depara. Pero si el límite es asumido, incorporado en la proyección de posibilidades, hay una transformación de la conciencia del ser frente a lo que reconoce como "misterio", entonces "yo capto mi sufrimiento como la parte que me ha correspondido, me quejo y en realidad sufro, no intento disimulármelo, vivo en tensión entre la voluntad de responder afirmativamente a mi sufrimiento y la de no poder hacerlo nunca de modo definitivo; lucho contra el dolor para limitarlo y diferirlo, pero teniéndolo como algo que me es extraño lo considero sin embargo como lo que pertenece" (Jaspers en Presas, 1971: 103). 
Pero ¿qué puede decirse del ser, un ser siempre en situación, si la situación remite inevitablemente a la condición encarnada y ésta presenta un límite al saber objetivo, cómo hablar a partir de experiencias de dolor, placer, etc. si pertenecen a la unidad de un "mi cuerpo" inaccesible al conocimiento sistematizado? "Cuando algo no puede convertirse en objeto, tampoco es posible según parece, hablar de ello, pues al hacerlo lo convertiríamos de todos modos en cierta objetividad" (Presas, 1978: 45-46). Dice Presas, "llegamos a los límites del conocimiento, pero no a los de la razón. Más allá de lo cognoscible y, por tanto, enunciable en categorías válidas y objetivas, están las ideas, las cuales, [...] no son dadas, sino vislumbradas o dadas pero como tarea infinita que orienta el conocimiento y la acción del hombre. Por el hecho de trascender a todos los conceptos del entendimiento, el reino de las ideas, puede decirse, es inefable" (1978: 103). Inefable es la realidad metafísica, no hay signos para enunciarla de manera objetiva, no se la puede conocer, pero sí pensar y evocar a través de la metáfora o de lo que Jaspers llamó “enunciación (objetiva) indirecta de lo inobjetivable", esto es, "un lenguaje objetivamente desprovisto de contenido" capaz de "volver a producir en el lector la intuición que se desea transmitir" (Presas, 1978: 42-43).

El lenguaje sólo puede proporcionarnos el acceso al mundo de la experiencia en tanto ésta sea traída al campo del lenguaje, es decir, éste no sólo representa la realidad sino que la revela: lo oculto se manifiesta a través del lenguaje. En este sentido Csordas se refiere a "metáforas encarnadas" (embodied) como aquellas que no se aplican sobre el cuerpo sino que emergen de la experiencia corporal (Csordas, 1992a). Son metáforas vividas pues, al contrario de actuar por imposición de un significado externo, arbitrario sobre la experiencia, forman parte del proceso de significación en el curso mismo de la experiencia, son imágenes que evocan conexiones al interior de la experiencia (Rabelo et al., 1999).

\section{El espectro de opciones de atención, la importancia de un enfoque relacional}

Volviendo al tema del proceso terapéutico, en tanto curso de un episodio de enfermedad pautado por la serie de decisiones dirigidas al diagnóstico y tratamiento, que conllevan una elección entre distintos espacios de atención a la salud, se considera importante su abordaje desde un enfoque relacional que permita describir y analizar el uso articulado y no excluyente de los diversos recursos de atención. 
Lo que domina en las sociedades actuales es lo que se conoce como pluralismo médico donde diversas formas de atención, en tanto actividades que buscan prevenir, dar tratamiento, controlar, aliviar y/o curar padecimientos coexisten de manera antagónica pero a la vez complementaria y son producto de las condiciones religiosas, étnicas, económico-políticas, técnicas y científicas de cada contexto (Menéndez, 2004; 2005). En términos generales Menéndez identifica cinco conjuntos de formas de atención:

- Formas de atención de tipo biomédica: corresponden a la medicina oficial y hegemónica de la cual este autor ha descrito y analizado alrededor de treinta características con las que elaboró su Modelo Médico Hegemónico ${ }^{7}$. El rasgo estructural dominante de este tipo de medicina es el biologicismo y su racionalidad científico-técnica, el cual "no sólo refiere a la fundamentación científica del diagnóstico y del tratamiento, sino que constituye el principal criterio de diferenciación con las otras formas de atención" [...] "la dimensión biológica es el núcleo de la formación profesional del médico. El aprendizaje se hace a partir de contenidos biológicos, donde los procesos sociales, culturales y psicológicos son anecdóticos, y donde no hay información sistemática sobre otras formas de atención. Es de la investigación biológica, bioquímica, genética, que la biomedicina extrae sus principales explicaciones y sobre todo sus principales instrumentos de curación" (Menéndez, 2004: 25). La racionalidad científico-técnica es el criterio decisivo de diferenciación de la biomedicina respecto de las otras formas de atención, que identificadas con criterios no científicos y con la dimensión cultural son relegadas a una posición subalterna, excluidas, ignoradas, estigmatizadas desde la biomedicina, que en el mejor de los casos realiza una aceptación crítica o apropiación de ciertas técnicas como uso complementario y siempre con carácter subordinado (Menéndez, 2004).

- Formas de atención de tipo "popular" o "tradicional" expresadas a través de curadores especializados (hueseros, culebreros, brujos, curanderos, espiritualistas, yerberos, etc.). Menéndez plantea la limitación de la noción de "tradicional" a la hora de establecer un criterio que permita identificar con este rótulo formas de atención actuales, en continuo cambio e incorporación de elementos. ¿Qué es lo que puede ser caracterizado como tradicional? Si el criterio es la profundidad histórica, ¿hasta dónde habría que remontarse para garantizar la tradicionalidad? ¿Cómo dar cuenta de la presencia en este saber popular de representaciones y prácticas derivadas de la medicina alopática y de aquellas vinculadas, por ejemplo, a la expansión de las iglesias protestantes y salvacionistas desde la década del cuarenta y del setenta? (Menéndez, 1994). Si bien el énfasis culturalista recuperó la

\footnotetext{
${ }^{7}$ Ver, por ejemplo, "Morir de alcohol. Saber y hegemonía médica” (Menéndez, 1992).
} 
importancia y validez de las prácticas y representaciones populares en torno a los procesos de salud-enfermedad-atención, condujo a una visión de la medicina tradicional como una totalidad entera y conservada y a plantear la relación medicina tradicional-medicina moderna en términos de oposición y mutua exclusión (Menéndez, 1985). En América Latina es un hecho constante que los curadores populares frecuentemente acompañen sus tratamientos tradicionales con la receta de, por ejemplo, antibióticos o vitaminas y que incorporen tanto prácticas como representaciones de la medicina alopática, lo que responde a una búsqueda de mayor eficacia por parte de los curadores pero también a que desde el Sector Salud se capacitó a personas de la comunidad como agentes de salud para suplir la carencia de recursos humanos en la atención primaria (Menéndez, 1994; 2004; 2005). Lo "tradicional" debe ser entendido, entonces, como "fuerza configurativa, como medio de incorporación práctica de nuevos elementos que conecta relaciones históricas con el presente actuante" (Módena, 1990: 136).

- Formas de atención alternativas, paralelas o new age (sanadores, bioenergéticos nuevas religiones curativas de tipo comunitario, etc.).

- Formas de atención devenidas de otras tradiciones académicas (acupuntura, medicina ayurvédica, medicina mandarina, etc.).

- Formas de atención centradas en la autoayuda, organizadas y orientadas por las personas que padecen o co-padecen algún tipo de problema.

Como ya se señaló respecto a los tipos de medicina tradicional y científica, las diferentes modalidades de respuesta a los procesos de salud-enfermedad no funcionan excluyentemente sino que se observa un proceso dinámico que opera en dos niveles:

- El de la articulación desde los propios curadores que se apropian de recursos (técnicas, denominaciones, farmacopea, etc.) provenientes de otros modelos de atención pero manteniendo la diferencia, hegemonía y/o exclusión al seguir proponiendo su forma de curar como la más idónea, como también ha señalado Palma (2002) al referirse a las influencias entre la medicina tradicional y la biomedicina en Argentina;

- El de la integración por parte de los sujetos y grupos, quienes superando la supuesta o real incompatibilidad que puede existir entre las diferentes formas de atención, se vinculan a éstas buscando soluciones pragmáticas a sus problemas de salud (Menéndez, 1994; 2004; 2005). En este nivel se observa un sincretismo, es decir, la orquestación de diferentes modos de percibir y actuar frente a la enfermedad provenientes de modelos explicativos aparentemente irreconciliables. Como indicó Módena, a pesar del mutuo cuestionamiento entre los diferentes tipos de medicina simultáneamente presentes, el mismo no aparece como 
tal para los conjuntos sociales involucrados, quienes reconociendo empíricamente las particulares eficacias, realizan una "combinación más o menos heteróclita y abigarrada" de diversos tipos de prácticas curativas (Módena, 1990: 45).

El reconocimiento del proceso relacional llevado a cabo por los sujetos y conjuntos sociales, quienes en el transcurso de sus trayectorias terapéuticas establecen la red de relaciones entre los diferentes servicios de salud, torna necesario encarar la identificación y descripción de los mismos a partir dichos actores y no de los curadores (biomédicos, tradicionales o alternativos). Desde la "carrera del enfermo" o "carrera del paciente" "podemos identificar todas o, por lo menos, la mayoría de las formas de atención que intervienen en un contexto determinado, lo cual sería difícil de obtener- por muy diversas razones- si partimos inicialmente de los curadores. Pero además, a través de los conjuntos sociales podemos observar el uso articulado de las diferentes formas que usa cada grupo y no los usos excluyentes" (Menéndez, 2004: 14; 2005: 37). Es desde la comprensión de esta articulación de saberes provenientes de diversos modelos de salud que se puede entender el saber de un grupo y "que no se define en términos de tradicional o moderno, ni de científico/no científico" (Menéndez, 1994: 76). Considerar tanto las perspectivas de la población como la de los diferentes tipos de curadores, quienes en tanto integrantes también del campo relacional expresan una parte del sistema de relaciones técnicas y sociales en las que intervienen, permite registrar las diferentes representaciones y prácticas presentes en un contexto determinado evitando una visión unilateral desde alguna de las formas de atención y principalmente asumir una “aproximación relacional” (Menéndez, 1990a; 1994; 2004) capaz de captar la dinámica con que los sujetos se vinculan a los diferentes servicios de salud. Sólo un enfoque relacional atento al nivel de las prácticas sociales, de las actividades desarrolladas por los grupos frente a padecimientos, podrá captar las relaciones entre los diferentes servicios médicos (hegemonía/subalternidad, cuestionamientos mutuos, articulación, etc.) mientras que un análisis basado sólo en las representaciones de los trabajadores de salud reforzará una visión de antagonismos (Menéndez, 1994; 2004). Sin negar la existencia de diferencias Menéndez alerta que "el reconocimiento de estas oposiciones suele darse sobre todo a través de las representaciones técnicas y sociales de los curadores de las diferentes formas de atención, pero mucho menos a nivel de las prácticas de los conjuntos sociales a través de las cuales observamos una tendencia a integrar las diferentes formas de atención más que a antagonizar, excluir o negar unas en función de otras" (Menéndez, 2004: 12; 2005: 35). Si se recurre a la noción de "hegemonía" es porque justamente las relaciones de dominación de un modelo médico sobre otro "no se realiza[n], en la práctica, por la exclusión 
actuante [lo que] se puede ver en el uso combinado de los recursos médicos y populares que hace la población. Si bien el discurso médico excluye las prácticas curativas populares, las sataniza y las proscribe abiertamente de su campo de acción, de hecho tiene que encontrarse con ellas en el terreno del primer nivel de atención” (Módena, 1990: 138).

\section{Navegando a través de un mar de elecciones terapéuticas}

En un examen general de estudios sobre la utilización de la atención a la salud se han identificado con un propósito heurístico, seis orientaciones o enfoques analíticamente distintos (Scambler y Scambler, 1990):

- Económico: centra la explicación en las limitaciones y posibilidades financieras;

- Sociodemográfico: atiende a la influencia de características como sexo, edad, educación en las conductas de búsqueda de atención

- Geográfico: hace hincapié en la relación entre la proximidad geográfica de los servicios y su utilización

- Sociocultural: examina asociaciones entre valores, normas, creencias y estilos de vida de diferentes grupos socioeconómicos y su utilización de los diferentes servicios

- El sistema organizacional: analiza los efectos de aspectos de organización del cuidado de la salud.

Esta clasificación recupera los criterios predominantes en las investigaciones en torno a la búsqueda de atención a la salud, reconociendo que generalmente las explicaciones no se limitan a uno solo de estos factores ignorando el peso de los demás. La elección del servicio de atención si bien está condicionada por los aspectos materiales que configuran su accesibilidad (distancias, posibilidades de traslado, costo monetario, obstáculos burocráticos, etc.) depende también de cómo se identifica la enfermedad, las nociones que se manejen sobre la misma, las formas de enfrentarla transmitidas por el grupo, el aprendizaje a partir de anteriores experiencias personales o relatadas por otros individuos, la evaluación del accionar y competencia de los profesionales y curadores, por mencionar sólo algunos de los elementos que entran en consideración.

Módena utiliza el concepto de "cultura de la salud" para referirse a "las formas de resolver o intentar resolver los problemas de salud y enfermedad" y desde un enfoque influido por el marxismo gramsciano, considera que dicha cultura de la salud se encuentra "determinada estructuralmente por las posibilidades de acceso a ciertos recursos, pero con una 
autonomía relativa en cuanto otros factores -como la tradición histórica plasmada en los usos y costumbres, en el reconocimiento a eficacias técnicas y/o simbólicas de prácticas tradicionales, a las normas del pudor, etc.- establec[en] una cierta homogeneidad local, al menos en algunos aspectos de la atención. En esta cultura de la salud se combina[n] los diferentes recursos médicos, la medicina tradicional u otras formas populares de atención" (Módena, 1990: 44).

Como se afirmó anteriormente, el proceso terapéutico se estructura a partir de la secuencia de decisiones dirigidas al diagnóstico y tratamiento. Los sujetos realizan elecciones terapéuticas orientados por un diagnóstico presuntivo (continuamente reelaborado a partir de la evolución del malestar en función de la terapéutica realizada) y limitados por factores como la accesibilidad física y económica a los diferentes servicios de atención presentes en su contexto de vida. No obstante el énfasis puesto en la decisión, elección y búsqueda de eficacia, las prácticas referidas al proceso terapéutico no deben ser pensadas en términos de costo/beneficio, "de una racionalidad del máximo rendimiento, sino como una estructura abierta redefinida por las posibilidades de instrumentación exitosa, pero siempre amenazada por la carencia de instrumentos y donde lo casi único seguro es uno mismo, el grupo doméstico o una parte del sector social y comunitario que presenta condiciones similares. Las prácticas no son siempre 'estrategias', sino que frecuentemente son actividades que necesitan adecuarse a lo posible y cuya condición de 'estrategia' puede ser referida a la actitud de síntesis continua que necesita desarrollar" (Menéndez, 1990a: 55-56).

También se ha señalado que uno de los disparadores o precipitadores clave de las consultas médicas es la opinión del núcleo de parientes y amigos (red de "consultores comunes" o "sistemas comunes de busca de ayuda médica") que influye y orienta la búsqueda de ayuda médica, inhibiendo o favoreciendo la utilización de alguno u otro servicio de salud, y que frecuentemente pesa como mandato moral, ejerciendo un "sancionamiento" sobre la conducta de los individuos enfermos (Freidson, 1970; Zola 1973 en Scambler y Scambler, 1990: 49-51).

\section{La autoatención}

Así como respecto al estudio de las representaciones sociales, se afirmó la centralidad del encuentro intersubjetivo en la construcción de significados y de una realidad y en el establecimiento de los sistemas de referencia desde los cuales toda experiencia tendrá sentido, 
también a la hora de analizar las prácticas de los sujetos hay que tener en cuenta que éstos las concretan desde su pertenencia grupal. En cuanto a las prácticas frente a los procesos de salud-enfermedad, la mayoría se llevan a cabo dentro del grupo doméstico, ámbito desde donde se busca asegurar la reproducción biológica y social (Menéndez, 1990a; 1990b; 1992a; 1992b).

Siendo los procesos de salud-enfermedad parte constitutiva de la vida cotidiana, un amplio espectro de acciones (desde la actitud consciente de no hacer nada hasta el uso de equipo de determinado grado de complejidad y la automedicación) son realizadas por los propios sujetos y su grupo familiar con el objeto de solucionar o al menos aliviar provisoriamente una situación de malestar (Menéndez, 1990b; 1992a). Este primer nivel de atención a la salud, en el que no interviene directamente un curador profesional, ha sido distinguido y caracterizado como "autoatención" por Menéndez, quien señala su centralidad en su propuesta de un enfoque relacional, pues es "donde se desarrollan la mayoría de las actividades inevitablemente relacionables; es en ella donde se sintetizan las concepciones y técnicas procedentes de diferentes servicios, es aquí donde se desarrollan las estrategias para controlar los padecimientos" (Menéndez, 1990a: 50). Autores que hablan de "medicina casera" también señalan que la misma "partiendo de una vertiente tradicional, se nutre de los conocimientos de la medicina formal por la masificación o popularización del uso de la farmacopea de ambas vertientes, originando un uso y una práctica médica de 'orden casero' basada en la experiencia heredada y adquirida. Otros autores agregan que la medicina doméstica es la que no trasciende ese ámbito como una oferta de servicios, permite la administración de tratamientos caseros o es el puntapié inicial para la derivación del enfermo" (Zolla y Mellado en Prece et al., 1996: 50). Pero por autoatención no se entiende sólo las actividades dirigidas a la curación, también se incluyen aquellas de prevención, alimentación, limpieza e higiene, de ahí que además de ser el recurso de salud primero y más constante sea el proceso que permite que las demás formas de atención puedan funcionar. "Una cosa es hablar de convalecencia y otra asumir que el papel decisivo en gran parte de las actividades de convalecencia está a cargo del sujeto y su grupo a través de acciones de autoatención" (Menéndez, 2005: 42-43). 


\section{Consideraciones metodológicas}

La información fue construida a partir de entrevistas y charlas casuales compartidas con los habitantes de Azampay (incluidos Chistín y La Agüita), observaciones y notas de campo, contando además con aquella obtenida en anteriores trabajos del equipo que facilitó una caracterización general de la población. El trabajo de campo se desarrolló en sucesivos viajes a la localidad (2004, 2005, 2006, 2007 y 2009) a lo largo de los cuales se establecieron relaciones con los lugareños compartiendo charlas en situaciones de trabajo o de ocio, sea en el espacio semipúblico de los patios y galerías de las viviendas, en encuentros casuales en torno a tareas al aire libre o en eventos comunitarios. Los profesionales médicos fueron entrevistados en sus respectivos lugares de trabajo en la ciudad de Belén, en el minihospital de Pozo de Piedra y en la posta de Azampay y el curandero local en su hogar. Se realizaron un total de 80 entrevistas (entre legos y curadores) y mediante observación participante, registrada en notas de campo, se pudo acceder a situaciones coetáneas que no tenían una presencia fuerte y clara en el discurso así como también a los recursos gestuales utilizados por los informantes frente a las limitaciones del lenguaje verbal para transmitir aspectos de la experiencia de enfermedad.

\section{Reflexiones sobre la elección de técnicas para un abordaje cualitativo}

La selección de técnicas se realizó dentro del cuerpo metodológico de la investigación cualitativa, desde donde es posible atender al ámbito de los significados inherentes a los actos, a las relaciones y a las estructuras sociales. La investigación cualitativa se interesa por los sentidos, la manera en que el mundo es comprendido, experimentado, producido por los actores sociales. Por ello es una práctica interpretativa, de resistencia a la naturalización del mundo social, que recupera la relevancia del concepto de mundo de la vida y prioriza la comprensión del punto de vista interno, del significado que la realidad tiene para los individuos y la manera en que estos significados se vinculan con sus comportamientos. De ahí que el principio rector de este modo de investigación sea el hacer posible la manifestación de ese "otro" sin ejercer sobre él la violencia cognitiva imponiéndole un código de interpretación 
al que nunca hubiera apelado para dar cuenta del sentido de sus acciones. Se sustenta fundamentalmente en la comunicación como proceso de investigación interactivo, considerando al lenguaje como recurso y creación, instrumento de reproducción pero también de producción del mundo social (Vasilachis de Gialdino, 2008). Los instrumentos de la investigación cualitativa presentan la ventaja de poder ser continuamente ajustados a las finalidades de la investigación, corregidos y readaptados durante el proceso del trabajo de campo, por lo que su empleo exige una actitud de apertura y flexibilidad, la capacidad de observación y de interacción con los actores sociales envueltos y el esfuerzo teórico de fundamentación presente en cada etapa (Minayo, 2004).

Para acceder a las representaciones y prácticas sociales, es decir, conocer qué se sabe, qué se cree, cómo se interpreta y qué se hace o cómo se actúa, el procedimiento clásico utilizado es el registro de un material discursivo producido en forma espontánea (conversaciones) o inducido por medio de entrevistas o cuestionarios (Araya Umaña, 2002). La técnica de relevamiento central escogida fue la entrevista, si bien con un mínimo de estructuración a partir de un guión temático previamente pautado, su modalidad abierta permitió descubrir e incorporar temáticas del universo del informante no previstas por el investigador. El guión orientó la entrevista, en tanto facilitador de apertura, de ampliación y de profundización de la misma, contribuyendo a la emergencia del punto de vista de los interlocutores, de los juicios y las relevancias respecto de los hechos y las relaciones que componen el objeto de estudio.

Ampliamente la entrevista es definida como un proceso comunicativo que involucra dos actores: el entrevistador y el entrevistado (Alonso, 1998; Valles, 1997), por medio del cual el investigador obtiene información sobre alguna cuestión objeto de su interés. Existen diferentes tipos de entrevistas según el grado de estructuración que adquiera la guía de preguntas y el tipo de respuestas que las mismas habilitan. Es posible pensar esto como un continuum cuyos extremos estarían representados por un lado, por el polo más estructurado conformado por el cuestionario estandarizado en donde tanto las preguntas como el orden en que serán formuladas las mismas está fijado con antelación. En el otro extremo se encuentra la entrevista abierta, en la cual no se haya pautado de antemano ni los temas ni las preguntas a tratar. La entrevista, al brindar una mayor libertad para la iniciativa del investigador e informante (en términos relativos respecto de la encuesta), permite obtener información rica y profunda sobre acontecimientos pasados y presentes, pertenecientes al entrevistado o a terceros, recabar la experiencia de los actores y el punto de vista de los mismos. 
La centralidad de la entrevista como instrumento de producción de información viene dada por ser la comunicación verbal una forma privilegiada de interacción, de gran densidad en cuanto hecho social; por ser el habla reveladora de condiciones estructurales, de sistemas de valores, normas y símbolos (siendo ella misma una de ellos) y al mismo tiempo transmitir, a través de un portavoz, las representaciones de grupos determinados, en condiciones históricas, socio-económicas y culturales específicas (Minayo, 2004).

La información que surge a partir del encuentro entre el investigador social y el entrevistado es producto de esa interacción, "no existe como información de antemano ni yace en algún rincón escondido, esperando a que un arqueólogo de la memoria la descubra. La experiencia surge como información en la medida que el entrevistador y el entrevistado la crean a través de la relación que entablan durante una entrevista" (Ocampo y Gracia, 1994: 51). Así como el entrevistado no es un mero relator de hechos objetivos, el entrevistador tampoco es un receptor neutro. "La narración es diálogo -presente de distintas maneras en el relato que luego será sometido a la lectura- porque es un acto de comunicación complejo. El entrevistador induce la narración, por parte del sujeto entrevistado, de su propia historia y a partir de allí se desarrolla ese acontecimiento singular de interacción entre los dos actores, en el cual cada uno participa desde la particular posición que ocupa en esa situación social" (Chirico, 1987: 442). Al preguntar se busca "establecer un puente o medio a través del cual sea posible ir y venir entre universos culturales", "activar con las preguntas los recursos culturales del actor para observarlos en operación" y en la interacción con el entrevistado conocer por experiencia estos contenidos ajenos encarnados en su conducta (Sanmartín Arce, 2000: 111, 121).

Así, hay dos niveles de subjetividad implicados en todo conocimiento basado en la experiencia del encuentro con el otro: por un lado, subjetividad "alude a una suerte de auscultación del mundo del otro: una aproximación al punto de vista del sujeto, a sus percepciones y significados profundos que se encuentran necesariamente mediados por conceptos, tipos ideales y meta-lenguajes. Acercarse al punto de vista del sujeto que se estudia nos enfrenta directamente con la naturaleza abierta de la interpretación y la exégesis, y con los límites de la arbitrariedad". Por otra parte, subjetividad refiere a "la relación dialógica entre ambos: los informantes no nos dan únicamente 'datos' sino que están comprometidos con nosotros en una crucial relación intersubjetiva y en un continuo diálogo. Es posible comprender la otra cultura no sobre la base de la acumulación de datos, sino cuando es posible relacionarse dialógicamente con los informantes, y cuando esta acción adquiere un sentido razonable para ambas partes. Esta segunda subjetividad, además de ser dialógica, 
como se dijo, es también desigual y asimétrica: a veces es el investigador el polo dominante, otras es el sujeto investigado (también los sujetos de estudio ejercen violencia y desconocimiento sobre los entrevistadores). La situación de entrevista entraña siempre una vulnerabilidad" (Makowski Muchnik, 2000: 3).

El contexto en el cual tiene lugar la entrevista es esencialmente problemático pues se constituye a partir de la confrontación entre dos mundos. Si la relación entre entrevistador y entrevistado no es dialógica, en el acto de oír al "informante" el entrevistador ejercerá un poder, subyacente a las relaciones humanas, empobreciendo el proceso cognitivo. Sólo en la medida en que se transforme ese informante en interlocutor, creándose condiciones de diálogo efectivo, podrá ocurrir aquella "fusión de horizontes" que posibilitará al investigador oír al nativo y ser igualmente oído por éste, sin temor de estar contaminando el discurso del nativo con elementos de su propio discurso. La situación de diálogo, de verdadera interacción, transforma la confrontación de horizontes semánticos, el del investigador y el del nativo, en un verdadero encuentro etnográfico, creando un espacio semántico compartido por ambos interlocutores (Cardoso de Oliveira, 1996).

Como toda interacción social, la entrevista está sujeta a la misma dinámica de las relaciones existentes en la sociedad por lo que la información construida en su transcurso debe incorporar también aquella extraíble del contexto (prácticas, gestos y complicidades, el habla informal sobre lo cotidiano), de ahí la importancia de mantener en dicha instancia la atención constante propia de la técnica de observación participante (Selltiz, et al., 1959). La entrevista, "se funda en la más amplia observación participante, sin cuyos datos difícilmente podría plantearse con eficacia; requiere, para cumplirse en su totalidad, que el entrevistador observe el hecho mismo de la entrevista y, finalmente, ella misma es observación de ese despliegue en vivo de los recursos culturales que hace el entrevistado en su discurso" (Sanmartín Arce, 2000: 111).

Vínculo entre experiencia y narración, la entrevista no se sitúa exclusivamente en el orden del hacer (campo de las prácticas) ni en el orden del decir (campo lingüístico), sino en el campo intermedio: el decir del hacer. La técnica de observación fue tenida en cuenta no por un afán de "corregir" las "distorsiones" entre prácticas y representaciones sino para analizar el vínculo complejo entre estos dos niveles y para recuperar aquello que no se enuncia; aquello que por razones afectivas o por pudor no es verbalizado, o que por no ser considerado de interés, o no ser del todo consciente no tiene una presencia fuerte y clara en el discurso. La observación participante, centrada en las relaciones informales del investigador en el campo, permite captar una variedad de situaciones o fenómenos que "transmiten lo que hay de más 
imponderable y evasivo en la vida real" (Neto, en Minayo et al., 2002: 47). Guber indica que el acto de participar no necesariamente implica encarnar algún rol local "establecer nuevas relaciones, seguir a los informantes en sus tareas, entablar conversaciones casuales o concertadas, acompañarlos al hospital, a la escuela o a visitar parientes y tomar notas son algunas de las actividades que se pueden desarrollar desde el rol de investigador" (Guber, 2004: 124). Si bien la observación participante "enfatiza las relaciones informales del investigador en el campo" esto no implica una disminución de la atención teórica (Minayo, 2004: 92), pues parte de estas charlas espontáneas "pueden servir a la función de las entrevistas, en las que otros miembros darán al observador información sobre sucesos ya pasados, sus reacciones ante acontecimientos presentes, etc. Tales entrevistas serán generalmente no estructuradas; el observador puede combinarlas con notas más específicamente observadoras en sus informes y análisis” (Selltiz et al., 1959: 241).

\section{EI trabajo de campo}

En una primera etapa, la de apertura, llevada a cabo durante los trabajos de campo de noviembre-diciembre de 2004, octubre de 2005 y marzo-abril de 2006, se trabajó con un guión de preguntas descriptivas (sucesivamente reelaborado conforme se avanzaba en el trabajo de campo y en el relevamiento bibliográfico) a los fines de armar un marco de términos y referencias, de ir construyendo los contextos discursivos desde los cuales avanzar hacia preguntas culturalmente relevantes y poder distinguir lo que pertenece al informante y lo que proviene de las propias inferencias y preconceptos, relativizando la perspectiva del investigador. La formulación de preguntas abiertas que se van encadenando sobre el discurso del informante permite el desarrollo de una categorización diferida en la que el investigador debe revisar sus propias pautas de categorización a la vez que identifica los intersticios del discurso del informante en donde "hacer pie" para reconocer y reconstruir su lógica (Guber, 2001). En términos generales, el guión estuvo orientado a suscitar la narración de las secuencias más o menos detalladas de percepciones sintomáticas, decisiones, búsqueda de atención, procedimientos terapéuticos realizados, evaluación de resultados.

Los trabajos de campo de marzo de 2007 y marzo de 2009 correspondieron a la etapa de focalización y profundización tendiente a abrir sentidos en determinadas direcciones e indagar las dimensiones de una categoría o noción. A medida que se identifican los temas y categorías recurrentes que configuran el marco interpretativo del actor se van planteando 
preguntas "contrastativas" para establecer distinciones entre categorías (por ej. enfermedades de los médicos/enfermedades de los curanderos o médicos campesinos) y preguntas "estructurales" para identificar relaciones entre las mismas (sensu Guber, 2001). Haber realizado la etapa de campo en cinco viajes permitió dicha focalización progresiva a la vez que posibilitó el seguimiento de procesos de salud-enfermedad-atención a lo largo de varios años (especialmente de aquellos malestares crónicos o aquellos de larga duración) congruentemente con lo anteriormente citado acerca de que los procesos terapéuticos se extienden más allá del evento agudo de malestar.

En el último viaje de campo se pudo constatar la saturación de la información. Como se sostiene en la investigación cualitativa, el concepto de representatividad se refiere a una "saturación del conocimiento", es decir, "llegar a un punto en la información o en la comprensión tal que lo aportado por nuevas entrevistas resulte ya sabido y redundante. Esa saturación de la información puede servir como criterio para estimar la suficiencia de la muestra etnográfica recogida" (Sanmartín Arce, 2000: 120).

Las entrevistas fueron grabadas y los diálogos casuales (registrados junto con las observaciones en la libreta de campo) fueron transcriptos inmediatamente después de la escucha y/o conversación.

Durante el primer trabajo de campo se colaboró con el equipo de odontólogos y antropólogos sociales en la realización de las encuestas para el estudio de las enfermedades periodontales. El mismo tenía como objetivo testear un modelo conceptual socioecológico para dichas enfermedades teniendo en cuenta la organización del cuidado de la salud, aspectos biológicos, factores comportamentales y medioambientales, a indagar mediante un examen clínico, una encuesta y una serie de entrevistas semiestructuradas. Considerando su utilidad secundaria para este trabajo, algunas preguntas generales no contempladas en dicho estudio fueron incorporadas a la encuesta de ese año. De allí se recuperaron, como aproximación inicial, los malestares mencionados por la población y la utilización de los diferentes servicios de atención médica. Cabe señalar que aunque las preguntas de la encuesta eran estructuradas y cerradas (conforme a los requerimientos del posterior análisis estadístico), fueron realizadas por antropólogos a modo de entrevistas semiestructuradas y las preguntas agregadas, al no formar parte del test estadístico fueron abiertas permitiendo una amplia variación de respuestas. Sin embargo, como se pudo comparar ya con las primeras entrevistas, una serie de 
malestares (la mayoría taxa vernáculos ${ }^{8}$ ) así como dos niveles de atención (el de la autoatención y el de la medicina tradicional) estuvieron ausentes en los diálogos planteados en torno a las encuestas, como si la vinculación de éstas al modelo biomédico subyacente a la práctica odontológica hubiera acotado implícitamente el tema de salud-enfermedad-atención a las enfermedades y servicios de cuidados contemplados por dicho modelo.

Para la realización de las entrevistas se tuvieron en cuenta tanto los adultos legos como algunos trabajadores de los diferentes servicios de atención a la salud, dado que el objetivo era identificar las enfermedades y dolencias predominantes (denominación, explicación causal), las estrategias y recursos terapéuticos utilizados (para el diagnóstico, prevención y atención) desde la perspectiva de los pobladores en general así como también desde la de quienes trabajan en los diferentes espacios de atención a la salud. Sin embargo, y de acuerdo a lo planteado por Menéndez, un enfoque que pretenda captar el proceso relacional llevado a cabo por los sujetos y conjuntos sociales, quienes en el transcurso de sus trayectorias terapéuticas establecen la red de relaciones entre los diferentes servicios de salud, torna necesario encarar la identificación y descripción de las diferentes formas de atención y la variedad en el uso articulado de las mismas a partir de lo que estos actores hacen y dicen y no de los curadores (biomédicos, tradicionales o alternativos). Lo cual "no supone que reduzcamos la identificación de los padeceres ni de las formas de atención sólo a los que reconocen los conjuntos sociales, sino que este es el punto de partida para establecer la existencia de los padeceres y de las formas de atención que los grupos no sólo reconocen sino que sobre todo utilizan" (Menéndez, 2004: 15). El autor advierte el riesgo de obtener visiones polarizadas si sólo se consideran las perspectivas de los trabajadores de los distintos servicios de salud, así como el frecuente error, en los estudios de medicina popular de asumir una univocidad entre el saber de los curadores populares y el saber comunitario. "Se asume implícitamente que dichos curadores expresan el saber tradicional en términos del portador/actor de la cosmovisión del grupo referida al proceso de salud/enfermedad/atención" [..] "la no inclusión de una diferenciación entre el saber del curador profesional y el saber de conjuntos sociales conduce a no observar la posible discrepancia entre los mismos, y a no tomar en cuenta los procesos de transformación que están operando, sobre todo en el saber de los conjuntos sociales, dada la multiplicidad de influencias que operan sobre sus

\footnotetext{
${ }^{8}$ El término "taxa vernáculos" es utilizado por Idoyaga Molina y Korman para referirse a categorías tradicionales de enfermedad irreductibles a los taxa biomédicos. Estos autores contraponen dicha denominación a la de "síndromes dependientes de la cultura" que implica una invisibilización del factor cultural de las categorías biomédicas a la vez que ignora la transculturalidad de muchos de los taxa tradicionales atribuyéndoles una pertenencia cultural exclusiva (Idoyaga Molina y Korman, 2002).
} 
representaciones y prácticas respecto del proceso salud/enfermedad/atención” (Menéndez, 1997: 264).

Se realizaron 70 entrevistas a legos ( 8 varones y 20 mujeres de entre 40 y 80 años y 10 mujeres de entre 17 y 35 años), habiéndose entrevistado además en todos los trabajos de campo a la enfermera de la posta sanitaria y al curandero azampeño, en el 2004 y 2009 al médico de zona, en el 2007 al director y a personal del área de estadística del Hospital de Belén, al director y a un pediatra de un sanatorio privado de la misma ciudad.

La prevalencia de mujeres entrevistadas se debe a la dinámica laboral y migratoria de la localidad por la que "la casa se constituye en un campo social nítidamente femenino" (Maffia, 2005: 117). Como esta autora señalara, "una parte de los hombres está fuera, trabajando la tierra, en los peridomicilios de sus viviendas, en la construcción o reparación de la casa propia, ajena o de los edificios públicos (iglesia, escuela, posta sanitaria, o caminos) y regresa a mediodía para almorzar y a la noche para dormir. Un elevado porcentaje de los hombres, en la franja etaria comprendida entre los 17 y 41 años, está fuera de Azampay durante la mayor parte del año, son los migrantes internos por razones laborales. Ellos regresan al hogar para las fiestas, los carnavales o en alguna otra ocasión especial. En estos últimos años se han sumado muchas jóvenes mujeres a este movimiento poblacional" (Maffia, 2005: 113). De ahí que también la mayoría de las mujeres entrevistadas correspondan a edades superiores a los 40 años.

\section{- ¿Cómo está?, - con el favor de dios y la mamá virgen, bien}

Indagar acerca de cuestiones de salud y enfermedad presentó por un lado la dificultad de trabajar con temas vinculados a la intimidad, al dolor, a la moral del cuidado y autocuidado: cómo presentar el interés por ese aspecto de la cotidianidad sin que parezca mera morbosidad, ya que no siendo trabajadora de la salud tampoco se ofrecían soluciones frente a los hechos sobre los que se preguntaba. Pero por otra parte, y siendo los procesos de salud-enfermedad-atención "una de las áreas de la vida colectiva donde se estructuran la mayor cantidad de simbolizaciones y representaciones colectivas", "uno de los principales ejes de construcción de significados colectivos" (Menéndez, 1994: 71), el tema emerge espontáneamente en las conversaciones, ante la mera pregunta "cómo anda?" que acompaña todo saludo e inicio de conversación. Como señala Mallart Guimerà, "en la mayoría de las sociedades, el mismo saludo lleva consigo una respuesta que hace referencia al tema de la 
salud, que fácilmente puede prolongarse ahondando en temas relacionados con enfermedades, síntomas, diagnósticos, médicos, fracasos, itinerarios terapéuticos, mención de consejos recibidos, opiniones sobre médicos o agentes de salud", recuperar "de qué manera enfermos y allegados hablan de las enfermedades, las designan y las describen [...] es perfectamente realizable en estos encuentros informales. Serán los primeros datos que luego serán completados y confrontados con otros obtenidos de manera más intencional" (Mallart Guimerà, 2008: 188). Así, la mayoría de las entrevistas se desarrollaron a partir de comentarios espontáneos acerca de algún padecimiento en curso o ya pasado de la persona entrevistada o de algún conocido de ésta. En cada trabajo de campo hubo situaciones que por su gravedad y/o inhabitualidad (fallecimientos, operaciones, crisis de padecimientos crónicos como epilepsia o desequilibrios mentales) eran motivo de conversación en cada hogar que se visitaba. Como se señaló anteriormente, momentos conflictivos, acontecimientos complejos y dolorosos generan en el conjunto social una "presión a la inferencia", una demanda de expresión de opiniones, posicionamientos y acciones frente a tales hechos. Esto permitió recuperar diferentes explicaciones, conjeturas y actitudes en torno a un mismo evento, aprovechando la emergencia no forzada del tema. De esta manera, las entrevistas siguieron el curso de las conversaciones donde las intervenciones propias apuntaron, como sugiere Sanmartín Arce, a ir "introduciendo los temas de nuestro interés en la conversación, sin cortar ni abrumar a nuestros informantes con un caudal de preguntas, sino cogiendo el paso o siguiendo el hilo de sus argumentos. De hecho, una vez que hemos presentado el tema ante el informante, la mayoría de nuestras preguntas no son propiamente tales, sino meros apoyos a su discurso con el fin de lograr que prosiga, que no pierda el hilo recordándole lo que él mismo ha dicho. Sólo cuando percibimos que su propio discurso ha cubierto un tramo argumental, ha terminado un razonamiento, una descripción o el propio informante ha perdido interés por las ideas que se están tratando, intentaremos introducir una nueva cuestión" (Sanmartín Arce, 2000: 118).

La participación que permitió realizar las observaciones, establecer relaciones con los lugareños a partir del involucramiento personal y ser incluida en charlas espontáneas, quedó planteada como presencia en carácter de visita, ya que fuera de la labor de investigadora no se llevó a cabo ninguna otra tarea. Mi intromisión en la cotidianidad de los azampeños tuvo lugar en el espacio semipúblico de los patios y galerías de las viviendas donde se realiza la mayoría de las labores domésticas (hilado, amasado del pan, secado de nueces, lavado de ropa) y donde también se reúnen familiares y amigos. Allí compartí charlas generalmente grupales en situaciones de trabajo o de ocio, adaptando el guión de entrevista a una serie 
encadenada de entrevista en profundidad, entrevista de grupo, conversación, observaciones y participación de acuerdo a la situación particular. La presencia de más de una persona resultó en conversaciones donde las diferentes opiniones se iban intercalando, retroalimentando y complejizando los temas comentados.

También estuve presente en eventos comunitarios como un día de elecciones (son llevados hasta la localidad vecina de La Ciénaga a votar, donde se les ofrece bebida y comida en lo que oficia de comité o unidad básica), la misa mensual, la fiesta de finalización del año escolar. Encuentros casuales en torno a tareas al aire libre como la cosecha y el riego, durante trayectos a pie o mientras esperan llamados en el teléfono público, fueron también oportunidades para dialogar. "A veces, en las conversaciones mantenidas durante los trayectos, los actores vierten frases que condensan ejemplarmente alguno de los elementos etnográficos que perseguimos. Ni se trata de una entrevista, ni es posible grabarla, pero el hecho ilustra el modo como irrumpe la etnografía que resulta relevante y a cuya ocurrencia hemos de amoldarnos, recordándola y anotándola lo antes posible. En realidad, lo que esos hechos revelan es algo enteramente usual en todo trabajo de campo. Es el proceso de interacción social el que marca la pauta para llevar a cabo nuestro trabajo. De ahí que no podamos concebir la entrevista como algo aislable del resto de técnicas y procesos del conjunto de una investigación de campo" (Sanmartín Arce, 2000: 116).

Ocasiones de especial atención por su directa relación con el tema de saludenfermedad fueron la espera en la posta durante la visita del médico de zona, una ida grupal al curandero de otra localidad, los viajes a la ciudad de Belén ya que uno de los principales motivos es la consulta médica, la consulta al curandero local (si bien no se me permitió observar el procedimiento por él realizado, en más de una ocasión estando yo de visita en su hogar llegaron individuos requiriendo su atención, en otras ocasiones yo acompañé a quien quería consultarlo).

Tener como lugar de residencia la escuela donde también pernoctan algunos docentes me hizo partícipe no sólo de algunas actividades escolares (actos, reunión de padres, momentos de esparcimiento con los niños) sino también de charlas entre el personal docente y no docente (trabajan allí 2 mujeres y 2 varones como ordenanzas y cocineros) durante los momentos de descanso o entretiempos. La directora, quien también se aloja en la escuela de lunes a viernes, y quien tiene lazos de compadrazgo con casi todo el pueblo, era frecuentemente consultada y requerida ante cualquier inconveniente, particularmente los de salud, por lo que en más de una ocasión presencié e incluso colaboré (se me pidió llevar algún 
recado, transmitir algún pedido, o si no tenía yo algún medicamento) en actividades que extienden el nivel de la autoatención más allá del grupo doméstico.

Algunas preadolescentes acostumbraban acompañar a la directora durante la cena quedándose a pasar la noche, actitud que extendieron a mi persona cuando me sabían sola. Si bien las entrevistas fueron planteadas entre adultos, las charlas con ellas aportaron muchas veces nueva información que se indagó en posteriores entrevistas. Además se estableció con ellas una relación cálida que facilitó entrevistarlas, ya como jóvenes mujeres, en los últimos viajes de campo. En más de una ocasión fui yo quien recibió visitas oficiando de anfitriona en la cocina de la escuela.

En todo momento fue crucial tener en mente el guión de entrevista pero no a la manera de "un diseño tan completo que ahogue la naturalidad social según la cual se producen las situaciones en el contexto" (Sanmartín Arce, 2000: 116) sino como una atención constante a detectar en el fluir de lo cotidiano los dichos y hechos relevantes a mi tema de estudio y a aprovechar la emergencia espontánea de los mismos para su indagación. Un día me encontraba leyendo en la cocina de la escuela cuando una de las ordenanzas, asomándose por la ventana, me preguntó si estaba ahí la directora. Tan inmersa estaba en mi lectura que su voz inesperada me sobresaltó en extremo. Pasado el segundo de sorpresa ambas nos reímos del suceso. A la mañana siguiente, cuando salía para realizar alguna de mis visitas me crucé con ella que estaba limpiando el patio de la escuela. Al saludarme, y tras la pregunta formal de cómo había amanecido, me preguntó si había dormido bien, si no había quedado "asustada" por lo sucedido el día anterior. Obviamente retrasé mi salida quedándome a charlar con ella acerca del susto, sus causas, síntomas y terapéuticas. Mi propia corporalidad fue en ocasiones disparador de conversaciones en torno a procesos de salud-enfermedad-atención: si bien tuve la suerte de realizar mi residencia en el campo sin mayores problemas, no faltó un resfrío, un malestar estomacal, alguna incomodidad corporal que generara comentarios, sugerencias, conjeturas y acciones terapéuticas por parte de los lugareños.

\section{Análisis de la información}

El cuerpo de información transcripto fue clasificado en torno a nodos temáticos utilizando el software ATLAS.ti, concebido para la gestión y análisis (cualitativo) de datos cualitativos. Este programa está pensado para trabajar con la lógica de la Grounded Theory (de Strauss y Corbin), dado que permite ir generando, desde los datos particulares, códigos 
para organizar la información y establecer, ya a un nivel de mayor abstracción, relaciones entre los mismos, así como la elaboración teórica en vinculación con los fragmentos concretos de las entrevistas.

Los códigos son palabras-clave que identifican lo seleccionado, indicadores de conceptos o de expresiones que interesan al investigador con los que se marcan (codifican) las citas. El programa ATLAS.ti admite que un código pueda marcar multitud de citas distintas en un número ilimitado de documentos y que a una misma cita se le atribuyan distintos códigos. Las citas pueden ser desde una palabra hasta muchos párrafos, pudiendo haber intersección o solapamiento entre ellas. Este programa permite realizar el proceso de codificación sin que los documentos primarios (en este caso las entrevistas completas) sean modificados, ya que los mismos permanecen almacenados independientemente; lo que esta herramienta informática acopia son referencias sobre los mismos, las citas, la fragmentación de los documentos en torno a códigos relacionados con su significación e interpretación.

Trabajar con los fragmentos codificados hizo posible una lectura transversal de las entrevistas en torno a cierto tema (representado en el nombre elegido como código). Realizar el proceso de codificación utilizando este programa facilitó la reunión y análisis de todos los datos que se refieren a un mismo tema (identificados bajo un mismo código) sin necesidad de crear un nuevo documento o texto independiente y manteniendo la unidad de la entrevista, y permitió editar códigos o unidades de análisis por separado o relacionados.

Cabe enfatizar que la asignación, definición y relación de códigos es tarea interpretativa del investigador. En la codificación, el material discursivo es fragmentado en unidades que son conceptualizadas, nominadas (se les adscribe una "etiqueta verbal" que interprete el significado) y luego articuladas analíticamente de un modo nuevo (Araya Umaña, 2002). Desde la Grounded Theory se propone llegar a conceptos o categorías no a partir de la impresión de un sólo incidente ni forzando los incidentes a entrar en conceptos preconcebidos sino a partir de la comparación constante de datos, de numerosos incidentes hasta la saturación de la información, que permitan descubrir cuidadosamente un patrón (Glaser, 2008). Este tipo de codificación se denomina codificación abierta pues las categorías empíricas se van estableciendo a partir de la lectura interrogativa, exhaustiva y repetida de las entrevistas, y en confrontación con las categorías analíticas teóricamente establecidas como señales de la investigación, buscando las relaciones dialécticas entre ambas (Minayo, 2004). 


\section{Caracterización geográfica y poblacional}

\section{El departamento de Belén}

La localidad de Azampay se halla a $50 \mathrm{~km}$ de la ciudad de Belén, cabecera del departamento homónimo, en la provincia de Catamarca. Este departamento posee una superficie de $12.945 \mathrm{~km}^{2}$ y una población de 20.926 habitantes, de los cuales 11.521 habitan en su capital (según el censo de población del año 2001). Formaciones montañosas con alturas mayores a los 3000 metros (sierras de Las Cuevas, Fiambalá y Culampajá) y que son parte del Cordón Central de las Sierras Pampeanas constituyen su topografía, junto con estructuras menores centrales como las sierras de Belén, Hualfín y La Alumbrera. El Río Belén es la principal cuenca de drenaje que sustenta no sólo la ciudad de Belén sino también las poblaciones de Hualfín, San Fernando, La Ciénaga, entre otras. Sobre la misma se cultivan importantes extensiones de aromáticas para condimentos, que junto con el cultivo de la vid, el nogal, olivo, duraznero y la papa constituyen la principal actividad agro industrial (procesamiento de aceitunas, conserva de hortalizas, dulces regionales, molinos pimenteros y bodegas).

Como industria artesanal se destaca la producción de tejidos en lanas de oveja, guanaco y llama (antiguamente también de vicuña y alpaca) siendo Belén un centro importante de desarrollo de la misma, basada casi exclusivamente en la mano de obra femenina (Hermite y Klein, 1972, en Maffia y Zubrzycki, 2001). La actividad ganadera principal es la cría de camélidos autóctonos y ovinos en las zonas altas $(99,9 \%$ y $81 \%$ del total provincial), y la cría caprina y bovina en las zonas llanas (48\% del total provincial).

La actividad minera, en manos de la empresa transnacional Bajo La Alumbrera Ltd. cobró importancia a partir de la década del noventa, debido a la existencia de yacimientos poli metálicos, entre ellos oro, plata y cobre. Si bien en el nivel macroeconómico la exportación del concentrado de cobre y otras provenientes del mismo sector, revirtieron el carácter internista del comercio provincial, que pasó de exportar 6 millones de dólares en 1990 a 462 millones en 1998 y 476 en 1999, el impacto en la economía local del proyecto, a partir de demanda de servicios y mano de obra y la participación regional del PBI, fue mucho menor de lo estimado (A. Mastrángelo, 2000, en Maffia y Zubrzycki, 2001), el “efecto derrame” no se cumplió y parece poco probable que tenga lugar de inmediato. 
Respecto a la situación económica del departamento de Belén, en el año 2001 el porcentaje de población en hogares con necesidades básicas insatisfechas (NBI) era de 28,8\% (sobre el total de población del departamento) ${ }^{9}$. Sobre lo que hay que considerar además que “el peso porcentual de la población rural pobre es superior al de la urbana en la mayor parte del territorio nacional", en el caso del NOA supera el 85\% (Murmis, 1996: 76 en Maffia y Zubrzycki, 2001).

\section{La localidad de Azampay}

Azampay (1800 msnm) se encuentra ubicada al pie de los cerros que limitan por el occidente al Valle de Hualfín, el cual se extiende desde las sierras homónimas por el norte hasta la Puerta de San José al sur, donde se estrecha en la Quebrada de Belén que separa las Sierras de Belén al oeste y el Atajo al este. Como el río corre recostado contra el macizo del Atajo, el valle presenta una forma asimétrica, con su margen occidental más expandido respaldado por Las Sierras de Altohuasi y el Cordón de La Falda. En el amplio explayado situado al pie del Cordón de La Falda, se abren de norte a sur las quebradas de El Carrizal, Azampay, Chistín, Agua Verde, Grande, del Tío, entre otras.

Alrededor de 1890 se establecieron las primeras viviendas que darían origen a Azampay y los puestos vecinos a partir de la ocupación paulatina por parte de puesteros y medieros que comprarán derechos sobre pequeñas parcelas destinadas a la vivienda familiar y cultivos para el consumo, junto al uso común de campos para pastoreo. Con el tiempo, a medida que los hijos crecían y formaban sus propias familias, se fueron subdividiendo las tierras, sin juicios sucesorios, originándose caseríos basados en vínculos de parentesco (Maffia y Zubrzycki, 2001).

Un camino de acceso medianamente transitable desde la ruta provincial $\mathrm{N}^{\circ} 40$ une Azampay con la localidad de Belén, caminos también de tierra y en algunos casos sólo sendas transitables a pie o a lomo de burro la vinculan con los puestos de Chistín (3 km), La Agüita $(5 \mathrm{~km})$, El Carrizal $(7 \mathrm{~km})$ y El Tolar (aproximadamente a 7 horas de camino por los cerros pues se halla a unos $3800 \mathrm{msnm}$ ). Aunque todas estas localidades (exceptuando El Tolar) dependen administrativamente de la Municipalidad de La Puerta de San José, es Azampay el núcleo de las relaciones económicas, religiosas, familiares, etc., dado que allí se encuentran la

\footnotetext{
${ }^{9}$ Fuente: INDEC. Censo Nacional de Población, Hogares y Viviendas, 2001.

En http://www.indec.mecon.ar/webcenso/index.asp
} 
única escuela, la iglesia (establecidas entre 1940 y 1960), el comedor infantil (dependiente de la municipalidad), el club (espacio de actividades comunales), un pequeño almacén y la posta sanitaria (desde principios de los 80) de la zona.

La población de Azampay, junto a la de Chistín, La Agüita y El Carrizal, conforme a los datos consignados en el informe "Control niño sano" de junio de 2006 realizado por el Área de Estadística del Hospital de Belén, era de 256 habitantes, distribuidos de la siguiente manera:

$\begin{array}{lcc} & \text { varones } & \text { mujeres } \\ \text { Menor de 1 año } & - & 2 \\ 1 \text { año } & 2 & 4 \\ 2 \text { a 4 años } & 8 & 7 \\ 5 \text { a 9 años } & 19 & 16 \\ 10 \text { a 14 años } & 19 & 10 \\ 15 \text { a 49 años } & 64 & 50 \\ \text { más de 50 años } & 23 & 32 \\ \text { total } & 135 & 121\end{array}$

La tasa global de fecundidad (promedio de hijos por mujer al término de su vida fértil) en Azampay es de 5,3 hijos por mujer, semejante a la tasa de 1955 para Catamarca donde el promedio era de 6 hijos, tasa que en 1991 llega a 4, nivel que se considera muy elevado si se tiene en cuenta que para el mismo año el total del país era 2,9 hijos por mujer (INDEC, Serie 11, 1997 en Maffia y Zubrzycki, 2001). Las jóvenes comienzan a tener hijos a partir de los 15 años, muchas veces cuando aún sus propias madres siguen teniendo embarazos, de manera que tíos y sobrinos se crían juntos (Maffia, Zubrzycki y Ballina, 2005).

La población de Azampay y los parajes vecinos está organizada en grupos domésticos constituidos por familias extensas y familias nucleares. En el caso de las primeras, que resultan de la extensión mediante los lazos de casamiento y la prolongación en el tiempo de las relaciones entre padres e hijos, sus miembros generalmente no residen en una misma vivienda sino en unidades habitacionales separadas, dentro de lo que parecen ser antiguas territorialidades familiares. Las familias nucleares tienden a agruparse y a vivir cerca de la casa paterna cualquiera sea ella, no haciendo referencia a un tipo de residencia patrilocal (Zubrzycki, 2007). "Las formas de ocupación del espacio en Azampay tienen que ver no sólo con las relaciones de parentesco, cooperación y solidaridad familiar, sino con la particular 
modalidad de tenencia de la tierra y usos del agua. La tenencia de la tierra es compartida haciendo uso común de los recursos (tierras para pastoreo, obtención de leña, recolección de algarroba, etc.), llamándose 'tierras indivisas', 'estancias' o 'campos comuneros'. Los individuos usufructúan sólo pequeñas parcelas aunque se reconocen con derechos sobre el total de estos inmuebles indivisos rurales" (Maffia y Zubrzycki, 2005: 36). Según los datos del relevamiento catastral (Dirección de Catastro de Catamarca) realizado en Azampay en 1981, el 72,5\% de los predios tienen una superficie menor a una hectárea, el 22,5\% entre una y cinco hectáreas y sólo el 5\% de los predios supera las cinco hectáreas (Maffia y Zubrzycki, 2005).

El agua se obtiene de los pequeños ríos que bajan por las quebradas y se distribuye a través de un sistema de acequias cavadas en la tierra. Cada familia se rige por un turno de agua estipulado en un listado "virtual" que todo el pueblo conoce y el cual se ha ido confeccionando a lo largo de los años. El mismo es empleado para el riego de parcelas relativamente grandes (para maíz, trigo, frutales), la hortalizas y verduras se cultivan en pequeñas huertas cerca de las casas y se las riega generalmente con agua corriente. La venta de "horas de agua", en algunos casos, es independiente de la venta de tierras. Durante el año 2009 miembros del proyecto "Desarrollo de un modelo productivo para la recuperación sociocultural de poblaciones marginales de la provincia de Catamarca: Azampay, una experiencia piloto"10, realizaron el análisis físico-químico y bacteriológico del agua de Azampay, Chistín y El Carrizal concluyendo que de acuerdo a los parámetros medidos y a la legislación vigente (artículo 982 del Código Alimentario Argentino) todas las muestras son aptas para consumo desde el punto físico químico. En cuanto al análisis bacteriológico, se observó un elevado número de UFC (unidades formadoras de colonia en placa por mililitro), pero ausencia de patógenos, por lo que consideraron recomendable clorar la red de distribución ${ }^{11}$.

La vivienda está conformada por varios recintos de planta rectangular distribuidos alrededor de un patio de tierra apisonada. Cada habitación tiene una pequeña ventana y la puerta que comunica a la galería abierta. En las construcciones más antiguas las paredes tienen cimiento de pirca doble y están hechas de bloques de adobe (barro y paja sin cocer), lo que ha sido reemplazado en los últimos 15 años por ladrillos huecos de cemento confeccionados allí mismo. Los pisos son de tierra apisonada y en contados casos de cemento

\footnotetext{
${ }^{10}$ Dirigido por la Dra. María Carlota Sempé y co-dirigido por la Dra. Susana Salceda. Acreditado por la Agencia Nacional de Promoción Científica y Tecnológica, Código PICTO 32142.

${ }^{11}$ Informes $n^{\circ} 1 \mathrm{~A}, 2 \mathrm{~A}, 3 \mathrm{~A}, 1 \mathrm{~B}, 2 \mathrm{~B}$ y 3B, Universidad Nacional de Catamarca, 29 de enero de 2010. Lic. Susana Martínez de Montiel, química y especialista en Gestión Ambiental.
} 
alisado. El techo de las habitaciones se prolonga hasta la galería donde se sostiene por horcones, está hecho de cañas y ramas dispuestas sobre vigas de álamo o cardón, con una capa de barro o dos (con nylon intercalado como aislante del agua). En algunas viviendas ha sido reemplazado por techos de chapa o losa, y se ha cerrado la galería que guarda ahora nuevos artefactos domésticos como la heladera, el televisor, equipo de música, etc. Hace alrededor de una década cuentan con electricidad y agua corriente (no potabilizada, se distribuye sin ningún tipo de tratamiento desde piletones que la colectan río arriba). A unos 15 metros de la vivienda se encuentra la letrina, pero en los últimos años y con ayuda del gobierno y la municipalidad se han construido baños con pozo más próximos a las habitaciones (Maffia, 2005).

\section{Ocupación y subsistencia en Azampay}

Zubrzycki ha destacado que los hogares azampeños no se desconectan o aíslan en una economía de subsistencia, sino que tratan de mantener o incrementar canales con la sociedad nacional mediante migraciones y especialmente con el Estado, a través de la escuela, el empleo público, las pensiones y retribuciones para pasivos y los planes sociales para los desocupados (Zubrzycki, 2007).

La actividad ganadera está restringida a ganado menor (cabras y ovejas), burros, mulas y escasos equinos. Sólo tres familias en Azampay, una en La Agüita y una en Chistín poseen hacienda, cuya producción se destina al consumo familiar y a la venta ocasional. Se aprovechan los pastos y aguadas del pie de monte y en invierno los de las zonas más húmedas cerro arriba, por lo que todos los días se liberan y guían los animales hacia sus pasturas encerrándolos al atardecer nuevamente en los corrales. Su alimentación se completa con alfalfa y chauchas de algarrobo. En algunas casas se crían cerdos que se consumen en ocasiones festivas, y gallinas, principalmente por sus huevos.

En una tierra que depende del agua sumamente escasa, sin inversiones ni mejoramiento tecnológico, los cultivos se limitan a alfalfa, maíz, zapallo, cebolla, trigo, poroto, papa, tomate, lechuga, zanahoria y acelga para consumo familiar, al igual que frutales como durazneros, membrillos, manzanos, perales y vid. El único cultivo para la venta es la nuez, con el apoyo de la municipalidad han realizado injertos para mejorar la variedad del fruto pero su producción es variable, habiendo años de buen rendimiento y otros donde, sea 
por la falta de agua o por lluvias inoportunas, apenas se obtienen frutos para el consumo. La cosecha exige un trabajo intenso durante los meses de febrero y marzo.

En 1998 miembros del equipo de investigación llevaron a cabo una encuesta (a un total de 77 encuestados, quienes, salvo 3 casos, estaban residiendo de forma permanente en la localidad) y entrevistas focalizadas para conocer la situación ocupacional y los movimientos migratorios de los pobladores, información que fue analizada en los trabajos aquí citados.

La ocupación principal de las mujeres está vinculada a la actividad textil (pullos, chales, ponchos, básicamente con lana de oveja) aunque se ha reducido considerablemente en las últimas décadas, como consecuencia de una significativa disminución en la venta y en su valor como bien de intercambio (Maffia y Zubrzycki, 2001). Esta labor junto a tareas vinculadas a la tierra ha permitido que las madres solteras y sus hijos constituyan el núcleo del grupo doméstico convirtiéndose en una unidad productiva viable, situación que comenzó en la época de la migración a la zafra: "Cuando migraban el pueblo se quedaba sólo de mujeres, ellas se ocupaban de la hacienda” (Maffia, Zubrzycki y Ballina, 2005: 96).

Los varones trabajan como agricultores y en mayor proporción en empleos de la municipalidad realizando tareas ligadas a la construcción, reparación de caminos y canales, etc. Dos varones y dos mujeres son empleados de la escuela (porteros) y un agente sanitario y una enfermera trabajan en la posta sanitaria. Aún aquellos que cuentan con una jubilación, pensión o plan social complementan sus ingresos con los beneficios resultantes de la producción agrícola-pastoril y el telar artesanal.

Los niños también realizan algunas actividades como hacer pastar los animales o cuidar las huertas, las niñas ayudan en el trabajo doméstico, cocina y limpieza de la casa, mientras que los varones realizan algunas "changuitas" para otros vecinos como atender el turno de riego o recolectar las nueces en la época de cosecha (Maffia, Zubrzycki y Ballina, 2005).

Para quienes están desocupados la única posibilidad de obtener un trabajo es desplazarse fuera de Azampay; casi todos los individuos incluidos en esta categoría migraron por trabajo en algún momento (el 17,1\% de las mujeres y el $24 \%$ de los varones). Muchos varones se trasladan hacia la provincia de La Rioja, especialmente a las localidades de Vichigasta y Aimogasta, a las cosechas de viñas, olivos y jojoba, ausentándose durante dos o tres meses y regresando a sus casas hasta la próxima actividad agrícola estacional. Aquellos que migran hacia centros urbanos desarrollan tareas en el rubro de la construcción, ya sea como obreros contratados en empresas constructoras, o por cuenta propia en las ciudades de Belén, San Fernando del Valle de Catamarca y diversas localidades de La Rioja. Este tipo de 
migración rural-urbana se caracteriza por un mayor tiempo de permanencia en los lugares de destino y por ser una opción también para las mujeres. Muchas jóvenes ya no se dedican al tejido y se emplean en el servicio doméstico en casas de familia, principalmente en las ciudades de Belén y San Fernando del Valle de Catamarca, retornando al menos una vez por año para las fiestas y enviando dinero y/o mercadería con variada frecuencia a la familia de origen y los hijos que quedan en Azampay. Generalmente algún pariente que se ha establecido fuera facilita este tipo de migración (Maffia y Zubrzycki, 2001). "De este modo, se plantea una situación similar a la descripta por G. Karasik (1985) para los pequeños conglomerados poblacionales de la Puna, donde se complementan los recursos propios de una economía de subsistencia con los que se generan a través de la migración estacional o las redes parentales de solidaridad que se extienden hasta los centros urbanos dentro y fuera de la región" (Maffia y Zubrzycki, 2005: 37).

Estos movimientos migratorios repercuten en la estructura y el funcionamiento familiar, muchas de las mujeres que migran dejan sus hijos en Azampay a cargo de los abuelos, que se desempeñan como "pater" y "mater" (padres sociales) de los hijos que genealógicamente son sus nietos. Ellos reemplazan o llenan el vacío que han dejado sus padres, en la condición de hijos, sustituyéndolos también en la calidad de herederos de las tierras y el agua, mientras que permanezcan en el seno familiar. En tanto que los hombres y mujeres que hayan migrado se mantengan solteros o sin uniones estables continúan perteneciendo a la familia de origen y aportando al mantenimiento de la unidad doméstica. Cuando constituyen una nueva familia en el lugar donde se han establecido, dejan de realizar estos aportes (Maffia y Zubrzycki, 2001, 2005).

El régimen de tenencia de la tierra, del agua y su sistema de reparto, que impide una mayor productividad, el creciente deterioro de la rentabilidad del tradicional trabajo textil, la presión demográfica, la escasez de otras oportunidades laborales en la zona, la atracción ejercida por la ciudad, las nuevas oportunidades en el mercado de trabajo extracomunitario, han impulsado la generación de estrategias individuales y grupales fuera de las localidades de origen o residencia. Mientras que décadas atrás era la zafra el motivo de emigración estacional de los varones, en la actualidad tanto varones como mujeres migran hacia centros urbanos incorporando prácticas, valores, símbolos y recursos materiales originados en el afuera. 
En los últimos años la presencia de planes sociales (en el 2004 había 20 mujeres y 4 varones beneficiarios del Plan Jefas y Jefes de $\operatorname{Hogar}^{12}$ ) ha permitido la retención de jóvenes en la localidad quienes deben cumplir 4 horas de trabajo diario en tareas de limpieza, cocina (en el comedor infantil), mantenimiento de caminos, acequias, etc.

\footnotetext{
${ }^{12}$ El Programa Jefas y Jefes de Hogar Desocupados ha sido creado a través del Decreto $\mathrm{N}^{\circ}$ 565/02 del Poder Ejecutivo Nacional y la normativa complementaria que reglamenta su ejecución, elaborada por el Ministerio de Trabajo, Empleo y Seguridad Social de la Nación. Tiene por objeto brindar una ayuda económica a las jefas y jefes de hogar desocupados con el fin de garantizar el Derecho Familiar de Inclusión Social, asegurando: la concurrencia escolar de los hijos, así como el control de salud de los mismos; la incorporación de los beneficiarios a la educación formal; su participación en cursos de capacitación que coadyuven a su futura reinserción laboral; su incorporación en proyectos productivos o en servicios comunitarios de impacto ponderable en materia ocupacional.

Fuente: http://www.trabajo.gov.ar/programas/sociales/jefes/files/instructivojefasyjefes.pdf
} 


\section{Descripción del sistema estatal de atención a la salud y del perfil epidemiológico de la población azampeña}

\section{El sistema estatal de atención a la salud en la provincia de Catamarca}

El sistema de salud de la provincia de Catamarca se encuentra organizado en 12 áreas programáticas atendidas por hospitales zonales y distintos puestos sanitarios (CAPS). Los departamentos de Belén y Antofagasta de la Sierra conforman el área programática $\mathrm{n}^{\mathrm{o}} 11$, el área más grande de la provincia: $43.000 \mathrm{Km} 2$, un 35\% de la superficie total de la provincia. El hospital cabecera de la misma es el hospital zonal de Belén, que consta de 68 camas con 4 servicios básicos: clínica médica, maternidad, cirugía y pediatría. El departamento de Belén cuenta con los hospitales seccionales con internación (alrededor de 12 camas) de Londres, Villa Vil, Hualfín, Antofagasta de la Sierra, y los hospitales seccionales sin internación de Pozo de Piedra, Puerta de Corral Quemado y Corral Quemado.

El Ministerio de Salud de la Provincia de Catamarca ha planteado como objetivo acercar la atención en salud al lugar de residencia y trabajo, en el marco del reconocimiento de que la atención primaria de la salud es la asistencia sanitaria esencial y el primer nivel de contacto de los individuos, la familia y la comunidad con el sistema de salud, por lo que debe considerarse núcleo principal del sistema nacional de salud. Desde 1968 hasta 1982 (con una interrupción entre 1973 y 1976) se desarrolló en Catamarca el Programa Asistido de Salud Rural logrando una cobertura del $87 \%$ de la población rural cuando los índices de mortalidad infantil estaban ubicados en el 130\%o. En 1992, cuando la tasa de mortalidad infantil se ubicaba en el 26.9\%o, la Atención Primaria se constituye en política del Estado Provincial y se capacitan e incorporan 251 agentes sanitarios. En 1994 mediante la firma del Decreto Acuerdo $N^{\circ} 341 / 94$, se brinda el marco legal en el que se desarrolla el Programa Provincial de Atención Primaria de la Salud y se crea la Unidad de Proyectos Especiales de Atención Primaria de la Salud, a nivel de Dirección y bajo dependencia directa de la Subsecretaría de Salud Pública del Ministerio de Salud y Acción Social. El accionar sostenido de esta política se refleja en un índice de mortalidad infantil en el año 2001 del 15,6\%o, valor ubicado por debajo de la media nacional ${ }^{13}$.

\footnotetext{
${ }^{13}$ Datos obtenidos de la página web del Ministerio de Salud de la provincia de Catamarca, consultada el 19 de setiembre de 2009. http://www.catamarca.gov.ar/salud/ministerio/index.php?option=com content\&task=view\&id=13\&Itemid=9
} 
Un componente del Programa de Reforma de Atención Primaria de la Salud es el Programa REMEDIAR que cuenta con financiación del Banco Interamericano de Desarrollo. Es un programa de emergencia sanitaria que provee medicamentos esenciales a la red de Atención Primaria a fin de reactivar la capacidad de respuesta de los servicios públicos de salud. En Catamarca el programa cubrió los centros de menos de 20 camas y médicos permanentes, inicialmente aquellos con más de 300 consultas mensuales y posteriormente se incorporaron 11 nuevos CAPS (Centro de Atención Primaria de la Salud) del interior provincial con más de 100 consultas mensuales.

Los CAPS están integrados por agentes sanitarios, enfermeros, médicos, en algunos casos obstetras y trabajadores sociales. Pero la figura clave en este nivel de salud básico, concebido como articulador entre la comunidad y el sistema de salud central, es el agente sanitario, el cual se espera sea efector de la política social, diagnosticando las necesidades de la población, gestionando ante el nivel central los recursos imprescindibles para contener situaciones que afectan de manera directa a los sectores más vulnerables, manteniendo un contacto permanente con las familias.

Son actividades del agente sanitario realizar el control de talla y peso de niños para la detección y captación de desnutridos, de niños enfermos para el control de tratamientos; realizar la vacunación con Sabin, Triple, Doble Niño, ANSI-sarampionosa, BCG, AntihepatitisB, Antigripal, etc.; la búsqueda y derivación de patologías varias (Tuberculosis, Infecciones Respiratorias Agudas, diarreas) supervisando sus tratamientos; el seguimiento de embarazos y promoción del parto hospitalario; la derivación de mujeres en edad fértil para planificación familiar y estudios preventivos de cáncer genito-mamario, o de próstata en el hombre; la distribución de leche del Plan Materno Infantil y módulos alimentarios; supervisar el desempeño de comedores comunitarios; colaborar con el censo de población, familias y viviendas mediante la ratificación de datos demográficos y contribuir en el diseño de acciones focalizadas a través de la visión que construye en base al monitoreo de su comunidad.

En el año 2007 la provincia de Catamarca contaba con 54 postas sanitarias y eran 395 los agentes sanitarios responsables de promover el ejercicio del derecho a la salud. Las postas de lo que se denomina Norte Chico (abarca los municipios de Pozo de Piedra y La Puerta de San José, con un total de 3800 habitantes) dependen de un solo médico, generalmente es el que tiene asignado el minihospital de Pozo de Piedra, y que realiza las visitas a las postas. Este médico de zona visita quincenalmente una totalidad de 13 postas sanitarias (Condorhuasi, La Toma, La Aguada, La Barranca, La Junta, La Estancia, Puerta de San José, La Ciénaga de Abajo, La Ciénaga de Arriba, Azampay y Chistín, entre otras). 
Los médicos entrevistados destacaron que es el Norte Chico la zona más desprotegida del área programática $\mathrm{n}^{\circ} 11$, por la ausencia de un médico permanente en las postas y la poca frecuencia de visita del médico de zona, sumado a las dificultades de transporte para el traslado de la población hacia el hospital más cercano y el acceso del médico de zona a ciertos poblados (la ambulancia no puede llegar a lugares como Chistín, La Agüita o El Carrizal por lo que sus pobladores deben acercarse hasta la posta de Azampay, dependiendo de que su estado físico se lo permita).

D: ... está muy olvidado, el sistema de salud está malo, funciona mal, te digo porque yo hice la zona, si bien que no hice Azampay, yo hacía la otra zona, del Norte Grande, yo hacía La Soledad, El Durazno, Jacipunco, Corral, Puerta de Corral, El Eje y San Fernando, por ejemplo, en San Fernando un día, yo pasé ese día, un día después que había fallecido un niño en la ruta, esperando un auto que lo trajera porque tenía convulsiones febriles, una cosa que no tiene nombre, un niño que fallece una convulsión por fiebre, no falleció porque tenía una meningitis o una hipoxia cerebral porque tuvo un, no nada, una cosa muy sencilla, le das ibuprofeno, que al estado le debe costar 3 pesos y se le acabó la fiebre y se le fue la convulsión y se salvó el chiquito, y no hay medios de transporte porque el chiquito salió a la ruta, estuvo tres horas, la madre con él en brazos y se le murió en brazos la criatura, yo que tengo hijos me pongo a pensar y es escalofriante, realmente es escalofriante (P8, médico pediatra del sanatorio) ${ }^{14}$.

Similares limitaciones fueron señaladas en un estudio sobre problemas de salud, enfermedad y atención en comunidades de los departamentos de Capayán y Belén: "La información registrada de entrevistas a sectores profesionalizados del sistema de salud oficial pone en evidencia esta limitación, para todos los conjuntos sociales pertenecientes a este contexto, sea por la falta de accesibilidad geográfica o por la incomunicación de los sujetos que pertenecen a sistemas culturales en situación de subalternidad" [...] "En algunos informantes estas percepciones aparecen como sentimientos de abandono y frustración, construyendo un discurso respecto de la salud oficial: “-ahora no hay médico de zona, estuvo el Dr. S era bastante acertado, pero se fue hace como dos años, vea, no duran los médicos acá”. Las distancias y el aislamiento hacen que los médicos del sistema oficial perduren poco tiempo en estas localidades, renunciando o solicitando traslado a localidades más urbanizadas” [...] “-El médico de la posta por la casa no venia nunca, sacar número y esperar hasta las 12 y a veces no la atendia y los partos me los he controlado en la ciudad, y también nacieron ahí, la leche y vacunas se las daban acá” (Torrent, 1998: 6).

\footnotetext{
${ }^{14}$ Los fragmentos de las entrevistas son citados con la numeración con que las mismas quedaron ordenadas en la Unidad Hermenéutica del Programa ATLAS.ti.
} 


\section{Los servicios de atención a la salud en Azampay}

La posta sanitaria de Azampay fue establecida en los años 80 y es atendida de lunes a viernes por una enfermera y un agente sanitario oriundos de dicha localidad (capacitados en Belén y Catamarca respectivamente) y cada 15 días por el médico de zona. Su llegada es anunciada generalmente por radio 3 o 4 días antes y los azampeños deben retirar un número para la consulta habiéndose establecido últimamente un máximo de 15 pacientes para ser atendidos. Ante dudas, los enfermeros consultan por teléfono al médico y en situaciones en las que por la cantidad de enfermos se quedan sin remedios lo llaman para que adelante su próxima visita.

El médico, dependiendo de su inserción laboral, lleva a la posta remedios desde el Hospital de Belén o el de Pozo de Piedra, el cual cuenta con la cobertura del Plan Remediar. De éstos, algunos pueden ser dejados en la posta ("un stock de remedios muy limitado que maneja la enfermera, como para bajar la temperatura, algo para el vómito, manejan síntomas nada más”, P9, director del Hospital de Belén) no así aquellos que necesitan la prescripción del médico. Además ocasionalmente reciben donaciones de la empresa minera La Alumbrera, que si bien significa una entrada apreciada de insumos, no contempla las necesidades locales.

D: las donaciones de La Alumbrera son relativas porque en realidad ellos no han pedido una lista de la medicación que se utiliza en un centro periférico entonces ellos te traen 5 litros de pervinox que vos no vas a usar nunca, porque las curaciones que se hacen acá, sí se hacen curaciones pero no vas a usar 10 litros por mes tampoco vas a usar la pila de guantes que te traen ni los paquetes de algodón y por ahi un ibuprofeno, una Novalgina que es lo más habitual vienen 3 frasquitos (P59, médica de zona).

Teóricamente el centro de atención primaria de Azampay debe trabajar en articulación con el hospital de Pozo de Piedra, el que debería proveerle medicamentos y demás insumos, y a donde deberían ser derivados los pacientes que necesitaran tratamientos más complejos. Sin embargo, no habiendo comunicación directa entre ambas localidades (se debe hacer un recorrido en U desde Azampay a la ruta 40 y de ésta a Pozo de Piedra, ver mapas anexos), los azampeños se dirigen a Belén, no sólo quienes necesitan atención médica sino también el agente sanitario que busca en el hospital medicamentos e insumos como guantes, vendas o lavandina, leche y los módulos alimenticios.

D: lo que pasa es que ellos bajan, salen a la ruta y pasan directamente derecho, ellos bajan hasta acá [señala la Puerta de San José en el mapa] y en vez de volver hasta acá 
para Pozo de Piedra pasan de largo y otro problema es el tema del transporte, cada vez que hay un problema en Azampay vía policia, se comunica por vía radial y nos avisan de que tenemos que mandar la ambulancia desde acá, a veces mandan la ambulancia de Hualfín pero a quien corresponde que es Pozo de Piedra no la mandamos porque es una ambulancia que no está en condiciones, es una F100 que encima gasta 3500 pesos en combustible (P9, director del Hospital de Belén).

El médico de zona eleva quincenalmente un informe al hospital de Belén y cuando la gravedad supera las soluciones que pueden darse desde la posta los pacientes son derivados a este hospital o al de la ciudad de Catamarca si requieren una especialidad carente en Belén (por ejemplo traumatología o neurología). También son derivados a Belén cuando deben realizarse estudios o análisis para precisar el diagnóstico (radiografía, ecografía, análisis de sangre, orina, coproparasitológico) y para posteriores consultas ya con los resultados de los mismos.

T: por ejemplo, hay un chiquito que tiene diarrea, entonces informamos la diarrea y él me pone si está controlada, si es un caso de desnutrición, viene acá y se interna, el médico que tenía un paciente en Chistín o Azampay lo deriva a este hospital cabecera se ingresa la demanda de atención médica se interna y según la patología que sea, si es algún caso complicado se lo deriva al hospital de niños, al hospital de niños de Catamarca (P23, Técnico del área de Estadística del Hospital de Belén).

Los embarazos son controlados desde la posta donde se le entrega a la futura mamá mensualmente 1 kilo de leche, 2 kilos desde el nacimiento hasta el año del bebé y nuevamente 1 kilo hasta los 2 años (aunque a veces por reducciones en la partida se prioriza la entrega de leche a los menores de 1 año). Además las mujeres son derivadas a Belén para consultas con el obstetra y la realización de los estudios de rutina. Se promueve que el parto sea también en la ciudad por lo que muchas mujeres se trasladan a la misma cuando la fecha estimada se acerca. Respecto a prácticas anticonceptivas en el año 2009 la médica de zona contaba sólo dos mujeres siguiendo el Programa de Planificación Familiar ${ }^{15}$ por el cual recibían pastillas anticonceptivas.

El Ministerio de Salud de la Provincia viene desarrollando el Programa Móvil Rural de Detección Precoz del Cáncer Génito-Mamario, el cual se lleva a cabo a través de una unidad móvil denominada MAMISAN a cargo de 2 profesionales especialistas, uno en ginecología y otro en imágenes que recorren la provincia realizando tareas preventivas (papanicolaou y mamografías) en beneficio de las mujeres que habitan áreas rurales. En el año 2008 eran 8 las mujeres de Azampay que habían accedido al mismo, sin detección de

\footnotetext{
${ }^{15}$ El Programa de Salud Sexual y Procreación Responsable fue creado por la Ley Nacional No 25.673. A fines del año 2006 alrededor de 6100 centros de salud y hospitales en todo el país ofrecían prestaciones del programa, siendo 1.900 .000 los usuarios del mismo. Su implementación consiste, entre otras actividades, en la entrega de insumos a las provincias para su distribución gratuita en los Centros de Atención Primaria y hospitales públicos a solicitud de los usuarios, con asesoramiento o consejería especializada.
} 
patologías.

\section{Caracterización del estado de salud de los azampeños}

Desde la caracterización de los médicos entrevistados, los azampeños se diferencian de los pacientes de la ciudad no por el tipo de problemas de salud sino porque llegan a los centros de atención con grados más avanzados de la enfermedad dadas las distancias y dificultades de transporte, porque en su mayoría tienen escasos recursos económicos y presentan, especialmente los niños, un estado de mal nutrición lo que afecta su sistema inmunitario, vulnerabilizándolos frente a enfermedades como la diarrea o las respiratorias, además de repercutir en su rendimiento escolar.

D: son niños que por ahí empiezan con una angina y al no tener la atención médica digamos a mano allá siempre termina progresando [...] la característica siempre es esa, que un niño que viene de allá, cuando viene, viene generalmente con un diagnóstico un poco más grave que un niño de acá de la zona, por el hecho de que siempre progresa hacia más. Otra cosa es que es gente muy humilde, muy humilde, que vos antes de recetarles, tenés que ponerte a pensar con la mano en el bolsillo del paciente y decir, hay cosas que vos sabés que le va a hacer bien y se lo tenés que recetar y no se lo podés, porque no lo va a poder comprar, es imposible comprarlo, por ejemplo un buen antibiótico [...] los niños tienen la misma incidencia de enfermedades que acá, tanto los de Azampay como los de otras [...] en el estado de mal nutrición que tienen, más allá que sea desnutrición o bajo peso, la mal nutrición que tienen eso a veces favorece algún tipo de enfermedad, como ser las enfermedades respiratorias que son las más frecuentes siempre en los niños, las enfermedades respiratorias tanto bajas como altas son las más frecuentes en los niños (P8, médico pediatra del sanatorio).

Las enfermedades frecuentes en la población de Azampay son las respiratorias (angina, bronquitis, neumonía), astralgias (explicada por las arduas condiciones de vida y trabajo), hipertensión arterial, problemas digestivos y parasitosis. La parasitosis es un problema en todo el departamento de Belén, según la opinión del pediatra un $90 \%$ de los niños tiene parásitos, consecuencia de la falta de potabilización del agua y de escasas medidas de higiene (entre ellas la carencia de sistemas de eliminación de aguas servidas) y una de las causas del bajo peso que presentan los niños. La mayoría de los niños azampeños tienen bajo peso y muchos presentan desnutriciones crónicas, es decir, ya tienen afectada la talla.

Según el estudio de crecimiento y nutrición realizado por antropólogos de la UNLP en la población infanto-adolescente de Azampay, se observaron altos porcentajes de individuos con malnutrición aguda y porcentajes inferiores de malnutridos crónicos, además de altas 
frecuencias de fluorosis ${ }^{16}$ y gingivitis y frecuencias medias a bajas de hipoplasia, periodontitis y caries, evidenciando una deficiencia de vitaminas y un incorrecto aseo bucal. En una población sin deficiencias nutricionales es esperable que el 10\% de los sujetos se encuentren por debajo del percentilo 10 de la distribución de referencia (OMS, 1986). En la población analizada, el porcentaje de niños con desmedro (baja talla para la edad) es inferior a lo citado, pero existe una alta prevalencia de las formas agudas de desnutrición (bajo peso para la estatura) (Padula et al., 2005).

Desde el hospital de Belén reciben gratuitamente el tratamiento contra las parasitosis y a través de la posta las familias con niños con bajo peso (en el año 2009 eran 4 niños) reciben módulos alimentarios (teóricamente la entrega es mensual, pero las madres de los niños afectados refirieron que la entrega no era regular), además la médica de zona distribuye ocasionalmente vitaminas con oligoelementos como el zinc y el hierro. En el ya citado informe "Control niño sano" de junio de 2006 consta que el 100\% de los niños azampeños había recibido las vacunas B.C.G., Sabin, cuadruple, triple viral, hepatitis A y B, refuerzo, triple bacteriana, doble adulto $1^{\mathrm{o}}$ y $2^{\mathrm{o}}$ refuerzo.

Dentro de la población infanto-adolescente azampeña hay tres casos de discapacidad: de acuerdo al diagnóstico de la médica de zona se trata de un caso de oligofrenia, una niña con hidrocefalia (usa silla de ruedas y sufre frecuentemente de infecciones urinarias, vinculadas a su estado) y un niño que no camina ni habla debido a "problemas constitucionales", en palabras de la doctora de zona. Los dos primeros casos tienen controles periódicos y siguen tratamientos en la ciudad de Catamarca para lo que cuentan ocasionalmente con pasajes por discapacidad. En el año 2007 comenzaron a tramitar una pensión por discapacidad de 400 pesos y en el año 2009 la madre del niño ya la estaba cobrando. También se registraron dos casos de adultos que padecían de trastornos convulsivos y estaban bajo tratamiento neurológico en la ciudad de Catamarca (uno de ellos obtiene la medicación en forma gratuita). Ocasionalmente quienes deben viajar regularmente a la ciudad de Catamarca obtienen apoyo monetario de la municipalidad, pero, según los entrevistados, el mismo está sujeto a la red de relaciones sociales y políticas que cada individuo posea.

Siendo el mal de chagas una enfermedad endémica en Catamarca, sumado a que las condiciones de vida rural favorecen la proliferación del vector, los médicos estiman una alta frecuencia de esta parasitosis en poblaciones como la de Azampay aunque se desconozcan las cifras reales de infectados para dicha localidad. Con el fin de evaluar la situación de esta

\footnotetext{
${ }^{16}$ En el citado análisis físico químico del agua se registraron valores de fluoruros de 1,526 y 1,803 mg/litro en Chistín y Azampay respectivamente. Si bien el CAA acepta hasta $2 \mathrm{mg} / \mathrm{l}$, cuando el valor supera los $1,2 \mathrm{mg} / 1$ se produce la fluorósis cuya característica es un esmalte moteado.
} 
afección según la percepción de sus pobladores, un grupo de docentes y alumnos de la cátedra Métodos y Técnicas de la Investigación Sociocultural de la carrera de Anropología de la UNLP realizó en 1996 un estudio inicial antropológico-epidemiológico sobre la enfermedad de Chagas en la localidad de Azampay. Se llevó a cabo una encuesta especialmente diseñada, de fácil respuesta independientemente del nivel de instrucción, a 56 personas de ambos sexos y de edades entre 11 y 78 años. De la misma se obtuvo que la gran mayoría conocía la vinchuca y aseguraba no haberla visto en su casa o alrededores; la mayoría reconocía que se habían realizado tareas de fumigación anti-vinchuca, sin embargo la dispersión del conocimiento sobre la última vez que se realizó la fumigación fue enorme (variando entre 1 mes y 10 años); casi todos desconocían personas picadas por vinchucas y la existencia de enfermos chagásicos aunque referían conocer una importante cantidad de individuos cardiópatas. Dado el largo período que por lo regular separa el momento del contagio del mal de Chagas con la aparición del daño (lo cual hace casi imposible establecer un vínculo entre el vector y la enfermedad), sumado a su evolución crónica y frecuentemente desapercibida, o al menos no relacionada con los síndromes agudos o las muertes súbitas y al hecho de que el conocimiento de la enfermedad no pueda conducir a una actuación dirigida a la cura, se entiende que no se alcanza a valorar la amenaza de esta enfermedad (Maffia et al., 2000).

D: el mal de chagas es una enfermedad rara, no es que te mata, te tira a la cama, es lento, muy lento y te da sintomas que no son muy visibles, porque el chagas agudo, cuando recién te pica la vinchuca, esté el ojo en compota, hematoma en el ojo, que es un hematoma muy característico pero fuera de eso lo único que te da es un bloqueo, te produce una arritmia cardiaca, y de ahi te puede dar algún grado de insuficiencia cardíaca ya cuando es más crónico pero es muy silente ( $\mathrm{P} 8$, médico pediatra del sanatorio).

Más allá de las apreciaciones sobre el estado de salud de ésta población, los médicos entrevistados describieron a los azampeños como pacientes comunicativos y expresivos (en comparación con otros pueblos) que acuden con frecuencia al hospital y sanatorio de Belén, y aunque a veces entre los adultos se observa que una vez reducido el síntoma no regresan a controlar la evolución de un tratamiento, sí retornan cuando el enfermo es un niño, siendo la madre quien generalmente se encarga de llevarlo. Refieren como característico de los pobladores rurales de la región el uso de yuyos y analgésicos de venta libre como modos de autoatención que sólo atenúan los síntomas o, en el mejor de los casos, producen una leve mejoría y la consulta a médicos curanderos sólo como primera opción justificada por la cercanía geográfica (desconociendo las situaciones en que la medicina oficial es la primera opción contrastada luego con consultas a un curandero) y cuyo accionar se basa en un 
conocimiento por ensayo y error.

D: vienen para acá, cuando se enferman vienen para acá y vienen por todo tipo de patologías, no era como antes que venía un viejito que había hecho una evolución de la enfermedad, crónica, digamos, y recién bajaba, no, no, ahora vienen, consultan al médico con más frecuencia, con mucho más frecuencia ( $\mathrm{P} 10$, director del sanatorio).

D: por ejemplo cuando están con infecciones urinarias "tomé palo azul, cola de caballo", son unos yuyos, tienen ciertas propiedades diuréticas y si bien que no hacen tratamiento especifico de la infección urinaria al mejorar la diuresis produce una limpieza de la vía urinaria y eso alivia mucho los síntomas, entonces para ellos, ya todo el mundo sabe que está con ardor al orinar y empiezan a tomar agua con esa infusión, con esos yuyos (P8, médico pediatra del sanatorio).

D: generalmente cuentan y dicen "bueno, yo ya fui a la médica campesina y no me ha hecho nada, por eso me tuve que venir", muchas veces la primera opción es el médico que tienen, o sea ellos "médico campesino" le dicen, la primera opción, como lo tienen a mano usan eso, si evoluciona mal, digamos, ya bajan

A: y qué les recetan?

D: los médicos campesinos generalmente recetan té y esas cosas [...] sabe qué le dan, es muy común, como ser Sertal, entonces dan Sertal para todo el mundo, Buscapina para todo el mundo, y vitaminas, generalmente viene el médico campesino toma una vitamina tal que uno le indica y como ha sido buena para él la indica para todo el mundo (P10, director del sanatorio). 


\section{Las opciones terapéuticas mencionadas por los azampeños}

Se relevaron los padecimientos predominantes mencionados por los entrevistados (padecidos personalmente o por familiares o conocidos, tanto en la actualidad como en tiempos pasados), junto a los conjuntos de síntomas considerados en el diagnóstico, los factores identificados como patógenos y las respuestas terapéuticas dadas en cada caso. A partir de esto último se identificaron las distintas opciones terapéuticas empleadas provenientes de modelos de atención diferenciados (la biomedicina, la medicina popular y la autoatención) así como los factores que influyen en la elección y el acceso a las mismas.

En Azampay se observa un uso combinado de los diferentes espacios de atención para la salud: el ámbito doméstico con sus respuestas caseras, la atención de curanderos dentro o fuera de la localidad, los servicios (bio)médicos locales y de las ciudades de Belén y Catamarca (públicos o privados).

\section{Recursos terapéuticos desde la medicina oficial}

Se distingue en las explicaciones y narraciones de los azampeños una jerarquización de los servicios brindados en la posta, el hospital de Belén, los sanatorios privados de esa ciudad y la atención en la ciudad de Catamarca, a partir del nivel de complejidad de los procedimientos de diagnóstico y tratamiento.

En cuanto al uso de la posta sanitaria, los motivos de consulta nombrados por la enfermera no difieren de los referidos por los mismos azampeños: enfermedades respiratorias (resfrío, tos, dolor de garganta que a veces terminan en angina o bronquitis), fiebre, vómitos, diarrea, dolor de estómago, de cabeza, de huesos y articulaciones, de muelas, presión alta, alergias y nervios. Las respuestas dadas desde este centro de atención consisten en jarabes para la fiebre, analgésicos, anti-inflamatorios, antibióticos (amoxilina, dipirona), sales de hidratación, vitaminas, complemento de hierro y/o calcio. También acuden mensualmente las mujeres embarazadas a quienes se pesa, se mide la presión y la altura del cuello uterino y se entrega la leche. Sólo por urgencia han tenido que atender algunos partos, pues cuando se aproxima la fecha se las deriva a Belén. 
La escasez de remedios y de otros insumos (jeringas, agujas, aparato de esterilización) es destacado por la enfermera, así como limitaciones para la resolución de problemas de vista, de dientes, inflamación a la vesícula, agravamiento de enfermedades respiratorias, entre otros, por lo que son derivados a Belén.

Con frecuencia los azampeños igualmente se dirigen a dicha ciudad por no haber quedado conformes con el diagnóstico y/o tratamiento dado en la posta, experiencia que es tenida en cuenta en posteriores eventos de enfermedad en los que se decide acudir directamente a los servicios de atención de Belén. Ellos señalan como incompetencia y limitación de los servicios ofrecidos en la posta el hecho de que en ausencia del médico, el diagnóstico realizado allí se base sólo en (y quede restringido a) las percepciones y construcciones explicativas del paciente.

La frecuencia de visita del médico y la modalidad de atención varía con el médico de zona, el cual es cambiado cada un par de años, por lo que en las referencias a la atención recibida, son frecuentes las comparaciones entre los distintos médicos que han "hecho zona" allí. Así mencionan que un médico anterior avisaba el mismo día que iba a ir por lo que muchos no se enteraban, o que a diferencia del actual que atiende sólo a 15 pacientes, el anterior atendía a todos los que concurrían (a veces entre 50 o 60 personas), evaluaciones que repercuten en la decisión de acudir o no a la consulta.

$P$ : no, no, éste [el médico de zona] es así muy, no es un médico que, por ejemplo usted lo lleva al chico ni lo revisa, ni lo toca nada, no, por ejemplo usted va y le dice "mire doctor, me duele aqui'", no, él la mira nomás y le hace la indicación de los remedios y le da los remedios [...] y dicen que es el doctor de zona nomás [...] hasta que por ahi lo cambien porque por ahi lo van a cambiar, si andan un tiempo y ya los llevan para otro lado, por ejemplo al doctor $S$ [médico anterior] lo han trasladado para el norte, ya por la antigüedad que tenía

A: y él cómo los trataba, cómo los atendía?

P: él los revisaba, pero los revisaba de bien! [...] uno le explicaba las cosas, por ejemplo, él nos preguntaba qué ha tenido, si cómo han empezado, por ejemplo cuando tenían vómitos así, él decía de cómo le había empezado, de cómo había sido cuando ha vomitado por primera vez, qué ha vomitado, cómo ha vomitado, y bueno, uno le explicaba ve? [...] ese doctor era rebueno

A: $y$ éste?

$P: y$ este por ahi es medio rebelde, por ahi uno va y hay veces que lo atiende pero hay veces que dice "no, ya atendí demasiado", ya no lo atiende (P19, mujer, 43 años).

L: no me cae muy bien [...] pero dicen que ... por ejemplo con mi mamá es bien buenito, le da los remedios, bien [...] pero digo yo, pero él le da remedios pero no le hace ningunos estudios, puede ser que esos remedios también algunos no le vayan bien (P16, mujer, 22 años). 
Por otra parte, la dificultad de traslado para quienes viven en La Agüita y Chistín desalienta el uso de la posta. Estando estos puestos a menos de $5 \mathrm{~km}$ de Azampay, que se considere más accesible ir hasta Belén que a la posta es ilustrativo, al igual que el nulo uso del hospital de Pozo de Piedra, de cómo el alcance de las fronteras espaciales es percibido y evaluado a partir de un sentimiento de distancia y de aislamiento, de líneas con otras comunidades, afectando la relación con los distintos servicios de salud (Bibeau, 1995).

Las dificultades de transporte son señaladas como un factor que eleva los riesgos, sobre todo en situaciones de urgencia médica. Desde el año 2006 un mini-bus administrado por la municipalidad realiza tres viajes semanales (busca pasajeros de madrugada y los trae a la tarde, el costo del viaje era de 5 pesos en el 2009) a Belén solucionando en gran medida dicha carencia, en su ausencia resta pagar un taxi (alrededor de 100 pesos en el año 2009) o conseguir casualmente algún vehículo que al menos vaya hasta la ruta y de allí un colectivo.

F: y la ambulancia a veces no está, está para viaje, en Belén, y si no está no hay caso, tiene que llamar lo que sea, si es una cosa de apuro (P44, mujer, 64 años).

R: se fue a Belén, porque justo, la suerte ya que ha venido la camioneta de la municipalidad y en eso se ha ido, pero había venido a diligencia de otro, ha venido, será la casualidad que la ha agarrado (P53, mujer, 66 años).

La imposibilidad de comprar los remedios en Azampay, la necesidad de viajar hasta Belén para acceder al tratamiento indicado en la posta, la frecuente derivación a dicha ciudad para realizar análisis que permitan precisar el diagnóstico, las situaciones de urgencia que requieren intervención quirúrgica, todo ello convierte la atención en la posta en una parada innecesaria en la trayectoria terapéutica que demoraría el proceso de cura.

F: aqui dicen que va mucha, yo voy poco, yo más directo me voy a Belén, porque a veces recetan los remedios, y no, y no trae el doctor este de aquí o no, en la posta menos no va [...] y va y lo hace ver allá y ahí nomás le compra los remedios y le empieza a hacer, más fácil nos queda allá, porque para venir, o hacerlos ver aqui y les receta, y en qué se va, asi es como ha sido el problema de este chico $M$, que lo han operado tan rápido, bueno, claro, usted sabe hay cosa ligeras y bueno hay que, a Belén hay que moverse (P44, mujer, 64 años).

M: no, así nomás, usted le indica qué es lo que le sucede pero que le hagan así estudios como para que usted tenga, para explicarle a usted, no, sólo que vaya a Belén o vaya a la ciudad, Catamarca, para que le hagan los estudios completos para ver bien qué es, por qué, qué es lo que le pasa [...] es distinto a como es aquí, le dan un tratamiento por ejemplo esta semana usted va hoy y vuelve a la otra semana para ver cómo sigue usted, si va mejor o peor, pero aquí no, porque el médico viene cada 15 días, y que vivimos lejos [La Agüita] (P5, mujer, 33 años). 
En Belén las personas tienen acceso a la atención del hospital público, de centros de salud privados (sobre todo para quienes poseen obra social, como los trabajadores y jubilados de la municipalidad) y a la compra de medicamentos en las farmacias. Como la mayoría de los azampeños tiene algún familiar o amigo en esta ciudad o en la capital de Catamarca (Tucumán, Córdoba, La Rioja y Buenos Aires también han sido mencionadas, si bien con mucha menor frecuencia), se pone en juego este capital social para poder permanecer allí el tiempo necesario para estudios, controles, cuidados postoperatorios. La opción del hospital ante malestares como el de presión alta, dolor de huesos o síntomas gripales (sobre todo de bebés y niños), se torna ineludible cuando se requiere internación por parto, situaciones de gravedad (tuberculosis, asma, bronquitis) u operación (apendicitis y problemas a la vesícula tienen una elevada incidencia, hernias). El diagnóstico apoyado en la realización de análisis (sangre, orina, radiografía, ecografía) junto a la presencia de profesionales especializados (pediatra, cardiólogo) son aspectos resaltados en la comparación posta-hospital y con frecuencia sustentan una actitud de desconfianza frente al tratamiento recibido en la posta.

L: pero él le da remedios pero no le hace ningunos estudios, puede ser que esos remedios también algunos no le vayan bien

A: él qué dice que es

L: y que es artrosis, reuma, cómo se le llama, y resulta que el médico le dijo que no es nada, que ella no tiene mucho reuma [...] el de Belén y por eso le dijeron que parece que era el corazón o mucha debilidad a los huesos también (P16, mujer, 22 años).

C: yo fui por dolor de la columna, a los huesos, me ha dado el doctor, yo tomaba y me hacia mal al hígado, yo he ido al hospital y le dije al doctor y me dijo: "¿y qué tomás?", le digo: "unas pastillas que me ha dado el doctor de zona y a mí me hacian mal al hígado", "y cómo sabés?" "y, me hinchaban, tomaba las patillas y me hinchaban al hígado, un ataque al hígado", dice:"a ver las pastillas, cuando te acordás traé las pastillas". Le llevo las pastillas que tomaba y dice: "pero! Esas tiralas a la basura! Si esas son unas pastillas, esas lo peor llevan para allá!". Yo le digo "cómo?!”, “y bueno, eso son los doctores los que llevan allá! Ellos se hacen quedar lo mejor y llevan lo peor para ustedes!" y me ha dicho que lo tire a la basura (P3, mujer, 56 años).

$R$ : [lleva a revisar su bebé a Belén] porque ahí le hacen todos los estudios, la talla el peso, en cambio acá no

A: yo pensé que el agente los pesaba y eso

$R$ : sí, a veces pero no como en Belén como allá hay médicos especiales para los niños (P20, mujer, 24 años).

Pero también el hospital es objeto de críticas debido a la demora de los turnos para análisis, ante ineficacia de tratamientos recibidos, la ausencia de especialistas y la limitación 
en la tecnología para el diagnóstico. En esta comparación los referentes son los sanatorios privados (accesible para los pocos que cuentan con mutual) y el hospital de Catamarca.

P: al hospital, a sacar el turno hasta el otro mes hasta que dan el turno, porque en el hospital, a la $R$ le han dado, el viernes es que han ido, y le han dado para el 15 el turno para que haga los análisis [...] de sangre y de orina [...] ella tenía dolor de estómago ese día, dolor de espalda, no sé qué más tenía, no sé qué más le dolía y le han dado para entonces, le digo yo "pero si ya te vas a morir!" (P38, mujer, 43 años).

R: en el mismo hospital [de Catamarca], la han internado ahi, le han empezado a hacer los estudios y ya salió que tenía neumonía, ahi te lo hacen en un momento le hacen todos los estudios no es lo mismo que en Belén, y ahi estuve 15 días con ella me la han curado bien (P77, mujer, 23 años).

G: cuando apenas va inmediatamente, te ponen el suero pero sin vitaminas, $y$ de ahi seguía del pie y seguía y seguí, como dos meses [...] me han hecho sufrir, estaba de llorar porque me agarraban de lastimado y me daban con una tijera y con el algodón, una gasa, la envolvían a la pierna, me limpiaban, me curaban, qué, me hacían correr la sangre por la pata! Y he estado 15 dias y no me han hecho nada, nada, y ahi me dice el doctor "ya estás churo, te voy a dar de alta" y bueno si me quiero ir con mi doctor, y ahi he vuelto al sanatorio [...] seguía mal y bueno, después los médicos me han sanado y ahi me curé (P33, varón, 80 años).

En el hospital de Belén no hay traumatólogo, oculista ni neurólogo, por lo que los azampeños han sido derivados a la capital de la provincia por traumatismos que requerían operación, para acceder al tratamiento y control de epilepsia (han sido referidos tres casos), para las operaciones de la vista (entre los individuos de mayor edad varios han sido operados debido a cataratas y otros tantos dicen que deberían hacerlo, generalmente consultan previamente al oculista que viene a atender a un sanatorio Belén y luego son derivados a la ciudad de Catamarca para la operación), por operación cardíaca y de tiroides y para internación en un hospital neuropsiquiátrico.

P: en Belén me lo ha visto [...] el doctor $M$ [pediatra] él me decía que tendríamos que llevarlo a la ciudad [de Catamarca] para que en la ciudad le hagan todos los estudios que tiene que tener porque en Belén estudios como los que hay en la ciudad no hay $[\ldots]$ estudios a la cabeza, un estudio computarizado (P19, mujer, 43 años).

$R$ : en Catamarca tienen muchos aparatos no es como en Belén

A: hay menos cosas en Belén?

$R$ : sí, y en Catamarca hay más aparatos y a veces están los médicos mejores para ahí, teniendo los aparatos les ayuda mucho (P79, mujer, 65 años).

Pero muchas veces, aunque no sean derivados desde el hospital de Belén y luego de haber recibido atención allí, no quedando conformes deciden ir a un sanatorio privado o hasta Catamarca en busca de una respuesta eficaz, a veces resultante de un cambio en el diagnóstico. 
C: En Belén me han corrido los doctores, "pero no tiene nada", le han dado el alta, "pero yo no quiero que me den el alta, yo quiero que me den el pase a la ciudad" [de Catamarca] porque en Belén no la han internado. En Catamarca la internaron y le hicieron los remedios por 6 meses, [...] han dicho que es meningitis (P11, mujer, 62 años).

\section{Recursos terapéuticos desde la medicina popular}

Los azampeños remarcan la gran cantidad de gente que se hace ver por curanderos no sólo el de Azampay sino de localidades vecinas o más alejadas como Londres y Belén, por lo que el recurso a esta medicina alternativa no se explica por una cercanía geográfica, tampoco por un menor costo económico (dado que quienes acuden a los curanderos pagan, entre servicio $^{17}$ y remedios, en ocasiones más de lo que hubieran debido pagar en el hospital), sino que se entiende en relación a la enfermedad que se pretende tratar y a una preferencia por uno u otro tipo de atención a la salud. Cuando se menciona la consulta a un curandero se lo hace generalmente en directa asociación a una serie de padecimientos: aire, susto, ojeadura, abertura de pecho (o caída de la paletilla), culebrilla, empacho y pata de cabra ${ }^{18}$.

Muchos de estos taxa vernáculos, con denominaciones similares o equiparables, se hallan ampliamente extendidos en todas las regiones del país y en otros países de América Latina (Idoyaga Molina, 2001; 2002; Idoyaga Molina y Korman, 2002). Idoyaga Molina afirma, basada en una exhaustiva revisión de trabajos etnográficos y de escritos médicos de la Europa de tiempos de la conquista, que a pesar de la gran dispersión, estos taxa muestran recurrentes similitudes que estarían revelando un origen común. El ojeo, por ejemplo, es una dolencia común en España, Italia, Grecia, pero también en el norte de África y Medio Oriente y el susto es un malestar que aún "reconocen y tratan los curanderos en España (Ribert, 1996) e Italia (Galt, 1982; Guggino, 1996)" (Idoyaga Molina y Korman 2002:186). Taxa como el susto, el ojeo o mal de ojo, el mal aire, son resultantes de la importación e imposición europea en América y de "la capacidad de innovación cultural de las sociedades para incorporar y refigurar ideas y prácticas culturales de otras sociedades" (Idoyaga Molina y Korman 2002: 192). “Al producirse la conquista [...] los españoles la importaron a América y la impusieron a

\footnotetext{
${ }^{17}$ Salvo algunas excepciones, el precio de la atención es "a voluntad", es decir, el paciente lo decide: 3, 5, 10 o 20 pesos fueron los montos referidos.

${ }^{18}$ No forman parte del conjunto de representaciones de los azampeños la aikadura, la agarradura o pilladura y la sopladura, que sí aparecen en el extremo norte, en la Puna, la Quebrada de Humahuaca y los valles y quebradas transversales (Idoyaga Molina, 2001:27-28). Como señala esta autora, la presencia de dichos taxa (correspondientes a enfermedades ocasionadas en desequilibrios religioso-rituales) es mucho menos frecuente en la subárea central del NOA (sur de Salta, Tucumán, Catamarca y Santiago del Estero) donde "van perdiendo fuerza las representaciones aborígenes y ganan espacio las creencias europeas" (Idoyaga Molina, 2002: 165).
} 
través de Las Escuelas Médicas, el trabajo en los hospitales y la labor misionera de sacerdotes y órdenes religiosas, que incluía las enseñanzas sobre la atención de la salud y las prácticas terapéuticas (Foster, 1994: 185) [...] Sin que esto implique negar procesos de refiguración en el momento de la conquista" (Idoyaga Molina 2006: 105).

Frente a estas enfermedades (la descripción individual de sus síntomas, causas y maneras de enfrentarlos será el tema del capítulo siguiente) se observa en Azampay un uso exclusivo de atención de curanderos justificado generalmente por el factor patógeno presente en la mayoría de las etiologías: el aire, y por el reconocimiento de que se trata de enfermedades que escapan al ámbito de acción de la biomedicina. La terapéutica de los curanderos consiste, en términos generales y desde lo comentado por los azampeños y el curandero local, en la receta de hierbas ${ }^{19}$ y "tónicos" (complementos vitamínicos, gotas y pastillas generalmente de venta libre), y en procedimientos de manipulación sobre el cuerpo del enfermo como masajes, el sobar, gestos de extracción del aire con las manos, el sahumar en forma de cruz, la aplicación de "ventoseras"20, el "hurgar" con cobre una carie, toques con alcohol. Todo ello junto a "los secretos", "las palabras" que el curandero "hace", rezos inaudibles para quienes presencian la cura. Este componente esencial de la cura, de pertenencia exclusiva de cada curandero, le otorga un valor de eficacia a su accionar que lo diferencia de las curas realizadas por los $\operatorname{legos}^{21}$. Considerándose su presencia imprescindible en la terapéutica del curandero y dado que, salvo que se perciba un movimiento de los labios o un susurro, generalmente no se los oye, tales rezos o "secretos" se dan por supuesto. También fue referida la cura a distancia, donde el curandero se compromete a realizar sus "secretos" horas después de la consulta y durante varios días, mientras el paciente debe leer una oración al santo del cual el curandero es devoto.

El uso de la señal de la cruz, la repetición de la cura tres veces, los rezos e invocaciones a santos, el sahúmo, son todos elementos de una medicina religiosa (en su mayoría de origen católico) de importante presencia en la medicina tradicional del NOA y Cuyo. Al respecto señala Idoyaga Molina que se trata de una apropiación del poder de las

\footnotetext{
${ }^{19}$ Las plantas empleadas, sea como parte de la prescripción del curandero o como respuesta casera, aunque van siendo mencionadas en torno a diferentes temáticas a lo largo de los capítulos, han sido organizadas en un listado anexo donde se incluye información sobre las formas de preparado, explicaciones sobre su valor terapéutico y otros comentarios realizados por los individuos al hablar sobre éstas.

${ }^{20}$ Descriptas como un vaso de vidrio puesto boca abajo sobre la piel, dentro del que se coloca un fósforo encendido que al apagarse "chupa la carne".

${ }^{21}$ Al respecto Idoyaga Molina también señala que "el curandero no sólo posee más conocimientos que los legos, sino que además posee más poder, en el sentido de sagrado, pues es asistido por sus santos y vírgenes auxiliares, además de invocar y hacer presente el poder del Dios cristiano por vía similares" (2001: 26). Cada curandero generalmente tiene su santo o virgen preferido en torno al cual desarrollan toda su actividad terapéutica, "vírgenes y santos pueden tomar, así, el perfil de auxiliares shamánicos, cuando son invocados en forma exclusiva por determinado curador para tratar cualquier dolencia" (Idoyaga Molina, 2001: 17).
} 
figuras cristianas, y aunque los individuos no sean del todo conscientes del simbolismo de muchas de estas prácticas, "son acciones que, en cuanto sagradas, refuerzan la acción terapéutica con independencia del sentido que esta última tenga" (Idoyaga Molina, 2001: 59): “La señal de la cruz refiere al poder de Cristo, especialmente su muerte y resurrección, consecuentemente es un símbolo de vida, cuya utilización en ocasión de la enfermedad la define como un poderoso elemento terapéutico" (Idoyaga Molina, 2001: 17); "el poder aniquilador del fuego se instrumenta a través del humo. La acción de sahumar permite que los vegetales, el poder de la palabra hecha sustancia, y el humo se introduzcan en el cuerpo del enfermo y expulsen la envidia. El sahumado se origina en las prácticas purificatorias y terapéuticas del catolicismo, en las que el incienso era un elemento primordial" (Idoyaga Molina, 2001: 32); "las técnicas destinadas a comunicarse con las deidades, tales como las invocaciones y los rezos -a Dios, Cristo, la Trinidad, Pachamama, santos y vírgenes-, el acto de persignarse y el encendido de velas [...] intentan apropiarse del poder de las deidades, se pretende una suma de poderes y voluntades que aporten eficacia a la cura. Se trata de acciones que se ejecutan en el tratamiento de cualquier doliente y de cualquier enfermedad" (Idoyaga Molina, 2001: 60). La autora destaca también, como un componente esencial de la medicina tradicional del NOA y Cuyo, el uso de vegetales cuya "eficacia curativa se atribuye a los olores y sabores fuertes y penetrantes -ácidos, amargos y agrios- los que justamente connotan su poder" (Idoyaga Molina, 2001: 63).

Los azampeños realizan comparaciones entre los distintos curanderos y distinciones en función de los padecimientos para cuya cura demuestran competencia.

I: claro ya sabíamos que él curaba, como él cura, Don X, Don $T$, pero no son como la curandera ésta

A: por qué, qué tienen de diferente?

I: claro ellos curan de unos mal [...] o por ahi le erran en la curación [...] ellas conocen bien, esa señora por ejemplo, usted lleva las aguas, le lee las aguas ${ }^{22}$, le dice de qué el mal que tiene, este no, estos no saben (P25, varón, 71 años).

A: y Don $F$ [curandero local] sabe esto de la pata de cabra?

$L$ : no, yo creo que no

T: debe ser que saben que hay esa enfermedad pero no lo curan

L: claro a lo mejor sabrán saber pero no la saben curar

(P70, mujeres, T: 72; L: 23 años).

A: y eso [culebrilla] acá Don $F$ [curandero local] no lo puede curar?

J: parece que no, no sabe, creo que no sabe, por ahí sabrá

A: así que deben ir hasta Condorhuasi? (P7, mujer, 42 años).

\footnotetext{
${ }^{22}$ La lectura de las aguas consiste en un procedimiento de diagnóstico a partir de mirar a través del orín del enfermo colocado en un recipiente translúcido.
} 
Si bien la opción por la medicina alternativa o su rechazo depende también de preferencias personales, generalmente el accionar de un curandero y el uso de yuyos es considerado en términos positivos, por lo que una intervención errada de éstos sólo tendría como desventaja el agravamiento de la enfermedad causado por la demora de la medicación correcta. En contraste, predomina una percepción de potenciales efectos iatrogénicos de medicamentos, inyecciones, intervenciones quirúrgicas.

F: yo no la conozco a la señora, yo, dice, ya sabrán ir, yo como le digo ahí en Belén la he visto pero me han dicho que ella atiende de salud, yo no la conozco, yo de aqui de mi casa nadie se ha hecho ver así que yo no puedo hablar, decir es una curandera muy buena ni nada, yo cuando he andado enferma me he hecho ver con el doctor, ahi en Belén, pero más de eso, sí si la nombran muy mucho no sé cómo sabrá ser, sabrá ser muy buena que yo he visto hacen cola (P31, mujer, 66 años).

R: para echarlo en la brasita y es el mismo olor con la yareta, para eso, a veces, así como estábamos conversando del dolor de muela, usted tiene a veces dolor de muela, así que le duele la cabeza, no sabe qué, usted lo hace así, lo muele a eso y lo echa en un a brasita, lo huele al humito ése [...] por ahi cuando es aire que uno le dice, pasa el dolor de muelas, y cuando, pero como no es malo, así que no impide nada de hacerse o no hacerse, no es malo ( $\mathrm{P} 40$, mujer, 62 años).

F: sí, me tengo que hacer operar en Catamarca

A: y lo va a hacer?

F: y no sé qué voy a hacer, tengo miedo de que me vayan a dejar ciega, no es como de que vaya a saber de estos yuyos, eso, algunos quedan bien, otros no (P31, mujer, 66 años).

E: primero han dicho que se le ha hinchado el brazo que le curaban, lo ha internado en La Rioja y decian que le han hecho en contra los remedios

A: por qué?

E: porque se ha hinchado entero dicen

A: y por qué los remedios le pueden hacer mal?

E: muchos antibióticos han dicho ellos, porque ha andado la madre también y parece que le han hecho mal los antibióticos que se ha hinchado entero, que no circulaba la sangre (P65, mujer, 78 años).

$N$ : se ha caído y fracturado la columna, pero ha quedado mal, no volvió a caminar porque ahí nomás lo han operado, le han puesto un fierro, quizá en cambio, si lo hubieran llevado a un médico campesino, que cura con secretos lo hubiera sanado, hay uno en Condorhuasi que es bueno para la columna, lo hubieran mandado a llamar (P11, mujer, 65 años). 


\section{Médico o curandero: disyuntiva o articulación}

En las situaciones en que se observa un uso exclusivo de la atención de curanderos, los individuos explicaron elegir dicha atención basándose en el reconocimiento de que se trata de una "enfermedad para médicos campesinos" resaltando la ineptitud de los profesionales de la biomedicina para realizar una identificación adecuada y un tratamiento eficaz de los mismos.

C: sabe por qué no lo curan? Porque no saben, con qué lo van a curar al aire, eso le llaman meningitis, el médico [...] claro, le dice tiene meningitis y con eso lo larga, qué tiene le van a decir y no le dan el remedio, si le ponen la inyección a veces lo matan casi al niño, porque eso lo pone en contra, eso es malo, malo

A: la inyección?

C: claro, claro, lo pone en contra eso, eso no es para el médico, eso es para los campesinos, el campesino sabe, cura más (P55, curandero, 84 años).

N: ya se había cansado de andar por todos los doctores, no le hacían nada, nada! Sabría tener 2 añitos...

A: y qué tenía?

N: y lloraba y bueno, qué sabría tener! Y ha venido aquí y ya la Vle ha dicho que lo lleve para... que era muy buen médico y "qué será tía?", "vea, m’hijito yo no le puedo decir porque yo nunca lo me hecho curar pero haga la prueba", le digo, vea, lo ha llevado 3 días y a los 3 días ha quedado sanito, no ha vuelto a enfermar

A: y qué era?

$R$ : le ha dicho que era ojeadura

A: $y$ de dónde venía su sobrino?

$N$ : de Vichigasta

A: y él lo había llevado a curanderos?

$N$ : no, a médicos

A: y el médico qué le decía?

$N$ : que eran los bronquios, le ha dado los remedios para que compre, le ha comprado y le ha dado pero no le hacían y lo ha traído para acá y lo ha llevado a curar con Don $F$ [curandero local] (P58, mujeres, N: 69 años; R: 58 años).

J: [...] Hemos ido a Londres a buscar al doctor A, después la hemos llevado a otro doctor en Belén y en Belén nos dijeron que eso era para campesinos

$G$ : los médicos de Belén le dijeron eso?

J: sí, sí, dice, eso, la culebrilla, es culebrilla dicen, y es para el campesino porque nosotros a veces la avivamos más con los remedios de médico. Y bueno, entonces buscamos una señora campesina y ella la empezó a curar

(P49, mujer, 40 años).

Por otra parte, problemas de la vista (que "falla", cataratas, ceguera), cardíacos, de apéndice y vesícula, enfermedades respiratorias (neumonía, bronquitis, asma, tuberculosis), hepatitis, sarampión, epilepsia ${ }^{23}$, se consideran casos que deben ser tratados por médicos. E1

\footnotetext{
${ }^{23}$ Algunos individuos usan el término "epilepsia", otros el de "convulsiones" para referirse a los mismos casos de malestar (tres en Azampay), entonces lo que inicialmente se codificó bajo marbetes distintos luego se unificó bajo un mismo código.
} 
término "infección" denota una enfermedad como de incumbencia médica (caries por infección, infección urinaria) y va asociado al de "antibiótico" como recurso necesario para la cura.

J: así nomás sin estudios, se llevan mucho de los curanderos, si los curanderos hacen lo que pueden pero póngale por ahi de un aire aquí pero bueno, ya mucho como ser, no sé qué puede hacer ante una vesícula, la infección urinaria bueno, con yuyos la corta pero no la corta del todo [...] qué le puede hacer un curandero? Sólo le lava con esas agüitas, con esos yuyos [...] es para el médico esas cosas (P7, mujer, 42 años).

Se esboza una divisoria, bien explícita en estos padecimientos, entre enfermedades "para el médico" y enfermedades "para el curandero", implicando una limitación del ámbito de competencia de ambos trabajadores de la salud. Pero dado que no hay una relación unívoca entre síntomas y categorías de padecimientos, la interpretación de los mismos como signos de una "enfermedad para médicos campesinos" o "para el médico" muchas veces se realiza luego de haber optado por un tipo de atención y no quedar conforme con el tratamiento. En estos casos, el pasaje de la atención de un médico a la de un curandero o viceversa conlleva la redefinición del diagnóstico: se trata de meningitis o de ojeadura, es una úlcera en el sistema digestivo o un caso de pulso, dolor de muelas por infección o por aire, parálisis facial por "derrame" o por aire, mal a la cabeza (locura) causada por problemas nerviosos o por un mal "hecho". Se destaca la circularidad entre diagnóstico y tratamiento: a partir de un diagnóstico se elabora el accionar orientado a revertir la situación de malestar identificada y desde los resultados percibidos durante el tratamiento el diagnóstico inicial se confirma, se ajusta o se descarta por completo, continuándose la búsqueda entre los diferentes servicios de salud, búsqueda no sólo de un cambio de la terapéutica sino también por una redefinición del malestar que conlleve a un tratamiento más eficaz, por una certeza en la identificación del mismo que asegure estar siguiendo el camino correcto hacia la cura. Como señala Menéndez, "cuando un sujeto acude al médico, a un quiropráctico, a una curandera o a un sanador "new age", va generalmente con un diagnóstico provisional del padecimiento, por el cual recurre a dicho curador" y es esta actividad diagnóstica ejercida por el propio sujeto y su microgrupo la que "posibilita una articulación práctico/ideológica entre las diferentes formas de atención, estableciendo una conexión entre las mismas a través de la carrera del enfermo" (Menéndez, 2005: 60).

El siguiente fragmento de entrevista resulta ilustrativo de varios aspectos hasta ahora señalados. Mis interlocutoras, madre e hija ( $\mathrm{N}$ y E) me refieren una situación de enfermedad de la bebé seismesina de E acontecida días atrás. Alarmada por la fiebre y el llanto y ante el 
temor de que esté afectada a los bronquios (basado en experiencias con otros niños de la familia, que posteriormente me refirió) la madre le dice a su hija que lleve a la nieta al hospital. Como esa madrugada pasaba el transporte, llegaría a hacerse atender en dicha ciudad antes de que la enfermera empezara a atender en la posta, primando por sobre la evaluación de la distancia, la consideración de la disponibilidad y tipo de atención. Una vez recibida la atención médica $\mathrm{E}$ descarta el diagnóstico dado, angina, basándose en la ausencia de síntomas que ella asocia a esta enfermedad y en lo que le dice una curandera (que además es pariente suya) con quien se encuentra en el mismo hospital. Ésta le diagnostica empacho, susto y ojeadura, y la cura con cierta eficacia (lo que reafirma su diagnóstico). En este contraste de diagnósticos y terapéuticas provenientes de modelos médicos contrapuestos se suma la desconfianza por la atención brindada en el hospital de Belén en comparación con la ofrecida (también desde la biomedicina) en la ciudad de Catamarca. No obstante la madre le aconseja guardar los remedios recibidos en el hospital para algún momento en que sí corresponda usarlos, incorporándose los medicamentos recetados al circuito de la medicina casera.

$N$ : [...] en el hospital ya nomás la ha curado de empacho y de la ojeadura se ha venido sanita

A: así que en el mismo hospital la señora te vio que vos salías...

E: claro, después del médico y dice "no la vayas a dejar internar" porque te le van a poner suero y esta no es enfermedad para los médicos [...] me dice llevála para ahí a las 9 y bueno, la he llevado, "no la vayas a dejar internada!" porque dice es fiebre del empacho y es mucho susto lo que tiene esa niña y me he llegado a las 9 y me la ha visto, la ha curado y se ha dormido

A: y la señora esa ya la conocías vos o es la primera vez?

$N$ : si es sobrina, son primas con ella, hija de un hermano mío [...]

E: cocinera en el hospital

A: y el médico, te dio él los remedios?

E: ahá, para anginas me ha traído los remedios

N: y ella que le ha dicho que no era angina

E: esto no es angina, es empacho

A: entonces vos los remedios de la angina no se los diste?

E: $n o$

N: yo digo que los guarde que por ahí le hace falta, no había tenido angina porque comía, comía bien, cuando a ella le duele la gargantita ya no quiere ni tomar la mamadera, ni tomar el pecho, no puede tragar

A: $y$ de qué les viene la angina?

$N$ : y también debe ser de los muchos fríos, pero no tenía ella angina, era así una fiebre que tenía porque estaba con la ropita mojada, transpiraba, por eso le he dicho yo que la lleve no vaya a ser de los bronquios

A: y la enfermera no estaba acá para verle la fiebre?

E: no, sí estaba pero como era la madrugada, eran las 3 de la mañana

N: la combi viene más temprano de lo que se va ella para allá, ahí mismo la ha llevado 
E: digo, la voy a llevar a Belén que me la revise el doctor, le venía así como, que yo... no va a ser que convulsiones [...]

A: y por qué el médico ahora te dijo que era angina? Por qué se equivocó?

E: no había doctor para niños, estaba el doctor F se llama y no sabe

N: poco le lleva el apunte a la gente, ellos nada más van y lo miran y dicen esto tiene nomás, no es como en otros lados, en Catamarca para curar le hace primeramente todos los estudios y recién ahí le van a comenzar a dar la medicación, pero aquí no, aqui lo ha mirado y dice, pero no le hace ningún estudio, nada! Por eso aquí no curan, en vez de curarlo para que sane lo enferman para peor

(P58, mujeres, N: 69; E: 27 años).

El cambio de terapeuta por disconformidad con el diagnóstico también se observa dentro de un mismo tipo de atención. Como se señaló anteriormente, dentro de la opción por la atención biomédica los individuos cambian del médico de posta a uno del hospital o de un sanatorio de Belén, o de la ciudad de Catamarca, buscando el diagnóstico y el tratamiento que resuelva su problema. El siguiente fragmento ilustra la situación donde la contrastación se da entre dos diagnósticos provenientes de dos curadores populares. También interviene una opinión de un curador biomédico que, junto a la ausencia de otros síntomas que de acuerdo al entrevistado deberían estar también presentes si el diagnóstico estuviera acertado, motiva a consultar al segundo curandero. Además se suman las posibilidades económicas y de transporte y estadía a la hora de decidir a quién se recurre:

L: él [su bebé] lloraba mucho y vomitaba, y dice [curandera de Belén] es pata de cabra que lo lleve a la noche... y como fui al hospital

A: él tenía los lunares? [nombrados anteriormente por la entrevistada como síntomas de pata de cabra]

L: no tenía nada, nada

A: y lo curó?

L: no, yo no he dejado que lo cure porque me cobraba 90 pesos para curar las 9 noches y bueno como yo no tenía donde estar en Belén [...] yo me he venido y lo he llevado a Doña $L$ [curandera de otra localidad vecina] y me dice que no porque la pata de cabra agarra vómitos, diarrea, de ahí se ponen flaquitos, bajan de peso, y él no, aumentaba en vez de bajar

A: vos por el vómito lo llevaste a la C? [curandera de Belén]

L: no, justo fui a Belén, pero dicen que el vómito es normal

A: eso quien? en el hospital?

L: claro, me dice la doctora que es normal porque es así gordito, toma la leche y vomita a veces porque se llenan de más [...] yo le dije que, me iba a venir para acá a comentar a ella [ T: su abuela] y ya iba a volver

A: $y$ te fuiste a Doña L?

L: sí, ahí nomás no?

T: ahí nomás, al otro día porque como ella le ha curado al hermano de ella, por ahí, porque le daba lo mismo pagar un viaje para Belén que para allá

$L: y$ dice que no que estaba bien, que no era nada $[. .$.$] ella dice que no porque$ siempre bajan de peso o tienen diarrea (P70, mujeres, T: 72; L: 23 años). 
La atención del curandero igualmente es buscada frente a padecimientos para los cuales también se utilizan los servicios biomédicos: en caso de "debilidad" o "desvaloramiento" (términos con los que se alude a estados de cansancio, falta de vitalidad, malestares generales que obstaculizan el andar y los quehaceres), dolor de articulaciones, de huesos, malestar al hígado, a la vesícula, a los riñones, irregularidad en el ciclo menstrual, resfrío, nervios, presión alta. Aquí el cambio de terapéutica no repercute en la identidad del padecimiento, lo que se cuestiona es el tipo de tratamiento en función de su eficacia.

P: ella [curandera] me lo ha visto una vez a él, y ella también me decía lo mismo que me decía el médico, que tiene nervios, y ella me daba una planta que se llama helecho, que le dé para los nervios (P19, mujer, 43 años).

A: y para curarla de la vesícula ella [curandera] también le hizo secretos?

$C$ : no sé si eso [...] a mí me ha dado remedios, tome remedios de la farmacia después de las comidas [...] y yo tomaba unas gotas, me dijo que tome, termine de comer y tome, y ella me ha dado agua de remedio [...] agua de yuyo (P25, mujer, 79 años).

Pero recurrir a un curandero no necesariamente cancela la opción de la biomedicina, siendo frecuente el uso articulado de terapéuticas provenientes de modelos de atención diferentes, incluso para tratar un mismo padecimiento. Así, hay quienes tras recibir un diagnóstico en la posta toman lo recetado por un curandero en otra ocasión para tratar el mismo malestar, o inversamente, habiendo escuchado el diagnóstico de un curandero se dirigen a la posta en busca del remedio recetado; muchos aprovechan el viaje a Belén para hacer una consulta tanto en el hospital como al curandero, contrastando las explicaciones obtenidas. Una informante, por ejemplo, contó haber llevado el orín del hijo (estaba muy nervioso, inquieto de noche, se mordía los dientes) a la curandera quien, a través de la lectura del orín del enfermo, le dijo que tenía parásitos ("Si iba a Belén le iban a tener que hacer estudios, análisis para saber que eran parásitos y recetarle lo mismo"). Le recetó unos remedios y ella los obtuvo en la posta.

L: tomé unas gotas para el hígado porque según el enfermero me dice que podría ser el hígado

A: y esas gotas te las dio el enfermero

$L:$ no esas gotas me las recetó la señora $L$ [curandera]

(P16, mujer, 22 años).

R: yo nunca le decía a ella lo que el doctor me decía, si no que ella me decía [le decía lo mismo], por eso digo yo que ella sabrá, me hacía los estudios y los hacía ver con el doctor y con ella (P20, mujer, 24 años). 


\section{La autoatención: la medicina casera, ejercicio del cuidado y autocuidado}

Los azampeños enfrentan con sus propios medios eventos de gripe o síntomas similares (resfrío, fiebre, tos, "trancazón" del pecho) combinando infusiones de yareta, nencia, carqueja, poleo y jarilla, o "quemadillos" 24 con medicamentos generalmente de venta libre (mencionan Bayaspirina, Geniol, Novalgina o simplemente "pastillas") comprados en Belén o a los proveedores de mercadería que llegan a Azampay, o anteriormente recetados por médicos. Contra dolores musculares, de huesos y articulaciones se realizan fricciones con alcohol o con pomadas compradas a vendedores ambulantes o en la farmacia e ingieren Novalgina o ibuprofeno. Para problemas digestivos, empacho, malestares estomacales, intestinales, del hígado o vesícula toman cedrón, carqueja, nencia, hierba matico, copana, maravilla, ruda con bicarbonato, pero también Sertal y Hepatalgina. Así mismo, recurren a hierbas para aliviar el malestar de los riñones (uña de gato, llantén y quimpi) y de presión alta (olivo, cedrón, y tilo, generalmente acompañando la medicación y los cuidados en la dieta indicados por el médico). Aunque identifican cada hierba con los malestares para los que es útil, muchas son empleadas como preventivo de una amplia gama de enfermedades, siendo frecuente su ingesta diaria en el mate o reemplazando la bebida de agua cruda. Es esta una costumbre transmitida por los padres y con la que explican que antes no fuera necesario recurrir al médico, que la gente fuera más sana y no existieran problemas como el de apéndice o vesícula. El uso de plantas locales y algunas foráneas, aunque continúe vigente y con una presencia notoria, aparece frecuentemente asociado a un saber "de los viejos", a una época en la que aún no se contaba con médicos pero que, en contraste con el presente, es caracterizada por la ausencia de malestares graves que requirieran intervención médica.

S: vea, era raro el que se enfermaba, porque nosotros sabíamos tomar esos yuyos y con eso, por ejemplo el estómago es una parte delicada, por ahi hace desarreglo, come alguna cosa en fin, se siente mal y nosotros ya tomamos esos montecitos y bueno y con eso ya uno se compone, o por ahi ya cuando dolía el estómago, lo curaban venía un purgante de aceite JA: no había casi médico [...] ahora reina muy mucho ese apéndis

S: $y$ cuántos los curaban con purgante

$J A$ : y ya la vesícula, y cuánta gente, ninguna se operaba

A: y cómo lo curaban?

S: toman el té, tomaba té usted (P50, JA: mujer, 64 años; S: varón, 76 años).

\footnotetext{
${ }^{24}$ Se elabora quemando azúcar con cáscara de naranja o limón o viruta de la jarilla y cocinando sobre ello una infusión con vira-vira, antes de beberlo se le puede agregar un poco de alcohol. Se lo bebe bien caliente y sirve para expulsar la tos, "destapar los pulmones", por lo que se lo compara con un jarabe.
} 
Para padecimientos ocasionados por aire (lo que se confirma si estos cesan o disminuyen luego de la cura) como dolor de cabeza, de muelas, susto, los azampeños acostumbran sahumarse con yareta, hojas de nogal o "incienso" (resina) del molle, azúcar y yerba, a veces en forma de cruz. El uso terapéutico de estas plantas es explicado a partir de una valoración positiva del aire que otorga fortaleza y propiedades curativas a lo que crece en zonas altas ("las plantas del cerro son más fuertes porque el aire es más fuerte"), a las plumas de cóndor o águila (por su asociación con la altura) y a la grasa del león (usada como ungüento por ser este un animal "airoso"). También la abertura de pecho y la ojeadura es curada por algún familiar o conocido que sabe y se muestra dispuesto a hacerlo.

F: sí, yo los sahumo

A: y a vos quién te enseñó?

F: no, yo, como veía que lo hacía mi tía, mi abuela, mi mamá, de ahí he aprendido, y ellos me iban indicando cómo los tenía que llamar, por ejemplo, yo tengo un primito que se llama $G$ que era perseguido por el susto, ojeadura, y entonces una noche dice mi tía, la mamá de $G$, dice que lo sahume yo, porque ella que le perseguía mucho el dolor de muela, bueno digo, y ella me ha preparado la yareta, la yerba y la azúcar y agarro yo y llevo los rescoldos y ella lo llevaba al bebé y ahí lo sahumaba yo, le decía " $G$ ", como se llama $G$, le decía " $G$ vení a tu casa, no te asustés", y lo sahumaba tres noches y ya decía que amanecía mejor (P30, mujer, 17 años).

La atención doméstica se apoya en el reconocimiento de poder manejar por los propios medios una situación de malestar ya conocida y de menor gravedad o ante la resignación frente a un padecimiento para el cual las distintas formas de atención no ofrecen solución (como a menudo manifiestan los que sufren de reuma). Sea por considerarse innecesaria la consulta médica, o por desconfianza de la eficacia del tratamiento que se vaya a recibir, los azampeños justifican no ir al médico afirmándose en sus recursos y saberes, recuperando un diagnóstico y tratamiento realizado por anteriores doctores o curanderos y que se consideró eficaz, o saberes populares como el uso de una hierba. Como afirma Garrote, los individuos cuentan con información principalmente "a través de las relaciones de su vida cotidiana, a partir de múltiples experiencias médico-asistenciales que se comparten familiar y vecinalmente. Así, llegan a apropiarse de una gran cantidad de información sobre sus propias patologías, sus tratamientos y los lugares a donde pueden acudir" [...] "Sus conocimientos tienen una carga existencial que los hace distintos a los del espacio oficial e involucran otro saber, pero esta decodificación particular no excluye el científico" (Garrote, 1995: 95, 99).

E: me he caido y me he golpeado el hombro [...] hemos comprado pomadas, en la farmacia en Belén, consulta y el farmacéutico ante dios nuestro señor, estos médicos del hospital a veces le erran la... en cambio el farmacéutico es mejor, le va y le consulta cómo son y le dice "bueno esto le va a..." yo ahí compré dos veces de esas pomadas con eso me he compuesto ( $\mathrm{P} 4$, mujer, 76 años). 
P: bueno, por ejemplo de alguna fiebre, así esas cosas, tienen mucha fiebre y se empiezan a desmayar así, no nunca, así como lo ve ahora, tose, pero a veces un poco que se los puede aguantar, no hay necesidad a veces de llevarlos al médico y a veces con un tesito, con alguna friccioncita se compone

A: fricción con qué le hacés?

P: con mentisan [...] esta la compramos en la farmacia [...] le pongo en el pechito cuando tuese mucho o cuando está muy resfriadito

A: y eso quién te dijo?

P: eso los médicos que hay, los campesinos [curandero] (P19, mujer, 43 años).

E: debe ser, me ha quedado una astillita [...] una cascarita del palo, de manzano era y le digo a la P que me vea y sí, dice tiene una cosa negra ahí, me dice ella y bueno, pero no ha hecho por sacarme como no tenía pinzas de esas para no ha querido ella hurgarme la vista y una noche me ha hincado más y justo hago asi y se me ha salido, ya la he sacado

A: y se lavó con algo?

E: sí con agüita con azúcar, porque esa es linda para la vista, es remedio, después me ha dado unas gotas Don $R$ [el agente sanitario] con eso me estaba componiendo, después ha venido el camión ése que hace el reparto y estaba enferma, viera cómo me dolía la vista y el chico que maneja también se habia enfermado de la vista y él habia comprado, el doctor le había recetado unas gotas y él la ha traído aquí, dice "con eso me he compuesto mucho"

A: se las regaló?

E: no, apenas para ese ratito

A: ah, le puso de las de él...

E: de las de él

A: y con una puesta ya se le curó?

E: sí, con eso me he compuesto de la vista

A: y qué gotas eran?

E: no me acuerdo, pero eran lindas, con eso se me pasó el dolor

(P65, mujer, 78 años).

Pero incluso habiendo realizado una consulta, y por disconformidad con el tratamiento indicado, los individuos lo reemplazan por una solución casera.

E: neumonía, hemos ido a Belén y ya me han dicho que estaba complicada con neumonía y me han curado ahí pero, me han curado pero no, después ya he salido de allá con la misma receta que tenía y he comprado la vacuna

A: de las viejas, que le daban antes

E: claro, y con eso me he curado, con esas vacunas (P27, mujer, 80 años).

L: [el médico en la posta] "no" dice "no es nada, tomate este jarabe", "bueno" le digo yo pero yo tampoco lo tomé porque, bah, no...

A: te lo dio y vos no lo tomaste?

L: claro porque no le creí, así se ve que me dio asi por darme así nomás para que me conforme yo, así que digo no, mejor no lo tomo, así cada tanto suelo tomar yuyos de la puna así que ya

A: porque pensaste que era por la puna? 
L: claro porque por ejemplo yo al cerro no puedo salir casi [...] allá a la lomita pero a gatas, me canso, y yo para allá para El Tolar llego hasta la mitad y me empiezo a cansar y marearme y dicen que es la puna, opina la gente (P16, mujer, 22 años).

Cuando los malestares persisten o se agravan se reconoce el carácter paliativo y provisorio de las respuestas caseras y la necesidad de recurrir al médico o curandero en cuanto sea posible. Por ejemplo, una entrevistada, cuyo hijo tuvo hepatitis, contaba que éste empezó con vómitos, y dolor de cabeza, como sucedió justo luego de las fiestas patronales y había comido mucho, su hermana le dio un Sertal. Pero siguió mal y ella notó que orinaba oscuro, "como coca-cola y fuerte". Como su otra hija ya había tenido hepatitis, y también había tenido la vista amarilla y el orín oscuro (fue revisada en su momento por el médico de zona, quien diagnosticó y recetó el tratamiento), al reconocer los mismos síntomas en su hijo le avisó a la enfermera.

Como se señalara anteriormente, la construcción de un diagnóstico que oriente la búsqueda terapéutica no es un proceso acabado sino que se va redefiniendo a partir de los resultados obtenidos de un tratamiento. Además, la misma percepción de lo mórbido "se da en distintas etapas: así, en la percepción de enfermedad, por ejemplo, primero se registran las molestias o el malestar, se distingue el área afectada ubicando el lugar, la intensidad del dolor, el sistema comprometido (óseo, muscular, respiratorio, etc.), luego se remiten estos síntomas a un cuadro mórbido y se arriba a un diagnóstico "casero". La severidad que se adjudique a este condiciona, entre otros factores, el lugar y la oportunidad de la consulta médica" (Durán, 1983, y Prece y Shufer, 1991 en Prece et al., 1996: 63).

Aún cuando se recurra a un médico o curandero, la autoatención está presente acompañando el tratamiento recetado como prácticas de auto e inter-cuidado ya sean sugeridas por los mismos curadores o pensadas desde el espacio doméstico (en el caso de hepatitis comentado, a la par del tratamiento indicado por el médico se le dio al enfermo té de maravilla considerada buena para el hígado). Restricciones en la dieta en casos de hepatitis, diabetes, colesterol, hipertensión, problemas a la vesícula o intestinales, reposo postoperatorio, son referidos junto a la ingesta de medicamentos y/o tisanas, como prácticas de cuidado que el enfermo debe incorporar a los fines de su recuperación. No afligirse, no pensar, estar tranquilo, no preocuparse, son mencionados como prescripciones para quienes padecen enfermedades en las que el factor psicológico forma parte de su etiología (es el caso del padecer de los nervios, presión alta, asma, afección al corazón, algunos casos de aire) pero también para un postoperatorio positivo luego de una operación a la vista. 
E: ha estado con los resfrio [...] le ha recetado el médico [...] en el hospital de Belén [...] ya nomás tenemos remeditos de esos, a la jarilla la pelamos, y hacemos viruta de jarilla y ya con eso se compone

A: y los remedios que le dio allá el médico no? O con las dos cosas?

E: y bueno, las gotas sí y ha quedado bien de una sola vez (P4, mujer, 76 años).

C: hay curandero que curan [de abertura de pecho], mi mamá también sabía curar mucho, ahora ya no porque a ella se le ha cortado mucho la vista, porque cuando vos estás muy airienta también jode a la persona que te está curando, claro vos tenés que curarte primero, sahumarte (P27, mujer, 56 años).

La madre de la entrevistada de la cita precedente ha sido operada de la vista y dentro de los cuidados que tiene en cuenta está el cese de una actividad (la cura de abertura de pecho) que por exponerla al aire perjudicaría su estado. En la articulación de cuidados caseros con los tratamientos recetados convergen distintas concepciones sobre etiologías y eficacias. Este contraste resulta más notorio cuando se yuxtaponen prácticas y representaciones domésticas a las prescripciones biomédicas, pues se trata de una población de individuos que no ha tenido formación científica (los adultos asistieron 3 o 4 años a la escuela, los jóvenes hasta $7 \mathrm{mo}$ ). Sin embargo como señala Fitzpatrick, los conceptos de los legos son pragmáticos, rara vez se producen con la idea de ser sometidos al escrutinio público, "difieren del saber teórico en que en su origen son sincréticas, es decir, que originalmente se derivan de una variedad de fuentes dispares y distintas. Las ideas se extraen selectivamente de una variedad de tradiciones diferentes y se ajustan conforme a los intereses y preocupaciones del individuo" (Fitzpatrick, 1990: 26).

\section{El embarazo y parto: de la autoatención y la medicina tradicional a su medicalización. ¿Todo tiempo pasado fue mejor?}

Si bien embarazo, parto y puerperio no son enfermedades (aunque algunos se refieren al momento del trabajo de parto como "estar enferma"), implican un estado excepcional que requiere un reajuste de las pautas de autocuidado y conllevan situaciones en que se torna necesaria la atención de especialistas y/o la ayuda y cuidados de personas cercanas. Como ya se afirmó, desde hace décadas el Estado viene promoviendo el parto hospitalario y los controles regulares del embarazo en articulación con (e incentivados por) la distribución de leche del Plan Materno Infantil. Los controles mensuales durante el embarazo y los posteriores al parto (plan de vacunas del neonato y seguimiento de sus primeros meses) 
pueden ser realizados en la posta, pero muchas mujeres optan por ir a la ciudad, generalmente a Belén (aprovechando que deben ir a cobrar el subsidio familiar), algunas a la ciudad de Catamarca o a localidades vecinas donde residen familiares (por ejemplo una mujer se instaló durante el embarazo, parto y postparto en Chilecito, donde vive su madre, otra lo hizo en Puerta de Corral Quemado, localidad de la familia de su pareja y que cuenta con un hospital seccional sin internación). Quienes permanecen en Azampay se trasladan a la ciudad cuando la fecha estimada se acerca. En todos estos casos se recurre a la red de relaciones más o menos estables que se extiende fuera de los límites de Azampay producto de la migración de familiares, lo que determina en gran parte la elección del servicio de atención que se empleará para el parto y los controles previos y posteriores.

$P$ : y en Belén, en el, hospital [...] me he ido como 3 días antes, que el doctor $S$ [médico de zona] ya me había dicho [...] así que yo me he ido antes y he estado en la casa de la tía, de la hermana de mi papá, después cuando yo me he sentido enferma en la tarde le digo a la tía "tía, no me siento bien, me voy a ir al hospital", "ay, bueno, hija, vamos, yo la llevo" y bueno, ya se ha ido ella conmigo, me ha dejado en el hospital [...] me he tenido que quedar, era sábado y me han tenido hasta el lunes, como me he ido para la casa de la tía P he estado como una semana en Belén (P19, mujer, 43 años).

L: [en Belén] a veces uno va y ya los médicos no tienen número ya no lo atienden en cambio allá no [...] es grande, en el hospital de Chilecito [...] me hacía los controles con la doctora que es la misma médica de mi mamá (P70, mujer, 23 años).

La medicalización del embarazo, parto y primera infancia, promovida por los agentes de salud, ha reemplazado la costumbre de hacerlo en el hogar con la intervención de curanderos, parteras (baquianas) y miembros de la familia (generalmente la madre o abuela de la parturienta). Los azampeños resaltan el carácter conminatorio y ya no opcional de tal cambio señalando que se dificulta la entrega de los certificados de nacimiento para la inscripción en el Registro Nacional de las Pesonas si el parto no se lleva a cabo en un hospital, a menos que se demuestre que se han realizado controles durante todo el embarazo.

E: porque ahora no admiten como antes, antes teníamos en las casas pero ahora ya no, ahora ya tiene que tener médico [...] ya si se enferman [comenzar con trabajo de parto] en las casas tienen que declarar quién la ha atendido y cómo, todo (P4, mujer, 75 años).

M: las mamás siempre optaron, más que todo antes optaban por quedarse acá, y bueno, ya después se ha puesto un control estricto, por ejemplo, si tenían acá no les querían llenar la planilla para el denuncio [...] para hacer archivarlo en el registro, no les querían dar, entonces las mamás se han tenido que ir a Belén sí o sí

A: y si nacen por casualidad, porque se les adelantó?

M: sí, si nacen aquí y, por ejemplo, si tienen un control médico sí les da, pero si no tienen el control médico... [...] si se hacen controlar desde que se quedan 
embarazadas hasta que quieren tener el niño no hay problema, porque el doctor se lo da, porque saben que está controlándose, pero si la madre no se controla no le da (P54, enfermera de la posta).

F: ella va a controlarlo en Belén, como él ha nacido ahi, tiene todo, todos los meses va ella a hacerle tomar el control al chico [...] todos los meses lo lleva a control a Belén, a ver cómo está de peso, de todo [...] antes no! [ríe] ahora todo, antes no era como, ahora control

A: usted lo tenía acá y cuándo lo veía el médico?

F: cuándo? [ríe] nunca! [...] no se enfermaban los chicos, sin control casi, sin nada, no sé por qué sabría ser ni nosotros, ni las madres no tenían control (P5, mujer, 66 años).

En la comparación con épocas pasadas, sostenida sobre todo por adultos mayores, testigos del cambio, emergen dos valoraciones de tal proceso de medicalización: por un lado hay quienes asocian la aparición de enfermedades graves en tiempos actuales (por ejemplo el cáncer, que en épocas anteriores no era identificada en Azampay y por ende "no existía" como posible riesgo para la salud y sobre cuya causa los mismos profesionales que la diagnostican no pueden dar una etiología concreta) con el manejo dado al parto y puerperio desde el hospital que, al dar el alta rápidamente no contempla el reposo y la dieta como parte del proceso de recuperación postparto. Pero inversamente, esta misma evaluación de un presente con enfermedades y problemas de salud más graves que en el pasado es alegada para justificar que embarazo, parto y primera infancia sean tratados hoy en día desde la biomedicina. Por otra parte, hay quienes evocan la ausencia de recursos biomédicos en el pasado como causa de un mayor número de defunciones, sea de la parturienta, del recién nacido o de ambos, considerando positiva la intervención médica en el parto, percibido como una circunstancia de riesgo para la salud y la vida.

F: los tres que he tenido, los tres me han salido bien, gracias a dios y a la virgen, bien, bien, aquí en mi casa, en poder de mi madre

A: y los nietos dónde nacieron?

F: ellos ya han nacido en manos de doctor en Belén, ellos han nacido allá [...] por eso vive sana, en cambio, va al hospital y es rápido, dicen, yo no lo sé por que no he ido, lo tiene rápido pero después vienen problemas, claro, como usted ve que lo tienen al chiquito y enseguida ya, dos días dicen ahora, no sé, y los mandan a la casa, y así ya haciendo todo un trabajo y por eso a veces, decían antes, la gente de antes porque antes nadie se iba al hospital, todos se lo tenían en las casas

A: y qué problemas pueden tener después?

$F$ : y... cómo dice... ya vienen de esas enfermedades grandes, como le dicen ese cáncer, que le dicen, que lo agarra, asi dicen, muchos dicen así, vaya a saber, cada uno sabremos tener los destinos, de cada cosa sabrá ser, no? [...] pero ahora ya no, tiene prohibido, tiene que ir a Belén, y estaba y si no lo tiene esta semana se va cargada, se vuelve cargada ésta, pero ahora ya no lo admiten en todo, tiene que tener todo historias clínicas [...] como ya viene el doctor aquí ya, la que está de 
encargue de eso, bueno, ya tiene que pasar al doctor, tiene que saber el doctor, porque ahora hay tanta cosa no? Por ahi se queda o mal alguna cosa y si no va al doctor ya lo tienen molestando, antes no, como no había

A: el doctor le dice algo?

F: claro, ya le dice "por qué no ha venido, no la han traído?" si tiene familiares, si tiene al padre de ese chico "por qué no lo ha traído?” ya la tienen hurgando [...] antes no, antes no había ningún control, cómo le voy a decir, no, no, pasábamos (P44, mujer 64 años).

A: usted los tuvo todos acá?

$R:$ no, ya algunos en Belén

O: ya agarró tiempos buenos [ríe] [...] [el parto] es delicado [...]

$R$ : chiquitos morían, moría la madre

$O$ : a veces se salvaba el niño y moría la madre o moría el niño y se salvaba la madre, han pasado vario casos así aquí (P2, O: varón, 58 años; R: mujer, 53 años).

N: ahí los bautizaba, les hacía como un bautismo, les daba esa agüita de socorro A: y eso para qué?

N: para ayudarlo al bebé

F: a veces que pasa que nacen, están una hora, dos y se mueren y por eso les daban agüita de socorro [...] y claro, cuando se muera ya está bautizado

(P58, mujeres, F: 62 años; N: 69 años).

E: [...] antes sí morían muchas mujeres con el niño en el vientre, había muchos duendes, de niños muertos sin bautizar (P4, mujer, 75 años).

La práctica del "agua de socorro", sustituto de urgencia del acto de bautismo, se refiere como algo frecuente en las épocas en que el parto tenía lugar en el hogar, cuando se presentaban complicaciones y se temía por la vida del bebé. El "agua de socorro" en calidad de bautismo permitía que el niño fallecido recibiera sepultura en el cementerio sagrado y no en el limbo.

Pero no obstante su medicalización, también fueron mencionados en la actualidad casos de fallecimiento o trastornos producidos durante el parto, y aunque fueran generalmente atribuidos a la negligencia del personal médico, refuerzan la percepción del mismo como instancia en que la vida se ve amenazada.

R: [...] una doctora mala, decimos que es mala con todos [...] a mí me ha tenido paciencia pero dicen que había ocurrido con varios que ha dejado que se mueran los bebés [...] todos decían que esa doctora es muy, que no te llevaba atención o qué se yo, deja que se pase la hora (P20, mujer, 24 años).

R: [...] porque siempre iba ella al médico de ése que salía para acá, entonces ya sabía el médico de zona, pero nunca le ha dicho nada así que no sé qué le ha dado, habrá sido el destino de ella, y ha tenido el chico, se lo han sacado ya muerto los doctores, pero después ellos decían que ella había quedado bien [...] esa tarde, qué se yo a qué hora le habrán sacado el chico [...] después que han llegado, más a las horas le han sacado recién el chico, para eso también tienen esa paciencia para atender! Recién 
le han sacado el chico [...] dicen que como a las 3 de la mañana se le había venido hemorragia y no hallaban, no sé qué faltaba para que pongan lo que necesitaba para que le sostenga la... [...] se le habrá terminado la sangre [...] de eso habrá muerto, ella terminó como a las 5

A: y los médicos?

R: que no habían podido hacer nada, no sé qué ha pasado ahí (P21, mujer, 63 años).

C: le dicen en la ciudad los doctores que al cerebro, lo han tironeado porque no podía tenerlo [...] ellos le habían recetado primero cesárea y los doctores no le querían hacer cesárea y ya la han visto mal a la chica y le han tirado de la cabecita, ahí le han embromado el cerebro, dice el doctor (P66, mujer, 60 años).

Sólo por urgencia han tenido que atender los enfermeros de la posta algunos partos (la enfermera recordaba tres) contando con la asistencia también de una señora reconocida como "baquiana" (partera) y cuyos cuidados son requeridos por las madres quienes confían en su experiencia, en la eficacia de sus "maniobras" y "masajes" para apurar el parto.

M: como ella sabe hacer sus maniobras, cuando antes, decía ella, no? que nosotros no sabemos, ella le hace los masajes para que nazca más pronto y ella le hace y nacen los niños muy pronto [...] que las mamás a veces ya le tienen confianza más a ella que, dicen que ella de joven ya ha empezado a atender a las mamás cuando tienen los bebitos, y bueno, ellas la hacen llamar, no es posible nosotros correrla, nosotros la dejamos porque sabe (P54, enfermera de la posta).

Las mujeres de alrededor de 50 años o más refieren haber dado a luz en sus hogares ayudadas por un familiar, alguna "baquiana" y/o un curandero (presente generalmente en momentos previos al parto). Las personas de mayor edad y el curandero local describieron prácticas realizadas por estas parteras y curanderos con el objeto de facilitar el parto. Una de ellas es el "manteo" que consiste en suspender a la embarazada sobre una manta y hacerla rodar de un extremo al otro mediante sacudidas de la misma para acomodar al bebé en la posición correcta para nacer. Con el mismo fin realizan masajes y soban el vientre de la embarazada. Otra práctica, cuando el parto se demora, consiste en darle al niño el nombre que llevará al nacer y 1 lamarlo ${ }^{25}$, generalmente acompañado de "secretos" y el gesto de la señal de la cruz sobre el vientre.

O: él ya en el vientre ya le elegía el nombre... que así lo iban a llamar y bueno el viejito se iba [...] y le gritaba ya del nombre[...] no lo podía tener, venía los curaba, secretos que tenía y le gritaba ya, gritan el nombre y el viejito se venía para acá y le gritaba "vení hijito, dejá que estás haciendo sufrir a tu madre" y entonces al poco tiempo ya nacía [...] todo, el nombre y el apellido (P2, varón, 58 años).

E: cuando estaban mal las manteaba, cuando no, no

A: y ella cómo se daba cuenta que estaba mal el bebé?

\footnotetext{
${ }^{25}$ En páginas siguientes se verá que el llamado por el nombre es un elemento característico de las terapéuticas tradicionales del NOA "que revela la importancia del nombre como entidad constitutiva del sujeto", entidad "que recibe directamente la energía y el poder restaurador de las palabras" (Idoyaga Molina, 2001: 21, 62).
} 
E: y porque no da la vuelta, es un solo bulto, mantear es poner el pullo viejo que le pone, le pone así y se lo duebla de una punta queda cuadrado y de la otra de allá así [lo dibuja en el suelo de tierra] hasta que llega hasta ahi [señala de un extremo al otro] y de aqui para allá y de allá hasta aquí

A: de una punta hacia la otra?

E: ida y vuelta, y ya se compone, ya nace

A: y eso lo hacía antes del parto o muchos meses antes

E: no, cuando está enferma [en trabajo de parto] porque no da la vuelta, no corona el chico $[. .$.$] está de través, se tiene que poner bien (P4, mujer, 76$ años).

En uno de mis viajes de campo me encontré con la novedad de dos nacimientos en circunstancias marcadamente distintas: una joven que no alcanzó a llegar a la ciudad para dar a luz y que fue atendida en su hogar por su abuela y otra mujer ya que, no siendo horario de atención de la posta, en ese momento la enfermera se encontraba en su casa (Chistín) y no se alcanzó a llamarla. Luego del parto sin inconvenientes fue enviada con el bebé al hospital de Belén para su revisación; Y el de otra muchacha (casualmente hija de la mujer que prestó ayuda en el parto local) quien aún habiendo llegado al hospital de Belén tuvo complicaciones y necesitó que se le hiciera cesárea.

En el primer caso las mujeres se refieren al parto casero con naturalidad, no sólo las dos que atendieron a la parturienta y que tenían la experiencia de haber parido a sus propios hijos en el hogar sino también la joven, quien había tenido a su primer hijo en el hospital. En el segundo caso, dada la gravedad de las dificultades que hacían peligrar la vida de la embarazada y del bebé, quienes lo narran no cuestionan la hospitalización del mismo, reconociendo el valor del accionar médico y la eficacia de la intervención quirúrgica. Es decir, no obstante la atribución de potenciales efectos iatrogénicos a las intervenciones quirúrgicas y la consideración del parto como un evento factible de ser autoatendido, la percepción de una situación de riesgo conduce a una apreciación positiva de lo que en otros casos se evalúa como compulsivo, es decir, la obligación de dar a luz en un hospital es visto aquí como una medida necesaria ${ }^{26}$.

P: pero fue en un rato

A: y qué hicieron?

$P: y$ asi la tuve $[. .$.$] en el piso$

A: y tenías miedo?

$P$ : sí, un poco

A: y a la enfermera no la llamaron?

P: y no porque ella estaba en Chistín... y ahi nomás [...]

\footnotetext{
${ }^{26}$ Módena notó entre las mujeres del pueblo mexicano donde trabajó, que no obstante la valoración positiva que tenían sobre las parteras y sus prácticas tradicionales, "ante la posibilidad del sufrimiento que puede ser paliado por la intervención médica, se inclinan por esta última al mismo tiempo que añoran las viejas costumbres", "las mujeres que habían tenido dificultades, sufrido maniobras inciertas en partos distócicos o que finalmente habían tenido que recurrir al médico iban construyendo el vector tendencial [...] hacia el empleo de la medicina hegemónica [...] que, aunque objetivándolas o violentándolas en sus pudores, podía salvarles la vida o evitarles largas horas de sufrimiento" (Módena, 2002: 354, 356).
} 
A: y el ombligo?

$P$ : lo ató mi mami [la abuela] y en Belén le pusieron el broche

A: y a vos te hicieron algo?

$P$ : no apenas me han revisado, estaba todo bien (P70, mujer, 22 años).

E: ella [su nieta] me ha avisado, yo estaba trabajando por ahi [...] el hecho es que me he venido, dice que estaba enferma, con dolores, pero habia dicho que iba a ir a Belén, ya tenía la camioneta de don X y no, ya me han dicho que ya estaba y ya he venido yo y la he levantado [ayudar en el parto], le he cortado el ombliguito y lo he envuelto hasta que ella se ha acomodado bien para que la bañemos ahi y ya está, yo estoy acostumbrada a levantar, ni las mías, yo nomás las levantaba a las chicas mías (P65, mujer, 78 años).

L: yo la he recibido y he tenido que cortar el ombligo [...] con la tijera, la limpié con alcohol para que no se le infecte

A: y con qué se lo ató?

L: con hilo de bovina

A: y eso usted lo habia hecho con todos sus hijos?

L: sí [...] yo con mamita y después sola, antes las mujeres aquí nomás parteaban

A: y nunca les pasaba nada?

L: gracias a dios y la virgen no [...] la levanté yo, el médico me daba para una fecha y resulta que no ha llegado, ha tomado de sorpresa, la levanté yo

A: y no le daba miedo estar sola? Que pasara algo?

L: no, y qué, usted se pone en brazos de dios y cuando las cosas van a pasar ojalá que sea con el médico, no? (P76, mujer, 45 años).

L: placenta previa, se le ha adelantado, de aquí la hemos llevado con pérdida y la querían pasar a Catamarca y el doctor no quería, dice que estaba muy riesgosa, en el camino como es largo viaje, entonces él se ha corajeado y la ha operado en Belén, hasta que yo he llegado de aqui ya la han operado pero gracias a dios ha salido todo bien (P76, mujer, 45 años).

Y: no sé por qué, pero si no la operaban se morían las dos, porque no la podía tener normal (P80, mujer, 19 años).

Los más jóvenes tienen más naturalizado el hecho de que los médicos supervisen el embarazo, parto, postparto y primera infancia; controles, análisis, ecografías, vacunas, etc. no son considerados opcionales. Sin embargo esto no anula las consultas con curanderos, con lo que complementan la atención a la salud y chequean o confrontan diagnósticos y terapéuticas.

R: claro, cuando uno está embarazada todos los meses para tener un buen parto, todos los meses a control, te hacen ecografías, te hacen análisis, cuando te ven mal ya te hacen todos los estudios, allá siempre [en Belén] yo me iba a cobrar y me iba al doctor y a doña $L$ [curandera]

A: a los dos?

R: sí, yo nunca le decía a ella lo que el doctor me decía, si no que ella me decía, por eso digo yo que ella sabrá [porque le decía y recetaba lo mismo] me hacía los estudios y los hacía ver con el doctor y con ella (P20, mujer, 24 años). 
Esta misma persona contaba que durante un embarazo al sufrir de mucho dolor de espalda fue a consultar a una curandera quien le dijo que se debía a que el bebé estaba mal ubicado. Le sobó la espalda con lo que el dolor pasó y cuando fue a Belén y le hicieron una ecografía se vio que el bebé ya se había reacomodado. Así, el uso articulado de la atención biomédica con la de curanderos además de cubrir las necesidades terapéuticas desde distintos frentes le permite al paciente cotejar los resultados de una práctica o lo acertado o no de un diagnóstico.

En relación a los cuidados postparto que ya no se tienen en cuenta dada la hospitalización del parto, algunas mujeres mencionaron no lavarse la cabeza durante los primeros 8 días después de dar a luz, no acercarse al fuego y a los vapores de la cocción, no exponerse al sol y andar con un pañuelo atado en la cabeza durante este período o más (algunas refirieron hasta 40 días) ${ }^{27}$. El mal que se quiere evitar es que la sangre "se vaya a la cabeza" provocando locura, debilidad a la cabeza. Que actualmente las mujeres no sigan estas precauciones sin sufrir por ello consecuencia alguna, es explicado a partir del hecho de que en el hospital las parturientas reciban medicaciones que aseguran su restablecimiento volviendo innecesarios los cuidados arriba mencionados. De esta manera se adaptan (sin necesidad de que ello comporte cambios significativos) antiguas concepciones a prácticas nuevas: el riesgo de que la sangre "se vaya a la cabeza" persiste al igual que sus causas y efectos pero una práctica nueva (la atención biomédica del parto y postparto), que altera las conductas orientadas a evitarlo, introduce otros elementos (inyecciones y medicamentos) a los que se les atribuye el carácter igualmente preventivo. Lo que no ocurre en el caso en que se asocia la medicalización del parto y postparto con enfermedades "nuevas" como el cáncer, aquí se identifica y vincula causalmente una práctica nueva con padecimientos nuevos (para los cuales no se cuenta con otras causas específicas claras).

\section{E: ahí nomás corren a bañarse y lavarse como a ellas les ponen la inyección y quedan bien \\ A: o sea, ella después de tenerlas a las nenas no se tuvo que cuidar de nada? \\ E: no, porque a ella ya la han agarrado, en el hospital ya la he tenido a la M y de ahí nomás le han puesto inyección y quedó bien y le han dicho que se bañe [...] nosotros teníamos miedo de que se enferme ella fiero después de tenerla pero no, estaba bien}

\footnotetext{
${ }^{27}$ Módena recupera en su trabajo en un pueblo mexicano de finales del siglo XX, que la interdicción del baño durante el embarazo, parto y postparto, sobre todo el contacto con agua fría, es una herencia de la costumbre popular española y de la obstetricia médica divulgada en México en el siglo XVIII que pretendía evitar la polaridad frío-caliente (dentro de esta visión el embarazo es considerado un estado caliente) así como un enfriamiento que ocasionaría la suspensión de los loquios y el retroceso de la leche (Módena, 2002). Cabe pensar que los cuidados aquí mencionados sean reelaboraciones de esta concepción médica pretérita. Aunque no hubo referencias a la identificación del parto y puerperio con un estado caliente, puede haber sido la idea subyacente (ahora desconocida) a la precaución de mantener alejada a la parturienta de toda fuente de calor. Así mismo puede verse una asociación entre el riesgo de alteración de los loquios y la idea presente en Azampay de que la sangre "se vaya a la cabeza".
} 
A: y por qué se puede enfermar después de tenerlo?

E: porque aqui es triste la vida, después de tenerla a la criatura, se tiene que cuidar del sol, tiene que madrugar, levantarse al baño porque si le da el sol ya...

A: después de tener el bebé no le tiene que dar el sol?

E: no, ni nada, no tiene que salir afuera, pero yo sí, yo andaba caminando, los tenía y salía a atender el fuego, a hacer todo, porque no se pueden arrimar las chicas así

A: y por qué?

E: porque eso es malo, se le iba la sangre a la cabeza pero yo no porque, ahora estos años las chicas no se atan la cabeza y yo sí porque eso hay que atarse bien con un pañuelo para que no se le iba la sangre para la cabeza y cuando el parto, tiene a la criatura así sin caminar, no le hace mal nada [...] allá ya la habían preparado, le ha puesto inyecciones ya ha venido bien ya

A: entonces no se tiene que cuidar del sol?

E: ella ya no, porque un día las tienen en el hospital en Belén

A: o sea que esos cuidados que usted tenía después de parir ellas ya no los tienen?

E: no (P65, mujer, 78 años).

L: así dicen muchos pero ahora ya no es así, si yo cuando lo he tenido a él, ahí nomás me bañé

A: y no te pasó nada?

L: no, y como me hicieron puntos me lavaba para que no se me infecte

T: y bueno, pero la $E$ los ha tenido a los niños aquí nomás, es diferente porque ella [señalando a L] ha tenido muchos medicamentos

A: después que tuvo el nene?

T: claro (P70, mujeres, T: 72; L: 23 años).

\section{A modo de síntesis}

En este capítulo dedicado a la descripción de los diferentes recursos empleados para dar solución a las situaciones de malestar se destacaron también los diversos factores que orientan su elección tales como características de la enfermedad identificada, la pertinencia de los distintos curadores en relación a la misma, evaluaciones de los servicios de atención, posibilidades de acceso a los mismos (definidas principalmente por la disponibilidad de transporte y de redes sociales que facilitan la permanencia fuera de Azampay). Que sea este el primer eje considerado para abordar la información responde al hecho de que se parte de reconstruir los procesos terapéuticos (a partir de las narraciones que los individuos elaboran para significar, objetivar y compartir las experiencias de malestar) para desde allí ir circunscribiendo y extrayendo las enfermedades identificadas junto con sus síntomas, etiologías y respuestas terapéuticas.

Considerar el proceso terapéutico como el curso de un episodio de enfermedad definido por la secuencia de observaciones, decisiones y acciones que conducen hacia los 
distintos recursos de atención a la salud, que se van modificando al contrastar con las observaciones de la evolución del malestar, con las experiencias compartidas por otros individuos y con los fragmentos de saberes transmitidos por los curadores, permitió destacar los procesos de significación y resignificación que median entre la percepción de molestias, dolores, y demás, y su configuración en síntoma. Desde un enfoque que reconoce el carácter construido y social de los procesos de salud-enfermedad y no considera las categorías de enfermedad como entidades en sí, se puede entender el diagnóstico del paciente no como algo que queda definido previamente a (y como requisito de) la elección de un tratamiento sino como una elaboración en constante reajuste con la información extraída a lo largo del proceso terapéutico. El hecho de que un malestar no se presenta de manera evidente y clara dictando la respuesta adecuada quedó reflejado en los casos en que la enfermedad era redefinida, destacando la pertinencia de lo anteriormente citado respecto a que los síntomas deben ser entendidos en tanto símbolos, atribuciones de sentidos, y por ende hechos sociales, no realidades naturales. La relación no unívoca entre síntomas y malestares explica que en la narración de un episodio de enfermedad aparezcan generalmente más de un padecimiento, ya que presentando síntomas similares, uno es reemplazado por otro cuando el diagnóstico es redefinido. Por ello la importancia de remarcar la circularidad entre diagnóstico y tratamiento: aunque se parta de un diagnóstico que oriente la elección terapéutica, este será siempre "presuntivo", una identificación provisoria de la enfermedad sujeta a redefiniciones a partir de los resultados parciales o finales del tratamiento realizado. Así, si bien la clasificación de ciertos malestares en enfermedades "para el médico" y "para el curandero" determina la elección del terapeuta solicitado, sosteniendo en el nivel discursivo usos excluyentes de la biomedicina y la medicina tradicional, con frecuencia se utilizan ambos recursos terapéuticos hasta dar con la respuesta más eficaz que será la que defina el diagnóstico final. En estos casos el pasaje de un tipo de atención a otra es justificado por un diagnóstico inicial erróneo que condujo a tratar por un médico una enfermedad que debía ser tratada desde la medicina tradicional o viceversa.

Se destaca el uso articulado de los diversos recursos de atención, visible al focalizar en las actividades y representaciones sostenidas por los sujetos, quienes se vinculan a éstos buscando soluciones pragmáticas a sus problemas de salud y superando la supuesta o real incompatibilidad que puedan sostener los diferentes curadores. Al respecto se advirtió la importancia de un enfoque relacional que ponga el énfasis en la perspectiva de los legos de manera de captar la dinámica con que ellos se vinculan a los diferentes servicios de salud. Esta combinación de la atención biomédica con la de curanderos además de cubrir las 
necesidades terapéuticas desde distintos frentes les permite a los azampeños evaluar los resultados de un tratamiento o lo acertado o no de un diagnóstico al compararlos con lo realizado y obtenido desde otra propuesta terapéutica.

Pero es en el espacio doméstico desde donde se concilian concepciones y técnicas procedentes de modelos de salud aparentemente antagónicos. Los individuos se afirman en sus recursos y saberes extraídos de una disparidad de fuentes para dar una respuesta inmediata frente a un diagnóstico preliminar. Así, se recupera un diagnóstico y tratamiento realizado por anteriores doctores o curanderos y que se consideró eficaz y se combinan infusiones de hierbas con medicamentos de venta libre o anteriormente recetados por médicos. El nivel de autoatención está presente en los casos en que los individuos asumen poder manejar por sus propios medios una situación de malestar ya conocida y de menor gravedad considerando innecesaria la consulta médica; frente a padecimientos para los cuales las distintas formas de atención no ofrecen solución; por desconfianza de la eficacia del tratamiento que se pueda recibir de los curadores; pero aún cuando se recurre a un médico o curandero es en este espacio donde se lleva a cabo el tratamiento recetado, las prácticas de auto e inter-cuidado prescriptas por los mismos curadores o concebidas desde el ámbito doméstico. Aquí también, dada la circularidad entre diagnóstico y tratamiento, las respuestas caseras son vistas como insuficientes o provisorias en caso de que el malestar persista o se agrave exigiendo la consulta a un especialista, lo cual en la mayoría de los casos trae aparejada una redefinición del diagnóstico.

Si bien la elección del servicio de atención es orientada por la enfermedad identificada, las nociones que se manejan sobre la misma, las formas de enfrentarla transmitidas por el grupo, el aprendizaje a partir de anteriores experiencias personales, así como la evaluación del accionar y competencia de los profesionales y curadores (que se tratará más profundamente en un capítulo posterior), está a su vez condicionada por los aspectos materiales que configuran su accesibilidad. Dentro de éstos, las posibilidades de transporte (más que la distancia geográfica concreta) aparece como limitante a la hora de optar por atención terapéutica fuera de Azampay, como es el caso de la nula utilización del minihospital de Pozo de Piedra por estar fuera del camino principal que vincula Azampay con la ciudad de Belén. Pero también para acudir a la posta los días de visita del médico de zona. Esta aparente paradoja (que se opte por ir hasta Belén en lugar de llegar a la posta a la consulta médica aunque la distancia sea marcadamente menor) se explica en la gran dificultad para quienes están enfermos de llegar a pie desde Chistín o La Agüita hasta la posta, mientras que el transporte municipal, que sí accede a estos caseríos, ofrece la posibilidad de ir y volver 
a Belén tres veces por semana y por un precio accesible. Las carencias del servicio local de atención a la salud (no disponer en los últimos años de un transporte adecuado al terreno, así como la escasez de remedios y demás recursos para la atención y el diagnóstico) junto a la reciente mayor accesibilidad (dada por el transporte) de los centros de atención en Belén lleva a que muchos opten por saltear este primer nivel de atención a la salud. Otro factor de fuerte peso a la hora de decidir por recursos para la salud alejados de Azampay es el contar con parientes viviendo en las ciudades, un capital social, como se dijo al describir los procesos migratorios de esta población, al que se apela para poder permanecer allí el tiempo necesario para estudios, tratamientos, controles. Además se mencionó el apoyo monetario de la municipalidad para quienes por procesos crónicos o de larga duración deben viajar regularmente a la ciudad de Catamarca, pero que depende de la red de relaciones sociales y políticas que cada individuo posea. Frente a la atención gratuita de los hospitales públicos, el recurso de los centros de atención privados de las ciudades de Belén y Catamarca es sólo accesible a los pocos que cuentan con obra social, así como la consulta a curanderos (sobre todo fuera de Azampay) depende de disponer de dinero para el pago, por mínimo que sea lo dado generalmente "a voluntad". La importancia de considerar estos factores materiales (no obstante el énfasis puesto en las actividades de decisión, elección y búsqueda de eficacia) permite que las prácticas sean vistas, como señala Menéndez, como adecuaciones a lo posible, amenazadas por la carencia de medios donde lo único seguro es el grupo doméstico.

En el caso del embarazo y parto, tanto su medicalización (siempre narrada como un cambio compulsivo, no opcional) como los eventuales partos domésticos (cuando la urgencia y la ausencia de transporte impidió su hospitalización), se destacan distintos factores que limitan la elección personal. La centralidad del recurso al grupo doméstico sobresale ante la inminencia del parto que torna insalvable la distancia y la ausencia de transporte. Frente a la medicalización de este evento vital se sostiene una opinión positiva entre quienes consideran el parto como una situación de riesgo y comparan la seguridad del parto hospitalizado actual con la dureza de tiempos pasados en los que no se contaba con este recurso; pero también hay una valoración negativa vinculada con la percepción de iatrogenia (que se analizará en apartados posteriores). Sin embargo, aunque la atención del embarazo, parto, postparto y primera infancia sea actualmente asumida, sobre todo por los más jóvenes, como ámbito de competencia de la biomedicina, ésto no excluye las consultas con curanderos para complementar y contrastar diagnósticos y terapéuticas, es decir, las prácticas de articulación de recursos terapéuticos se sostienen aún en condiciones de fuerte influencia y aceptación del modelo biomédico. 


\title{
Padecimientos "para curanderos". Representaciones y prácticas en torno a taxa tradicionales. Aportes de estudios transregionales. Generalidades y singularidades del caso azampeño.
}

\author{
"El susto, la ojeadura, el aire, tantos males que hay, a veces no son males \\ para los médicos"
}

En el capítulo precedente se afirmó que la mención de la consulta a curanderos fue siempre en directa asociación a un conjunto de padecimientos identificados con nombres tradicionales y como enfermedades "para médicos campesinos" (curanderos). El taxón más frecuentemente nombrado es "aire”, pero se describirán primero los demás taxa siguiendo el orden de mayor a menor frecuencia con que aparecen en las entrevistas, y finalmente se analizará lo que se ha preferido denominar "fenómeno del aire", ya que "aire" es un término usado por los lugareños para referirse tanto a un malestar particular como a un factor patógeno de diversos orígenes y causante de varios padecimientos.

Dentro de los taxa vernáculos el más nombrado es el susto. Los síntomas en niños y bebés son llanto, gritos entrecortados a la noche, intranquilidad, no dormir bien, sobresalto en la cama, pesadillas y hablar dormido. En personas mayores se lo reconoce por dolor de cabeza, desvaloramiento (cansancio o falta de tonicidad muscular), "se golpea", "se tulle", "se les cae el brazo, las piernas tiene desvaloradas" (se diferencia del malestar asociado a una gripe, porque en este caso no hay tos ni molestia en la garganta), nerviosismo, "uno se anda espantando con uno mismo".

A: y qué siente la persona que tiene un susto?

E: y bueno, la persona que tiene un susto hay veces que sueña fiero en la noche o que se asusta, y la cabeza duele mucho por eso saben que tiene, que sea susto, ya ataca a la cabeza, dolor de cabeza o si no tiene un desahucionamiento

A: cómo?

E: desahuciado, no tiene ganas de nada, debe ser el susto, pero yo aquí tengo una manera [...] de los cerros, se llama yareta, yo la muelo bien y busco azúcar y yerba y le echo y hago una humareda, yo la sé ahumar a ella cuando sana ya queda bien, duerme bien

A: usted qué le nota?

E: porque ella cuando está asustada llora de noche pero no llora desvelarnos sino unos grititos (P4, mujer, 75 años). 
Como se señaló anteriormente, el susto aparece desde México hasta Argentina y Chile así como en algunas regiones de Europa, y más allá de las particularidades se caracteriza por ser un padecimiento causado por la pérdida del alma o espíritu a raíz de una experiencia de sobresalto o espanto, y estar asociado a un conjunto de síntomas constantes y recurrentes: debilidad física, decaimiento, intranquilidad, dificultades para dormir, estados de sobresalto, desigualdad en el largo de las piernas, entre otros (Idoyaga Molina, 2001; Idoyaga Molina y Korman, 2002). El sahúmo con sustancias como la ruda y el copal (en Azampay es la resina del molle o la yareta, subrayándose que lo esencial de esta planta para las curas es la resina que produce), la yerba y el azúcar y el llamado del espíritu constituyen las prácticas terapéuticas más frecuentemente asociadas al susto, particularmente el llamado del espíritu a través del nombre del enfermo, "la reiteración del nombre del doliente apunta a la unidad armónica de sus identidades y es, por ende, terapéutica", “el llamado de la persona mantiene la unidad entre el cuerpo y el espíritu” (Idoyaga Molina, 2001: 30, 38).

En Azampay la pérdida del alma o espíritu es referida sólo implícitamente cuando al hablar de las formas de cura se mencionan aquellas que consisten en llamar a la persona, pronunciar su nombre y ordenarle que vuelva, o explícitamente en los casos en que el susto se produjo estando la persona en un río. La causa última del susto es el aire que entra en la persona a raíz de sufrir un sobresalto y se agrava si esto ocurre en el agua o en cercanía de un río dada la asociación entre estos sitios y la presencia de aire. También situaciones de aflicción o preocupación en la embarazada ocasionan estados de susto recurrentes en el bebé.

R: eso que uno le dice, le estaba diciendo yo que el susto, si usted ve alguna cosa que usted le tiene miedo, bueno es como si usted le viene algo novedoso al cuerpo y eso es que se, después le duele la cabeza, al tiempo por ahi le duelen las muelas, los dientes [...] del mismo susto (P40, mujer, 62 años).

A: y el susto qué es?

J: y bueno, también es como un aire que, se asusta, usted va y de golpe ve, algún chiquito va corriendo y algún otro chico lo hace asustar, le sale de golpe, ve? Y se asustan, y lo hacen curar con Don P [curandero local] (P49, mujer, 40 años).

E: y mañana justamente va a estar una médica [curandera] en Belén [...] esa cura muy lindo, quería llevarla [a la nieta]

A: y por qué la quería llevar?

E: quería que la vea, que la cure de aire

A: y por qué tiene aire?

E: y bueno, se asusta, brinca a la noche [...] ella llora en la noche y salta así se asusta en al cama y llora

A: $y$ de qué se asustó?

E: y a veces se asustan de cualquier cosa, o ha visto, el otro día habia una víbora por aqui y esa la habíamos muerto y parece que eso la ha hecho asustar 
(P65, mujer, 78 años).

$F:[. .$.$] y hay otros que están durmiendo y abren los ojos y comienzan a gritar, así, a$ decir cosas que ven algo, por ejemplo yo tenía un hermanito, un primito, que una tarde se había ido a jugar en el río jugaba en el agua y a la tarde, así, a la noche, cuando se acostaba, entonces decía que veía un viejito chiquitito, y era lo mismo parece que lo que jugaba mucho con el agua dentro del río

A: eso le puede traer susto?

F: sí, como dicen que el río también tiene mucho aire, más cuando pasan las crecientes, esas cosas, y ellos sabían irse a jugar todas las tardes al río con el agua, y ya sentían que le gritaba, así, y era por eso (P30, mujer, 17 años).

J: el aire del agua por ejemplo usted se está bañando y te llegás a asustar es el peor susto porque el agua le lleva el espíritu y a dónde lo va a ir a buscar al espíritu, usted no sabe a dónde va el agua

A: y cómo lo curan a eso?

J: y bueno, eso curanderos, muy buenos curanderos lo salvan, la mayoría de la gente que se a asustado asi ha muerto (P7, mujer, 42 años).

E: dicen que es aire muy fuerte, igual que el agua cuando les lleva, cuando se caen en el agua les lleva el agua el espíritu, raro la persona que sana, se muere nomás, yo aqui un sobrino, para el cerro que iba a la zafra al norte y dice que se ha caído en el agua y de allá ha venido como viento y justo al tiempo se ha enfermado, ha muerto! (P65, mujer, 78 años).

A: pero a los grandes les puede pasar también?

J: también, también les pasa, cuando es susto grande [...] ya no puede dormir, se siente mal, no sí, cuando es susto grande si también, a veces anda la persona mal así enferma y a veces capaz que es un susto nomás y usted va a los médicos y todo, médico clínico, no?

A: y él qué te dice que es?

$J: y$ no, porque ellos no entienden eso [...] y le empiezan a hacer estudios y estudios $y$ usted sigue dolorida, dolorida, mal, decaída, sin fuerzas [...] y la curan y queda lo más bien, como que, como que le vuelve el espíritu al cuerpo (P7, mujer, 42 años).

Desde el nivel de la autoatención la respuesta terapéutica consiste en el sahúmo con yareta, azúcar y yerba, generalmente reproduciendo la señal de la cruz al pasar las brasas en torno al enfermo, acción que frecuentemente se repite tres noches seguidas y puede ir acompañada del llamado por el nombre, donde se insta a la persona enferma a que "vuelva". En relación a este último componente de la cura, fueron referidas, aunque sólo por dos informantes, la técnica de quemar un marlo donde se asustó la persona y desde allí regresar a la casa del enfermo llamándolo por el nombre, o llevar la ropa del enfermo al lugar donde se asustó y golpearla mientras se lo llama por el nombre. Aunque también están quienes sólo le dan a la persona asustada un vaso de agua "para que vuelva el alma al cuerpo", o los que no consideran necesario pagar la atención del curandero, la mayoría realiza la cura casera o 
acude a un curandero. Las técnicas de éstos últimos consisten en toques de la cabeza con alcohol y/o alcanfor, sobar la cabeza, pecho y brazos, frotar con alcohol, aplicación de "ventoseras" en la espalda, receta de yuyos (generalmente té de ruda), todo ello acompañado por los rezos, la cura "en secreto", y la repetición del procedimiento tres días.

Con menor frecuencia aparece en las narraciones la ojeadura, a veces no claramente diferenciada del susto dado que la causa última también es el aire. Cuando se señala la diferencia entre ambos malestares se remarca que la causa de la ojeadura es el aire de las personas que quieren al niño "de lejos", es decir, desearlo y no tocarlo, extrañarlo y evocarlo a la distancia. Si bien hubo alguna referencia a que también adultos pueden sufrir de ojeadura, los niños son los principales afectados dada su debilidad frente al aire o la "presión" más fuerte de la persona que los mira o desea y la fragilidad de su estructura ósea aún inmadura (la consecuencia final del aire de la ojeadura es que se le "parte la cabeza" al niño). El síntoma principal es el dolor de cabeza, presupuesto en los niños que aún no hablan, por el llanto, la intranquilidad y especialmente por movimientos hacia atrás de la cabeza ("se antarcan").

A: Y la ojeadura ella [la curandera consultada] de qué te dice que es?

$P$ : de la ojeadura porque, a veces, dice, que alguna persona, nos ha dicho, que alguna persona lo quiere y no lo toca y ahí se ojean

A: y qué le hace la ojeadura?

P: dice que se le parte la cabecita, porque ella me decía ese día que yo la he llevado, dice "no te dabas cuenta" dice "mirá cómo tiene aqui", "ahí tiene abierto" me dice y claro, y yo no me fijaba, cuando ella me ha dicho asi "mirá tócale" me dice entonces yo la he tocado y tenía hundido ahí, tenía abierto la cabecita (P38, mujer, 43 años).

A: qué vendría a ser la ojeadura?

$R$ : porque esos campesinos que curan de ojeadura, ellos lo que dicen que es porque, la ojeadura que a veces alguno lo quiere a la criatura y no lo toca y es aire fuerte la persona que lo quiere y lo, de eso la agarra a la criatura. [...] la persona grande está fuerte y el chiquito por cierto es más débil que el grande y bueno, eso mismo, que no lo toca al chiquito le cae mal, y eso es la ojeadura (P40, mujer, 62 años).

F: porque eso es el aire de las personas

A: y cómo sabe usted que es ojeadura o que es aire?

$F$ : pero el aire de la ojeadura es aire

A: es otro aire?

F: aire de las personas, porque a un chico usted lo quiere, lo está mirando allí, lo ve, usted no lo toca al chico, no lo alza, usted lo enaira al chico [...]

A: y entonces el chico con qué empieza, qué le nota usted para saber que tiene ojeadura?

F: y, porque él comienza a llorar, se siente mal, llora y llora, y ya no duerme, ya está el aire en la cabecita y hay que curarlo, y se cura con sal, el aceite, el agua y después se pone el alcohol (P55, curandero, 84 años).

J: y bueno, acá dicen, eh... de que cuando por ejemplo usted quiere a una criaturita y 
no la toca, por ejemplo, yo soy de humor fuerte, lo miro, lo miro y no lo toco y eso es ojearla, asi me explicaban a mí, no sé

A: humor fuerte?

$J:$ ahá

A: qué quiere decir eso?

J: es, por ejemplo, hay personas que usted se pone y la miran, y la miran y la miran, yo por ejemplo a esas personas así, yo, por ahí son de mirada fuerte, así, yo no la aguanto, ya en seguida bajo la mirada, no? Y bueno, eso dicen, que son así de humor fuerte, son más fuerte que uno y hay veces que uno está débil y ahí, porque yo cuando estaba en Buenos Aires me decían que las personas grandes también se ojean, sí, decían que también son ojeadas

A: pero a ellos también se les parte la cabeza?

J: y ya no, ya no, agarra mucho dolor de cabeza me decían (P49, mujer, 40 años).

Al igual que el susto, el ojeo está presente en sociedades de culturas tan diversas como las del norte de África, el medio oriente, países europeos y sociedades americanas (Idoyaga Molina y Korman, 2002). Siendo sus causas "los celos o los malos deseos y sentimientos de las personas" o un "exceso de poder, de energía o de fuerza" (cuando la causa del ojeo es involuntaria) estos autores lo incluyen entre los padecimientos originados en "desequilibrios sociales" (Idoyaga Molina y Korman, 2002: 190; Idoyaga Molina, 2001: 21): "el pensamiento, deseo o mirada fluyen como una emanación desde el ojeador y se introducen en el cuerpo del niño o la persona enfermándolo. Es la fuerza o energía de las personas la que causa la dolencia, más concretamente, son los individuos con mayor caudal energético los que dañan a las personas de menor energía. Dado que el crecimiento energético es paralelo al desarrollo físico, espiritual y anímico, los niños son siempre más débiles que los adultos, y por ende, propensos a ser víctimas del ojeo y de los daños” (Idoyaga Molina y Korman, 2002: 191). Los síntomas característicos del ojeo u ojeadura son "cefaleas, anorexia, desgano, desasosiego, movimientos anormales de la cabeza" y es considerado especialmente peligroso (mortal) en niños. Idoyaga Molina señala que si bien "Pérez de Nucci ha identificado algunos ojeados como casos de meningitis (1989: 82)", "los diagnósticos de ojeo son muy comunes y habitualmente tratados exitosamente, por lo cual es fácil deducir que se trata de cuadros que no presentan mayor gravedad” (2001: 21). Este autor explica la frecuente asociación entre "mal de ojo" y "meningite" por una cercanía entre los síntomas (movimientos anormales de la cabeza y la "abertura en la cabeza", persistencia de las fontanelas, en el caso de "mal de ojo", y rigidez de la nuca y abombamiento de las fontanelas, en el cuadro de meningitis), que "en algún momento pudo haber planteado un diagnóstico diferencial al curador" (Pérez de Nucci, 1995: 89). 
La vinculación entre ojeadura y meningitis también está presente en Azampay, sea como definiciones contrapuestas provenientes de modelos médicos diferentes o como una relación de causa-efecto donde un agravamiento de la ojeadura deriva en meningitis.

$R:$ [...] ya uno está más o menos práctico a las enfermedades esas, aquí siempre uno es más, eh... no como en otras partes, en otras partes lo llevan, sienten enfermo y bueno, los llevan al médico, y el médico, la ojeadura el médico le dice la meningitis, porque dicen que se parte la cabeza

A: eso lo dice el médico?

$R$ : el médico lo dice, eso le dice la meningitis, hay muchos que yo ya he escuchado por radio que dicen que es meningitis, que no se va a componer, que hay algunos, claro, ya los pasa y se mueren pero curándolo se componen y el médico no sabe que es de esos aires, le dice meningitis y lo siguen y bueno lo vence el aire y lo mata, pero si uno es conciente de que lo tiene que hacer curar y lo hacemos curar, porque aquí gracias a dios nunca pasó un caso asi de que se hayan muerto chiquitos así con la ojeadura (P40, mujer, 62 años).

A: ah tuvo meningitis? Y eso de qué le vino?

$N$ : dicen alguno de que los ojean

A: también?

N: ahá

A: y no la pudieron curar con un curandero?

N: y ya cuando la han llevado ya estaba muy pasada y el curandero ya no le ha hecho nada

A: $y$ ahi qué le hicieron?

$N$ : y bueno, le han hecho inyecciones

A: y la curaron en el hospital?

$N$ : sí, sí, he sufrido más porque me dijeron que no iba a caminar, que no iba a hablar (P58, mujer, 69 años).

Como terapéuticas caseras contra la ojeadura sólo fueron referidas algunas curas de ciertos individuos mediante rezos o invocaciones en voz baja mientras se soba la cabeza. Estas formas de atención no son realizadas a cambio de alguna forma de pago y no trascienden el ámbito doméstico como una oferta de servicios.

A: y cuando la $M$ [la nieta] estaba mal la curaba usted?

$R$ : no, a eso lo curaba, se acuerda de la $N$, Doña F también, la $N$, la enfermera que era antes, ella también curaba

A: ella curaba, y cómo lo curaba?

R: eso sobándole la cabeza, habrá sabido tener secretos, secretos debe ser que tiene, porque no cualquiera lo cura, por eso pienso yo que ella debe tener secretos ( $\mathrm{P} 40$, mujer, 62 años).

Las curas realizadas por curadores populares consisten, según lo descripto por los pacientes y por el curandero local, en verter sobre un plato con agua gotas de aceite y sal más la realización de "secretos", o en la manipulación de una cinta roja extendida frente al niño enfermo realizando la señal de la cruz en el rostro y boca del mismo más la indicación de 
mantenerle atada la cabeza luego con una vincha o pañuelo y darle una aspirineta para el dolor de cabeza, en ambos casos aparece la repetición de la cura tres veces. Respecto a la primera técnica, Idoyaga Molina ha señalado que tratándose de una terapéutica que a la vez es parte del diagnóstico, "se dice que la expansión del aceite en pequeños círculos representa a los ojos que han causado la dolencia” (2001: 22). Si bien esto fue mencionado también por uno de los entrevistados, no hay en las descripciones de la terapéutica una intención de hallar al responsable de la ojeadura y aunque frecuentemente su identidad se supone, no apareció ninguna actitud de persuasión frente a quien, con su deseo estaría ocasionando el mal.

$R$ : [su nieta está ojeada porque un primo de su madre la extraña y cada vez que llama por teléfono pregunta por ella] estaba llorando, estaba gorda nomás...ya lo que la quiere ve? [...] un primo, son primos hermanos [...] porque él ha tenido una enfermedad y ella [la madre de la bebé ojeada] se ha ido a Vichigasta para acompañarlo, ahi la ha conocido [a la bebé] era chiquita y de allá ha vuelto grande!

A: y él la extraña, y no puede usted hacer algo para evitar que se ojee ella?

$R$ : y no, algunos curan, esta médica que vive para la Puerta de Corral (P58, mujer, 58 años).

R: a la tarde ya le ha dado por llorar y ha empezado a llorar y llorar y después le he dado aspirina y ha estado más grave, digo un calor más grande, y ha venido y lo hemos metido al agua y se ha resfriado y bueno al último ya calló y se ha dormido, al rato a la noche ha molestado, oh! porque lo extrañaba al padre, porque nunca se separaban tan sólo él cuando se iba al trabajo

A: pero usted dice que el nene extrañaba al padre o que el padre extrañaba al nene?

$R$ : ambos se extrañaban, él lo extrañaba al padre y el padre lo sabría extrañar al hijo

A: y eso lo ojea al chico?

R: eso lo atrae al chico y por eso también, así que no ve la hora de verlo (P79, mujer, 65 años).

La tristeza y estados asociados a ésta, como llanto, inapetencia, decaimiento, palidez, desgano, vómitos, náuseas conforman los síntomas de otro malestar ampliamente registrado en el NOA: la tirisia o tisiadura, común en los niños y producido por la pérdida de lazos familiares importantes, sea por fallecimiento o por ausencia prolongada, o por la pérdida de lazos sociales en situaciones de desarraigo (Idoyaga Molina, 2001; 2002). Aunque este taxón no está presente en Azampay, sí aparece su etiología (como lo ilustra el fragmento de entrevista precedente) dentro de las causas de la ojeadura.

Otro taxón vernáculo registrado en Azampay es la abertura de pecho o "paletilla ladeada", mal que se manifiesta en dolor de pecho (también espalda y cadera), hundimiento de la "paletilla" en los niños (lo que se explica por la fragilidad de su complexión), y puede estar acompañado por vómitos o fiebre. El hundimiento de la paletilla, identificado como el 
hueso xifoides ${ }^{28}$, ha sido referido como parte del conjunto de síntomas del taxón susto (Idoyaga Molina y Korman, 2002: 187; Pérez de Nucci, 1995: 79), sin embargo en Azampay aparece como un malestar independiente causado por un mal esfuerzo durante faenas, tratándose de adultos, o producto de juegos bruscos o caídas en el caso de los niños.

$R$ : a los chiquitos más que todo, porque claro, tienen las carnes blanditas, los huesitos delgaditos, les viene vómito a veces [...] cuando se golpean o a veces porque uno los alza mal y claro son chiquitos, el cuerpo chiquito (P40, mujer, 62 años).

La terapéutica referida consiste en frotar el cuerpo con alcohol y aplicar un parche ${ }^{29}$ que se fija durante días con una faja en el torso. También fue referido el uso de "ventoseras". Ambos procedimientos fueron mencionados tanto por quienes acudieron a curadores populares y por el curandero local, como por quienes fueron atendidos por algún miembro de la familia que sabía realizarlo y por las mismas personas que realizan la cura dentro del ámbito doméstico. Pérez de Nucci describe la misma terapéutica y adjudica al uso de ventosas y de dichos parches "el sentido de succión permanente que el curador no puede ejercitar a lo largo del tiempo de curación” (Pérez de Nucci ,1995: 84).

C: le agarra vómitos, te agarra fiebre

A: y eso quién lo cura?

C: y bueno a eso algún curandero que sabe curar de pecho, te pone un parche, lo igualás bien la paletillita, lo ponés bien como es un cristiano, le ponés el parche y ya está para sanar ya

A: un parche de qué?

$C:$ un parche de esos, porosos puede ser, de ese parche que viene, ha visto?

A: ah, los compran?

C: esos parches de incienso le hacen aquí, gente que cura de aquí hacen de incienso del molle, incienso del árbol o del incienso de la yareta también

A: y quien lo cura acá?

C: hay curandero que curan, mi mamá también sabía curar mucho

(P27, mujer, 56 años).

R: bueno, eso es a veces cuando los voltian y se les, así de pancita, se les hunde esta cosita finita que uno tiene aquí en el pecho, eso parece se les hunde, se les duebla y de eso les viene vómito y después, la gente de antes, bueno ahora tiene alguno que sobándolo así y le ponen con un vasito lo prenden así, lo vuelcan y eso lo chupa, no sé si usted lo habrá...

A: me habian dicho las ventoseras?

$R$ : eso, ve

A: ah, y es para esto?

R: levanta ese, le sabian decir antes la paletilla, al huesito ese finito que uno tiene en el pecho, no sé si usted se habrá tanteado una vez ahí (P40, mujer, 62 años).

\footnotetext{
28 'La paletilla corresponde anatómicamente al hueso xifoides, es decir, a la punta del esternón. La 'caída' es un presunto hundimiento del apéndice xifoides, que puede llegar a provocar una severa diarrea en el niño- generalmente son los niños los más afectados- y llevarlo a la muerte" (Pérez de Nucci, 1995: 79).

${ }^{29}$ Lo mencionan como "parche poroso", comprado en las farmacias de la ciudad o de origen casero, confeccionado con un pedazo de tela firme y untado con la resina, el "incienso" o "mito", de la yareta o el molle.
} 
R: nunca le pasó, pero mis otros chicos sí, los otros grandes que yo tenía, por eso digo yo esas cosas ya más de antiguo, a veces uno en andar así, uno trabajaba mucho y bueno en una de esa por eso sabrían nacer asi

A: ya nacian con eso?

R: ya sabría nacer por eso una mínima cosa que pasaba ya se le venía ya se les notaba ése que se les hundía para adentro la cosita esa y ya empezaban a vomitar, curándolos ya sanaban y quedan bien

A: y usted los curaba o otra persona?

R: yo los curaba (P40, mujer, 62 años).

En el fragmento precedente, el arduo trabajo durante el embarazo es mencionado como posible causante de una predisposición en el niño a contraer dicho malestar. Como se verá en el capítulo siguiente, aunque la aikadura (resultado de la violación de un tabú durante el embarazo) no es conocida en Azampay, hay toda una serie de factores patógenos que, presentes durante el periodo de embarazo, tienen repercusiones en la salud del niño.

Aunque al nombrar las causas de la abertura de pecho no hubo referencias explícitas al aire, su participación en la etiología de este malestar apareció entre las explicaciones de la terapéutica: comparando los parches comprados en la farmacia con los caseros, se señaló que estos últimos eran mejores porque llevan el incienso de molle, el "mito" del molle o de la yareta que "son buenos para el aire", también al referir que a quien cura de abertura de pecho le afecta el aire del enfermo.

C: hay curandero que curan, mi mamá también sabía curar mucho, ahora ya no porque a ella se le ha cortado mucho la vista, porque cuando vos estás muy airienta también jode a la persona que te está curando, claro vos tenés que curarte primero, sahumarte para curar [...] con los yuyos mismos que está curando, por ejemplo con la yareta con la, también que es buena para el aire, la salva blanca

(P27, mujer, 56 años).

El empacho y la culebrilla son otras categorías de enfermedad bien conocidas y extendidas en nuestro país y América Latina (Idoyaga Molina, 2001; Idoyaga Molina y Korman, 2002) también presentes en Azampay, (aunque con menor frecuencia que los males anteriormente nombrados) y que requieren la atención de curadores populares. El empacho se manifiesta casi siempre en niños como un endurecimiento del abdomen ("panza dura") acompañado de fiebre y llanto y asociado a una ingesta excesiva que sería su causa. Como respuestas caseras fueron nombradas diversas hierbas que se toman en infusión (apio de la puna, anís del campo y paico) y quienes han acudido a un curador popular refirieron una cura que consiste en la colocación de huevo (yema o clara) sobre el abdomen más los "secretos" y una cura con una cinta azul extendida frente al enfermo también acompañada por "secretos". Aunque quienes refirieron esta última cura no pudieron dar más detalles, por la mímica que 
acompañó la explicación puede pensarse que la misma no se diferencia mucho de la descripta por Idoyaga Molina, donde indica el uso de una cinta "que permite realizar el diagnóstico y comprobar el éxito del tratamiento, midiendo durante tres días consecutivos el antebrazo en relación con la boca del estómago" (2001: 13). La cura del empacho, al igual que la cura de la abertura de pecho, también la realizan algunos conocidos dentro de lo que se planteó como autoatención o medicina casera. En un caso el empacho fue asociado a eventos de frío, por lo que la curadora recetó baños con hojas de malva para que calentara el cuerpo ${ }^{30}$.

Y: porque es cuando come algo y come, come, come hasta que lo devuelve y después ya tiene el aliento descompuesto, no quiere comer nada y lo que comió ya no lo quiere ver siquiera $[. .$.$] se le pone la pancita dura$

A: y cómo lo cura ella a eso?

Y: bate un huevo, creo que echa alcohol y pone en algodón y lo pone en la panza y creo que van también con palabras [...] en un algodón le dejan en la pancita y lo fajan, le envuelven en la...

A: y por cuánto tiempo?

Y: y hasta el otro día hasta que lo vuelven a curar

A: también son tres curas?

Y: si (P22, mujer, 17 años).

A: y me han dicho que la $N$ también cura el empacho?

T: y también, son secretos que aprenden por ahí y deben estar mirando cómo curan el empacho, ella cura con cinta pero hacen el secreto también (P70, mujer, 72 años).

La culebrilla, descripta como un problema dérmico, una erupción en la piel siguiendo una línea (si ésta circunda el cuerpo uniendo sus dos puntas trae consecuencias fatales para el paciente) es causada por una iguana o lagartija pequeña, víbora o culebra, que por lo general no es vista, pero contamina las prendas que entran en contacto con su rastro, o al pasar por ejemplo, sobre la ropa extendida para su secado (Martínez y Planchuelo, 2003). Desde la biomedicina se la ha identificado como herpes zoster, una erupción vesicular aguda, dolorosa, limitada a la región de la piel inervada por un solo ganglio sensitivo (por lo cual es imposible que el círculo se cierre ya que no hay conexión entre los nervios intercostales izquierdos y derechos), producida por la activación del virus latente varicela-zoster. Martínez y Planchuelo recuperan dicha asociación de la mano de Di Lullo (1944) en sus estudios de medicina popular en Santiago del Estero, pero advierten que este tipo de comparaciones entre taxa tradicionales y biomédicos con el objeto de establecer equivalencias puede ser "distorsionante de las representaciones de un grupo sin que haya correspondencia entre un tipo de mal y un tipo de medicina (Idoyaga Molina, 1999a, d)" (Martínez y Planchuelo, 2003: 110). Estos autores refieren la cura a partir de oraciones y cubriendo o escribiendo con tinta china en la

\footnotetext{
${ }^{30}$ Al respecto señala Idoyaga Molina (2001: 19) que el baño y las infusiones son terapias de carácter cálido con las que se tratan males definidos como fríos (en este caso, que tiene su causa en el frío).
} 
parte afectada (también en Idoyaga Molina, 2001; Idoyaga Molina y Korman, 2002). En Azampay las curas mencionadas fueron realizadas por curadores populares de otras localidades, y consistieron en la aplicación de un sapo vivo sobre la zona irritada ${ }^{31}$ junto al uso de tinta china y de "secretos".

A: ayer me decía $M$ [nieta de la afectada por culebrilla] que habian ido a uno de Condorhuasi, a Don $R$ [curandero]

$J$ : sí, don $R$, sí, han ido porque le ha salido culebrilla a tu mamá [volviéndose a su marido] eso es una ronchazón que le sale en el cuerpo, según dicen que es una víbora, a mi me contaban en Belén que es una víbora, la víbora ciega que por donde pasa la víbora ciega deja la baba y a veces por ahi usted tiene la mala costumbre que en el baño se le cae la ropa y bueno, esos baños, los water que le digo, esos baños de antes, bueno, por el agua todo la víbora entra y vuelve a salir y deja la baba esa, por ahi anda por los cercos, los alambres y deja la baba y de eso dice que va en la ropa por eso dicen que uno muchas veces hasta la ropa interior hay que plancharla, porque el calor de la plancha quema todo los virus y bueno [...] él la cura en secreto, la cura con un sapo

A: y eso acá Don $F$ [curandero local] no lo puede curar?

$J$ : parece que no, no sabe, creo que no sabe

A: y la $M$ me decía que había ido al médico y el médico le dijo que fueran al curandero

$J$ : sí, porque ellos los médicos clínicos no le hacen nada (P7, mujer, 42 años).

$J$ : es culebrilla dicen, y es para el campesino porque nosotros a veces la avivamos más con los remedios de médico. Y bueno, entonces buscamos una señora campesina y ella la empezó a curar, pero a mi mamá, para que le corten, pero no le han cortado del todo, no, digamos, se le ha ido esas escamas, esas cosas que ella tenía, y... dice que ella la tenía para dentro, por dentro, y al curarla en secreto, y le pasaban un sapo, porque ha visto que la panza del sapo es helada? Dice que es una fiebre que agarra por adentro y eso la ha sacado para afuera, la ha sacado todo, y esas ampollas han salido (P49, mujer, 40 años).

A: y por qué le pasa el sapo?

R: por la piel, no sé qué sabrá tener el sapo, como es tan helado, el sapo es helado, como yo tenía fiebre y remedios de farmacia que no es bueno tomar para eso

A: por qué no es bueno?

$R$ : no sé, asi dice el doctor que remedios de farmacia no me daba porque ése no es para tomar [...] estábamos en el mes de agosto todos los sapos guardados a gatas [...] a La Ciénaga a lo de mi hermano, me ha mandado 3 sapos, tenían que ser 3 curas (P79, mujer, 65 años).

Por último, se registró también como enfermedad "para los curanderos" la pata de cabra. Aunque se trató de un sólo niño afectado, el taxón era conocido por otros individuos quienes habían escuchado algún caso y tenían alguna idea de los síntomas por los que se lo identifica, particularmente las manchas violáceas en la espalda, lunares morados a la altura de

\footnotetext{
${ }^{31}$ El uso de este animal se explica en que siendo frío extrae el calor de la erupción, similar al uso de boídeos (y ungüentos a base de éstos) para tratar males cálidos dado su carácter frío (Idoyaga Molina, 2001; 2002).
} 
la columna acompañado de vómitos, diarrea, fiebre y delgadez. Ninguno supo decir alguna causa de tal padecimiento, salvo la madre del niño afectado, que suponía que era por debilidad, pero varios afirmaron que de no buscar la cura de un curandero podía llevar a la muerte del niño. Aunque una entrevistada dijo que los adultos también podían ser aquejados por dicho malestar, los casos referidos eran de niños menores de 4 años.

T: sí, pata de cabra sí, esos lunares, el hermano de ella cuando era más grande que él [refiriéndose al bebé de su nieta] ya caminaba el chico... los lunares que se le hacen en la espalda, y tenía los lunares en la colita... ya se le han ido

A: pero se sentía mal?

T: sí, tenía vómitos, diarrea, fiebre, estaba flaquito y han ido para allá, para el norte una señora, la L [curandera], ella lo ha sanado al chico

A: y qué le hizo?

T: y no sé cómo lo habrá curado ella

A: y ella le dijo que era pata de cabra?

T: si y lo ha sanado, lo han llevado

A: $y$ de qué le viene?

T: y no sé, de mal así que se enferman pero el changuito ése tenía vómito y diarrea, estaba flaco! Cabeza nomás! ... le aparecen las manchas [...] y la pata de cabra dicen que cuando no la cura lo... nomás al niño (P70, mujer, 72 años).

F: y una vez lo había llevado, por las dudas nomás lo habia llevado a ver con la señora, uh pero le ha dicho que era para morirse tiene pata de cabra

A: ah se pueden morir?

F: y claro, eso va por la columna

$N$ : dicen que va y llega a la cabecita

A: desde abajo para arriba?

$N$ : de abajo para arriba dicen ya se muere, dice que estaba para morir

A: y de qué le viene?

$N, F$ : qué sabrá ser?

A: y cómo se lo curó?

F: no le hemos preguntado cómo habrá sido (P58, mujeres, F: 62 años; N: 69 años).

P: esa señora [curandera de Belén] cura de susto, cura de pata de cabra, yo una vez lo he tenido a él enfermo y lo he llevado al médico y el médico no me ha dado nada y él seguía lloraba, lloraba, lloraba y bueno esa señora lo he llevado yo para esta señora $C$ que era vecina de la tía $P$, y esta señora me ha dicho "mirá, lo que tiene D es pata de cabra, yo lo voy a curar" porque él tenía unas manchas moradas asi y ella lo ha curado 9 días y se ha compuesto

A: y de qué le vino eso?

$P$ : y no sé, según dicen que viene de mucha debilidad pero no sé (P76, mujer, 45 años).

Respecto a la terapéutica realizada, la única descripción obtenida fue la de la madre del niño enfermo (el curandero local no cura pata de cabra) y consistió en la aplicación de tinta china sobre las manchas y los supuestos "secretos".

P: y sabía ser unos lunares morados que se hacen por ahi la espina así, manchitas así 
[...] sueltito, no tenía firmeza él, el cuellito para todos lados [...]

A: y cómo es la cura esa?

$P$ : con una tinta, con un frasquito así y de ahi le sacaba con un palito así como si fuera un cañito de lapicera ...era un palito largo y ella ya metía y sacaba y ya ...en cada mancha, en cada manchita

A: 9 días vos lo llevabas, y a parte hacía otra cosa?

$P$ : sabrá ser que decía algún secreto ella porque, ella me decía que lo ponga boca abajo y le levantaba la ropita y asi le bajaba el pañal que tenía porque de ahí sobre la colita tenía las manchitas y parecía que en cada manchita le hacía ella

(P38, mujer, 43 años).

En su estudio sobre prácticas y representaciones sociales relativas a la desnutrición infantil en el Gran La Plata, Ortale observó que la pata de cabra aparece como una conceptualización popular que refiere casi siempre al niño desnutrido. El síntoma central señalado por la autora es "un hematoma producido por la disminución del panículo adiposo en la zona del sacro y la permanencia del niño en la cuna o cama" (Ortale, 2003), generalmente acompañado sea de diarrea, vómitos, llanto continuo, nerviosismo, sueño excesivo, y que acontece en niños pequeños. Sus informantes explicaron que dichas manchas dan cuenta de la existencia de un "bicho" que, "a medida que va subiendo por el espinazo, lo va secando", "lo chupa por dentro", produce pérdida de peso y puede provocar la muerte. Ortale notó que si bien la pata de cabra era conocida por la mayoría de las madres entrevistadas, entre quienes no habían tenido hijos con desnutrición se trataba de un conocimiento indirecto, a través de comentarios ya que no habían tenido ningún caso de pata de cabra entre sus hijos, mientras que las madres de hijos que habían sufrido desnutrición se refirieron a la pata de cabra asociada al hijo desnutrido: excepto un caso, todos los niños desnutridos habían padecido, al tiempo de la desnutrición, pata de cabra. Aunque pata de cabra y desnutrición son claramente distinguidos por sus entrevistadas (en el caso de pata de cabra el bajo peso está acompañado por vómitos y diarrea), la mayoría estableció una relación en términos de causalidad: la pata de cabra produce desnutrición en la medida que causa un brusco descenso de peso. Así mismo todas sostuvieron que se trata de una enfermedad que incumbe a la medicina popular dado que la medicina oficial resulta impotente para curarla. Las terapéuticas referidas consisten en la cura por palabra, imposición de manos, frotamiento con velas, con aceites, realización de cruces en la espalda con tinta china, e indicación de ciertas prescripciones y/o proscripciones alimentarias.

La similitud de síntomas recuperados en esta descripción, aunque proveniente de un contexto muy diferente al azampeño, induce a pensar que estamos frente a una misma entidad y no sólo frente al uso generalizado de un término denotando situaciones marcadamente 
diferentes. Respecto a la relación señalada por Ortale entre pata de cabra y desnutrición, en Azampay no fue recogida ninguna expresión que vinculara el estado de bajo peso en el niño con el evento de pata de cabra. No obstante, es importante tener en cuenta que el único caso de pata de cabra registrado allí es el de un niño que presenta un retraso motriz y psíquico (con más de 5 años aún no caminaba ni hablaba). Se trata del caso anteriormente referido al mencionar los niños con discapacidad y que en palabras de la médica de zona, se debe a problemas constitucionales. En el ya citado informe "Control niño sano" de junio del 2006, figura como un niño con desnutrición de primer grado, y en el 2008 había sido incorporado a un plan que provee módulos alimentarios a las familias con niños con bajo peso.

Los taxa vernáculos han sido el eje central de los estudios sobre medicina tradicional desde el enfoque de la etnomedicina, originalmente dedicada a las sociedades denominadas folk o tradicionales, considerándolos expresión paradigmática de la perspectiva emic, de las percepciones nativas y por ende culturales de la enfermedad. De allí la tendencia, aquí cuestionada, de buscar establecer equivalencias entre estos taxa tradicionales y los biomédicos con el objeto de facilitar la comunicación entre la población nativa y los profesionales de la salud. Si bien se mencionaron los vínculos establecidos en anteriores trabajos entre por ejemplo ojeadura y meningitis, culebrilla y herpes zoster o la descripción de la caída de la paletilla como el hueso xifoides, se advirtió que este tipo de comparaciones puede ser distorsionante de las representaciones del grupo además de incurrir en una reificación de las categorías biomédicas de enfermedad, en tanto nombres de entidades existentes en sí posibles de ser identificadas, aunque con otra nominación y modelo explicativo, en la cultura de estudio.

De igual manera se citaron los trabajos que, basados en amplios estudios comparados, reconocen la herencia europea de la mayoría de estos taxa vernáculos pero sin negar los procesos de refiguración que le otorgan en cada contexto su particularidad. Desde el enfoque constructivista, las categorías de enfermedad implican una configuración histórico-social de etiologías, síntomas, efectos y terapéuticas en torno a un malestar, vinculada a procesos económico-sociales, políticos e ideológicos, por lo que tal configuración difícilmente será la misma en otro contexto aún cuando el nombre del malestar coincida. Por ésto, y sin entrar en una comparación detallada de las descripciones para cada taxón en los distintos contextos, se señalaron las diferencias contrastativas y estructurales entre lo descripto para el caso 
azampeño y lo reseñado de otros trabajos también para el NOA. Por ejemplo, el hundimiento de la paletilla ha sido referido como parte del conjunto de síntomas del taxón susto, mientras que en Azampay aparece como un malestar independiente causado por un mal esfuerzo. Inversamente, el aire aparece como causa última del susto y la ojeadura y también figura, si bien menos explícitamente, en las explicaciones de la abertura de pecho, mientras que en otras descripciones para el NOA en general se ha conceptualizado al susto, la ojeadura y la abertura de pecho como enfermedades independientes del aire. La vinculación entre ojeadura y meningitis aparece entre los azampeños como definiciones contrapuestas (etiologías y respuestas terapéuticas distintas para una misma sintomatología) provenientes de modelos médicos diferentes (la medicina popular y la biomedicina respectivamente) o como una relación de causa-efecto donde un agravamiento de la ojeadura deriva en meningitis. Por otra parte la aikadura (resultado de la violación de un tabú durante el embarazo) no es un taxa vigente en Azampay aunque se reconoce toda una serie de factores que estando presentes en el periodo de gestación tienen consecuencias sobre la salud del niño. Lo mismo ocurre con la tirisia o tisiadura, ausente en Azampay como un conjunto de síntomas específicos asociados causalmente con la pérdida de lazos familiares o sociales, aunque esta etiología aparece dentro de las causas de la ojeadura.

Respecto a las terapéuticas de curanderos, como se planteó inicialmente, es necesario rechazar una visión de la medicina tradicional como una totalidad entera y conservada y considerarla como un ámbito de incorporación práctica de nuevos recursos, prácticas y representaciones de la medicina alopática u otras alternativas. Así se puede entender que los curanderos receten pastillas de venta libre o suplementos vitamínicos, aún para tratar un malestar considerado "para curanderos" como es el caso de la debilidad provocada por aire. Esto además conduce a otra cuestión que será tratada a continuación, y que es la de la relación entre etiologías y terapéuticas, la cual se observa que no es siempre directa y lineal, sustrayéndose a clasificaciones simplistas como por ejemplo la de sostener que a etiologías naturales corresponden terapéuticas naturales frente a etiologías místicas con sus terapéuticas místicas.

\section{El aire como enfermedad o causa última de ciertos padecimientos}

Como ya se señaló, los individuos justificaron su elección por la atención de un curandero con el reconocimiento de que se trata de una "enfermedad para médicos 
campesinos", precisión que muchas veces se alcanza luego de haber acudido al médico sin obtener resultado positivos. Las consecuencias de un diagnóstico errado que condujera a tratar un padecimiento "para médicos campesinos" mediante tratamientos médicos se consideran más graves que si la equivocación fuera a la inversa, es decir, hacerse curar por un curandero cuando se trata de una enfermedad "para médicos". Esto es explicado por la gravedad del factor patógeno presente en la etiología de la mayoría de las enfermedades "para médicos campesinos": el aire, sumado a la visión negativa de las terapéuticas biomédicas (medicamentos, inyecciones, intervenciones quirúrgicas) potencialmente iatrogénicas.

F: el médico le ha quemado la sangre, las venas [...] las narices le ha quemado, y bueno, ése es el remedio del médico, que lo destroza al paciente, cómo, y yo con, yo ni un remedio de nada [...] basta mis manos que han ido a la cabeza, si ella hubiérase ido aquí nomás y le vuelvo a repetir la curación, curaba (P55, curandero, 84 años).

C: ella [su hermana] se perdía de la cabeza

E: se descontrolaba y no sabía qué es lo que hacía

C: y ella los medicamentos que le daba el doctor no quería tomar

E: ella dice que peor se sentía

A: y por qué esos remedios le hacían mal?

E: y porque ha sido alguna enfermedad que no es para los doctores, ella decía que las pastillas que le daban le daban ganas de caminar, de caminar y caminar le agarraba así un desasosiego y le dolía el estómago y cuando se hizo ver con este otro ya [curandero]

$C: y$ bueno, dicen así que es el aire que tiene [...] los curanderos

(P60, mujeres, E: 80 años; C: 57 años).

Un repertorio bastante heterogéneo de dolores y molestias es agrupado bajo la denominación de "aire" con la que los azampeños los identifican. Síntomas como dolor de cabeza, endurecimiento del rostro, molestia a la vista, sordera, dolor de muela, mareo, malestar general, debilidad, nerviosismo, locura (conductas descontroladas y desvarío mental), son sólo algunos de los mencionados al describir el padecimiento de aire, siendo también frecuente el uso de metáforas para objetivarlos, circunscribirlos y comunicarlos. Por otra parte, como se notó anteriormente, el aire aparece como causa última del susto y la ojeadura y también figura, si bien menos explícitamente, en las explicaciones de la abertura de pecho. Aquí se nota una diferencia respecto a otras descripciones para el NOA en general que han conceptualizado al susto, la ojeadura y la abertura de pecho como enfermedades independientes del aire, el cual ha sido identificado en tanto padecimiento como "mal aire" (Palma, 1973, 1978; Bianchetti, 1996; Pérez de Nucci, 1995).

E: y dependerá del aire, toma un aire fuerte porque aquí dicen que hay mucha puna, a los bebés, a los chicos por eso no se los saca al viento porque toma el aire ése de la puna y le molesta y ya le puede hacer mal 
A: y es el mismo aire de la ojeadura?

E: mismo, mismo, el mismo aire que lo toma al niño

A: pero entonces si no estuviera en una zona de puna...

E: no se enaira el chico

A: pero si lo ojean aunque esté en una zona que no hay puna le puede dar ojeadura?

E: sí, porque eso dicen que de la misma gente que lo quiere y no lo ve, ahí dicen que lo ojea (P64, mujer, 51 años).

E: y se ponen locas, como cuentan, no sé si usted se habrá enterado, la chica esa de $N$, bueno, ésa debe tener eso, y bueno, ellos han sido de los cerros y bueno, allá habrán tenido los guaguas y el aire de los cerros, la puna, una cosa fuerte puede ser que eso se le ha subido a la cabeza, por eso hay tiempos que anda mal, dicen, yo no la he visto nunca ni la quisiera ver, ha dicho que estaba en La Merced [hospital psiquiátrico de la ciudad de Catamarca] (P65, mujer, 78 años).

Pero también otras enfermedades (de las identificadas como "para el médico") reciben en Azampay una explicación a partir de la acción del aire, por ejemplo un caso de alergia asociado a la tierra ("a veces vienen unas tierras muy fuertes, muy espesas queda oscuro y de ahí viene ese, como un aire") o el de una persona que, quejándose de padecer asma, mencionó que hilar lana de llama, animal que tiene mucho aire, empeoraba su estado.

\section{Los procedimientos terapéuticos para los casos de aire}

Desde el ámbito de la autoatención el sahumarse con yareta, azúcar y yerba, a veces en forma de cruz, es utilizado para hacer frente al dolor de cabeza a causa del aire (lo que se confirma si ante el procedimiento cesa el dolor). Se colocan alumbre molido u hojas de molle sobre la carie y se cura si la misma se debe al aire. El uso terapéutico de la yareta, del "incienso" del molle, de "agua de nogal" es explicado a partir de una valoración positiva del aire que otorga fortaleza y propiedades curativas a las plantas que crecen en zonas altas ("las plantas del cerro son más fuertes porque el aire es más fuerte”), a las plumas de cóndor o águila ( por su asociación con la altura) y a la grasa del león (animal "airoso"), justificando un vínculo de carácter simpatético entre la causa y el remedio con que se enfrenta el padecimiento.

En cuanto a la atención de los curanderos, la misma consiste en procedimientos de manipulación sobre el cuerpo del enfermo como masajes, el sobar, gestos de extracción del aire con las manos, el sahumar en forma de cruz, el "hurgar" con cobre una carie, toques con alcohol, todo ello junto a "sus secretos". Para la "debilidad" provocada por aire algunos 
curanderos recetan "tónicos" (pastillas de venta libre, suplementos vitamínicos) que a diferencia del resto de productos biomédicos, no son vistos con desconfianza.

Como preventivo contra el aire un curandero refirió recetar un preparado de ajo, cebolla, agua y pimienta ("pues calientan los intestinos", explicación que asocia implícitamente el aire con el frío), y algo similar que él mismo toma antes y después de la cura para mitigar los efectos del aire que "se le pasa" (a veces la debilidad persiste y se agrava siendo necesario recurrir al médico o a otro curandero para que recete "tónicos" o vitaminas, "remedios de dentro"). Algunos entrevistados mencionaron la precaución de sahumarse con los mismos elementos con que sahumarán luego al enfermo. También entre las conductas preventivas fue señalado el mantenerse caliente el rostro (parte afectada por el aire) durante el invierno y cubrirse la cabeza al cruzar el río para evitar su aire.

\section{El aire: factor patógeno, fuerza que cura.}

El entorno físico tiene una fuerte presencia a la hora de identificar las causas de las enfermedades, los factores enfermantes más evocados corresponden a elementos sobresalientes en el espacio azampeño: el frío, el agua, el viento (y la tierra que suspende) y la altitud. La localidad de Azampay se encuentra a $1800 \mathrm{msnm}$ en torno a una quebrada con presencia permanente de agua. Durante el invierno y debido a la altitud, las temperaturas son muy bajas y durante los meses de Zonda, los días de viento la tierra suspendida cubre por completo el paisaje serrano. El aire como elemento patógeno proviene de estos cuatro componentes ambientales: El aire del río y de animales del agua; el de las zonas elevadas y animales asociados con la altura (la llama, por ejemplo, manipular su lana o comer su carne); el aire asociado al frío; el aire como viento (en sentido literal) y vinculado a la tierra, al polvo que levanta.

J: ah, la llama, claro, sí, la llama también es muy airosa, por la carne

A: por qué?

J: y no sé, debe ser por las alturas, bueno, el pato, me decía, por el agua, que es muy, que tiene mucho aire por el agua, y bueno, pero póngale otros que, por ejemplo el cóndor, el águila, la pluma de ellos, a veces los curanderos curan del aire con la pluma de ellos, que andan también por muy alto, ha visto? Por muchos aires (P49, mujer, 40 años). 
Además, plantas como la higuera y el nogal son consideradas "airientas" o "airosas" y su proximidad o manipulación transmite aire (cabe recordar que la nuez es el principal de los escasos cultivos que se realizan a una escala mayor para su comercialización).

Otras causas son las vinculadas a conductas que ocasionan un "desarreglo" (como la falta de cuidado que consiste en lavarse y acercarse al fuego, salir al sol o andar). Al arduo trabajo se le imputan muchas dolencias de gente de edad avanzada que recuerda haber gozado de buena salud durante su juventud, identificando en las labores excesivas la causa de malestares a raíz de un desgaste corporal: origen del reuma, de los dolores de rodilla, de huesos, de la "debilidad" y asociado a ésta, del aire.

Como se señaló ya para el caso de la abertura de pecho, el aire se transmite desde el individuo que lo padece a quien realiza la cura, con una intensidad que indica la gravedad del padecimiento. Al respecto, también Idoyaga Molina ha remarcado que "el manipuleo de poder en las prácticas terapéuticas sin contar con la energía suficiente suele ocasionar que el curador contraiga el mal que extrae del paciente" (Idoyaga Molina, 2001: 33). Este efecto negativo de la cura en el curador es señalado como uno de los motivos por los que la misma se realiza en varias sesiones espaciadas permitiendo la parcial recuperación del curador.

J: Sí, porque ya estaba muy airada yo y dice que él [curandero] ya lo amortigua mucho, lo... o sea que estaba muy, muy fuerte el aire que yo tenía G: y a él qué le hace?

J: que le amortiguaba las manos, viste? Le agarraba dolor en las manos, después a la noche no podía dormir y como que mi enfermedad le pasaba a él (P49, mujer, 40 años).

A: y por qué tu tía no lo curó?

F: porque decía que ella le perseguía mucho el dolor de muela y entonces ella decía que no porque le va a agarrar el aire a ella y le iba a empezar a doler las muelas, por eso no lo curaba ella si no ella lo iba a curar (P30, mujer, 17 años).

También han sido referidas causas de orden psicológico: aire debido a situaciones de tensión o rabias acumuladas y ante un miedo o sobresalto, como es el caso del susto.

A: pero no entiendo bien qué es esto del aire?

$R$ : eso que uno le dice, le estaba diciendo yo que el susto, si usted ve alguna cosa que usted le tiene miedo, bueno es como si usted le viene algo novedoso al cuerpo y eso es que se, después le duele la cabeza, al tiempo por ahi le duelen las muelas, los dientes (P40, mujer, 62 años).

A: y P qué tiene?

J: también aire, así, sí porque él es muy nervioso, él es calladito, póngale, él se agarra una rabia y está calladito, así, solo se la, por dentro, digamos va la procesión, en cambio yo lloro, me lo saco algo pero por ahi no me lo saco a todo y así, pero yo siempre, en eso sí creo, siempre me hago curar (P49, mujer, 40 años). 
Y causas de orden social: envidia, codicia, deseo, el "humor" más fuerte de otra persona (es el caso de la ojeadura). La envidia o la codicia son identificadas como factores causantes de aire sin que deba mediar un accionar voluntario por parte de quienes envidian; si es éste el caso la causa del padecimiento reside en que "le han hecho un trabajo" o "maleficio". Idoyaga Molina ha hallado también ampliamente extendida la idea de que la envidia, "en cuanto pensamientos y deseos negativos sustancializados, penetra el cuerpo de la víctima y se manifiesta como dolencia física", "los sentimientos egoístas y envidiosos causan por sí mismos la enfermedad y pueden originar conductas concretas en perjuicio de la persona envidiada, o yendo más lejos, recurrir a procedimientos de daño" (Idoyaga Molina, 2001: 30, 31) pero en el caso de Azampay es siempre el aire lo que media entre la envidia y el malestar, al igual que en la etiología de la ojeadura y el susto, el aire aparece como el eslabón entre la causa última (psicológica o social) y el padecimiento.

También están quienes tienen una complexión favorable a padecer de aire, son personas "airientas", desde el nacimiento manifiestan una debilidad y propensión a contraer malestares vinculados al aire, lo que se atribuye a eventos de susto mal curados o situaciones de preocupación en la madre durante el embarazo. Idoyaga Molina señala que esta disposición a contraer mal aire "tiene que ver con las representaciones de la corporalidad, hay personas de sangre más fuerte y resistente a los ambientes hostiles, mientras que otras son de sangre débil y están más expuestas a mayor cantidad de riesgos" (Idoyaga Molina, 2002: 160).

El aire en tanto elemento patógeno tiene un carácter polifacético y omnipresente en el espacio físico y social de la localidad, de ahí su predominancia en las explicaciones causales de los padecimientos.

J: claro, uno digamos, no lo termina de saber, no? El aire, qué... por eso yo le decía eso a Don $P$ [curandero] "pero el aire cómo es, entonces no tendría que salir de la casa para que no me dé el aire?!'” [...] y por eso digo yo, se ve que hay muchos aires (P49, mujer, 40 años).

Por otra parte, dentro del conjunto de sus connotaciones hay también una valoración positiva en lo que refiere al uso de ciertas plantas y elementos de origen animal en las prácticas terapéuticas. Las propiedades curativas de estos elementos son atribuidas a que los mismos proceden de espacios vinculados al aire. El aire presenta entonces cierta ambivalencia, elemento que tanto otorga fuerza como debilita, responsable de enfermar pero también de sanar.

A: y la grasa de león? 
F: sirve para curar como pomada, como la injundia de la gallina que se pone sobre el pecho, cuando anda mal ya le calienta, sirve para todo porque tiene aire (P32, mujer, 69 años).

\section{F: Las plantas del cerro son más fuertes porque el aire es más fuerte (P45, mujer, 68 años).}

Se puede pensar el "fenómeno del aire" como una kratofanía, en el sentido propuesto por Eliade para referirse a la singularización de ciertos fenómenos a partir de las nociones de fuerza y eficacia pero donde el carácter sagrado está ausente (a diferencia de las hierofanías). Tanto las kratofanías como las hierofanías implican la selección de un objeto con respecto a los demás, "lo elegido es implícitamente fuerte, eficaz, temido o fértil, incluso cuando la elección se debe a la singularización de lo insólito, de lo nuevo, de lo extraordinario; lo que ha sido elegido y revelado como tal por medio de una hierofanía o de una kratofanía, se convierte a menudo en peligroso, prohibido o manchado"(Eliade, 1954: 36). Según este autor es ésto lo que explica la lógica del tabú, "ciertas cosas, personas o regiones participan de un régimen ontológico absolutamente distinto y en consecuencia su contacto produce una ruptura del nivel ontológico, que podría ser fatal" (Eliade, 1954: 30). Como ejemplos, Eliade menciona la noción de mana del pueblo melanesio, fuerza "capaz de hacer a las cosas poderosas, reales en el sentido pleno del vocablo", "los Siux llaman a esa fuerza wakan; circula por el Cosmos entero, pero no se manifiesta más que en los fenómenos extraordinarios (como el sol, la luna, el trueno, el viento, etc.), y en las personalidades fuertes (el hechicero, el misionero, cristiano, los seres míticos y legendarios, etc.)", "los Iroqueses emplean el término orenda para designar la misma noción: una tempestad tiene orenda, el orenda de un pájaro difícil de cazar es muy sutil, un hombre enfurecido está dominado por su orenda" (Eliade, 1954: 33). Respecto a qué fenómenos son generalmente connotados con la idea de fuerza y poder, Eliade destaca que se trata generalmente de "regiones superiores, inaccesibles al hombre, las zonas siderales, adquieren los prestigios divinos de lo trascendente, de la realidad absoluta, de la perennidad" (Eliade, 1954: 52). El agua es también un elemento ampliamente presente como kratofanía, "por desintegrar toda forma y abolir toda historia, poseen las aguas esa virtud de purificación, de regeneración y de renacimiento; todo lo que en ella se sumerge 'muere', y sale de las aguas como un niño sin pecado y sin "historia"” [...] "cualquiera que sea el conjunto religioso en que se presente, la función de las aguas es siempre la misma: la de desintegrar, abolir las formas, 'lavar los pecados"” (Eliade, 1954: 191, 205). Así, por efecto de las kratofanías y hierofanías, "la naturaleza sufre una transfiguración de la que sale cargada de mitos", "la naturaleza está cargada de historia humana" (Eliade, 1954: 345). 


\section{El "mal aire" más allá de Azampay}

Idoyaga Molina sostiene que la noción de "aire" o "mal aire" fue introducida en América durante la conquista y colonización y por las posteriores poblaciones de inmigrantes, lo que explicaría "la homogeneidad cultural respecto de la mayoría de estas ideas" en el área mesoamericana, "en toda la América indígena y mestiza con 500 años de contacto con los españoles y entre población no indígena descendiente de europeos y árabes, tal como sucede en la Argentina" y que tal taxón aparezca en poblaciones de origen europeo que nunca han estado en contacto con indígenas, por ejemplo en la España medieval y actual (Idoyaga Molina, 2006: 87, 94).

La noción de "mal aire" refiere a una gran variedad de síntomas y de causas. Entre los primeros figuran dolores musculares (de cuello, contracturas, tortícolis), dolor de oídos, hemiplejía, parálisis facial, ojo lloroso y problemas en la piel (Idoyaga Molina 2001, 2002). En cuanto a su origen, el mal aire ha sido definido como un padecimiento causado por desequilibrios entre el individuo y el ambiente ya que generalmente es ocasionado por una emanación del ambiente, "potencia negativa" que penetra el cuerpo cuando la persona atraviesa o permanece en ciertos lugares nocivos (ciertos cerros, algunos montes y algunas cuevas cordilleranas) o por desbalances térmicos (Idoyaga Molina 2001, 2002). Pero también ha sido identificado como la consecuencia del "daño", es decir, aire manipulado y enviado como enfermedad (Idoyaga Molina 2001, 2002) y del mal de ojo (Kearney, 1969; Idoyaga Molina, 2006). La disposición personal a ser afectado por el aire también ha sido registrada por esta autora, "hay individuos de sangre fuerte y resistente a los ambientes hostiles, mientras que otros son de sangre débil y están más expuestos a los espacios contaminantes y nocivos" (Idoyaga Molina, 2001: 42).

Las terapias están dirigidas a extraer el aire del enfermo mediante la técnica del sahumado que "canaliza el poder del vegetal a través del humo, el que es de por sí purificatorio y terapéutico, y que al penetrar en el cuerpo del doliente disipa la sustancia maligna” (Idoyaga Molina, 2001: 42), junto a la invocación a las deidades. Además se ha registrado, generalmente desde la medicina casera, el uso de barras de azufre, embudos de papel encendido, humo de cigarrillos de contrahierba, todas ellas "terapias cálidas que mediante la acción del fuego o del humo, o del calor producido por el azufre, extraen el airesustancia, es decir, una dolencia fría" (Idoyaga Molina, 2001: 24) en función de la idea de desbalance térmico. Respecto al valor terapéutico de ciertas plantas (romero, ruda, salvia de la 
Puna y contrahierba) para la cura del aire Idoyaga Molina señala que el mismo se explica a partir de una apreciación positiva de los espacios donde éstas crecen: "En las tierras altas, son de calidad propicia para el hombre las planicies donde crecen diversas plantas y es factible la vida. Estos ámbitos se contraponen a las cumbres de los cerros y a las abras, lugares de calidad negativa y que transmiten enfermedades, entre ellas el mal aire" (Idoyaga Molina, 2002: 164).

\section{Discusión en torno a viejas dicotomías a partir de la noción de aire. Enfermedades naturales vs enfermedades sobrenaturales: etiologías empíricas vs etiologías místicas, terapéuticas empíricas vs terapéuticas mágicas.}

Los rasgos particulares hallados en Azampay en torno al "fenómeno de aire" condujeron a cuestionar ciertos enfoques de análisis utilizados que, sosteniendo una mirada estereotipada de la "medicina tradicional" y reproduciendo viejas dicotomías, fuerzan los datos a entrar en clasificaciones que dejan fuera los aspectos que permitirían una lectura más compleja de los mismos.

Varios trabajos realizados sobre "medicina popular" o "tradicional" en el NOA, sea con la intención de construir un modelo general sobre la misma o de realizar una caracterización para el Area Cultural Andina, sostienen una distinción entre enfermedades naturales o empíricas y enfermedades sobrenaturales, místicas o mágicas a partir de identificar la atribución de una etiología natural o sobrenatural respectivamente. Dentro de las enfermedades sobrenaturales distinguen aquellas cuya explicación consiste en una etiología centrífuga en oposición a las que responden a una etiología centrípeta. Entre las primeras se ubicaría la pilladura y el susto pues se originan en la evasión o pérdida involuntaria del alma, por robo intencional de la misma o abandono del cuerpo por un hecho traumático o sobresalto (Bianchetti, 1996: 62, 63). La etiología centrípeta alude a la "concepción del cuerpo extraño": entrada al cuerpo de una fuerza que va deteriorando la salud. Es el caso de la sopladura, como insuflación de un gas maléfico, o mal aire, en tanto incorporación de efluvios malignos o aires de enfermedad, y de la ojeadura, mal deseo o mal de ojo, cuando la enfermedad entra en el cuerpo a través de la envidia, el deseo o la admiración, frecuentemente vehiculizada por la mirada (Pérez De Nucci, 1995: 65, 88). 
La atribución de una naturaleza mágica, de un origen sobrenatural a ciertas enfermedades, es analizada como un intento de los individuos por comprender todos aquellos malestares que no pueden ser explicados por causas naturales visibles. Se ha planteado una “espiritualización del mundo microscópico", en el sentido que frente a aquello que no se ve, no se toca, no es perceptible por la vía de los sentidos y la experiencia, se recurre a definiciones de carácter místico-animológico: "la medicina popular, enfrentada a la enfermedad que no puede explicar por fuerzas naturales, tiende a explicar la realidad microscópica de su génesis, reduciendo el concepto al mundo invisible de los espíritus" [...] "Esto hace que las enfermedades de causa no visible tengan un fuerte contenido definitorio místico, concepto que incluye por supuesto a toda la concepción de la enfermedad y su curación" (Pérez De Nucci, 1995: 50). Y con la misma orientación se ha analizado el uso de la terminología médica en "sectores socioculturales" donde "no tiene lugar aquella concepción de las causas microbiológicas de la enfermedad": "La ocasional utilización de términos de la ciencia médica, en casi todos los casos, representa el modo de comunicación que, a tientas, procura conseguir la cultura tradicional con la ciencia médica oficial encarnada por los médicos, con los que sus enfermos tienen contacto. Y esto es así, porque la concepción que tiene de las causas de las enfermedades y su cura, siguen siendo fundamentalmente metafísicas, no obstante los términos científicos que puedan llegar a emplearse" (Palma, 2002: 76, el resaltado es mío).

En la categoría opuesta de enfermedades empíricas han sido clasificados padecimientos como el "golpe de aire" ("trastornos que sobre el organismo produce el cambio repentino de temperatura: pasar, por ejemplo, de un ambiente cálido a uno más fresco, o salir de noche de una habitación al exterior, puede ocasionar dolores musculares y otros malestares fisiológicos", Palma, 1973: 70) y el dolor de muelas, malestares que en el caso azampeño forman parte también de aquellos causados por el aire (e incluso, como se hizo notar, alergias y crisis de asma tiene una etiología vinculada al aire).

A partir de lo registrado en Azampay se observa que el aire atraviesa la (arbitraria) distinción entre enfermedades naturales y sobrenaturales y cruza las diferentes categorías de enfermedades clasificadas como "místicas" (susto, mal aire, ojeadura). Entre un aire provocado por haber sido "agarrado por un aire cruzado" (equiparable al "golpe de aire") y uno producto del trabajar entre los nogales (plantas “airientas") los individuos no señalan una distinción que permita plantear una separación entre un padecimiento originado en el plano natural y uno en el sobrenatural. Palma señaló que el concepto de aire es "el ubicuo personaje" en la mayor parte de las explicaciones de las patologías populares de "América 
autóctona" (Palma, 1973: 39), sin embargo al describir las diferentes enfermedades no focaliza en la presencia recurrente del mismo. Y si bien reconoce lo convencional de la subdivisión entre patologías "místicas" y "no místicas o naturales", lo hace destacando la presencia de elementos místicos en las terapéuticas con las que se tratan enfermedades "naturales" (las que en sus etiologías no presentan elementos místicos). La relación inversa, es decir, la presencia de explicaciones y terapéuticas del orden natural aún en aquellas enfermedades consideradas por los teóricos como "místicas" no es planteada.

La idea de una "concepción metafísica de las causas" (Palma, 2002: 76), la atribución de un carácter místico (relacionado con la divinidad o las cosas espirituales) a las mismas es cuestionable a partir de lo aquí descripto sobre las procedencias del aire. En tanto factor patógeno, no es identificado como algo sobrenatural, por el contrario, como señalé anteriormente, se presenta asociado a factores naturales, a conductas concernientes al cuidado corporal y a factores psicosociales. Lo que se destaca es la pluralidad de existencias que posee el aire y la variedad de malestares que provoca, y si bien la aseveración de una limitación del accionar médico para curarlos evoca una escisión entre enfermedades para el médico y enfermedades para el médico campesino, la misma no se plantea en términos de un nivel natural y uno espiritual. Y mucho menos a partir de la identificación de enfermedades cuyas causas son visibles frente a aquellas de etiología invisible, la causa del aire puede ser tan invisible como la de la hepatitis ("enfermedad para el médico") y la transmisión del mismo desde los nogales o el plumaje de un pato alude a una conexión tan indiscutible a la vez que invisible como resulta la idea del contagio de la hepatitis.

Cuando los azampeños se refireron a las "enfermedades para el médico" las nombraron utilizando términos pertenecientes a la ciencia médica, como "meningitis", "cistitis", "cáncer", "infección" o los nombres de órganos como "riñones", "vesícula" y "apéndice" para aludir a disfunciones de estos, sin que ello implique una comprensión de las enfermedades en la dirección y con la profundidad analítico-descriptiva alcanzada por la ciencia biomédica. Sin embargo, considero que este uso diferencial de los términos biomédicos no sólo tiene lugar dentro de ciertos "sectores culturales" sino siempre que la consulta la realice un paciente sin formación en el campo de las ciencias biológicas, y no necesariamente encubrirá explicaciones metafísicas o místicas de los padecimientos identificados. La denominación obtenida en la consulta médica es utilizada por el paciente no sólo como mediación entre su lenguaje y el del médico sino como vehículo de sentidos para la comunicación con otros interlocutores legos. Estos términos y nociones del individuo lego tienen una carga existencial producto de experiencias, situaciones, vivencias que se van 
transmitiendo, que los hace distintos a los del espacio oficial e involucran otro saberes, sin implicar esta significación particular un contenido místico.

Lo que cuestiono es la directa atribución de un pensamiento "místico", de una “espiritualización” de las explicaciones de los procesos de enfermedad, frente a fenómenos no visibles y ante la ausencia de una interpretación científica (Pérez De Nucci, 1995: 64). Plantear la existencia de explicaciones del orden sobrenatural implica sostener que ciertos fenómenos mundanos y humanos son entendidos y explicados desde una perspectiva religiosa, que los individuos reconocen un conjunto de realidades no entitativamente naturales, accesibles sólo por revelación y admitidas por fe. En este sentido no se halló en las narraciones de los lugareños ninguna alusión a etiologías de carácter místico, ya sea que estuvieran refiriéndose a enfermedades para el médico o para el médico campesino ${ }^{32}$. Donde sí hay un elemento vinculado a la revelación y a la fe es en lo concerniente a la cura. Como fue descripto, la cura realizada por el curandero implica el uso de "secretos", rezos adquiridos por revelación, dados por "alguien de arriba", está presente la imagen de un santo y a menudo incluye la señal de la cruz. Estos elementos son utilizados tanto tratándose de malestares causados por el aire como de padecimientos originados, por ejemplo, en algo que se comió o por un "desarreglo" de la sangre, y su presencia se debe, según las interpretaciones referidas por quienes han asistido a una cura, a que el curandero invoca la ayuda del santo del cual es devoto. Como se analizará en el capítulo dedicado la eficacia terapéutica, ésta es atribuida a la fe, pero dicho contenido místico no se limita a los elementos religiosos involucrados en las curas tradicionales sino que también esta presente en referencias a la atención médica y al consumo de hierbas con fines terapéuticos.

J: y bueno, uno acá por ejemplo, yo en el mate cebado, o por ahí me siento, póngale, así como con fiebre, así, y hago un tesito de cualquier cosa y... y me pasa, no sé si es la fe que uno le tiene a los yuyos ( $\mathrm{P} 49$, mujer, 40 años).

Que enfermedades de etiologías no místicas sean tratadas mediante elementos religiosos como los arriba descriptos, que se recurra a los curanderos para tratarse malestares que no son exclusivamente competencia de éstos (como la hipertensión, consecuencias de golpes o caídas, problemas de vesícula, riñón, etc.), o que se busque la atención del médico con sus "tónicos, remedios de adentro" para tratar la debilidad causada por el aire, ha sido explicado de diversas maneras en los trabajos aquí citados: Como una "inconsistencia en el uso terapéutico de elementos naturales y sobrenaturales: una enfermedad puede ser

\footnotetext{
${ }^{32}$ Como se notó anteriormente, no aparecen las enfermedades ocasionadas en desequilibrios religioso-rituales: aikadura, agarradura o pilladura y sopladura, que sí aparecen en el extremo norte, en la Puna, la Quebrada de Humahuaca y los valles y quebradas transversales frecuentemente en vinculación a la deidad de la Pachamama.
} 
interpretada de un modo o de otro" debido a que "no se ha desarrollado una noción general de lo 'sobrenatural' como diferente y opuesto a lo natural. Una separación neta entre lo sagrado y lo profano, lo mágico y lo científico, no existe en la medicina primitiva" (Gil, 1969: 25, en Palma, 1973: 33); como el reconocimiento de que diversas afecciones se presentan asociadas y de ahí la necesidad de combinar en el tratamiento diferentes técnicas, empleando, los curanderos, terapias múltiples, donde lo mágico es tratado junto con los trastornos físicos u orgánicos (Bianchetti, 1996: 84); o como la presencia de una explicación mística en todos los procesos de enfermedad (sean tratados por el médico o por el curandero) dada la carencia de un saber científico en ciertos sectores socioculturales ${ }^{33}$.

Estimo que tales análisis quedan atrapados en la distinción analítica entre enfermedades naturales y sobrenaturales que además se espera se correspondan con terapéuticas físicas (o naturales) y mágicas respectivamente. Una vez elaborada la clasificación aquello que no se presenta conforme a la misma es interpretado en términos de inconsistencia, confusión o ignorancia. Además considero que no hay una asociación directa entre la identificación causal y el tipo de terapéutica. Con frecuencia se sostiene que como consecuencia del reconocimiento de una etiología social el tratamiento irá dirigido a esa síntesis de orden moral, social y físico, que el curandero "nunca olvida que la enfermedad es ante todo un hecho socio-cultural, y así hace participar al enfermo y sus familiares en la terapia misma" (Magrassi y Radovich, 1982: 19). Conforme a mis datos, en el caso del aire producido por la envidia, o de la ojeadura, efecto del deseo fuerte de otros, si bien la causa es identificada como social, la cura no apunta a mejorar las relaciones sociales, ni a expiar conflictos grupales, el tratamiento es individual y enfrenta estas enfermedades como otras ocasionadas por aire de origen no social. Lo cual no niega que el mismo pueda cumplir, como señala Módena para su caso de estudio respecto al "espanto" y su terapéutica, "una función importante en tanto mecanismos liberadores de ansiedad personal, o mejor dicho, de las formas personales de la angustia gestada en el ambiente natural y social" (Módena, 1990: 189).

Si se asume que a enfermedades sobrenaturales le corresponden terapéuticas místicas y a enfermedades naturales, terapéuticas físico-químicas, no se puede pensar que una terapéutica de carácter religioso pueda intervenir ante una enfermedad cuya causa se clasifica

\footnotetext{
${ }^{33}$ Esta presencia de elementos místicos en la cura lleva a Palma a reconocer "dudas sobre estas formas de agrupar, de manera tan tajante, los hechos humanos en el contexto folk [...] Si tenemos en cuenta que aún en nuestro medio ciudadano se recurre a diversas formas 'místicas' para complementar el tratamiento de una enfermedad, sin excluir a los individuos mejor informados por la civilización, como es la de encomendarse a algún santo, ofrecer oraciones, dedicar misas, realizar alguna obra de beneficencia en nombre de Dios, etc., comprenderemos cuánto más difícil e insegura resultará esta forma de sistematizar la enfermedad y su cura, en medios como el que aquí investigamos." (1973: 69, 70) No obstante esto, sostiene dicha clasificación.
} 
como natural, y a la inversa, que ante un padecimiento identificado como de origen sobrenatural se recurra al médico para que le dé tónicos, o se compren vitaminas en la farmacia. Como señala Scheper-Hughes "los antropólogos continúan aferrados a la ortodoxia epistemológica (biomédica) occidental (por ejemplo las dicotomías cuerpo/mente, visible/invisible, real/no real), la cual inhibe nuestra habilidad para comprender formas paradójicas de experiencia y particularmente de sanación" (Scheper-Hughes, 1990, traducción Claudia Oxman).

En esta clasificación natural-sobrenatural los padecimientos originados por la envidia, la codicia o el deseo, aún en los casos en que no median acciones voluntarias (magia, hechicería), son conceptualizados en el segundo de estos órdenes. ¿Es la envidia o el deseo algo sobrenatural? ¿Se puede intentar comprender, evitando adjudicar directamente un pensamiento mágico, el hecho de que factores sociales como el deseo, la codicia o el mirar intenso de otros sean la causa de malestares físicos?

Considero que los trabajos aquí discutidos, que si bien tienen otros referentes pretenden realizar generalizaciones para toda un área cultural, plantean una clasificación que no refleja las rupturas y continuidades conceptuales "nativas". Poligénico, el aire, para el caso azampeño, no se sostiene en explicaciones del orden sobrenatural (salvo en los pocos casos referidos de aire producto de un daño o maleficio, cuya adscripción a un orden sobrenatural habría que analizar), sino que se halla fuertemente vinculado a ciertos elementos del espacio geográfico, a ciertas situaciones sociales y estados anímicos. Aunque se sitúa en el conjunto de enfermedades "para el médico campesino" y con su gravedad instala el límite del accionar médico, no falta la excepción, como cuando el curandero acude al médico para que le dé "tónicos" contra la debilidad causada por el aire, así como también se acude a un curandero para tratarse otros padecimientos no causados por el aire. Es decir, las identificaciones etiológicas no determinan unívocamente el tipo de atención terapéutica que se buscará.

Desde la Antropología Médica Crítica se ha objetado la aplicación de categorías que reproducen dicotomías arraigadas en una visión, llámesela occidental, positivista y/o biomédica $^{34}$. Taussig también señala, cuestionando la interpretación de Evans Pritchard sobre la epistemología azande, que ésta, no obstante la "elegante simplicidad" de análisis, con sus categorías de "mística", "científica” y "empírica", resulta de dudoso valor teórico a la hora de

\footnotetext{
34 "Entre estos supuestos está principalmente el tan mentado dualismo cartesiano que separa mente de cuerpo, espíritu de materia y real (es decir, visible, palpable) de irreal. Dado que esta tradición epistemológica es una construcción cultural e histórica y no una universalmente compartida, es esencial que empecemos nuestro proyecto en antropología médica con una suspensión de nuestra creencia usual y nuestro compromiso cultural con las oposiciones mente/cuerpo, visible/invisible, natural/sobrenatural, mágico/racional, racional/irracional y real/irreal y presupuestos que han caracterizado mucho de la antropología etnomédica a la fecha" (Scheper-hughes y Lock, 1987: 6, traducción personal).
} 
analizar que "por detrás de cada teoría cosificada de la enfermedad en nuestra sociedad, se agazapa un campo organizado de dilemas morales" (Taussig, 1992: 122).

Se puede realizar un análisis mucho más claro partiendo de reconocer que algunos ejes de clasificación tan familiares para el investigador pueden estar ausentes en el caso estudiado, como planteó Turner al referirse al orden cósmico de los Ndembu: "La palabra "natural" no resulta aquí pertinente, ya que los ndembu no distinguen como nosotros entre el orden natural y el sobrenatural. Para ellos existe sólo un orden cósmico único, aunque algunas partes de él son "totalmente claras" y otras "oscuras", unas visibles y otras invisibles" (Turner, 1980: $337)$.

\section{El aire como significante}

En otra dirección apuntó un trabajo de Kearney desarrollado a partir de trabajo de campo en una comunidad agraria en la Sierra de Juárez en Oaxaca, México (1969). En éste aborda el fenómeno del aire en tanto concepto implicado en la mayoría de las descripciones nativas de enfermedades, persistiendo junto con el susto como nociones de enfermedad alternativas a las de la medicina moderna. Si bien distingue distintos usos del término, el vinculado a la "naturaleza puramente física de la atmósfera" y el que refiere a las "cualidades maléficas", señala que en la práctica no existe tal distinción, el aspecto natural y el carácter morboso se hallan entrelazados como connotaciones de un mismo término. Lo interesante es que no analiza el fenómeno, el "sistema del aire", partiendo de la dicotomía naturalsobrenatural, sino que lo hace preguntándose por la función que presenta dicho concepto dentro de la visión del mundo, como "sistema proyector" de una visión del mundo que el autor identificó cargada de peligros físicos, sobrenaturales y sociales ${ }^{35}$.

Pero indagar los significados, las representaciones idiosincrásicas y colectivas del aire, en tanto construcción polisémica y el vínculo que expone entre el orden natural, psicosocial y físico, no debe llevar a ignorar el hecho de que dicho término esté presente en sociedades mestizas y entre grupos descendientes de europeos y árabes de América Latina. Que el aire con sus connotaciones de peligrosidad, gravedad, morbosidad y fuerza forme parte de las representaciones de sociedades tan dispersas geográfica y temporalmente se debe a que, como

\footnotetext{
${ }^{35}$ Sin embargo, son cuestionables las conclusiones de dicho autor en cuanto habla de una "cosmovisión paranoica" en su población de estudio pues, como contra-argumenta Idoyaga Molina, las nociones y comportamientos de dicha cosmovisión deberían ser "de origen indígena o, al menos, una elaboración claramente indígena ante la opresión” y no saberes y prácticas impuestas por los conquistadores, es decir "antiguas teorías de la medicina occidental" $(2006: 94,96)$.
} 
señala Idoyaga Molina, fue un elemento central en la ciencia médica de la edad moderna europea introducida en América desde la conquista: "la noción de que las enfermedades se trasmiten por el aire", "la caracterización del mismo como peligroso" y "la idea de que el mal de ojo se contagia por el aire" [...] "tales conocimientos, nociones y muchas de las prácticas asociadas son simplemente la teoría de élite que sostenían los españoles y, en general, las sociedades europeas, en el siglo XVI (Ciruelo, 1551; Marqués de Villena, 1425)” [...] "por los aires llegaba la enfermedad, pues en el siglo XVI todavía no se conocían los gérmenes, ni las bacterias, ni los virus. Se entendía que el aire era el portador de las enfermedades y el canal de los contagios. Se utilizaba, entre otros aspectos, el marco explicativo de la teoría humoral, en términos de desequilibrios frío/cálido y seco/húmedo. Por otra parte, las creencias respecto del mal de ojo, también conocido como aojamiento y fascinación no eran creencias populares (folk) y tenidas por supersticiones de ignorantes, en la edad moderna muchos fueron los médicos que se ocuparon de definir y atender el mal de ojo (Aragón, Marqués de Villena, 1425, Castañega, 1946; Ciruelo, 1551). Este era un taxón reconocido por la medicina oficial y tuvo su explicación natural" (2006: 94). Finalmente la autora hace notar que la idea de peligrosidad potencial del aire "se advierte inclusive en la teoría higienista sostenida por la biomedicina hasta principios del siglo XX. El aire era contaminante, por eso se recomendaba en hospitales y unidades de salud hacer circular el aire, abrir las ventanas y mantener el aire limpio sin olores, ni vicios, ni contaminaciones” (Idoyaga Molina, 2006: 105).

Como ya se advirtió anteriormente, reconocer la herencia europea en la mayoría de los taxa vernáculos, no significa negar procesos de refiguración que le otorgan a cada contexto la particularidad que tanto aprecia el método etnográfico. Partiendo del señalamiento de Lock y Scheper-Hughes acerca de que "lo que es crucialmente importante para la antropología médica es demostrar la manera en que constructos polisémicos tales como nevra, solidao, hara, estrés y menopausia y el lenguaje del trance, del ritual, de los sueños, del carnaval, etc. pueden ser usados para facilitar la toma de conciencia del vínculo entre el orden político y social y el malestar físico" (Lock y Scheper-Hughes, 1996: 68) se recuperaron los usos sociales e individuales del aire, en tanto construcción polisémica, y el vínculo que expone entre el orden natural y psicosocial y físico.

El aire en tanto factor patógeno derivado de ciertos elementos de la naturaleza, expresa la incidencia del entorno físico sobre el cuerpo de los lugareños. La mención del padecimiento de aire a causa del arduo trabajo (que durante la recogida de nueces además de intensificarse, se le suma el hecho de que estas plantas sean "airientas" y de por sí provoquen malestar) aparece generalmente vinculada a un reconocimiento del esfuerzo, del valor del trabajo 
realizado. En este contexto el aire suma méritos pero también motivos de queja. Lo mismo sucede con la exposición al aire que conlleva la curación y que no es mencionada como un riesgo más de contagio sino como parte del tratamiento donde el curador involucra su propia salud en el ejercicio de sus capacidades terapéuticas.

F: la curación, algunos dicen que cobro caro, y es claro, no venga! Si para mí, yo no, más vale que no vengan porque si saben me hace mal [...] es que me sienta mal, ya me jode mucho, ...bueno, qué voy a hacer!, esa es la cosa (P55, curandero, 84 años).

En el reconocimiento de las causas psicosociales del aire, se halla implícitamente negado el dualismo mente-cuerpo. La explicitación de sus etiologías psicosociales y de sus síntomas corporales, de sus consecuencias orgánicamente percibidas (y orgánicamente representadas) resalta el carácter psicosomático de ciertas enfermedades, no hay explicación que dé cuenta del pasaje de un plano psicosocial a uno orgánico porque no hay salto alguno, la explicación es el aire y éste puede provenir de ciertos elementos del entorno social y causar malestares corporales.

Por otra parte, en los padecimientos a los que se le asigna una etiología social encuentran expresión ciertas apreciaciones sobre la relación con los otros cercanos. Las percepciones de envidia, de codicia, deseo y fortaleza de quienes comparten el espacio social hallan un anclaje en los síntomas del aire, no constituyen meras suposiciones, su existencia se torna innegable pues se corrobora en los síntomas. A su vez, son estos factores de las relaciones sociales sobre los que se construye una explicación del por qué de ciertos padecimientos. Como señala Taussig a partir de un análisis sobre los Azande, "las manifestaciones físicas no están desgarradas de sus contextos sociales y, por lo tanto, no se requiere un gran esfuerzo mental para leer relaciones sociales dentro de los acontecimientos materiales". [...] "cosas como mis órganos corporales son en un momento meramente cosas y, en otro, me cuestionan insistentemente, con una voz demasiado humana, sobre el significado social de su mal-estar". [...] "la dimensión del "por qué" o del "malestar" de la enfermedad se proyecta sobre los valores que confieren sentido a la vida, forzándonos a examinar las causas morales y sociales de la enfermedad" (Taussig, 1992: 113, 142). En este sentido resultan paradigmáticas las reflexiones de una persona que se quejaba de padecer frecuentemente de aire:

J: y bueno, yo lo que no puedo salir de la duda es de por qué me agarra el aire [...] dicen que es a veces cuando una tiene mucha envidia, cuando a uno le codician mucho, esas cosas, pero yo digo, por qué?! Tanta envidia o tanta codicia, si yo no tengo hijos, yo quisiera tener un hijo, unito solo digo, para enseñarle y para que me ayude a hacer las cosas y digo, y hay otros por ejemplo que tienen muchos chicos [...] porque dicen que el aire es la envidia, porque me decían el mal, el mal, y bueno, y yo 
siempre, como ha visto, preguntona 'pero cómo es el mal?', yo pensaba que me venían, me ponían algo en la casa o me tiraban algo y me dicen, no, la envidia, el humor de la otra persona es más fuerte que vos, capaz que se van a sentir mal porque vos te reís a carcajadas y sos feliz, aunque no tengas plata, pero ellos están [...] la envidia es eso que vos te reís feliz y bueno, porque yo digo qué me pueden envidiar, si no tengo plata, estamos haciendo así a todo sacrificio (P49, mujer, 40 años).

Este fragmento ejemplifica los tres puntos señalados más arriba: el aire como acción sobre el cuerpo de factores psicosociales, como corroboración de la existencia de aspectos negativos en las relaciones sociales y como explicación moral de la presencia de ciertos padecimientos. Como sintetiza Taussig, "los temas del 'cómo' y del 'por qué' se fusionan: la etiología es simultáneamente física, social y moral. La causa de mi evidente desgracia física se encuentra localizada en mi nexo de relaciones sociales que incluye la injusta malevolencia del otro" (Taussig, 1992: 113). 


\section{Etiologías, factores patógenos; terapéuticas, elementos de sanación}

\section{La identificación de las causas en el proceso de atribución de sentido a las experiencias de enfermedad}

La identificación de los factores a partir de los cuales se elaboran los por qué y cómo de una enfermedad fue un aspecto central en el guión de entrevistas dada su importancia dentro del modelo explicativo que le otorga sentido a la misma. Elementos cognoscitivos, afectivos y experienciales integran estos esquemas explicativos connotando aspectos del mundo con una carga valorativa en función de su carácter patogénico o sanador. La dimensión corporal, además de informarnos sobre nuestra experiencia, dota de sentido al mundo en que vivimos, así, por ejemplo, la experiencia de síntomas de aire le da sentido de "airiento" a una zona.

La importancia de las ideas sobre las causas de enfermedad, el peso que tiene la búsqueda de eventos causales en las historias de salud, así como la variedad y complejidad de los factores que son evocados en las etiologías, ha sido destacado por Fitzpatrick (1990), quien remarca cuán activo, constructivo y selectivo es el proceso de darle sentido a la enfermedad, integrando a través de asociaciones múltiples, ideas provenientes de fuentes diversas. Esta búsqueda de atribuciones causales se ve acentuada por la experiencia misma de la enfermedad. El autor recupera el trabajo de Linn, Linn y Stein (1982) en torno al cáncer, donde se notó que las explicaciones de individuos no afectados por tal enfermedad se mantenían en el nivel de los estereotipos y generalizaciones acerca de los factores de riesgo asociados a la misma, mientras que aquellas construidas por quienes padecían cáncer incorporaban a la etiología elementos de su historia personal. Es decir, las ideas generales difundidas en los medios, los modelos explicativos impersonales "explican sólo parcialmente por qué ese individuo ha sido afectado y no otros sujetos al mismo riesgo", primando en las personas aquejadas por la enfermedad, una "inmensa necesidad de dar sentido a su desventura personal", sobre todo tratándose de padecimientos que amenazan su vida (Fitzpatrick, 1990: 28).

El papel que juega la historia personal en la atribución de causalidades también fue señalado en un trabajo con pacientes con enfermedades crónicas (hipertensión, diabetes y 
artrosis), donde si bien la mayoría aceptaba las causas dadas desde el modelo biomédico (herencia y dieta, entre otras), las incorporaba a modelos causales específicos ajustados a la historia personal y consistentes con las experiencias particulares. La explicación causal que los pacientes elaboraban apuntaba a aquello que podría haber estado mal en sus propias biografías, como circunstancias estresantes de vida, conductas o eventos identificados como nocivos (Campos-Navarro et al., 2002). Los eventos personales incorporados a la explicación causal dan cuenta del por qué y no sólo del cómo, es el "por qué a mí" que desde la explicación general e impersonal queda sin responder.

La influencia de la experiencia en la conformación del conocimiento lego de una enfermedad conlleva además que el mismo sea continuamente reformulado en función de los cambios propios del padecimiento y de la confrontación con diferentes opiniones de terapeutas y legos. “Así, como argumenta Young (1981, 1982), se espera que el individuo produzca más de un tipo de explicación sobre su enfermedad, porque su conocimiento es siempre recurrente y procesual" (Alves, 1993: 5). Ésto suma complejidad a las descripciones que cristalizan los modelos explicativos en el momento de cada entrevista, obteniéndose para un mismo padecimiento diferentes atribuciones causales incluso tratándose del mismo individuo pero entrevistado en momentos distintos.

Entre los azampeños entrevistados hubo quienes al ser interrogados acerca de la etiología de las enfermedades se mantuvieron en un "no sé" cautelosos o poco interesados en hipotetizar causas, otros dieron sus explicaciones remarcando que las mismas las habían oído de médicos y curadores, mientras que otros desplegaron una red de asociaciones, de conexiones causales para explicar situaciones de enfermedad propias o de conocidos. Estas tendencias se mantuvieron a lo largo de las consecutivas estadías en Azampay y en las sucesivas entrevistas, de manera que se las puede entender como idiosincráticas. Así, con ciertos individuos resultaba infructuoso preguntar e insistir por las causas, cuando la respuesta era "no sé", "le ha dimanado" o "es el destino", o si se refería algún factor etiológico, al indagar por cómo se explicaba que tal elemento fuera patogénico se obtenía una afirmación sin justificativos: es por el agua, son los vapores, es el calor, la explicación causal (si la había) terminaba allí. Mientras que de otros entrevistados se escucharon complejas cadenas de causalidad y amplias explicaciones anatomo-fisiológicas de los efectos que conducían al desencadenamiento del padecimiento. En estos casos, como afirma Taussig parafraseando a una entrevistada "se nos presenta un sistema de interrelaciones, una serie de contingencias enquistadas que penetran una dentro del potencial de la otra hasta formar un modelo maestro 
o, más bien, hasta formar 'un pequeño rompecabezas en el que las piezas encajan perfectamente"' (1992: 123).

\section{Las experiencias de enfermedades crónicas como "Iugares de memoria"}

A la hora de nombrar las causas de malestares crónicos, para los que generalmente no se cuenta con una etiología precisa, como dolor de huesos, reuma, problemas a la vista, discapacidad, dolor de cabeza frecuente, mis interlocutores recurrentemente se retrotrajeron a eventos ocurridos años atrás, cuyo vínculo con el malestar actual no me parecía, formada dentro de una concepción biomédica de las enfermedades, tan evidente. Me exigía un esfuerzo de comprensión identificar como factores patógenos circunstancias temporalmente tan alejadas, lo que me llevó a detenerme en esta particular relación entre tiempo y narración. Como señala Portelli allí donde "el historiador tiende a procurar una secuencia cronológica lineal, el narrador puede tener más interés en seguir y reunir manojos de relaciones y temas a lo largo de la extensión lineal de su vida" (Portelli, 1993: 200). Nos encontramos entonces escuchando "un flujo libre de asociaciones no cronológicas. Esta es la manera más frecuente de las entrevistas de historia oral, una manera determinada por la acción recíproca de la estructura de la memoria y el empleo del diálogo. En la memoria esto se convierte en 'espacio': todo el recuerdo del pasado existe simultáneamente en el mismo 'lugar'. Los oradores, por lo tanto, pueden tender a ordenar los acontecimientos en líneas paradigmáticas de similitud en lugar de líneas sintagmáticas de secuencia cronológica” (Portelli, 1992: 8). Se pueden pensar las experiencias de malestar como "lugares de memoria" en torno a las que se nuclean, asocian eventos anteriores, a veces bastante alejados en el tiempo, donde un suceso de malestar no se cierra, no concluye sino que se prolonga hasta el presente a través de sus secuelas.

El acceso a esta asociación creativa de acontecimientos es posibilitado por la técnica de entrevista no estructurada, porque a partir de una pregunta abierta como un "¿cómo le va?" se van desglosando una serie de temas vinculados a los procesos de salud-enfermedad, desde síntomas hasta prácticas terapéuticas, desde opiniones sobre la atención médica hasta juicios sobre relaciones familiares o sociales. Prefiero decir que es una asociación creativa y no "libre" porque la selección de los acontecimientos dependerá del significado que éstos tengan en relación al padecimiento, significado que no deriva de una asignación individual sino de procesos de construcción social donde entran en juego representaciones anatómicas y 
valoraciones de factores como patológicos o curativos, socialmente compartidas. En una charla con Doña N, acompañándola con sus nietos de regreso de la escuela distante a 4 kilómetros por un camino serrano que lleva de Azampay hasta otro caserío, me fue exponiendo una serie de padecimientos y acontecimientos entretejidos, a partir de quejarse de tener que lavar tantos guardapolvos. Tratándose de una charla informal, caminando a su lado, tuve que valerme de mi memoria y aferrarme a su hilo conductor (a su lógica causal) para poder reproducir posteriormente la secuencia de eventos significativos que ella fue enlazando:

De tanto lavar es que le duelen los brazos, es a causa del agua que sufre de reuma. Cuando una de las nietas nació, la madre, como había estado vomitando durante todo el embarazo y no comió durante los 8 meses (al final nació de 8 meses y tuvo que estar en incubadora y ya de ahí tiene problema en la vista) de la debilidad se enfermó de pulmón blanco, [piensa hasta que encuentra el nombre] Tuberculosis, y tuvo que estar internada dos años en la ciudad de Belén, por esto fue Doña $\mathrm{N}$ quien se encargó del bebé, y de tanto lavar pañales, el agua y el frío le produjeron reuma. Luego retomó el tema del problema de la vista de la nieta, incorporando una explicación paralela a la anterior: les decía un conocido, apoyándose en que a un hijo suyo le había pasado lo mismo, que la nena tiene problemas de la vista porque cuando tendría alrededor de un mes de edad y aún no abría los ojos debían sacarle como un huesillo duro entre los párpados, algo que ella en su momento no hizo por ignorarlo.

En el párrafo anterior se puede apreciar la estructura de "muñecas rusas" (el uso de paréntesis y oraciones subordinadas es la manera en que mejor se refleja esto en la escritura) donde al interior de un tema se desarrollan otros subordinados, traídos a colación para completar la explicación causal. La narradora va introduciendo los eventos vinculados a la explicación, quedando todos articulados por la narración que intenta expresar el devenir de los acontecimientos.

Portelli, analizando cómo los narradores seleccionan ciertos acontecimientos para construir sus historias de vida, señala que "podemos definir estos acontecimientos como 'lugares de memoria' y su importancia como tales es revelada por la organización formal de la narrativa" (Portelli, 1992: 8). Pero si bien se trata de acontecimientos clave, el significado por el cual se tornan punto de referencia en el relato no les es inherente sino que depende de la red de relaciones en la que se insertan. Para recalcar este carácter relacional del significado Portelli compara el acontecimiento con el fonema, señalando que así como los fonemas "rompen el continuo del sonido (del tiempo) en unidades discretas y aparentemente 
puntuales" pero no por ello "existen en y por sí mismos: existen en un patrón convencional de relaciones con otros sonidos pertinentes" [...] "lo mismo ocurre con los acontecimientos. Se los identifica como tales de acuerdo con el patrón de significado por el cual lo que puede ser un acontecimiento para nosotros" no lo es para nuestros interlocutores y viceversa (Portelli, 1993: 212). Los eventos evocados por los azampeños para explicar las etiologías de padecimientos crónicos fueron golpes, accidentes, operaciones, enfermedades durante la infancia o años atrás, acontecimientos durante el embarazo, descuidos o esfuerzos asociados al agua, al frío, al sol, al trabajo, a veces también situaciones de tensión o rabias acumuladas, miedo o sobresalto, todos los cuales, como se verá, forman parte del conjunto de elementos identificados como factores patógenos y que están implicados en las etiologías de otros malestares, no sólo los crónicos.

M: a mi y a la A nos dio una fiebre que hasta el pelo se nos ha caido, fijese que fiera sabrá ser, cuando éramos chicas, claro, se nos derramaba todo el pelo de la fiebre que teníamos, yo y la A y justo las dos somos enfermas de los huesos, ella de la pierna y yo de las rodillas

A: será de eso?

M: será de eso, digo yo, como no nos llevaban a curar, nada, éramos chicas nosotras (P11, mujer, 56 años).

\section{Sobre las lógicas causales implicadas}

Respecto a las lógicas subyacentes a las explicaciones causales, Fitzpatrick (1990) y Kornblit y Mendes Diz (2000) citan el modelo general de Chrisman (1977) basado en un cuerpo intercultural de ideas populares sobre la enfermedad, que reúne los diversos modos de pensar en las causas de las enfermedades en cuatro clases:

1. Una lógica de degeneración, en la cual la enfermedad sigue al desgaste del cuerpo.

2. Una lógica mecánica, en la cual la enfermedad es resultado de bloqueos o de daños a estructuras corporales.

3. Una lógica de equilibrio, en la cual la enfermedad sigue a la ruptura de la armonía entre partes, o entre el individuo y el medio.

4. Una lógica de invasión, que incluye la teoría del germen y otras intrusiones materiales de las que resulta la enfermedad. (Fitzpatrick, 1990: 24).

Este marco facilita la identificación en términos generales de las lógicas causales implicadas en los modelos explicativos. Pero dado que los distintos factores enfermantes están frecuentemente vinculados, las lógicas causales se entrecruzan por lo que no serán aquí el eje vertebrador de la presentación de los diversos elementos patógenos, sino que se ha preferido 
organizarlos en función de sus procedencias y características. La mayoría de éstos aparecieron recurrentemente en las explicaciones etiológicas y generalmente de más de una enfermedad. Es decir, en muchos casos no se halló una relación unívoca entre factores patógenos y enfermedades, un mismo elemento enfermante aparece asociado a varias enfermedades (no siempre emparentadas) así como una enfermedad presenta una pluricausalidad.

Se describirán los elementos identificados como patógenos junto con las enfermedades que provocan y las terapéuticas correspondientes, ya que a menudo fue la explicación del accionar de una terapéutica y la justificación de su elección lo que hizo explícita la causa del malestar. Esto se observó principalmente en las terapéuticas caseras, para las que se contaba con mayores explicaciones a diferencia de las respuestas recibidas desde la biomedicina cuya eficacia permanece en un nivel más insondable. Como se sostuvo en capítulos precedentes, la asociación entre la identificación causal y el tipo de terapéutica no es directa ni responde a una sola lógica (sea, por ejemplo, cura por extracción, por compensación con opuestos, cura homeopática o cura por restablecimiento de relaciones sociales), por lo que debe ser analizada en cada caso particular.

\section{El medioambiente como responsable de padecimientos}

Dice Idoyaga Molina, "el espacio no es homogéneo ni neutro sino un conjunto de ámbitos de calidad y poderes diferentes, de allí que haya espacios propicios y perjudiciales, no sólo en virtud de que los habite una entidad mítica, como sucede con cerros y abras en los que mora la Pachamama o con los bosques donde habitan espíritus, sino también debido a la calidad intrínseca del espacio. Lo dicho obviamente implica una representación de la naturaleza en términos de poder" (Idoyaga Molina, 2002: 157). Como ya se mencionó al ennumerar los orígenes del aire, los factores enfermantes más evocados corresponden a elementos sobresalientes del espacio azampeño: el frío, el calor, el sol, el agua, el viento (y la tierra que suspende), y la altitud.

Durante el invierno y debido a la altitud, las temperaturas son muy bajas; nevadas y heladas son motivo de lamento por las pérdidas de animales y frutales, además de dificultar la cotidianidad en un ambiente donde la única forma de calefacción es el fogón (fueron frecuentes comentarios como el de una niña acerca de cómo en invierno debían echar agua caliente sobre la canilla para descongelarla, o el de una madre remarcando el sacrificio en los niños de lavarse y salir temprano hacia la escuela en invierno). Al frío se le atribuyen 
enfermedades respiratorias (neumonía, algunos la llaman "costado escondido", resfríos, gripes, angina, mal a los bronquios, asma, síntomas como tos y trancazón en el pecho). Para estas enfermedades recurren generalmente a la posta o a los centros de atención oficial de Belén, donde reciben como tratamiento jarabes, vacunas, inyecciones. Desde la autoatención, acompañando o reemplazando la consulta médica, toman pastillas de venta libre (geniol, aspirina) y realizan masajes en el pecho con grasa de gallina (explicando su valor terapéutico en que es cálida, calentadora), toman miel o arrope caliente y quemadillos.

F: directamente los llevamos a Belén porque ahí les da una gripe, cualquier de eso nomás de esas gripes que eran en tiempo de frío aquí, porque ha estado frío aqui [...] A: y se enferman más en invierno o en verano?

M: y en el invierno es por el frio

$F$ : a veces les da unos resfrios, unas gripes, tos, por ahi una enfermedad, madrugan, como usted sabe que el invierno es más temprano el horario, claro, tienen que levantarse más temprano

M: en invierno empieza frío, quema más el frío que el calor, el agua quema, se escarcha, da miedo lavarse la cara! en abril hasta agosto

(P5, mujeres, M: 33; F: 66 años).

F: y la vira esa que le decía la Rosalba esa es para las gripes, se hace un té, y se quema la azúcar, se hace, decimos aquí, un quemadillo

A: cómo?

F: tuesta la azúcar en un jarrito y después le echa el agua, le echa la vira, le echa la viruta de la jarilla, trae un palo de jarilla y lo limpia bien todo, como es negro el palo, lo deja entonces blanquito, lo va sacando y va, y eso lo echa ahí, y lo hace un té, y eso es como un jarabe, para la tos, enseguida ya lo compone, es como si le destapara los pulmones, el pecho, no?, ese, es como un jarabe, es ese, la vira con la jarilla, la viruta le decimos aqui nosotros (P44, mujer, 64 años).

En el caso de quienes sufren asma o recurrentemente problemas en los bronquios, la explicación fue que se trataba de fríos internados, muchas veces por resfríos mal curados. Esta idea de una incorporación del frío que penetra el cuerpo fijándose en su interior también aparece en la atribución causal del reuma y la artrosis.

E: y bueno de ahí nomás no, ... que no me han cortado del todo y me ha quedado y me ha quedado, dos años, entonces, como digo yo, entonces me ha dado grave [...] me agarró la bronquitis [...] y ahora este año me ha vuelto a tentar, para el invierno, con el frio, nevadas que hay... y bueno estaba de frio y dele nevar y yo como andaba sana, ibamos a la leña nosotros, asi hacíamos hasta que ha pasado todo de nevada, después cuando ya ha pasado todo ya ahi he caído otra vez enferma, ya me ha tentado otra vez lo mismo

C: [...] claro porque ese mal curable, ese resfrío que ella no se curaba bien y va quedando [...] me han dado unos remedios, no sé, una inyecciones así que me hicieron para los bronquios con eso me han curado allá, he estado como dos días por ahí internada, me han cortado ahí nomás porque como hacía poco, en cambio ella no, ella ya sabrá ser hace muchos años que sufre de eso por eso la ha agarrado muy fuerte a ella (P27, mujeres, C: 56; E: 80 años). 
F: este año he ido recién al hospital, fijese, por el asunto este de la vista, de la presión, me han hecho análisis de sangre, me han hecho análisis de orines, me han hecho dos veces electro y me han hecho una radiografía, de la radiografia me ha salido sólo eso, de que tengo los bronquios, todo eso un frío que tengo, claro de estas gripes que nos dan así que, tengo un frío a la ... eso me dio (P44, mujer, 64 años).

\section{JA: claro, yo digo que el reuma viene de fríos internados que se internan}

S: cuando uno es joven, uno es chango, es guapo, buen mozo trabaja en el agua, yo he trabajado en el agua regando, en el agua los pies limpios, no se usaba bota como ahora ya hay muchas cosas que se han... todo ha cambiado, todo ha cambiado, yo cuando trabajaba que tenía un patrón, me decía, va a atender el agua esta noche, y bueno, no me daba ese patrón no me daba unas botas, como botas de goma... y bueno, todo se ubica, todo se ubica, todo, todo se ubica, y de ahi dice que me ha agarrado

$J A$ : se interna el frío en las coyunturas, eso, y de ahí pienso

(P50, JA: mujer, 64 años; S: varón, 76 años).

Otros casos de acción del frío sobre el aparato motor son dolor de espalda y parálisis facial, identificados como aire (por lo que se recurre a un curandero y se realizan cuidados caseros como la aplicación de un paño caliente sobre la zona afectada) y la falta de tonicidad muscular, el caso del niño discapacitado que no camina (su madre refirió que tanto el médico de zona como una curadora recetaron baños con una mezcla de yuyos, donde cada yuyo aporta su "caloría")

$J$ : dice [La curadora luego de curarle una parálisis facial, "como un derrame” a causa de aire] "usted para el invierno va a sentir que la cara se le quiere ir de vuelta, entonces usted trate de estar cerca del fuego, cerca de... ponerse bufanda, taparse la cara" dice, "porque le va a volver a querer tirar", y es cierto, usted sabe que este invierno, el frío que ha hecho, lo sentía que se me volvía la cara, usted sabe, así que yo asi de bien que estaba me ponía la mano, me calentaba, calentaba en el fuego, me ponía, y así pasé (P49, mujer, 40 años).

El curandero local también refirió un episodio similar, cuando era chico trabajando en Hualfín, con la nieve y el frío, le pasó lo mismo por el aire del frío. Se fue a Londres a ver a un amigo boliviano que lo curó con un carozo que le ponía en la boca (en el caso precedente, la curadora le colocó una nuez moscada) y los secretos y en tres días lo sanó.

J: eso es un golpe de aire que agarran esos dolores en la espalda o frío, o es mucho frío, también puede ser que ha andado desabrigada y le ha agarrado el frío [...] pero ha visto que uno transpira y después uno descansa en la sombra y ahi se le secó esa transpiración y ahí dicen que son los golpes de aire, cuando duelen más las espaldas A: y eso cómo lo curan, o cómo se pasa?

J: eso por ejemplo usted pone algo caliente y le pasa porque es aire frío lo que le agarra [...] calienta un trapito con la plancha, lo pone ahi o en el fuego, en la hornalla o en lo que sea, usted lo calienta al trapito y se lo pone y a veces le pasa, cuando es golpe de aire se le pasa, eso a mí también siempre me sucede que me 
agarra dolor de espalda yo por eso le venía diciendo esta mañana a la I que tengo guardados unos chalecos y ayer he tosido y digo que anoche me tapaba y me calmaba la tos, me destapaba y me volvía la tos, digo así que capaz que tengo que es más de frí y sí, porque otros años sabía andar con el chaleco, no se sacaba

(P7, mujer, 42 años).

P: "bañalo con yuyos" me decía "hacé hervir vos por ahi unos yuyos, hacete hervir un montón de yuyos en una olla y bañalo y arropalo bien cosa no se enfríe porque ese chico capaz que tiene mucho frío"y doña $L$ [curadora] también decía lo mismo, que habia que hervir hoja de nogal, tramontana, si no que haga hervir ese cosito marrón que sale de los hormigueros que se llama casa de hormiga [...] para que se endurezca él, porque él era muy blando [...] y porque como dicen que las hormigas llevan toda clase de yuyos y bueno dicen que tantos yuyos que lleva la hormiga se forma toda una sola curación, así decía doña $L$ [...] y el doctor $S$ [médico de zona] me decía que haga hervir yuyos, "juntate un poco de yuyos", me decía él "y hacete hervir en una olla y báñalo" dice "porque capaz que tiene mucho frío"! Y bueno con eso se ha ayudado mucho se ha empezado a endurecer [...] porque esos yuyos me decía que calientan mucho [...] cada remedio tiene su caloría [...] y bueno sabría ser porque él estaba mucho más, cómo le voy a decir, yo lo hacía para así y él no se paraba (P19, mujer, 43 años).

Otra asociación del aire con el frío surgió en una charla con el curandero al refirir la toma de una cucharada de ajo crudo picado con agua, cebolla y pimienta porque "son buenos contra el aire pues calientan los intestinos". El malestar causado por frío en los intestinos fue nombrado por dicho curandero como "pulso" en contraposición al diagnóstico de úlcera dado desde la biomedicina. La descompostura estomacal fue atribuida en algunos casos al frío pero ninguno de los azampeños se refirió al "pulso", por lo que esta categoría no fue incluida en el capítulo anterior sobre taxa vernáculos.

F: la úlcera, que le dice el médico, nosotros la llamamos pulso [...] eso viene del resfrío y debilidad llega al intestino, pero el doctor dice úlcera y lo opera, pero eso si lo opera, bueno, raro el que salva, que eso es una cosa que te corta el intestino, que se hace con, ahi, esa grande, esa sierra, el intestino [...] del fuerte frio, porque le da frío al estómago (P55, curandero, 84 años).

Por último se atribuyeron al frío malestares tan disímiles como problema de la vista, hepatitis y un caso de muerte por paro cardíaco.

J: le vino un paro al corazón [...] ese día se ha levantado a las 5 y estaba frío

A: y eso le puede haber hecho mal?

J: haber hecho mal...la ha llevado a cobrar, ha hecho las compritas ahi en San Jorge A: $y$ qué es el paro?

J: y puede ser baja la presión, un bajón de presión muy fuerte [...] debe ser que un fuerte bajón de presión y baja las defensas (P69, varón, 40 años).

R: se ha ido a cobrar, se han ido de aqui y la gente que le ha dicho que iba con frio, salió la trafic a las 4 de la mañana los ha llevado y en el mes de abril que ya está haciendo frio y justo amaneció así medio, habrá amanecido frio, ya el cuerpo de 
grande no es como el de joven, en una de esas habrá estad tentada de gripe digo yo (P79, mujer, 65 años).

A: [hablando de unos casos de hepatitis] y cómo se la habrán agarrado?

M: y no sé, no sé, por que dice el doctor que posiblemente era por el mucho frío, posiblemente era, no, no sabia, puede ser por mucho frío, porque ha hecho un frio terrible (P51, enfermera de la posta).

En las terapéuticas mencionadas, tanto las elaboradas desde la autoatención como las recetadas por curadores populares, se lee una lógica de su accionar por contrarios, es decir, respuestas cálidas (estar cerca del fuego, aplicación de paños calientes, elementos considerados calientes como la grasa de gallina, la mezcla de ajo, cebolla y pimienta, baños con yuyos) junto a la precaución de no exponerse al frío, de usar abrigos ${ }^{36}$.

Gripe, fiebre, resfrío (no contagioso), reuma y dolor de huesos pueden tener también su causa en el calor, o en el contraste calor-frío en períodos de cambio estacional o producto de conductas como bañarse y salir al sol o acercarse al fuego ("desarreglos"). El calor conlleva también el riesgo de deshidratación (más mencionado en niños y en vinculación con la advertencia de doctores de darles bastante agua), y de malestar (agitación) en quienes padecen de presión alta. Asociado al calor se halla otro factor identificado como patógeno: el sol, a este también se le imputan resfrío, dolor cabeza, de oídos, de garganta, de huesos, fiebre, alergia (sarpullido), problemas de la vista y en un caso extremo de insolación, trastorno mental.

A: cuándo vienen las gripes?

$R$ : más cerca de julio, a veces más en el mes de noviembre como aquí empieza un día que hace calor, sí, al rato ya está frío (P21, mujer, 63 años).

R: también hay veces que uno suele andar en mucho sol y ya agarra también esa trancazón de nariz o a veces dolor de huesos

A: Ah, el sol también da dolor de huesos?

R: sí, por el mucho sol

A: Ah, eso no lo sabía...

$R$ : bueno aquí porque son soles penetrantes y como para allá son soles lentos porque es húmedo no? no se nota mucho el sol y como allá más sabrán vivir en sombra que en sol, en cambio aquí no, aquí uno vive... sí, también el sol hace doler los huesos (P40, mujer, 62 años).

A: y de qué era el dolor de rodillas, qué le dijeron que tenía?

T: que ya de vieja [ríe] ya de tanto trajinar, lo que yo solía tejer muchos pullos, muchas telas, iba a la leña yo sabía tener un burrito, uh! En el verano un sol tremendo y de ahí me ha venido dolor a los huesos, dolor en las piernas, y los

\footnotetext{
${ }^{36}$ Este principio de los opuestos ha sido identificado para el área andina como "el concepto de una magia alopática o de opuestos, basada en la reacción contraria, o efecto contrario" (Palma, 1978: 171; Bianchetti, 1996: 83) sin considerar el origen histórico de la clasificación en fríos y cálidos de los elementos patogénicos y terapéuticos, eje de la medicina humoral importada por los europeos a América (Idoyaga Molina, 2002).
} 
doctores me han dicho que eso me ha hecho mal, que me ha hecho mucho calor a los huesos (P70, mujer, 72 años).

A: qué le pasó, qué tuvo, por qué se perdía de la cabeza?

R: y muchos dicen que parece ser que se ha insolado, el sol la, tenido mucha sed, y ya la han levantado y la han traído y aquí ha reaccionado, decíamos, bien, quizá le ha faltado alguna revisación médica, en el tiempo ese no la han hecho ver, bueno, y al tiempo ya ha empezado a fallarle la vista, [...] y después perdió la memoria

A: y por qué perdió la memoria?

$R$ : vaya a saber de qué sería

F: debe ser de la misma debilidad, el sol le ha quemado la cabeza, secado algún... del cerebro, decían que ya no conocía, renegaba,

$R$ : ya no se ubicaba, que no sabía a dónde vivía

(P21, R: mujer, 63 años; F: varón, 43 años).

Respecto a las terapéuticas, salvo el consumo de analgésicos de venta libre, sólo fue referida la aplicación de vinagre o leche fresca para el dolor de cabeza y de cuajo y hojas de una planta para una inflamación. En ambos casos está en juego la idea de extraer el calor mediante elementos frescos que lo absorben.

L: asi la saco de la heladera y el vinagre bien fresquito que lo haga con algo y me ponga así [en un paño en la frente] y me cura, al rato me ha sacado el dolor

A: y por qué el vinagre?

L: no sé por qué [...] dicen que la cabeza tiene mucho calor, y siempre uno anda en el sol, y dicen que eso es como si refrescara

A: te saca el calor? Y por eso decís que se te secó?

L: y claro, debe ser

A: y se te fue el dolor?

L: sí [...] mami dice que use la leche que también refresca...en un pañito hasta que se seque, pero hoy he tomado ibuprofeno pero ay, me ha agarrado un dolor de estómago! Otro día he tomado bayaspirina pero no me hizo nada

(P70, mujer, 23 años).

J: y que se revientan las venas, se me puso toda la canilla morada, de la rodilla para abajo, pero más cuando a más por vapor se me ha inflamado, falta de circulación [...] me fui al médico de Belén, dice "noooo, esto es una flebitis que tenés, mirá gorda, tenés que ir y poner el pie para arriba, no andés en los vapores, no caminés"

A: y por qué el vapor?

$J:$ y parece que inflama, me hincha la canilla [...]

A: y el cuajo cómo te lo ponés?

J: como un refrescante, que me saca el calor, le saca el vapor, por ejemplo todo esto [señala el suelo que está baldeando] yo estoy alzando para ahí, ha visto? Y eso me pone primero rojo, después se pone como verde, después se pone morado, negro, y voy en la casa y me pongo eso y a la hoja del lampazo, una hoja grande, verde, esa me la pongo pero sale seca, usted sabe? Cómo sale, seca!

A: la aplicás con el cuajo mismo?

J: no, no, sola, me la pega, y después cuando la saco pero seca, como si le habrá hecho fuego! (P68, mujer, 43 años). 
En este último fragmento aparece, vinculado al calor, otro elemento patógeno, el vapor ("los vapores"), en el que se conjugan varios factores enfermantes: el calor, el sol, el fuego (fuente de calor) y el agua, y que explica, junto con la percepcion de nocividad del contraste frío-calor, que conductas como bañarse y salir sol, jugar con agua al sol, o mojarse, transpirar y secarse al calor del sol sean consideradas también como causa de enfemedades (resfríos, vómitos, diarrea, fiebre, dolores de huesos, aire).

JA: le ha dicho que era de las rodillas y que le ha hecho mal, cuando se es joven uno camina muy mucho y de eso que se acumulan los males porque ya se moja al sol y todo y se baña y se seca la ropa en el cuerpo (P56, mujer, 67 años).

A: y a J cómo le vino ese aire, también por ojeadura?

F: no, no, a ella le viene porque pasa un mal desarreglo, o quizá les anda mal el cuerpo, se baña, se lava, se le empeora se lava y va al fuego, o se lava y sale al sol, a andar (P55, curandero, 84 años).

Entre los cuidados postoperatorios (sobre todo de operaciones de la vista y en un caso de operación de tiroides) hicieron hincapié en no acercarse al fuego y a los vapores de la cocción, no exponerse al sol. Como ya se mencionó, en tiempos pasados estas precauciones también se tenían luego del parto, y ahora, como el mismo se lleva a cabo en el hospital, se consideran innecesarias puesto que ahí las parturientas reciben medicaciones que aseguran su restablecimiento.

E: nosotros teníamos miedo de que se enferme ella fiero después de tenerla pero no, estaba bien

A: y por qué se puede enfermar después de tenerlo?

E: porque aqui es triste la vida, después de tenerla a la criatura, se tiene que cuidar del sol, tiene que madrugar ... el día levantarse al baño porque si le da el sol ya

A: después de tener el bebé no le tiene que dar el sol?

E: no, ni nada, no tiene que salir afuera, pero yo sí, yo andaba caminando, los tenía y salía a atender el fuego, a hacer todo, porque no se pueden arrimar las chicas así A: y por qué?

E: porque eso es malo, se le iba la sangre a la cabeza pero yo no porque ahora estos años las chicas no se atan la cabeza y yo si porque eso hay que atarse bien con un pañuelo para que no se le iba la sangre para la cabeza y cuando el parto, tiene a la criatura así sin caminar, no le hace mal nada (P65, mujer, 78 años).

A: pero ya las chicas que han tenido hijos ahora no lo hacen

$C$ : no, porque los han tenido en el hospital, nosotros antes los hemos tenido aquí nomás, y en el hospital les ponen las inyecciones

F: las curan ahí nomás, entonces del parto después ya...

$C:$ nosotros no

A: y por qué con el fuego se le va a ir la sangre?

$C$ : claro se le va la sangre

$F$ : claro se machaba de la cabeza

A: pero sólo después del parto? 
Fr: del parto 8 días no salía a la cocina

A: no se acercaba a la cocina?

F: no, nada! A ninguna cosa (P66, F: curandero, 88 años, C: mujer, 60 años).

Algunas mujeres mencionaron también no lavarse la cabeza durante los primeros 8 días después del parto. El mal que se quiere evitar es que la sangre "se vaya a la cabeza" provocando locura, debilidad a la cabeza (a esto se refiere el curandero con "macharse" de la cabeza, pero "estar machado" significa estar borracho).

A: y cuando acá dicen que se le sube la sangre a la cabeza, qué es?

JA: y claro, tiene la menstruación que le llaman, no? O está enferma de parto, también es muy peligroso [...] después de tener el bebé no tenían que acercarse al fuego

A: y por qué?

JA: bueno, ahora van a los doctores, no?

A: no se cuidan ahora de eso?

JA: y bueno pero el doctor lo cuida bien

A: qué le hace el doctor?

JA: dicen, yo nunca he ido al doctor a tener mis hijos

A: los tuvo todos acá?

JA: todos, con el favor de dios y mamá virgen [...] mi suegra venía a atenderme, sí, estaba hasta 8 días ella y yo no podía llegar al fuego,

A: usted durante 8 días no se acercaba al fuego?

JA: no, es malo eso, no yendo al médico mejor dicho, y la mujer que va al médico ya lo sabrá curar bien

A: y esa si se puede acercar al fuego?

JA: y sí, se vienen, tranquilas andan (P56, mujer, 67 años).

P: no, ahora no, por lo menos yo cuando he salido del hospital me he ido a la casa, lo único en el hospital me decía el doctor que no me lavara la cabeza, que me lave el cuerpo pero menos la cabeza

A: por qué no?

P: porque dice que a veces la sangre se va a la cabeza [...] por unos 8 días, 10 días, "aguántate, no te vayas a estar lavando la cabeza porque se te puede ir..."

A: la sangre se te va a la cabeza, y qué te hace eso?

P: y bueno, vaya a saber, no sé

A: algunos dicen que cuando se está indispuesto tampoco?

$P$ : sí, tampoco, decían que no

A: y qué pasa?

P: eso era lo que decían que le había pasado a $N$, ella dicen que ha andado indispuesta y se ha bañado y bueno dicen que, decía la $C$ que les había dicho un médico campesino, que la sangre se le había ido a la cabeza a la chica, la ha seguido enfermando, y eso la ha trastornado, la ha perdido, decía, pero bah, no sé (P19, mujer, 43 años).

De acuerdo a la opinión de muchos, esta es la causa de un caso puntual de locura en Azampay: una mujer de alrededor de 30 años, que pasaba por momentos de tranquilidad y crisis donde su conducta se volvía enajenada y violenta, había estado internada en el hospital 
psiquiátrico La Merced, en la ciudad de Catamarca, pero también la hacían tratar con diversos curanderos. Aquí la "debilidad a la cabeza” había sido causada por lavarse la cabeza o, según otras opiniones, por un "golpe de calor" en la cabeza (estando en la peluquería en Belén) estando indispuesta. En este esquema, los días postparto y de menstruación son momentos que exigen un cuidado especial de mantener la cabeza alejada de fuentes de calor, pero independientemente de esos momentos especiales en la vida de la mujer, como se notó anteriormente en el caso de insolación, el exceso de calor en la cabeza puede causar locura, debilidad mental. También en el caso del niño que debía recibir baños de yuyos para mejorar su tonicidad muscular, aparece la advertencia de mantener la cabeza alejada de esa fuente de calor.

P: claro pero él me decía que lo bañe de aquí para abajo nomás [...] y la cabeza que no le lave porque esos yuyos me decía que calientan mucho (P19, mujer, 43 años).

Repensando aquí el esquema de Chrisman se puede ver que si bien predomina una lógica del equilibrio (los malestares como producto de un desequilibrio entre el individuo y el medio lo que a su vez produce un desequilibrio interno) también está presente la lógica de degeneración, es decir, la enfermedad como un desgaste del cuerpo. Es el caso del reuma, del asma, de los dolores de hueso crónicos debido a "fríos internados" o a recurrentes exposiciones al sol, y que dan cuenta una acumulación en el cuerpo de los efectos negativos del ambiente.

Según Idoyaga Molina, la concepción de la enfermedad como originada en desbalances térmicos implica una idea de salud como el equilibrio entre dos extremos (cálido y frío) y conlleva la clasificación en fríos y cálidos tanto de los elementos patogénicos como de los terapéuticos así como de los males mismos (Idoyaga Molina, 2002).

Referido ya como uno de los diversos orígenes de aire y en vinculación a la noción de "vapores", el agua es otro de los elementos del medio frecuentemente nombrado en las atribuciones causales de los padeceres. La trascendencia y las particularidades del tema del agua entre los habitantes de Azampay ha sido señalada por Ballina (2006) en su analisis de procesos de adscripción identitaria en dicha localidad. El autor identificó cuatro núcleos de significación: el agua como dadora de muerte en el tiempo mítico: muerte por ahogo de los indios; como dadora de muerte en el presente: escasez del agua; como dadora de vida en el tiempo mítico (abundancia/fecundidad): la asociación de los indios o antiguos con el río, los estanques, y la abundancia de agua que existía y ya no existe; y como dadora de vida en el presente: la trascendencia del agua para el riego y el consumo en un contexto de escasez de este recurso. En el conjunto de representaciones que connota al agua con capacidades 
enfermantes, no es su abundacia o escasez el motivo de lamentos y quejas, sino su calidad para ingerirla y los efectos negativos del contacto y exposición prolongada con el cuerpo.

En Azampay desde hace alrededor de una década cuentan con agua corriente pero no potabilizada, es colectada río arriba en piletones desde los que se la distribuye pero sin ningún tipo de tratamiento. A esto le achacan malestares como vómitos, diarrea, fiebre con dolor huesos, infección urinaria, tener parásitos, deber ser operado de apéndice o vesícula. Algunos explican que los malestares provienen de la presencia de microbios o virus por la falta de potabilización, pero la mayoría sólo menciona como causa el hecho de que el agua "no está curada", sin explicitar otro eslabón en la cadena de factores que lleva del agua a los padecimientos.

E: los chicos de mi hermana ellos cada tanto ya tienen problemas de gripe, que ya los agarra vómitos, diarrea

A: $y$ de qué les viene eso?

E: y eso algunos dicen que es de debilidad otros dicen que no, que viene del agua

A: del agua?

E: asi dicen

A: y por qué?

E: vaya a saber qué sabrá tener (P64, mujer, 51 años).

J: [...] yo decía del agua, hay para el invierno diarrea, vómitos, para el verano es esa infección urinaria [...] por el agua también, y bueno, de qué viene tanto, si grandes y chicos, eso abunda mucho aqui la infección urinaria [...] yo digo que del agua debe ser porque póngale si no la curan nada al agua, el agua viene derecho la meten en un caño allá arriba y por el caño viene hasta los grifos, si usted la ve al agua a la mañana, cuando hay aumento del agua, cuando hay lluvia para los cerros viene aumento y pone en una botella y la deja así... coloraditos, como viboritas, chiquititos, entonces en la casa la congelamos al agua, las metemos a las botellas en el congelador y ahi lo dejamos sobre la mesa, así, porque cuando yo le tomo agua cruda, cruda, enseguida... parece que se mueren ahi, claro porque abajo cuando se asienta el agua queda como una borra y entremedio de eso andan [...] haciéndola hervir también mata los virus [...] por eso yo digo, usted va a una reunión y usted pide al intendente que ya haga algo porque no es posible estar tomando agua tan cruda, porque no se filtra, por la arena nada más pero póngale hay sapos, hay víboras allá en la pileta esa de arriba cuando llegan a limpiar saca sapos, deshaciéndose (P7, mujer, 42 años).

L: son parásitos

A: y eso de qué?

L: y bueno, sabrá ser del agua, como aquí no hay agua, no cloreada

(P17, mujer, 45 años).

M: eso dijo el doctor que era del agua [...] dice que para allá, para el norte chico dice que toda la dirección del norte chico habian hecho un estudio del agua, dice que el agua estaba fiera

A: qué tiene? 
M: no me acuerdo cómo era... y eso le ha hecho diarrea y vómito [...] tenemos que clorar el agua

A: y le explican a la gente?

M: y sí porque él nos decía que agregarle lavandina para el consumo más que todo, para cocinar ya va a hervir el agua

A: y la gente lo hace?

M: nunca lo hace

A: por qué, es muy cara la lavandina?

M: no, no es porque sea caro sino que a ellos no les gusta

$X$ : el cloro en la panza a los chiquitos les hace...

(P18, M: enfermera de la posta, X: mujer, 56 años).

Salvo una excepción, nadie dijo tener la precaución de echar gotas de cloro al agua, algunos justificándose en que éste puede ser nocivo o porque le da mal sabor. Como cuidados algunos refirieron tomar "agua de yuyos" (infusiones frías) en reemplazo del agua "cruda" y sólo una entrevistada refirió dejarla asentar y congelarla. No obstante esta identificación del agua como factor patógeno, fue también frecuente que muchos de quienes la enunciaron lo hicieran atribuyéndole la idea al doctor o a otros y oponiéndole su propia convicción de que el agua no puede ser la causa pues estarían todos enfermos, de que siempre consumieron el agua proveniente de la misma fuente y nunca tuvieron problemas. Son los mismos que sostienen que no es necesario clorar o hervir el agua porque ellos ya están acostumbrados (en contraposición a mi propia precaución durante mis estadías de echarle gotas de cloro).

A: $y$ ustedes le echan lavandina?

J: no, no usamos de eso, yo primero la congelaba al agua

$R$ : nos decían y nosotros tenemos pero nosotros no somos de echarle

A: y por qué?

J: y sí, yo también la lavandina no me falta pero uno no se acostumbra a poner, y eso cuántas gotitas dicen hay que poner?

A: dicen que 2 por litro

$J$ : y sí, lo que pasa es que uno no se acostumbra, y bueno, ustedes vienen y nunca se enferman porque cloran el agua, y si de repente te agarra la sed y bueno, uno toma agua así nomás y a veces los desconoce el tiempo

(P68, mujeres, R: 65 años; J: 43 años).

J: claro, y a veces por ahí a ustedes lo que les puede sentir mal aquí en este lado, ya nosotros estamos acostumbrados, ya como que el estómago todo ya se acostumbra, el agua

A: sí, también puede haber sido el agua?

J: el agua puede ser que también le haya producido eso, dolor de estómago y diarrea (P49, mujer, 40 años).

La contrastación de la idea de que un padecimiento es causado por el agua con la observación de que no todos los lugareños (quienes consumen la misma agua) sufren tal enfermedad, también surgió en las explicaciones causales del problema de tiroides. Cuatro 
mujeres, dos hermanas y sus respectivas hijas sufrían de bocio, una de ellas fue operada días antes de mi llegada por lo que el tema estaba en boca de todos los lugareños, lo que facilitó la escucha de las diversas representaciones vigentes en torno a dicho padecimiento. Una de las causas nombradas fue el agua, en algunos casos completada con la explicación de que el problema era la falta de yodo en el agua. Sin embargo, el hecho de que sólo los miembros de una familia sufrieran de bocio ponía en duda esta atribución causal dándole más credibilidad a la idea de una enfermedad hereditaria.

A: $y$ de qué habrá sido?

I: y debe ser porque es hereditario, mi mamá tiene también, del agua [...] según dicen que es el agua, allá en Londres la gente es también de tener esos bocios, ha visto que les da a la tiroides y según dicen porque les falta el yodo al agua A: y acá también?

J: y lo mismo, claro, allá en Belén les decimos a los de Londres, cogotudos, cuando se pelean con un amigo "callate, londrino cogotudo!" cuando éramos chicos, y decían que es por falta de yodo (P7, mujeres, J: 42 años; I: 42 años).

JA: tenía coto, mejor dicho bocio

A: y qué es eso?

S: se le hincha aquí

$J A$ : sabrá ser de nacimiento

A: siempre fue así?

JA: sí, la conoce a la V? Bueno ella también tiene

$S:$ se les pone muy grueso ahi

A: y por qué les pasa eso?

JA: algunos dicen, no sé, dicen que es del agua

A: del agua?

$J A$ : dicen

A: por qué, qué tiene el agua?

JA: pero eso no puede ser, qué va a ser! Para ser del agua tendríamos todos

(P56, JA: mujer, 67 años; S: varón, 79 años).

El agua bebida es también identificada como causa de problemas dentales. Como se señaló anteriormente, se han registrado altas frecuencias de fluorosis y los azampeños señalan como rasgo distintivo de quienes no se han criado allí el hecho de que tengan los dientes blancos. Las manchas son asociadas a las caries y posterior pérdida de las piezas dentales. Si bien algunos también señalan como causa el comer dulces, el agua es el factor central, en opinión de algunos por no estar "curada", en opinión de otros por tener antimonio (también a raíz de no ser potabilizada). En el primer caso, se asocia la presencia de sarro (responsable de las manchas) con la falta de potabilización y la ausencia de cloro, elemento que evitaría el manchado y pérdida de los dientes. Según el curandero local, una de las fuentes que aporta el agua para el consumo es de color amarillo, manchando hasta las piedras del cauce debido a su contenido de antimonio (no se pudo indagar de donde había escuchado tal término y su 
asociación con el agua). Así se asocia el color de este agua y su efecto en las piedras con las manchas en los dientes (ausentes en foráneos) y esto con la carie y consecuente pérdida de las piezas dentales.

\section{M: se manchan y se caen}

A: por la misma mancha se caen?

M: sí, porque eso es cosa que empieza asi a comerse, como los palos viejos que empiezan a comerse, usted sabe cómo duelen, uh! Es un dolor terrible, yo este me he sacado

A: y te ponés postizo o te queda el huequito?

M: no... me quedo... total es atrás, dicen que es por el agua

A: y por qué del agua?

M: porque no es potable, es agua así nomás que viene... eso de las cañerías que se le terminan tapando

A: y no les ponen ustedes cloro, una gotitas?

M: sí, cuando nos dan siempre ponemos unas gotitas de lavandina

A: quiénes les dan? La Municipalidad?

M: no, de lavandina que compramos, eso previene, es el sarro del agua, dicen que es de la misma tierra que cuando usted la hace hervir al agua empieza a juntarse, ese es el sarro como juntan todas las cosas las ollas, las pavas, así se juntan en los dientes me han dicho y eso es lo que mancha

A: y eso después te lo carea?

M: sí, se pone negro

A: asi que no hay manera de evitarlo?

M: no, dicen que es por el cloro, el agua tiene que tener cloro

(P64, mujer 34 años).

Independientemente de la ausencia de la potabilización, el contacto prolongado con el agua sumado al frío durante la realización de tareas (lavado, riego, trabajos a la intemperie y jugar con agua en el caso de niños) es causa de enfermedades respiratorias (resfríos, bronquitis, crisis de asma), reuma, de dolores de hueso, de rodilla $\mathrm{y}$, si bien menos frecuentemente mencionado, de picazón en la piel. Situaciones puntuales de mojarse son causa de dolores circunstanciales, pero episodios recurrentes en la historia de los individuos son la causa de reuma y dolores crónicos. Una mujer comentaba que tenía intenciones de ir hasta un poblado vecino pero como llovía no había salido para no hacerse mal a las rodillas, le pregunté si sufría de algún malestar al respecto (ya que varios mencionaron que los días de mal tiempo se intensifican los dolores de hueso y articulaciones) y dijo que no, pero que justamente no salía como prevención.

$R$ : ha pasado resfriada nomás, la he llevado a Catamarca al médico porque ella estaba 2 o 3 días bien y le volvía el resfrio [...] parece de lo que llovía, la humedad [...] se arrastraba así para el invierno, toda esa humedad

A: gateaba mucho

R: ahá y toda esa humedad (P77, mujer, 23 años). 
L: yo enfermé por andar molestando con las plantas, sacando los yuyos de ahi y estaba re-húmedo por la lluvia y he empezado a sacar los yuyos y recoger las nueces todo eso me he mojado los pies con las plantitas que están llenas de agua abajo, yo digo a lo mejor eso me habrá, como no estoy acostumbrada, nunca ando molestando con yuyos, por ahi eso me habrá hecho, la humedad a los bronquios, y otra cosa qué puede ser? (P70, mujer, 23 años).

M: no, por ahí me duelen los huesos, por ahí

A: y de qué será eso?

M: no sé, parece que me hace mal cuando baldeo acá y por ahí se me moja el calzado y eso parece que me hace mal, si

A: $y$ ahí tomás algo para el dolor de huesos?

M: no, me pongo un poquito de alcohol y con eso se me pasa

(P51, enfermera de la posta).

Por último, y como ya se mencionara en torno al susto y al aire, las fuentes de agua (ríos y aguadas) tienen una connotación negativa por ser zonas de aire, por lo que cuando las atraviesan toman la precaución de cubrirse la cabeza, sobre todo si acaban de hacerse curar de aire por el curandero.

J: por ejemplo yo me voy para Chistín y en ese río ancho, ese río anchosado que le dicen, no sé si usted lo distingue, es donde va subiendo y es un ancho el río y en medio hay un arbolito, ahi por ejemplo a mi se me destempla la dentadura

A: cuando pasás por ahi?

$J:$ ahá, se me destempla la dentadura, se me tapan los oídos, entonces dice la I porque hay mucho aire ahí

A: en esa zona, y es por el río?

J: por el río, sí, sí, igual por ejemplo cuando uno se va a hacer curar con Don $F$ y tiene que venir de allá atarse la cabeza con algo o ponerse una gorrita para cruzar el río porque todos los ríos tienen aire, unos menos, otros más, a usted no le ha pasado eso?

A: no lo he sentido, pero por ahí yo no me he dado cuenta

$J$ : claro (P7, mujer, 42 años).

$C:$ el mal aire es otra cosa

A: y eso cuándo le agarra?

$C$ : no, eso hay partes dicen que hay eso

I: el rio, aguadas, los médanos, la humedad

A: pero no es lo mismo que la puna?

I, C: no (P15, C: mujer, 79 años; I: varón, 71 años).

En las variadas atribuciones causales al agua se distinguen distintas lógicas en juego: respecto a las enfermedades a través de su ingesta, subyace la lógica de invasión (virus, gérmenes o intrusión de elementos) en el caso de las enfermedades causadas por tomar agua "no curada" y la lógica mecánica (bloqueos o daños de estructuras corporales) para explicar los problemas dentales, y el bocio (en tanto se atribuye al agua, como enfermedad hereditaria responde a una lógica de degeneración); en cuanto a los malestares ocasionados por contacto 
prolongado con el agua, se lee la lógica mecánica a la que se suma la idea de desgaste del cuerpo en el caso de malestares crónicos; los efectos negativos de aguadas y ríos por ser zonas de aire responden a la lógica de ruptura de la armonía entre el individuo y el medio aunque la idea de intrusión también está implícita en la precaución de cubrirse la cabeza al atravesar dichas zonas.

Otro elemento del ambiente que participa en la lógica de enfermedad por desarmonía entre el medio y el cuerpo es la altitud, al que se le imputan la causa, en este caso exclusiva, de dos padecimientos: problemas de presión (con unas pocas excepciones de baja presión, una gran mayoría se queja de hipertensión) y el apunamiento o puna (usan el mismo término tanto para el malestar como para la zona que lo provoca). Los síntomas que identifican como puna son decaimiento, dolor de cabeza, agitación, cansancio, se nubla la vista, sangrado de nariz, vómitos, todo ello producto de la falta de acostumbramiento a la zona elevada, es decir, lo padecen quienes vienen de zonas más bajas. De ahí que se mostraran sorprendidos de que yo estuviera todo el día caminando de un punto a otro sin síntomas de agitación ni cansancio, mi persona, como representante de lo foráneo citadino fue un disparador de esta apreciación del ambiente en contraste con un "afuera". Quienes personalmente han padecido la puna ha sido durante una ida a El Tolar (a unos 3800 msnm, aproximadamente a 7 horas de camino por los cerros) o hacia algún otro sitio ubicado a mayor altitud que Azampay.

M: cuando se va para el Tolar caminando [...] yo me agito al caminar

A: y qué es eso de la puna, por qué les cae mal a la gente

M: claro, la gente que es de los bajos, no camina, algunos van, capaz que mueran por la puna, agarra fuerte la puna, dicen que sabrá ser como un mal aire que les toma

A: qué diferencia hay entre aire y mal aire

M: no sabrá ser ninguna, al enfermo ya le sale sangre de la nariz, o que ya tiene... ya siente mal, a algunos les cae muy mal la puna si no son de aquí

(P11, mujer, 56 años).

L: [...] así cada tanto suelo tomar yuyos de la puna así que ya

A: porque pensaste que era por la puna?

L: claro porque por ejemplo yo al cerro no puedo salir casi, yo al cerro salgo, allá a la lomita pero a gatas, me canso, y yo para allá para El Tolar llego hasta la mitad y me empiezo a cansar y marearme y dicen que es la puna, opina la gente

A: y por qué la puna...?

L: que es un aire, cómo lo llaman, que es un aire que te toma cuando no sos para la zona no, o sea te cansás, pero yo digo, si por ahí vienen gente así como vienen ustedes, vio y salen así pero...

A: claro, yo no me agito, camino acá y nunca me agité nada

L: claro cómo puede ser que uno se agite?! (P16, mujer, 22 años). 
E: ya se ha agitado por la puna como ella vive donde no hay puna y ha venido aquí, dicen que hay puna, nosotros criados aquí no lo sentimos, pero gentes que vienen se cansan

A: yo sabe que no me canso, voy a La Agüita, a Chistín y no lo siento

M: eso era lo que yo le decía, “mirá la niña como camina de rápido, camina como si fuese...! (P64, mujeres, E: 51 años; M: 34 años).

La presión alta también se atribuye a la altitud, quizá debido a que se les presenta con síntomas similares (decaimiento, dolor de cabeza, agitación, cansancio). Por la altura a la que está situada Azampay se explican la alta frecuencia de gente con hipertensión, casi siempre apoyando esta idea en la recomendación de médicos y curanderos de no vivir más en Azampay. En mi último viaje, ante la ausencia de una pareja que había entrevistado anteriormente, se me explicó que debieron mudarse a Belén a raíz de que a él le diera un ataque de presión y a ella un "derrame" (se refieren a la paralisis facial no siempre asociada a una crisis de presión). Salvo este caso, el resto que menciona esas recomendaciones no planteó tener la intención de trasladarse.

F: sufro ahora la presión que yo la altura dicen que no, andar, yo tengo la presión alta, tengo la presión, ahora últimamente me sube a 28

A: y le dieron algo?

F: sí, yo me he mantenido ahora con pastilla [...] una para la mañana otra a la tarde [...] siempre, ya eso me ha dicho el doctor que siempre, siempre tomarlo [...] de la presión que yo tengo porque a mí la altura, él me ha dicho que yo no me venga aquí a vivir casi, pero sabe qué, por los chicos que tenemos en la escuela, la chica trabaja... (P44, mujer, 64 años).

La presión alta y los efectos de la puna son a su vez considerados causas de problemas al corazón, asociación motivada en parte por la similitud de síntomas (agitación, ahogo, debilidad, mareo, dolor de cabeza, trancazón en el pecho) y probablemente por la influencia del discurso médico (quienes sufren de hipertensión acuden a los diferentes centros de atención biomédica, acompañando el consumo de pastillas allí recetado con cuidados caseros $\mathrm{y}$, en algunos casos, con lo indicado por curanderos).

L: puede ser al corazón, como a ella hay veces que se le levanta mucho la presión [...] hay veces que está mal, así mareada o con mucho sueño y es seguro que le ha levantado la presión [...] se va a la posta, se toma la presión [...] el té del olivo, las hojitas del olivo eso toma y le normaliza la presión

A: $y$ de qué es que se le sube?

L: no sé, porque ha visto que algunos dicen tenés presión normal, otros tenés presión baja, alta o sabrá ser la zona, que es muy alta [...] ella cuando va a Belén está bien, y viene acá y se vuelve a enfermar

A: pero ella se crió acá?

L: y sí (P16, mujer, 22 años).

A: y Don L? Pero qué le pasó? 
JA: le ha venido ataque al corazón

A: y de qué?

JA: y vaya a saber lo que era tan gordo sabría ser [...] que tal vez la gordura y después al venir aquí, acá hay mucha puna y debe ser que eso

A: y afecta al corazón la puna?

JA: le afecta al corazón

S: sabrá ser que cuando uno es gordo ya el corazón sufre

JA: la puna es peor cuando están gordos, la gente de otro lado más...

(P56, JA: mujer, 67 años; S: varón, 79 años).

En este último fragmento hablamos de una persona que había fallecido poco antes de mi llegada. Para explicar las razones de su ataque al corazón todos mencionaron que sufría de presión, que siendo originaria de Belén la altura de Azampay la afectaría, sumado a que era una persona obesa, que bebía bastante alcohol y en quien notaban que se agitaba al caminar. Como se verá más adelante, los problemas cardíacos tienen además otras explicaciones causales pero, como se señaló anteriormente, en cada caso se entretejen diversas causas atendiendo a las particularidades biográficas para dar cuenta por qué dicho padecimiento afecta a determinadas personas.

Al indagar por qué las zonas elevadas tienen estos efectos negativos en quienes las transitan, la respuesta es el aire o mal aire que de ellas proviene. Predomina la idea de que el aire es la causa última de los malestares asociados a la altitud. Esto también fue explicitado cuando fueron mencionados otros efectos además del apunamiento y la hipertensión: las zonas elevadas pueden provocar aire (como malestar) y locura o debilidad a la cabeza también causada por aire; la llama y el cóndor fueron nombrados como animales "airosos" por estar asociados a la altura.

F: la puna es el cansancio que la agarra el mismo aire que corre, que sube hacia los cerros le decimos "se ha apunado" porque es un cansancio que le viene del mismo aire [...] del aire de la zona y muchas personas que sufren de presión, de todo eso vio, y eso es la puna, de la presión, hay personas que no le sienta subir a la altura, ve? como ser a los cerros, andar asi, no les sienta, hay muchas personas

A: y qué sienten?

$F$ : y bueno, lo sienten como descaimiento al cuerpo, ve, un desvaloramiento, que se le ponen, ya no puede salir así a caminar al cerro (P5, mujer, 66 años).

E: y dependerá del aire, toma un aire fuerte porque aquí dicen que hay mucha puna, a los bebés, a los chicos por eso no se los saca al viento porque toma el aire ese de la puna y le molesta y ya le puede hacer mal

A: y es el mismo aire de la ojeadura?

E: mismo, mismo, el mismo aire que lo toma al niño

A: pero entonces si no estuviera en una zona de puna...

E: no se enaira el chico

A: pero si lo ojean aunque esté en una zona que no hay puna le puede dar ojeadura? 
E: sí, porque eso dicen que de la misma gente que lo quiere y no lo ve, ahi dicen que lo ojea (P64, mujer, 51 años).

E: y se ponen locas, como cuentan, no sé si usted se habrá enterado, la chica esa de $N$, bueno, ésa debe tener eso, y bueno, ellos han sido de los cerros y bueno, allá habrán tenido los guaguas y el aire de los cerros, la puna, una cosa fuerte puede ser que eso se le ha subido a la cabeza, por eso hay tiempos que anda mal, dicen, yo no la he visto nunca ni la quisiera ver, ha dicho que estaba en La Merced [hospital psiquiátrico de la ciudad de Catamarca] (P65, mujer, 78 años).

Para enfrentar el malestar de puna los individuos apelan a respuestas caseras a base de plantas: coca (en coqueo), té de chachacoma, arca, olivo, ajenjo y la raíz de "paja" (de ésta se sacude la tierra de la raíz en una taza con agua, se deja asentar y se bebe). Se explica su eficacia en que la mayoría de éstas crecen en zonas altas, de igual manera se justifica que algunos curanderos sahúmen con plumas de cóndor por el poder que este animal tiene por andar en zonas altas. Lo que subyace es una lógica de cura homeopática, es decir, tratar el malestar de la puna con "remedios de la puna" sumado a la valoración positiva del aire, anteriormente señalada, que otorga fortaleza y propiedades curativas a lo que crece en zonas altas ("las plantas del cerro son más fuertes porque el aire es más fuerte").

También quienes padecen de presión alta, si bien acuden por ello al médico, acompañan el consumo de pastillas y los cuidados en la dieta recetados por éste, con la toma de las mismas infusiones. En este caso se observa lo que se señalara anteriomente acerca de que las identificaciones etiológicas no determinan unívocamente el tipo de atención terapéutica que se buscará. Si bien el aire se identifica como el factor causal que hace necesaria la atención por curanderos, el problema de hipertensión, aunque participa de dicha causalidad, es tratado desde la biomedicina.

A: y qué toman para la puna?

$F$ : y toman el remedio de la puna [...] el arca es de la puna, todas esas cosas de la puna (P5, mujer, 66 años).

C: por que la chachacoma se cría donde hay puna, entonces compone, ya hay algo que le cura (P15, C: mujer, 79 años).

Otro elemento del ambiente imbricado en la red de causalidad ambiental hasta aquí descripta es el viento, sobre todo el Zonda (viento cálido y seco que sopla en el noroeste de Argentina, especialmente en el área de la cordillera) y las nubes de tierra que acarrea y cubren a veces por completo el paisaje serrano. Alergia (como sarpullido en la piel, picazón de ojos o carraspera), resfrío, gripe, angina, dolor de cabeza, de huesos y de oídos son imputados al viento y a la tierra, ésta también acumulada en la lana que se manipula al hilar es motivo de 
queja pues provoca tos, "trancazón" del pecho, sobre todo en quienes padecen asma (como medida de cuidado dicen evitar esta fase del tejido, cuando la lana aún no está lavada). La vista es vulnerable al viento que la torna borrosa y puede perjudicarla luego de la operación de cataratas (no exponerse al mismo tiene un lugar central entre los cuidados postoperatorios). En un caso también se mencionó que el viento cálido empeoraba el estado de quienes padecían de presión alta.

F: a veces les da una gripe en agosto así, en esos meses de abril, mayo, junio, julio, no es tanto aquí, más agosto ya empiezan

A: y por qué en agosto?

M: debe ser porque hay mucho viento, porque también cuando hay esos vientos zonda, ay! Es cansador ese viento zonda... Ilena de tierra, no puede salir a ningún lado

A: y eso les enferma, la tierra?

M: claro, la tierra ... como alergia (P5, mujeres, M: 33; F: 66 años).

A: $y$ de qué se han estado enfermando este año las personas?

M: mucha gripe, más que todo angina

A: y de qué?

M: bueno, ha habido mucha zonda, mucho viento y ese viento, más a los chiquitos, mucho dolor de cabeza y mucho dolor de hueso (P18, M: enfermera de la posta).

$R:[\ldots]$ vienen esas tierritas, esas como si fueran que le hacen [...] las tierras que vienen ya bajan con mucha tierra de eso resfría que uno aspira esa tierra (P21, mujer, 63 años).

Para las alergias refirieron consultar a médicos y curanderos quienes recetaron pomadas, para las afecciones respiratorias recibieron algún paliativo en la posta o en los centros médicos de Belén, y desde la autoatención sólo refirieron las precauciones de no exponerse al viento o de cubrirse principalmente la cabeza y oídos. En algunos casos se acude exclusivamente al curandero debido a que situaciones en que "agarra un aire cruzado" o de "bañarse y salir viento" causan el malestar de aire.

Y: sí, porque por ejemplo después de bañarse y salir al viento yo pienso cuando hay mucho viento lo agarra el aire así y le duelen mucho los oídos o si no por ahí le duele mucho la cabeza y eso es lo que es el aire (P22, mujer, 17 años).

A: me han dicho que el río de acá tiene aire

E: tiene aire porque es un río que corre viento, mucho y ese enferma, el aire

A: y yendo para chistín también me han dicho

E: sí, ese también, todo río tiene mucho aire [...] por eso el que se hace curar tiene que estar un rato ahi, y se atan la cabeza [...] pero si apenas se hace curar y no se ata la cabeza sí, lo toma el viento ese, bueno, ese es el aire (P65, mujer, 78 años).

J: [...] los curanderos, dice "no, sabe qué pasa, que a él lo ha agarrado el aire cruzado” y bueno, entonces le digo "¿cómo el aire cruzado?”, porque en mi casa tenemos así una galería y es abierta, digamos, esa parte cerrada así y todo esto es 
abierto, entonces él se sienta acá y el aire siempre es de abajo, y dice que él se ha sentado asi y lo ha agarrado de atrás el aire cruzado, porque por ahi de a veces, el aire o se pone de allá, o se pone de allá

A: y cruzado qué quiere decir? Que se cruzaron dos aires? Uno de frente y otro de costado?

J: ahá

A: pero ahi se refería al aire, al viento?

$J$ : al viento, claro, claro, al aire, al aire, claro, y por eso digo yo, se ve que hay muchos aires (P49, mujer, 40 años).

Como en el caso de la altitud, aparece la idea de que es el aire asociado al viento y la tierra lo que explica que éstos sean factores patógenos.

$J A$ : a veces vienen unas tierras muy fuertes, muy espesas queda oscuro $S$ : de eso dice que tiene alergia, y de ahí viene ese, claro como un aire (P50, JA: mujer, 64 años; S: varón, 76 años).

C: no... el aire puede ser que cuando uno anda mucho en el cerro y te da mucho el viento, te da la zonda, eso puede ser un aire que puede ser también que emana (P3, mujer, 56 años).

M: También del viento mismo los agarra, los enferma, ya viene ese "mal aire" yendo para arriba, la puna. (P11, mujer, 56 años).

Se ve aquí cómo, al vincularse los distintos factores enfermantes, las causalidades se entretejen reforzando uno el carácter patógeno del otro: el aire justificando que el viento, la tierra y la altitud enfermen, el viento como fuente y manifestación palpable del aire de la puna y del río.

Siguiendo con la descripción de los elementos del medioambiente identificados como patógenos, cabe recuperar aquí lo señalado en el capítulo anterior acerca de la higuera y el nogal en tanto fuentes de aire, plantas "airientas" o "airosas", al igual que la víbora (su presencia cercana, además del susto que puede ocasionar, transmite aire). Los efectos de éstos son tratados, como la mayoría de los malestares causado por aire, por curanderos y desde la autoatención mediante el sahúmo con las mismas hojas del nogal.

$N$ : [la curandera] ha dicho que era mucho aire de la víbora que nos ha agarrado

A: pero por qué?

N: claro, nos ha asustado, qué susto, dios mio, qué!

$C$ : ella tiene un aire

A: tiene un aire la víbora?

$C$ : ella tiene ese aire, tiene un aire fuerte... no podia dormir

A: y con qué la curó?

$C$ : remeditos, yuyitos

$N$ : y ella cura en secreto

A: y qué pasa si eso no se cura?

$N$ : uy, se mueren algunos, yo por eso animal que le tengo odio 
(P11, mujeres, N: 65 años; C: 62 años).

Tábanos y zancudos se identifican como causantes de picaduras (en el 2009 una sola informante mencionó la posibilidad de que transmitieran dengue aludiendo a lo divulgado en los medios provinciales dada la epidemia que afectó a gran parte del norte argentino a principios de ese año) sobre las que se colocan alcohol o vinagre y la vinchuca como causante de chagas pero asociada a un tiempo pasado, antes de que con campañas de desinfección se menguara su presencia en el poblado.

P: ese dicen que antes había vinchucas, dicen y parece que a algunos los habría picado, pero, de qué viene el chagas? De las vinchucas dicen

A: y qué le afecta?

P: le afecta al corazón (P75, mujer, 35 años).

\section{Alimentos como factores patógenos}

La comida en términos generales es señalada como la causa de "apéndice" (operación por apendicitis), problemas de vesícula (algunos especifican que se trata de cálculos y muchos han sido operados), malestares al hígado y al estómago. A partir de las prescripciones y advertencias recibidas de médicos y curanderos ante tales eventos de malestar, algunos componentes de la dieta habitual de los azampeños son identificados como dañinos: la grasa y las frituras, en el caso del apéndice una entrevistada especificó que podrían ser la semillas del tomate las que lo afectarían. Alergias y sarpullidos fueron también atribuidos al consumo de frituras y grasas. Las dietas indicadas generalmente consisten en reemplazar el pan casero por pan francés o amasarlo con aceite en lugar de grasa (en Azampay el pan es amasado en los hogares y ante la falta de tiempo se reemplaza por "tortilla", a base de harina y grasa sin el leudado), arroz blanco, bife o pollo sin piel, utilizar aceite en lugar de grasa, evitar los picantes. Esto también se menciona dentro de los cuidados postoperatorios de apéndice, vesícula, hernia, luego de un tratamiento con "drogas" (en casos de cáncer), durante el embarazo y luego del parto y en los casos de hepatitis. En tanto causantes de los malestares nombrados, se menciona evitar grasas, frituras y el mate (sin yuyos y con azúcar) sea como prevención o como cuidados durante la convalecencia, pero además, dado que igualmente se los consume, si su ingesta provoca malestar se considera sintomático de alguno de estos padeceres.

También refirieron evitar el consumo de grasa y azúcar respecto a un caso de colesterol y diabetes (pero sin distinguir ambos males ni los respectivos efectos de estos dos 
componentes de la dieta) y en casos de sobrepeso. El azúcar se señaló como causante de caries, y algunos que padecían presión alta evitaban el café y la sal, siempre aludiendo a lo recomendado y prescripto por médicos y curanderos. La carne de llama puede causar dolores digestivos o del cuerpo en general debido a que es "airosa" pero en contraposición atribuyen el buen estado de salud de un anciano de más de 80 años al hecho de que de vez en cuando comía carne de león, también animal "airoso", un ejemplo más del doble carácter, positivo y negativo del aire.

A: y lo de la vesícula de qué le vino a ella?

L: eso dicen que a veces uno come comidas pesadas, frituras y cosas que no le caen bien al estómago y dicen que es eso, que se hacen como unas piedritas adentro, según dicen los médicos (P70, mujer, 23 años).

C: [...] no podían saber que era vesícula porque a mí no me hacian mal las comidas, dicen que cuando están enfermos de la vesícula les hacen mal las comidas y a mí no, comía de todo y no me hacía mal, nada, por ahí... un tecito de cedrón y si usted lo deja andar mal... he llegado al punto que ya me ha reventado ya no podía (P3, mujer, 56 años).

$J:$ [...] le decía "hágase ver $F$, vaya al médico, puede ser vesícula o puede ser apéndice" porque el apéndice también agarra, provoca vómito, ya come algo y todo le hace mal (P49, mujer, 40 años).

Cuando ya se comió algo que causó malestar al estómago o al hígado, se recurre a las infusiones de coca, cedrón, poposa, arca, ajenjo, ruda, carqueja, y también a la Buscapina, Hepatalgina, Sertal, carqueja en gotas, a veces por receta de médicos o curanderos, otras recuperando ante situaciones recurrentes respuestas de experiencias anteriores. Como forma de prevención realizada en épocas pasadas se mencionó el uso de purgantes (sales y aceites) que limpiaban el sistema digestivo evitando sarpullidos y permitiendo un consumo menos cuidadoso.

A: la sal inglesa? Y eso le limpiaba la sangre?

O: claro, la purga con eso... así que fijese, comían carne de chivo, grasa de chivo, pan, tortilla! Y no nos hacía nada

A: y cada cuánto tomaban eso?

O: y una cada mes, a la mañana en ayunas, eso tomábamos nosotros uh! Claro, nos íbamos por el inodoro, y bueno un aceite de bacalao, ah, ese era peor, una cucharada, lo recetaba el farmacéutico, como antes poco usábamos no... la gente de antes ya sabía que eso era bueno [...] para la sangre y el estómago, esto que sale [señala mis granitos] debe ser del estómago, tiene que tomar eso

(P78, varón, 60 años).

Por otra parte hay una causalidad vinculada a los alimentos pero en relación a excesos y carencias. Un exceso de carne es señalado como causa de dolor de rodillas y articulaciones 
en general, de artrosis, en tanto que una carencia de ésta, o la escasa alimentación se considera causa de anemia, asociada a la delgadez y debilidad, también comer poco durante el embarazo provocaría esta debilidad en el bebé, así como el reemplazo del amamantamiento o la leche de las propias cabras por leche comprada (en opinión de algunos puede llegar a provocar la muerte del bebé). Con frecuencia acuden al médico o al curandero esperando que les recete vitaminas, calcio y hierro para enfrentar la debilidad, se refieren a éstas como "pastillas para alimento", "tónicos".

A: y cuando hablan de la anemia qué es?

JA: y bueno, yo creo se siente débil

S: debilidad

$J A$ : porque hoy en día no se fortifican bien

A: por qué?

JA: les falta alimento

A: $y$ antes qué comían para estar más fuertes?

S: antes tenía la leche natural de la hacienda

JA: ya no

$S$ : ahora les dan leche que viene en tarro

JA: mucha gente la usa para criar a los chiquitos

$S:$ ya se crían con eso

A: no les dan el seno?

$J A$ : no, y la leche de la mujer es muy alimento

$S$ : decían que era muy fuerte la de cabra

A: $y$ hay algo para la anemia?

JA: y bueno, que así se traten con el doctor

A: y qué sienten las personas que tienen eso?

JA: y bueno, aqui gente grande no, los chicos que no maman de la madre son los que les pasa eso, están flaquitos, poco comen, debe ser que no tienen apetito de comer (P56, JA: mujer, 67 años; S: varón, 79 años).

P: [...] pero le digo "doctor, no necesita la vitamina?", "no" me dice, y bueno, el otro doctor me daba siempre vitaminas, me daba ese sulfato ferroso, me daba calcevita, todas esas vitaminas, ve [...] una pastillita por dia, antes de comida

A: y este te dijo que no?

P: este no, este doctor dos veces que me lo ha visto me ha dicho que no le hace falta vitamina y bueno yo la otra vez le decía al papi que lo voy a llevar a él para el médico a ver qué me dicen, a Belén (P19, mujer, 43 años).

R: [...] que tenía anemia lo que no toma pecho, que lo complemente hasta los dos años con vitaminas [llevó a su hija menor de un año al hospital de Belén porque le sangraba la nariz] (P20, mujer, 24 años).

El empacho es el malestar reconocible por el dolor de estómago, "panza dura", en ocasiones también fiebre y vómitos, todo ello asociado a una ingestión excesiva, es decir, estos mismos síntomas se pueden presentar pero en ausencia de dicho evento causal no se identifica como empacho sino que se atribuye al agua (como se vio anteriormente) o a la 
"peste". Es más frecuente en niños a quienes se lleva al curandero y se les da en infusión apio de la puna, anís del campo y paico, en adultos, en cambio, un exceso de comida es aliviado con infusiones o remedios de venta libre, como se señaló en los párrafos precedentes.

Por último la ingesta excesiva de alcohol se señala como causa de mal al hígado, algunos mencionaron "cirrosis" ("se rompe el hígado"), de cáncer, empeorando a quienes sufren de presión alta o del corazón, e impidiendo la cicatrización de heridas y el accionar de remedios. Si bien algunos refirieron que la bebida excesiva de alcohol era un problema bastante generalizado en el pueblo, la mayoría lo mencionó como defecto de la conducta sólo de ciertas personas (varones jóvenes y mayores, no fueron mencionados casos de mujeres).

En las explicaciones que identifican la comida como causa de ciertos malestares se observa una vez más cómo las lógicas distinguidas por Chrisman se entrecruzan, siendo difícil distinguir si es su lógica mecánica (enfermedad por bloqueos o daños a estructuras corporales) o su lógica de invasión (enfermedad por intrusiones materiales) la que se puede hallar subyaciendo a este grupo de explicaciones etiológicas. Pareciera ser una combinatoria de ambas, pues tratándose de alimentos su efecto negativo es resultado de su incorporación (o intrusión) pero provocando daños o bloqueos de las estructuras corporales (hígado, vesícula, estómago, apéndice). También está presente la lógica del equilibrio (enfermedad por ruptura de armonía entre individuo y el medio) dado que los elementos considerados nocivos (grasas, frituras, azúcar, picantes, alcohol), siendo parte de la dieta cotidiana, no quedan eliminados sino que se plantea (al menos en el nivel discursivo) reducir su ingesta, compensarla mediante la toma de infusiones y remedios o evitarlos en momentos críticos para la salud (durante malestares pasajeros, postoperatorios, embarazos y postpartos). La lógica del equilibrio es más evidente en las explicaciones etiológicas por excesos y carencias de alimentos.

\section{Iatrogenia}

Otro grupo de elementos mencionados como causas de malestares son aquellos derivados de la práctica biomédica, es decir, corresponden a una identificación de la iatrogenia, en tanto alteración dañina del estado del paciente, enfermedad o afección provocada por los médicos y sus terapéuticas. Ya se hizo alusión a cómo, en contraste con la terapéutica popular, predomina una percepción del potencial peligro de medicamentos, inyecciones, intervenciones quirúrgicas. 
Dolor de cabeza, mareo, malestar de hígado o estomacal, infección urinaria, vómitos y desmayo han sido identificados en algunas ocasiones como efectos de remedios e inyecciones. Esto es explicado por la particular contextura que no tolera la ingestión de remedios, por debilidad frente al mismo o alergia; por la mala calidad de los medicamentos; o porque corresponden a un tratamiento equivocado (como cuando se trata de "enfermedades para el curandero", frente a lo que resultan contraproducentes). Como ya se señaló al comentar las valoraciones de la atención en los distintos centros médicos, la limitación de las herramientas para realizar el diagnóstico y la poca disponibilidad de medicamentos en la posta sustentan una actitud de desconfianza frente a los tratamientos allí recibidos. Además está el temor de que la ingesta diaria de remedios (por ejemplo, los de la presión o para el corazón) genere acostumbramiento y dependencia.

C: yo fui por dolor de la columna, a los huesos, me ha dado el doctor yo tomaba y me hacía mal al hígado, yo he ido al hospital y le dije al doctor y me dijo "y qué tomás?", le digo "unas pastillas que me ha dado el doctor de zona y a mí me hacían mal al hígado", "y cómo sabés?", "y, me hinchaban tomaba las patillas y me hinchaban al hígado, un ataque al hígado", dice "a ver las pastillas, cuando te acordás traé las pastillas", le llevo las pastillas que tomaba y dice "pero! Esas tirálas a la basura! Si esas son unas pastillas, esas lo peor llevan para allá!" yo le digo "cómo?”, "y bueno, eso son los doctores los que llevan allá! Ellos se hacen quedar lo mejor y llevan lo peor para ustedes!" y me ha dicho que lo tire a la basura [...] usted sabe que me han puesto una inyección y venía donde está el zanjón y ahi he caído, mareada he caído [...] me ha agarrado asi vómito he botado todo [...] esa inyección me ha hecho venir, estaría mal vaya a saber, me ha agarrado alergia a los remedios, estaría mal vaya a saber era la Novalgina y... que no puedo yo tomar ( $\mathrm{P} 3$, mujer, 56 años).

G: no me sentía mal, una tarde ya me sentí muy mal y tengo de las otras para el corazón y he tomado pastillas para el corazón y ya ha venido justo ha venido... y me ha mandado de la presión

A: y esa cuándo la toma?

G: el doctor me ha dicho que la tome todos los días, los enfermeros me han dicho que la tome todos los días y yo no quiero tomarla todos los días

A: por qué?

G: porque no me vaya a acostumbrar a, tiene que tener continuo, tiene que estar dando (P14, varón, 79 años).

F: me recetaron pastillas para la presión, pero son caras, tomo una cada 2 o 3 días, pero ya se acostumbra mal y si ya no tiene para comprarlas ya se pone mal, cuando me siento muy mal ahí las tomo, si no tomo yuyos, cedrón, tilo en mate o en té después de la comida, eso si no le hace bien, mal no le va a hacer (P31, mujer 66 años).

M: parece que tiene dolor de vesícula, es de la infección urinaria por la mucha medicación que ella toma, así es la L también, ella de la mucha medicación, como ellas toman tarde y mañana siempre les agarra infección urinaria

(P72, enfermera de la posta). 
Cuando el diagnóstico y el tratamiento son adecuados, es el carácter fuerte de los remedios actuando en un cuerpo débil lo que provoca malestar, y lo que también explica el hecho de que embarazadas no deban tomarlos porque podrían afectar al bebé, incluso provocar un aborto.

M: siempre me da las pastillas para alimento, pastillas esas de hierro, pero usted sabe que es como que me cayeran mal esas, me hacen doler la cabeza, sabrá ser que soy débil tal vez yo [...] me hacen doler la cabeza, entero el cuerpo, será mucha la debilidad así que la he tomado y la he dejado, he tomado unita, ya me ha dado dolor de cabeza, no voy a tomar digo porque a mi el doctor de Catamarca me ha recetado otras pastillas para alimento, esas me sentaban muy bien (P11, mujer, 56 años).

$R$ : dicen que cuando uno está embarazada y está enferma no puede tomar cualquier remedio, yo para él tomaba un Sertal especial que viene para embarazadas, para los dos, y cuando uno se siente resfriado no, yo no tomaba nada, andaba asi hasta que me pasaba

A: por qué, le puede hacer mal al bebé?

$R$ : sí, problemas de nacimiento [...] ya no te pueden dar antibiótico porque es muy fuerte, perderlo al bebé cuando tomás esos remedios (P20, mujer, 24 años).

La atribución de esta iatrogenia debido al carácter fuerte del medicamento es central en el uso y significado dados al término de "droga". Éste sólo lo emplearon al comentar casos de cáncer o tumor donde no hay alternativa a un tratamiento agresivo, que "seque", "corte" el mal, es decir, significando la idea de "medicamento" pero con connotaciones de peligrosidad, agresividad, aunque por ello también de eficacia para tratar un mal igualmente agresivo. La fuerza de las drogas para "quemar" el mal ocasiona también daños, debilidad, caída de pelo, incluso un estado general peor en quien es tratado y también trastornos mentales. Este último efecto se vincula con otro sentido de droga que apareció en algunas charlas, aquél asociado a las adicciones y no exento de una valoración moral negativa, como algo que trastorna la conducta, actitudes desquiciadas son explicadas en que su autor toma "droga", o al menos se comporta "como drogado".

$R$ : de no renegar, de no trabajar mucho, no trabajar pesado [...] porque estaba muy débil adentro, el organismo de ella, porque le han hecho muchas drogas y la han quemado tanto para dentro, cortarle eso, comer tiene que comer ciertas comidas [...] estaba prohibida del pan así con mucha grasa (P21, mujer, 63 años).

L: que dicen que le iban hacer ahi unas drogas, tiene que ser una inyecciones muy fuertes [...] el médico le ha dicho que le van a hacer la droga pero ya que está a dos A: cómo a dos?

L: que se cure o se muera, así que le ha dicho el médico

A: $y$ de qué depende eso?

L: dice que es muy fuerte la droga...

$P$ : que era una cosa como si le quemara, como si le quemara la enfermedad que él tiene 
L: él en ese momento a lo mejor se va a desmayar... es que él está muy débil como hace un mes que está de dieta, le han dado dieta

(P76, mujeres, P: 45 años; L: 47 años).

M: pero ella a los tres días estaba sin uñas, sin cejas, sin nada, sin cabello, todo! La droga le ha caído todo, dice, pelada pero total! Brazos, todo, todo y después se recupera

A: y por qué?

M: es muy fuerte

L: claro eso dijo el médico que tenía que avisarle a él porque a él a lo mejor después se le va a caer el pelo

M: 3 días le hicieron curar, dicen que la chica lloraba porque no quería que la vieran, pero a los 15 días, 20 días ya estaba de nuevo con...

A: y por qué serán tan fuertes esas drogas?

L: y parece que lo quema al tumor

(P72, M: enfermera de la posta, L: mujer, 47 años).

E: De allá [del hospital en la ciudad de Catamarca] ella ha venido mal y para peor, que dios nos ampare, se ha trastornado de la cabeza, habia hombres que cuidaban porque ya les tenía miedo, yo no sé...

A: y de qué se trastornó de la cabeza?

E: de lo mismo, yo no sé, bueno, debe haber sido de las drogas [en voz baja] porque tomaba muchas

A: ah, que le pueden trastornar la cabeza?

E: claro, le han dado muchas drogas, sí, y bueno, ha muerto (P4, mujer, 76 años).

La intervención quirúrgica forma parte también de esta noción de iatrogenia por distintas razones: la operación en sí misma es vista como un riesgo de muerte; las advertencias que dicen recibir de los mismos profesionales médicos acerca de la posibilidad de que no se obtengan los resultados buscados, o incluso empeore la condición que se buscaba mejorar (particularmente el cáncer se considera un mal que empeora al operarse); una mala recuperación postoperatoria; la operación como evento desencadenante de malestares recurrentes, como un punto que marca el inicio de una situación de malestar sostenido. Todo ello lleva a muchos azampeños a optar por evitar o posponer su ingreso a la sala de operaciones. Las operaciones más frecuentes mencionadas en Azampay son de la vista (entre los individuos de mayor edad varios han sido operados de cataratas y otros tantos dicen que deberían hacerlo), de apéndice, vesícula (de acuerdo a la opinión de los médicos entrevistados, la alta proporción de estas patologías se debe al tipo de dieta escasa en fibras y líquidos), con menor incidencia operaciones cardíacas, de tiroides, hernias y traumatismos. Cuando no han sido de urgencia, como suele ser el caso de apendicitis o traumatismos, los individuos la postergan, ayudándose con paliativos caseros (generalmente infusiones) y consultas a curanderos. Al realizar el trabajo de campo en sucesivos viajes a lo largo de 5 
años se pudieron seguir casos (como el de una operación de bocio, dos operaciones cardíacas y una a la vista) en los que primero se registraron negaciones y justificaciones para evitar operarse y finalmente las narraciones en torno a la operación y a los cuidados postoperatorios.

C: que si no se operaba... chau! yo no quería que se opere!, ya ha hecho las diligencias en Catamarca, papeles todo, yo no quería porque iba a ir a dos había dicho el doctor

A: cómo a dos?

C: que se iba a morir cuando lo operen (P66, mujer, 60 años).

$S:$ [...] tiene que hacerse operar pero a mi el doctor me dijo que no me haga operar [...] buen doctor me ha hecho, me ha operado de la vesícula, me ha dado un tratamiento hasta que ande más o menos churo, churo, y bueno, me ha dicho, "pero usted es dueño si usted ve... pero yo no te puedo decir que podés quedar bien, bien, no le puedo asegurar" ( $\mathrm{P} 50$, varón, 76 años).

R: y al tiempo ya ha empezado a fallarle la vista, años, bueno después la han operado de la vista, bueno, eso es lo que la ha echado a perder peor [...] ha sido inútil porque ha quedado cieguita, no se le ha mejorado nada la vista, al contrario quedó peor, ha perdido ya los dos ojos y después perdió la memoria (P21, mujer, 63 años).

$J$ : Don C tenía infección, en los riñones me parece, y lo han abierto y se le ha complicado la infección con el páncreas, con todo y por eso le han empezado a venir los ataques y ha muerto. Él tenía infección y bueno, le han venido los ataques al corazón y después le han empezado a hacer estudios y tenía infección a los riñones y lo estaban por operar del páncreas o algo asi y cuando lo han abierto se ha complicado (P7, mujer, 42 años).

La identificación de malestares recurrentes o crónicos como secuelas de una operación, puede explicarse en parte por una asociación temporal (por ejemplo una operación a la vesícula es significada como causante de un dolor de rodillas posterior), sumada a una asociación por cercanía anatómica, pero además por estar inserta en un conjunto de representaciones de salud-enfermedad en el que la percepción de una potencial iatrogenia ocupa un lugar importante. Así se atribuye una hernia abdominal, o quedar en un estado delicado permanente del hígado a una operación de vesícula, dificultad para caminar o renguera debido a un "corte de tendón” para "despegar los intestinos" (operación de vesícula) o para "remover" un tumor.

Hay otro elemento que interviene en las operaciones y que también es señalado como nocivo, si bien no se especificó su efecto: se trata de la anestesia. En varias ocasiones, al hablar de operaciones propias o de conocidos se mencionó la importancia de "devolver" la anestesia, de que la misma no quede en el cuerpo.

Por último, la transfusión de sangre, si bien se la considera una solución frente a la anemia ("falta sangre") también se la identificó como desencadenante de malestar e incluso 
muerte debido a que quien la recibió estaba demasiado débil. Se lee aquí el mismo mecanismo explicativo (y siguiendo la lógica de ruptura del equilibrio entre el medio y el cuerpo) del efecto negativo de remedios en quien está demasiado débil. Pero también donar sangre fue considerado agravante del estado de quien ya padecía problemas cardíacos y debió operarse, siendo posible reconocer aquí, como en las iatrogenias derivadas de operaciones, la lógica mecánica, evidente en el uso de expresiones como "trancar", “cortar”, “despegar", "remover”, etc.

P: ya cuando ha estado en el hospital le han hecho suero, ya no comía, después el médico le ha hecho nuevos estudios y ha dicho que le faltaba sangre, porque estaba anémica y bueno, ahí, ha sido como si la sangre la habrá muerto, claro, porque cuando a ella le han hecho sangre, el día que él se ha venido para acá ella se había quedado hablando, conversando, estaba bien [...] la sangre la ha tomado muy débil, la sangre ha sido muy fuerte y ella ha estado muy débil, eso nos ha dicho el médico [...] y bueno, se suponía que sí, porque ella estaba muy flaquita, ha quedado bien flaquita, estaba pero sequita, y el médico les había dicho asi en el sanatorio, que ha sido la sangre que la ha agarrado muy débil a ella, porque ella después empezó ya con ese quejidito, cuando le terminaron de poner la sangre ya la han visto más mal así (P19, mujer, 43 años).

A: y de qué le vino eso del corazón?

$C$ : él se descomponía, una vuelta ha donado sangre se le trancó la arteria [...] de eso de donar sangre, cuando le han sacado sangre...tenía sangre gruesa, algo iba a tener porque a los pulmones todo a la cabeza se le iba la sangre [...] que si no se operaba... chau! (P66, mujer, 60 años).

\section{El trabajo}

La actividad física, siempre vinculada a tareas laborales, es señalada como causante de malestares crónicos o recurrentes: reuma, artrosis, dolor de rodillas, de espalda y columna, debilidad a los huesos, hernias, y en un caso se mencionó también apendicitis. Caminar por el terreno serrano para cuidar las cabras o recoger leña, trabajos de riego y cultivo, la cosecha de nueces, el cortado de bloques u otras tareas de construcción, sumado a la exposición al frío, al sol y al agua que generalmente acompaña estas actividades, todo ello es evocado para explicar la etiología de dichos padecimientos. La lógica aquí es la de un desgaste del cuerpo en el que la acción incisiva del arduo trabajo y bajo condiciones ambientales adversas se va acumulando con el paso del tiempo, por lo que el factor de la edad está también implicado: la fuerza se acaba, el cansancio se junta, se empiezan a sentir cosas que antes no se sufrían (la 
puna, debilidad frente a remedios, o para enfrentar una operación, la presión alta), falla la vista y la cabeza, las "carnes viejas" se lastiman y los huesos se debilitan.

JA: también, también ha andado y también le ha dicho que era de las rodillas y que le ha hecho mal, cuando se es joven uno camina muy mucho y de eso que se acumulan los males porque ya se moja al sol y todo y se baña y se seca la ropa en el cuerpo S: que me cuide, que muchas enfermedades se juntan, cansancio de que cuando uno es joven camina (P56, JA: mujer, 67 años; S: varón, 79 años).

A: $y$ de qué le viene eso?

L: debilidad a los huesos? Y dicen que de lo mucho caminar, como antes caminaban mucho por las cabritas

A: y la artrosis?

L: y claro y no se alimentan los huesos, no toman vitaminas y han dicho que de eso puede ser, últimamente estaba tomando calcio (P16, mujer, 22 años).

O: le habrá jodido la cabeza [...] leña, todo traía en la cabeza y de eso parece que le ha agarrado algo, qué se yo, cosas pesadas [...] debe ser que enferma algo tiene que trabajar mal, no es como la espalda que usted lleva parejo [...] estaba trabajando y se había venido de la Ciénaga con cosas en la espalda y ha caído en el bajo, se ha insolado [...] uno mismo ve? Si yo veo que no tengo cómo llegar a mi casa con las cosas... (P2, varón, 58 años).

M: esta mañana ya he amanecido con dolor en la espalda, le digo a mi hija "con esa nuez, he estado de ayer juntando, vea como deja la marca" [...] me cansa las espaldas, anteayer he levantado con el tarro, cuando ya hay humedad y está partida la nuez ya se entra esa agua y se pone negra, ya no la quieren comprar así que juntar antes de ayer, ayer, esta mañana (P11, mujer, 56 años).

En esta lógica del desgaste se asume que el dolor crónico de articulaciones y huesos (algunos hablan de reuma o artrosis) y en gente de edad avanzada no tiene solución, por lo que recurren al médico o al curandero en busca de vitaminas, calcio, hierro, tónicos sólo para contrarrestar la debilidad de los huesos. A diferencia de la anemia, esta "debilidad" no es explicada por la carencia de calcio, hierro o vitaminas en la dieta, por lo que no se busca compensarla con ciertos alimentos. Quienes tienen una hernia o dolor en la cintura mencionaron fajarse al menos para trabajar.

Otra actividad laboral central en la vida de los azampeños y por lo tanto también frecuentemente mencionada como origen de malestares es el tejido. Es una tarea realizada generalmente por las mujeres e incluye el proceso de hilado, lavado y a veces teñido de la lana antes de montar el telar donde se elaboran tejidos de tamaño variable pero generalmente como para cubrir una cama. De allí que los malestares atribuidos a este trabajo sean por un lado los vinculados a la preparación de la lana: problemas al pulmón, bronquitis, trancazón en el pecho, tos, ronquera y alergia en las manos debido al polvillo (como ya se señaló al 
mencionar la tierra como factor patógeno) o al aire si se trata de lana de llama o lana "mortecina" (de una animal muerto); y cansancio o problemas a la vista, dolor de espalda, brazos, columna, rodillas debido a las largas jornadas frente al telar.

M: él me ha dado que tome siempre el remedio, pastillas para alimento, no? Porque tenía débil el pulmón lo que mucho hilar [...] yo me sentaba en un rato llenaba un huso y ya sacaba y volvía a hilar [...] y allá me ha dicho que eso me sabría hacer mal porque estaba débil el pulmón [...]

A: porque a mi me habian dicho que era cuando la lana era mortecina

M: claro, podía ser eso pero yo no, yo siempre compraba lana que la esquilaban

A: y la mortecina por qué hará mal?

M: sabrá ser mala porque no deja que ya ese olor tan fiero, a veces sabíamos hilar también lana de esa que uno compraba de todas partes, yo compraba todas las veces de Belén y de ahí me ha venido a enfermar, yo he comprado una lana una lana fea [...] y eso digo yo que eso me habrá caído mal [...] yo sentía que se me comenzaba a dormir los brazos, hilaba un rato y ya me agarraba, que los brazos se me caían ya, y así he comenzado, comenzado hasta que me ha agarrado dolor en la espalda

(P11, mujer, 56 años).

A: y de qué era el dolor de rodillas, qué le dijeron que tenía?

T: que ya de vieja [ríe] ya de tanto trajinar, lo que yo solía tejer muchos pullos, muchas telas, iba a la leña yo sabía tener un burrito, uh! En el verano un sol tremendo y de ahi me ha venido dolor a los huesos, dolor en las piernas, y los doctores me han dicho que eso me ha hecho mal, que me ha hecho mucho calor a los huesos [...] me hacía mal el tejido el trabajo, tejer, por eso no hago telas (P70, mujer, 72 años).

En las etiologías elaboradas para explicar el reuma o artrosis, dolores de espalda, cintura, brazos, articulaciones y huesos en general, se observa cómo se articulan las distintas causalidades, coadyuvando a la aparición de estos padecimientos una variedad de factores identificados como patógenos: los factores ambientales (frío, calor, sol, agua) agravando los efectos del trabajo, la edad agregando el hecho de que tales efectos se acumulen y que torna débil al individuo frente a los remedios, lo que a su vez favorece la potencial iatrogenia de los mismos.

Golpes y malos esfuerzos, por lo general producto también de las actividades laborales, son causa no sólo de dolores agudos y pasajeros (entre los que cuenta la ya mencionada abertura de pecho), sino también de dolores crónicos (huesos, miembros, cabeza), de disfunciones crónicas (golpes en la cabeza son evocados como causantes de epilepsia, problemas de vista, sinusitis, "debilidad al cerebro", como se refieren a problemas mentales) y de la manifestación mucho tiempo después de problemas de apéndice, vesícula, riñones, la generación de tumores y flebitis. El golpe ocasionaría un "apostema" o moretón interno que con el correr del tiempo desencadenaría alguna de las afecciones de este último grupo. 
Subyace aquí la lógica mecánica identificada por Chrisman, tanto más evidente cuanto más extensas y descriptivas son las explicaciones. Golpes y malos esfuerzos durante el embarazo son mencionados como causa de discapacidades en el niño y de una predisposición a sufrir de abertura de pecho, y evitar realizar esfuerzos forma parte de los cuidados durante este período así como también luego del parto y de cualquier operación.

E: ella cuando hace fuerza, cuando va a talar el monte, a la columna también dicen que es...

A: en dónde trabajaba ella?

E: jefa de hogar... sacar todas esas piedras grandes [...] mal quedó, la mala fuerza [...] le duele, le han dicho que tiene mal la columna (P61, mujer, 81 años).

R: cuando ella ha querido hacer para subir se ha retirado la mula y ella se ha rodado, pero no se ha caído al piso, ha caído asi parada y lo que ella ha caído le ha dado una patada, le ha pegado en esta parte, en el estómago y bueno, andaba bien cuando si dolor, como no ha ido a ningún médico, no debe haber médicos por aquí nadie suponíamos de médicos, y bueno de ahi se le había hecho, hace muchos años, en esa época, habrá sido, cuántos años, de esto le ha dimanado, sentía otra vez ese dolor, ese dolor, como que no podía comer, como vómitos [...] años después, después, y bueno, de eso le habían dicho no sé quién a mi hermano que era, que se le ha formado, del golpe, por eso mismo una apostema, para dentro

A: qué son los apostemas?

$R$ : eso parece que es alguna cosa que se hace del mismo golpe sería, queda sangre golpeada, carne golpeada que le ha quedado para dentro, porque afecta mucho ese, la gente, bueno doctor le dicen el bazo, nosotros a la hacienda le decimos el zorrito (P21, mujer, 63 años).

R: que era del mismo golpe que ha tenido en la cabeza

A: y por qué, qué le hizo el golpe en la cabeza?

$R$ : le ha golpeado una válvula que tenemos tantas

A: una válvula, qué es eso?

$R:$ y yo pienso que deben ser esos, nosotros les decimos venitas, como las cabras aquí uno tiene que carnea, muchas venitas y uno les corta y le chifla la sangre, yo pienso que debe ser eso

A: que se ha golpeado?

R: claro, se ha molido y se le ha cerrado, eso parece que se le ha reventado y se le ha cerrado, y no puede circular bien la sangre, cuando se le tapa esa cosa y no puede circular bien la sangre ahí es cuando se descompone [caso de epilepsia]

A: y las pastillas...

R: las pastillas sabrá ser que le hacen circular por eso ya de que ha empezado a tomar (P79, mujer, 65 años).

C: cuando he sido jovencita me ha golpeado una mula me he golpeado la cabeza y eso mismo me ha afectado la vista, muy corta de vista... con anteojos pero no me quiero acostumbrar mucho porque cuando uno se acostumbra mucho y ya por ahí se saca los antejos y se olvida ya no... así que por eso no me quiero acostumbrar... pero ya por ahí me canso, miro mucho y ya por ahi es como se me cansara la vista y ya así para tejer a dos agujas, coser también

A: y es del golpe? 
C: hace mucho los médicos me han sacado unos estudios y me ha salido ahí que es un golpe que debe ser de la cabeza, me han dado remedios pero dice que eso... ya falla la vista

A: y los remedios eran para la vista o para la cabeza?

C: para la cabeza, para la vista ya me ha recetado el oculista me ha dicho que siempre use los anteojos

A: y el que te dijo que había sido un golpe era el oculista?

$C$ : no, no, era el doctor de la cabeza y él me dice que al golpearme se me ha movido el cerebro, y eso mismo también me quería agarrar sinusitis, del mismo golpe dicen que se hace sinusitis

A: y vos a él por qué lo consultaste?

C: porque tenía mucho dolor a la cabeza, la vista se me lloraba mucho, se me cansaba,

A: y el golpe cuándo lo tuviste?

C: uh tendría 18 años

A: ya hora cuántos tenés?

C: más de 50... de eso debe ser, del golpe al cerebro (P60, mujer, 57 años).

Como respuesta inmediata frente a eventos de golpes se mencionó el recurso a la biomedicina (sobre todo en casos de quebraduras), a la medicina popular (los curanderos soban y recetan pomadas) o a soluciones caseras (por ejemplo, pomadas compradas en farmacias o a vendedores ambulantes). Los casos de epilepsia, problemas de vista, apéndice, vesícula y tumores han sido motivo de consulta en centros médicos incluso de la ciudad de Catamarca (sobre todo para epilepsia y tumores), mientras que malestares como flebitis, riñones, sinusitis, “debilidad al cerebro" y los dolores crónicos de huesos y demás, son motivo de consulta tanto en centros médicos como a curanderos.

Cabe señalar que paralelamente a esta identificación negativa de la actividad física, se presenta una valoración positiva de la misma, siendo la inactividad lo que provoca o empeora malestares. Esta percepción se registró en algunas etiologías de trastornos mentales (depresión, "carbura la cabeza"), en quienes referían que los dolores de huesos, reuma, y demás se disipan (“se pasan") con el caminar, en las opiniones de que para mantenerse en buen estado se debe estar activo, en recomendaciones para el restablecimiento postoperatorio de caminar (pues le hace bien al corazón y al pulmón) y durante el embarazo para propiciar un parto rápido.

P: ella se perdía de la cabeza

A: por qué, qué tenía?

P: bueno, el doctor nos decía que era como una depresión que le agarraba a lo que ella había sido tan andante, tan caminante, y que ella al estar en cama nomás, ahí, ella dice que le carburaba la cabeza, y que no estaba en la casa, que se tenía que ir a la casa de ella, se perdía, artoro, arteroesclerosis, no sé cómo era el nombre que nos daba el doctor [...] él nos decía que era de eso, porque ella cuando ha sido más joven, de la edad que yo tenía que me he acordado, ella no estaba en la casa, ella se iba a 
trabajar, ella se iba si había una jugada de pelota ella se iba, bueno así, ve [...] cuando se iba la virgencita de peregrinación ella no se perdía, ella se iba

(P19, mujer, 43 años).

R: yo caminaba y caminaba, dicen que es bueno

A: es bueno para el parto?

$R$ : sí, asi que la tuve en un parto rápido, con ella cómo que caminaba [...] caminaba y caminaba, en cambio de él yo estaba en Belén, me pasaba en cama, por eso debe ser que se demoró, en cambio de ella yo decía voy a caminar mucho así nace rápido (P20, mujer, 24 años).

S: yo cuando me siento así como estoy ahora siento más, como si sintiera más las rodillas, como si tuviera una intranquilidad, una debilidad, pero yo cuando me levanto, hago alguna cosa, camino, estoy haciendo alguna cosita, ya se me pasa, se me va todo... pero yo al estar así muy calladito ya ahí (P56, varón, 79 años).

\section{Etiología psicosocial}

En el fragmento de entrevista precedente se observa cómo el malestar físico (dolor de rodillas) está entretejido con otro síntoma, la intranquilidad, que si bien expresa una inestabilidad a nivel anímico no deja de ser enunciado como algo experienciable a nivel corporal. Como ya se señalara al hablar de las causas psicosociales del aire, se observa una ausencia del dualismo mente-cuerpo. La explicitación de etiologías psicosociales para malestares con síntomas corporales, orgánicamente percibidos y orgánicamente representados, destaca una perspectiva psicosomática de las enfermedades donde no hay explicación que dé cuenta del pasaje de un plano psicosocial a uno orgánico dado que no se representan como dos niveles separados.

Pensar cosas feas, renegar, afligirse, llorar afecta la presión y el corazón (causa de paro cardíaco, soplo), causa “derrame”, agrava a quien sufre de asma, cáncer o tumor, impide una recuperación adecuada luego de operaciones al corazón y a la vista, y en los días de postparto o menstruales puede ser una causa de que la sangre se "vaya a la cabeza". Cabe recordar aquí que situaciones de tensión y rabias acumuladas son causa de aire así como el miedo o un sobresalto o la muerte de un ser querido (en el caso más específico del susto). Afligirse durante el embarazo puede ocasionar estados de susto recurrentes en el bebé o problemas de epilepsia en el niño, así como un susto no curado en la embarazada se considera causa de discapacidades mentales o motoras en el niño.

P: pero después ya no ha empezado a ver nada, primero ha sido de un ojo, después del otro [...] el doctor le ha dicho que no habia hecho las cosas que tenía que hacer, que él le había dicho, porque el doctor le había dicho que no tenía que afligirse, que 
no tenía que renegar, que no tenía que llorar, y bueno a veces que ella era renegona, y eso era lo que le ha sentado mal

A: al ojo?

P: al ojo, los nervios, así que bueno, ha quedado ya sentada, ya no se manejaba casi para nada, ya había que sacarla al baño, volverla a traer, llevarle la comida, darle de comer (P19, mujer, 43 años).

L: el médico le ha dicho que no se ponga mal, que no se ponga nervioso, no piense, que tenga mucha fe y valor para que todo salga bien

A: eso se lo dijo el curandero?

L: si

A: pero el médico de La Rioja...

L: también le ha dicho lo mismo, lo mismo [...] porque él piensa y piensa en la enfermedad y está pendiente, nos han dicho que no tenemos que dejarlo solo, porque él cuando queda solo está pensando y eso a él lo empeora (P72, mujer, 47 años).

A: y cuando dicen que se le sube la sangre a la cabeza, qué es?

JA: y bueno, que dicen cuando la mujer no anda bien de la menstruación y bueno, si reniega, eso se va a la cabeza

A: y por qué no anda bien?

JA: y claro, tiene la menstruación que le llaman, no? O está enferma de parto, también es muy peligroso

A: y por qué se le va a ir la sangre a la cabeza?

$J A$ : por algo que reniega sabrá ser (P56, mujer, 67 años).

N: ella [la curandera] me la ha curado hace como dos semanas que le han dicho que tiene muy aire, se ha asustado en el vientre de ella, como que cuando ha muerto la $M$ como ella ha tenido una muerte tan pronto

A: y E estaba embarazada...

N: estaba embarazada, y se ha asustado en el vientre de ella

A: y qué le ha notado, por qué la llevó con L [la curandera]?

N: y porque lloraba y tenía, así como parece que tenía fiebre y lloraba y lloraba y hasta que la hemos llevado [...] ya ha vuelto bien, y ya ayer se asustaría otra vez, llorando y... pero fiebre no tiene sino y llora y llora (P58, mujer, 69 años).

Salvo los casos de aire y susto en los que se recurre a un curandero, el resto de los malestares provocados o agravados por estos factores anímicos son tratados generalmente desde la atención biomédica (sobre todo los problemas de presión y corazón, asma, cáncer o tumor), a veces combinada con la consulta a curanderos (frecuentemente cuando se trata de “derrame”, y en algunos casos de problemas de presión, asma y cáncer). La tranquilidad, evitar discusiones y preocupaciones, es mencionada como un aspecto preventivo, parte del autocuidado.

La envidia o la codicia son identificadas como factores causantes de aire sin que deba mediar un accionar voluntario por parte de quienes envidian; si es éste el caso, el malestar se 
debe a que "le han hecho un trabajo" o maleficio. También se señaló en el caso de la ojeadura, que el deseo, el "humor" más fuerte de otra persona son la causa del aire.

El mal hecho o maleficio alude a un trabajo realizado por curanderos que se dedican a ocasionar un malestar por encargue de quien tiene interés en perjudicar a la víctima. Los malestares atribuidos a posibles maleficios fueron locura o "debilidad al cerebro", dolores de pie y brazos, complicaciones en un parto que requirió cesárea y malestares diagnosticados desde la atención biomédica como problemas a la vesícula, tumor o cáncer. Se trata de casos en los que el pasaje de la atención de un médico a la de un curandero conllevó la redefinición del diagnóstico. Se destaca que en todos los casos de maleficio mencionados se había recurrido a la biomedicina y no quedando conformes con la respuesta obtenida o ante la ausencia de una explicación del origen del padecimiento se consultó al curandero (por ejemplo en el caso de la cesárea no se cuestionó el proceder médico que salvó la vida de madre e hijo, pero la posibilidad de que la complicación fuera resultado de un mal hecho respondía al por qué de la misma). Es decir, el mal hecho, identificando la causa del malestar en el accionar intencionado de otros, da una respuesta al por qué del padecimiento, en el sentido no del “cómo” sino del “¿por qué a mí?”. No obstante en ningún caso se mencionó la búsqueda del responsable, la idea de que se trata de un mal hecho queda planteada generalmente como una posibilidad y la identidad del culpable es sólo presupuesta a partir de percepciones en las relaciones sociales.

F: han dicho que lo traigan [a quien presuntamente padecía de un tumor y estaba viviendo en La Rioja] que se venga puede hallar un médico que lo va a sanar

A: un médico de acá?

F: claro, esos males que tiene no son males que dios le ha dado, eso le han hecho un mal

A: otros males de qué?

F: los que hacen a cualquiera, cualquiera

A: usted dice que le han hecho un mal?

F: claro!

A: y por qué, tendrá gente en contra?

$F$ : vaya a saber a veces cuando no hay gente en contra ya lo hacen porque quieren hacerlo, ya estudian para eso

A: $y$ usted dice que por eso no lo pueden curar allá [en el hospital]?

$F$ : no! Eso nunca lo van a curar! (P66, curandero, 88 años).

Como prevención contra la envidia o los maleficios el curandero elabora "reliquias", una bolsita con ajo, lavanda u "otros remedios" que se cuelga en la habitación, en la cama o donde se la pueda ver, también se mencionó la realización de la señal de la cruz sobre el mate que se recibe de quien haya motivos para desconfiar. Cabe señalar que la atribución causal a la envidia y al mal hecho así como las medidas preventivas sólo fueron mencionadas en 
contadas ocasiones, es decir, estos factores sociales no se encuentran involucrados con mucha frecuencia en las etiologías de los padeceres.

\section{Transmisión de enfermedades}

Cuando malestares como vómitos, diarrea, dolor de cuerpo, cabeza o huesos acompañado de fiebre, gripe, picazón en los ojos, problemas de apéndice o vesícula se presentan simultanea o sucesivamente en varios individuos, se habla de "peste". Si bien este término a veces es empleado como sinónimo de enfermedad, generalmente lo usan para referirse al hecho de que se trata de un malestar que "se va pasando" de un individuo a otro centrándose la etiología en este aspecto y descartándose otras causas posibles. La palabra “contagio" casi no es utilizada para expresar esta idea de transmisión espontánea e inintencionada de una enfermedad, y en un caso se lo usó connotando una mala intención por parte de quien contagió. En cuanto a medidas de prevención, sólo fueron referidas en un caso de hepatitis las recomendaciones de aislamiento e higiene dadas por el médico, es decir, en la noción de "peste" se reconoce la posibilidad de transmisión de las enfermedades pero esto no conlleva ninguna forma de cuidado.

Y: que les agarra la peste, es como una gripe, es una enfermedad, un resfrio, dolor de estómago, que les agarra a varios (P22, mujer, 17 años).

F: andaba de peste, dolor de cabeza, fiebre, vómito, diarrea

A: y los llevó al médico de acá?

F: si

A: y qué les dijo él?

$F$ : no, él decía que era por el agua y no sé, ahora ya están mejor

A: $y$ les dio algo?

F: sí unos jarabes, para la fiebre les da

A: y por qué decís vos que era la peste, cómo es la peste?

$F$ : porque por ejemplo le agarraba a uno, al otro día amanecía el otro, así (P30, mujer, 17 años).

M: contagio, ha habido un hombre que ha venido con ese mal de tuberculosis y pasaba por acá y yo tanto le tenía aprensión, se me hacía que me iba a contagiar alguna cosa [...] venía y conversábamos así [...] muy cerca, yo le tenía aprensión, hacer mal [...] así me decía el doctor $V$, el que me atendió a mí, dice "para vos no es que te ha dado un mal del pulmón, es un contagio que te han hecho" y en Catamarca me han dicho lo mismo (P11, mujer, 56 años).

Con frecuencia aparece asociado el término de "virus" aludiendo al elemento vivo que al pasar de una persona a otra transmite el malestar generando el efecto de peste. Sin otros 
significados explicitados, la noción de virus sólo es empleada, al igual que "peste", cuando no se identifican otras causas o en algunos casos en que se busca explicar la acción patógena de ciertos elementos y la medida preventiva: el virus es aquello que hace que el agua enferme o que un tipo de víbora al entrar en contacto con las prendas de vestir cause la culebrilla, es aquello que se mata al agregar cloro al agua o al planchar la ropa.

O: primero era como peste el apéndice aquí, cualquiera, qué le pasa?... apéndice, tiene que operar, después... vesícula pero yo no sé de qué depende eso [...] yo digo peste porque es como contagio, que le da a uno, le da a otro, será como un virus que entra, por ejemplo hay gripes, yo le voy a contar, me acuerdo un año que... yo era chico todavía, toda la familia de él, antes tampoco se usaba cama, cuero de vaca que tiraban, había un virus, de esas gripes que nos ha dejado tirado [...] ha quedado a penas mi mamá

(P2, varón, 58 años).

A: y por qué algún virus?

$O$ : puede ser, como hay tantas cosas de enfermedad ahora que uno no las conoce

A: y el sarampión de qué es?

O: y no sé de qué viene, bueno un virus (P78, varón, 60 años).

Otra forma de transmisión mencionada es la que ocurre de la embarazada al bebé, ya se mencionó que golpes, malos esfuerzos, susto, preocupaciones y la toma de medicamentos durante el embarazo se consideran causa de problemas de nacimiento, también eventos de enfermedad (infección urinaria y chagas) en la embarazada fueron identificados como el origen del mismo padecimiento en el bebé. También fue mencionada la transmisión a través del amamantamiento de fiebre o un estado general de malestar.

L: dice la señora que le dé el paracetamol a él pero en gotitas, porque puede ser que le contagie la fiebre, y no, ya me ha pasado igual la fiebre, no siento ya fiebre pero lo que siento es el dolor...

A: y el paracetamol en gotas ya lo tenías?

L: si ese me lo ha dado la doctora para él [...] para cuando asi se ponga, tenga fiebre, vea yo que tiene temperatura que le dé 3 gotitas o 5 pero como es chiquito todavía 3

(P70, mujer, 23 años).

Por último se registraron algunas referencias a la herencia como etiología de bocio y cataratas. En ambos casos se trataba de explicar una relativa alta frecuencia de estos males, en personas además vinculadas por lazos de parentesco y ante la ausencia de otra explicación causal (como se vio anteriormente al refutarse la idea del agua como causante de bocio).

C: mucha gente en Catamarca se hace operar de cataratas pero allí no tejen así que será de familia, como herencia (P3, mujer, 56 años).

J: dicen que le han sacado una pelota de carne

A: pero por qué se le armó ahí? 
J: no sé, será que es hereditario mi mamá era así [...] la sobrina y la madre de ella también tenía bocio (P69, varón, 40 años).

En las etiologías de los padecimientos se observa la recurrencia de un número de elementos considerados patógenos que permite agrupar en torno a éstos las diversas enfermedades identificadas por los azampeños. Es decir, en muchos casos no se halló una relación unívoca entre factores patógenos y enfermedades, un mismo elemento enfermante aparece asociado a varias enfermedades. A su vez se observa una pluricausalidad de los padecimientos con una superposición de lógicas causales, de manera que la particularidad de cada uno de ellos se la otorga la combinación de los diversos elementos en su etiología (así como sus síntomas y devenir). Al vincularse los distintos factores enfermantes refuerzan mutuamente su carácter patógeno, como se vio respecto al aire en tanto causa subyacente a que el viento, la tierra y la altitud enfermen, y el viento a su vez como fuente y manifestación palpable del aire de la puna y del río.

Describiendo los elementos identificados como patógenos junto con las terapéuticas correspondientes se pudo notar lo anteriormente señalado acerca de que las identificaciones etiológicas no determinan unívocamente el tipo de atención terapéutica. Por ejemplo, si bien el aire se identifica como el factor causal que hace necesaria la atención por curanderos, el problema de hipertensión, aunque tiene a este factor dentro de sus causas, es tratado desde la biomedicina. En el mismo sentido se notó que frente a enfermedades que tenían en sus etiologías factores psicosociales, con excepción de los casos de aire y susto, generalmente se busca la atención biomédica (sobre todo los problemas de presión y corazón, asma, cáncer o tumor), a veces combinada con la consulta a curanderos, es decir, no se buscan terapéuticas orientadas a contrarrestar el malestar desde el orden psicosocial. Pero además, esta atribución de causas psicosociales a malestares orgánicamente percibidos y orgánicamente representados destaca una perspectiva psicosomática de los procesos de salud-enfermedad ajena a la dicotomía mente-cuerpo, por lo que no se plantea la búsqueda de terapéuticas físicas para males corporales y de terapéuticas psicosociales para malestares anímicos.

Los factores patógenos más evocados corresponden a elementos sobresalientes del ambiente azampeño (el frío, el calor, el sol, el agua, la altitud, el viento y la tierra que suspende), y a la actividad física producto de las tareas laborales. La acción incisiva del arduo trabajo y los efectos negativos del ambiente se van acumulando en el cuerpo. Desde la antropología médica crítica se enfatiza que los procesos de salud-enfermedad-atención son 
emergentes estructurales de las condiciones históricas de vida y de trabajo en una sociedad dada, aquí son los sujetos mismos quienes remarcan el impacto que las condiciones materiales ejercen sobre el cuerpo.

\section{"Lo que está en juego" en torno a las etiologías. Factores patógenos y vulnerabilidad corporal.}

“... porque aqui es triste la vida...”

A partir de lo hasta aquí descripto se puede identificar una apreciación del espacio azampeño y de las labores diarias allí requeridas en términos de dureza, de condiciones que tornan la vida más difícil en contraste con la vida en la ciudad. También tratándose de los alimentos, aquellos señalados como dañinos para la salud corresponden a elementos cotidianos de Azampay como el pan casero y el uso de la grasa, su reemplazo por aquellos que cumplan con las recomendaciones de dietas y cuidados implica tener acceso a su compra en la ciudad.

Pero por otra parte la percepción de iatrogenias en contraste con una valoración positiva de los yuyos y remedios caseros y de la terapéutica de curanderos marca una distinción entre un "aquí" y un "en otras partes" donde prima el discurso médico que frecuentemente conduce a un tratamiento errado o con efectos secundarios negativos.

R: no, así que uno ya está hecho, ya uno está más o menos práctico a las enfermedades esas, aquí siempre uno es más, eh, no como en otras partes, en otras partes lo llevan, sienten enfermo y bueno, los llevan al médico, y el médico, la ojeadura el médico le dice la meningitis [...] el médico no sabe que es de esos aires, le dice meningitis y lo siguen y bueno lo vence el aire y lo mata, pero si uno es conciente de que lo tiene que hacer curar y lo hacemos curar, porque aqui gracias a dios nunca pasó un caso así de que se hayan muerto chiquitos así con la ojeadura, que dicen que somos muy creyentes a las cosas malas ( $\mathrm{P} 40$, mujer, 62 años).

Kleinman señala que la experiencia (en tanto espacio emergente de la interacción de categorías culturales y estructuras sociales con los procesos psicológicos y fisiológicos) es definida por lo que está vitalmente en juego para grupos e individuos. Es la construcción de lo que está en juego (what is most at stake) para personas y familias lo que articula a partir de variadas preferencias y prioridades un vínculo sociosomático entre el sistema de símbolos y el cuerpo, lo que hace que los sentidos culturales puedan proveer una estructura para la atención, la memoria, el afecto y los correlatos neurológicos. Se trata de las estructuras de relevancia 
culturalmente elaboradas, pero dependientes también de las particularidades históricas y de las idiosincrasias personales, que significan los procesos de resistencia al flujo de la experiencia, a los planes de vida, a las acciones prácticas con que la condición humana constriñe la experiencia vivida y de los que resulta el sufrimiento. "What is at stake" es propuesta por el autor como la categoría crucial para una etnografía de la experiencia, lo que está en juego para participantes particulares en situaciones particulares debe ser la cuestión central y orientadora pues en torno a ello se vislumbran otros aspectos de la experiencia: la presión existencial por coherencia y unidad en los mundos locales, la inmediatez de su cualidad sensorial, el carácter de resistencia bruta al plan de vida que debe ser trascendida y que expresa la finitud de la experiencia. Uno de los casos que toma para ejemplificar esto es el de los sobrevivientes de la revolución cultural de china, quienes en sus narraciones de enfermedad asociaron sus síntomas con las condiciones brutales de la revolución, narrar sus historias de enfermedad era una manera de desahogar agravios angustiantes y odios hacia lo que ellos percibían como las fuentes sociopolíticas de sus desgracias (Kleinman y Kleinman, 1991; Kleinman, 1994).

En el caso azampeño "lo que está en juego", aquello relevante a partir de lo cual se otorgan significados al sufrimiento, es la aprehensión del ambiente como un medio severo, imperioso, exigente de labores arduas y desgastantes. En la asignación de una cualidad patógena a los elementos característicos de la geografía azampeña y a las actividades laborales vitales en ese medio (especialmente al explicar la etiología de malestares crónicos o recurrentes), tiene expresión el reconocimiento de una vida marcada por sacrificios en contraposición a la vida en la ciudad. Como ya se señalara en torno al aire, la atribución causal de padecimientos al arduo trabajo implica una apreciación del esfuerzo, del valor del trabajo realizado. La frecuente mención de recomendaciones de médicos y curanderos de no vivir más allí (aunque sólo una pareja se mudó a la ciudad por motivos de salud), subraya aún más, apoyándose en opiniones "de afuera" y de individuos a quienes se atribuye un saber en torno a la salud, la actitud de estoicismo de quienes viven allí. Pero también "está en juego" una distinción en términos positivos de lo local con sus saberes tradicionales frente al accionar desde la biomedicina, presente en el señalamiento de las diversas iatrogenias en contraste con la apreciación de eficacia o, en su defecto, inocuidad de los yuyos y remedios caseros y de la terapéutica de curanderos.

Por otra parte, identificar y analizar los elementos que son considerados enfermantes conlleva pensar cuál es la imagen corporal implicada en la relación con el medio que contiene estos elementos, cuáles son las "representaciones idiosincrásicas y colectivas que tiene un individuo acerca del cuerpo y sus relaciones con el medioambiente, incluyendo percepciones 
internas y externas, memorias, afectos, cogniciones y acciones" (Lock y Scheper-Hughes, 1996: 54) y que sustentan las explicaciones causales.

Se entreve implícita una imagen del cuerpo vulnerable a los elementos más destacados del medio natural de cuya acción sutil pero a la vez constante e incisiva se lamentan; un cuerpo que se ve afectado por elementos básicos de la dieta local; un cuerpo donde se acumulan los efectos del exceso de trabajo y los de curar a quienes padecen algún malestar vinculado con el aire; un cuerpo inerme frente a las potenciales iatrogenias; un cuerpo que recibe además el impacto de la envidia, del deseo, del "humor más fuerte" de otras personas; un cuerpo en el que repercuten el miedo, el sobresalto y las rabias acumuladas. Como recuerdan las autoras citadas, en muchos sistemas etnomédicos "el cuerpo es vulnerable a los sentimientos, deseos y acciones de los otros" y "las relaciones sociales son también entendidas como una causante clave en la salud y enfermedad individual" (Lock y ScheperHughes, 1996: 58-59).

El cuerpo no es un universo independiente, replegado sobre sí mismo sino que vincula al hombre con todas las energías visibles e invisibles que recorren el mundo, "el hombre, bien encarnado (en el sentido simbólico), es un campo de fuerza poderoso de acción sobre el mundo y está siempre disponible para ser influido por éste" (Le Breton, 1995: 33). 


\section{Las representaciones del cuerpo a partir de las explicaciones y sentidos atribuidos a los procesos de salud-enfermedad}

\section{La experiencia de malestar: acicate de la enunciación indirecta del cuerpo propio y de su objetivación}

Las explicaciones y sentidos atribuidos a los procesos de salud-enfermedad refieren a y se sustentan en las representaciones del cuerpo dado que la experiencia de malestar, como toda experiencia, emerge del vínculo sociosomático entre el sistema de símbolos y el cuerpo, vínculo que posibilita que los sentidos culturales proporcionen una estructura para la percepción. Siendo la experiencia el resultado de la interacción de categorías culturales y estructuras sociales con los procesos psicológicos y fisiológicos, se parte siempre de una conciencia inmediata, pre-reflexiva de la misma (pero no por ello pre-cultural), y su objetivación, la construcción de un saber a partir de ésta, conlleva la distorsión del lazo existencial entre conciencia y experiencia por modelos dualistas que cosifican tanto el cuerpo como la mente. Las representaciones anatómicas y fisiológicas se basan en saberes, conceptos, modelos que adoptan el punto de vista del "otro", la captación objetiva del cuerpo conlleva un extrañamiento del cuerpo propio para poder contemplarlo y pensarlo. Estas representaciones están entretejidas con las explicaciones etiológicas y con las decisiones terapéuticas, ya que tanto la acción de los factores patógenos como las eficacias o fracasos terapéuticos se entienden y se evalúan teniendo en cuenta las representaciones en torno al funcionamiento y necesidades corporales. Dada esta articulación, las descripciones anatomofisiológicas más detalladas surgieron en las conversaciones con quienes más ahondaban en las explicaciones causales.

Como se citó anteriormente, y recuperando la perspectiva de las filosofías de la existencia, el punto de partida de todo conocimiento "no está dado por un dato intelectual "claro y distinto", al estilo cartesiano, sino por una experiencia vivida de la cual hay que hacerse cargo por un movimiento reflexivo. Se trata, en cierto modo, de recobrar una originaria participación en el mundo a través de la mediación de mi cuerpo" (Presas, 1971: 101). Decir "mi cuerpo" es una cierta forma de decir "yo mismo", pero para poder decir "soy mi cuerpo" es necesario negar cualquier asimilación de éste a un objeto o cosa. El ser está ligado a "su cuerpo" de manera esencial y no accidental, éste es el sentido que Marcel quiere 
dar a la palabra "encarnación", situación que no puede ser captada objetivamente, en el plano de las cosas, "mi cuerpo es mío en tanto no lo contemplo, en tanto no coloco entre él y yo un intervalo, en tanto no es objeto para mí, sino que yo soy mi cuerpo" (Marcel, 1953: 101, 102).

El ser es siempre en situación, es el cuerpo propio la posibilidad y fundamento de todo conocimiento y por ello inaccesible él mismo, en tanto "para-sí" a toda sistematización o saber objetivado. El cuerpo propio es el punto de vista (el punto cero), siempre trascendido, sobre el cual no se puede adoptar otro punto de vista. Toda reflexión se realiza ya sobre la base de una conciencia no-reflexiva "hay un cogito pre-reflexivo que es la condición del cogito cartesiano" y "así como un objeto extenso está obligado a existir según las tres dimensiones, así también una intención, un placer, un dolor no podrían existir sino como conciencia inmediata (de) sí mismos" (Sartre, 2006: 21). A partir de identificar esta conciencia irreflexiva como constitutiva de toda percepción, de toda conciencia posicional, el análisis de la relación conciencia-cuerpo puede evitar la confusión generada al intentar unir una conciencia captada como "interioridad absoluta" a un cuerpo en tanto objeto, cosa definida desde afuera, el cuerpo "de los otros" (Sartre, 2006: 420). Sartre distingue tres modos en que la conciencia existe el cuerpo: "ser-para-sí”, "ser-para-otro” y "ser-para-sí-como-paraotro", que en el caso particular de las experiencias de malestar se corresponden con tres modos de existir dolorosamente el cuerpo: "el dolor vivido", "el mal padecido" y "la enfermedad".

\section{"Ser-para-sí": el "dolor vivido"}

Al analizar el vínculo conciencia-cuerpo en la dimensión del "ser-para-sí", es central la anterior identificación de la conciencia espontánea, irreflexiva, dado que lo que caracteriza al cuerpo para mí es que "no puede ser para mí trascendente y conocido", "instrumento que no puedo utilizar por medio de otro instrumento". En esta dimensión no hay "conciencia del cuerpo" sino una conciencia inmediata e irreflexiva: "la conciencia existe su cuerpo", la relación conciencia-cuerpo es existencial, la conciencia es el cuerpo. Y aunque el cuerpo para mí sea siempre lo trascendido, "aquello de que se hace caso omiso, lo que se calla" (Sartre, 2006: 455), la conciencia del cuerpo existe, como existe la conciencia del signo: "la conciencia del signo existe, si no, no podríamos comprender la significación. Pero el signo es lo trascendido hacia la significación, aquello de que se hace caso omiso en aras del sentido, 
lo que nunca es captado en sí mismo, aquello más allá de lo cual se dirige perpetuamente la mirada" (Sartre, 2006: 456).

Sartre desarrolla su análisis de la relación conciencia-cuerpo en torno a la experiencia del dolor llamado "físico", con el ejemplo concreto del caso de alguien que padece dolor de ojos mientras lee. En la dimensión del cuerpo para mí, el dolor no puede ser analizado desde un punto de vista objetivo, no es algo conocido, no existe en tanto objeto del universo, no se distingue de la manera en que se lleva a cabo la lectura, aunque sí se distingue "por su ser mismo de los demás dolores posibles". El dolor es "la materia translúcida de la conciencia, su ser-ahí, su vinculación con el mundo, la contingencia propia del acto de lectura" (Sartre, 2006: 459). La conciencia existe su dolor, el dolor es la textura de la conciencia, es una forma, como el placer es otra, en que se da la conciencia y habrá incontables maneras contingentes de existir la contingencia pues la conciencia tendrá (existirá) siempre un cuerpo, pero ante la ausencia de placer, displacer o cualquier otro modo cualificado de existencia, la captación noposicional de esta contingencia "sin color" será una "pura aprehensión de sí como existencia de hecho", lo que Sartre denominó Náusea ${ }^{37}$ (Sartre, 2006: 466).

En esta instancia pre-reflexiva Sartre prefiere hablar de "dolor-ojos o dolor-visión" pues la denominación "dolor de ojos" supone ya un trabajo reflexivo que analizará más adelante. No obstante, aún en este nivel el dolor contiene una información acerca de sí mismo (de lo contrario no podría distinguirse entre un dolor-ojos y un dolor-dedos), pero esta información no tiene el carácter de una "remisión intencional a un objeto trascendente, a mi cuerpo precisamente en tanto que existe fuera, en el mundo" sino que el dolor "es precisamente los ojos en tanto que la conciencia 'los existe"' (Sartre, 2006: 459). Pero los existe dolorosamente (como obstáculo a la vida, impedimento en la existencia empírica, en términos de Marcel y Jaspers), y esta contextura dolorosa de la conciencia se evidencia en "la manera en que el libro aparece como 'debiendo ser leído con ritmo precipitado', en "la manera en que el universo íntegro está afectado de inquietud, en un proyectarse hacia una conciencia ulterior sin dolor. La conciencia dolorosa implica un 'escaparse', un 'arrancamiento a sí', insinúa 'lo inefable que se quiere rehuir'” (Sartre, 2006: 460).

Y así como afirmara anteriormente que la conciencia es el cuerpo, los ojos son la contextura misma de la conciencia de ver (los ojos en tanto órgano sensorial corresponden al plano del cuerpo-para-otro). Esta conciencia de ver forma parte de una conciencia más amplia del mundo. Dado que tener conciencia es siempre tener conciencia del mundo, éste y el

\footnotetext{
37 "Una náusea discreta e incoercible revela perpetuamente mi cuerpo a mi conciencia: puede ocurrir que busquemos lo agradable o el dolor físico para librarnos de ella, pero, desde que el dolor o el agrado son existidos por la conciencia, manifiestan a su vez su facticidad y contingencia, y se develan sobre fondo de náusea” (Sartre, 2006: 467).
} 
cuerpo como parte de él son siempre presentes (si bien de modos distintos) a la conciencia, presentes como fondo. De ahí que “mientras se lee es más fácil 'distraerse' de un dolor de índice o de los riñones que de un dolor de ojos. Pues el dolor de ojos es precisamente mi lectura, y las palabras que leo me remiten a cada instante a él, mientras que mi dolor del dedo o de los riñones siendo la aprehensión del mundo como fondo, queda perdido, como estructura parcial, en el cuerpo como aprehensión fundamental del fondo de mundo". Pero basta con que se emplee el dedo doliente para volver las páginas del libro, y el dolor-dedo, hasta entonces existido como "mi cuerpo en general", "pasará a la categoría de contingencia existida como forma sobre una nueva organización de mi cuerpo como fondo total de contingencia" (Sartre, 2006: 462).

En la misma dirección, Marcel considera el mal, la enfermedad en tanto modo de existencia, estado donde la situación del ser se presenta notoriamente como obstáculo, resistencia a la vida. Pensar el mal o la enfermedad como problemas, como disfunciones de una máquina que puedo observar para buscar y atacar sus causas (igualmente objetivas) implica negar el aspecto central de estas experiencias, esto es, su carácter de sufrido, de padecido. "El mal puramente comprobado o, aún, contemplado deja de ser el mal sufrido, creo, simplemente, que deja de ser el mal. En realidad, yo no capto el mal como tal sino en la medida en que me atañe, es decir, en la medida en que estoy implicado en él [...] y es esta implicación lo fundamental aquí. No puedo hacer abstracción de esta implicación, como no sea por una operación legítima en cierto respecto, pero ficticia” (Marcel, 1992: 105). El sufrimiento, el dolor, el placer, el amor, etc., no existen por fuera del yo que padece o goza. Reconocerlos como misterio es aprehenderlos como modos de presencia, que lejos de poder aislarse como datos-problema, "invaden", dirá Presas, "la jurisdicción del sujeto que lo plantea (Presas, 1971: 104).

El cuerpo propio existe activamente y es inseparable del mundo (incluidas las relaciones con los "otros") hacia el que orienta su intencionalidad dotándolo de sentido, "las cosas nos solicitan gestos, al percibirlas se da una secuencia propia de movimientos que es diferente para cada objeto, para poder tratar con él" (De Castro et al., 2006: 133). Estos autores señalan, basándose en "Imaginación carnal" de Merleau-Ponty, que toda percepción se realiza desde un esquema corporal el cual no es una representación estática de las distintas partes del cuerpo, sino la integración dinámica de las mismas en los proyectos motores del organismo. En palabras de Turner "el cuerpo nunca es tan sólo un objeto físico, sino en todo momento una corporificación de la conciencia" [...] "el mundo objetivo, "exterior", se halla siempre conectado con mi cuerpo en términos de los actos de éste o de las potenciales 
acciones sobre ellos. Percibir el mundo es reflejar las posibles acciones de mi cuerpo sobre aquél. De forma similar experimento mi cuerpo como mío por medio de mi íntimo y concreto control sobre él” (Turner, 1989: 82). Por ello es que toda experiencia de sufrimiento, al tensionar la relación cotidianamente no problemática entre cuerpo y práctica, da visibilidad al cuerpo silenciado, obviado, colocándolo en el foco de la experiencia en tanto materialidad, obstáculo que constriñe y limita la capacidad de agencia de la persona (Alonso, 2008). El sufrimiento es el resultado de procesos de resistencia al flujo vivido de experiencia, a los planes de vida, a las acciones prácticas (Kleinman y Kleinman, 1991; Kleinman, 1994).

Tratándose de la instancia pre-objetiva, este primer momento sartreano, la dimensión del "ser-para-sí", del "dolor vivido", es recuperada en las entrevistas, naturalmente, a posteriori del padecimiento, sólo a través de los esfuerzos lingüísticos para dar expresión a las sensaciones (para nombrar lo inefable) y cuando los entrevistados se refieren a los malestares en términos de lo que no pueden hacer, como obstáculo a la vida, impedimento, inadecuación al medio y a las actividades que quieren realizar y que otrora realizaron sin problemas.

\section{El sufrimiento como resistencia al "ser-en-el-mundo"}

En el proceso de identificación perceptual del malestar son consideradas como síntomas las discapacidades y disfunciones que implican una ruptura de la cotidianidad, caracterizándose las enfermedades a partir de las actividades que éstas impiden u obstaculizan realizar, aquellas que normalmente se llevan a cabo de manera espontánea e irreflexiva, como respirar, tragar, hablar, ver, digerir, orinar, dormir o mover los miembros, porque forman parte del hecho de "ser-del-mundo". El susto se reconoce en no poder dormir; no poder descansar y la hiperactividad (sentirse impelido a caminar o realizar tareas) son efecto de sufrir problemas de nervios; "desvaloramiento", "decaimiento" son términos frecuentemente empleados para describir el estado de incapacidad para realizar tareas y desplazamientos causados por la puna y el susto; dificultad para tragar o respirar se asocia a enfermedades respiratorias; problemas en la digestión se consideran sintomáticos de malestares de hígado, vesícula y estómago; no poder orinar es síntoma de infección urinaria grave; discapacidades motoras señalan las secuelas de traumatismos o efectos no deseados de intervenciones quirúrgicas, traspiés en la conversación o en la realización de tareas indican el padecimiento de un mal hecho. 
I: Se tiene dolor de cabeza, no puede dormir, no come, se le caen las piernas, no puede caminar, está desvalorado, no tiene valor para hacer nada [acerca del susto] (P48, varón, 68 años).

J: no quería ir al médico, y bueno, hasta que ha caído, se le han trancado los orines, todo [...] no podía orinar y le han puesto sonda, y entonces el médico dice que tenía una infección bárbara a los riñones (P49, mujer, 40 años).

S: nosotros sentimos alguna cosa que parece que va a ser para que nos revise el doctor, bueno, vamos, así como yo tomaba mate antes de que me han hecho el trabajo ese de la vesícula, tomaba mate y ya me sentía aquí, en el momento ya se me ponía hinchado, ya estaba por arrojar (P50, varón, 76 años).

J: me ha agarrado como un derrame así, la ceja esta se me había ido por acá, esto así, se me ha cruzado esto para acá y esto para acá, se me quedó dura la cara, usted sabe, y bueno, anduve como 3 meses en el quinesiólogo, ha visto?, que le hacen masajes, todo eso, sí, quinesiólogo me parece que es, y no me hacía nada, si me quería meter la cuchara de comida y se me derramaba todo por el costado de la boca (P49, mujer, 40 años).

M: me hinchaba los brazos, los pies, no me podía poner ni las zapatillas, tenía que andar de ojotas, de chinelas (P11, mujer, 56 años).

A: qué sentiría yo, cómo me doy cuenta que tengo un maleficio?

F: porque usted se va a asentir mal, cualquier cosa en la cabeza, o que le falta alguna cosa en la conversación o se siente en la cabeza, en los brazos, en el cuerpo, quiere hacer una cosa y va a ir en contra [...] o si tiene cualquier cosa ya se le vuelca (P55, curandero, 84 años).

Pero donde más interfieren los padecimientos es en las actividades laborales: no poder trabajar ni caminar debido a la agitación es mencionado respecto a problemas de presión, corazón, asma, gordura, bocio, cáncer; no poder hilar, tejer, amasar debido a hernias, reuma, artrosis. Frecuentemente emplean la expresión "no ser dueño de" denotando el proceso de extrañamiento del cuerpo propio que deja de responder conforme a las intenciones, en palabras de un entrevistado: estar "como mano ajena". Como expresa Merleau-Ponty, "lo que en nosotros rechaza la mutilación y la deficiencia es un Yo empeñado en cierto mundo físico e interhumano, un Yo que continúa tendiéndose hacia su mundo... [negando] lo que se opone al movimiento natural que nos arroja a nuestras tareas, nuestras preocupaciones, nuestra situación, nuestros horizontes familiares" (Merleau-Ponty, 1984: 100).

C: No era dueña de salir hasta el portón cuando me agarraba [el asma] (P27, mujer, 56).

C: Después de abril empecé con un dolor de espaldas, antes me dolía pero poco, y hombro, no podía estar sentada ni caminar fuerte. No puedo lavar ni hacer tortillas 
porque me cae mal, cuando movía el brazo me sonaba la espalda como si estuviera rota, no podía mover el brazo (P48, mujer, 77 años).

E: este brazo no lo aguanto porque hay veces que el codo este me duele, me duele el codo cuando voy a buscar unas leñas, no? Yo no las puedo alzar así [doblando el brazo], tengo que ponerlas así para poder alzar alguna leña (P4, mujer, 75 años).

N: porque ya no podía caminar, para caminar se agitaba mucho y bueno, ya tenía que operarse [de bocio] porque se le ha criado muy grande, la quijada le asentaba sobre eso, y ya no podía caminar, decía que a gatas llegaba de...

(P58, mujer, 69 años).

R: ya para trabajar no es dueño de hacer fuerza porque justo a las piernas, a la cintura, a las caderas [...] dolor, ya no puede caminar, pero ya no puede a veces ni barrer [...] dicen que el cáncer ataca también el hueso (P79, mujer, 65 años).

C: él no puede digamos trabajar nada, no podía trabajar, porque no podía caminar se agitaba $[\ldots]$ por la presión (P15, mujer, 79 años).

Aquí se encuentran nuevamente los aspectos señalados anteriormente como "lo que está en juego" en el caso azampeño, aquello relevante a partir de lo cual se otorgan significados al sufrimiento aparece ahora como lo que pone en evidencia la resistencia que los malestares le imponen al plan de vida. Lo que mayormente se ve afectado (resistido) por los diversos padecimientos es el trabajo, el quehacer necesario en un ambiente que exige esfuerzos físicos; no poder caminar no es un mero contratiempo en un medio donde las distancias domésticas son amplias sumado a la irregularidad del terreno que torna casi imposible otro modo de desplazamiento; dado que hilar, tejer, realizar las tareas hortícolas o amasar constituyen labores centrales para el sostén y la reproducción de las familias, la incapacidad de realizarlas conlleva una reducción del sentido de utilidad y suficiencia agregando sentimientos de descontento e insatisfacción a los dolores propios del malestar. Además, teniendo en cuenta la valoración positiva de la actividad física donde la inactividad se considera que provoca o empeora malestares, se mencionan a veces circunstancias de retroalimentación positiva que llevan a un agravamiento del estado de enfermedad debido a que la misma obligó al reposo.

Como se notó al tratar la identificación de las etiologías, las actividades laborales son señaladas como causas de malestares y por lo tanto restringirlas forma parte de los cuidados prescriptos, a ésto se le suma lo aquí recuperado respecto a la inactividad como efecto de malestares: en un contexto donde se subrayan los méritos del trabajo, la inactividad es justificada sólo en tanto forma de cura prescripta o por ser efecto inevitable de un malestar. 
E: estaban los médicos... que no hile, porque ya tenía esta ronquera, me afectaba mucho y ya me dijeron que me afectaba

C: le afectaba mucho al pulmón, la bronquitis que tenía le afectaba mucho al pulmón, por eso la lana que ese polvillo que se levanta

E: me privaron que no hile y bueno yo no hacía caso, después ya mis hijas también ya no querían que hile [...] y bueno sufría así como tres años pero era una intranquilidad para mí, no pasaba bien porque yo he sido una persona que desde chica trabajar, o si ya sabía tejer saco con dos agujas, al crochet [...] me han dicho que deje el trabajo... pero una pena para mí, yo no podía estar, uno tenía que estar haciendo alguna cosa, y bueno, cuánto! yo no pasaba un día o dos, tres no estaba en el telar, ya ponía la tela y era un gusto para mí, a tejer

(P27, mujeres, C: 56; E: 80 años).

S: y ahora ando triste, una cosa como entristecido

A: de lo mismo?

S: claro, sabrá ser de lo que andaba enfermo, de lo que yo me notaba por ejemplo yo estoy aqui yo me levanto, ando, pero cuando uno ya está enfermo ya es una cosa, otra, ya no va a levantar (P56, varón, 79 años).

M: la A que ya está renga, a ella le duele la pierna, que ya no puede caminar, de última ya no sale para ninguna parte, ya pobrecita, yo por la rodilla me duele, sí pero voy para el trabajo [...] ya vea así como trabajar, trabajo mucho

(P11, mujer, 56 años).

Los referentes de la salud y de la enfermedad provienen generalmente del mundo y la actividad sociales más que del estado patológico mismo, y la (in-) capacidad de llevar a cabo las tareas cotidianas, el "valerse" de sí mismo, es uno de los principales ejes del discurso mórbido, como también se destaca, por ejemplo, en un estudio sobre personas con artritis reumatoide (Devillard, Otegui, García, 1991 en Devillard, 2002: 608).

Sea vivida como un estado que se debe aprender a tratar de manera adecuada o que se debe combatir, o como resignación frente a un sufrimiento agudo o preludio de la muerte, la enfermedad en tanto experiencia, sin constituirse en "enfermedad-para-sí", destaca la articulación de lo vital con lo espiritual.

\section{El valor de la metáfora para una etnografía de la experiencia}

“... se ha levantado al otro domingo pero a gatas, todavía, como cabra flaca tiritando...”

Dado que la dimensión del "ser-para-sí", del "dolor vivido" es la de la conciencia inmediata, pre-reflexiva, anterior a todo saber objetivado, sería inaccesible también a la investigación quedando cautiva en la conciencia del sujeto. Pero por más personal que sea la 
vivencia de malestar, la misma podrá incorporar sus sentidos sólo a partir de modelos de experiencia culturalmente compartidos. En esta síntesis pre-objetiva vivida, corporizada, que es la experiencia, se puede analizar cómo lo social, la base cultural de la experiencia se carga como un rasgo de la existencia corporal, cómo el significado cultural es intrínseco a toda experiencia corporal (Csordas,1992b). Los individuos realizan un esfuerzo por evocar las experiencias de malestar recurriendo a lo que Jaspers llamó "enunciación (objetiva) indirecta de lo inobjetivable", esto es, "un lenguaje objetivamente desprovisto de contenido" capaz de volver a producir en el oyente "la intuición que se desea transmitir" (Presas, 1978: 42-43). En la comunicación indirecta "se deja sentir una verdad que, en el médium de las objetividades, se revela como la subjetividad de la excepción histórica. Esta verdad es inseparable del hombre en el que ha llegado a ser certidumbre; jamás es posible apropiársela de modo idéntico, sino sólo transformada; ella obra despertando [a cada uno] para su propio desarrollo" (Jaspers, 1958: 761 en Presas, 1978: 52). El lenguaje permite acceder al mundo de la experiencia ajena en tanto la revela incluso para quien la vive; lo oculto se manifiesta a través del lenguaje en la medida en que suprimiéndose su objetividad, evoca lo inobjetivable.

Este uso "indirecto" del lenguaje es el que sustenta todo enunciado metafórico: la metáfora no es mera representación, es innovación, construcción que se vale de los campos asociativos, "no hay metáforas en el diccionario, sólo existen en el discurso; en este sentido, la atribución metafórica expresa, mejor que cualquier otro recurso del lenguaje, lo que es una palabra viva (Ricoeur, 2001: 132). Dice Ricoeur que la eficacia de la metáfora consiste en crear "el absurdo lógico, en el orden de la significación primaria, como medio para liberar la significación secundaria", "crear indicios que orienten hacia el segundo nivel de significación", lo cual se logra mediante una "atribución autocontradictoria" que se "destruye a sí misma", la incompatibilidad entre designaciones en el orden primario de la significación “obliga al lector a extraer de todo el abanico de connotaciones las significaciones secundarias susceptibles de hacer de un enunciado que se destruye a sí mismo una "atribución autocontradictoria significante" (Ricoeur, 2001: 129-130). "Ya se trate de llenar un vacío auténtico, ya de evitar una palabra tabú, o de dar libre curso a las emociones o a una necesidad de expresividad", lo que lleva a buscar un desplazamiento de la designación a la connotación mediante la "colisión semántica" es siempre un esfuerzo de expresión (Ricoeur, 2001: 161). Aquí se trata de poder circunscribir con palabras el cuerpo propio, referente que persiste "sólo como una especie de ausencia o pérdida, aquello que el lenguaje no puede captar y que, en cambio, lo impulsa a repetir el intento de captarlo, de circunscribirlo y a fracasar en tal intento" (Butler, 2005: 109). Csordas habla de "metáforas encarnadas" 
(embodied) para destacar el hecho de que las mismas no se aplican sobre el cuerpo sino que emergen de la experiencia corporal (Csordas, 1992a), "metáforas vividas" porque no actúan por imposición de un significado externo, arbitrario sobre la experiencia, sino que forman parte del proceso de significación en el curso mismo de la experiencia evocando conexiones al interior de la misma (Rabelo et al., 1999). O como expresó Cortázar en su Rayuela, "lenguaje quiere decir residencia en una realidad, vivencia en una realidad. Aunque sea cierto que el lenguaje que usamos nos traiciona no basta con querer liberarlo de sus tabúes. Hay que re-vivirlo [...] No se puede revivir el lenguaje si no se empieza por intuir de otra manera casi todo lo que constituye nuestra realidad. Del ser al verbo, no del verbo al ser".

En los relatos de los azampeños los "es como si", "es como que", "es como un/a" generalmente introducen la figura metafórica y sirven de pasaje entre la complejidad de la vivencia y la enunciación que en su imposibilidad de significarlo todo, la recorta. Gestos acompañan y complementan la expresión de aquello para lo cual no se hallan las palabras del todo adecuadas.

J: los oídos me hacían tuc-tuc [acompaña con un gesto de abrir y cerrar la mano] E: cuando los oidos hacen asi es porque es aire (P12, mujeres, J: 42 años; E: 62 años).

L: me zumbaba adentro de los oídos, como si tuviera tamborcitos adentro de los oídos [acerca de puna] (P16, mujer, 22 años).

El siguiente fragmento de lo expresado por una entrevistada acerca de sus padecimientos causados por aire es ilustrativo del empeño por traducir la experiencia a un lenguaje compartido:

J: no, no, es una cosa como que tengo una cosa quieta ahí, como embolsada, así, como que está en una bolsa atada, por ahí, no sé, me imagino yo, es como que, que no me irriga bien ahí, como que va la sangre y no pasa, como que... ahi en esta parte [se señala la coronilla] esa vuelta tenía así el oído, bah, no lo tenía, sino que yo me lo imaginaba... así largo y eso es lo que me decía Don $C$ [curandero] que es el aire [...] y ahora esta mañana le digo a la $X$ "ay! Cómo me molesta este ojo, me baila, me baila, se me mueve todo esto" [se señala el párpado] todo eso es el aire, sí, sí, y me curan y quedo livianita, despejada, hay veces cuando ya tengo mucho aire, es como si tuviese una tela delante de los ojos y esa lagañita que se hace, ha visto? Que es constante, que me limpio y me limpio y no tengo nada, me limpio los ojos y no tengo nada, es ya cuando ya estoy airada... porque a mí cuando me agarra el aire así, se me destempla toda la dentadura, es como que usted muerde algo y como que lo tiene abierto a los filos de los dientes, como que toma algo y como que se le va por el filo de los dientes el líquido, o si es caliente lo mismo (P49, mujer, 40 años).

Los malestares como el aire, el susto, la puna, problemas de presión, al no tratarse de la afección de una estructura corporal particular, son percibidos desde diversas localizaciones somáticas: oídos "largos" o "con tamborcitos" dentro, ojos que bailan, dentadura "abierta", la 
sangre que "no pasa"; en el caso de la puna, el susto, el reuma o dolores de hueso, términos como "desvaloramiento", "decaimiento", "deshauciamiento" son frecuentemente empleados para describir la sensación general de debilidad, cansancio e incapacidad.

S: deshaucionamiento en el cuerpo, un deshaucionamiento como si estuviera muy débil

A: y por qué está débil?

$S:$ parece que se juntan los males, que se junta el reuma, todo, dicen ellos

A: y qué siente con ese deshaucionamiento?

S: desvaloramiento en el cuerpo, como si no tuviera aliento, fuerza, así pasa mucho tiempo, pasaba noches aquí solo [...] un descaecimiento, un desarmamiento al cuerpo [...] muchas enfermedades se juntan, cansancio de que cuando uno es joven camina (P56, varón, 79 años).

E: tiene un desahucionamiento

A: cómo?

E: desahuciado, no tiene ganas de nada, debe ser el susto [...] el grande se desvalora, se golpea, se tulle también

A: se tulle?

E: claro, se les cae el brazo, las piernas tiene desvaloradas, todo, por qué, por el aire, el susto (P4, mujer, 75 años).

A: y qué sienten?

F: y bueno, lo sienten como descaimiento al cuerpo, ve, un desvaloramiento, que se le ponen, ya no puede salir asi a caminar al cerro, y esa es la puna

(P5, mujer, 66 años).

C: usted siente decaimiento, uno siente a veces decaído

$N$ : no se puede levantar está desarmado

C: claro mareada me sentía y a veces caminaba y era como que caminara me pesara la espalda [acerca del susto] (P11, mujeres, C: 62 años; $\mathrm{N}$ : 65 años).

L: me ha agarrado dolor ahí, en la espalda y esto eran como si me hubieran pegado así, tenía todo machacado (P70, mujer, 23 años).

M: yo sentí que se me comenzaba a dormir los brazos, hilaba un rato y ya me agarraba, que los brazos se me caían ya [acerca de tuberculosis]

(P11, mujer, 56 años).

En los casos de dolor de huesos también se registraron expresiones como "pinchar" o "punzar" que refieren a sensaciones más puntuales.

J: claro, la humedad, el mal tiempo, ya los huesos empiezan a punzarle por todos lados (P7, mujer, 42 años).

F: como si me hincaran una aguja [...] donde se juntan las caderas [...] quedaba un rato... curquincho, andaba con bastón (P79, varón, 45 años). 
Cuando el narrador significa y describe un malestar mediante una semejanza o parentesco no establecidos en el lenguaje habitual, apela a que los mismos sean también percibidos por su interlocutor, facilitándole su intención comunicativa:

J: la culebrilla, no sé si la habrá sentido nombrar, que se le cierra, como la que, dicen que es como la víbora y que va ciñéndola a usted... Eran unas ampollas de agua, eran como el lomo del sapo, ha visto? Así, una sobre otra, así, lo ha visto? Escamoso el lomo del sapo, así, y ya ella tenía desde la columna todo por acá hasta el pupo (P49, mujer, 40 años).

Si se evoca el lomo del sapo o el comportamiento de la víbora para significar algo de la experiencia, es porque se espera que el oyente cuente con significantes mínimamente equiparables a los propios, de lo contrario el enunciado metafórico (que rompiendo creativamente con usos establecidos del lenguaje pretende decir algo nuevo acerca de la experiencia subjetiva, difícilmente expresable de otro modo) no realizaría su valor comunicativo. Aunque las metáforas se destaquen como creaciones originales de los individuos, no se las puede reducir a fenómenos meramente subjetivos, "la comprensión de un enunciado metafórico se efectúa siempre en los términos de aquello que es dado en una situación de interlocución. El sujeto comprende a través del mundo compartido de significados, de modo que la metáfora nos remite al mundo de la intersubjetividad", y no sólo respecto a que las metáforas sean entendidas por los otros sino también a su construcción misma, la cual "no consiste en un acto individual de percibir una experiencia interior como problemática. La conciencia no constituye sus objetos ex nihilo, por autonomía de la interioridad subjetiva. La enfermedad se dota subjetivamente de sentido en la medida que se afirma como real para los miembros de la sociedad, que a su vez la aceptan como real. Es real justamente porque se origina en el mundo del sentido común (Alves, 1993: 269). Así, la enfermedad es construcción intersubjetiva, esto es, formada a partir de procesos comunicativos de definición e interpretación” (Rabelo et al., 1999: 175, 178). Y esto me costó un traspié en mi comprensión de la caracterización que hizo un azampeño acerca de los ataques de asma de su cónyuge: "se le trancan las arterias, le hacía frío", ¿con qué sentido estaba usando el término "arterias”? ¿se refería a los vasos sanguíneos hablando de una crisis de asma? Mi interlocutor no se detuvo en esta descripción, no agregó más explicación a algo que supuso formaba parte del universo de significaciones compartido. En posteriores entrevistas pudo registrarse este uso particular y recurrente del término "arteria", donde si bien el mismo está asociado al sistema circulatorio y al corazón, también lo está con la respiración, de ahí que "trancazón de arterias" aparezca tanto en las descripciones de malestares respiratorios como cardíacos (también en el caso de la puna, donde ambas 
disfunciones se cruzan) y con frecuencia no del todo diferenciada de expresiones como "trancazón del pecho" o "en los bronquios" para dar cuenta de la dificultad de respirar, taquicardia, agitación y dolor en el pecho.

C: $y$ dicen que se ha ido a dormir y ha muerto... un ataque cardíaco le ha agarrado, dicen que se le trancan las arterias, no puede respirar y termina (P60, mujer, 57 años).

G: me saltaba el corazón por la garganta, una cosa que sentía el corazón... [acompaña con el gesto de abrir y cerrar el puño] y me ha venido oscuridad a la vista yo no veía nada [...] me he venido, para casa, dije caiga, caiga acá [...] sentía la trancazón aquí (P14, varón, 79 años).

O: ese malestar que lo agarra y éste [señalándose el pecho] martilla, es eso la puna, y siente un decaimiento ( $\mathrm{P} 2$, varón, 58 años).

F: como una trancazón aquí al pecho, ve? Así una pesadez, yo camino y es una cosa como si me faltara aire [acerca de mal a los bronquios] (P44, mujer, 64 años).

Aunque con el término "arteria" se desvía el análisis del eje de la metáfora hacia el de la dimensión del saber objetivo (en tanto pretende dar cuenta de estructuras corporales) su empleo junto a la noción de "trancado", "trancar" lo ubica aún en el nivel de la enunciación indirecta de las sensaciones.

A: y cuando dicen que la arteria se le tranca, qué es?

Y: esa palabra, quiere decir que se le cierra algo, se le cierra la arteria [...] porque cuando quieren decir que "cierren el grifo" en vez de decir "que cierren" dicen "tranquen” (P22, mujer, 17 años).

E: ando embromada, me agarra la trancazón en el pecho [...] y a mí me agarra, bien que estoy y ahi nomás me agarra bronquitis, ya me agarra una tos que yo no puedo sostenerla, una tos y bien trancado el pecho, un dolor aquí, ahí me agarra el dolor [...] como si estuviera juntada de aquí (P27, mujer, 80 años).

De la misma manera se registró el uso del término "vena" en ocasiones no vinculado a lo sanguíneo sino a lo muscular y a una percepción lineal del dolor en este nivel.

J: la columna parece que era una venita de agua (P12, mujer, 42 años).

E: me habrá torcido alguna venita, no sé, por ahí me duele el cuello [...] hay días que no me duele nada, de repente así cuando como le doy la vuelta es un grito porque es como si me diera vuelta no sé qué vena ( $\mathrm{P} 4$, mujer, 75 años).

L: no lo único que me dolía la rodilla me dolía mucho, de esta parte para arriba, dicen que cuando una está embarazada se empiezan a estirar los músculos y dicen que se me han estirado mal las venitas de acá de las caderas (P70, mujer, 23 años). 
Por ejemplo, una mujer, mientras va desmenuzando la lana aún no hilada, se queja de que ya no puede tejer tanto porque le duelen los brazos, se le cansan mucho, nota "cansancio en las venas". Al preguntarle por qué piensa que es en las venas, responde que es porque ya no puede levantarlos. En la brevedad de este comentario espontáneo se condensan varios de los aspectos señalados: la vivencia del malestar en tanto resistencia a las acciones cotidianas; el carácter central de las labores en tanto causa del malestar y como aquello donde el padecimiento se evidencia como impedimento; los brazos como la contextura de la conciencia de tejer y la conciencia existiendo los brazos de manera dolorosa, cansada; el empleo maleable del lenguaje para expresar la experiencia ubicando el dolor en "las venas".

Las metáforas como estrategias de innovación semántica extienden sentidos habituales a otros dominios mediante la analogía y la introducción de aspectos sensoriales, afectivos y cognitivos. El enunciado metafórico obtiene su eficacia instituyendo lo absurdo que se revela al intentar aplicarle una interpretación literal, presupone una interpretación literal que se autodestruye en una contradicción, imponiendo una plasticidad, una deformación de las palabras, una extensión de sentido (Rabelo et al., 1999). Así, el empleo de términos como “pinchar”, “punzar”, “machacar”, “caer”, "pesar/pesadez”, “desarmar”, “quemar”, "despegar", "estar embolsada", "quedar liviana" para describir estados corporales crea un parentesco no percibido ordinariamente y permite transmitir estados y sentimientos sutiles para los cuales el lenguaje denotativo resulta limitado. El lenguaje connotativo, al poner en relación sentidos explícitos e implícitos ofrece recursos lingüísticos que permiten crear mediaciones entre lo vivido y lo significado.

C: a veces hago mala fuerza y me pega un, va a creer como que estoy despegada me duele, me fastidia [acerca de secuelas de operación de vesícula] (P3, mujer, 56 años).

J: la cistitis es terrible, es un ardor que agarra que como que quema por adentro, claro, yo digo, deben ser como infecciones (P49, mujer, 40 años).

S: siento como flojera, que el huesito se me va a zafar [se señala la rótula haciendo el gesto de un movimiento para el costado] (P50, varón, 76 años).

El empleo de las metáforas, extendiendo la experiencia pre-reflexiva del sujeto a dominios concretos y fácilmente reconocibles por los otros, le permite compartirla a la vez que organizarla y desarrollarla de forma socialmente reconocida. En este camino hacia la objetivación los individuos realizan un esfuerzo por precisar el origen exacto del malestar ya que las presunciones diagnósticas se construyen a partir de las percepciones del dolor o signo de alarma y de su ubicación, lo más precisa posible, en el espacio corporal. 
F: claro, yo sentía que me dolía la cabeza, la cabeza, la cabeza así, pero no todo si no esta parte [se señala la frente] y el doctor me ha dicho que es de la vista

A: ah, la frente?

F: claro, todo esto me dolía así, como un golpe era (P44, mujer, 64 años).

C: he tenido siempre sinusitis, duele la cabeza, los ojos, atrás de los ojos (P43, mujer, 54 años).

R: pero no daba a demostrar él que sentía ese dolor aquí y el médico le dijo que era la pierna y se le venía aquí [se señala la ingle] [...] jodía lo que era la cintura, siempre solía tener ese dolor de cintura [...] y decían que es de los riñones, había una señora que ya lo curaba de los riñones, con montecito [...] no le ha hallado que tenía así apéndice y si ahora tan pronto, tan de urgencia que lo ha agarrado [...] acá en la pierna le dolía, después se le ha ido arriba, le dolía nomás aquí arriba y bueno, sentía fiebre, él decía que era frío, pero era fiebre, si el lunes cuando le ha tomado la fiebre aqui la enfermera, en la posta, tenía 38 [...] pero a él le daban esas pastillas para el dolor de los huesos porque siempre sentía dolor de huesos, eso sentía él, las rodillas (P53, mujer, 66 años).

Estados emocionales forman parte también de las sensaciones descriptas en torno a las experiencias de malestar, sobre todo tratándose de problemas cardíacos, de presión y con menor frecuencia, respiratorios. Expresiones de decaimiento y debilidad aparecen acompañadas por otras de tristeza y aflicción. Así como respecto a los factores etiológicos se señaló la identificación de etiologías psicosociales en malestares que eran generalmente percibidos y representados a partir del cuerpo, también surgieron descripciones de sensaciones anímicas atribuidas a malestares cuya explicación causal no era centralmente psicosocial (por ejemplo problemas de presión o asma).

A: qué siente con la presión?

F: me pone como triste, como de aquí [alza la mano desde el vientre hasta la garganta y la boca], como si fuera la sangre, no puedo estar sentada, me acuesto, me siento (P31, mujer 66 años).

A: y qué sentía?

E: dolor al corazón, un dolor que me afligía, una aflicción, no podía tomar el sueño [acerca de una crisis de asma] (P27, mujer, 80 años).

Donde más se evidencia la supresión del dualismo cuerpo-espíritu es en torno a los problemas cardíacos (muchas veces asociados a problemas de presión y respiratorios, como en el ejemplo precedente), para los que frecuentemente se mencionaron causas emocionales (feos pensamientos, renegar, afligirse, llorar) así como síntomas anímicos, entretejidos con explicaciones etiológicas y descripciones sintomáticas en términos somáticos.

A: y para qué sirve el cedro?

JA: y dicen corazón, cuando uno se siente abajoneado, con decaimiento toma un té de ésto (P56, mujer, 67 años). 
$J$ : andaba mal, nerviosa, si ibamos a lo de $R$ [su suegra] y era como que no la aceptaba, como que me agarraban nervios, ha visto, como que chocábamos [...] no me quería enojar pero era una cosa como que me agarraba electricidad parecía que me levantaban de los pies, mi papá nunca se ha enfermado y de repente él se ha enfermado, ha visto, como que no aceptaba la enfermedad de él, de día no lloraba, no me desahogaba pero en la noche me agarraba, me ponía a llorar hasta qué hora y le decía a dios por qué con él que andaba tan bien y era como que sola me daba manija [...] de noche me despertaba con esa cosa como que me ahogaban, como que me ponían un hilo aquí [se señala el cuello] y que se me reventaban las venas que uno tiene [...] y eso es lo que me empezó a asustar y por eso he ido al médico, me agitaba mucho para caminar, a gatas llegaba, parecía que me iban a saltar los ojos [...] él me ha dicho que andaba muy nerviosa y a parte que tenía el problema coronario

A: y eso qué es?

J: en el corazón, las arterias se tapan, se tapan las arterias del corazón, por eso es que vienen los paros, todos esos, si yo había momentos que por ahí renegaba y era que me agarraba una debilidad, mire, me tiraba en la cama y me dormía, era una cosa como que, me sedaban, y después me despertaba, y me despertaba mareada, con dolor de cabeza [...] estaba asi tranquila pero adentro una cosa que me zapateaba y eso me llevaba a ponerme por cualquier cosa nerviosa (P7, mujer, 42 años).

Este fragmento compendia mucho de lo hasta aquí señalado: la persona sufriente reúne en su explicación causal aspectos tanto del orden anímico (preocupación por la enfermedad del padre) como somático (problemas coronarios, las arterias que se tapan); el malestar es percibido como trastornos en el nivel psicológico (enojo, irritación, nervios) pero también como ahogo, mareos, dolor de cabeza y debilidad; la vivencia del padecimiento en tanto resistencia al flujo de vida abarca aquí tanto una acción motora (no poder caminar debido a la agitación) como relaciones afectivas (obstáculos en el trato con su suegra); y finalmente el empleo de metáforas para expresar sensaciones más complejas e indefinidas para las cuales el lenguaje denotativo resulta limitado ("electricidad", como que la "levantan de los pies", "hilo en el cuello", "revientan las venas", “zapateo").

Si bien ya se ha dado un paso hacia la objetivación de la experiencia (dado que a lo largo de las entrevistas los sujetos la evocan y la traducen al lenguaje con los fines de transmitirme algunos aspectos de la misma), es posible distinguir un intento por captar y representar la vivencia del sufrimiento, el padecimiento afectando el "cuerpo propio" en el que no se puede escindir la carne del espíritu, donde tiene sentido decir que una preocupación provoca un malestar que "viene de golpe, subiendo desde los pies", una intranquilidad que "le tirita" y no deja dormir. 


\section{"Ser-para-otro": "el mal padecido"}

La relación existencial con el cuerpo primeramente captada por una conciencia preobjetiva (Marcel habla de una "conciencia exclamativa de sí" que en el niño pequeño se traduce en gritos y estremecimientos) es progresivamente mediatizada por estructuras del pensamiento que conducen a una objetivación del cuerpo como instrumento y de la actividad reflexiva como espíritu o mente. "Tendemos a convertirnos en burócratas, y no solamente en nuestro comportamiento exterior, sino en las relaciones con nosotros mismos, lo que significa que entre nosotros y la existencia interponemos pantallas cada vez más gruesas" (Marcel, 1953: 94). La captación inmediata, indubitable del ser en situación es reemplazada por lo que Marcel denomina "reflexión primaria", que rompiendo el lazo implicado en el posesivo de "mi cuerpo" lo considera como a uno cualquiera, con las mismas propiedades, sujeto a las mismas leyes, destinado a la misma destrucción que los otros cuerpos. Considerar el cuerpo como instrumento (aquello que prolonga un poder del cuerpo) exige sostener la existencia de otro cuerpo (mental, espiritual, etc.) que utilice al cuerpo físico como instrumento, lo que conduce a una regresión infinita. Sólo una reflexión posterior, "segunda", intentará suprimir ese intervalo, reunificar los elementos que la reflexión primaria, en sus diferentes versiones dualistas, planteó como separados.

El conocimiento del dolor se adquiere al dirigir sobre este $\mathrm{y}$, por ende, sobre la conciencia-actividad (conciencia refleja, conciencia-tejido, en el ejemplo de párrafos anteriores, o conciencia-visión, en el caso que utiliza Sartre) una conciencia reflexiva. La reflexión es, en palabras de Sartre, "captación totalitaria y sin punto de vista, un conocimiento rebalsado por sí mismo, que tiende a objetivarse, a proyectar a distancia el contenido para poder contemplarlo y pensarlo" (Sartre, 2006: 462). El dolor, textura actual de la conciencia refleja, es captado y "puesto" por la conciencia reflexiva como "objeto-dolor" trascendiendo la cualidad conciencial pura. Este objeto-dolor es un objeto psíquico particular, es "el mal”, y la conciencia reflexiva es conciencia "del" mal. Para la conciencia reflexiva el mal se distingue del cuerpo, a diferencia de la instancia anteriormente descripta donde el dolor era el cuerpo. El movimiento reflexivo construye este objeto psíquico con algo puramente vivido: las experiencias de dolor, organiza la alternancia de conciencias dolorosas y conciencias no dolorosas en una entidad con forma temporal propia: "cuando aparece, no es como un fenómeno nuevo, sino que, dirá el enfermo, es "mi crisis de la tarde" (Sartre, 2006: 463). La relación entre mal y dolor no será del tipo causa-efecto sino todo-partes, "ocurre con cada 
dolor concreto como con una nota en una melodía" así como "las breves treguas forman parte del mal, tal como los silencios forman parte de una melodía" (Sartre, 2006: 463). De la mano de esta escisión objetivadora del mal como algo independiente del cuerpo se da una especie de “animismo del mal”, dirá Sartre, en el sentido de que esta entidad, además de presentarse con una temporalidad propia, es dotada de hábitos, de voluntad (para irse o regresar), entablando con el enfermo una relación distinta a la que éste mantiene con objetos corrientes, "si no veo ya la mesa, se debe a que he vuelto la cabeza; pero, si no siento ya mi mal, se debe a que 'se ha ido"” (Sartre, 2006: 463).

Esta primera instancia de separación del mal respecto de la persona que lo padece aparece en las narraciones en el uso de verbos que colocan al primero como sujeto de la acción: no se "está" enfermo ni se "tiene" tal dolor, sino que se trata de algo que "viene", "dimana", "reina mucho", el mal "agarra" a la persona. Este modo de referirse a la enfermedad se observó generalmente en la narración de eventos repentinos (“ataques": de corazón, de diarrea y vómitos, de asma, de nervios, de vesícula, "derrame"; cáncer, apendicitis, a veces también un resfrío o gripe inexplicable) para los cuales no se elaboraron mayores explicaciones causales que las contenidas en tales verbos, es decir, el mal simplemente "vino" o "dimanó", etc. También cuando hablan de "peste", ya que, como se señaló anteriormente, este término es empleado generalmente para referirse al hecho de que se trata de un malestar que "se va pasando" de un individuo a otro centrándose la etiología en este aspecto y descartándose otras causas posibles.

O: le decían cáncer dormido [...] ese está, cuando despierta es como el apéndice, usted anda no lo siente y de repente se le prende o vesícula según parece que asi el mal está [...] primero era como peste el apéndice aquí, cualquiera qué le pasa: apéndice, tiene que operar, después: vesícula pero yo no sé de qué depende eso [...] que le da a uno, le da a otro, será como un virus que entra (P2, varón, 58 años).

P: el resfrio se le ha ido ahí nomás, ahí nomás se le ha ido (P38, mujer, 43 años).

$J$ : a ella le venían los ataques como epelepsia [...] y le agarraba y quedaba media redura, o le quedaba la lengua saliendo asi para un lado, ha visto? de los ataques que le daban, y desde que él la empezó a tratar nunca más le han vuelto esos ataques (P7, mujer, 42 años).

M: siempre me agarra dolor de estómago, de la vesícula [...] cuando me agarra, me agarra feo, a veces me agarra acá en el trabajo (P51, enfermera de la posta).

E: ahora ya mucho no hay de esas gripes fuertes, ahogos, neumonía no hay ya [...] había otra que la sabian llamar la neumonía doble, pero esa no me acuerdo cómo era (P4, mujer, 75 años). 
$R$ : a veces peste que anda, sabrá ser [...] hay veces que viene, como una gripe que viene, viene y agarra a veces a grandes, a chiquitos (P40, mujer, 62 años).

Este "animismo del mal", como lo llama Sartre, es resaltado en la caracterización de los padecimientos mediante adjetivos temperamentales, que evocan una relación interpersonal, de familiaridad o trato cotidiano con ciertas enfermedades.

R: están esas gripes que siempre la agarran porque ella es muy amiga de la gripe, cada tanto la agarra, parece que son muy conocidos [ríe] y corre a la cama, ya no tiene más que correr a la cama y esperar que le pase, no, siempre tengo así remedio yo para darle, ya le doy y tengo que cuidarla porque es muy perseguida de la fiebre, que será que la fiebre tiene que agarrarla (P53, mujer, 66 años).

JA: en estos tiempos dicen que la alergia es más porfiada ahora por las plantas que están floreciendo (P50, mujer, 64 años)

$J$ : [la gripe] este año estuvo muy brava, porque se componían y volvían otra vez (P49, mujer, 40 años).

Pero hasta aquí el mal no es conocido sino padecido, la reflexión debe apelar a lo que conoce a partir del cuerpo-del-otro (el ser-del-otro-para-mí que Sartre considera equivalente al ser-para-otro) para volcar estas estructuras cognoscitivas sobre el ser-para-sí. De ahí la tercera dimensión del cuerpo que Sartre distingue: ser-para-sí-como-para-otro.

\section{"Ser-para-sí-como-para-otro": "la enfermedad"}

Para conocer el mal es necesario encararlo en su En-sí, es decir, como es para los "otros" (su ser-para-otro) de manera de poder incorporar (en pos del conocimiento) saberes, conceptos, modelos inconcebibles desde la dimensión del cuerpo-para-sí. Y esto porque cronológicamente (Sartre evoca etapas cognitivas de la primera infancia) la percepción objetivada del propio cuerpo se alcanza después de la del cuerpo del prójimo. Con las herramientas del lenguaje, adoptando el punto de vista del prójimo, es que se conoce el propio cuerpo (y el propio dolor), por eso esta captación cognitiva, objetiva del dolor/cuerpo conlleva un distanciamiento (un olvido, un dejar en suspenso) del en-sí, extrañamiento propio de la reflexión y que, como se citó anteriormente, Sartre describe como "captación totalitaria y sin punto de vista" alcanzada proyectando "a distancia el contenido para poder contemplarlo y pensarlo". El movimiento de reflexión lleva entonces del dolor vivido hacia el mal padecido y (estructuras del ser-para-otro mediante) de este hacia la Enfermedad. El Mal padecido, por ejemplo, un malestar de estómago, es trascendido mediante el saber objetivante hacia el 
estómago nombrado, descripto, esquematizado (con diferentes grados de minuciosidad, de profundidad analítica, de conocimientos anatomo-fisiológicos), analogado, metafóricamente enunciado: "tiene forma de gaita", el mal es "algo que roe", es "ligera podredumbre interna", etc.(Sartre, 2006: 489).

Es en la dimensión del cuerpo-en-sí donde se elaboran las explicaciones anátomo fisiológicas y etiológicas. Como afirma Le Breton, "las representaciones sociales le asignan al cuerpo una posición determinada dentro del simbolismo general de la sociedad. Sirven para nombrar las diferentes partes que lo componen, hacen explícitas sus relaciones, penetran el interior invisible del cuerpo para depositar allí imágenes precisas, le otorgan una ubicación en el cosmos y en la ecología de la comunidad humana", este conjunto de representaciones "le permite otorgarle sentido al espesor de su carne, saber de qué está hecho, vincular sus enfermedades o sufrimientos con causas precisas y según la visión del mundo de su sociedad; le permite, finalmente, conocer su posición frente a la naturaleza y al resto de los hombres a través de un sistema de valores" (Le Breton, 1995: 13). Este cuerpo de nociones con las que los individuos cuentan para identificar sus malestares se nutre desde distintos conjuntos de saberes: el de la ciencia médica, el de las medicinas populares, y uno mucho menos delimitado conformado por información de experiencias, situaciones, vivencias que se van transmitiendo y con las cuales el individuo compara, completa, ilustra o refuta aquello que el médico o curandero le dice.

$R$ : y ha ido a hacerse ver y el doctor le ha dicho que era tipo aborto, pero "son macanas que el doctor habla", le he dicho yo a ella, porque le ligaron las trompas cuando tuvo al tercer hijo, y si le ligan las trompas es para que no tengan [...] a la otra semana le han hecho un raspaje y le siguen desparpajando la vida (P53, mujer, 66 años).

$P$ : [la curandera] dice que se le parte la cabecita, porque ella me decía ese día que yo la he llevado, dice "no te dabas cuenta" dice "mirá cómo tiene aqui", "ahí tiene abierto" me dice y claro, y yo no me fijaba, cuando ella me ha dicho así "mirá tócale" me dice entonces yo la he tocado y tenía hundido ahí, tenía abierto la cabecita [...] arriba de la cabecita y entonces me ha dicho ella, después me ha dicho, cuando ya la ha curado me ha dicho "mirá, vas a buscar un pañuelito y así le vas a atar firme la cabeza”, me ha dicho ella así (P38, mujer, 43 años).

Respecto a la incorporación de términos biomédicos por las clases populares se ha dicho que "el paciente realiza por su cuenta una selección en el discurso autocensurado del médico y retiene sólo los términos que reconoce... aunque ignore su significación científica" y, "puesto que el pensamiento popular no puede asimilar y utilizar más que lo ya conocido, las nuevas categorías que toma prestadas a la ciencia, así como las palabras que la sustentan 
quedan inmediatamente sumergidas en las categorías más antiguas y más generales, esas de las cuales los miembros de las clases populares hacen uso consciente y que le resultan familiares... Por consiguiente, puede aparecer que el pensamiento popular se enriquece o se transforma, sin que realmente se modifique su material conceptual básico" (Boltanski 1977 en Menéndez, 1990b: 185-186). Menéndez cuestiona esta visión estática que entiende el uso de términos biomédicos por parte de individuos pertenecientes a clases subalternas como mera aceptación e incorporación de vocablos y no analiza los procesos de apropiación autónoma que dicho uso implica. En este sentido, Garrote, analizando la relación entre el saber médico y las necesidades cognitivas del paciente, destaca que este último cuenta con información principalmente "de las relaciones de su vida cotidiana, a partir de múltiples experiencias médico-asistenciales que se comparten familiar y vecinalmente. Así, llegan a apropiarse de una gran cantidad de información sobre sus propias patologías, sus tratamientos y los lugares a donde pueden acudir" [...] "El proceso comunicacional del paciente está sustentado socialmente en su grupo de pertenencia (familiares, vecinos, amigos) y en su grupo de referencia (otros pacientes, ex-pacientes). Las ideas que tenga sobre su enfermedad dependerán de los vínculos que sostenga con ambos en su vida cotidiana, en su situación de enfermedad y especialmente en el proceso terapéutico. Sus conocimientos tienen una carga existencial que los hace distintos a los del espacio oficial e involucran otro saber, pero esta decodificación particular no excluye el científico" (Garrote, 1995: 95, 99).

En Azampay se refieren a las "enfermedades para los médicos" utilizando términos como "meningitis", "tuberculosis", “cistitis", “cáncer”, "infección”; los nombres de órganos como "riñones", "vesícula" y "apéndice" para aludir a disfunciones de éstos; destacan los valores de presión alta al evocar una situación de hipertensión o los de temperatura en caso de fiebre, y hablan de "colocación de clavos de platino", "ligazón de trompas", "raspaje", cuando cuentan en sus historias clínicas con este tipo intervenciones médicas. Esto evidencia una apropiación de ciertos términos a través del trato con los profesionales en la participación de los servicios médicos disponibles sin que ello implique una comprensión de las enfermedades en la dirección y con la profundidad analítico-descriptiva alcanzada por la ciencia biomédica. Considero que esta situación no es privativa de un "sector sociocultural" donde "no tiene lugar aquella concepción de las causas microbiológicas de la enfermedad" (Palma, 2002: 76), sino siempre que la consulta la realice un paciente lego en el campo de las ciencias naturales. Se acude al médico en busca de una identificación del malestar que dirija un accionar orientado a la cura (o al menos al control del mismo) y que posibilite elaborar una explicación de su origen que sustente a su vez estrategias preventivas; sin que ello requiera un 
entendimiento, por parte del enfermo, de los procesos microbiológicos de la enfermedad y bioquímicos de la medicación. Al recorte que elabora el profesional médico, basándose en su idea de lo que debe ser explicado al paciente y en su juicio de la capacidad del mismo para entender lo que él le comunique (no le dirá lo mismo a un paciente-biólogo que a un pacienteama de casa), el enfermo le agrega connotaciones propias (individuales y grupales) conservando en su memoria lo que haya entendido e interpretado de lo escuchado en la consulta como parte del cuerpo discursivo para nombrar y explicar su experiencia de malestar.

$R$ : dice que el cáncer ataca también el hueso

A: ah, pero no era de la matriz?

R: y sí, pero como la matriz la tenemos pegada sabrá ser en estas partes del espinazo que le decimos nosotros y bueno, de eso está afectando los huesos y como está pegado a las piernas ella sentía mucho dolor de piernas, yo hablo lo que los médicos dicen que curan de ese mal (P79, mujer, 65 años).

Muchos de los términos utilizados por los profesionales serán recursos nominativos con los que contarán los individuos, aunque ello conlleve variaciones de significado de los mismos, como se notó anteriormente respecto a los sentidos particulares con que se emplean nombres como "arteria" y "vena". La denominación obtenida en la consulta médica es utilizada por el paciente no sólo como mediación entre su lenguaje y el del médico sino como vehículo de sentidos que facilita su comunicación con otros interlocutores legos, familiares, amigos, simples conocidos u extraños, a quienes participa de las experiencias de enfermedad. Como señala Fitzpatrick, "la comunicación de cualquier tipo es un proceso activo y constructivo en el sentido de que las partes en comunicación deben integrar y completar el sentido que se oculta tras la información que reciben. Este constructivo "dar sentido" se logra por medio de los supuestos, creencias e ideas del actor" [...] "Esta capacidad de ver pautas y sentido en las expresiones de otros es un elemento esencial de la comunicación humana. Cuando la terminología es la misma, es facilísimo imaginar que el significado atribuido por ambas partes se sobrepone por completo" (Fitzpatrick, 1990: 35). Así, en las charlas de las que participé, los individuos empleaban términos médicos asumiendo que los demás presentes (incluida yo) compartían el sentido general de los mismos, por encima de las variaciones de sentido originadas a partir de experiencias, vivencias e informaciones particulares (las que en ocasiones se comparten acrecentando las connotaciones de cada término).

$S$ : en el sanatorio el doctor dice "no... si ella está bien, el corazón tiene bien, los pulmones los tiene bien, colesterol y esas cosas no tiene, chagas menos [...] ahí le han hecho todos los estudios [...] y tiene que estar anémica

A: no le dijeron de qué era eso?

S: y no, de eso la verdad es que no han dicho nada, dice "consigan sangre para que le pongamos, ya la pueden llevar porque esta mujer está bien” (P19, varón, 70 años). 
En la construcción de saberes anatómicos influyen además imágenes de fuentes tan diversas como aquellas provenientes del uso de radiografías y ecografías (interpretadas a la luz de los conocimientos propios y de lo que se haya dialogado con el médico), y las que derivan de la manipulación de animales de cría y consumo con cuya constitución se establecen analogías sirviendo de modelo para entender el cuerpo humano.

J: ví en la radiografía como si fuera una llaga en el corazón, que gotea, que el corazón se agranda [respecto a la enfermedad de Chagas de un pariente] (P49, mujer, 40 años).

R: me hacian la ecografia y me salia bien [...] y ahí se veía bien los derrames así como un yuyo así chiquitito, salía todo (P20, mujer, 24 años).

R: le ha golpeado una válvula que tenemos tantas

A: una válvula, qué sería eso?

$R$ : y yo pienso que deben ser esos, nosotros les decimos venitas, como las cabras aquí uno tiene que carnea, muchas venitas y uno les corta y le chifla la sangre, yo pienso que debe ser eso [...] se ha molido y se le ha cerrado, eso parece que se le ha reventado y se le ha cerrado, y no puede circular bien la sangre, cuando se le tapa esa cosa y no puede circular bien la sangre ahi es cuando se descompone (P79, mujer, 65 años).

R: afecta mucho ese, la gente, bueno, el doctor le dicen el bazo, nosotros a la hacienda le decimos el zorrito

A: el zorrito para el bazo de la hacienda?

$R$ : claro, comentaban, dicen que es ese, que uno le dice el zorrito y ellos le dicen el bazo, la cosa más delicada de la persona (P21, mujer, 63 años).

C: el tubo que deja, una bolsa, una bomba, una bolsa así colgada con cable y esa bolsa con cable estaba para dentro para chuparme el líquido que tenemos para dentro [...] he ido al médico allá y dice "pero cómo! esto ya muy pegado" estaba yo inflamada para dentro, esa inflamación que tenía y al pegarle un estirón el tubo ha saltado, ha despegado todo, me ha hecho venir ahí nomás una infección porque me ha vaciado todo el intestino [...] porque estaba, como ser que carneriaba

A: como qué?

C: como si carniaría porque ha brincado la sangre (P3, mujer, 56 años).

$C$ : [refiriéndose al tamaño del tajo realizado en el pecho de su marido operado del corazón] como un chivo, en la parte del corazón, le pusieron una manguera adentro [...] para destrancar la arteria (P66, mujer, 60 años).

La analogía entre intervenciones quirúrgicas y el carnear animales vulgariza las representaciones de esta labor médica tornándola asequible a explicaciones mecánicas, pero a la vez subraya el trato cosificante (e igualmente vulgarizado) del que es objeto el cuerpo humano en estas prácticas. Las descripciones en torno a las operaciones se basan en expresiones que resaltan la manipulación del cuerpo como objeto: raspaje, quemar, despegar, 
cortar, ligar, drenar, vaciar, lavar, limpiar, colocación de tubos, mangueras. ¿Crudeza en la explicación o crudeza en la intervención? Que términos como éstos vayan frecuentemente acompañados de apreciaciones de temor, riesgos, resultados no deseados, evidencia una valoración negativa de las operaciones, ya mencionada anteriormente al analizar las causas de iatrogenia identificadas.

C: operación muy grande y da gracias, que le dice, "vas a cuidar a tu hermana porque no sé si irá a quedar bien de la columna, capaz que va a quedar piernita corta"

A: y por qué?

C: que han cortado un tendón del lado de la columna para la misma operación [...] para despegar todo el intestino, para sacar todas esas piedras (P3, mujer, 56 años).

F: cuando ha nacido ha nacido con una bolillita, una cosita así aqui en la columna y al mes lo han operado y me lo han dejado medio mal para caminar [...] le han quedado las piernitas no firmes porque dicen que le han tocado casi la médula, la columna, porque él es operado ahí, claro tan chiquitito porque al mes me han dicho los doctores que lo lleve a Catamarca y lo haga, usted sabe chiquitito, de un mes, qué va a saber de a dónde tiene para sacarle eso (P5, mujer, 66 años).

F: pero el doctor dice úlcera y lo opera, pero eso si lo opera, bueno, raro el que salva, que eso es una cosa que te corta el intestino, que se hace con, ahí, esa grande, esa sierra (P55, curandero, 84 años).

E: pero me iban a llevar a Catamarca y yo no quería, porque tenía miedo que me corten

A: que la operen?

E: ahá, porque es el sapo, cómo le voy a decir, ese coso [se señala el bicep] el músculo ese

A: sapo le dicen? y por qué piensa que la iban a cortar

E: porque entonces estaba fiero, no se notaba bien pero ahora ya...

(P4, mujer, 75 años).

Más allá de las apreciaciones negativas, las explicaciones de las intervenciones quirúrgicas se articulan con las representaciones de los males frente a los cuales éstas se plantean como respuestas terapéuticas. Así, la noción de "raspaje" fue empleada generalmente al referir las operaciones de cataratas, descriptas como nube o carnaza que debe ser quitada; con un sentido más peyorativo una entrevistada, hablando del tratamiento realizado a quien padecía de cáncer de matriz, mencionó "raspaje" asociado a la realización de químicas que "queman" por dentro. Connotaciones de peligrosidad y agresividad de un tratamiento, aunque por ello también de eficacia para tratar un mal igualmente agresivo (cáncer o tumor) ya fueron mencionadas en torno al uso del término "droga". En lo que respecta a las representaciones en torno al cáncer hay una carencia de descripciones, sólo se presenta la idea de gravedad y de posible empeoramiento en caso de ser operado. En cambio la noción de "tumor", aunque 
asociada a la de "cáncer" por la semejanza de terapéuticas y por la superposición en los diagnósticos, aparece vinculada a la idea de crecimiento anormal de "carnes", "bolillitas", "pelotitas" que interfieren en alguna función corporal y que deben o pueden ser removidas mediante una operación. Esta imagen de "carnes que se crían de más" aparece también para explicar el desarrollo del bocio. Aquí también la solución es la intervención quirúrgica para sacar esas sobrecarnes cuyo crecimiento termina dificultando la respiración.

C: ella se ha operado el bocio que le sale en la garganta, como hay algunas personas que tienen bocio

A: y eso qué es?

C: es que crece, vaya a saber cómo, carne que se... cuando lo operan le sacan que es una cosas como si le saliera otra carne (P60, mujer, 57 años).

$N$ : bocio

A: y eso de qué era?

N: de qué sabrá ser eso? Dice que eran unas pelotas de carne en la garganta

A: y qué le decidió por operarse?

N: porque ya no podía caminar, para caminar se agitaba mucho y bueno, ya tenía que operarse porque se le ha criado muy grande, la quijada le asentaba sobre eso, y ya no podía caminar, decía que a gatas llegaba de... [...] eso ya lo sacan y no crece más [...] pero ella tiene como si fuera una manzana (P58, mujer, 69 años).

También hablan de la "carne" al referirse al tejido muscular y dérmico: en los casos de hernia la carne "se abre" por un mal esfuerzo, se la debe "coser" (operación mediante) o al menos "fajar" para mantenerla en su lugar; con la edad la carne se "pone más delgada" dificultando la cicatrización de heridas o úlceras, que le van "comiendo" el tejido hacia dentro.

A: y cuando dicen hernia, qué es?

$J A$ : dicen que se le sale la carne, sabrá ser el tejido así esta parte [se señala el estómago] que se abren los tejidos, hay mucha gente

A: $y$ de qué se le abren?

JA: y bueno, hace mala fuerza, claro, trabajan, hacen alguna mala fuerza, está delicado, sabrá ser que está la gente débil, vaya a saber, aquí el que era el $S$, pero no sé si se habrá hecho operar

A: eso se opera?

JA: sí, eso se opera, así como del apéndice, como la vesícula, los rajan y los sabrán coser

A: y hay alguna manera de cuidarse?

$J A$ : y sí, tienen que fajarse, cuidar no se suelta (P56, mujer, 67 años).

F: yo me han sacado la dentadura hoy día, mañana tengo cicatrizado todo, tengo una carne, viera! Qué decirle! es una suerte, fijese, yo doy gracias a dios (P44, mujer, 64 años).

A: y qué le ha pasado a Don G? 
E: del pie, como úlcera, así en la carne, parece que se le ha infeccionado [...] como uno ya se pone delgadita la piel asi que cualquier cosita, uno se raspa y ya se lastima (P62, mujer, 76 años).

R: una úlcera primero se le ha abierto así un pedacito después se le ha avanzado mucho más, le ha ido comiendo [...] se le seguía haciendo

A: y en la operación qué le han hecho?

$R$ : creo que le han hecho un injerto [...] han dicho que le han puesto, creo que, no sé, le han puesto prótesis, algo así digamos (P77, mujer, 25 años).

Otro componente corporal que se ve afectado por la edad son los huesos. Como ya se indicó, los dolores de huesos se atribuyen a un desgaste de los mismos, del "esmalte de la coyuntura" producto de los efectos acumulados del caminar y trabajar sumado a la falta de vitaminas y calcio que provocan su debilitamiento. Si bien señalan que la ingesta de estos complementos alimenticios mejora su estado, se considera que tratándose de un malestar emplazado en los huesos, es irreversible.

E: por más que me duela una significancia de dolores, no me va a hacer nada el doctor porque esto ya está de hueso ( $\mathrm{P} 4$, mujer, 75 años).

Pero por otra parte se destaca un endurecimiento de los huesos con la edad con lo que se explica la propensión en bebés y niños a padecer de abertura de pecho y que la ojeadura tenga en ellos el efecto de "partir la cabeza", así como la recomendación de realizar tratamientos correctivos a temprana edad (cuando los huesos aún pueden cambiar) y tener hijos antes de los 25 años (cuanto más duros los huesos mayor dificultad en el parto).

R: a mi la doctora me dijo "vos tenés seguidito a los chicos, vos cuando tengas al bebé no lo vas a sentir casi, vos no lo vas a sentir mucho ahora [...] vos hasta los 25 los huesos todavía están blanditos después de los 25 se ponen duros y ya te cuesta tener un bebé [...] cómo ha sufrido porque ella tiene como 35 años, dicen que sufrió mucho, de eso de que ya es grande, igual la hija de doña $F$, a ella le hicieron cesárea (P20, mujer, 24 años).

Y: cuando nacen tienen así como un agujero en la cabeza, que no se, al año creo que se les llega a cerrar y a eso le que dicen que se les parte la mollera [...] hasta que cumplen el año recién se les cierra, por eso tratan de no golpearlos a los bebés (P22, mujer, 17 años).

Otros padecimientos que atañen al sistema óseo son los que resultan de traumatismos: sacadura o zafadura del calcáneo, desvío de un disco de la cadera, fisuras, quebraduras. En estos dos últimos casos se recurre a la biomedicina, siendo generalmente derivados al hospital de la ciudad de Catamarca para operación y aplicación de yeso. Colocación de "fierros", "clavos", "placas", "platino", injertos y prótesis se mencionan como componentes de la respuesta quirúrgica y contribuyen, con sus connotaciones mecánicas, a la objetivación de las 
zonas corporales afectadas pero también, como se notó anteriormente, a representaciones de la intervención quirúrgica en tanto manipulación cosificante del cuerpo y que, dado su carácter intrusivo, puede tener efectos perjudiciales como infección, rechazo o secuelas permanentes.

M: al ponerle la prótesis le han torcido la médula, está apretándose la médula y eso a él le impide, mucho dolor de cabeza

A: prótesis de qué?

M: una prótesis acá en la columna, porque le ha tenido un accidente y ha quedado en silla de ruedas, no camina [...] no era para que le pongan prótesis, eso le decía [...] saquen y destuerzan los músculos [...] es como que se le han salido los fierros para afuera (P72, enfermera de la posta).

G: lo topó [una burra] así con el cuerpo, que los huesos también están falsos ya, cuando está viejo, y con eso ha terminado, lo he llevado a Catamarca, le han puesto un clavo [...] ya estaba débil y ya la vejez, hay que tener mucho cuidado, en cambio yo, ve? salgo con un bastón, yo no voy, pero yo tengo el mayor cuidado, vaya y haga una mala pisada y me caiga, me puedo golpear... ya las rodillas me fallan

E: y sí, ya uno entra en una edad ya no queda

(P33, G: varón, 78 años; E: mujer, 73 años).

En el fragmento precedente se ilustra cómo se entreteje en la etiología la percepción de desgaste y debilitamiento de los huesos debido a la edad con la causa accidental, potenciando una los efectos nocivos de la otra y sumado a una terapéutica ("le han puesto un clavo") que no promovió la recuperación del afectado. Cuando se trata de zafadura, de algún hueso que está "fuera de lugar", "desacomodo" por golpes o malos movimientos, generalmente recurren a la atención de un curandero, cuya terapéutica consiste en masajes, maniobras de estiramiento y reacomodamiento, fijación mediante vendajes y aplicación de pomadas, otros les dan una respuesta desde la autoatención, por medio de pomadas compradas en la ciudad o a vendedores ambulantes y mediante el uso de fajas y vendas. Las zonas más frecuentemente afectadas y por ello nombradas son los "nudos" (articulaciones, sobre todo la que une la pierna a la cadera, generalmente se acompañaba su expresión con el gesto del puño cerrado dentro de la palma, como representando la unión de la cabeza del fémur con el coxal), la cadera en vinculación con las piernas (hablan de "cadera corta" en un caso de renguera) y con la columna (como cuando hablan de "desvío de un disco de la cadera" para referir un dolor en la región lumbar o en la sacra), las rodillas (el hueso de las rodillas que parece "se quiere zafar") y la "paletilla" (que se correspondería con el hueso xifoides) cuya "caída" provoca el conjunto de malestares identificados como abertura de pecho (descripto entre los taxa vernáculos) más frecuente en niños debido a su complexión ósea aún "blanda". 
F: [el curandero] me tenía que sobar, eso es un huesito de la columna... yo no puedo estirarme mucho, un huesito que traba [...] se me acomodó [...] eso de cuando uno hace mala fuerza [...] los mismos golpes que uno le da a los bloques todo va aquí [se señala la cintura] donde se juntan las caderas [...] me mandaron de regalo la faja, con eso ando bien [...] yo siento la espalda ya para enderezarme así de golpe, primero no podía, me enderezaba de golpe y ya me... y con esto ya (P79, varón, 45 años).

F: estas cosas de sacadura, safadura del calcáneo, de los nudos [...] juegan a la pelota y ya vienen por ahí [...] están jugando y alguno cae, queda en los pastos, se golpean, se tronchan, en fin, yo lo compongo ahi de nuevo

A: y cómo lo cura usted?

F: con masajes, hay que masajearlo, tirarlo, poner bien y dejarlo y atarlo como vendado [...] con telas, claro, trae un trapo, que sea, algo, y ahi una semana, por ahi a veces vienen, no se hacen sobar nada y bueh, andan rengos y rengos, hasta, cuando a mí se me curan en una semana, dos [...] hay remedios para ponerle en los nudos así A: y qué tipo de remedio son?

F: y eso tengo alguno de los bolivianos, que dicen, de Bolivia, yo, compra y tiene para eso [...] pomadas, traen de todo (P55, curandero, 84 años).

$R$ : a veces cuando los voltian [...] se les hunde esta cosita finita que uno tiene aquí en el pecho, eso parece se les hunde, se les duebla y de eso les viene vómito [...] alguno que sobándolo asi y le ponen con un vasito lo prenden así, lo vuelcan y eso lo chupa [...] levanta ese, le sabían decir antes la paletilla, al huesito ese finito que uno tiene en el pecho, no sé si usted se habrá tanteado una vez ahí

A: y a los chicos les pasa nomás?

$R$ : sí, a los chiquitos más que todo, porque claro, tienen las carnes blanditas, los huesitos delgaditos, les viene vómito a veces ( $\mathrm{P} 40$, mujer, 62 años).

Como se señaló anteriormente, el cuerpo se considera receptor de los efectos de los elementos más destacados del ambiente y del exceso de trabajo. En los huesos y vísceras impacta y se acumula el frío ("fríos internados") y persisten las repercusiones de golpes y esfuerzos.

El frío se "interna"en los bronquios provocando "trancazón” de las arterias, de ahí que se busque su mejoría tomando arrope, miel o bebidas calientes. Como se hizo notar anteriormente, el término "arteria" aparece asociado tanto a las vías respiratorias como al sistema sanguíneo y corazón. El vínculo entre estos dos sistemas es explicado por la proximidad anatómica de los mismos, por el hecho de que sus disfunciones comparten los mismos síntomas (dificultad en la respiración, agitación, dolor en el pecho y taquicardia) y por la relación causal que se establece en algunos casos donde problemas para respirar son parte de la etiología de la falla del corazón. En cuanto a los problemas cardíacos, aquí también la intervención quirúrgica contribuye a la objetivación de esta zona del cuerpo: se opera para destapar las arterias trancadas, cambiar válvulas. 
P: del corazón lo han operado, de una arteria tapada, lo han operado con eso de rayo láser [...] le han operado ahi, por esa parte [se señala la cadera] por ahí le han operado, unos huequitos chiquitos [...] ahora anda otra vez con ese mismo cansancio, y bueno ha ido otra vez a la ciudad y dice que le han dado turno para que se opere otra vez, porque le tienen que poner una válvula

A: y qué es eso?

$P$ : será de alguna arteria que le van a cambiar ( $\mathrm{P} 19$, mujer, 43 años).

E: sería de lo gordo que estaba, muy gordo, que ya se le notaba que para respirar le costaba, respiraba por arriba nomás [se señala la garganta] tenía gordo el cuello, sería que la gordura que le aplastaba el corazón [acerca de una muerte por infarto] (P63, mujer, 58 años).

F: porque el pulmón están pegados al corazón, que tenía ella los óvulos rojos han vencido a los blancos, ella tenía blancos los óvulos, más blancos que rojos

A: y eso de qué es?

F: ha de ser de la sangre, parece que ha estado muy débil la sangre, sabrá ser!

A: y eso le puede haber hecho algo al corazón?

F: claro (P67, mujer, 67 años).

M: tuberculosis, sí, de ahí han dicho que le ha quedado un pulmón chico, le andaban muy poco los pulmones y bueno... dicen que al venir muy poco la presión ya no tenía la acción para el corazón y los pulmones (P72, enfermera de la posta).

Problemas de presión y de la sangre (sangre débil) considerados como afecciones distintas e independientes de la "trancazón de arterias" son enunciados como causas de "infarto", al que se refieren también como "paro", "ataque" o "falla" del corazón y que explican como consecuencia (fatal) de que el corazón se "parte", "revienta", se "desgarra". Por otra parte, si bien mencionados con mucha menor frecuencia, el soplo fue referido como una "herida" del corazón congénita o causada por aflicción y el mal de chagas como generador de una "llaga" en el corazón. Esta imagen de rotura, hendidura de un órgano para entender su mal funcionamiento apareció también en una explicación sobre la hepatitis, donde el hígado se agrieta.

O: claro, la hepatitis por ejemplo le ataca al hígado

$R$ : grietas al hígado

O: y después el orín baja color de té, de café, una grieta, claro

$R$ : pero tiene que hacer reposo

O: claro, reposo hasta que sella todo eso (P78, O: varón, 60 años: R: mujer, 55años).

Retomando las lógicas causales distinguidas por Chrisman, se destaca cómo en el caso de los problemas cardíacos o en este último de la hepatitis, predomina una lógica mecánica, donde lo que causa la enfermedad son bloqueos o daños de estructuras corporales.

R: sería un infarto que le ha dado [...] eso que ataca al corazón dicen los médicos A: y el infarto qué le hace? 
$R$ : y bueno, eso dicen que revienta el corazón, dicen los médicos... hablamos lo que hablan ellos [...] dicen ellos que la presión alta ataca al corazón, le sale mucho la sangre que son débiles y le ataca al corazón y le desgarra el corazón por eso ha terminado ahí nomás (P79, mujer, 65 años).

C: dicen los médicos que es un soplo al corazón [...] hay alguno que nacen así y otros que no, que se enferman porque se afligen lo que el corazón dicen que es como un reloj, cuando para el corazón ya paran la pata [...] dicen los médicos que el soplo es como una herida [...] sabrá ser que le ha agarrado un ataque al corazón, que cuando el corazón le falla ya... como es como un reloj (P60, mujer, 57 años).

En estos últimos fragmentos, junto a las representaciones en torno a los problemas cardíacos, aparece explícita la influencia del discurso médico en la construcción de un saber objetivo del cuerpo y de la enfermedad. Como se expuso anteriormente, términos y explicaciones utilizados por los profesionales al ser aprehendidos e interpretados por los legos pasan a formar parte de sus representaciones sobre salud y enfermedad, sobre todo de aquellas que conforman el conjunto de conocimientos, es decir, el nivel del "ser-para-sí-como-paraotro", conocimiento desde el punto de vista del "otro". Que la apropiación de recursos nominativos y explicativos implica una resignificación en función de los saberes propios, queda resaltado en expresiones como "los óvulos rojos han vencido a los blancos, ella tenía blancos los óvulos, más blancos que rojos". Pero lo que se puede ver también en los últimos fragmentos es que en la explicitación de la fuente de la que procede la explicación ("dicen los médicos... hablamos lo que hablan ellos") se apela a una opinión autorizada desde la cual sustentar y validar la visión presentada. Como señala Bourdieu "el lenguaje de autoridad gobierna siempre con la colaboración de aquellos a quienes gobierna, es decir, mediante la asistencia de los mecanismos sociales capaces de producir esta complicidad, fundada en el desconocimiento" (Bourdieu, 1985: 77).

En este nivel de objetivación de las descripciones del cuerpo y las enfermedades, la captación de estas últimas en tanto disfunciones corporales promueve la elaboración de explicaciones a partir de metáforas mecanicistas que evocan una percepción utilitaria del cuerpo. El corazón es "un reloj" de cuya marcha depende la continuidad de la vida, el estómago es "un motor" que se carga y debe limpiarse.

S: lo que le ha echado usted a esta máquina, esto es una máquina, el estómago, es como un motor, eso tiene que curarlo [...] nos sentía mal y bueno ya decía, tiene que purgarse (P50, varón, 76 años).

El estómago y los intestinos son considerados como estructuras asociadas y que debido a la incorporación de ciertas comidas se ensucian, lo que se expresa en ocasiones a 
través de manchas o sarpullidos en la piel. Esta representación se manifiesta cuando refieren las terapéuticas y su accionar para restablecer el estado de salud: se trata de lavar, limpiar el estómago o los intestinos mediante purgantes caseros o de manera directa en el quirófano.

JA: el purgante se lo compra en la farmacia y ese usted le da una cucharadita y bueno, y al otro día tenía que tenerla con sopita y gallina, mejor dicho, todo el día, con sopita de gallina

S: para que, por ejemplo se sentía mal del estómago, se sentía mal y con eso usted ese lo hacia, decían lo hacía purga, lo hacía botar lo que tenía, lo que tenía lo hacía botar en el orín y ya usted quedaba bien (P50, JA: mujer, 64 años; S: varón, 76 años).

C: que ha sido del golpe de los intestinos de eso se ha hecho como apostema, por eso no podían saber que era vesícula porque a mí no me hacían mal las comidas [...] he llegado al punto que ya me ha reventado ya no podia... según dice mi hermana que le ha dicho el doctor le ha explicado que a mí me han sacado el intestino por eso tira muy mucho, ahí en la operación me han sacado el intestino, han hecho un lavaje después lo han dejado dos meses más dice que tenía que estar, no tocar nada, nada porque se tienen que pegar los intestinos [...] le dijo el doctor a mi hermana que me han puesto un tubo para despedir las piedras ( $\mathrm{P} 3$, mujer, 56 años).

Al estómago y los intestinos también los afecta el frío que se "interna" (es el caso de "pulso" ya descripto), y un golpe, como se lee en el fragmento precedente, donde también aparece la asociación de estos componentes del sistema digestivo con la vesícula. Apéndice y vesícula son vinculados al estómago e intestino a través de etiologías compartidas (ciertos alimentos y, con menor frecuencia, golpes). Al mencionar los factores patógenos identificados en los problemas de apéndice y vesícula, malestar de estómago e hígado, se identificó una combinación de las lógicas mecánica y de invasión, pues se trataba de la incorporación (o intrusión) de alimentos que provocan daños o bloqueos de las estructuras corporales. El apéndice es como "una tripa" que se inflama, y si no se lo opera y se lo extrae a tiempo puede reventarse desparramándose el líquido de la inflamación, la vesícula es "como una bolsa chiquita" que se llena de piedras (producto de la "suciedad" del estómago) que deben ser extraídas, algunos emplean el término "cálculos" y muchos refieren haberlas visto luego de la operación.

L: tenía una manchitas porque esto es del estómago, de la misma suciedad que tenía en el estómago, porque ella tenía manchada la cara, blanca ha quedado! [...] y ya como le han sacado todas esas piedritas que tenía ya se le ha limpiado el rostro, ha visto que tienen unas manchitas así, eso dicen que es porque a veces comen esas comidas... le sienta mal al estómago [...] le han dado con rayos láser, que le han puesto por el ombligo y otro ahi y otro ahí [se señala el seno y abajo del seno] son tres puntitos los que tiene nada más y dicen que por ahi le sacaron la vesícula

A: ah, se la sacan a la vesícula?

L: se la sacan [...] sabrá ser como una bolsa, con agüita, mi padrastro dice que es, que la vesícula de la mamá era como una bolsa chiquita así que estaba llena pero 
llena de piedritas chiquititas adentro, "qué?! has comido ripio?!” dice [ríe] "ha comido piedras la vieja?!” (P70, mujer, 23 años).

O: y no sé de qué depende que se hacen como piedras, los doctores dicen piedras pero una cosa dura medias verdes, son así chiquititas, deber cuando la vesícula no trabaja bien se ve que sale eso de la vesícula, algo, o puede ser de las comidas, no sé, yo no entiendo bien eso [...] no tuve esa suerte de preguntarles a los médicos de qué se hace eso ( $\mathrm{P} 78$, varón, 60 años).

JA: hay ocasiones que dicen que el apéndis también es peligroso pero no aquí no pasó asi

A: por qué?

JA: se revienta ese también si no lo operan, si está muy avanzado

A: ah, y hubo algún caso acá?

JA: ninguno, ninguno, siempre cuando se sienten asi medio enfermo se van al hospital A: y qué pasa cuando se revienta, qué le pasa a la persona?

JA: y ya tienen que marcharlo a Catamarca porque ahí lo lavan bien dicen, lo lavan adentro porque dicen que es un líquido muy fuerte (P1, mujer, 65 años).

El factor agravante que torna ineludible la intervención quirúrgica (muchos mencionan postergar la operación de vesícula, aliviando sus síntomas con la toma de infusiones) es el "líquido" de la inflamación que termina reventando el apéndice o la vesícula y desparramándose por la zona abdominal. Esta idea de un líquido que "se junta" también se presenta en la noción de infección, en algunas explicaciones del dolor de rodillas y en el caso de la niña con hidrocefalia. Las terapéuticas consisten en "drenaje", "lavaje”, "punzar", el "suero con antibióticos"que "limpia la inflamación", una droga que "seca", "tubos", "válvulas" por los que sale el líquido.

S: me dicen algunas personas que ese es un líquido que se junta vaya a saber, el doctor también me dijo, que se junta un líquido bajo de ahí, pero claro que tiene que hacerse operar [acerca del dolor de rodillas] (P50, varón, 76 años).

C: el tubo que deja, una bolsa, una bomba, una bolsa asi colgada con cable y esa bolsa con cable estaba para dentro para chuparme el líquido que tenemos para dentro [...] cuando ya no tiene nada ya se lo sacan, cuando ya chupa todo eso, claro como una inflamación [...] el drenaje ese que digo yo que está chupando la inflamación (P3, mujer, 56 años).

La identificación de la enfermedad con la generación y acumulación de un líquido va asociada a una idea del desplazamiento de la misma, que se desparrama, se ramifica, baja o llega a la cabeza, se interna, agravándose el estado de enfermedad. De manera similar ocurre con el frío "que se interna" provocando malestares crónicos, o cuando eventos febriles y efectos de golpes son considerados trastornos que deben ser "sacados afuera" para promover la sanación. También el agravamiento de una úlcera o lastimadura es visto como que "sigue 
comiendo para dentro" y se considera que la secreción mucosa o flema si no se logra expulsar queda pegada al pulmón. De ahí que, siguiendo esta lógica del avance de la enfermedad hacia dentro o desplazamiento hacia otras partes, la acción de las terapéuticas en estos casos sea explicada focalizando en el tratamiento del síntoma (en términos de extracción, de "secar", detener su avance, promover su manifestación externa) y no de la causa.

R: se le ha tapado el pulmoncito [...] estuvo 15 días internada [...] ya estaba así como un quejido, quejaba no podía respirar [...] la han internado ahi, le han empezado a hacer los estudios y ya salió que tenía neumonía [...] de resfríos mal curados, que no han curado bien, ella de chiquita no podía tirar los mocos, ella todo se los tragaba [...] el tema es la nariz tiene que tirar solo y ella no podía tirar a ella le sacaban [...] se le han pegado los mocos en el pulmón (P77, mujer, 25 años).

N: uh! Él ha tenido fiebre así, estaba helado entero [...] por afuera está helada toda la piel, pero por adentro todo está fuego, porque todo eso está para dentro, y ella le ha dado un jarabe que era para la fiebre, qué, cuando ya hemos querido ya se estaba el pelo entero transpiraba, como goteras de agua

A: empezó a transpirar?

N: claro, ya le ha calentado el cuerpo (P58, mujer, 69 años).

J: esa infección urinaria le va subiendo, le va subiendo, y si usted no se cura, porque el campesino le dará yuyos pero para cortar tiene que ser un antibiótico fuerte

(P7, mujer, 42 años).

O: he hecho mucha fuerza y me ha bajado para abajo la papera [se señala la ingle]

A: y algún remedio le dieron?

O: penicilina

A: así que ahí la borraja...

O: no, no funcionó

A: y por qué?

O: porque ya estaba grave, porque la fuerza que he hecho se me ha bajado para abajo

A: o sea que a veces los yuyos no pueden...

O: ya no, eso ya tiene que ir al doctor y el reposo (P78, varón, 60 años).

En esta asociación desplazamiento-agravamiento ocupa una posición de mayor gravedad la posibilidad de que el mal se extienda hacia la cabeza, con consecuencias letales en la mayoría de los casos. La cabeza (algunos hablan del cerebro) es considerada el punto terminal de una enfermedad que no se ha podido superar así como una zona de mayor vulnerabilidad y fragilidad. Ya se mencionó el malestar particular en que "la sangre se va a la cabeza" provocado por una exposición de la misma a fuentes de calor durante el postparto y la menstruación, y que, independientemente de esos momentos especiales en la vida de la mujer, se considera que el exceso de calor en la cabeza puede causar locura o debilidad mental. Así mismo cabe recordar aquí también la advertencia de no lavar la cabeza con el baño de yuyos 
recetado para mejorar la tonicidad muscular debido a las "calorías" que las plantas aportan, el uso de pañuelos en la cabeza durante el postparto y luego de una curación de aire y el cubrirse la cabeza al transitar por zonas asociadas al aire como medidas preventivas. Además golpes o cargar peso sobre la cabeza fueron mencionados como causas de "debilidad" mental ("se pierde", “desconoce"), epilepsia, sinusitis y problemas de la vista. Todo ello destaca la susceptibilidad de esta parte del cuerpo.

$F$ : uh! pero le ha dicho que era para morirse tiene pata de cabra!

A: ah se pueden morir?

$F:$ y claro, eso va por la columna

$N$ : dicen que va y llega a la cabecita [...] de abajo para arriba, dicen ya se muere, dice que estaba para morir (P58, mujeres, F: 62 años; N: 69 años).

O: la diarrea le ha dado [...] muy mal ya que le suba a la cabeza chau [...] ha sido fuerte que si no la agarró paro ese día... la ha dejado mal de la cabeza, como ella tiene unas pastillas para eso así que tiene que tomar eso, no toma eso ya queda dura [...] ya dice el doctor que del mismo mal que tiene le está trabajando adentro (P37, varón, 55 años).

F: Porque yo sabía que andaba mal de la cabeza, mareo, en la cama, me acostaba y en la cama era una cosa que me venía como si me quisiera descomponer, cuando vino el médico voy y le comunico, digo, porque yo creo, siento debe llegar al cerebro [...] porque yo sentía debilidad, bueh, me ha recetado y me ha dado unas vitaminas, y con eso, con las vitaminas estoy mejor [...] porque eso tiene que darles remedios, tónicos, cosos que sean de dentro [...] de los aires que uno cura, todo eso mismo lo debilita a uno (P55, curandero, 84 años).

O: leña todo traía en la cabeza y de eso parece que le ha agarrado algo, qué se yo, cosas pesadas [...] debe ser que enferma algo tiene que trabajar mal, no es como la espalda que usted lleva parejo ( $\mathrm{P} 2$, varón, 58 años).

C: el doctor de la cabeza, él me dice que al golpearme se me ha movido el cerebro, y eso mismo también me quería agarrar sinusitis, del mismo golpe dicen que se hace sinusitis (P60, mujer, 57 años).

La fragilidad de la cabeza es aún mayor tratándose de bebés o niños pequeños ya que se conjuga con la debilidad ósea asociada a la primera infancia. Paradigma de ello es el efecto grave (incluso mortal) de la ojeadura en esta edad, donde la expresión de que "se parte la cabeza" debido al dolor es dicha en sentido literal: la cabecita, la frente "se abre", abertura de las "secuelitas", de las "costillitas" de la cabeza, la "mollera" se les parte.

C: le dicen en la ciudad los doctores que al cerebro, lo han tironeado porque no podía tenerlo [...] todos los meses va a Catamarca, pero del cerebro le habían dicho que estaba bien, ahora la vista se le desvía [...] ellos le habian recetado primero cesárea y los doctores no le querían hacer cesárea y ya la han visto mal a la chica y le han tirado de la cabecita, ahí le han embromado el cerebro dice el doctor (P66, mujer, 60 años). 
A: qué pasa si no los curan? [de ojeadura]

$R: y$ dicen que se mueren [recuerda un caso de Jacipunco que ya lo traía a Belén y a la altura de La Ciénaga se murió el bebé] se le partió la cabeza, porque son chiquitos y ya no les aguantan los huesos el dolor de cabeza, al año se le endurece (P20, mujer, 24 años).

N: abertura de las secuelitas, me han dicho que es meningitis y el doctor me ha enseñado dónde tenía abierta la cabeza [se señala en la línea perpendicular a la frente] que casi le llegaba la abertura a la nuca, en cambio en los lados [se señala líneas perpendiculares a las orejas] no tenía tan abierto todavía porque si no, se muere (P11, mujer, 65 años).

Pero también otras partes del cuerpo fueron señaladas como "lo más delicado" de la persona, significando con ello tanto una idea de fragilidad de las mismas como su carácter vital, de manera que su daño o deficiencia pone en riesgo la vida de la persona o por lo menos desencadena otras dificultades y experiencias de resistencia al flujo de vida. Entre las estructuras óseas figura la cadera, entre las vísceras, bazo, hígado y corazón, de los sentidos, la vista.

C: decían que le ha dicho el doctor que era el corazón, pero no creo que sea el corazón porque cuando es el corazón ya tiene que morirse [...] porque si el corazón ya es tiene que pasar algo, porque el corazón es muy delicado [...] digo yo, para ser de las arterias no debe ser tan grave, al corazón ya es más difícil [...] pero dicen que anda bien (P60, mujer, 57 años).

F: le han dicho que le ha reventado el hígado, la vesícula, los pulmones, pero cómo?! No estaría vivo! Si el hígado es la parte más delicada de la persona! (P66, curandero, 88 años).

O: [hablando del fusil en su época de servicio militar] había que cuidarlo como el ojo de la cara! ( $\mathrm{P} 2$, varón, 58 años).

F: uh! ella perdió la vista [...] la han operado de la vista y claro no se habrá cuidado [...] claro la vista es una cosa delicada, es una cosa tan delicada!

(P31, mujer 66 años).

Un último componente dentro de las representaciones anatómicas y que vincula a varios de los anteriormente nombrados lo constituye la sangre. En el capítulo precedente se la mencionó como eslabón en las explicaciones de varias etiologías: la locura o debilidad a la cabeza debido a que la sangre "se va a la cabeza"; la transfusión de sangre, solución frente a la anemia ("falta sangre") pero desencadenante de malestar e incluso muerte debido a que quien la recibió estaba demasiado débil, y agravante del estado del donante, quien ya padecía problemas cardíacos; efecto inmediato de golpes generando "apostemas" que con el tiempo desencadenan problemas de apéndice, vesícula, riñones, la generación de tumores y flebitis. 
Debido a un golpe se revientan las venas y la sangre golpeada (algunos hablan de "coágulo") se acumula, queda "para dentro", debe ser sacada para que no impida que el resto circule bien. Se presenta aquí una lógica explicativa semejante a la descripta anteriormente en torno a la acumulación de líquidos: la zona se infecta, se hincha y puede llegar a reventar. También se refirieron casos en los cuales la no circulación se da a nivel más generalizado provocando hinchazón de amplias zonas del cuerpo. En este caso la atribución causal no es unívoca, no se trata de un golpe o una lesión puntual sino que la explicación se busca en otros rasgos del evento particular de malestar (en una situación, por ejemplo, fue la acción negativa de remedios).

\section{J: flebitis}

A: y eso qué es?

$J:$ y que se revientan las venas, se me puso toda la canilla morada, de la rodilla para abajo, pero más cuando ando más por vapor se me ha inflamado, falta de circulación [...] porque yo tuve un golpe hace años y tenía unos moretones, yo digo que eso, camino mucho o lo que paso mucho parada, pesada yo capaz que me desparramó ese morado [...] es una infección que la sangre de las venas sale, que se desparrama, dicen que llega hasta podrir! (P68, mujer, 43 años).

R: le ha golpeado una válvula que tenemos tantas [...] se ha molido y se le ha cerrado, eso parece que se le ha reventado y se le ha cerrado, y no puede circular bien la sangre, cuando se le tapa esa cosa y no puede circular bien la sangre ahi es cuando se descompone (P79, mujer, 65 años).

$R$ : esos puntos se me infectaron [...] sacar esos puntos, me sacaron todo, esa sangre que tenía, dicen que una sangre que se había acumulado ahí (P20, mujer, 24 años).

E: primero se le ha hinchado el brazo que le curaban, lo ha internado en La Rioja y decian que le han hecho en contra los remedios [...] porque se ha hinchado entero dicen

A: y por qué los remedios le pueden hacer mal?

E: muchos antibióticos han dicho ellos [...] parece que le han hecho mal los antibióticos que se ha hinchado entero, que no circulaba la sangre

(P65, mujer, 78 años).

Cuando la disfunción en la circulación atañe a problemas cardíacos no se habla de sangre acumulada ni de coágulos, sólo se menciona que las arterias se trancan. Como ya se señaló, los términos "venas" y "arterias", cuando no denotan los vasos sanguíneos, son empleados con connotaciones distintas, el primero asociado al aparato motor, a lo muscular, el segundo vinculado al sistema respiratorio. Cuando son usados para hablar de la circulación, se utiliza "arterias" en vinculación al corazón y "venas" para zonas más periféricas. En algunos casos se estableció la relación sangre-problemas cardíacos no a través de alteraciones 
en la circulación sino del estado débil de la sangre asociado a una debilidad en términos generales causada por otros malestares.

F: del trabajo le ha atacado al pulmón, tejía telas, hilaba, tejía y eso la tenían siempre en Catamarca por gripes [...] lo que ella tejía tanto, tejía, hilar y tejer, todos los días, cansa la espalda, parece le ha atacado al pulmón

A: y eso habrá tenido que ver con el corazón?

F: claro, claro, porque el pulmón están pegados al corazón, que tenía ella los óvulos rojos han vencido a los blancos, ella tenía blancos los óvulos, más blancos que rojos A: y eso de qué es?

$F$ : ha de ser de la sangre, parece que ha estado muy débil la sangre, sabrá ser!

A: y eso le puede haber hecho algo al corazón?

F: claro (P67, mujer, 67 años).

L: la debilidad que él tiene, él tiene los glóbulos rojos los tiene blancos, eso dicen que le ha dicho el doctor que a él primero lo van a alimentar, le van a hacer vitaminas y recién le van a poner tienen como un aparato [para ponerle la droga] [...]

A: y esto de los glóbulos rojos que dice que los tenía blancos?

M: y porque dicen que ya la sangre está más débil

(P72, M: enfermera de la posta, L: mujer, 47 años).

R: dicen ellos que la presión alta ataca al corazón, le sale mucho la sangre que son débiles y le ataca al corazón y le desgarra el corazón (P79, mujer, 65 años).

Aunque en el fragmento precedente la presión alta aparece asociada a la debilidad de la sangre, salvo esta excepción y aunque la hipertensión fuera evocada con bastante frecuencia, no se registraron explicaciones donde explícita o implícitamente se planteara una relación entre estos dos factores (sangre y presión). Es decir, como causa de los problemas cardíacos se identifica a veces la presión alta con la que comparte varios síntomas (agitación, ahogo, debilidad, mareo, dolor de cabeza, trancazón en el pecho), y en otras ocasiones la sangre débil, pero entre las representaciones de la sangre y las de la hipertensión no se registraron nexos.

Pero la expresión "sangre débil" no es sinónimo de "estar anémico" aunque esta última se vincule también a la sangre y a un estado de debilidad. Mientras que las causas de la "sangre débil" son más vagas y generales (trabajo, cansancio, una situación de enfermedad previa) y se evoca una mayoría de glóbulos blancos en desmedro de los rojos, en el caso de la anemia, la debilidad es atribuida a una carencia alimentaria o pérdida de sangre ("hemorragia", la sangre que se termina, que falta).

Por último, "andar mal de la sangre" refiere a la idea de que la sangre no circula bien (manifestándose en sarpullido, ronchas o picazón) o a trastornos del ciclo menstrual. En el primer caso se establece una asociación con el sistema digestivo ya que se sostiene como terapéutica la purificación de la sangre mediante la ingesta de purgantes que limpian el 
estómago o de infusiones de hierbas a las que se les atribuyen propiedades purificantes (muña, romero, ruda). Té de escorzonera o muña es bebido para "calentar" la sangre en los casos de irregularidad del ciclo menstrual pues se considera que quien la padece tiene la sangre fría o "es" una persona fría.

$J$ : cuando salen esos sarpullidos así como ronchitas en el cuerpo, entonces dicen que uno anda mal de la sangre [...] la ruda porque es como purificante, como que le hace circular más la sangre, la ruda y, ahora que me acuerdo, la otra es la escorzonera [...] eso, por ejemplo, cuando una mujer por ahi se le atrasa el período, eso tomaban para... porque hay, dicen, hay gente que es normal y gente que, póngale, yo soy muy dura, muy fría, muy helada, y la escorzonera dice que como que le calienta la sangre (P49, mujer, 40 años).

A: la sal inglesa? y eso le limpiaba la sangre?

O: claro, la purga con eso... asi que fijese, comían carne de chivo, grasa de chivo, pan tortilla! Y no nos hacía nada [...] uh! Claro, nos íbamos por el inodoro, y bueno un aceite de bacalao, ah, ése era peor, una cucharada, lo recetaba el farmacéutico [...] para la sangre y el estómago, esto que sale [señala mi piel]

A: granitos?

O: debe ser del estómago, tiene que tomar eso (P78, varón, 60 años).

\section{El lenguaje como objetivación y comunicación de la experiencia de enfermedad}

En el apartado sobre aspectos metodológicos se señaló que la mayoría de las entrevistas se desarrollaron a partir de comentarios espontáneos acerca de algún padecimiento en curso o pasado de la persona entrevistada o de algún conocido de ésta y que el tema de salud-enfermedad emergió naturalmente y de manera recurrente en las conversaciones ante la mera pregunta “¿cómo anda?” con la que se inicia toda conversación. Al respecto se citó a Menéndez, quien afirma que los procesos de salud-enfermedad-atención constituyen "una de las áreas de la vida colectiva donde se estructuran la mayor cantidad de simbolizaciones y representaciones colectivas", "uno de los principales ejes de construcción de significados colectivos" (Menéndez, 1994: 71). ¿Por qué se esmeran los individuos en representar sus vivencias de padecimiento explayándose en detalles, describiendo los pasos del proceso terapéutico en el que tienen protagonismo?

En el acto lingüístico se concretan dos funciones del lenguaje: el lenguaje como objetivador de la experiencia a la vez que vehículo del proceso comunicativo, es decir, el lenguaje en tanto doble mediación: pasaje entre lo vivido y lo significado y puente entre interlocutores. Dado el carácter intersubjetivo de la experiencia y del lenguaje, la función 
objetivadora está entretejida con la función comunicativa: no sólo nos valemos de las formas posibles de representarnos nuestras experiencias a través del mundo compartido de significados sino que tarde o temprano ansiamos volcarlas nuevamente al espacio comunicativo, compartirlas, hacer partícipes de las mismas a quienes se cuenten como interlocutores; hasta el poeta que busca la perfección y precisión en el pasaje experiencialenguaje aparentemente a solas, lo hace con la intención de que el monólogo frente al papel se prolongue en un diálogo con el lector.

En el caso de las experiencias de sufrimiento y malestar, objetivación y comunicación han sido destacadas como elementos fundamentales del proceso terapéutico. Dichas experiencias a menudo alienan el cuerpo del sujeto y circunscriben en torno al enfermo un mundo extraño no compartido con el resto. Toda cura apelará, en mayor o menor grado, al poder del lenguaje para nombrar y describir con exactitud un sufrimiento y su explicación, para definir sus límites y así controlarlo. Si se cuenta con una interpretación de la enfermedad socialmente aceptada y validada, la realidad del padecimiento y del mundo del enfermo es asumida permitiendo la elaboración de nuevas experiencias dirigidas al restablecimiento de la salud. Respecto a la cura misma, las indagaciones acerca de la eficacia simbólica sugieren "la existencia de pasajes que vinculan cuerpo y mente, siendo estos el locus de una influencia amplia de la metáfora y el símbolo en los procesos biológicos" (Kleinman y Csordas, 1996: 16).

La objetivación verbal reafirma la integración del individuo en el mundo y su participación como autor y rector de sus actividades (Good, 1994a). Como afirma Le Breton,"la tarea de los especialistas (médicos, curanderos, adivinadores de la suerte, psicólogos, etc.) es reintroducir sentido allí donde éste falta, establecer una coherencia allí donde lo colectivo se inclina por ver sólo desorden. La carga de angustia inherente a las manifestaciones no habituales también se suprime y se atenúa por medio de la simbolización que se realiza con la ayuda del terapeuta" (Le Breton, 1995: 94). La definición de un malestar como enfermedad permite orientar una respuesta más activa para contrarrestar el sufrimiento, "una transformación fundamental de la experiencia ocurre cuando el sufrimiento es redefinido como enfermedad en la práctica médica. La práctica moral es transformada en práctica técnica, y esta última define cómo el resultado será definido, manejado y apreciado" (Kleinman y Csordas, 1996: 5). Sin embargo, dice Sartre, la enfermedad, en tanto objeto intersubjetivamente elaborado, conserva rasgos de la experiencia personal del dolor, del padecimiento del mal, son esos "caracteres de espontaneidad mágica, de finalidad destructora, de potencia maligna" que la Enfermedad ejerce en "su familiaridad conmigo y sobre sus 
relaciones concretas con mi ser, pues es, ante todo, mi enfermedad" (Sartre, 2006: 490, cursivas en el original).

Los individuos vuelcan en sus narraciones aquello de la experiencia que se deja aprehender por el lenguaje, para lo cual las metáforas amplían la capacidad del mismo. Además, como se señaló en párrafos anteriores, no sólo se valen de términos del sentido común, sino que también incorporan aquellos del campo biomédico y de los saberes de curanderos, cuyo valor como organizadores y descriptores de la realidad no es menor en tanto provienen de individuos en quienes se reconoce su competencia y autoridad en el tema de salud-enfermedad.

Dentro de esta perspectiva que considera al lenguaje en tanto constitutivo de la experiencia de enfermedad y no sólo su mera expresión, se entiende que la percepción y la identificación de las sensaciones mórbidas dependen de la riqueza y de la precisión de vocabulario, de la capacidad "socialmente condicionada, para manipular y memorizar las taxonomías mórbidas y sintomáticas” (Boltanski, 1975: 38). Pero este autor, cuyas conclusiones han tenido amplia influencia en posteriores trabajos sobre salud-enfermedad, considera por riqueza y precisión del vocabulario (lo que él denomina "competencia médica") sólo lo correspondiente a la jerga médica, como si el lenguaje de las sensaciones se nutriera sólo de vocablos biomédicos. En consecuencia, los miembros de las clases populares son considerados incapaces de describir correctamente su estado, de presentar al médico síntomas claros, inteligibles y significativos, quejándose frecuentemente sólo de dolores no localizados, de debilidad generalizada: "poco diestros para la descripción de lo que nos figuramos ha de ser su experiencia vivida de la enfermedad", conformándose "con la repetición de lo que recuerdan haberle escuchado al médico- fragmentos de palabras y de términos científicos enunciados en desorden y casi con vergüenza, desarrollando un discurso entrecortado y desprovisto de coherencia aparente" [...] "Los individuos situados más abajo en la escala social, que cuentan con un vocabulario de la sensación más limitado y más arcaico- puesto que el lenguaje de las sensaciones comprende las sucesivas experiencias de la ciencia médicaen primer lugar, sólo pueden identificar un número limitado de sensaciones o pueden percibir sensaciones no habituales sin interpretarlas como signos o síntomas de enfermedades alarmantes y, si éstos no son demasiado intensos, sin prestarles demasiada atención" (Boltanski, 1975: 29, 49). El consumo médico, es decir, la frecuencia del recurso al médico dependerá del nivel de "competencia médica", de ahí que éste aumente "según la proporción de diplomados". Pero como a su vez dicho consumo es considerado por Boltanski como indicador de la intensidad de necesidad médica sentida por los miembros de cada clase, la 
intensidad con la que se perciben y toleran las sensaciones mórbidas, el autor concluye que el interés y la atención que las personas dan al cuerpo aumenta a medida que se sube en la jerarquía social y disminuye la resistencia física exigida por las condiciones de vida. Como afirman otras autoras, desde la misma perspectiva, tanto la "falta de educación sanitaria, que dificulta la identificación de la enfermedad" como un "uso intensivo del cuerpo -característico de los estratos socioeconómicos bajos-" condicionan la percepción de las sensaciones relativas a la salud y la enfermedad, promoviendo la "negación de los síntomas al elevar el "umbral" para sentirse enfermo", "en los sectores populares, la cultura somática -ese poder sentir, escuchar al cuerpo- es escasa y la lucha por la supervivencia "eclipsa" la temática de la salud; la imposición de conseguir el sustento diario hace que se retarde la concurrencia a la consulta médica y, a veces, dificulta el registro de las molestias hasta que éstas se imponen cuando ya es imposible no registrarlas" (Kornblit y Mendes Diz, 2000: 15).

Desde lo descripto para el caso azampeño quiero hacer tres cuestionamientos a la perspectiva anteriormente presentada: primero en lo que refiere a la capacidad de expresar y transmitir las sensaciones de malestar, es decir, la "competencia médica", al ser considerada sólo como el cuerpo de vocablos biomédicos obtenidos a partir de una "educación sanitaria" ("taxonomías mórbidas y sintomáticas" que se deben "memorizar") es caracterizada en los sectores populares en términos de escasez o pobreza de vocabulario pues se ignoran otros recursos lingüísticos (términos del sentido común, empleo de metáforas, analogías, etc.) cuya profusión en las descripciones de las experiencias de malestar dan muestra de que tampoco se puede hablar de pobreza de percepción. Tanto desde la opinión de los médicos entrevistados como de los azampeños no fueron señaladas dificultades lingüísticas que afectaran el desenvolvimiento de la consulta médica (más adelante se verá que las críticas realizadas respecto a la atención médica no aluden a desencuentros lingüísticos). Como advierte Fitzpatrick, con frecuencia se ha hecho hincapié en el "abismo" entre conceptos ordinarios y médicos, lo que quizá contribuya a autoperpetuar el estereotipo del paciente con poca o ninguna capacidad para comprender el lenguaje médico (los médicos, dando por sentado que el paciente está mal informado, evitan ampliar el análisis en la consulta). Si bien, incluso cuando se emplean términos idénticos no debe inferirse que se trata del mismo referente en los dos sistemas, la idea de un abismo cultural entre modos profesionales y ordinarios de pensamiento puede ser exagerada si se tiene en cuenta que la práctica clínica difiere bastante de la medicina consagrada en los libros de texto. "La práctica de la medicina general puede estar influida más directamente por conceptos ordinarios o populares y puede ser vista como 
un sistema de pensamiento situado a la mitad del camino entre la medicina de hospital y las ideas ordinarias" (Fitzpatrick, 1990: 33).

El segundo punto que cuestiono es que al considerar la frecuencia con que se acude al médico como indicador de la intensidad de "necesidad médica", de la intensidad con la que se perciben y toleran las sensaciones mórbidas, no se están teniendo en cuenta otros recursos terapéuticos como las formas de atención alternativas y las respuestas desde el nivel de la autoatención. Una elevada frecuencia de consultas a curanderos o de usos caseros estaría indicando un "umbral" bajo para sentirse enfermo, es decir un elevado registro de las molestias y un estado de alerta susceptible.

Por último, en el esquema de Boltanski la baja percepción de las sensaciones de malestar, además de corresponderse con una carencia de vocablos para nombrar los síntomas, se debe a un mayor grado de utilización del cuerpo en la vida laboral el cual a su vez es función de un nivel menor de instrucción. Es decir, cuanto mayor es el esfuerzo físico exigido, menor es la atención que los individuos prestan a su cuerpo manteniendo con él una relación menos consciente. De lo que se concluye que tal vez el desarrollo de una relación reflexiva con el cuerpo sea poco compatible con su utilización intensa, que quien necesita hacer una utilización máxima de su cuerpo no puede mantener con él una relación atenta, escucharlo, analizarlo y comprenderlo. En el caso de la población azampeña, el quehacer necesario en un ambiente que exige esfuerzos físicos, labores arduas y desgastantes no parece reducir la percepción del cuerpo propio, sino al contrario, ponerlo en evidencia, volverlo explícito cuando debido a un malestar no responde de la manera asumida como natural. Es decir, los individuos perciben que algo está mal cuando no pueden llevar a cabo ciertas tareas de manera natural o espontánea; sin actividades que demanden algo del cuerpo el carácter de resistencia al flujo de vida que presentan los malestares estaría ausente. Retomando los ejemplos de fragmentos anteriormente transcriptos, si no se debiera lavar o hacer tortilla no se notaría la imposibilidad de mover el brazo, si no se necesitara cargar leña no se notaría el dolor en el codo, sin la necesidad de caminar o barrer no se percibiría la agitación. El cuerpo está mucho más presente en la conciencia cuando se utilizan sus recursos en la vida cotidiana, las actividades físicas vinculadas con el trabajo y el quehacer doméstico resaltan el anclaje corporal de la existencia. "La movilidad y la motilidad del cuerpo permiten el enriquecimiento de percepciones indispensables para la estructuración del yo. Disminuir, incluso suprimir este dinamismo, fijar al máximo actitudes y comportamientos, es perturbar gravemente a la persona y lesionar las facultades de intervención en la realidad" (Virilio 1976 en Le Breton, 1995: 163). 


\section{La eficacia terapéutica}

\section{Una conceptualización fluida de eficacia: entre las expectativas y los cambios percibidos}

La evaluación de los distintos recursos terapéuticos, la decisión de cambiar de un modo de atención a otro o de complementarlo, la búsqueda por una redefinición del diagnóstico y/o por otras respuestas terapéuticas, todo ello se sustenta en la apreciación que los individuos realizan de los resultados obtenidos. Cabe recordar aquí la definición anteriormente citada de resultados terapéuticos como la disposición de los participantes en un determinado punto final del proceso terapéutico tanto respecto a su satisfacción expresada (elevada o baja) como al cambio positivo o negativo de los síntomas, la patología o el funcionamiento (Kleinman y Csordas, 1996). El reconocimiento de la eficacia es realizado de diferente manera por los diferentes actores involucrados en un episodio de enfermedad, cada cual con sus percepciones, experiencias y motivaciones, con su particular visión de los resultados anticipados y los obtenidos de un tratamiento, "participants have a sense that their healing system 'works' when a sickness episode is consistent with their expectations... Insofar as these alternative healing systems adequately match adherents' expectations with their experiences, they 'work' (McGuire, 1991: 189). Expectations, of course, are developed by the individual patient based on prior knowledge of both healing specifics and broader cultural understandings. But this personal understanding of efficacy does not distinguish traditional or alternative medicine from biomedicine"38 (Waldram, 2000: 614). Este autor cita una definición amplia de eficacia donde el acento está puesto en las esperanzas y expectativas de los actores involucrados en un proceso terapéutico: "Young, conceptualizing efficacy in terms of goals, has defined it broadly as "the ability to purposively affect the real world in some observable way, to bring about the kinds of results that the actors anticipate will be brought about" [...] "regardless of whether or not the sick person's situation has been improved by the healer's activities" (Young, 1976: 7), "the perceived capacity of a given practice to affect

\footnotetext{
38 "Los participantes tienen un sentido de que su sistema de cura 'actúa' cuando el episodio de enfermedad se corresponde con sus expectativas... en la medida en que estos sistemas de curas alternativas acoplan adecuadamente las expectativas de sus adherentes con sus experiencias, 'actúan' (McGuire, 1991: 189). Las expectativas, obviamente, son desarrolladas por el paciente a partir de su conocimiento previo tanto de especificidades de cura como una comprensión cultural general. Pero este entendimiento personal de la eficacia no distingue medicina tradicional o alternativa de la biomedicina" (traducción personal).
} 
sickness in some desirable way" (Young, 1983:1208)"39 (Waldram, 2000: 606). Así como se señaló que los sujetos acuden a las consultas con un diagnóstico provisional (Menéndez, 2005) también lo hacen portando expectativas de los resultados del tratamiento basadas en conocimientos previos, y la medida en que éstas son cumplidas influirá en el grado de conformidad con las acciones y prescripciones terapéuticas, en las apreciaciones de eficacia y de la necesidad de realizar consultas a otros curadores.

Las perspectivas del paciente y del curador en torno a la eficacia pueden ser marcadamente distintas o similares, pero interactúan y se influyen: el terapeuta pregunta al paciente acerca de su estado y la respuesta puede llevarlo a determinar el éxito del tratamiento, y a su vez al informar al paciente sobre los resultados de un estudio o procedimiento influye en las evaluaciones que éste realiza de su condición. Igualmente el fracaso es racionalizado ya sea evitando cuestionar la legitimidad del sistema terapéutico empleado pero redefiniendo las nociones de salud y enfermedad, adjudicándoselo a las prácticas terapéuticas empleadas o sirviendo de prueba de la poca habilidad del terapeuta (sosteniendo atribuciones de competencia, ineptitud o negligencia, base para la distinción de especializaciones y jerarquías entre curadores). Cómo la eficacia es definida y cuándo se considera alcanzada varía también a lo largo del episodio de enfermedad, por ello debe ser concebida no como una noción fija anclada en una perspectiva particular de salud-enfermedad sino como algo cambiante, constantemente negociado entre los diversos actores. Así mismo, los parámetros con los que se evalúe la eficacia o el fracaso terapéutico son relativos a cada sistema médico por lo que una conceptualización fluida de eficacia se torna ineludible a la hora de entender situaciones de pluralismo médico (Waldram, 2000).

Consecuentemente, este autor sugiere que la investigación en antropología médica debe explorar y comprender cómo la eficacia es entendida desde el mismo sistema médico tradicional y no empleando conceptos y métodos biomédicos que buscan un aparente paralelismo entre los distintos sistemas médicos (Waldram, 2000: 619). En la misma dirección apuntaba la crítica anteriormente citada de Scheper-Hughes respecto a la limitación de la antropología médica para comprender formas paradójicas de experiencia y sanación en tanto permanezca fiel a la ortodoxia epistemológica occidental (biomédica) con sus dicotomías cuerpo/mente, visible/invisible, real/no real. Otra limitación en los análisis sobre eficacia terapéutica es el hecho de que se realicen focalizando en las prácticas y saberes de los

\footnotetext{
39 "Young, conceptualizando la eficacia en términos de objetivos, la ha definido ampliamente como "la habilidad de afectar intencionalmente el mundo real de una manera observable, de ocasionar el tipo de resultados que los actores prevén que tendrán lugar" [...] "no importando si la situación de la persona enferma ha mejorado o no debido a las actividades del curador" (Young, 1976: 7), "la capacidad percibida de una práctica determinada para afectar la enfermedad de una manera deseable" (Young, 1983: 1208)" (traducción personal).
} 
curadores restándole atención a la experiencia del paciente, quien es quien sufre las transformaciones y cambios que permiten hablar de eficacia o fracaso de la cura (Csordas, 1994). Ésta es la razón por la que la mayoría de los intentos por comprender el accionar de las terapéuticas que por su naturaleza resisten las explicaciones biomédicas (por ejemplo las curas religiosas o en términos más amplios, simbólicas) no van más allá de entenderlas a partir de mecanismos globales como el trance, la catarsis, el efecto placebo y la sugestión, permaneciendo el mecanismo en sí (qué es lo que hace terapéutico al trance o cualquiera de ellos) como una caja negra (Csordas, 1994). Por otra parte, y como señala Mallart Guimerà, "la antropología no está equipada para elucidar si unas plantas, por ejemplo, están dotadas de aquellos principios activos que permitan afirmar o negar su eficacia en el tratamiento de la enfermedad por la cual han sido utilizadas. Sólo farmacéuticos y químicos, equipados con sus laboratorios podrían llegar a tales conclusiones. Pero sí, en cambio, el etnógrafo puede interesarse por la manera en que una sociedad piensa la noción de eficacia que atribuye a las plantas que elige en sus tratamientos" (Mallart Guimerà, 2008: 192).

El complejo tema de la eficacia terapéutica será primeramente abordado desde la perspectiva de los individuos que buscan solucionar y entender sus padecimientos, dado que, como se expresó anteriormente, es a partir de sus criterios de eficacia y fracaso que se orienta la elección de las terapias. Se intenta elucidar en qué fundamentan sus conclusiones de eficacia o fracaso, cómo explican la eficacia, a qué cualidades o elementos la atribuyen, lo cual, como se vio anteriormente, con frecuencia emerge entretejido con los elementos identificados como patogénicos, sobre todo cuando explicitan una relación clara entre la causa del malestar y el accionar de la terapéutica correspondiente.

\section{Sobre la eficacia de las terapéuticas biomédicas}

Cuando se refieren a los tratamientos biomédicos (y también a la ingesta de pastillas o jarabes prescriptos por curanderos o autoadministrados), la afirmación de la eficacia o del fracaso de los mismos en la mayoría de los casos no es explicada sino que es evidenciada a partir de la asociación temporal entre su ingesta y la posterior percepción de cambios (o no) sintomáticos y si éstos son positivos o negativos. Los remedios (pastillas, antibióticos, inyecciones, pomadas, vitaminas) solucionan o no, "lo tomo y ando bien", "con eso estoy mejor", "queda bien", "ha quedado sanito", "lo ha curado bien", "con eso se ha compuesto" o "no me hacen nada", "no sentía curación". 
F: yo le dije porque yo sentía debilidad, bueh, me ha recetado y me ha dado unas vitaminas, y con eso, con las vitaminas estoy mejor

A: se curó?

F: claro! [...] porque eso tiene que darles remedios, tónicos, cosos que sean de dentro (P55, curandero, 84 años).

JA: pero ahora tengo mejorcito que hace como dos meses ya he andado a la médica la de alergia [...] aquí en Belén, dice que, me compro pomadas, me hacía inyección y ahí he andado dos veces, ahora luego

S: va mejor (P50, JA: mujer, 64 años; S: varón, 76 años).

M: no, hay otros que vienen con dolor de piernas otros, dolor de huesos [...] y bueno, les da un remedio y hay veces gente que lo cura muy bien, que le sienta bien, le hace inyección para el dolor de huesos (P51, enfermera de la posta).

E: y sí, le han dado remedios, todo, pero ha estado internado y ha quedado bien, y después ha vuelto a ir y ya está bien y me he dicho él a mí que le han dicho que ya no va a sentir tantos dolores (P65, mujer, 78 años).

R: ha sufrido muchos años con eso, tenía 17 años y mire ahora cuánto se ha hecho ver como a los 30, de grande se ha hecho ver en Catamarca

A: y en Belén no le daban nada?

$R$ : y le recetaban una gotas pero no le hacían nada [...] cuando ha ido a Catamarca le han dado estas pastillas [...] en Catamarca lo ha estado de un lado a otro y no le hacían nada y una hermana de él, mi hija lo llevó a... habia encontrado y lo ha hecho ver y ahí ha empezado bien ya, porque él tiene que tener estas pastillas [...] eso parece que se le ha reventado y se le ha cerrado, y no puede circular bien la sangre, cuando se le tapa esa cosa y no puede circular bien la sangre ahi es cuando se descompone [...] las pastillas sabrá ser que le hacen circular por eso ya de que ha empezado a tomar... (P79, mujer, 65 años).

M: y dicen que a ella le han hecho la droga y dicen que se ha secado, ella tenía así una cabeza, se le hinchaba la cabeza, las manitos no, porque es como entra a la cabeza y se le ha infeccionado ahi dicen que hay una doctora que es especial para eso, en Catamarca, para cualquier tumor, dicen, ella tiene un equipo de médicos en Bs As y ella le ha puesto la droga a la chinita, decían que no la iban a operar, que no tenía remedio, pero dicen que ella le ha hecho las 3 drogas y la ha llevado a Bs As y la han operado se lo han sacado y dicen que está bien (P72, enfermera de la posta)

En los dos últimos fragmentos hay un intento de explicación del accionar del remedio deduciéndolo de la causa identificada, pero generalmente la afirmación de la eficacia se sostuvo, sin mayores explicaciones, en la testificación de un cese o disminución de los síntomas luego de la terapéutica, a veces reforzada con otras experiencias positivas con el mismo remedio o con la aseveración de que una medicación dada "es para" tal órgano o malestar.

A: el ibuprofeno? 
L: dicen que es muy bueno, no? [...] porque mi abuelita, para los dolores de rodilla ella se toma una pastilla de ibuprofeno y anda como una joven [...] la Buscapina fem son para el hígado

A: las compraste vos?

L: también las traje de la farmacia, esa las compro

A: sola, ya sabias o te las recetó alguien?

L: no me las receta también la señora de Corral [curandera] ella me recetó porque tengo mucho dolor de ovarios más que todo cuando ando indispuesta, dice que es muy buena esa pastilla [...] dice que es analgésico algo, no sé cómo sabrá ser el nombre y antiaspasmódico, no sé, yo tomé eso y con eso anduve bien (P16, mujer, 22 años).

L: una es para convulsión y la otra es para los nervios, toma dos por día, pero lo mismo le dan, no le dan fuerte pero le dan (P76, mujer, 47 años).

E: me ha dado unos remedios y unas pastillas que tome para la debilidad y me he compuesto (P64, mujer, 51 años).

F: lo ha atacado a los bronquitos, del frío es, porque en invierno es frio! [...] le ha dado unos jarabes, inyecciones que le ha hecho y se ha compuesto (P44, mujer, 64 años).

$J:[\ldots]$ andaba mal, nerviosa [...] como que me agarraban nervios, ha visto? como que chocábamos, y ahora desde que he empezado a tomar los remedios no, ando tranquila (P7, mujer, 42 años).

J: como epelepsia, y le agarraba y quedaba media redura, o le quedaba la lengua saliendo asi para un lado, ha visto? de los ataques que le daban, y desde que él la empezó a tratar nunca más le han vuelto esos ataques (P7, mujer, 42 años).

La aplicación de suero en casos de internación es identificada como el componente principal de la terapéutica ya que se reconoce que en el suero se administran los medicamentos pero también por su asociación con la idea de lavaje: el "suero con antibióticos" "limpia la inflamación", lo que se considera eficaz en casos de infección o de dolor de rodillas dado que estos se explican por un líquido que "se junta" o "desparrama".

P: le han hecho suero, ahora anda bien [...] se ha compuesto (P19, mujer, 43 años).

R: si anda bien, hace un tiempo anda bien, si ahora parece que pocos dias, dos días ha estado internada... curaciones y ya la han dado de alta

A: y para qué la han internado?

$R$ : para hacerle curaciones porque eso es con el suero

A: y el suero para qué?

$R$ : no sé para qué le sabrán poner, siempre le ponen el suero para lavarle (P21, mujer, 63 años).

M: ahí nomás le dieron suero y los medicamentos que le hacen en el suero

A: y cuando la llevaron de acá ya se había despertado?

M: no, estaba desmayada 
A: todo el viaje inconsciente?

M: sí, exactamente, cuando hemos llegado ya la doctora la ha atendido, los medicamentos y se ha despertado (P64, mujer 34 años).

A: cuánto estuvo internada?

$G$ : tres dias con suero, suero y vitaminas, gratis no se lo ponen a la vitaminas o antibióticos

A: y mejoró?

G: ah sí! (P14, varón, 79 años).

G: de las rodillas me he dicho que me tenía que curar, cuando estaba allá me iba y me internaba, meta suero y suero, ya andaba bien

A: y qué le hacian cuando se internaba para curarle las rodillas?

G: en las rodillas, como yo andaba, sí, muchas vitaminas en el suero, ahí en el suero le ponen, no me ponían aparte, en el suero iba todo adentro

A: y estaba muchos dias internado?

G: y una semana, volvía, me volvía a venir, "querés que te interne?" me decía el doctor, "y claro, a eso he venido!", ya estaba acostumbrado, en el sanatorio Francés (P33, varón, 78 años).

La explicación de la acción terapéutica se explaya un poco más cuando se trata de tratamientos de heridas o en casos de intervenciones quirúrgicas: se lava, limpia, raspa, quema, despega, corta, liga, drena, vacía, expresiones frecuentemente acompañadas por apreciaciones de peligrosidad y agresividad del tratamiento fundamentadas en la observación de resultados no deseados. Como se vio anteriormente, prima la percepción de una potencial iatrogenia aunque en algunos casos también se reconozca la eficacia de tales intervenciones (cuando el resultado es positivo y cuando, dado las particularidades del malestar, tales respuestas terapéuticas se consideran ineludibles).

E: no, no es nada, le hacen una curación, una limpieza le han de hacer un lavaje, si ha hablado que está bien, dicen que el lunes creo que va a venir

(P64, mujer, 51 años).

N: bocio

A: y eso de qué era?

N: de qué sabrá ser eso? Dice que eran unas pelotas de carne en la garganta

A: y qué se decidió por operarse?

$N$ : porque ya no podía caminar, para caminar se agitaba mucho y bueno, ya tenía que operarse porque se le ha criado muy grande, la quijada le asentaba sobre eso, y ya no podía caminar, decía que a gatas llegaba de...

A: y se ha operado en Catamarca?

N: en Catamarca

A: $y$ ha quedado bien?

N: hasta ahora ha quedado bien, nada más que la voz se le ha bajado, pero como eso, en la medida que se va, va a hablar mejor recuperando porque la hermana mía, la madre de la $V$, esa también ha sido operada

A: hace mucho? 
N: uy ya muchos años [...] y ella ha quedado bien, no, eso ya lo sacan y no crece más (P58, mujer, 69 años).

G: Vea yo ahi tenía una úlcera de pie, lastimado [...] cuando apenas va inmediatamente, te ponen el suero pero sin vitaminas, y de ahí seguía del pie y seguía y seguía, como dos meses y hemos ido para el otro hospital [primero fue al público luego al sanatorio] me han hecho sufrir, estaba de llorar porque me agarraban de lastimado y me daban con una tijera y con el algodón, una gasa, la envolvían a la pierna, me limpiaban, me curaban, qué, me hacían correr la sangre por la pata! Y he estado 15 días y no me han hecho nada, nada, y ahi me dice el doctor "ya estás churo, te voy a dar de alta" y bueno si me quiero ir con mi doctor, $y$ ahi he vuelto al sanatorio [...] seguía mal y bueno, después los médicos me han sanado y ahí me curé

A: y en el sanatorio qué le hicieron?

G: todos con enfermera... me limpiaban con la pomadita (P33, varón, 78 años).

En este último fragmento se observa cómo el paciente acude con ciertas expectativas sobre la terapéutica, por ejemplo su duración y que en el suero se incluyan medicamentos o vitaminas, cuando ésta se prolonga sin observarse resultados positivos decide cambiar de terapeuta y de centro de atención. Aquí se evidencia también cómo difieren las apreciaciones de eficacia entre el médico que le da el alta y el paciente que percibe que su herida no ha sanado, lo que repercute en las valoraciones de los distintos centros y de los distintos profesionales.

Al igual que en el caso de las intervenciones quirúrgicas, la ingesta de remedios puede ocasionar cambios negativos empeorando el estado del enfermo con nuevos síntomas ya no causados por la enfermedad sino atribuidos al medicamento (sea por su mala calidad, porque corresponden a un tratamiento equivocado o por alergia o debilidad frente al mismo).

A: y al médico de acá no fue, al que viene acá a la posta?

M: si [...] siempre me da las pastillas para alimento, pastillas esas de hierro, pero usted sabe que es como que me cayeran mal esas, me hacen doler la cabeza, sabrá ser que soy débil tal vez yo [...] me hacen doler la cabeza, entero el cuerpo, será mucha la debilidad asi que la he tomado y la he dejado, he tomado unita, ya me ha dado dolor de cabeza, no voy a tomar, digo, porque a mí el doctor de Catamarca me ha recetado otras pastillas para alimento, esas me sentaban muy bien (P11, mujer, 56 años).

J: no, me fui a Belén, fui a la ciudad [Catamarca] y con antibióticos, antibióticos, para colmo ahora al último ya me hacen alergia y me sale que soy alérgica a la penicilina así que estoy tomando un mínimo de antibiótico, el más simple [...] porque me he empezado a enronchar toda, un picazón terrible que me ha agarrado, una desesperación que me agarra, me quería lastimar, y el médico me hizo análisis, me dice "no, sos alérgica a la penicilina, a los antibióticos, asi que te voy a dar lo más simple" y bueno, pero lo más simple me agarra, lo tomo y al tercer día se me... en el cuerpo [...] me dice "bueno, veremos de otra cosa" pero no sabe qué darme porque 
es lo más simple, y bueno yo me la aguanto pero él me dice "no, porque por ahí te levanta la presión y en un rato" [...] por ahí me va a agarrar como un paro

A: por la misma alergia?

J: por la misma alergia [...] después, fui [a un curandero] como a los 5 o 6 meses recién fui porque ya no me hacían nada los remedios, ya no me hacían nada, no sentía efecto, curación, y bueno, ya me empecé a desesperar [...] porque digo, dios mío esto es ya de terminar y me da la impaciencia de que tenía que estar sentada con los pies para arriba o en cama con los pies para arriba y cada dos por tres ya tenía que estar con el suero. Sueros, antibióticos... [...] es una infección que la sangre de las venas sale, que se desparrama, dicen que llega hasta podrir! claro... más lo que me fui a enfermar, porque fui al médico este, fui a un flebólogo! Fui, e iban unos con así unos agujeros en las piernas, eran como la casa de hormigas! Y de adentro le salía de a poquito la sangre así pero seca! Como la casa de hormiga! Y digo no! yo no vuelvo más, y me empecé a hacer remedios caseros [...] y aqui un hombrecito de La Estancia me daba que me ponga el cuajo con el que forman el queso y el suero y después que haga hervir un monte [...] y él me está componiendo más [...]

A: y el cuajo cómo te lo ponés?

J: como un refrescante, que me saca el calor, le saca el vapor, por ejemplo todo ésto [señala el suelo que está baldeando] yo estoy alzando para ahí, ha visto? Y eso me pone primero rojo, después se pone como verde, después se pone morado, negro, y voy en la casa y me pongo eso y a la hoja del lampazo, una hoja grande, verde [...] y esa me la pongo pero sale seca [...] como si le habrá hecho fuego! [...] y bueno con todos los remedios caseros se me fue yendo, gracias a dios (P68, mujer, 43 años).

En el primer fragmento la entrevistada compara los efectos de las pastillas dadas por distintos profesionales (el médico de zona y uno que la atiende en Catamarca) y en función de dicha comparación establece la eficacia de una y el fracaso de la otra sumado a sus efectos adversos. Ésto la motiva a interrumpir el tratamiento y contribuye a la actitud de desconfianza hacia las respuestas dadas desde la posta. En el segundo fragmento el fracaso atribuido a los remedios dados por el clínico lleva a la paciente a buscar atención con un curandero, sin que ello implique un cambio en el diagnóstico pero sí en la respuesta terapéutica. En este ejemplo se puede observar cómo la eficacia (ausente) se evalúa en relación al tiempo transcurrido sin que se perciba una mejoría, sumado a resultados contraproducentes del remedio (alergia y riesgo cardíaco), a la observación del estado de gravedad de numerosos pacientes que acudían al mismo médico (de lo que la entrevistada dedujo escasos éxitos terapéuticos) y a la comparación con los cambios positivos resultantes de lo recetado por el curandero. En los fragmentos siguientes el fracaso terapéutico de la biomedicina se explica por una inadecuación de sus recursos frente a enfermedades "para curanderos", por lo que el cambio de terapeuta conlleva una redefinición del diagnóstico.

$E:[. .$.$] dice "no la vayas a dejar internar, porque te le van a poner suero y esta no es$ enfermedad para los médicos" [...] "no la vayas a dejar internada!" porque dice es fiebre del empacho y es mucho susto lo que tiene esa niña y me he llegado a las 9 y me la ha visto, la ha curado y se ha dormido (P58, mujer, 27 años). 

A: pero qué sentía ella?
C: ella se perdía de la cabeza
E: se descontrolaba y no sabía qué es lo que hacía
$C:$ y ella los medicamentos que le daba el doctor no quería tomar
E: ella dice que peor se sentía
A: y por qué esos remedios le hacían mal?
E: y porque ha sido alguna enfermedad que no es para los doctores, ella decía que las pastillas que le daban le daban ganas de caminar, de caminar y caminar le agarraba así un desasosiego y le dolía el estómago y cuando se hizo ver con este otro ya [con un curandero]
C: y ése la está curando de aire, que tiene mucho aire
E: [...] él le da té de montes, yuyitos [...] la ha curado 3 veces [...] y ya ha dejado después ya empezó a sentirse bien (P60, mujeres, E: 80 años; C: 57 años).

En unos casos la expectativa de sufrir nuevos malestares a partir de la aplicación o ingesta de medicamentos fue mencionada como parte constitutiva del proceso de cura. Fue cuando se refirieron a casos de cáncer o tumor que debían ser tratados con "drogas" que "sequen" y "corten" el mal. Como se destacó, la palabra "droga" es empleada resaltando el carácter fuerte del medicamento y su potencial iatrogenia. La fuerza de las drogas para "quemar" el mal ocasiona también daños, debilidad, caída de pelo, pero a su vez se reconoce en este estado general de empeoramiento un indicador de que la droga está haciendo efecto, es decir, ciertos malestares que surgen en el contexto del tratamiento son interpretados como indicios del proceso de cura (ésto también fue referido en un caso que no se trataba de cáncer).

L: [...] cuando le hace bien dice que tiene reacciones, desmayo, se pone mal, y cuando dice que no, dice que lo más bien [...]

M: claro, dicen que hay reacciones buenas y reacciones malas, demoran muchos dias cuando... ahi nomás, a los 8 días cuando ya lo sacan de la sala, pero si a ella le han hecho cuando tenía 12 años![...] cómo ha resistido! Pero ella a los tres días estaba sin uñas, sin cejas, sin nada, sin cabello, todo! La droga le ha caído todo, dice, pelada pero total! Brazos, todo, todo Y después se recupera

A: y por qué?

M: es muy fuerte

L: claro eso dijo el médico que tenía que avisarle a él porque a él a lo mejor después se le va a caer el pelo

M: 3 días le hicieron curar, dicen que la chica lloraba porque no quería que la vieran, pero a los 15 días, 20 días ya estaba de nuevo con...

A: y por qué serán tan fuertes esas drogas?

L: y parece que lo quema la tumor

(P72, M: enfermera de la posta, L: mujer, 47 años).

Esta idea de empeoramiento sintomático como señal del proceso de cura constituye un principio interpretativo que hace inteligible las experiencias de terceros (narrada aquí por la 
enfermera) y las advertencias del médico (de lo que desde la biomedicina se consideran efectos secundarios) orientando la manera en que esta información influirá en las expectativas del proceso terapéutico, en cuáles serán las reacciones esperables a lo largo del mismo.

$J:$ [...] era una cosa como que me sedaban, y después me despertaba, y me despertaba mareada, con dolor de cabeza, y por eso me empezó a dar miedo, por ahi solía ser que era la siesta y me levantaba con un dolor de cabeza, nunca me sabia dar dolor de cabeza, pero yo digo deben ser que los remedios me están moviendo

A: cómo moviendo?

J: y moviendo el mal, porque cuando usted empieza a tomar es como que le hacen peor [...] y después recién le empieza a mejorar pero yo en esto por ejemplo, estas pastillas que me ha dado para que tome antes de comer, una hora antes de comer y hay otras pastillas que las tomo cada 8 horas, esa es como que la he sentido, pero a la otra que me da para los nervios no (P7, mujer, 42 años).

Dado que la eficacia de las terapéuticas biomédicas es atribuida (con la salvedad hecha respecto a las intervenciones quirúrgicas) al accionar de los medicamentos a partir de percibir una disminución o cese de los síntomas, y puesto que el fracaso de las mismas se adjudica a efectos adversos de los medicamentos o a una aplicación errada de los mismos, el mérito otorgado a los terapeutas reside en su esmero en el diagnóstico (si los revisó o no y si les hizo "hacer estudios": análisis, diagnóstico por imágenes). Ante la ausencia de mejoría durante el tratamiento, la poca dedicación puesta para diagnosticar aumentará las sospechas de un error en la medicación y será enunciada para explicar el fracaso terapéutico percibido y la decisión de cambiar de terapeuta.

P: no es un médico que, por ejemplo usted lo lleva al chico ni lo revisa, ni lo toca nada, no, por ejemplo usted va y le dice "mire doctor, me duele aqui", no él la mira nomás y le hace la indicación de los remedios y le da los remedios [compara con otro doctor] él los revisaba, pero los revisaba de bien [...] uno le explicaba las cosas, uno le explicaba al doctor $S$, por ejemplo, él nos preguntaba qué ha tenido, si cómo han empezado, por ejemplo cuando tenían vómitos así, él decía de cómo le había empezado, de cómo había sido cuando ha vomitado por primera vez, qué ha vomitado, cómo ha vomitado, y bueno, uno le explicaba (P19, mujer, 43 años).

R: poco le lleva el apunte a la gente, ellos nada más van y lo miran y dicen esto tiene nomás

N: no es como en otros lados, en Catamarca ahí para curar le hace primeramente todos los estudios y recién ahí le van a comenzar a dar la medicación, pero aquí no, aquí lo ha mirado y dice, pero no le hace ningún estudio, nada! Por eso aquí no curan, en vez de curarlo para que sane lo enferman para peor

(P58, mujeres, N: 69; R: 58 años).

$R$ : no volví para ahi [la posta] [...] fui para Belén [...] yo siempre la llevo a ella que se resfriaba, pero no... estudios no, le daba remedios pero se le pasaba andaba unos días y ya le volvía otra vez y la volvía a llevar al médico [...] en el mismo hospital [de la ciudad de Catamarca] la han internado ahí, le han empezado a hacer los estudios y 
ya salió que tenía neumonía, ahí te lo hacen en un momento le hacen todos los estudios no es lo mismo que en Belén, y ahí estuve 15 días con ella me la han curado bien

A: y qué le dan?

$R$ : antibióticos, por el suero le ponen todo (P77, mujer, 23 años).

E: [...] y hemos venido a Belén y hemos encontrado con el doctor y la doctora y esos me han hecho estudios y ellos me han recetado la vacuna esa, y esa vacuna... me compone el cuerpo, tiene un tiempo, cada 3 meses me ha dicho el doctor, muy buena médica la doctora, ella me controló primero y después ya ella y el doctor, y ellos me han puesto sana, ya he andado sana, todo el pecho, bien, bien, no me dolía nada, ni los huesos y después ya cuando ellos se han ido, ya no me han, ya no he ido a control porque ya no estaba el doctor (P27, mujer, 80 años).

\section{Sobre la eficacia de las terapéuticas tradicionales}

Cuando se refieren a las terapéuticas de curanderos describen, además de los remedios recetados (yuyos y medicamentos), las acciones de cura llevadas a cabo en la instancia de consulta y los elementos empleados en las mismas. Si bien se señaló anteriormente que el componente esencial de estas prácticas de cura son los "secretos" que el curandero dice para sí, éstos van siempre acompañados por acciones de manipulación del cuerpo del enfermo, con frecuencia utilizando elementos a los cuales se les atribuye parte de la eficacia: la acción de sobar o palpar, gestos de extracción del aire con las manos, la señal de la cruz, maniobras con una cinta, toques con un algodón con alcohol o con una barra de azufre o alcanfor, aplicaciones de huevo, tinta, sahúmo con yareta, yerba, azúcar, lana, entre otros.

T: ya le tantea la cabeza y está asustadito dice

A: y cómo lo cura él?

T: sabe mucho él, hace una cruz, tendrá secretos [...] se tranquiliza

L: agarra unas barritas de azufre y le hace pasar así en cruz [se señala la frente y la nariz] no sé qué podrá rezar porque reza muy despacito y le hace por ahí una cruz así [en la cabeza] después le soba así la cabecita y la espalda y después agarra y moja un algodón en un poquitito de alcohol y le hace pasar ahi y ahí [señal de la cruz en la frente y en la cabeza] y le aprieta, así le hace [de frente y de costado] y eso es todo T: ya vuelve el espiritu (P70, mujeres, T: 72; L: 23 años).

F: y yo con, yo ni un remedio de nada, ni he dicho venga este remedio, este otro, basta mis manos que han ido a la cabeza, si ella hubiérase ido aqui nomás y le vuelvo a repetir la curación, curaba (P55, curandero, 84 años).

Y: la cura en secreto, la cura con alcohol, alcanfor [...] la moja con un algodón con alcohol y le hace pasar por la cabeza y una barrita de azufre A: le pasa por la cabeza? 
Y: sí, para sacar el aire, él siempre los cura así, en voz baja, él pide el nombre del que lo está curando y nada más, la cura en voz baja [...] 3 veces

A: o sea que mañana la vas a tener que llevar?

$Y$ : mañana a la mañana y a la tarde

A: y ya hoy...?

Y: sí, ya andaba lo más contenta, porque ella lo quiere a Don F él la cura siempre [...] cura con un santito, con alcohol y el azufre

A: y eso para el susto y para otra cosa?

Y: y para el mal de ojo, la ojeadura, para saber echa agua en el plato, una gotita de aceite y sal en cruz creo y no sé más [...] ella cura de empacho, la ha curado a la D cuando era chiquita [...] bate un huevo, creo que echa alcohol y pone en algodón y lo pone en la panza y creo que van también con palabras [...] en un algodón le dejan en la pancita y lo fajan [...] hasta el otro día hasta que lo vuelven a curar

A: también son tres curas?

Y: sí (P22, mujer, 17 años).

F: de susto [...] él les sobaba aquí, la corona como le dicen, asi en forma de cruz también, aquí en los oídos le untaba así alcohol, por acá por sobre los hombros así lo sobaba y también lo curaba tres días (P30, mujer, 17 años).

P: la señora me ha dicho "mirá, hacé hervir el helecho y dale por agüita y por tesito" [...] para curar del empacho tiene una cinta azul, con un nudito, tiene un tantito así y ahí queda la corbata, una corbata azul y para curar de ojeadura tiene una corbata roja también tiene un nudito, también tiene un pedacito así para abajo [...] lo pone ahí y de aquí de la tira [...] van diciendo algún secreto [...] porque ella, la señora tiene la boca cerrada, no hace nada, ningún movimiento, lo único cuando llega allá y ella lo tiene al bebé... una crucita

A: una cruz en la cara [verbalizando sus gestos]

$P$ : en la carita y aquí

A: en la boca

P: y se vuelve otra vez para allá y allá hace lo mismo tres veces, pero ella la boca cerrada, no habla nada [...] lo ha empezado a curar de pata de cabra, 9 días lo ha curado [...] con una tinta, con un frasquito así y de ahi le sacaba con un palito así como si fuera un cañito de lapicera [...] en cada mancha, en cada manchita [...] sabrá ser que decía algún secreto ella porque, ella me decía que lo ponga boca abajo y le levantaba la ropita y asi le bajaba el pañal que tenía porque de ahí sobre la colita tenía las manchitas y parecía que en cada manchita le hacía ella

(P38, mujer, 43 años).

Como ya se señaló al describir las prácticas médicas tradicionales (con grandes similitudes en toda la región del NOA y Cuyo), se destaca el carácter religioso (católico) de varios de sus elementos: el uso de la señal de la cruz, la repetición de la cura tres veces, los rezos e invocaciones a santos, el sahúmo, que invocan el poder de las figuras cristianas y refuerzan la acción terapéutica, aún cuando los individuos ignoren el completo simbolismo de muchas de estas prácticas (Idoyaga Molina, 2001). Así, por ejemplo, cuando ante la constante mención de que las curas con curanderos debían realizarse tres veces consecutivas (o nueve 
en casos de gravedad) se indagó el por qué de esta cantidad ${ }^{40}$ no se obtuvieron explicaciones sino aseveraciones de su requerimiento para garantizar la eficacia de las curas. Idea que en algunos casos también apareció respaldando interpretaciones de la eficacia terapéutica de prácticas biomédicas. De manera similar la eficacia del sahumado (que "se origina en las prácticas purificatorias y terapéuticas del catolicismo, en las que el incienso era un elemento primordial", Idoyaga Molina, 2001: 32) se atribuye aquí a los elementos que se queman, considerados en sí curativos, sin mención de la tradición religiosa.

$R:[. .$.$] tenían que ser 3$ curas

A: por qué 3?

$R$ : no sé, tienen que ser 3 o 7 o 9, dichos de la gente de antes, tienen que ser nones, no pares, porque si van 6 son $2,4,6 \ldots$

A: es par

R: claro

A: y por qué será eso?

R: por qué sabrá ser? [...] bien me ha curado, a la noche he dormido bien

A: y por que cree usted que cura eso?

$R$ : porque me ha tomado, me ha tomado verdaderamente [...] él [curandero] me ha dicho así, que me tenía que hacer curar con 3 porque no me iba a agarrar, tiene que darse las 3 me ha dicho [...] una un día, al otro día el otro y al tercer día el otro (P79, mujer, 65 años).

M: [...] hay una doctora que es especial para eso, en Catamarca, para cualquier tumor, dicen, ella tiene un equipo de médicos en Bs As y ella le ha puesto la droga a la chinita, decían que no la iban a operar, que no tenía remedio, pero dicen que ella le ha hecho las 3 drogas y la ha llevado a Bs As y la han operado se lo han sacado y dicen que está bien

A: tres drogas?

M: claro, 3, o sea que le ha hecho 3 dosis (P72, enfermera de la posta).

F: ese humo tiene que tener el remedio, tiene que ser azufre, el incienso de la yareta o el molle

A: si es humo de leña no?

$F$ : no, hay otros que, la yerba, el azúcar, la lana negra [...] es bueno el azúcar, hacer el humo como le dicen sahúmo, le echa azúcar en las brasas y con eso para ahi [...] vuelta a la cabeza porque ese es el aire que le va derecho a la cabeza, eso lo agarra esto ve? (P66, curandero, 88 años).

A: por qué el sahúmo cura?

T: cura, cura! Puede ser que el humo tiene algo y por eso cura

A: pero un humo de madera?

T: no, tiene que ser yuyos, y algunos yuyos, por ejemplo el romero, la yareta, la lana negra (P70, mujer, 72 años).

\footnotetext{
${ }^{40}$ Idoyaga Molina señala que se trataría de una apropiación "del poder sagrado del número tres, el que deviene de ser el número de la Santísima Trinidad” (Idoyaga Molina, 2001: 15).
} 
Aunque el cese del malestar es el elemento que define en última instancia la eficacia de la atención del curandero, el primer síntoma que identifican como prueba del éxito terapéutico es el restablecimiento del sueño tranquilo. El verbo "curar" es utilizado tanto para expresar la acción terapéutica como el resultado, es decir, cuando los entrevistados dicen que un curandero "lo ha curado" están refiriendo a su desempeño, cuya eficacia es inmanente o consustancial.

J: y después me dice una señora "ay," dice "J, cómo no se va para Londres, hay una señora, T, que ella, sabe, cómo cura!", dice, "los derrames esos", "si?", "si", me dice, "vaya". Usted sabe que he ido la primera tarde y me ha curado, no sé, ella me ha puesto una cremita, pero no sé qué cremita era, y bueno, y el secreto de ella, y ya he sentido como que me ha largado eso, porque me sentía así tirante y se me ha empezado a largar, largar y fui 6 días y me dejó la cara bien [...] es una cosa que, el hombre a usted, cuando está muy, muy airada, o muy asustada, usted se duerme, después que él se va usted se duerme, se duerme, se duerme, y cuando usted se duerme es como que mejor le hace la cura, como que siente que ha estado muy mal, no? Y la ha aliviado, y él al otro día cuando vuelve le pregunta si ha dormido o no, "sí, he descansado", "entonces le ha hecho efecto la cura” (P49, mujer, 40 años).

$P:[. .$.$] también habia otra señora que se llama C$ de $M$, esa señora también cura la misma forma que cura esta señora [...] ahi en la ciudad de Belén, y ella me decía que sí, que sí estaba ojeada y que le ate la cabeza, porque lloraba un rato ella y me dice que era la cabeza la que le dolía, que le dé una aspirineta entonces yo le he dado la aspirineta y después se ha dormido ya sanaría, ha dormido lindo (P38, mujer, 43 años).

P: esa señora, porque esa señora cura de susto, cura de pata de cabra, yo una vez lo he tenido a él enfermo y lo he llevado al médico y el médico no me ha dado nada y él seguía lloraba, lloraba, lloraba y bueno esa señora lo he llevado yo para esta señora $C$ que era vecina de la tía $P$, y esta señora me he dicho "mira, lo que tiene D es pata de cabra, yo lo voy a curar" porque él tenía unas manchas moradas así y ella lo ha curado 9 días y se ha compuesto [...] al $J$ le ha recetado té de manzanilla y de tilo para el dolor de cabeza y se le ha ido (P76, mujer, 45 años).

N: ya nomás la ha curado de empacho y de la ojeadura se ha venido sanita

E: se ha dormido, la ha curado a las 9 de la mañana [...] la he llevado, "no la vayas a dejar internada!" porque dice es fiebre del empacho y es mucho susto lo que tiene esa niña y me he llegado a las 9 y me la ha visto, la ha curado y se ha dormido (P58, mujeres, N: 69; E: 27 años).

F: no, un pedacito que va a la muela, y esa muela por aire

G: también por aire es?

F: el aire, y esa muela se cura, sana, ni sabe cuando se le cae la muela

$G$ : ah, se le cae?

F: sin dolor [si "es por aire" con tres curas alcanza, si el dolor persiste se trata de "infección" y se debe ir al médico] (P55, curandero, 84 años). 
La eliminación del síntoma es la prueba de sanación (aunque la muela se pierda), cuando el malestar persiste se explica por el avance y agravamiento del malestar que hace necesario repetir las curas (y en algunos casos recurrir a la biomedicina), o por un error del diagnóstico (se trataría de un malestar "para médicos") pero la terapéutica en sí no se cuestiona.

F: cuando está nuevo el mal con una sola curación ya se fue [...] tranquilo va, pero si se deja mucho tiempo, no (P55, curandero, 84 años).

$J:[. .$.$] pero no le han cortado del todo, no, digamos, se le ha ido esas escamas, esas$ cosas que ella tenía, y... dice que ella la tenía para dentro, por dentro, y al curarla en secreto, y le pasaban un sapo, porque ha visto que la panza del sapo es helada? Dice que es una fiebre que agarra por adentro y eso la ha sacado para afuera, la ha sacado todo, y esas ampollas han salido [...] la han tenido que curar 9 curanderos a ella! Para que se le vaya todo eso [...] uh! Mi mamá anduvo casi los 6 meses (P49, mujer, 40 años).

F: [...] si es una enfermedad como ser el susto que no está muy avanzado lo curan 3 y si no ya 9 días [...] porque a veces no creímos y eso a veces el niño a veces queda tentadito cualquier cosa tiene que pasarle porque un aire fuerte lo ataca muy fuerte (P58, mujer, 62 años).

A: ah tuvo meningitis? Y eso de qué le vino?

$N$ : dicen alguno de que los ojean

A: también?

$N$ : ahá

A: y no la pudieron curar con un curandero?

N: y ya cuando la han llevado ya estaba muy pasada y el curandero ya no le ha hecho nada

A: y ahí qué le hicieron?

$N$ : y bueno, le han hecho inyecciones (P58, mujer, 69 años).

El factor temporal, es decir, la prontitud o tardanza con que se recurra a una terapéutica, fue mencionado como algo que influye y a veces determina el éxito o fracaso terapéutico. Igualmente para casos de intervención quirúrgica, dado que, como se señaló anteriormente, a ésta se le reconoce eficiencia en situaciones de urgencia y donde se considera que no hay alternativa (de lo contrario, y dado el riesgo iatrogénico que se les atribuye, los individuos las postergan o reemplazan por otros medios).

A: de qué lo han operado?

R: tumor [...] pero a él lo han agarrado a tiempo [...] se lo han sacado, se han ido a Córdoba y le han hecho todo [...] es una cosa que se le hace como infección así que ahí nomás lo han agarrado a tiempo, lo han operado, se lo han sacado y con el remedio no? Lo han llevado a Córdoba y le han hecho todo ahí, esta otra semana se ha hecho los estudios dice que gracias a dios le ha salido todo bien (P58, mujer, 58 años). 
La eficacia atribuida a la terapéutica de los curanderos frente a enfermedades contra las cuales los recursos biomédicos disponibles se mostraron incompetentes es lo que en parte sustenta la distinción entre "enfermedades para médicos campesinos o curanderos" y “enfermedades para doctores" permitiendo mantener esperanzas de cura a partir de la posibilidad de que se haya errado en el diagnóstico y por ende se esté utilizando un tratamiento equivocado.

N: [...] ya se había cansado de andar por todos los doctores, no le hacían nada, nada! [...] Y ha venido aqui y ya la $V$ le ha dicho que lo lleve para... que era muy buen médico y "qué será tía?", "vea, m'hijito yo no le puedo decir porque yo nunca lo me hecho curar pero haga la prueba", le digo, vea, lo ha llevado 3 días y a los 3 días ha quedado sanito, no ha vuelto a enfermar

$R$ : le ha dicho que era ojeadura

A: $y$ de dónde venía su sobrino?

N: de Vichigasta

A: y él lo había llevado a curanderos?

N: no, a médicos

A: y el médico qué le decía?

$N$ : que eran los bronquios, la ha dado los remedios para que compre, le ha comprado y le ha dado pero no le hacían y lo ha traido para acá y lo ha llevado a curar con Don F (P58, mujeres, N: 69 años; R: 58 años).

$J A:[\ldots]$ querían hacerlo pasar para ver para allá, para el médico campesino, quieren hacerle medicinas con médico campesino

A: por qué, y los otros médicos?

JA: ya lo han desahuciado, que no tiene remedio le han dicho los médicos doctores así que van a probar a ver qué le dice el médico campesino (P56, mujer, 67 años).

Fr: pero si el doctor le ha dicho que se venga puede hallar un médico que lo va a sanar

A: un médico de acá?

Fr: claro, esos males que tiene no son males que dios le ha dado, eso le han hecho un mal

A: otros males de qué?

Fr: los que hacen a cualquiera, cualquiera

A: usted dice que le han hecho un mal?

Fr: claro!

A: y por qué, tendrá gente en contra?

Fr: vaya a saber a veces cuando no hay gente en contra ya lo hacen porque quieren hacerlo, ya estudian para eso [...] eso nunca lo van a curar! [refiriéndose a la atención que el enfermo estaba recibiendo desde la biomedicina]

(P66, curandero, 88 años).

P: hay un hombrecito que ha dicho que lo va a curar, porque a él le habían dicho que tenía todo el hígado deshecho, pero dice que no, que no es verdad

A: y el señor cómo sabe? 
P: y porque le llevan la foto, por la fecha de nacimiento y él se fija ahí [...] les ha pedido los estudios para comprobar y después de que le hacen los estudios los ha traido para comprobar ahí, a ver si es verdad lo que ellos dicen, los doctores

A: y por qué será que se equivocan los doctores?

P: y bueno porque dicen que, ha visto, que hay gente que hacen maldades a veces, por ejemplo, como le voy a decir?, no le gusta esta persona y bueno, le mando a hacer un mal, y bueno, dicen que a veces no son para curar los doctores, los curan los médicos campesinos ( $\mathrm{P} 75$, mujer, 35 años).

Mientras que tratándose de la atención médica las apreciaciones de su éxito o fracaso son explicadas en parte por la dedicación del profesional para evaluar y diagnosticar al paciente, en el caso de la atención de curanderos se resalta como prueba de sus facultades el realizar el diagnóstico mediante escasos datos sin ver al enfermo (el nombre y número de documento, una foto, una prenda de vestir, el orín).

A: y cómo sabe el señor?

$P$ : por el número de documento ya sabe lo que tiene (P76, mujer, 45 años).

$R$ : a veces le llevo la pis [...] con la ropita también, de él cuando... en la Puerta de Corral yo le mandé la pis para él, ha llevado una remera de mi mamá, tenía bastante susto él, tenía que comprarme el de los parásitos y que lo iba curar 9 noches

A: qué hace ella [una curandera]?

$R$ : no sé, debe ser con el mismo nombre (P20, mujer, 24 años).

A: ah, las aguas del nene, no llevó usted al nene?

I: no, mi señora lo llevó cuando era chico, la segunda vez [...] ella mira las aguas, pone así al solcito o le hace con una linterna y ya sabe qué es lo que tiene el chico A: y con qué lo curó?

I: le ha dado unos yuyos y unas pastillas [...] se ha compuesto, ha quedado bien [...] conoce bien, esa señora por ejemplo, usted lleva las aguas, le lee las aguas, le dice de qué el mal que tiene (P25, varón, 71 años).

Esta capacidad de diagnosticar a partir de ciertos elementos del enfermo así como la de curar a distancia denota lo que Idoyaga Molina expresó como una "vivencia de la corporalidad" que "incluye no sólo al cuerpo biológico sino también al espíritu, el nombre, la materia fecal, el orín, las vestimentas, los adornos, los tatuajes, los peinados y todos aquellos elementos que se constituyen en códigos y mensajes sociales que develan el estatus, los roles y la identidad de la persona" (Idoyaga Molina, 2001: 68). Siendo el nombre una de las entidades que conforman a la persona, la cura de palabra puede realizarse incluso sobre éste "sin necesidad de que el paciente esté presente, lo que revela la importancia del nombre como entidad constitutiva del sujeto", entidad "que recibe directamente la energía y el poder restaurador de las palabras" (Idoyaga Molina, 2001: 21, 62). Cabe pensar que este vínculo percibido entre elementos o accesorios del cuerpo y la persona, que permite conocer su estado 
de salud a partir de indagar en ellos, es el que sustenta también las nociones de "estudios" y "análisis". Tanto la lectura de los orines como el análisis de sangre, por ejemplo, se consideran una vía de acceso directa y fidedigna a la información sobre el estado de salud de la persona pero que requiere un saber especializado (y de tecnología moderna, en el caso del diagnóstico por imágenes) capaz de descifrar el diagnóstico a partir de estos elementos.

O: [...] conocían las enfermedades los curanderitos que habia, viejitos curiosos, conocían del orín, qué se yo, era como si le hacen una ecografía ahora, ponían el vasito con el orín [...] y lo ponen en un papel blanco y empiezan a mirar "aquí está esto, aqui está esto” (P2, varón, 58 años).

A: y qué estudios le hicieron?

R: y no sé

A: cómo se dio cuenta el médico?

R: debe ser que de la cabeza, en todo el cuerpo le hicieron... en Catamarca tienen muchos aparatos no es como en Belén [...] en Catamarca hay más aparatos y a veces están los médicos mejores para ahí, teniendo los aparatos les ayuda mucho (P79, mujer, 65 años).

P: él me decía que tendríamos que llevarlo a la ciudad para que en la ciudad [de Catamarca] le hagan todos los estudios que tiene que tener porque en Belén estudios como los que hay en la ciudad no hay

A: como ser? qué le tienen que hacer?

P: bueno, estudios a la cabeza, un estudio computarizado (P19, mujer, 43 años).

A: ah! Y cómo se dieron cuenta que tenía eso?

M: porque le ha agarrado una gripe y ha empezado a echar sangre por la boca y la he llevado a Belén y le han detectado eso que tenía [...] le hicieron placa, le hicieron análisis del escarro

A: qué es el escarro?

M: de la saliva y análisis de sangre, de orina, todo (P51, enfermera de la posta).

R: a ella le hicieron radiografía para el pulmoncito, análisis de sangre, de orina, análisis para ver si estaba débil también (P77, mujer, 23 años).

Cuando la opción por acudir al curandero no es justificada por la especificidad del malestar ("enfermedad para médicos campesinos") sino por el tipo de tratamiento, la ponderación de las terapéuticas se realiza en términos de eficiencia, es decir, no sólo valorando la obtención de resultados sino también el empleo de los mejores medios posibles. Dada la percepción de potenciales efectos iatrogénicos de medicamentos, inyecciones e intervenciones quirúrgicas, frente a un mismo diagnóstico las respuestas del curandero o de la medicina casera cuentan con mayor aprobación que los recursos biomédicos, ya que de resultar ineficaces no se cuestiona su valor terapéutico sino el diagnóstico.

F: y la lleva al médico y no ve lo que estaba bien, y ha ido allá, lo ha visto el médico otra vez y allá ha vuelto otra vez, bueno, el médico le ha quemado la sangre, las venas 
[...] las narices le ha quemado, y bueno, ése es el remedio del médico, que lo destroza al paciente, cómo, y yo con, yo ni un remedio de nada, ni he dicho venga este remedio, este otro, basta mis manos que han ido a la cabeza, si ella hubiérase ido aquí nomás y le vuelvo a repetir la curación, curaba (P55, curandero, 84 años).

L: "no" dice [el médico de zona] "no es nada, tomate este jarabe", "bueno" le digo yo, pero yo tampoco lo tomé porque, bah, no

A: te lo dio y vos no lo tomaste?

L: claro porque no le creí, así se ve que me dio así por darme así nomás para que me conforme yo, así que digo no, mejor no lo tomo, así cada tanto suelo tomar yuyos de la puna así que ya... (P16, mujer, 22 años).

\section{Sobre la eficacia de las terapéuticas caseras}

Mientras que el poder terapéutico de las respuestas biomédicas se atribuye al remedio, cuya eficacia o fracaso no es explicada sino que se constata en los cambios sintomáticos percibidos luego de su ingesta, y cuando se refieren a las terapéuticas de curanderos, aunque hay una mayor descripción de las acciones realizadas y los elementos empleados, también se afirma una eficacia inherente a los mismos; es al mencionar las respuestas caseras y el uso de hierbas (desde el ámbito doméstico pero también las recetadas por un curador) donde emergen mayores explicaciones para dar cuenta de sus efectos.

Al hablar de terapéuticas realizadas desde el nivel de la autoatención (con excepción de la ingesta de medicamentos de venta libre o conservados de anteriores consultas médicas cuya eficacia es, como ya se señaló, afirmada y no explicada) las explicaciones de su accionar son más frecuentes y detalladas que en el caso de aquellas tradicionales no caseras y sobre todo de las biomédicas, es decir, para las respuestas dadas desde la autoatención y para algunos elementos de las terapias de curanderos los individuos disponen de más representaciones que dan cuenta de la eficacia. Si bien se advirtió que la asociación entre la identificación causal y el tipo de terapéutica no es siempre directa, cuando se explica el accionar de una terapéutica generalmente se lo hace en relación a la causa que ésta combate justificando con ello su elección. Así, por ejemplo, se explica la eficacia por extracción del calor mediante elementos frescos (como el sapo, paños de vinagre o leche), por expulsión mediante la transpiración, por calentamiento mediante baños con ciertos yuyos cuando la causa es el frío. Al mencionar el uso de hierbas se lo hace identificando el órgano o malestar para el cual se lo toma, sea por conocimiento propio o por indicación de un curandero (que a 
su vez pasará a formar parte del saber doméstico), de manera similar a ciertos remedios en que les reconocen una función específica, pero en el caso de los yuyos se registraron más explicaciones en torno a su accionar para contrarrestar el malestar.

Como se señaló anteriormente, la medicina casera se basa en la experiencia heredada y adquirida dentro del grupo doméstico y del entorno de conocidos, donde tiene lugar la mayor parte de los intercambios dialógicos de los que resultan la construcción y transmisión de información, la expresión de acuerdos o de divergencias a propósito de objetos de interés común, la interpretación de temas pertinentes para la vida de los participantes en la interacción, y la posibilidad de creación de significados o de resignificaciones. De allí la mayor elaboración de explicaciones brindadas en torno a las prácticas terapéuticas caseras que, en el caso azampeño, están además más influidas por la medicina popular o tradicional (en el sentido aquí definido) que por la biomedicina dada la ausencia de formación científica en esta población.

J: se hace como un jarabe, y eso usted después, cuando está caliente así, eso lo tiene que hacer cuando ya se va a poner en la cama, y caliente así como está le echa un chorrito de alcohol y se pone en cama y usted se tapa y eso la hace transpirar a usted, y mientras usted siente que transpira no se tiene que destapar, y ahí eso lo hace tirar todo, pareciera como que por la transpiración le sale la peste (P49, mujer, 40 años).

$P$ : el doctor me decía que haga hervir yuyos, "juntate un poco de yuyos”, me decía él "y hacete hervir en una olla y bañálo" dice "porque capaz que tiene mucho frío!" Y bueno con eso se ha ayudado mucho se ha empezado a endurecer [...] y la cabeza que no le lave porque esos yuyos me decía que calientan mucho A: y si lo bañás con agua sola aunque está caliente no lo va a calentar igual?

$P$ : no, porque dice que cada remedio tiene su caloría, decía la señora doña $L, y$ bueno sabría ser porque él estaba mucho más, cómo le voy a decir, yo lo hacía para así y él no se paraba [lo tiene al nene en brazos y me muestra como se sostiene en pie] A: mirá, ahora se para!

$P$ : él no se paraba ni hacía ningún ademán ni nada [...] él camina, él hace unos pasos (P19, mujer, 43 años).

$N:[. .$.$] a lo mejor será una inflamación del frío [...] inflamación, que dice que la$ bañe para que se le caliente el cuerpo (P58, mujer. 69 años).

\section{La eficacia simbólica desde distintas perspectivas teóricas. La especificidad de la cura religiosa}

Dentro de las prácticas terapéuticas del curandero el empleo de sus "secretos" requiere un análisis particular dado que a este componente (ausente en las curas realizadas desde el 
ámbito de la medicina casera) se le atribuye gran parte de la eficacia terapéutica de la medicina tradicional aquí descripta. Aunque inaudibles para quienes participan de la cura (de allí que se hable de "secretos") su presencia, a veces percibida en un movimiento de labios o un susurro, se considera imprescindible y se presupone que se trata de rezos, "palabras" que el curandero "hace" para invocar por lo general a algún santo o virgen del cual es devoto.

A: y cómo lo cura?

R: eso sobándole la cabeza, habrá sabido tener secretos, secretos debe ser que tiene, porque no cualquiera lo cura, por eso pienso yo que ella debe tener secretos (P40, mujer, 62 años).

A: y usted no lo sahúma? Por qué lo lleva al bebé a Don F que lo cure?

T: pero él debe ser que sahúma pero con secretos

A: el sahúmo solo no?

T: no porque tiene que secreto ( $\mathrm{P} 70$, mujer, 72 años).

J: y el secreto de ellos, claro, el secreto

A: vos oís cuando ellos lo dicen?

$J:$ no, no, porque ellos lo dicen entre ellos nomás, usted a veces... [bisbisea] es lo único que escucha, y ahi tienen su santito, ellos lo pueden tener a San Cayetanito, San Antonio, viste?[...] son credos que le rezan, no sé cuántos, por ahi usted de vez en cuando le escucha algo [...] le piden a dios, le piden al santito que la ayude, que le saque el mal que usted tiene, que la alivie del mal que usted tiene [...] ellos lo invocan a dios (P49, mujer, 40 años).

$R$ : él me sanó [...] me ha curado la C porque él le ha dado secretos a la C para que cure

A: él le enseñó?

$R$ : sí, y me ha terminado de curar la $C$

A: y cómo le curó la $C$ ?

$R$ : lo curan con un sapo [...] con un sapo le limpian el órgano yo creo que sabrán tener algún secreto [...] por eso digo yo que tiene secretos por eso le ha enseñado [...] digo yo que debe tener algún secreto (P79, mujer, 65 años).

Según Idoyaga Molina la cura de palabra, componente de la medicina religiosa (católica) de marcada presencia en la medicina tradicional del NOA y Cuyo, "responde a la idea de que palabras, pensamientos o intenciones son sustancias que fluyen de un emisor y que penetran en el cuerpo de la persona a la que van dirigidas. Estas palabras, pensamientos e intenciones actualizan el poder de las figuras míticas invocadas y tienen la capacidad enunciada en los rezos, o definida en el pensamiento, de deshacer y/o expulsar la enfermedad sustancia que se encuentra en el cuerpo del doliente" (Idoyaga Molina, 2001: 18).

Pero más allá de esta lógica, presente con mayor o menor grado de perspicuidad en las afirmaciones de los entrevistados, quienes no cuestionan la eficacia de tal práctica terapéutica, 
cabe hacerse las preguntas planteadas por Csordas acerca de la cura religiosa: ¿Cómo trabaja la cura religiosa, si realmente actúa?, ¿cuál es la naturaleza de esa eficacia terapéutica?, ¿qué es lo que es realmente sanado a través de la performance del shamán o curandero? (Csordas, 1994). ¿Desde qué marco teórico se puede abordar y explicar la eficacia de esta terapéutica? Este autor critica diversos enfoques que plantean ya sea una correspondencia entre un nivel simbólico y uno orgánico, o una transacción entre un nivel emocional y uno somático, pero que no pueden dar cuenta de la mediación en sí y de por qué intervenir en el plano simbólico o social conllevaría cambios también en el plano corporal (resultando por ello eficaz). Así, por ejemplo, la eficacia de la cura religiosa se asume ya sea estableciendo una analogía con la psicoterapia (actúa porque es como la psicoterapia, que también actúa) u otorgándosele un poder inherente a la correspondencia u homología entre los actos simbólicos, metáforas, estructuras cosmológicas por un lado y pensamientos, emociones, enfermedades por el otro (es el caso de la hipótesis estructuralista del paradigmático trabajo de Lévi-Strauss) quedando sin explicar por qué esa homología permitiría la cura. También la hipótesis del soporte social (mejor caracterizada por el trabajo de Turner con los Ndembu) que sostiene que el principal efecto terapéutico de la cura yace en mejorar o aumentar la solidaridad comunal, resolviendo las tensiones interpersonales y proveyendo un medio emocionalmente sano para los individuos sufrientes, deja sin indagar por qué estos cambios en las relaciones sociales tendrían eficacia para restablecer la salud individual. La misma crítica recibe la hipótesis persuasiva, donde es la cultivación de la fe y de una actitud expectante a través de la influencia personal de un curador y de recursos retóricos lo que produce un cambio en el mundo asumido y presupuesto del paciente y por ende en la calidad y contenido de la experiencia. Desde una perspectiva clínica se apela a nociones vagas como sugestión o efecto placebo pero que tampoco explican por qué un acto, pensamiento o idea tendría consecuencias orgánicamente observables. De acuerdo a Csordas, todas estas hipótesis, que no son mutuamente excluyentes, representan diferentes descripciones de cómo es pensada la eficacia terapéutica, que no llegan a profundizar en los mecanismos que la provocan debido a la escasa atención dada a la propia experiencia del enfermo. Él sostiene que es en la especificidad experiencial del efecto de la cura religiosa donde debe indagarse el por qué de su eficacia.

Ya Mauss en su "Effet physique chez l'individu de l'idée de mort suggérée par la collectivité (Australie, Nouvelle-Zélande)" indicaba que hay hechos que él denominó “totales" porque muestran la vinculación directa de lo físico, lo psíquico y lo moral o social; en los que la naturaleza social se une directamente con la naturaleza biológica del hombre; y 
para cuyo análisis no alcanza la consideración de lo "psico-orgánico" sino que es necesario incorporar lo social ${ }^{41}$ (Mauss, 1950). Pero Csordas señala que no basta con reconocer la naturaleza social para explicar las formas de eficacia llamada "simbólica" sino que se debe indagar qué hay de religioso en las curas religiosas y en qué consiste su especificidad, sin reducir "lo sagrado", como critica en Durkheim, a un fenómeno simplemente social ${ }^{42}$.

En los casos que presenta, Mauss identifica como social la causa del malestar, estableciendo la mediación entre el nivel social y el somático en la idea de ruptura de un tabú, de pecado o culpa, es decir, en el nivel psicológico. "Este temor aterrorizador que desorganiza todo en la conciencia, hasta aquello que llamamos instinto de conservación, desorganiza sobre todo la vida misma. La cadena psicológica es visible, sólida: la conciencia. El individuo hechizado o en estado de pecado mortal pierde todo control sobre su vida, toda elección, toda independencia, toda su personalidad"43 (Mauss, 1950: 329). Por lo que igualmente la cura simbólica apelaría a lo social (todo acto ritual) que vía psique restablecería la salud física. En la misma orientación Turner plantea, acerca del ritual de cura Ndembu, que los esfuerzos terapéuticos están dirigidos a las relaciones sociales conflictivas que han generado manifestaciones sintomáticas, enfrentándose "una fuerza invisible por medios visibles que pretenden ser simbólicos, y como tales se interpretan" (Turner 1980: 382). El proceso terapéutico consiste en "hacer visibles, y por tanto accesibles, cosas ocultas y secretas, cuando estas son dañinas, para poder corregirlas y remediarlas" (Turner 1980: 337) considerando también el valor de aspectos psicológicos como "el aire autoritario del doctor-herborista, la estructura intencional del procedimiento, el "tratamiento de shock" [...] y el sentido de que se está haciendo algo de tipo tradicional que afecta a una situación nombrada y conocida" comparables a "los placebos, que se dan a los pacientes para contentarlos más que para curarlos, pero que a pesar de ello tienen como resultado una mejoría de la salud" (Turner 1980: 397).

Para el caso azampeño, como ya se señalara en torno al mal hecho (maleficio) y al aire producto de la envidia o el deseo fuerte de otros (es el caso de la ojeadura), si bien la causa es

\footnotetext{
41 "Il y avait des faits [...] qui montrent la liaison directe, chez l'homme, du physique, du psychologique, et du moral, c'est-àdire du social" [...] "où la nature sociale rejoint très directement la nature biologique de l'homme. ces faits sont aussi de ces faits «totaux» que je crois qu'il faut étudier. La considération du psychique ou mieux du psycho-organique ne suffit pas ici, même pour décrire le complexus entier. Il y faut la considération du social" (Mauss, 1950: 312, 329).

${ }^{42}$ El argumento de Durkheim no fue más allá de destacar que la sociedad crea lo sagrado como algo radicalmente "otro" y por fuera de lo individual, estableciendo una autoridad moral absoluta en la masividad y el misterio de esta otredad, lo que según Csordas conllevó un reduccionismo social del análisis del fenómeno religioso sin dar lugar a una teoría auténticamente fenomenológica y psicocultural de la religión (Csordas, 1990).

43 "Cette peur panique qui désorganise tout dans la conscience, jusqu'à ce qu'on appelle l'instinct de conservation, desorganise surtout la vie elle-même. Le chaînon psychologique est visible, solide: la conscience. Mais il n'est pas gros; l'individu enchanté, ou en état de péché mortel, perd tout contrôle de sa vie, tout choix, toute indépendance, toute sa personnalité" (Mauss, 1950: 329).
} 
identificada en el nivel social la cura no apunta a mejorar las relaciones sociales, ni a expiar conflictos grupales, el tratamiento es individual y enfrenta estas enfermedades como otras ocasionadas por aire de origen no social, el accionar del curandero consiste en sacar el mal y no en restaurar vínculos sociales. ¿Es suficiente, para dar cuenta de la eficacia terapéutica, afirmar que la cura se logra por la tranquilidad del paciente de que se está haciendo algo por su salud, es decir, un convencimiento, una idea optimista promoviendo la cura desde la psique?

Por otra parte, el carácter inaudible, "secreto", de las palabras del curandero no permite explicar su eficacia desde la perspectiva de Lévi-Strauss, donde es el pasaje a la expresión verbal, propiciado por el lenguaje del shamán, de estados informulados e informulables por otros medios, lo que "provoca el desbloqueo del proceso fisiológico, es decir, la reorganización, en un sentido favorable, de la secuencia cuyo desenvolvimiento sufre la enferma" permitiéndole "vivir bajo una forma ordenada e inteligible una experiencia actual que, sin ello, sería anárquica e inefable" (Lévi-Strauss, 1968: 178-179). La cura consistiría en "volver pensable una situación dada al comienzo en términos afectivos" mediante la palabra del curandero, "geografía afectiva que identifica cada punto de resistencia, cada dolor" describiéndolos y presentándolos al enfermo "bajo una forma que pueda ser aprehendida por el pensamiento consciente o inconsciente" (Lévi-Strauss, 1968: 176). Según este autor la eficacia simbólica se basa en la posibilidad de "inducir una transformación orgánica, consistente, en esencia, en una reorganización estructural, haciendo que el enfermo viva intensamente un mito -ya recibido, ya producido- y cuya estructura sería, en el plano del psiquismo inconsciente, análoga a aquella cuya formación se quiere obtener en el nivel del cuerpo". Inducción que es factible debido a la existencia de "ciertas estructuras formalmente homólogas capaces de constituirse, con materiales diferentes, en diferentes niveles del ser vivo: procesos orgánicos, psiquismo inconsciente, pensamiento reflexivo" (Lévi-Strauss, 1968: 182).

En las curas tradicionales aquí descriptas, si bien los individuos se refieren a “palabras”, el valor de las mismas no se apoya en su contenido lingüístico (sólo presupuesto y asumido como invocación a una figura religiosa). A diferencia del mito relatado por el shamán en el análisis de Lévi-Strauss, donde es posible atribuirle un valor a su rol descriptivo, objetivante y reorganizador de la experiencia disruptiva, lo que es identificado como promotor de cura en las "palabras" del curandero es su carácter performativo (en el sentido de que no describen un hecho sino que su expresión realiza el hecho): el curandero no "dice" (aunque se 
trate de "palabras"), no "reza" (aunque se trate de "rezos"), el curandero "hace" los secretos, cura "con" las palabras.

El habla, dice Csordas, es un acto o gesto fonético en el cual uno asume una posición existencial en el mundo estableciendo una relación viviente con sigo mismo y con los demás. El lenguaje no es simplemente un instrumento, un medio del significado sino que es una manifestación del ser íntimo y del vínculo psíquico que nos une con el mundo. Pero este elemento de communitas en la pronunciación lingüística es eclipsado por el hecho de que una vez roto el silencio por el acto de expresión, un mundo cultural y lingüístico es constituido, el habla se fusiona con el lenguaje constituido y la palabra hablante se convierte en palabra hablada, en lo dicho (Csordas, 1990). Este autor recupera el significado gestual o existencial del lenguaje para analizar el fenómeno de la glosolalia, donde al quedar eliminado el nivel semántico se resalta dicho elemento de communitas. El hablar en lenguas es siempre un puro acto de expresión, nunca sujeto a codificación, a la petrificación de la palabra en un idioma y en un significado particular. La quita de la dimensión semántica en la glosolalia no es una ausencia, sino la retirada del telón discursivo para dejar ver el fundamento del lenguaje en la vida natural, como un acto corporal. La glosolalia revela la condición encarnada del lenguaje. Además, dado que este don de lenguaje ritual es otorgado por dios, hablar en lenguas es un ritual de afirmación de que los hablantes habitan un mundo sagrado (Csordas, 1990).

Considero que estas elucidaciones acerca de la característica gestual del lenguaje son iluminadoras para entender el valor de los "secretos" dentro del acto terapéutico, ya que por su carácter confidencial no puede explicarse su intervención en el enfermo como un conocimiento que posibilita la reelaboración de la experiencia, la reactualización de los conflictos en un orden y en un plano que permitan su libre desenvolvimiento y desenlace.

El aspecto oculto de este elemento de la terapéutica contribuye al reconocimiento de la autoridad del curandero, quien en tanto poseedor de los "secretos" cuenta con un poder contra la enfermedad ausente en las prácticas de autoatención. Bourdieu sostiene que la eficacia simbólica se basa en la relación entre desconocimiento y atribución de autoridad, "la eficacia simbólica de las palabras sólo se ejerce en la medida en que quienes la experimentan reconocen que quien la ejerce está autorizado para ejercerla" (Bourdieu, 1985: 77), autoridad que se le concede en tanto se le atribuye un conocimiento del que otros carecen, es decir, el reconocimiento de la autoridad se funda en un desconocimiento. Todo discurso de autoridad para poder ejercerse en tanto tal, además de ser pronunciado en una situación legítima y por la persona legitimada para pronunciarlo, requiere de "la disposición al reconocimiento como 
desconocimiento y creencia", es decir, de "la delegación de autoridad que confiere autoridad al discurso autorizado" (Bourdieu, 1985: 73).

Sin embargo, más allá de contribuir a legitimar la autoridad del curandero, sus "secretos" en tanto gesto, en tanto acto corporal identificado como una invocación al poder de figuras religiosas reafirman la existencia de un mundo sagrado, de una "Realidad Esencial" entendida como "aquello que condiciona y sostiene todo", que "impresiona al hombre como exaltado por encima de todo poder finito", caracterizada por el misterio, la espontaneidad, la creatividad, energía y poder (Wach, 1967: 99, 128). El gesto cultual (sea una plegaria, la exclamación del nombre divino, el uso de una palabra numinosa, un sacrificio o el silencio) constituye el reconocimiento de la presencia divina que puede ser invocada en busca de fuerza, sustento e inspiración (Wach, 1967).

F: rezan una oración para un santo en especial, que parece que es muy devoto él, una virgen es, no me acuerdo cómo se llama el nombre de la virgencita, y ahí se me hace que le reza un credo, no me acuerdo bien porque es también en secreto (P30, mujer, 17 años).

Csordas, en su interés por especificar el ámbito de acción de la cura religiosa, operacionaliza lo sagrado a través del criterio de otredad, es decir, la naturaleza sui generis de lo sagrado es definida por la propensión humana a tematizar ciertas experiencias como radicalmente "otras". Dado que la otredad es una característica de la conciencia humana más que una realidad objetiva, cualquier cosa puede ser percibida como "otro" dependiendo de las condiciones y configuraciones de la circunstancias, de manera que definir lo sagrado se vuelve un problema etnográfico. Así, en los grupos carismáticos por él estudiados, un pensamiento que aparece de pronto en la conciencia es considerado enviado por dios, identificándose la presencia de dios en esa adecuación espontánea de la inspiración con las circunstancias; o ante una falta de control de cierta conducta no es la propia personalidad la causa sino que se está bajo la influencia de un espíritu maligno (en ambos casos el carácter sagrado se construye sobre una percepción de enajenación: "no soy yo" el responsable de esas conductas sino que soy el instrumento pasivo de voluntades suprahumanas) (Csordas, 1990). El sentido de otredad está fenomenológicamente fundado en el ser "encarnado": gestos espontáneos, experiencias pre-reflexivas no atribuibles a un sujeto consciente, rector de sus actos, son considerados señal de lo divino (en el caso azampeño, el curandero refirió no haber aprendido los "secretos", sino haberlos hallado, extraído de su mente, en otro momento hizo alusión a que "alguien de arriba se los daba").

$F:[\ldots]$ son cosas secretas, yo hago mis secretos solo [...] yo prácticamente los he hecho con, todo de mi memoriales he sacado (P55, curandero, 84 años). 
Relacionando esta identificación de lo sagrado con su análisis del aspecto gestual del lenguaje resaltado en los eventos de glosolalia, lo que está fuera de lo común, lo que se vive como otredad y es por ello tematizado como sacro, es la evocación en ritual de disposiciones preorquestadas, es lo pre-reflexivo y encarnado del lenguaje, esa manifestación del ser íntimo que tiende sus vínculos hacia el mundo. La práctica religiosa explota lo pre-objetivo para producir objetivaciones nuevas y sagradas. El locus de lo sagrado es, entonces, el cuerpo en tanto base existencial de la cultura (Csordas, 1990). Siguiendo este planteo Csordas sostendrá que los efectos transformativos de la cura religiosa no se localizan ni en el síntoma, ni en el desorden psíquico, ni en las relaciones sociales, ni en los significados simbólicos, sino en el self, entendiendo por ello el locus de la percepción y de la práctica en el cual todo ésto (síntoma, desorden psíquico, relaciones sociales, significados) es incluido, de allí la especificidad de su eficacia. El self no es ni sustancia ni entidad sino una capacidad indeterminada de orientarse o articularse hacia el mundo caracterizada por esfuerzo y reflexividad. Es el resultado de una conjunción de la experiencia corporal pre-reflexiva, el medio culturalmente constituido y el habitus (especificidad situacional) (Csordas, 1994).

La dificultad por dar cuenta del vínculo entre niveles (psíquico y somático, o sociocultural, psíquico y somático) que este autor critica en los demás enfoques, se elimina sosteniendo una concepción de persona (su self) no como un agregado de entidades ligadas de manera misteriosa (por la que los mecanismos de eficacia simbólica resultan también insondables) sino como espacio de intersección de procesos culturales, sociales, psicológicos y fisiológicos, sólo analíticamente distinguidos a partir de focalizar en ciertos aspectos, pero en la realidad entretejidos y cooriginados. Esta perspectiva, anteriormente presentada al tomar su definición de experiencia (Csordas, 1992b), remite a niveles pre-objetivos donde la escisión entre lo biológico y lo cultural se evidencia como producto (y no punto de partida) de la actividad reflexiva. Las terapéuticas que apelan en mayor grado a recursos simbólicos exigen, para poder dar cuenta de su eficacia, romper con nociones de persona y cuerpo que desde un realismo ingenuo sostienen en el plano fenomenológico la artificialidad analítica de los niveles socio-cultural, psíquico y somático.

F: yo para el derrame de sangre que hay de la nariz, eso yo lo curo, bueno, yo tengo mi secreto, yo lo mando a la corona, ahi está el secreto (P55, curandero, 84 años). 


\section{"... con la gracia de dios..."}

Ya fueron presentados y analizados diferentes elementos religiosos que forman parte de la medicina tradicional, la señal de la cruz, el sahúmo, el número tres, imágenes de santos y vírgenes, invocación y rezos son utilizados con fines terapéuticos. Si bien, como se advirtió, no siempre los individuos cuentan con el completo significado de tales símbolos, y aunque en algunos casos (sobre todo en el empleo del sahúmo y en la afirmación de la importancia de realizar tres curas) parece primar una apreciación meramente instrumental de tales actos, están sostenidos en una actitud religiosa que les otorga credibilidad. Los azampeños profesan el credo católico, concurren a misa cuando el cura visita la localidad (una vez al mes), participan en todas las celebraciones religiosas de la zona (fiestas patronales, procesiones y visita de otras localidades portando la imagen de la virgen de Azampay) y más allá de los caracteres religiosos actualizados con fines específicamente terapéuticos, la actitud religiosa o espiritualidad está notoriamente presente cuando se habla de salud y enfermedad. Como apunta Weber, la conducta religiosa se origina en los intereses mundanos, en la salud y la riqueza, "las formas más elementales de conducta motivadas por factores religiosos o mágicos se encuentran orientadas hacia este mundo" aunque bajo la influencia del clero y su sistematización intelectual de las creencias religiosas se pretenda reemplazar estos intereses mundanos con "metas no económicas ultraterrenas" (Turner, 1989: 93). En palabras de Simmel, "toda la actitud religiosa: sacrificio, rito, sacerdocio, plegaria, festividades, ascetismo, etc., no tiene más que un solo sentido: ganar el favor de los dioses, ya sea para la duración de la vida terrena, ya sea para una esperanza más allá de la tumba”, por "íntima, sublimada y fantástica" que sea la "utilidad" que conceden ciertos modos de actitud religiosa, "permanecen en el engranaje vital-teleológico", "no está cortado el cordón umbilical con la vida que le dio origen" (Simmel, 1950 [1918]: 85). Así, independientemente de los rezossecretos del curandero, los individuos refieren rezar para pedir salud. En tanto se considera que dios y la virgen propician bienestar, se les pide o reclama salud y se les reconoce su intervención cuando se evalúa positivamente una situación (si se constata una mejoría o cuando se considera que el problema de salud podría haber sido de mayor gravedad). Frases de gratitud o de invocación como "con la gracia de dios", "rezando un poquito", "gracias a dios y a la virgen", "gracias a dios a nuestro señor!", "dios no permita de tener así una molestia", "con el favor de dios y mamá virgen" aparecen intercaladas profusamente en las narraciones en torno a eventos de salud o enfermedad. 
F: [...] enfermedades grandes, graves no, con el favor de dios y de la virgen no, siempre asi uno se hace ver de gripe, de eso, resfrío, de eso, ya otra cosa no, para qué le vamos a decir, con el favor de dios [...] así que uno ha vivido sano, sabrá ser, no sé, o sabrá ser la grande providencia de nuestro señor que uno tiene (P44, mujer, 64 años).

\section{$S:[. .$.$] nosotros gracias a dios no sentimos enfermedades grandes, no$} $J A$ : ahora no, que dios nos ampare y nos favorezca, no siente asi enfermo (P50, JA: mujer, 64 años; S: varón, 76 años).

E: [...] pero gracias a dios este es sanito, no es enfermito, hay chicos que son enfermitos (P64, mujer, 51 años).

M: [...] pero en una de esas, que dios y la virgen nos ayude y pueda sanar bien (P72, enfermera de la posta).

La religión, señala Wach, es aquello que el hombre "da por seguro, que concierne a su relación vital con este misterioso universo, y a su deber y destino en él" (Wach, 1967: 38). La experiencia religiosa se basa en la relación con la "Realidad Esencial", entendida como "un poder trascendente del cual no está apartada la vida sino que de él depende", "aquello que condiciona y sostiene todo", que "nos impresiona y nos desafía" y una de cuyas características es el misterio (Wach, 1967: 99). De ahí que se manifieste de manera tan notoria frente a experiencias como las de enfermedad, reveladoras del límite que la condición encarnada le depara al hombre.

$J:[\ldots]$ esa noche lo iban a abrir al chico para operarlo de la vesícula y bueno, no sé, dios los habrá tocado, habrá dicho esperen los análisis, van los análisis, le sale infección urinaria terrible, mire si lo habrían al chico, en la vesícula no iba a tener nada y bueno, al abrirlo ya se le complica la infección! (P7, mujer, 42 años).

L: antes las mujeres aquí nomás parteaban

A: y nunca les pasaba nada?

L: gracias a dios y la virgen no [...] la levanté yo [ayudar en el parto], el médico me daba para una fecha y resulta que no ha llegado, ha tomado de sorpresa, la levanté yo

A: y no le daba miedo estar sola? Que pasara algo?

L: no, y qué, usted se pone en brazos de dios y cuando las cosas van a pasar ojalá que sea con el médico, no? [...] y a la ha visto el enfermero y todo con el favor de dios (P76, mujer, 47 años).

R: Quedamos a la voluntad de nuestro señor, el único médico que tenemos aquí (P79, mujer, 65 años).

Resaltando el papel que se le atribuye a dios como velador de la salud en ocasiones se establece una analogía entre éste y el médico, también algunos santos son preferidos por considerarse que tienen una función específica de atender a la salud (una señora me encargó 
que le llevara en mi siguiente viaje una figura de San Roque, a quien calificó como "el abogado de las pestes", "médico", "santo de los enfermos", e invoca cuando alguien se enferma). Una entrevistada contó que frente a la perspectiva pesimista de los médicos (que la nieta no iba a hablar ni a caminar tras haber sufrido de meningitis) acudió al santuario de una virgen particular llevándole un muñequito de plata que representa a la niña enferma, quien desde ese instante comenzó a mostrar signos de mejoría y en la actualidad camina y habla. La apelación al poder sagrado puede consistir en la única respuesta cuando otros recursos terapéuticos se muestran incompetentes o ausentes, pero frecuentemente se observa su uso como refuerzo de otras prácticas terapéuticas.

F: ahí nomás antes de tomarlo [al té], darlo de tomar, usted mismo lo bendice al remedio ese que está en un jarro o en el vaso, lo bendice y le da. Eso, todo hay que hacerlo, si lo hace todo sale bien (P55, curandero, 84 años).

Otra mujer refirió que recurrentemente debía hacer curar a su bebé de susto hasta su bautismo: "se ve que andaba queriendo el bautismo porque luego se calmó". Idoyaga Molina (2001) ha señalado que esta idea frecuente de que los no bautizados están más expuestos a sufrir enfermedades evidencia un uso terapéutico y preventivo del bautismo y consecuentemente del poder de dios y de las deidades del catolicismo.

Si bien, como ya se hizo notar, no aparecen en Azampay enfermedades ocasionadas en desequilibrios religioso-rituales, en ocasiones se apela a la idea de dios como causa última de la enfermedad. Pero ésto no supone una moralidad religiosa vinculada a las etiologías, en el sentido de reconocer la intervención del poder sagrado para causar el mal en respuesta a conductas reprobadas, sino que implica el reconocimiento del "misterio" frente a las "situaciones límites". Las experiencias de enfermedad y sufrimiento conducen a la conciencia de ser mortal, de limitación o destrucción de las fuerzas vitales, resultando inabarcables en sus múltiples manifestaciones por el conocimiento objetivo. Ese misterio del sufrimiento, el "¿por qué a mí?" es respondido por la nociones de dios y destino. Dice Presas, “el límite cumple su verdadera función: siendo aún inmanente (esto es, dado en el mundo), apunta empero a ese "algo más" que Jaspers denomina Trascendencia" y si bien "límite significa barrera, pero también, y con mayor razón, apunta a una conciencia todavía oscura de que "hay algo más" tras el límite, de que la vida no se reduce precisamente a soportar situaciones y a formalizarlas intelectualmente" (Presas, 1971: 102).

A: tenía un hija discapacitada? por qué?

C: de qué sabrá venir, que algunos crian así, que dios nos ha dado destino (P60, mujer, 57 años). 
E: a éstos los ha criado a mamadera

A: y cómo no se murieron?

E: ya vea, no sé, estos otros no sé, ya es una providencia, tata dios no les ha querido llevar (P64, mujer, 51 años).

R: disposición de dios, el destino que habrá tenido... y que no iba a terminar en la casa porque quizá peor porque en la casa quedaba sola [sobre un fallecimiento repentino] (P79, mujer, 65 años).

J: bueno, cuando llega la pelada llega y qué vamos a hacer, diosito dice hasta aquí has llegado y chau! Pero si uno se dá manija es peor! (P68, mujer, 43 años).

R: todavía me lamento con los chicos que se me han muerto pero sé que esos se los ha llevado dios (P79, mujer, 65 años).

J: mi papá nunca se ha enfermado y de repente él se ha enfermado, ha visto? como que no aceptaba la enfermedad de él, de día no lloraba, no me desahogaba pero en la noche me agarraba, me ponía a llorar hasta que hora y le decía a dios por qué con él que andaba tan bien! (P7, mujer, 42 años).

A: un médico de acá

Fr: claro, esos males que tiene no son males que dios le ha dado, eso le han hecho un mal (P66, curandero, 88 años).

Nótese que no se trata de sostener la presencia de causas sobrenaturales, justamente en el fragmento de entrevista precedente el curandero identifica como "males que dios le ha dado" a todas las enfermedades que no son causadas por un maleficio o mal hecho, es decir, por la mala intención de otra persona. Como ya se discutió anteriormente, la dicotomía enfermedades naturales/enfermedades místicas o sobrenaturales no resulta de validez descriptiva ni mucho menos heurística. Aquí vemos que el componente místico (relacionado con la divinidad o las cosas espirituales) se haya presente aún en enfermedades para las cuales se cuenta con explicaciones causales terrenales, porque viene a responder no a la pregunta del cómo del sufrimiento sino del por qué, a la "tensión entre la voluntad de responder afirmativamente a mi sufrimiento y la de no poder hacerlo nunca de modo definitivo" (Jaspers, 1956 en Presas, 1971: 103).

\section{Fe en la eficacia y la eficacia de la fe}

Retomando el tema de la eficacia y luego de haber planteado y analizado los aspectos religiosos entretejidos en los procesos de salud-enfermedad, resta desarrollar el punto de cruce de ambas cuestiones: así como anteriormente se expresó que los individuos apelaban a dios 
como explicación última (pero ella misma inexplicable y por lo tanto incuestionable) del padecimiento, apelan a la fe como explicación última de la eficacia de las distintas terapéuticas.

Si bien cada curandero parecía tener su santo o virgen preferida y las personas comunes se refirieron generalmente a santos particulares invocados ante situaciones de enfermedad, al indagar sobre tales preferencias se me aclaró en más de una ocasión que lo que importaba para la cura era la fe, la creencia sin importar en qué santo. Igualmente la eficacia de los "secretos" y de las terapéuticas de los curanderos así como también el accionar exitoso de yuyos, remedios y de las prácticas de los médicos fueron explicados en última instancia por la fe en ellos. La fe es considerada condición para la eficacia de la cura tanto de curanderos como de médicos, del accionar de yuyos y demás prácticas de medicina casera.

A: y por qué cura el secreto, por qué sana a la gente eso?

E: y bueno porque ya le tiene fe, la fe como es en los doctores, si uno tiene fe va a sanar y si uno no tiene fe queda lo mismo nomás

A: aunque tome el remedio?

E: aunque tome el remedio, queda lo mismo [...] 3 curaciones dicen cuando uno no está muy enteramente airado, cuando uno está muy enairado le hacen 9 días de curación, y en el santo, y hay que tenerle la fe porque si no tiene fe lo mismo que se haga curar 3 días como 9 días no te va a curar nada tampoco (P64, mujer, 51 años).

L: el médico me ha dicho que está complicado, que está muy complicado, que sí o sí tienen que hacerle la droga, con gracia de dios, tengan mucha fe, porque si él la recibe, dice, bueno sana [...] el médico le ha dicho que no se ponga mal, que no se ponga nervioso, no piense, que tenga mucha fe y valor para que todo salga bien (P72, mujer, 47 años).

J: por ahí me siento, póngale, así como con fiebre, así, y hago un tesito de cualquier cosa y... y me pasa, no sé si es la fe que uno le tiene a los yuyos

(P49, mujer, 40 años).

C: es la fe de uno, si vos no tenés fe no te van a... [...] y bueno, la fe, qué sabrá ser la fe, de tener fe, por ejemplo vos si creés en una cosa, si te duele la cabeza después vos podés ir con Don F "me va a curar Don F?" "y sí, si usted..."

A: ah, él cura?

$C$ : sí, pero no, esa fe que vas a tener vos, que yo si tengo dolor de cabeza "me va a curar Don F?" y si dice él "sí, la voy a curar" y si vos le tenés fe te va a curar y te va a sanar, esa es la fe dicen que la fe de uno, cuando tenemos fe en cada persona

A: fe en el médico campesino?

C: sí, en el médico campesino, si es doctor lo mismo

A: en el doctor igual?

C: $y$ claro, esa es la fe [...] esa chica no le gusta tomar remedios, dice que no, que somos nosotros los enfermos, ella tiene problemas a la mente [...] a veces está incrédula y a veces está bien, los médicos dicen que es una locura [...] ella no toma los remedios, no los quiere tomar [...] no les tiene fe

A: por qué? 
C: y qué sabrá que cada uno que tenemos, que a veces uno cree...

(P3, mujer, 56 años).

J: eso es de la fe, póngale que usted me haga sólo el humo, si yo le tengo fe me voy a componer

A: Aunque no haga los secretos?

$J$ : claro, aunque no, porque si todo hace la fe, por ejemplo, mi mamá al doctor homeópata que ella la atiende, ella va grave y no aguanta los dolores, pero ella sólo que lo ha visto al doctor sentado ahí, se compone (P49, mujer, 40 años).

J: me sentía mareada, machada [...] y don $P$ me ha curado aquí, entonces yo de esa vuelta le tengo mucha fe a él (P7, mujer, 42 años).

Aunque en algunos casos, como en el fragmento precedente, la fe en cierto médico o curandero se justificó en anteriores éxitos terapéuticos, generalmente no se obtuvo explicación que diera cuenta de la presencia o ausencia de esta predisposición a creer en la fiabilidad de los distintos recursos curativos (que es alegada, como se verá luego, al referir la elección y preferencia por ciertos médicos o curanderos). Tener o no tener fe no se trata de confianza o desconfianza en la capacidad del médico o curandero, sustentada como se vio anteriormente a partir de las evaluaciones de la eficacia de sus respectivas prácticas $\mathrm{y}$, como se verá luego, de las apreciaciones sobre sus modos de relacionarse con el paciente. La fe no se apoya en pruebas, razonamientos o evidencias sino que implica un posicionamiento incondicionalmente positivo frente a algo o alguien de quien dependen eventos futuros. "Hay numerosas situaciones de la vida, en parte intranímicas, en parte interindividuales, que ostentan directamente carácter religioso" pero que "en sí no son de intención religiosa sino puramente vital", señala Simmel, "cuando en la vida empírica "creemos" en una persona; cuando en relación con la patria o con la humanidad, con la personalidad "superior" o amada, experimentamos la peculiar mezcolanza o tensión de humildad y exaltación, de entrega y anhelo, de distancia y fusión; cuando a un tiempo nos sabemos propiamente sacrificados y garantidos, dependientes y responsables [...] se eleva entonces la religión en cuanto esos estados y sentimientos se desprenden de su materia terrena que los provoca, se hacen en cierto sentido absolutos y desde sí crean su objeto absoluto" (Simmel, 1950 [1918]: 84).

Más allá de los elementos arriba descriptos sobre los cuales descansan las explicaciones de la eficacia terapéutica, el promotor último de la misma lo aporta el enfermo: su creencia incuestionable en la capacidad de algo o alguien para producir cambios en el estado de salud. La fe (en la eficacia) es la responsable última de la eficacia. 


\title{
Evaluaciones y apreciaciones sobre los terapeutas y su relación con el paciente
}

\author{
“... era un doctor que tiene voluntad, el doctor tiene que ser como nosotros, \\ conversador, éste es un respingón, dice 'andate nomás'..."
}

Anteriormente se indicó que los azampeños evalúan la atención médica a partir de establecer comparaciones entre los distintos centros de atención biomédica (posta, hospital de Belén, sanatorios de la misma ciudad, hospital y sanatorios de la ciudad de Catamarca) y entre los distintos terapeutas. En ambos casos el criterio central de distinción es la obtención de un diagnóstico acertado y la correspondiente terapéutica eficaz. Las diferencias de éxitos y fracasos en estas dos fases del proceso terapéutico se explican en el primer caso por la desigual disponibilidad material para la realización de estudios e intervenciones quirúrgicas y de especialistas en los distintos espacios de atención, estableciéndose a partir de ello una jerarquización de los mismos. Cuando la comparación se realiza entre terapeutas, eficacia o inoperancia, certeza o error se atribuyen a la competencia de su saber en función del tipo de malestar (si es un mal para curanderos o médicos) y a la aptitud particular de cada terapeuta. Así como un diagnóstico asignado sin la realización previa de análisis o estudios es motivo de desconfianza (que en ocasiones conduce a desoír el tratamiento prescripto), lo es también la falta de escucha por parte del médico de los síntomas que el enfermo desea transmitir y la escasa inspección corporal. Son motivo de queja y de apreciación desfavorable sobre el médico su desinterés por las percepciones que el paciente desea comunicar así como la carencia de explicaciones que éste ansía oír del profesional. Como ya se subrayó, las críticas realizadas respecto a la instancia de la consulta médica no refirieron a desencuentros lingüísticos que dificultaran la comunicación sino a la voluntad y predisposición del profesional, merced a lo cual a veces hasta la consulta misma se halla sujeta.

P: no, no, no, este es así muy, no es un médico que, por ejemplo usted lo lleva al chico ni lo revisa, ni lo toca nada, no, por ejemplo usted va y le dice "mire doctor, me duele aquí", no él la mira nomás y le hace la indicación de los remedios y le da los remedios [...] y dicen que es el doctor de zona nomás [...] hasta que por ahí lo cambien porque por ahi lo van a cambiar, si andan un tiempo y ya los llevan para otro lado, por ejemplo al doctor $X$ [anterior médico de zona] lo han trasladado para el norte, ya por la antigüedad que tenía [...] él los revisaba, pero los revisaba de bien [...] uno le explicaba las cosas, por ejemplo, él nos preguntaba qué ha tenido, si cómo han empezado, por ejemplo cuando tenían vómitos así, él decía de cómo le 
había empezado, de cómo había sido cuando ha vomitado por primera vez, qué ha vomitado, cómo ha vomitado, y bueno, uno le explicaba (P19, mujer, 43 años).

J: [...] cuando no le pregunta, ha visto? Por ahi usted se calla, en cambio cuando uno es preguntón, ya uno "pero qué es el mal” y bueno, ya le dicen ahí [...] pregunta bien "bueno doctor, qué me quiere decir con eso, qué mal tengo"

(P49, mujer, 40 años).

A: y los médicos qué le dijeron?

$R$ : y como nunca dicen qué es lo que uno tiene, que ya no tenía remedio, que ya tenía que descansar [...] le sabian hacer remedios pero ya no le han hecho nada de bien hasta que ha ido y ha terminado pobre de sufrir (P21, mujer, 63 años).

L: es de carácter fuerte, así no da mucho, yo fui con él [su bebé] y no me ha atendido, y según ella me dice que ya no tenía número, que ya estaba por irse, iba por él, a control de él, y me dice que no, que la próxima, bueno la próxima, en abril ya va a venir, me ha quedado un mes sin control [...] lo pesan, lo miden y le miran las piernitas, a ver si se sienta, cuántos minutos permanece sentado

A: y a ella no le importó que quedara sin controlar?

L: no, yo le dije y dice bueno, que estaba ocupada... media hora lo que tarda! (P70, mujer, 23 años).

R: me ha atendido una doctora buenita, de él me ha atendido una doctora mala, decimos que es mala con todos [...] a mí me ha tenido paciencia pero dicen que había ocurrido con varios que ha dejado que se mueran los bebés, de él sabía ya porque todos decían que esa doctora es muy, que no te llevaba atención o qué se yo, deja que se pase la hora [...] yo quería que me atendiera la doctora que me atendía a mí, que me hizo el control pero no, era una que trabajaba con ella [...] ella meta cantar y me decía "fuerza, fuerza", esa tarde estaba hasta las 10 de la noche y ya salía ella, así que pasaba cantando y ya ni, no sé me ha ayudado lo que, parecía que estaba en la casa, de ahí, cuando tocan así doctores ya así... a parte yo soy muy nerviosa y cuando me ponen el suero yo no recibo el suero (P20, mujer, 24 años).

A la desconfianza generada en la falta de explicaciones del profesional se le suma la incertidumbre ante resultados no deseados, inefectividad de tratamientos, percepción de negligencias que se confirman en la comparación con la atención recibida de otros terapeutas (biomédicos, enfermeros, curanderos), con el saber de experiencias previas y con los conocimientos compartidos entre familiares y amigos.

$R$ : serán médicos pero a veces no avisan lo que... ya hace mucho que está enfermo, ya va a hacer 2 meses

A: pero qué le anda pasando?

$R$ : que se le ha empezado a hinchar un brazo, lo han llevado al médico dice que lo han... y lo han seguido estudiando y estudiando y no le podían hallar de qué le ha venido y lo tienen así y después que le han encontrado que tiene un tumor en el hígado (P79, mujer, 65 años).

L: años, tres años ha hecho [...] lo curaban pero se ve que le curaban por encima, lo veía el médico de zona, lo veían en Belén, lo han tenido en Córdoba, en Buenos Aires 
[...] le decían que ya iba a sanar, que siga con el tratamiento y que ya se iba a mejorar y no

A: $y$ tomaba algún remedio?

L: sí, tomaba medicación (P17, mujer, 45 años).

R: me hicieron tacto y me dicen "está dilatando bien" 8 de dilatación, y esa noche no ha nacido, yo decía "me han mentido" al otro día dicen "a la sala de parto, usted que estaba... qué ha pasado que no ha nacido el bebé” y ya me llevaron, me hicieron tacto dice "quiere salir y no puede" (P20, mujer, 24 años).

G: $y$ he estado 15 días y no me han hecho nada, nada, y ahi me dice el doctor "ya estás churo, te voy a dar de alta" y bueno sí, me quiero ir con mi doctor, y ahí he vuelto al sanatorio (P33, varón, 78 años).

P: a pesar de que yo le había dicho a la doctora que me diera vitaminas, me ha dicho que no le hacía falta, yo digo, como niño especial puede ser que le haga falta la vitamina, pero ella me ha dicho que no, asi que nunca me ha dado vitaminas, el doctor M [de Belén] sí me ha dado vitaminas [...] una vez me ha dado el Polper B12 que salía como 22 pesos con el descuento del carnet del papi, de obra social [...] todos los días antes de comer, una hora antes de comer me decía el doctor

A: No te dijo ella por qué no te da vitaminas?

$P$ : no... no me dijo nada

A: $y$ vos por qué creés que puede necesitar vitaminas?

$P$ : y bueno, como es un niño especial y es más delgadito que los otros digo yo que puede necesitar vitaminas como para que se endurezca un poco más, tenga un poco más de firmeza, digo yo, yo a mi prima que es enfermera también le he comentado lo mismo y ella me decía lo mismo [...] ella me decía "sí, puede ser, para que pueda tener un poco más de firmeza, un poco más de defensa cuando le den las gripes, para que esté un poquito más fuerte" y bueno pero los doctores no... el doctor M le ha dado ese Polper y el doctor $S$ [anterior médico de zona] también le sabía recetar vitaminas pero esta doctora nunca me ha recetado (P76, mujer, 45 años).

P: hay un hombrecito que ha dicho que lo va a curar, porque a él le habían dicho que tenía todo el hígado deshecho, pero dice que no, que no es verdad

A: y el señor cómo sabe?

P: y porque le llevan la foto, por la fecha de nacimiento y él se fija ahí, les ha pedido los estudios para comprobar y después de que le hacen los estudios los ha traído para comprobar ahí, a ver si es verdad lo que ellos dicen, los doctores

A: y por qué será que se equivocan los doctores?

$P$ : y bueno porque dicen que, ha visto, que hay gente que hacen maldades a veces, por ejemplo, como le voy a decir?, no le gusta esta persona y bueno, le mando a hacer un mal, y bueno, dicen que a veces no son para curar los doctores, los curan los médicos campesinos (P75, mujer, 35 años).

Independientemente de las críticas al quehacer médico, varios entrevistados se definieron a sí mismos como "opuesto a los médicos", "arisca para los médicos", que no les gusta ir al médico, "ser en contra del doctor", "no llevarse" con el doctor. Ante mis indagaciones sobre el motivo de esta actitud no dieron explicaciones, no se justificaron en 
experiencias negativas con dichos profesionales ni en una tradición o posicionamiento grupal o familiar al respecto sino que lo plantearon como un aspecto idiosincrásico, atinente a su persona, en ocasiones expresado como una cuestión de fe ("mucho no les cree") o de desconfianza general hacia esa profesión .

C: y bueno, sólo dios sabe, porque ellos dicen una cosa y nunca es verdad

A: quién?

C: los médicos (P3, mujer, 56 años).

Cuando se refieren al doctor que los atendió por un malestar particular lo hacen siempre recordando su apellido y su especialización, ya sea tratándose del médico de zona, de Belén o de la ciudad de Catamarca. Al expresarse de manera positiva sobre algún médico, entrelazan con las valoraciones sobre su labor profesional comentarios sobre el trato personal que mantienen con él, con frecuencia se refieren a éste como un buen conocido, sea por una asiduidad de las consultas o por compartir con él fiestas o eventos comunitarios. El carácter y la simpatía se destaca a la par que el interés que muestra por el paciente, "churo" y "buenito" son los adjetivos positivos frecuentemente empleados, el primero aludiendo a su dedicación profesional ("poner afición”), el segundo, a un carácter afable; como contraparte, "respingón”, "raro", "rebelde”, "rezongón” subrayan también la importancia que tiene el temperamento del médico en su trato personal con el paciente a la hora de pronunciar una valoración sobre el profesional.

$R$ : con nosotros siempre era muy bueno, siempre le gustaba hacernos broma [...] el $X$, S era bueno con nosotros $[. .$.$] era muy churo (P79, mujer, 65$ años).

A: qué tal es este nuevo?

M: buenito también, y ahí va a estar, han dicho que después de la semana Santa ya va a venir, es muy buenito el doctor, es muy buenito, aquí viene, le convido mate dice “con este ya llego a Pozo” (P11, mujer, 56 años).

$P$ : sí, porque antes estaba el doctor $S$, pero ese doctor era rebueno

A: $y$ éste?

$P: y$ éste por ahí es medio rebelde, por ahí uno va y hay veces que lo atiende pero hay veces que dice "no, ya atendi demasiado", ya no lo atiende, a mí me lo ha hecho dos veces así, yo lo llevaba a él [señala su hijo de 4 años]

A: y por qué lo llevaste?

P: bueno un día lo he llevado, la primera vez lo he llevado porque estaba medio resfriadito tenía una tos y lo he llevado y bueno, ya había atendido a otros adelante y cuando ha ido me dice "siempre las mismas caras!", pero yo era primera vez que he ido, le digo " doctor yo vengo por primera vez, yo no he venido nunca a visitarlo", "siempre las mismas caras!" dice "recién he visto a una señora con todos resfriados, la familia!”... no me ha dicho más nada [...]

A: y la vez que fuiste de nuevo, qué pasó? 
P: y bueno, después he ido también y ya nos ha dicho que ha atendido los 17 que tenía que atender y no ha atendido más pacientes

A: $y$ cada cuánto viene?

P: bueno, viene cada 15 días, cada 20 días, cuando se acuerda, si no tiene, como decir, fijos los días para venir, así que no, no he ido más yo

A: y qué hacés si tenés algún problema?

P: bueno, que gracias a dios no se nos enferma asi de cosas graves, vea así una simple tosita, una cosita así, pero de una enfermedad más grande así no

A: como ser, cuál sería una enfermedad más grave?

P: bueno, por ejemplo de alguna fiebre, asi esas cosas, tienen mucha fiebre y se empiezan a desmayar así, no nunca, así como lo ve ahora, tose, pero a veces un poco que se los puede aguantar, no hay necesidad a veces de llevarlos al médico y a veces con un tesito, con alguna friccioncita se compone (P19, mujer, 43 años).

Los médicos entrevistados tampoco mencionaron barreras lingüísticas que dificultaran el desarrollo de las consultas, pero sí refirieron que la presencia o ausencia de una inclinación afectiva hacia el profesional por parte del paciente era un factor que influía en la decisión de recurrir a sus servicios.

A: y el diálogo con ellos?

D: es muy fluido, muy fluido, es más, ellos vienen y el médico es como el cura, o sea, al médico ellos le cuentan todo [...] por ahí los jóvenes porque son más pudorosos, más vergonzosos, la madre lo trae y "contále!" y si no cuenta ya larga a contar la madre y ya más el chico se anima y eso, pero no hay problema con el diálogo (P8, médico pediatra del sanatorio.)

D: hay algunas personas con las que uno hace cierta empatía que sí, que vuelven, pero por ejemplo tengo una embarazada que no sé si no lo gustó el diagnóstico o qué la última vez que la vi porque no volvió más, la chica esta... que yo le dije que tenía una toxoplasmosis que tenía que tomar una medicación [...] no sé si no le gustó a ella el diagnóstico o le parece que yo estoy errada, pero no volvió más [...] por estos lugares se da bastante es que la gente concurra a la consulta si la persona que viene a atenderlos les cae bien, eso es normal (P59, médica de zona).

Si bien se ha remarcado el uso combinado de diferentes servicios terapéuticos (la comparación entre los mismos, la contrastación entre distintos terapeutas, que orienta la aceptación o rechazo de los tratamientos y consecuentemente posteriores consultas en pos de una redefinición del diagnóstico o al menos un cambio en la terapéutica prescripta), fragmentos como el precedente advierten que más allá del ejercicio de una evaluación y elección de los terapeutas el individuo se enfrenta a las constricciones en el acceso a los espacios de salud: no siempre se puede optar por un médico que "caiga bien" y la alternativa de prescindir de la consulta es asumida sólo en ausencia de señales alarmantes. Se observa aquí que lo que eleva el "umbral" de las percepciones de molestias para acudir al médico, lo que "hace que se retarde la concurrencia a la consulta médica" no es, como subrayan los 
autores anteriormente cuestionados, la "lucha por la supervivencia", la "imposición de conseguir el sustento diario" sino el talante del profesional. El carácter del terapeuta, sus maneras para con los pacientes no atañen meramente al vínculo personal entre ambos sino que repercute en la calidad de la atención inhibiendo en ocasiones la consulta. El hecho de que los individuos caractericen y evalúen la atención recibida no sólo a partir de apreciaciones de eficiencias y negligencias sino también refiriendo a aspectos personales o subjetivos del profesional exige pensar estas valoraciones no como simples expresiones de afinidad, capricho y parcialidad. Lo que recalcan a través de estos aspectos idiosincrásicos es la voluntad del terapeuta, a cuya merced se perciben los individuos, para quienes de la predisposición del profesional depende en última instancia el que sean atendidos o no. La importancia de contar con la buena voluntad del médico para acceder a sus servicios se evidencia también cuando mencionan que callan u ocultan el haber realizado consultas con otros curadores, sobre todo si se trata de la medicina popular, como una estrategia para evitar el enojo que podría llevar al profesional a negarse a dar la consulta.

C: a veces que los médicos no les hallan se van a ella [curandera] y ella los cura, eso como tantos males que hay, a veces no son males para los médicos y ya los cura ella A: y después le cuentan al médico o no le dicen nada?

C: no!, no decimos nada!

A: por qué, se enoja?

C: claro!

A: puede ser que a algunos no les moleste?

C: pero a algunos sí!, no! no decimos nada, cuando ellos preguntan si hacemos cosas y a le decimos pero no, y claro, porque si no, no nos van a querer curar más (P11, mujer, 62 años).

$R$ : a los doctores no les digo porque se van a enojar [...] acá una señora que le dijo al doctor y él le dijo "entonces vaya y siga haciéndose atender con L" pero enojado, molesto (P20, mujer, 24 años).

\section{"... es muy buena curanderita..."}

Por otra parte, cuando los entrevistados pronunciaron opiniones sobre diversos curadores populares con frecuencia utilizaron términos como "buenito", "curioso" pero nunca adjetivos negativos como los empleados para los profesionales médicos. En ningún caso fueron referidas actitudes de desinterés, trato adusto o descortés o escasa disposición para la atención por parte de curanderos, nadie mencionó evitar la consulta con alguno de ellos a causa de su mal talante. Las situaciones de ineficacia de la terapéutica o de diagnóstico errado 
por parte de los curanderos son explicadas por el tipo de malestar (enfermedad "para el médico" o competencia de otro curandero) y no por negligencia o mala predisposición del terapeuta. Como el número y tipo de enfermedades que pueden curar varía de un curador a otro se establecen comparaciones entre los distintos curadores reconociendo las limitaciones de unos frente a otros sin por ello menoscabar su aptitud para curar otros males. Por ejemplo, la cura de malestar de riñones, vesícula, dolores musculares u óseos, "males hechos", cura a distancia y diagnóstico a través de la "lectura de las aguas" (orines) son capacidades que no todos ostentan, mientras que la cura de aire, susto, ojeadura o empacho al ser más comunes no son un factor de distinción. Otro elemento que es utilizado para resaltar positivamente la labor de un curandero es la coincidencia de su diagnóstico (sin recurrir a estudios o análisis) con el recibido por el biomédico o el conocimiento de la historia clínica del paciente sin que éste se la haya narrado. Es notorio que lo que en la apreciación de la labor del médico es considerado elemento de desconfianza (diagnosticar y prescribir medicamentos sin realizar estudios) en el caso del curandero es considerado factor de mérito.

$P$ : es buena la señora, es buena esa señora, esa señora me lo ha curado a $D$ [su hijo] de pata de cabra (P38, mujer, 43 años).

A: y van por otras cosas a verla a doña L o sólo por susto?

C: no por todas las enfermedades, si es bien curiosa [...] a veces que los médicos no les hallan se van a ella y ella los cura (P11, mujer, 62 años).

R: yo nunca le decía a ella lo que el doctor me decía, si no que ella me decía, por eso digo yo que ella sabrá [...] [porque le recetaba lo mismo] me hacía los estudios y los hacía ver con el doctor y con ella (P20, mujer, 24 años).

$P:$ [...] yo he dicho "si me está diciendo lo mismo", porque la señora L [curandera], el médico también me dijo que él tenía posibilidades de caminar teniendo la rehabilitación y bueno doña L. también me decía lo mismo [...] pero ella me ha dicho más antes, ve?, ella me ha dicho más antes, entonces le digo, "señora L, el doctor me ha dicho lo que usted me ha dicho" (P19, mujer, 40 años).

J: sí, los curanderos hacen lo que pueden pero póngale por ahí de un aire aquí pero bueno, ya mucho como ser, no sé qué puede hacer ante una vesícula, la infección urinaria bueno, con yuyos la corta pero no la corta del todo (P7, mujer, 42 años).

También hubo algunos individuos que se mostraron escépticos ante la labor de los curanderos, posicionándose en una actitud de incredulidad que, como se registró en el caso de quienes "no les creen a los médicos", no fue justificada por experiencias negativas con dichos terapeutas sino afirmada como una cuestión de fe.

E: [hablando de curanderos] dicen que curan de susto pero no les tengo fe a esos médicos porque tiene que tenerles fe para hacerse curar 
A: y por qué no les tiene fe?

E: porque no les creo [...] a él le creo, a don F sí, cura bien y sana la chica

(P4, mujer, 75 años).

\section{El discurso médico moralizante}

Hay además otro aspecto en torno al cual contrastan las opiniones sobre la atención de médicos y curanderos y que es evocado en directa asociación con las apreciaciones personales negativas del profesional biomédico: se trata del discurso moralizante con que los individuos refieren ser culpabilizados o al menos amonestados en ocasión de la consulta médica. Discurso que está ausente en lo que cuentan escuchar del curandero, si bien aquí también aparecen elementos morales, no es el enfermo o quienes lo cuidan los culpabilizados sino un "otro" generalmente no identificado, causante del mal a través de su envidia, o más intencionalmente, por medio de maleficios.

P: no es muy buena, bah, para atender, no es de carácter muy buena, no porque si uno va, por ejemplo, lleva, para el invierno se resfrían todos y uno los lleva y dice "qué hacen que se resfrían?! No los cuidás?!” y los chicos se levantan temprano para ir a la escuela, más vale que se resfrían [...] uno los lleva a control pero si están muy enfermos los atiende y si no, no [...] ése [otro médico] también atendía, también una vez me dijo por qué los dejo resfriar? Para qué los llevo a todos juntos? Y al último, le digo, “atiéndame si quiere, le digo, si no déjeme!”

A: y qué te dijo?

P: "no, me dice, perdóname, vení, vení, te voy a atender" [ríe] y una vez la había retado a la mamá de ella [señala a una nena presente] que andaba con todos los chicos también, después entro yo, dice “otra más con la ponchada de hijos!” [ríe] “y qué quiere que haga?! Se enferman!” y yo ya no voy casi al médico, a no ser que estén muy enfermos, sí los llevo

A: y muy enfermos de qué?

P: gripe a veces cuando les agarra mucha fiebre, pero son de los mismo resfrios a veces (P75, mujer, 35 años).

M: [...] que vuelva en diciembre... que vaya ahora, me va a correr [ríe] él me dijo que ya estaba bien del pulmón [...] me ha dicho "vení, yo te voy a dejar sana" y ya ni he vuelto en diciembre cuando, ahora me van a retar (P11, mujer, 56 años).

Paralelamente a las connotaciones morales atribuidas a la voz de los terapeutas, aseveraciones morales por parte de los entrevistados encuentran una vía de expresión en la narración en torno a los procesos de salud-enfermedad-atención, y en tanto apreciaciones sobre las relaciones sociales, contextualizan y en algunos casos explican los eventos de enfermedad y cura. Como señala Freidson, "si bien la designación de enfermedad parece realmente funcionar para desanimar reacciones punitivas, no desalienta las reacciones 
condenatorias. Se condena la "enfermedad" más que la persona, pero se condena de todos modos. La persona es tratada con simpatía más que con reprensión, pero se espera que se libere del atributo o de la conducta condenada. De este modo, si bien (idealmente) la persona puede no ser juzgada, su enfermedad ciertamente es juzgada y su enfermedad es parte de él. La neutralidad moral sólo existe cuando a una persona se le permite ser o hacer lo que desea, sin observaciones o discusiones" (Freidson, 1978: 254-255). Las narraciones en torno a padecimientos dan lugar a apreciaciones acerca de la conducta concerniente al cuidado personal e interpersonal y también a la expresión de juicios sobre las relaciones sociales y modos de comportamiento. 


\section{Apreciaciones sobre las relaciones sociales y connotaciones morales en torno a los procesos de salud-enfermedad-atención}

Hasta aquí se recuperaron las valoraciones en torno a la relación con los terapeutas, pero como las situaciones de enfermedad resaltan las responsabilidades del enfermo y sus familiares, los entrevistados pronunciaron también sus opiniones sobre los deberes del enfermo y de su núcleo más íntimo, sobre todo al referirse a eventos de enfermedad sobrellevados por terceros. El apoyo y acompañamiento del enfermo por un familiar se destaca como un deber ser, como función ineludible, y consecuentemente una actitud de desatención o descuido suscita expresiones de reprobación. En cuanto al propio enfermo, no cumplir con el tratamiento indicado o no acudir al médico o curandero son motivo de desaprobación, crítica, e incluso de culpabilización en situaciones de agravamiento.

\section{El cuidado del enfermo, responsabilidades y deberes}

Como ya se señaló, la mayoría de los azampeños tiene algún familiar viviendo fuera de Azampay, generalmente en zonas urbanas (la ciudad Belén, de Catamarca, y con mucha menor frecuencia Tucumán, Córdoba, La Rioja y Buenos Aires) que facilita el contacto con los centros de atención y su permanencia allí el tiempo necesario para realizar estudios, controles, cuidados postoperatorios. En sus relatos de las trayectorias terapéuticas generalmente hacen referencia al familiar que les brindó hospedaje cuando el servicio de atención buscado estaba fuera de Azampay, quien los acompañó, los cuidó durante el tratamiento y también en algunos casos dio su apoyo económico (sea cubriendo directamente un gasto monetario o permitiendo el uso de su mutual).

P: asi que yo me he ido antes y he estado en la casa de la tía, de la hermana de mi papá, después cuando yo me he sentido enferma en la tarde le digo a la tía "tía, no me siento bien, me voy a ir al hospital", "ay, bueno, hija, vamos, yo la llevo" y bueno, ya se ha ido ella conmigo, me ha dejado en el hospital [...] era sábado y me han tenido hasta el lunes, como me he ido para la casa de la tía P he estado como una semana en Belén (P19, mujer, 40 años). 
F: claro, mi hija, la que trabaja en Belén, ella alquila, no casa propia menos tengo, alquila ahi la chica, y ahí he estado un mes yo, un mes y 10 días

(P44, mujer, 64 años).

A: Y vos qué hacias, te quedaste los 6 meses? [su madre había tenido que ser internada por tuberculosis]

M: no, yo no porque yo no podía, tenía que trabajar, se iba mi hermana, estaba un mes mi hermana, otro mes estaba mi otra hermana, como somos cuatro

A: se repartian

M: sí, después ya se iba mi hija a cuidarla porque yo no podía (P51, mujer, 30 años).

P: sí, en el sanatorio le digo yo si me podría cubrir algo la obra social de mi papá, como es jubilado y no, no me cubre esa, esa no me cubre, para comprar alguna orden me cubre, por ejemplo para comprar órdenes para análisis me cubre pero para así, para hacer rehabilitación ya no me cubre la obra social de mi papá ni la obra social de mi tía que también tiene obra social (P38, mujer, 44 años).

P: claro, el médico les había dicho que ella ya no tenía curación, que si la querían retirar del sanatorio que pagaran la ambulancia, 150 pesos, estaba un tío mío, el otro hermano de papi y él trabaja [...] y ha dicho "yo voy a pagar ésto". Yo de aqui he ido varias veces a verla, ella ha estado como 10 días, 14 días, no ha estado más"

(P19, mujer, 44 años).

El familiar que vive fuera de Azampay significa una extensión de la red de recursos

(no sólo monetarios) a los que se puede apelar en caso de enfermedad y que amortigua las dificultades originadas por la distancia geográfica.

R: porque él tiene que tener estas pastillas todos los días toma la dosis

A: $y$ de dónde las saca él?

$R$ : en Catamarca se las da el doctor

A: las compra o se las dan?

$R$ : y bueno, cuando no le dan tiene que comprarlas y pero ya tiene que tener receta siempre es lo mismo

A: o sea que él tiene que viajar a Catamarca a buscarla?

$R$ : primero viajaba todos los meses y después [...] el otro hijo mío [...] los retira mi hijo, le da la orden para que él retire

A: se las paga su otro hijo allá?

$R$ : claro, y ya paga para mandar también [...] me las manda por el colectivo, lo que si lo tiene que ir a buscar a la terminal

A: o sea que viaja hasta Belén a buscarla?

$R$ : a veces le encargamos a la chica de mi hermano, ya las retira ella y ya es más fácil (P79, mujer, 65 años).

R: estábamos en el mes de agosto todos los sapos guardados a gatas... de La Ciénaga a lo de mi hermano, me ha mandado 3 sapos, tenían que ser 3 curas

(P79, mujer, 65 años).

Recíprocamente también mencionaron viajar hacia el lugar de residencia del familiar para prestarle apoyo y compañía en caso de enfermedad, es decir, aunque el recurrir al 
pariente fuera de Azampay implica ventajas materiales (hospedaje, obra social, medicamentos, etc.) el rol del familiar para con el enfermo no se reduce a ésto. La presencia de los familiares tiene un valor en sí mismo pues el componente afectivo se considera que promueve el restablecimiento de la salud. Como se desarrolló anteriormente en torno a las etiologías psicosociales, la tranquilidad, evitar discusiones y preocupaciones, es mencionada como parte del cuidado y autocuidado.

R: porque él ha tenido una enfermedad y ella se ha ido a Vichigasta para acompañarlo porque a él lo iban a operar [...] se han ido a Córdoba y le han hecho todo

A: y entonces viajó la $F$ con la E? [madre y hermana del enfermo]

$R$ : claro (P58, mujer, 58 años).

P: se ha ido a La Rioja a ver al hermano enfermo [...] si él quiere venirse a Belén lo traen a Belén y si no lo traen para acá [...] como le habian dicho que después que le hagan el medicamento ese lo van a derivar a Belén para que ahi le hagan un control, para que esté más cerca también de los familiares (P75, mujer, 35 años).

A: y porqué en Belén?

L: [el médico] dice que él necesita que a él lo atienda la familia, tiene que distraer, conversar, charla, distracción y ahora está solo allá [en La Rioja], internado está solo, tiene la señora pero está con los chicos [...] a nosotros se nos hace difícil porque ya nosotros más lejos, son más gastos! en cambio en Belén es más cerca y de aquí hay mucha gente, van a ir a verlo, lo van a saludar, a él le ha hecho bien, dicen que ahora cuando ha ido la chica se ha sentido mejor, sobre todo el día, la noche pensando... le hace peor, el bajón, me han dicho que busque una persona fuerte para que a él le hace... [...]

$P$ : para que lo curen aquí los médicos campesinos

A: por qué, no lo están curando bien los médicos de allá?

P: porque ese médico campesino, un hombre que dicen que es médico aquí para el norte por ahi ha andado el viernes la $\mathbf{L}$ [hermana del enfermo], se ha ido hasta allí con un sobrino que tiene una moto [...] y según decían que ese señor le ha dicho que lo que él tiene, la enfermedad, el problema que él tiene no es para médicos cirujano, es para un médico campesino

A: y cómo sabe el señor?

P: por el número de documento ya sabe lo que tiene

A: y ha dicho qué tiene? Qué enfermedad es?

P: no sé, pero así me ha dicho la madre el viernes a la tarde, que lo tiene que traer y llevarlo para curarlo [...] y de aqui se han ido los hermanos, los cuñados, se han ido a verlo y de ahi han vuelto con que estaba más enfermo, de que lo llevaban a Córdoba, después se ha ido ella, doña $\boldsymbol{S}$ [madre del enfermo]

(P76, mujeres, P: 45 años; L: 47 años).

En este último fragmento aparece, junto al reconocimiento del valor terapéutico del componente afectivo, la movilización de otro recurso con que cuentan quienes permanecen en Azampay para ayudar al enfermo migrado: la atención con curanderos de la zona. En el ejemplo se observa la red de parientes movilizados para contactar al curador oriundo de una 
localidad vecina, concretar la consulta, lograr el traslado del enfermo, incluso realizaron una colecta entre todos los lugareños para recaudar fondos para los viajes (la entrevista arriba citada tuvo lugar en la casa de $\mathrm{P}$ coincidiendo mi visita con la de L, hermana del enfermo, encargada de dicha colecta).

La referencia constante al apoyo de un familiar destaca la función que el mismo cumple en torno al cuidado del enfermo; siendo este acompañamiento la actitud esperada, su ausencia suscita expresiones de reprobación.

Y: él dice "me voy a tener que operar" y se va solo

A: y nadie lo cuida?

Y: y haga de cuenta que no tiene familia (P22, mujer, 16 años).

O: como a veces uno no conoce algunas cosas de la familia, o no se ha acordado de preguntar, bueno ya parece que el marido, en el matrimonio uno se siente mal y dice "me voy a Belén" si ella [señalando a su esposa] se siente mal hay que llevarla... a $X$ la han descuidado mucho [hablando sobre el reciente fallecimiento de $\mathrm{X}$ ] (P2, varón, 58 años).

C: Ya la edad y la debilidad no podía alimentarse porque $T$ [la hija] la dejaba sola, el doctor dijo que estaba muy desnutrida, la pobre estaba agotada, la podrían haber llevado a un hotel de ancianos que hay en Belén, como él [el marido] es jubilado podría haber pagado, ahí hubiera estado atendida ( $\mathrm{P} 3$, mujer, 57 años).

El cónyugue o los hijos adultos son los responsables de llevar al enfermo al centro de atención, de velar por su salud; en el caso de los niños, aunque a veces se menciona a ambos padres, con mayor frecuencia se señala a la madre como la persona que debe preocuparse por la salud del hijo.

$R$ : [hablando de los hijos únicos] es feo tener uno solo ya cuando se enferman los padres para cuidarlos es mejor de a dos (P21, mujer, 67 años).

M: De la fiebre sabrá ser digo yo, y cómo nuestros padres no nos llevaban al hospital, nada, no sabría haber doctor, digo yo

A: no habia?

M: no sabría haber, como no nos llevaban (P11, mujer, 58 años).

E: Los médicos campesinos dicen que es ojeadura, ojeo, sabrá ser del aire, que la quiere mucho a una persona, también porque la madre, a veces son caprichosas, no la cuidan, lo sacan de bebito al viento, al aire ( $\mathrm{P} 4$, mujer, 76 años).

A: qué pasa si no los curan? [hablando de ojeadura]

$R$ : y dicen que se mueren, un caso de Jacipunco que ya lo traía a Belén y por La Ciénaga se murió el bebé, se le partió la cabeza, porque son chiquitos y ya no les aguantan los huesos el dolor de cabeza, la madre nunca lo hacía curar (P20, mujer, 25 años). 
O: y bueno, claro, porque ella no llevaba mucho la atención de eso, la preocupación de ella, poca preocupación [...] si ellos no hacen por los hijitos quién lo va a hacer? [...] tiene la saliva que se les cae... al chico este la vez pasada me daba lástima, claro, sentado (P78, varón, 60 años).

La figura del familiar está presente también cuando se relata la decisión de recurrir a un curador (sea médico o curandero), es un familiar preocupado el que aconseja e incentiva la consulta.

M: porque ella tiene esa descompostura, convulsiones, se ha compuesto anda bien ahora, primero era un susto para todas las mujeres, hasta que un día se ha caido en el fuego, claro y ya la han hecho comprender a mi hermana que la mande a Catamarca, la ha llevado ella y le ha hecho controles y le han seguido haciendo controles (P11, mujer, 66 años).

P: ha venido la tía, la hermana de mami y dice "P, por qué usted no lo lleva para Belén a esta criatura, cómo se lo nota de enfermo!” (P38, mujer, 44 años).

J: eso es lo que me decía ahora mi cuñada, "venite a Catamarca, venite asi te hacés un tratamiento" (P49, mujer, 43 años).

Lógicamente es en el ámbito de la autoatención, de la medicina casera, donde la intervención terapéutica de algún miembro de la familia es central, dado que dicho nivel de atención es definido a partir de las prácticas de apelación a la ayuda del familiar o amigo, quien le comparte algún remedio, sea de venta libre o que conserva de anteriores consultas médicas, le proporciona alguna tisana, le realiza algún tipo de cura, etc.

F: y esas [diversas plantas] las venimos tomando nosotros desde, quién nos habrá enseñado, nuestros padres, y ellos nos hablaban a nosotros y asi se va quedando como una cadena (P44, mujer, 64 años).

M: se acostó a dormir y me ha dicho que le lleve agua, y como a las 3 de la mañana me habla y me dice que le duele un poco el estómago, se levanta mi marido y le hace un tecito, de yuyo, de ese ruda, porque me dice ella que era al hígado (P72, mujer, 34 años).

F: sí, yo los sahúmo

A: y a vos quién te enseñó?

F: no, yo, como veía que lo hacía mi tía, mi abuela, mi mamá, de ahí he aprendido, y ellas me iban indicando cómo los tenía que llamar, por ejemplo, yo tengo un primito que se llama $G$ que era perseguido por el susto, ojeadura, y entonces una noche dice mi tía, la mamá de $G$, dice que lo sahúme yo, porque ella que le perseguía mucho el dolor de muela, bueno digo, y ella me ha preparado la yareta, la yerba y la azúcar y agarro yo y llevo los rescoldos y ella lo llevaba al bebé y ahi lo sahumaba yo (P30, mujer, 15 años).

$N$ : a $J$ [su nieto] le ha dado cuando tenía un año, le ha dado bronquitis, ah! lo he llevado enfermo [...] eso le viene de mucho frio [...] ha tenido fiebre asi, estaba helado 
entero, yo me había puesto a amasar y la señorita [su hija, madre del niño] lo ha bañado y lo ha tirado en el dormitorio, destapadito, apenas con un pullo y no le ha puesto colchas, nada, me voy a verlo y uh! Helado, respiraba poquito, uh! Le digo, "cómo está de enfermo este chico!" y lo he envuelto en una colcha y lo he sacado para afuera, le digo, estaba mi hermana de la otra casa, me dice "me voy a ir corriendo a traer remedio para los chicos míos para ver si se le baja, porque él tiene tanta fiebre, está helado por la fiebre que le está cocinando por dentro" [...] y ella le ha dado un jarabe que era para la fiebre [...] porque es muy descuidada, si yo tengo que estar, "ponéle las medias, ponéle las zapatillas, ponéle la ropa” y cuando no estoy yo son ellas [sus hermanas, tías de la madre del niño] (P58, mujer, 69 años).

\section{El autocuidado como "deber ser", los usos moralizadores del relato}

Respecto al autocuidado, se mencionaron, asociadas a los diferentes padecimientos, las prácticas que el enfermo debe incorporar a los fines de su recuperación. Restricciones en la dieta en casos de hepatitis, diabetes, colesterol, hipertensión, problemas a la vesícula o intestinales, reposo postoperatorio, son referidos junto a la ingesta de medicamentos o tisanas, como parte de la terapéutica asumida. No afligirse, no pensar, estar tranquilo, no preocuparse, son señalados como prescripciones para quienes padecen enfermedades en las que el factor psicológico forma parte de su etiología (como presión alta, asma, afección al corazón, algunos casos de aire) pero también para un postoperatorio óptimo. Estas conductas consideradas enfermantes (intranquilidad, llanto, preocupación, aflicción) generalmente son señaladas por los azampeños como producto de tensiones en las relaciones personales por lo que se destacó una etiología psicosocial, pero dado el carácter volitivo de las mismas, la responsabilización recae más en el enfermo que en su entorno.

O: no ha hecho el reposo como le ha indicado el oculista, dicen que lo más malo es llorar y ella lloraba por venirse para aqui y ha quedado mal, de ahi ha perdido nomás la vista (P2, varón, 58 años).

A: por qué quedó mal? [hablando de una persona que fuera operada de la vista]

C: porque no se cuidaba, trajinaba, se metía cerca del fuego, o sería que era muy nerviosa y no le sientan bien las operaciones. Cuando es tranquilo se cura mejor (P3, mujer, 56 años).

G: [dice padecer del corazón e hipertensión] ahora nomás me ha afligido un poquito y el doctor me dice que no me aflija... [ríe] por ahí reniego yo ahora que ya me viene un ataque... porque el chango [su hijo] se ha ido para el campo y no ha vuelto (P33, varón, 78 años).

No cumplir con el tratamiento indicado o no acudir al médico o curandero son motivo de desaprobación y crítica, con frecuencia sustentadas y validadas apelando a la voz del 
terapeuta en tanto autoridad reconocida. No obstante predominar una percepción de un elevado riesgo de iatrogenia en las operaciones, en ocasiones los resultados negativos se atribuyen al incumplimiento por parte del paciente de los cuidados indicados.

P: el doctor le ha dicho que no había hecho las cosas que tenía que hacer, que él le había dicho, porque el doctor le había dicho que no tenía que afligirse, que no tenía que renegar, que no tenía que llorar, y bueno a veces que ella era renegona, y eso era lo que le ha sentado mal

A: al ojo

$P$ : al ojo, los nervios (P19, mujer, 44 años).

G: luego de la operación se tenía que cuidar del viento, del sol, del vapor de la cocina, $F$ ha quedado mal, un hermano de $X$ también, será porque han hecho desarreglo, no se han cuidado (P33, varón, 78 años).

C: le ha dicho que son muchos nervios, muchos males pensar que ella no tiene que pensar en cosas que no puede pensar y pensar [...] cuando uno está pensando mal, piensa en tonteras y en lugar ella de seguir bien ella sigue pensando macanas y eso es lo que... [...] ella no le tiene fe a nadie... póngale que le falte algún calcio a la cabeza y ella no le toma ni un... a veces que los remedios no los quiere tomar (P3, mujer, 56 años).

El consumo excesivo de alcohol, ya referido entre los factores enfermantes, es evocado para explicar malestares de hígado, algún evento particular de cáncer, complicaciones de cicatrización y del estado de quienes sufren de presión alta o del corazón, pero siempre con una connotación moralista achacando al enfermo la causa de su estado.

L: no se le cicatriza

A: y por qué será?

L: vaya a saber... sigue tomando vino

A: y eso...

L: claro, eso le hace mal [...] porque él toma y no se cuida, tiene que cuidar (P76, mujer, 47 años).

J: al corazón, le ha venido

A: y fue de golpe?

J: y sí, se tenía que tratar pero no entendía, ni le tomaba las pastillas para la presión, nada

A: ah tenía presión alta?

J: y sufría de la presión por el mismo alcohol, tomaba mucho! Y digo yo, jóvenes que pueden salir adelante, salir de eso, pero bueh, será más fuerte lo que él desea no? (P68, mujer, 43 años).

Dentro de los cuidados mencionados para restablecer la salud figura la restricción de las actividades laborales, de ahí que se censure la conducta de quienes a pesar de estar sufriendo un padecimiento continúan trabajando. Pero inversamente cuando el relato es autorreferencial, en un contexto donde se subrayan los méritos del trabajo y la inactividad 
sólo es justificada en tanto forma de cura prescripta o por ser efecto inevitable de un malestar, el continuar trabajando a pesar de estar enfermo es testimoniado como prueba de laboriosidad y sacrificio.

E: y bueno ella se ha venido y ha estado trabajando, noches antes 3 de la mañana cosiendo pullos y tejiendo flecos lo que sea, y bueno eso es lo que le debe haber hecho porque si no se cuidan! (P65, mujer, 78 años).

E: en la cabeza se ha golpeado, anda con dolores de cabeza, se tiene que ir a la cama [...] dice que le dolía todo el cuerpo, no podía caminar mucho ni nada, era del golpe, ha vuelto a ir a Catamarca a hacerse ver y ahi le han dicho que no vaya a querer entrar a trabajar todavía porque no estaba bien, y como aquí son! Aquí con la piedra está trabajando pero qué van a decir los demás, ellos son dueños!

(P65, mujer, 78 años).

J: es que... bah, da la impresión que uno se siente así, da la impresión que los demás creen que uno se hace el enfermo y bueno, yo hay veces que tengo que seguir callada y lo mismo porque es así, qué va a, con decir y si uno no lo van a componer tampoco [ríe] (P68, mujer, 43 años).

M: nosotros [su familia] trabajamos todo el día, no como otros que ni se enferman lo que están todo el día sentados esperando una pensión del gobierno

(P11, mujer, 56 años).

El tema del cuidado aludido al referir conductas de terceros, saca a relucir los usos moralizadores del relato, de reafirmación de un deber ser respecto del accionar del enfermo y de sus familiares. Sonderéguer señala que a través de la interpelación a diferentes interlocutores, de la referencia a los "otros", los entrevistados aspiran en sus discursos a una enseñanza y a sustentar la propia visión. "Así como la narración pone orden en el mundo, da sentido a los hechos, la argumentación se basa en el deseo de persuadir, de consensuar opiniones. Argumentar supone convencer a otro de la justeza de una proposición. En su despliegue, los testimonios buscan la adhesión de los interlocutores, su consentimiento, su concurso mental: elipsis, alusiones, recursos retóricos y lexicales pueden pensarse, por tanto, como una "política del recuerdo", una praxis narrativa que sostiene un discurso didáctico y político y propone una intervención que interpela al presente, rescata pactos, insinúa responsabilidades" (Sonderéguer, 2001: 9).

J: a él también le han dicho que tenía un mal, que lo estaban curando de la vesícula y mire, a él lo estaban curando de la vesícula con yuyos y qué, había tenido apéndice, yo, como digo, no soy curandera pero le decía a $F$ "hágase ver $F$, vaya al médico, puede ser vesícula o puede ser apéndice”, porque el apéndice también agarra, provoca vómito, ya come algo y todo le hace mal, y era duro, no se quería hacer ver, pobre, hasta que al último... Pero yo por ejemplo así en enfermedades muy, muy, ya desconfio, no todo creo, no?

A: en enfermedades muy qué? 
J: póngale, como ser el apéndice, la vesícula, qué le puede hacer un curandero? Sólo le lava con esas agüitas, con esos yuyos [...] ya es médico, es para el médico esas cosas, claro, yo por ejemplo, como le digo, el susto, la ojeadura, el aire, sí, yo creo en esas cosas, son cosas, pero ya así, de los riñones póngale, qué le puede hacer un curandero? Claro, uno se alivia [...] yo tenía un primo que andaba con infección urinaria y él ya me contaba que le dolian las espaldas, los riñones, todo, y bueno, que no quería ir al médico, y bueno, hasta que ha caído, ha caído, se le han trancado los orines, todo

A: cómo trancado?

$J$ : no podía orinar y le han puesto sonda, y entonces el médico dice que tenía una infección bárbara a los riñones, si

A: pero se habia hecho tratar con algún curandero?

$J:$ no, no, no quería ir a nadie, por vergüenza [...] no quería ir al médico y hasta que cayó a la cama [...] yo digo que debe ser por el agua, porque como acá tomamos agua cruda, viene del chorro el agua y de ahi entra a un caño y pasa por los caños para acá y uno saca del grifo y la toma y yo digo que de eso, porque de qué más podemos agarrar tanta infección urinaria, así, bah, a mí nunca me agarró porque una siempre, hago aguas así de llantel, de quimpi, de este, de gramilla, que es todo para los riñones, ha visto? Que le lavan, le limpian [...] hiervo el agua y sí, siempre tomo, y no, nunca me agarró [...] deben ser como infecciones, para mi eso hay que ir al médico, ya no a las curanderas, y bueno, los curanderos dan yuyos [...] no se hacen tratar con el médico y no preguntan bien "bueno doctor, qué me quiere decir con eso, qué mal tengo" y bueno y directamente atinan a los curanderos (P49, mujer, 43 años).

En este fragmento se puede observar cómo se entretejen en el discurso las descripciones sintomáticas y las explicaciones etiológicas de una enfermedad con la reprobación del accionar de terceros: la entrevistada comienza hablando de lo que padeció otro habitante de Azampay, quien había tenido que ser operado de urgencia de apendicitis. A medida que enuncia lo que para ella son los síntomas de "apéndice" y los de "vesícula" reproduce el consejo que ella le dio, contrastando lo que el enfermo hizo (con consecuencias graves) con lo que según ella debería hacerse en tal situación. Luego toma otro ejemplo, el caso de un primo que padeciendo infección urinaria tampoco hizo lo-que-debería-hacerse con consecuencias también negativas. En función de la explicación etiológica que sostiene, presenta sus medidas preventivas y remarca lo que en su opinión es la terapéutica acertada. Los dos casos que la entrevistada evoca contribuyen desde su particularidad al conjunto de nociones con que ella cuenta para representarse las enfermedades. De esta manera los saberes sobre salud-enfermedad se elaboran no sólo a partir de la experiencia propia de malestar sino también desde lo acontecido a terceros sucesivamente reconstruido desde la aprobación o la crítica. Toda narración, afirma Sonderéguer, es una especie de alegoría, apunta a una moraleja o dota a los acontecimientos de una significación que no poseen como mera secuencia, tiende a moralizar la realidad. "La memoria es ejemplar, dice Todorov, cuando el recuerdo de los 
hechos del pasado se abre a la analogía y a la generalización; entonces deviene ejemplo y propone una lección. [...] el recuerdo puede ser utilizado como modelo para comprender situaciones nuevas y el pasado se convierte en principio de acción para el presente" (Sonderéguer, 2001: 6).

\section{El relato de trayectorias terapéuticas como impugnación de prácticas y representaciones}

La referencia al "otro" sirve de contraste para la afirmación de los valores y principios de acción propios del narrador, quien remarca lo acertado de su accionar (pues en su opinión resulta eficaz) comparándolo con el proceder de un "otro" que no tuvo consecuencias positivas. El narrador se vale de la reproducción de diálogos que sostuvo con estos personajes que cumplen el rol de oposición para, como señala Chirico, poner en escena la propia representación de sí mismo. Esta autora habla de un "interlocutor fantasma" para referirse a este "dispositivo enunciativo por el cual se construye a un adversario con quien polemizar" (Chirico, 1987: 443). Aquí también se recuperó la reproducción de diálogos donde el "otro" aconseja e incentiva la consulta con un curador, no buscando el narrador discutir con esa opinión sino reafirmar desde esta voz externa la importancia y pertinencia de la decisión por la consulta.

Por otra parte, la discusión con el "otro" no sólo le permite al narrador destacar y valorizar su postura sino también cuestionar representaciones y prácticas ampliamente sostenidas, cuando no hegemónicas. Como señala Barbieri, “muchas veces las pequeñas historias que relatan son un intento de inscribirse en la gran historia, de hacerse visibles cuando no tiene reconocimiento [...] Otras veces las versiones individuales que brindan los sujetos tienden a impugnar construcciones hegemónicas que distorsionan las experiencias vividas y el pasado" (Barbieri, 2007: 3). En los diálogos con el curandero local, él fue contrastando cada explicación y caracterización propia de una enfermedad con la definición biomédica que conoce, resaltando la ineptitud de los profesionales de la biomedicina para realizar una identificación adecuada y un tratamiento eficaz cuando se trata de "enfermedades para el curandero". Aunque les reconoce su competencia frente a otras enfermedades y él mismo cubrió el rol de enfermero aplicando vacunas e inyecciones durante más de 35 años en la zona (hasta la instalación de la posta en los 80), cuestiona la agresividad de los tratamientos médicos, su ineficacia y sus iatrogenias: 
F: se ladea la boca, todo, bueno, eso como le dicen que es parasis o cómo le dice el doctor? [...] No es eso, es el fuerte aire que tienen, si se lo curan ellos lo echan a perder peor

A: y usted cómo sabe que es el aire?

F: y sí, porque yo conozco más o menos cómo es, yo le pregunto cómo es mal, lo que siente, qué siente, cómo se siente [...] pulso, pulsación que tiene, que está en el intestino [...] eso viene del resfrio y debilidad llega al intestino, pero el doctor dice úlcera y lo opera, pero eso si lo opera, bueno, raro el que salva, que eso es una cosa que te corta el intestino, que se hace con, ahi, esa grande, esa sierra, el intestino [...] se iba al doctor todos los días, iba al doctor a Belén, volvía, al otro día ya estaba muriendo [...] vaya a saber qué le decían, no sabían, le dicen pero no lo curan, sabe que lo atienden pero no lo curan

A: por qué cree usted que no lo curan?

F: sabe por qué no lo curan? Porque no saben, con qué lo van a curar al aire, eso le llaman meningitis, el médico [...] le dice tiene meningitis y con eso lo larga, qué tiene le van a decir y no le dan el remedio, si le ponen la inyección a veces lo matan casi al niño, porque eso lo pone en contra, eso es malo, malo

A: la inyección?

F: claro, claro, lo pone en contra eso, eso no es para el médico, eso es para los campesinos, el campesino sabe cura más [...] estaba un trapo lleno de sangre [...] y he hecho una curación, paró, a la hora otra vez [...] a las dos curaciones ya estaba, ya salía poquita [...] quedó sana y bueno mire, pasa esa noche, ese día y la lleva al médico y no ve lo que estaba bien, y ha ido allá, lo ha visto el médico otra vez y allá ha vuelto otra vez, bueno, el médico le ha quemado la sangre, las venas [...] las narices le ha quemado, y bueno, ése es el remedio del médico, que lo destroza al paciente, cómo, y yo con, yo ni un remedio de nada, ni he dicho venga este remedio, este otro, basta mis manos que han ido a la cabeza, si ella hubiérase ido aquí nomás y le vuelvo a repetir la curación, curaba [...] la llevaron los hijos, ya que lo han llevado, porque siempre me pasó así varias veces, algunos se hacen curar o vienen y se hacen curar una vez, tienen que volver mañana, no, así como venir para acá me voy a ver a Belén a llevar plata porque este no me cobra lo que me cobra el médico allá y bueh [...] porque la plata les estorba, le dan allá al médico, ya que no me den nada a mí, me dan un peso, dos pesos y ya ven que es un gasto muy grande pero cien pesos que van y le dan al otro médico allá, ese no es gasto para ellos

(P55, curandero, 84 años).

Aquí el "otro" impugnado es el discurso biomédico pero también se cuestionan las decisiones terapéuticas de los legos que optan por esta medicina. En un diálogo con R, sin ser ella curandera pero hablando sobre enfermedades "para curanderos", su "otro" es el "en otras partes" donde prima el discurso biomédico que conduce a un tratamiento errado de ciertos malestares y desde el que se critica el saber y el proceder de un "aquí". Como ya se señaló al identificar "lo que está en juego" (aquello relevante desde lo cual se significan las experiencias de enfermedad), predomina una valoración positiva de lo local con sus saberes tradicionales frente al accionar desde la biomedicina.

A: si usted la tiene que curar de susto o si la tiene que curar de ojeadura, cómo se da cuenta? 
R: no, así que uno ya está hecho, ya uno está más o menos práctico a las enfermedades esas, aqui siempre uno es más... eh... no como en otras partes, en otras partes lo llevan, sienten enfermo y bueno, los llevan al médico, y el médico, la ojeadura el médico le dice la meningitis, porque dicen que se parte la cabeza [...] hay muchos que yo ya he escuchado por radio que dicen que es meningitis, que no se va a componer, que hay algunos, claro, ya los pasa y se mueren pero curándolo se componen y el médico no sabe que es de esos aires, le dice meningitis y lo siguen y bueno lo vence el aire y lo mata, pero si uno es conciente de que lo tiene que hacer curar y lo hacemos curar, porque aquí gracias a dios nunca pasó un caso así de que se hayan muerto chiquitos así con la ojeadura, que dicen que somos muy creyentes a las cosas malas (P40, mujer, 67 años).

\section{Aspectos enfermantes de las relaciones sociales}

Además de las referencias al auto e inter-cuidado que, reafirmando un deber ser respecto del accionar del enfermo y familiares, suscitan juicios negativos sobre relaciones sociales, la explicitación de una causalidad social para ciertos padecimientos también vehiculiza la expresión de tensiones en la relación con los otros cercanos. A través de una imagen del cuerpo vulnerable a factores del orden social, se condenan aspectos de las relaciones sociales por ejercer una acción patógena directa sobre el individuo.

Así como ciertos aspectos de las relaciones sociales permiten explicar el "por qué" de algunos padecimientos, las narraciones en torno a éstos promueven la exteriorización de percepciones de hostilidad, animadversión o envidia. La envidia fue nombrada como causante de aire sin que deba mediar un accionar iatrogénico por parte de quienes envidian y variados padecimientos (locura, "debilidad" en el cerebro, dolor en los pies, complicaciones en el embarazo y parto, malestares diagnosticados desde la biomedicina como problemas de vesícula y cáncer) fueron atribuidos a un maleficio o "trabajo" que "le han hecho". Si bien el ejemplo subyacente procede de la voz de quien fuera acusado de realizar un maleficio, en el resto de los casos referidos no se identifica al autor aunque se infiere un accionar plenamente dirigido a causar el daño recurriendo a los servicios de quienes "estudian para eso".

P: que nosotros le habiamos hecho hacer mal, que éramos unos brujos

A: y por qué se le ocurrió eso?

$P:$ y eso le han dicho [...] si es una parienta cómo le voy a hacer un mal! y de ahí él [su hijo] no viene

A: y a $C$ [pareja de su hijo] qué le pasó con el parto?

$P$ : decían que estaba muy enferma, yo como no la he visto no sé, según decían que estaba muy grave, que le han hecho cesárea [...] asi me ha dicho, que yo la había hecho curar para que ella se enferme fiero, pero si yo a los médicos campesinos nunca voy! [...] él me ha dicho a mí, se ha enojado, me ha retado y bueno yo mucho 
caso no le he hecho porque yo le he dicho "me van a aclarar!" yo los iba a denunciar para que él me aclare quién le había dicho!

A: y con quién lo ibas a denunciar?

P: con la policía, y el papi no me ha dejado, no ha querido (P76, mujer, 45 años).

F: esos males que tiene no son males que dios le ha dado, eso le han hecho un mal $[\ldots]$

A: y por qué, tendrá gente en contra?

$F$ : vaya a saber, a veces cuando no hay gente en contra ya lo hacen porque quieren hacerlo, ya estudian para eso

(P66, curandero, 88 años).

J: yo le preguntaba al curandero, si hace eso el mal, y eso él me explicaba que no es que me hagan el mal si no que la envidia es todo eso, la envidia, me decía [...] porque yo digo "qué me pueden envidiar, si no tengo plata, estamos haciendo así a todo sacrificio, cuántos años vamos con la casita, ellos mismos son testigos de que nos ven a veces hasta las 12 de la noche cortar bloques, todo, pero claro, hay que estar, ha visto? En el trabajo, al otro día levantarse dolorida e irse a trabajar en el trabajo que uno tiene, pero bueno [...] a veces la ven trabajar y no se ponen a hacer lo mismo que usted, no imitan, más fácil es envidiar (P49, mujer, 40 años).

J: hay mucha envidia, que hay mucha maldad, y bueno, eso de la envidia yo pienso que en todos lados, y si usted no trabaja para tener nunca va a tener y yo pienso que los envidiosos son los que se sientan y creen que les van a venir las cosas de arriba, eso me parece a mi que son los envidiosos [...] al hombre que tiene una finca de nogales si sé lo que ha trabajado ese hombre, y uno ve lo que trabaja y cansa, uno llega tirado a la noche en la cama, y bueno, es sacrificio del hombre que él ha tenido, y hay otra gente que ese sacrificio no lo quiere hacer pero quiere tener lo mismo que el otro (P7, mujer, 42 años).

Aparece aquí nuevamente la importancia atribuida al trabajo, al esfuerzo cotidiano: se censura en el "otro" la envidia y la desidia a la par que se recalca el reconocimiento de una vida marcada por sacrificios.

Además del vínculo causal entre sentimientos y actitudes negativas y ciertos padecimientos, cabe señalar otra relación que se establece, aunque con menor frecuencia, entre estos dos niveles de fenómenos: la que identifica como síntomas de enfermedad ciertas conductas que podrían caratularse como anti-sociales o disruptivas (pues se las menciona enfatizando estos rasgos). Es el caso de locura (debilidad al cerebro, estar "machadito de la cabeza") y el de padecimiento de nervios, donde la enfermedad explica y justifica ciertos comportamientos que interfieren en las relaciones sociales y que son motivo de reprobación:

$J$ : me ha empezado con mi papá, y después andaba mal, nerviosa, si íbamos a lo de $X$ [su suegra] y era como que no la aceptaba, como que me agarraban nervios, ha visto, como que chocábamos, asi ha visto, y ahora desde que he empezado a tomar los remedios no, ando tranquila, voy, converso, no me quería enojar pero era una cosa como que me agarraba electricidad 
A: con cualquiera?

$J:$ no, no, no, con ella, con doña $X[. .$.$] por ahí está enojada, por ahí está que una$ cosa, que la otra, pero ahora no... ya pasa, ha visto, en cambio antes parecía que me levantaban de los pies, y no me gustaba y bueno, me veía mal, nerviosa (P7, mujer, 42 años).

P: no sé cómo sabrá ser, anteayer yo la he visto y bueh, diré que bien, pero ayer ya no [...] a la gordita de doña $S$, que la ha amenazado de castigarla, a aporrearla a la nena porque ella cuando parece que le viene esos ataques, esas boladas de nervios así agarra a cualquiera si la vez pasada la ha aporreado a doña S! [...] la agarra y le pega con lo que tiene, de los cabellos [...] lo que tiene realmente no sé, porque ella hay veces es como para decir está bien pero por ahí de inmediato sale ella mal [...] le ha deshecho los vidrios de las ventanas, de ahi ha pasado frente a la banda y ha agarrado el teléfono lo ha deshecho, en la banda, los vidrios de la casa de $R$ le ha deshecho, todo le ha roto (P19, mujer, 43 años).

Algunos niegan que tales conductas sean síntoma de una enfermedad y las explican como resultado de y respuesta al trato recibido de otras personas. Es decir, reconocen una causa social en tales comportamientos, pero éstos no se conceptualizan como enfermedades (lo que sí se plantea cuando se mencionaron las enfermedades cuyas etiologías son sociales).

$R$ : decian que tenía malestar, mentían que los retaba, no sé, porque a mí gracias a dios con nosotros siempre así, si nos ve por ahí nos saludaba, conversábamos A: y la gente qué decía?

$R$ : que los retaba [...] si se portan mal más vale los va a retar [...] y la gente más que, yo no creo que ella sea mala, acá con nosotros nunca ha sido, ni nunca nos ha hecho nada, no tenemos qué hablar, al contrario me da lástima (P79, mujer, 65 años).

En conclusión, tanto a través de la identificación de factores sociales como aspectos patógenos, como por los elementos actitudinales y conductuales implicados en los procesos de cura y cuidado, la enfermedad impone no sólo la afirmación de un deber ser respecto a las prácticas del cuidado sino que constituye también un motivo para reafirmar valores morales mediante la evaluación de conductas y un detonante para la expresión de tensiones en las relaciones sociales. Como señala Epele, si bien se distingue el sufrimiento físico y corporal del sufrimiento social y moral (relacionado con las valores de justicia y responsabilidad), "sea como resultado de la somatización o encarnación, o por las implicaciones morales y de sentido de los procesos de enfermedad, en la mayoría de los casos, estos dos tipos de sufrimiento se superponen" (Epele, 2001: 123). 


\section{Conclusiones}

Retomando los objetivos planteados, a saber: identificar y analizar la denominación, clasificación y explicación causal de las enfermedades predominantes en la localidad de Azampay, los recursos terapéuticos con que cuentan los azampeños desde los distintos modelos de atención y los factores que determinan la elección y el acceso a los mismos, cabría esperar que la primera aproximación a la información obtenida hubiera sido la presentación de un listado de malestares con su inventario de síntomas, causas y respuestas terapéuticas. Sin embargo el primer eje considerado para organizar la información fue el de los recursos empleados para cada situación de malestar, señalando las características de la enfermedad que orientaban su elección así como las evaluaciones de las distintas formas de atención y otros factores que influían en las decisiones frente al malestar. Ello responde al hecho de que se partió de las narraciones que los individuos elaboran para significar, objetivar y compartir las experiencias de malestar, reconstruyendo los procesos terapéuticos para desde allí circunscribir las enfermedades identificadas junto con sus síntomas y etiologías. Así, por ejemplo, la clasificación de ciertas enfermedades en "enfermedad para el médico" o "enfermedad para el curandero" se hizo notoria al analizar los factores considerados en la elección de los distintos recursos terapéuticos, así como los niveles de gravedad de las enfermedades se evidenciaron en relación a la jerarquización de los espacios de atención en función de la calidad y complejidad de la terapéutica.

Considerar el proceso terapéutico como el curso de un episodio de malestar definido por la secuencia de observaciones, decisiones y acciones que conducen hacia las distintas formas de atención a la salud, que se van modificando al contrastar con las observaciones de la evolución del malestar, con las experiencias compartidas por otros individuos y con los fragmentos de saberes transmitidos por los curadores, permitió destacar los procesos de significación y resignificación que median entre la percepción de molestias, dolores, disfunciones y su configuración en síntoma. Reconocer el carácter construido y social de los procesos de salud-enfermedad y no considerar las categorías de enfermedad como unidades naturales de síntomas-causas-efectos conlleva entender el diagnóstico del paciente no como algo que queda definido previamente a (y como requisito de) la elección de un tratamiento 
sino como una elaboración en constante reajuste con la información extraída a lo largo del proceso terapéutico. El hecho de que un malestar no se presenta de manera evidente y clara dictando la respuesta adecuada fue bien notorio en los casos en los que la enfermedad era redefinida. La importancia de considerar los síntomas en tanto símbolos, atribuciones de sentidos (hechos sociales, no realidades naturales), permite entender que en la narración de un episodio de enfermedad aparezca generalmente más de un padecimiento: dado que la relación entre éste y los signos considerados como síntomas no es unívoca, una enfermedad es reemplazada por otra cuando se redefine el diagnóstico. Por ello el énfasis puesto en la circularidad entre diagnóstico y tratamiento evitando la reificación de las categorías de enfermedad: aunque se parta de un diagnóstico que oriente la elección terapéutica, este será siempre "presuntivo", una identificación provisoria de la enfermedad sujeta a redefiniciones a partir de los resultados parciales o finales del tratamiento realizado. Así, si bien la clasificación de ciertos malestares en enfermedades "para el médico" y "para el curandero" determina la elección del terapeuta solicitado, sosteniendo en el nivel discursivo usos excluyentes de la biomedicina y la medicina tradicional, con frecuencia se utilizan ambos recursos terapéuticos hasta dar con la respuesta más eficaz que será la que defina el diagnóstico final. En estos casos el pasaje de un tipo de atención a otra es justificado por un diagnóstico inicial erróneo que condujo a tratar por un médico una enfermedad que debía ser tratada desde la medicina tradicional o viceversa.

Al focalizar en la perspectiva de los legos, en cómo ellos describen las actividades y representaciones en torno a los diversos recursos terapéuticos, se destacó un uso articulado de los mismos para dar solución a sus problemas de salud, y que también les permite, mediante la comparación y contrastación, evaluar los resultados de un tratamiento o lo acertado o no de un diagnóstico. La conciliación de concepciones y técnicas procedentes de modelos de salud aparentemente antagónicos se lleva a cabo desde el nivel de la autoatención, donde se apela a los recursos y saberes extraídos de una disparidad de fuentes para dar una respuesta inmediata frente a un diagnóstico preliminar. El nivel de autoatención está presente en los casos en que los individuos asumen poder manejar por sus propios medios una situación de malestar ya conocida y de menor gravedad considerando innecesaria la consulta a especialistas; frente a padecimientos para los cuales las distintas formas de atención no ofrecen solución; por desconfianza de la eficacia del tratamiento que se pueda recibir de los curadores; pero aún cuando se recurre a un médico o curandero es en este espacio donde se lleva a cabo el tratamiento recetado y las prácticas de auto e inter-cuidado prescriptas por los mismos curadores o concebidas desde el ámbito doméstico. Aquí también, dada la circularidad entre 
diagnóstico y tratamiento, las respuestas caseras son vistas como insuficientes o provisorias en caso de que el malestar persista o se agrave exigiendo la consulta a un especialista, lo cual en la mayoría de los casos trae aparejada una redefinición del diagnóstico.

Si bien la elección del servicio de atención es orientada por la enfermedad identificada, las nociones que se manejan sobre la misma, las formas de enfrentarla transmitidas por el grupo, el aprendizaje a partir de anteriores experiencias personales, así como la evaluación del accionar y competencia de los curadores, está a su vez condicionada por los aspectos materiales que configuran su accesibilidad. Dentro de éstos, el transporte (más que la distancia geográfica concreta) aparece como limitante a la hora de optar por atención terapéutica: es el caso de la nula utilización del minihospital de Pozo de Piedra, más próximo a Azampay que la ciudad de Belén pero fuera del camino principal, la ruta que vincula Azampay con esta ciudad. Pero también para acudir a la posta los días de visita del médico de zona: los pocos kilómetros que separan Chistín y La Agüita de la posta al deber ser recorridos a pie por los enfermos se convierten en un obstáculo mientras que los 50 kilómtros a Belén pueden ser salvados gracias al transporte municipal que sí accede a estos caseríos. Las carencias del servicio local de atención a la salud (no disponer en los últimos años de un transporte adecuado al terreno para que el médico pueda llegar a los caseríos, así como la escasez de remedios y demás recursos para el diagnóstico y el tratamiento) junto a la reciente mayor accesibilidad (dada por el transporte) a los centros de atención en Belén lleva a que muchos opten por saltear este primer nivel de atención a la salud. Otro factor de fuerte peso a la hora de decidir por recursos para la salud alejados de Azampay (sean centros de atención biomédica o curanderos) es el contar con algún pariente viviendo fuera, quien facilita el hospedaje mientras se accede a la consulta y tratamiento, generalmente conoce y recomienda el terapeuta, acompaña al enfermo, solicita turnos, retira recetas o medicación, etc., es decir, constituye un capital social que es producto de los procesos migratorios descriptos para esta población. También se mencionó el apoyo monetario de la municipalidad para quienes por padecimientos crónicos u otros de larga duración deben viajar regularmente a la ciudad de Catamarca, pero que está supeditado a la red de relaciones sociales y políticas que cada individuo posea. Frente a la atención gratuita de los hospitales públicos, el recurso de los centros de atención privados de las ciudades de Belén y Catamarca es sólo accesible a los pocos que cuentan con obra social, así como la consulta a curanderos (sobre todo fuera de Azampay) depende de disponer de dinero para el pago, por mínimo que sea lo dado generalmente "a voluntad". 
Aunque a menudo los factores identificados en la etiología de la enfermedad orientan la respuesta buscada, se advirtió que la relación entre explicación causal y recursos terapéuticos no es lineal, es decir, las identificaciones etiológicas no determinan directamente el tipo de atención terapéutica. Se destaca una perspectiva psicosomática de los procesos de salud-enfermedad ajena a la dicotomía mente-cuerpo y desde la cual no se plantea la búsqueda de terapéuticas físicas para males corporales y de terapéuticas psicosociales para malestares anímicos. Fueron mencionados numerosos ejemplos en que la persona sufriente reúne en su explicación causal aspectos tanto del orden anímico como somático, en que el malestar es percibido como trastornos en el nivel psicológico (enojo, irritación, nervios) pero también como ahogo, mareos, dolor de cabeza, debilidad; en que la vivencia del padecimiento en tanto resistencia al flujo de vida se presenta como obstáculo al desarrollo de actividades motoras pero también interfiriendo en las relaciones sociales. La identificación de etiologías "naturales" y "psicosociales", la percepción de síntomas orgánicos y psicológicos, el empleo de terapéuticas físico-químicas y simbólicas se conjugan de manera no unívoca, es decir, una enfermedad ocasionada por un factor ambiental se manifiesta en síntomas tanto orgánicos como anímicos y puede ser tratada con medios simbólicos, o inversamente, un malestar cuya causa se identifica en el plano psicosocial, se manifiesta en síntomas orgánicos y es tratada mediante recursos biomédicos. Este entrecruzamiento de esferas, lejos de analizarse en términos de inconsistencia o contradicción, exige renunciar a viejos dualismos tales como cuerpo/espíritu, visible/invisible, natural/sobrenatural, racional/mágico, real/irreal, que aunque naturalizados por el investigador (entre otros) pueden estar ausentes en el caso estudiado. También para poder dar cuenta de la eficacia de las terapéuticas que se basan en mayor grado en recursos simbólicos hubo que apelar a una concepción de persona no como un compuesto de niveles psíquico y somático articulados de manera difusa e influidos por factores socioculturales, sino como una conjunción de la experiencia corporal pre-reflexiva con procesos culturales, sociales y psicológicos.

A partir del análisis en torno al "aire" y posteriormente en el capítulo dedicado a explicaciones causales y terapéuticas, se señaló que un modelo que planteaba la dicotomía enfermedades naturales/enfermedades sobrenaturales y su correspondencia con terapéuticas orgánicas/terapéuticas místicas no se ajustaba a las descripciones nativas. Que tal dicotomía no resultaba de validez descriptiva ni mucho menos heurística se destacó también al indagar los elementos místicos, es decir, aquellos relacionados con deidades o seres espirituales. Si bien no se identificaron en Azampay enfermedades ocasionadas por desequilibrios religiosorituales, en ocasiones se apela a la idea de dios como causa última de la enfermedad. Pero esto 
no supone una moralidad religiosa vinculada a las etiologías, en el sentido de reconocer la intervención del poder sagrado para causar el mal en respuesta a conductas reprobables, sino que implica el reconocimiento del "misterio" frente a las "situaciones límites". Las experiencias de enfermedad y sufrimiento conducen a la conciencia de ser mortal, de limitación o destrucción de las fuerzas vitales, resultando inabarcables en sus múltiples manifestaciones por el conocimiento objetivo. Ese misterio del sufrimiento, el por qué trascendental, es respondido por la nociones de dios y destino, aunque se trate de enfermedades para las que se cuenta con explicaciones causales terrenales. La enfermedad como "situación límite" apunta a una conciencia todavía oscura de que "hay algo más" tras el límite que no puede ser formalizado intelectualmente. Asimismo se considera que dios y la virgen propician bienestar, se les pide o reclama salud y se les reconoce su intervención ante resultados positivos. Frases de gratitud o de invocación, de apelación al poder sagrado consisten a veces en la única respuesta cuando otros recursos se muestran incompetentes o ausentes, pero en la mayoría de los casos se observa su uso como refuerzo de otras prácticas terapéuticas.

Al sistematizar los factores nombrados como causantes de malestares se notó entre ellos una marcada presencia de los elementos característicos de la geografía azampeña y de las actividades laborales vitales en ese medio. La acción incisiva del arduo trabajo y los efectos negativos del ambiente (el frío, el calor, el sol, el agua, la altitud, el viento y la tierra que suspende) que se van acumulando en el cuerpo enfermándolo, remarca, desde la perspeciva de los sujetos, el impacto que las condiciones materiales ejercen sobre el estado de salud. Esta aprehensión del ambiente como un medio severo, exigente de labores desgastantes fue distinguida en el análisis como "lo que está en juego", aquello relevante a partir de lo cual se otorgan significados al sufrimiento, expresándose en torno a éste una apreciación del esfuerzo, del valor del trabajo realizado, el reconocimiento de una vida marcada por sacrificios en contraposición a la vida en la ciudad. A su vez, la identificación y análisis de los elementos considerados enfermantes requirió pensar cuál es la imagen corporal que subyace a estas explicaciones causales. El cuerpo para los azampeños es vulnerable al accionar constante e incisivo de los elementos más destacados del espacio geográfico, en él se acumulan los efectos del trabajo (incluidos los de curar a quienes padecen algún malestar vinculado con el aire), es inerme frente a las potenciales iatrogenias, afectado por componentes básicos de la dieta local, por la envidia, el deseo, el "humor más fuerte" de otras personas, por el miedo, el sobresalto y las rabias acumuladas. 
Partir del reconocimiento de que la escisión entre lo biológico y lo cultural es producto (y no punto de partida) de la actividad reflexiva, fue crucial para poder analizar la vivencia de padecimiento desde una conceptualización de la experiencia como instancia pre-objetiva, resultado de la interacción de categorías culturales y estructuras sociales con los procesos psicológicos y fisiológicos. Al recuperar formas de expresión que intentan aprehender la experiencia de malestar en su carácter vivido, previo a (y primer paso hacia) su objetivación, y siendo la experiencia de sufrimiento el resultado de procesos de resistencia a las acciones prácticas, a la relación cotidianamente no problemática entre cuerpo y mundo, se señaló que los azampeños se refieren a los malestares en términos de lo que no pueden hacer, como impedimento, inadecuación al medio y a las actividades que quieren realizar y que otrora realizaron sin problemas. Aquí se encuentran nuevamente los aspectos señalados como "lo que está en juego" en el caso azampeño, ahora poniendo en evidencia la resistencia que los malestares le imponen al plan de vida. Lo que mayormente se ve afectado (resistido) por los diversos padecimientos es el trabajo, el quehacer necesario en un ambiente que exige esfuerzos físicos; no poder caminar no es un mero contratiempo en un medio donde las distancias domésticas son amplias sumado a la irregularidad del terreno que torna casi imposible otro modo de desplazamiento. Dado que hilar, tejer, realizar las tareas hortícolas o amasar constituyen labores centrales para el sostén y la reproducción de las familias, la incapacidad de realizarlas conlleva una reducción del sentido de utilidad y suficiencia agregando sentimientos de descontento e insatisfacción a los dolores propios del malestar.

Si bien la noción de salud de los azampeños no fue objeto de indagación directa, es factible pensarla en contraposición a aquello que es percibido como señal de malestar, aquello que tensiona la relación entre cuerpo y mundo exigiendo visibilizar y significar el cuerpo propio, normalmente obviado. Como se dijo anteriormente, los referentes de la salud y de la enfermedad provienen de la inserción en el mundo y de las actividades implicadas, más que del estado patológico mismo; la incapacidad de llevar a cabo las tareas cotidianas es uno de los principales ejes del discurso mórbido. Si, entre los azampeños, lo que mayormente se ve resistido por los diversos padecimientos es el trabajo, las actividades necesarias en un ambiente que demanda una inversión del cuerpo intensiva y continua, se puede afirmar que el estado de salud es identificado con el poder realizar esas tareas sin inconvenientes, el valerse de sí mismo, la capacidad de agencia de la persona sostenida en un buen funcionamiento del cuerpo pero, como se señaló, éste entendido desde una perspectiva psicosomática, es decir, un buen funcionamiento que incluye la tranquilidad espiritual y el poder reaccionar emocionalmente de manera adecuada. También es señal de salud el poder realizar de manera 
espontánea e irreflexiva acciones como respirar, tragar, hablar, ver, digerir, orinar, dormir o mover los miembros, que conforman el hecho de "ser-en-el-mundo".

Dentro de los esfuerzos lingüísticos para dar expresión a las sensaciones, para nombrar lo inefable de la experiencia vivida, se recuperó también el rol central del lenguaje connotativo que mediante estrategias de "enunciación (objetiva) indirecta de lo inobjetivable" (como la metáfora) proporciona una mediación entre lo vivido y lo significado. El empleo de términos como "estar embolsada", "quedar liviana", sentir una "electricidad", un "hilo en el cuello", un "zapateo" o que le "revientan las venas", creando un parentesco no percibido ordinariamente, permite transmitir estados y sentimientos sutiles para los cuales el lenguaje denotativo resulta limitado. Este uso flexible del lenguaje no cumple sólo la función de representar y expresar la experiencia de padecimiento sino que, en tanto ésta es una síntesis pre-objetiva vivida, el lenguaje la revela, la organiza y desarrolla de forma socialmente reconocida, extiende la experiencia del sujeto a dominios concretos y reconocibles por los otros.

Entretejidas con las etiologías y con las descripciones de las respuestas terapéuticas emergen también las explicaciones anatomo-fisiológicas que dan cuenta del accionar tanto del factor patógeno como de los elementos de cura. En el pasaje hacia la objetivación de la experiencia de enfermedad los individuos realizan un esfuerzo por precisar el origen exacto del malestar ya que las presunciones diagnósticas se construyen a partir de las percepciones del dolor o signo de alarma y de su ubicación, lo más precisa posible, en el espacio corporal. La mirada objetivada del cuerpo y la enfermedad se nutre de distintos conjuntos de saberes: el de la ciencia médica, el de las medicinas populares, y uno mucho menos delimitado conformado por información de experiencias, vivencias que se van transmitiendo y con las cuales el individuo compara, completa o refuta aquello que el médico o curandero le dice. Imágenes de fuentes tan diversas como aquellas provenientes del uso de radiografías y ecografías (interpretadas a la luz de los conocimientos propios y de lo que se haya dialogado con el médico), y las que derivan de la manipulación de animales de cría y consumo con cuya constitución se establecen analogías, sirven de modelo para entender el cuerpo humano. Las descripciones en torno a las operaciones se basan en expresiones que resaltan la manipulación del cuerpo como objeto: raspar, quemar, despegar, cortar, drenar, vaciar, lavar, colocación de tubos, mangueras; que a su vez se articulan con las representaciones de los males frente a los cuales éstas se plantean como respuestas terapéuticas: suciedad que limpiar, líquido que drenar o secar, carnes crecidas que hay que cortar. También se notó que la percepción de las 
enfermedades en tanto disfunciones corporales promueve la elaboración de explicaciones a partir de metáforas mecanicistas que evocan una concepción utilitaria del cuerpo.

Respecto al empleo de términos biomédicos, se cuestionó la perspectiva que ve en ello una mera incorporación de vocablos sin un enriquecimiento cognitivo dada la carencia de educación científica y que no analiza los procesos de apropiación y connotación individual y grupal. A diferencia de los estudios sobre taxa tradicionales cuyo carácter de construcción sociocultural es indiscutido así como la tarea de indagar sus significados particulares, tratándose de términos biomédicos empleados por los legos, la tendencia es imaginar que el significado atribuido por ambas partes se equipara por completo o, en su defecto, que tal apropiación se realiza de manera defectuosa, incompleta o vacía de significados. A partir de lo hallado en el caso azampeño, se señaló que muchos términos biomédicos constituyen recursos nominativos con los que cuentan los individuos no sólo como mediación entre su lenguaje y el del médico sino como vehículo de sentidos que facilita la comunicación y el intercambio de experiencias de enfermedad con interlocutores legos. Dado que las denominaciones obtenidas a través del trato con los profesionales no implican una comprensión de las enfermedades en la dirección analítico-descriptiva desarrollada por las ciencias naturales, se analizaron los sentidos particulares con que tales términos eran empleados. Por ejemplo, las distintas significaciones en torno a "vena" y "arteria": cuando refieren al sistema circulatorio, se utiliza "arterias" en vinculación al corazón y "venas" para zonas más periféricas; cuando no denotan los vasos sanguíneos, "vena" es asociado a lo muscular y "arteria" es vinculado al sistema respiratorio. Otro ejemplo fue el de la asociación entre problemas cardíacos e hipertensión dada por los síntomas (agitación, ahogo, debilidad, mareo, dolor de cabeza, trancazón en el pecho) pero sin registrarse nexos entre las representaciones de la sangre y las de la hipertensión, cuando se planteó la relación sangreproblemas cardíacos no fue por alteraciones en la circulación sino por el estado débil de la sangre asociado a una debilidad general derivada de otros malestares.

Dada la plétora de recursos lingüísticos (términos biomédicos, de la medicina tradicional y del sentido común, empleo de metáforas, analogías, etc.) registrada en las descripciones de las experiencias de malestar se cuestionó la visión que atribuye a los sectores populares una "competencia médica" reducida, una pobreza de vocabulario y consecuentemente una acotada capacidad de percepción. También se discutió la asociación planteada para estos mismos sectores entre un uso intensivo del cuerpo y una menor escucha de los síntomas. Lejos de inhibir la relación reflexiva con el cuerpo propio, se vio que su intensa implicación en un ambiente que exige esfuerzos físicos y labores arduas pone en 
evidencia las irregularidades que instala un malestar, tornándolas inacallables en tanto implican una resistencia a las actividades cotidianas. Como se señaló de la mano de Marcel, la reflexión se realiza frente a algo que se presenta como obstáculo a la vida, que exige un reajuste, un cambio, de ahí que las experiencias de malestar promuevan la (re) elaboración de representaciones sobre el cuerpo propio y los factores que lo afectan o lo curan. Se destacó cuán activo, constructivo y selectivo es el proceso de darle sentido a la enfermedad sobre todo tratándose de un padecimiento sufrido en carne propia. En la elaboración de explicaciones causales se entretejen los elementos identificados como patógenos con eventos de la historia personal, con aquello que pudo haber estado mal en la propia biografía, de manera de dar cuenta del por qué (el "por qué a mí’) y no sólo del cómo de la enfermedad. La influencia de la experiencia en la conformación del conocimiento lego de una enfermedad conlleva además que el mismo sea continuamente reformulado en función de los cambios propios del padecimiento y de la confrontación con diferentes opiniones de terapeutas y legos.

Siendo el factor vivencial uno de los elementos que integran los esquemas de referencia que le dan sentido al episodio de enfermedad, se señaló la importancia de considerar no sólo las explicaciones etiológicas sino también las concepciones de eficacia como cambiantes a lo largo del proceso terapéutico. Así como el diagnóstico es chequeado y reformulado en función de los resultados (parciales o finales), las explicaciones causales y las evaluaciones de la eficacia o fracaso terapéutico también varían en función del desenvolvimiento del evento de enfermedad y del intercambio o confrontación con las opiniones de legos y curadores. Se señaló que, si bien el recurso de atención a la salud se decide en función de la enfermedad identificada, de los factores etiológicos reconocidos para la misma y de las representaciones del cuerpo implicadas, cuando se trata de enfermedades que se considera que pueden ser atendidas tanto desde la biomedicina como desde la medicina popular, lo que orienta la elección es la apreciación de la terapéutica en sí, de cómo es percibida su eficacia y la valoración del terapeuta, lo cual a su vez también se halla vinculado con los factores identificados como causa del malestar (contra los que la terapéutica debe actuar), y con las representaciones del cuerpo, de cómo un elemento provoca el malestar o disfunción (y que es lo que la terapéutica debe contrarrestar o revertir).

En el caso de las respuestas biomédicas, la eficacia terapéutica es atribuida a los medicamentos (sin explicaciones que ahonden en su accionar) y el fracaso, a sus efectos adversos o a una aplicación errada de los mismos, por lo que el mérito otorgado a los terapeutas reside en su dedicación para arribar al diagnóstico. Dado que el cuestionamiento a la terapéutica biomédica se centra en la posibilidad de que los remedios sean ineficaces y/o 
contraproducentes por un error en el diagnóstico, el cual a su vez se considera que depende no sólo de la capacidad del médico sino, y en gran medida, de la realización de "estudios" y análisis, se establece una jerarquía de los servicios donde la posta sanitaria ocupa el nivel más bajo, le sigue el hospital de Belén, luego los sanatorios privados y los centros de atención de la ciudad de Catamarca (en algunos casos Tucumán, La Rioja, Córdoba y Buenos Aires). Las postas sanitarias han sido concebidas como el primer nivel de atención, más próximo y accesible para la gente, para resolver circunstancias de menor gravedad, aspectos cotidianos vinculados a la salud evitando el traslado hasta el hospital (y su sobreutilización). Allí tendría lugar la detección de cuadros de mayor gravedad que ameritarían la derivación a centros más complejos, pero, como se dijo anteriormente, dada la distancia y las dificultades de transporte, si se cuenta con la posibilidad de ir hasta Belén los individuos no dudan en saltear esta primera instancia de atención y dirigirse directamente al hospital o a sanatorios de la ciudad, aunque se trate de síntomas leves pero ya no manejables sólo desde la medicina casera. La posta sanitaria (en ausencia del médico de zona) es considerada un recurso no mucho más sofisticado que los disponibles en el nivel de la autoatención ya que el diagnóstico realizado allí se basa en y se limita al nivel de las percepciones y construcciones explicativas del paciente y los remedios con los que se cuenta son limitados (muchos de venta libre que también poseen los individuos y circulan en el nivel de la autoatención).

La apreciación de la labor del médico se realiza sobre su dedicación para examinar al paciente, su interés por las percepciones que éste le pueda comunicar y la solicitud de realización de estudios, todo lo cual se considera necesario para arribar a un diagnóstico acertado. El carácter del terapeuta, su trato con los pacientes, sus explicaciones sobre el evento de enfermedad por el que se lo consulta, su predisposición para atender, son aspectos tenidos en cuenta por los azampeños no como elementos accesorios que le otorgan un cariz afectivo pero prescindible a la consulta, sino como aquello de lo que depende en última instancia el que sean atendidos o no.

En el caso de la medicina tradicional se observó que hay una mayor descripción de las acciones de cura afirmándose una eficacia inherente tanto a los elementos empleados, sean los “secretos" o las hierbas y remedios recetados, como a los trabajos de manipulación sobre el cuerpo del enfermo. No hay una explicación mayor de su eficacia (salvo en el caso de los yuyos y algunos de los elementos utilizados) pero tampoco un cuestionamiento, si el malestar persiste se explica por su estado de avance y agravamiento o porque se trata de un malestar “para médicos”, pero la terapéutica en sí no se desacredita. Aquello que en la apreciación de la labor del médico es considerado elemento de desconfianza (diagnosticar y prescribir 
medicamentos sin realizar estudios) en el caso del curandero es vista como meritoria la capacidad de diagnosticar sin recursos tecnológicos. Respecto a la evaluación de los curanderos en ningún caso fueron referidas actitudes de desinterés, trato descortés, negligencia o mala predisposición que motivaran evitar la consulta con alguno de ellos. Si bien se establecen comparaciones entre los distintos curadores reconociendo las limitaciones de algunos para curar ciertos males, ello no menoscaba su aptitud para curar otras enfermedades.

Dada esta diferencia en las apreciaciones de la eficacia terapéutica y de la capacidad de médicos y curanderos, cabría esperar que la frecuencia con la que se recurra a la biomedicina fuera mucho menor que para la medicina tradicional; sin embargo, además del reconocimiento de enfermedades para las cuales sólo la biomedicina es eficaz, se admite también su eficacia para otros males y la existencia de "buenos doctores". Podría afirmarse que a la hora de buscar soluciones a eventos de malestar se tiene en cuenta la eficacia de la biomedicina (atribuida a los medicamentos y recursos tecnológicos) pero se la utiliza con una reticencia y suspicacia que no se observan en el uso de la medicina tradicional. Como se señaló, en muchas ocasiones cotejan y contrastan las opiniones y acciones de los curadores consultados, advirtiéndose que cuando la comparación incluye discrepancias entre las opiniones de médicos y curanderos, es el primero el desacreditado, nunca el segundo.

Algo similar ocurre con el uso de hierbas y medicamentos: si bien ambos elementos son considerados "remedios" y en algunos casos se les atribuye una función específica nombrando el órgano o malestar para el cual se los ingiere, subyace una percepción de potenciales efectos negativos de los medicamentos, mientras que en el caso de los "yuyos" se considera que tienen una eficacia general (un accionar de "amplio espectro") y que, en caso de no resultar suficientes para la cura de ciertas enfermedades, su ingesta es inocua. ¿Por qué el yuyo tiene poder para curar pero no para dañar en caso de uso inadecuado? A través de las apreciaciones sobre los curanderos y la eficacia de sus terapéuticas, del valor curativo y preventivo de las hierbas, se expresa una valorización positiva de lo local con sus saberes tradicionales frente al accionar desde la biomedicina, proveniente de un "afuera" citadino. Aunque muchos curanderos sean consultados en ciudades, aunque varios de los yuyos que recetan deban comprarse en farmacias de la ciudad porque no crecen en la zona, este recurso no es considerado foráneo cuando destacan la distinción entre un "nosotros" y un "afuera" sino que forma parte de lo considerado tradicional y distintivo de lo local. También se notó que son algunos elementos de la atención de los curanderos pero sobre todo las terapéuticas realizadas desde el nivel de la autoatención las que cuentan con una mayor cantidad y detalle 
de explicaciones sobre su accionar y eficacia dado que es en el espacio doméstico y el entorno de conocidos donde tiene lugar la mayor parte de los intercambios dialógicos de los que resultan la construcción y transmisión de información, la interpretación de temas cotidianos y vitales. Considerando la ausencia de formación científica entre los azampeños, la reproducción, creación y reelaboración de sentidos en torno a los procesos de saludenfermedad-atención están más influidas por la medicina popular que por la biomedicina. No obstante el uso frecuente de los servicios de atención biomédica, la apropiación de términos médicos y la incorporación de algunos de sus elementos en las terapéuticas de curanderos y en el nivel de la autoatención, las prácticas y recursos biomédicos permanecen en la esfera de lo ajeno, lo foráneo, lo que quizá explique en parte la actitud de recelo en su consideración, sustentada también por experiencias negativas donde se puso de manifiesto la peligrosidad de los mismos.

Teniendo en cuenta las condiciones materiales que dificultan el acceso a las diversas terapéuticas fuera de Azampay, cabría esperar una baja frecuencia de consultas a las mismas. Si bien el recurso reciente del transporte administrado por la municipalidad ha permitido que los azampeños contaran con tres viajes semanales a Belén, en muchas situaciones de enfermedad no pueden esperar el próximo viaje por lo que se recurre a algún vehículo que casualmente esté en Azampay y al menos facilite el traslado hasta la ruta donde es posible interceptar algún transporte a la ciudad, o en última instancia se llama un taxi (debiendo pagar alrededor de 100 pesos). Aún viajando en el transporte de la municipalidad y regresando esa misma tarde se deben afrontar los gastos de ese día fuera del hogar. Aunque contar con familiares en la ciudad reduce las dificultades causadas por la distancia e inaccesibilidad, la búsqueda de atención a la salud más allá de Azampay implica disponer al menos de gran parte del día o más si deben quedarse en la ciudad para la realización de estudios, controles, o la repetición de las curas en el caso de la atención del curandero además de una inversión considerable de dinero. No obstante y a pesar de estos obstáculos, hay una demanda continua de atención a la salud; el transporte municipal va siempre lleno y la mayoría de los pasajeros van por razones de salud (aunque se aproveche el viaje para realizar compras, cobro del plan social u otras diligencias), cuando se pidió la disposición de este vehículo para ir a consultar a una curandera de otra localidad no quedaron lugares vacíos, con anteriores médicos de zona que no limitaban el número de pacientes, entre 50 y 60 personas acudían el día de su llegada, siendo la queja principal sobre los médicos de zona recientes el que sólo reciban a 15 pacientes dejando al resto sin tratar (últimamente dejan de ir, desanimados ante las pocas expectativas de ser atendidos). Además, el uso articulado de distintos servicios, como es el 
consultar tanto al médico como al curandero conlleva además de gastos, una mayor dedicación de tiempo, descuidando sus quehaceres cotidianos o delegándolos en otros miembros del grupo doméstico. Todo ello llevó a cuestionar la visión de que en los sectores populares "la cultura somática" (entendida como capacidad de sentir y escuchar el cuerpo) sea escasa debido a las carencias del medio que dificultan conseguir el sustento diario y exigen postergar el registro de las molestias hasta que adquieren una gravedad ineludible. Como se subrayó párrafos atrás, el intenso trabajo físico no suspende la percepción de malestares sino que éstos emergen en tanto constituyen obstáculos a la realización de las actividades diarias. Además la perspectiva aquí cuestionada considera como indicador de la intensidad de "necesidad médica" (percepción y tolerancia de las sensaciones mórbidas) sólo la frecuencia con que se acude al médico, sin tener en cuenta la participación de los demás recursos terapéuticos. Si, como señalaron los médicos entrevistados, los azampeños al igual que otros pobladores rurales a menudo llegan al hospital con estados más avanzados de la enfermedad, ello no se debe a que posean un umbral de percepción sintomática, de alerta, más elevado sino porque se intentó primeramente resolver el problema desde la autoatención, desde la posta o desde la medicina tradicional (en caso de que los síntomas fueran similares a los atribuidos a enfermedades "para el curandero"), y/o porque, sujetos a las limitaciones de transporte no podían resolver con prontitud su llegada al centro de salud aún habiendo reconocido la pertinencia de este tipo de atención.

Siendo algo básico para asegurar el acceso a los centros de salud, el medio de transporte no parece haber sido contemplado al establecer el mini-hospital de Pozo de Piedra con la pretensión de que articule con el centro de atención primaria de Azampay supliéndolo de insumos y atención en casos de derivación de pacientes. Tampoco se tiene en cuenta al enviar al médico de zona en una ambulancia que, no siendo un vehículo adecuado para el terreno, no puede llegar hasta los caseríos de Chistín, La Agüita y El Carrizal, debiendo sus pobladores acercarse hasta la posta por sus propios medios.

A la par de y coherentemente con esta asidua búsqueda de atención a la salud se observó la ya mencionada profusión de recursos lingüísticos para significar, objetivar, expresar y comunicar las experiencias de malestar, desde la cual se cuestionó la atribución a sectores populares de una de una pobreza de vocabulario y consecuentemente de una acotada capacidad de percepción. Si bien es corriente la apelación a una brecha lingüística entre el profesional médico y los pacientes de bajo nivel educativo para explicar dificultades en la consulta médica y la mayor afinidad de éstos con los curadores populares, los azampeños y los médicos entrevistados no hicieron referencia a trabas lingüísticas que afectaran la consulta 
médica. Pero sí destacaron los azampeños como obstáculo de la atención biomédica rasgos del temperamento del profesional tales como mal carácter o antipatía, ser poco comunicativo (no escuchar al paciente ni darle una explicación), atender con desinterés o poca predisposición y sobre todo el discurso moralizante con el que culpabiliza al paciente. Que los individuos caractericen y evalúen la atención recibida no sólo a partir de apreciaciones de eficiencia y negligencia sino también refiriendo a aspectos personales del profesional exige pensar estas valoraciones no como simples expresiones de afinidad sino como el reconocimiento del rol decisivo que juega la voluntad del terapeuta, a cuya merced se perciben los individuos. De la buena predisposición del profesional depende en última instancia el que sean atendidos o no. Esto quedó también resaltado cuando los azampeños mencionaron que callan u ocultan el haber realizado consultas con otros curadores, sobre todo si se trata de la medicina popular, para evitar el enojo que podría llevar al profesional a negarse a dar la consulta. Aquí se ve la importancia de un enfoque relacional para captar las relaciones de hegemonía/subalternidad entre los diferentes servicios médicos, ya que si bien se remarcó que para los sujetos legos es plausible la articulación de terapéuticas diferentes, no desconocen que éstas son consideradas antagónicas por los distintos curadores y en una relación hegemonía de la biomedicina respecto a las terapéuticas populares: Si bien el curandero local destaca los efectos negativos de pretender dar respuesta biomédica a enfermedades que son de su competencia, no cuestiona la legitimidad de esa medicina, tampoco frente a otros curanderos los azampeños dijeron ocultar la consulta a un médico, pero inversamente sí mencionaron y con frecuencia, la precaución de no referirle al médico la consulta a curanderos.

Dado que los azampeños no siempre disponen de más de una opción dentro de la atención biomédica, si los síntomas no se consideran tan alarmantes optan por prescindir de la consulta cuando el profesional detenta mal talante. De manera que en estos casos lo que eleva el "umbral" de lo considerado grave como para ameritar la consulta, lo que "hace que se retarde la concurrencia a la consulta médica" no es, como sostienen algunos autores, el "uso intensivo del cuerpo" que "eclipsa" los síntomas, sino la actitud misma del profesional. Es su falta de empatía lo que inhibe la consulta, lo que motiva posponerla si el malestar no parece ser tan grave. La empatía no es en sí misma una emoción sino la experiencia de una emoción como resultado de reconocer tal emoción en el otro, es sentir una emoción por causa indirecta (Prinz, 2010). Su presencia en la consulta médica permitiría reconocer que el paciente no acude para ser juzgado o amonestado, para escuchar un discurso moral sino que lo hace buscando una explicación y una solución para sus padecimientos. Lo cual no implica que los 
pacientes no realicen evaluaciones acerca de la conducta concerniente al cuidado personal e interpersonal, juicios sobre las relaciones sociales y comportamientos en torno a los procesos de salud-enfermedad-atención. Los azampeños a través de sus narraciones de eventos de enfermedad y cura expresaron también aseveraciones morales y apreciaciones sobre las relaciones sociales que contextualizaron y en algunos casos explicaron tales eventos. Pero la consulta médica no es buscada para oír otra moral o ser objeto de juicios y regaños, sino para solucionar el problema de salud, para lo que ellos señalaron como necesario tanto la escucha atenta del médico de los síntomas e inquietudes del paciente como su comunicación del por qué del malestar y cómo hacerle frente. En una nota del New York Times ${ }^{44}$, la doctora P. W. Chen recupera un estudio publicado en The Archives of Internal Medicine ${ }^{45}$, donde se afirma que una atención más empática, lejos de prolongar la duración de las consultas tiene por efecto disminuir el tiempo de las mismas, contrariamente muy poca empatía o sólo expresada al final de la consulta tiene por resultado una prolongación del tiempo de encuentro médicopaciente. Es decir, la empatía en la práctica médica, minimizada desde el justificativo de que no se dispone con tiempo suficiente para destinarlo a un componente superfluo de la atención a la salud, es reivindicada apelando a su valor instrumental en términos de rendimiento medido en cantidad de pacientes atendidos por unidad de tiempo. Considero que más allá de señalar esta utilidad (para el sistema médico y sus trabajadores) de la empatía en tanto reduce el tiempo empleado en la consulta, debe ser un factor a tener en cuenta cuando se pretende indagar los obstáculos, los motivos por los que el sistema médico no capta al paciente en momentos oportunos de la enfermedad.

Al describir las prácticas y representaciones en torno a los procesos de saludenfermedad se presentó una variedad de recursos de atención a los que los individuos apelan orientados por las representaciones compartidas. Se intentó dar cuenta también de la multiplicidad lingüística y semántica de la que disponen para significar las experiencias y las prácticas y de cómo los sentidos que circulan sustentando las prácticas vinculadas a la salud, enfermedad y atención están entretejidos con significados más amplios como por ejemplo las condiciones de vida en Azampay, las relaciones sociales, la moral, etc. Cuestionando los enfoques que enfatizan una carencia en el nivel del lenguaje y de la percepción (causantes de un menor uso de la medicina) para explicar los niveles de salud inferiores en sectores populares, se notó que en Azampay las falencias que obstaculizan el acceso a los espacios de atención a la salud son principalmente el transporte (que vincule no sólo Azampay con las

\footnotetext{
44 “Taking Time for Empathy", New York Times, September 25, 2008.

${ }^{45}$ A cargo de Dr. Diane Morse de la University of Rochester School of Medicine
} 
localidades vecinas además de la ciudad de Belén, sino también que permita al médico de zona acceder a los caseríos distantes de la posta) la disponibilidad y la predisposición para atender de los profesionales. Si bien se destacó el uso combinado de los diferentes servicios terapéuticos pautado por las elecciones a partir de evaluaciones (comparación entre los servicios, contrastación entre distintos terapeutas, aceptación o rechazo de los tratamientos en función de los resultados obtenidos y esperados), señalar también las condiciones que restringen el acceso a los mismos permite entender las prácticas como "una estructura abierta redefinida por las posibilidades de instrumentación exitosa, pero siempre amenazada por la carencia de instrumentos", como "actividades que necesitan adecuarse a lo posible y cuya condición de 'estrategia' puede ser referida a la actitud de síntesis continua que necesita desarrollar" (Menéndez, 1990a: 55-56). 


\begin{abstract}
Anexo
“... ella no tomaba el mate sin el remedio, por eso, digo yo, sabrá ser tan sana la gente...”
\end{abstract}

Como quedó expuesto, el empleo de hierbas ("yuyos", "montes") con fines medicinales ocupa un lugar importante dentro de las terapéuticas pautadas por el curandero y sobre todo dentro de las respuestas desde la autoatención. La certeza de su valor curativo se manifiesta en el hecho de que con frecuencia se hace referencia a éstos con el término "remedios" (a veces aclarando: "remedios caseros" en contraposición a los "remedios de farmacia") y aunque su accionar puede no ser suficiente para la cura de ciertas enfermedades, se considera que su ingesta no provoca daño.

Muchos crecen en zonas altas de los cerros o son traídos de parajes como El Tolar (aproximadamente a $3800 \mathrm{msnm}$ ) y se relaciona la altitud de su lugar de origen con su poder curativo: a mayor altura se considera que el aire es más fuerte, luego los yuyos son más fuertes. Su procedencia de la puna explica que sirvan para curar trastornos a causa de la altura, o del aire, evidenciando una asociación de carácter simpatético (el medio de cura comparte un aspecto de la existencia o estado del elemento etiológico) a la vez que resalta también el poder curativo del aire.

M: eso es rica para hacer bien la digestión de la comida [...] no les hace mal, chicas, no vayan a pensar... para nada!

F: no, es, es mucho remedios que hay [...] ahi la vende a la chachacoma

A: por qué, no crece acá?

F: no, no crece, aqui no crece, crece encima, de ahi la traen [...] para el hígado, para la vesícula, todo eso, cura de eso [...] para la puna, porque es muy de la puna ésa (P44, mujeres, F: 64 años; M: 31 años).

C: porque la chachacoma se cría donde hay puna, entonces compone, ya hay algo que le cura (P15, C: mujer, 79 años).

J: yo digo que debe ser por el agua, porque como acá tomamos agua cruda [...] yo digo que de eso, porque de qué más podemos agarrar tanta infección urinaria, a mí nunca me agarró porque una siempre, hago aguas así de llantel, de quimpi, de este, de gramilla, que es todo para los riñones, ha visto? Que le lavan, le limpian [...] hiervo el agua y si, siempre tomo, y no, nunca me agarró (P49, mujer, 43 años). 
Aunque se les reconoce valor terapéutico para órganos o malestares específicos, son considerados con una utilidad de "amplio espectro", por lo que se los ingiere frecuentemente como preventivos de una amplia gama de malestares. Si bien algunos yuyos son recetados por curanderos (sobre todo los foráneos que compran en farmacias o herboristerías de la ciudad o a vendedores ambulantes), su empleo con fines medicinales se basa en gran medida en saberes y prácticas transmitidas en el grupo doméstico, de los miembros ancianos a los jóvenes. De allí que se lo vincule a costumbres "de antes", de una época en la que no se tenía fácil acceso a médicos ni a otro tipo de curadores, aunque en la práctica su uso continúe vigente y, lejos de haber disminuido su presencia en la cotidianidad, persista con incidencia notoria.

A: y de dónde saben ustedes qué planta tomar, cuál es buena para ésto, cuál es buena para...?

F: y esas las venimos tomando nosotros desde, quién nos habrá enseñado, nuestros padres, y ellos nos hablaban a nosotros y así se va quedando como una cadena [...] los remedios, o el medicamento [ríe], bueno, como le digo, recién primera vez, si yo antes no [tomaba medicamentos], yo venía antes, venía del campo, cuando sabía tener a mi papá la hacienda yo venía del campo y tomaba, hacía la mamita el mate con remedio, matecocido con el remedio, con el arca, hay otro monte que le dicen el apio [...] también es para la fiebre, para el dolor del estómago que agarra, para cualquiera, es muy, son remedios que uno los usa para, aquí en estos lugares, para todo, es curativo, muy curativo, esos remedios [...] uh! La madre nuestra ya, ponía, ella no tomaba el mate sin el remedio, por eso digo yo sabrá ser tan sana la gente (P44, mujer, 64 años).

S: vea, era raro el que se enfermaba porque nosotros sabíamos tomar esos yuyos y con eso...

JA: y ya la vesícula, todo y cuánta gente, ninguna se operaba

A: y cómo lo curaban?

S: toman el té, tomaba té usted (P50, JA: mujer, 64 años; S: varón, 76 años).

O: la neumonía esa dicen que viene por las gripes mal curadas... con yuyos nos curábamos antes, quemadillo, vira-vira (P2, varón, 58 años).

F: sí muchos yuyos, siempre por estas zonas tomaban yuyos, tomaban mate con yuyos (P5, mujer, 66 años).

La asociación del uso de hierbas con tiempos pasados sumado a su valoración positiva es tomado como explicación de que antes no existieran los malestares actuales cuya gravedad hace necesario el recurso de la biomedicina con sus medicamentos e intervenciones quirúrgicas.

Además, la terapéutica herbaria es considerada un rasgo tradicional de los población de Azampay que la distingue en términos positivos de un "afuera" citadino con sus saberes y prácticas biomédicos no exentos de peligrosidad. En esta distinción Azampay-“otras partes”, 
mi persona fue resaltada como representante de ese "afuera", quien por su procedencia ignoraba los usos terapéuticos de yuyos de la zona y a quien se le atribuyeron prácticas asociadas con la ciudad (aunque en Azampay los individuos consumen y están familiarizados con el Sertal o Buscapina a la vez que varios de los yuyos recetados por curanderos son comprados en la ciudad). Retomando lo señalado en el apartado sobre la metodología, respecto al origen relacional de la información, se nota aquí cómo la distinción Azampayafuera emergió, en parte, a partir del encuentro entre el investigador platense y los azampeños. Además, fue mi carácter foráneo lo que justificó mis preguntas, mi interés por ciertas prácticas, mi afán por explicitar lo que para ellos podría ser obvio.

M: así como ustedes toman la Buscapina, el Sertal, nosotros tomamos los yuyos, aquí toda la gente toma yuyos. Mucha gente los llevan, se llevan bolsas y los venden, las maestras preguntan para qué sirven y toman y se llevan (P44, mujer, 31 años).

\section{JA: aquí mucho somos de tomarlo los remedios, cualquier remedio toma} (P56, mujer, 67 años).

A los yuyos se los ingiere generalmente en infusión, en "quemadillo", "como aguas" 46 reemplazando la bebida de agua "cruda" o dentro del mate, en algunos casos se los quema para sahumar el ambiente o simplemente se inhala su aroma. Cuando hablan de té lo hacen en el sentido propio de una infusión, es decir, se hace hirviendo el agua y agregándosela a las hojas y no hirviendo directamente éstas, lo cual, advierten, volvería demasiado fuerte el accionar de sus propiedades.

Dada la recurrencia con que eran nombrados los diversos recursos herbolarios, en uno de los últimos viajes llevé copias del poema "Una historia verde" de David Burín ${ }^{47}$ que sirvió como disparador del tema del uso medicinal de ciertas plantas. Los individuos contrastaron lo

\footnotetext{
${ }^{46}$ Scarpa identifica dentro de las prácticas de medicina tradicional del Chaco Noroccidental dos formas de preparación e ingesta de las decocciones "que se traducen en dos clases de dosis: una más concentrada cuando se toma por té, y una menos concentrada cuando se ingiere por agua. Tomar un remedio vegetal por agua significa ingerir una decocción preparada con abundante cantidad de agua (medio litro, un litro o más), a temperatura ambiente y en diferentes tomas a lo largo del día (sería el equivalente a "bajas dosis" del remedio vegetal). Tomar un remedio por té significa beber la decocción lo más caliente posible en pequeñas cantidades (una taza o menos) y solamente una vez al día -frecuentemente en ayunas- (sería el equivalente a "altas dosis")" (Scarpa, 2002: 5). En Azampay no fueron mencionadas estas diferencias de concentración y de frecuencia en la ingesta, sólo la temperatura marca la distinción entre tomar té o tomar "por agua".

47 "Y así termina la historia/ de la Nínai y la Noemí/ pero no termina ahí (qué va!)/ sino que recién empieza/ metidas en la maleza/ cortando flores y yuyos/ haciendo tés pa'los suyos/ como me gustan a mí. Charlando entre los vecinos/ intercambiando experiencia/ que es la mejor ciencia/ para curar a la gente/ sabiendo que es diferente/ lo grave y lo pasajero/y sin poner ningún pero!/ aconsejando a conciencia: Para tomar cualquier cosa/ tómese un té de lucera/ podrá vivir sin problema/ también con menta y cedrón/ que es bueno pa'l corazón/ pero también para el mate./ Palán palán use y saque / de una vez la picazón./ La ruda ahuyenta a la envidia/ pero también a la sarna,/ para la tos use malva,/ para el riñón: el tutiá./ Es bueno el mburucuyá/ si usted anda mal de los nervios/ y si un chico es el enfermo/ déle el naranja-jai. Vescícula es lo que cura/ la raíz del abrojito./ Ajenjo pero un poquito/ si el hígado da trabajo./ Para cerrar ese tajo/ use tallo de mastuerzo/ romero como refuerzo/ que es bueno, se lo repito./ Y así yo le recomiendo/ borraja en el sarampión/ y pa'bajar la hinchazón/ hojas de salvia morada/ la cáscara de granada/ cuando el vientre está muy flojo/ pero si tiene un antojo/ no lo cura una infusión./ Hágame caso mi amigo/ que el diablo sabe por viejo/ acepte usted estos consejos/ no piense que le harán mal/ acérquese hasta el yuyal/ para evitar que le duela/ y acuérdese de su abuela/ como la amiga Nínai" (En "Salud y plantas medicinales", Kossmann y Vicente, 1992: 44-45).
} 
que se refería allí con sus propios saberes, asintiendo y estableciendo diferencias, derivando la conversación hacia las enfermedades para las cuales las hierbas eran empleadas, las referencias sintomáticas, explicaciones causales, otros recursos terapéuticos, etc.

Las plantas mencionadas fueron organizadas en un listado recuperando, junto al malestar para cuyo tratamiento se las utiliza, información sobre las formas de preparado, explicaciones sobre su valor terapéutico y otros comentarios realizados por los individuos al hablar sobre éstas. No fue posible elaborar un herbario para la identificación botánica de las mismas dado que no siempre tenían en su posesión la planta mencionada, muchas no crecen en la zona así que son compradas o traídas personalmente o por encargue de zonas aledañas, y corresponden sólo a las partes consumibles, ya deshidratadas, fraccionadas o trituradas.

Abrojo: Para los riñones. Infusión del fruto (la "algarrobita").

Ajenco o ajenjo: Para el dolor de estómago, malestar del estómago cuando la comida cae mal ("toma un té y le asienta"), para evitar que caiga mal el mate, para el hígado, para la puna (crece en los cerros, siendo de la puna sirve para contrarrestar el malestar de la puna). En té. Aloe: Para las manchas en la cara en embarazadas, para la alergia en la piel. Colocación directa.

Anís del campo: Para el dolor de estómago, empacho y fiebre. En té.

Apio de la puna: Para el hígado, dolor de estómago, fiebre, empacho. En té.

Arca: Digestivo (para "sentar la comida cuando se come mucho"), para el dolor de estómago, para los intestinos. En el mate o té.

Borraja: Para paperas y sarampión. té de la hoja ("bien asperita") y la flor ("morada").

Carqueja: Para el hígado, la vesícula, fiebre, dolor de estómago, digestivo (cuando la comida le hace mal al hígado). En té.

Cedrón o cedro: Para el corazón, cuando se anda "bajoneado", con tristeza, digestivo, para la presión alta. En té.

Chachacoma: Para el hígado, la vesícula, para la gripe, malestar de la puna (porque es de la puna). En pequeña cantidad en el mate, se la puede coquear (accionar más fuerte), o simplemente inhalando su aroma ayuda a respirar (síntoma de la puna).

Clavel del aire: para el corazón. En té (recetado por curandero, comprado en una farmacia).

Coca: Coqueada contra la puna, da más ánimo para el trabajo, contra el cansancio, reduce la sed y el hambre. En té digestivo, para el estómago y el hígado.

Copana: para la presión, para el hígado. En té. 
Escorzonera: Para irregularidad del ciclo menstrual ("calienta" la sangre, ya que el problema reside en que la persona "es fría". Ejemplo de explicación de la eficacia por el principio de los opuestos)

Espinilla: para la tos, el resfrío. Crece en El Tolar. En té o quemadillo.

Granada: se muele la cáscara del fruto y se agrega al "tulpito" de harina (cocción de agua y harina) para "secar el vientre".

Jarilla: para resfrío, fiebre, trancazón o dolor en el pecho, para los bronquios. Se utiliza la corteza de los troncos ("viruta"), en té o quemadillo.

Liga de peral o de jarilla: Para la presión alta (porque crece en plantas altas). En té, se usan las ramificaciones que salen del nudo del tronco afectado y las flores si las hay.

Llantel o llantén: para infección urinaria, mal de los riñones (recetado por curandera). Tomar "por agua”, infusión ya fría en reemplazo del agua.

Malva: para la tos, fiebre. En baño calienta el cuerpo (contra la causa: el frío).

Mandarina: para los nervios. Té de la hoja.

Maravilla: para el hígado y la vesícula. En té.

Matico: para el hígado. En té.

Molle: contra el aire. Se muele su incienso ${ }^{48}$ y se coloca en los parches para la apertura de pecho, también usado para sahumar, coqueo de la hoja para el dolor de muela (causado por aire).

Muña: para los diabéticos, para la sangre (mal de la sangre, se va la sangre a la cabeza). En infusión con alcohol (vino) agregado calienta la sangre ya que el problema reside en que la persona "es fría". Crece en los cerros.

Menta: para los nervios. En té.

Nencia: para fiebre, gripe, para dolor de estómago, hígado, seca de vientre. Infusión de la flor (celeste), en pequeñas cantidades dado su amargor, algunos agregan limón. Crece en los cerros.

Nicora: para el corazón. En té (recetado por curandero, comprado en una farmacia).

Olivo: para presión alta. Infusión de las hojas.

Paico: para empacho. En té.

\footnotetext{
${ }^{48} R$ : como si lloraran las plantas [...] en el mes de agosto, setiembre nomás lloran y ella seca, esas cositas claritas, como la gotita de agua, la hace asi y ése ya cuando se seca más ya se pone más duro

A: y ése para qué lo usan?

R: y ése por ahi también para sahu..., para echarlo en la brasita y es el mismo olor con la yareta, para eso, a veces, así como estábamos conversando del dolor de muela, usted tiene a veces dolor de muela, asi que le duele la cabeza, no sabe qué, usted lo hace así, lo muele a eso y lo echa en una brasita, lo huele al humito ése [gesto de pasarlo por delante de la cara] y por ahi cuando es aire que uno le dice, pasa el dolor de muelas, y cuando, pero como no es malo, asi que no impide nada de hacerse o no hacerse, no es malo (P40, mujer, 62 años).
} 
Palo amarillo: para los nervios, intestinos, vejiga, "las vías", la cintura. En té.

Pasionaria: para los nervios (recetado por curandero, comprado en una farmacia, me lo encargaron a mí).

Poleo: para dolor de estómago, hígado, vesícula. En té, quemadillo junto con cáscara de limón para destapar la nariz.

Poposa: digestivo.

Quimpi: para los riñones. Toma "por agua", infusión ya fría en reemplazo del agua, lavan, limpian los riñones.

Romanza: para los riñones. Toma "por agua", infusión ya fría en reemplazo del agua, lavan, limpian los riñones (recetado por curandero, comprado en una farmacia).

Romero: para la sangre, cuando no circula bien la sangre. En té. Para dolor de cabeza por aire en sahúmo.

Ruda: para malestar causado por la excesiva bebida de alcohol, para el mal de la sangre (hace circular la sangre, la purifica), para la envidia, dolor de estómago y diarrea, para susto junto a terapéuticas de curanderos. En té, con bicarbonato o sal (para el pulso). Como "reliquia" (colgada de la cama) contra el Mal.

Tilo: para presión alta. Té (comprado en la ciudad).

Uña de gato: Para dolor de cintura o riñón (comprada a vendedores ambulantes).

Vira: para gripe. Se prepara como "quemadillo". El té se compara con un jarabe para la tos, que destapa los pulmones, el pecho. También se le puede agregar en caliente un chorrito de alcohol, se lo bebe y se guarda cama inmediatamente, bien abrigado para transpirar, pues en la transpiración el té "lo hace tirar todo". Crece en zonas altas, cerca del Tolar.

Yareta: para dolor de cabeza, muela o cualquier otro malestar causado por el aire. Se utiliza para sahumar (como "desinfectante" del ambiente), se muele su incienso y se coloca en los parches para la apertura de pecho. En té para el cansancio, dolor de huesos, de espalda. En quemadillo para los bronquios ${ }^{49}$. Crece en zonas altas, se le atribuye por ello aire que sirve para contrarrestar el aireque causa el malestar ${ }^{50}$.

\footnotetext{
${ }^{49} \mathrm{R}$ : pero eso hay que ponerle muy poquitito porque esa tiene el incienso, así como mito, ése por ejemplo, aqui la usamos para, usted lo muele así finito y le pone en una brasita y lo echa a eso en una brasita y se hace andar así, lo huele, es lindo para destrancar asi la nariz, esas cosas, la yareta, y para tomarlo pero tiene que ponerle muy poquitito porque larga ese coso como mito, no es malo, también dicen que cura el pulmón, si está usted agripada, muy afectada al pulmón le sienta bien, pero hay que ponerle así, bueno, ya estando seca ya no larga, cuando recién la junta porque está fresquita, mojadita, pero ya seca ya no larga casi [...] una cosita como grasita, que es el incienso [...] para hacer el té así enterito un pedacito chiquito nomás y lo hace hervir y lo toma al té, no es amarga, así un poquitito, casi nada de amarguito, pero es linda para tomarlo (P40, mujer, 62 años).

${ }^{50}$ E: claro el aire de la yareta [...] eso se lleva el aire (P65, mujer, 78 años).
} 


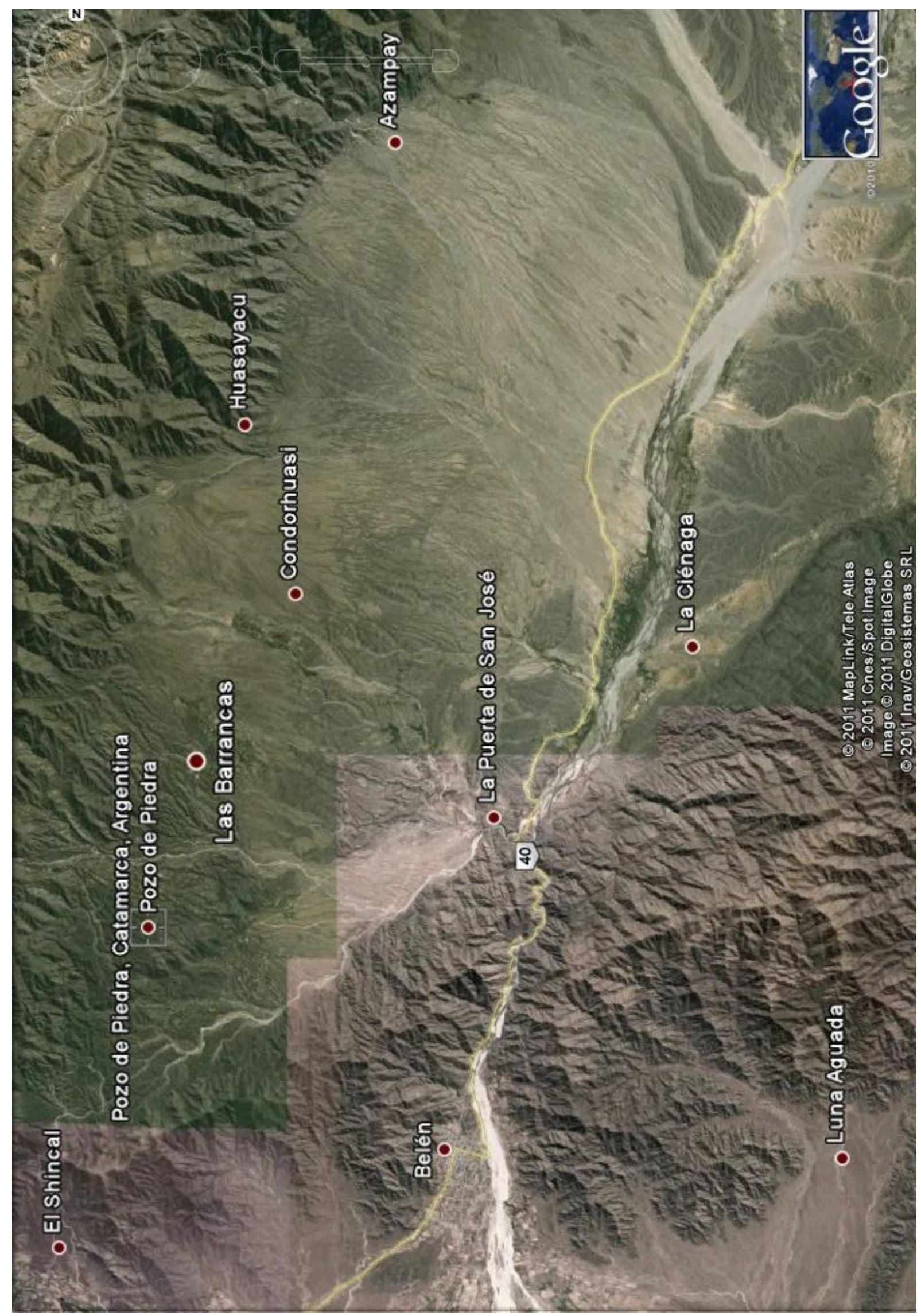

Imagen tomada de Google Earth 6.0 (20/6/2011), disponible en http://earth.google.es 


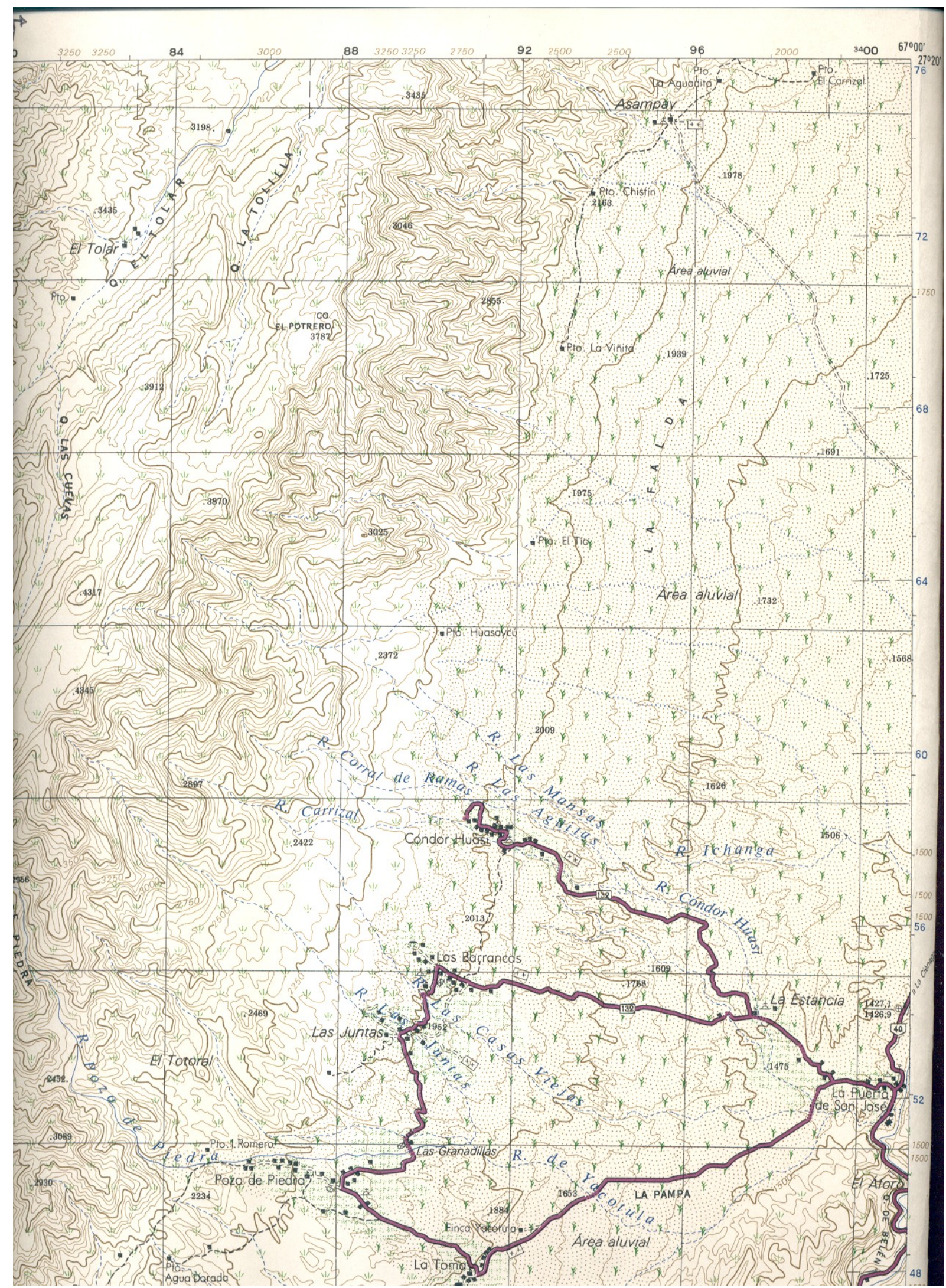

Carta Topográfica Belén. Instituto Geográfico Militar (IGM), 1985. 


\section{Bibliografía}

ALONSO, L. E., 1998. La Mirada Cualitativa en Sociología. Una Aproximación Interpretativa. Editorial Fundamentos, Colección Ciencia. Madrid.

ALONSO, J. P., 2008. "Cuerpo, dolor e incertidumbre. Experiencia de la enfermedad y formas de interpelar el cuerpo en pacientes de Cuidados Paliativos". En (Con)textos. Revista d'antropologia i investigació social, n², diciembre, pp. 36-50. ISSN: 2013-0864.

ALVES, P. C., 1993. “Experiencing Illness: Theoretical Considerations”. Cad. Saúde Pública, Rio de Janeiro, 9 (3): 263-271, jul/sep.

ARAYA UMAÑA, S., 2002. "Las representaciones sociales: ejes teóricos para su discusión". Cuaderno de Ciencias Sociales, 127. FLACSO. Costa Rica.

BALLINA S., 2006. "Llovió y llovió hasta que quedó cielo y tierra... y todo se terminó ahí’: representaciones de lo indígena en la comunidad de Asampay, Catamarca. En: Revista Papeles de Trabajo, Rosario.

BARBIERI, M. A., 2007. "Uso y metodología de los testimonios de vida en la producción de conocimiento social". En: 2do. Encuentro internacional de historia oral, Panamá, enero, 2007.

BIANCHETTI, M. C., 1996. Cosmovisión sobrenatural de la locura. pautas populares de salud mental en la puna argentina. Victor Manuel Hanne Editor.

BIBEAU, G y E. CORIN, 1995. “Culturaliser l'épidémiologie psychiatrique. Les systèmes de signes, de sens et d'action en santé mentale." En: Les Presses de l'Université Laval. $1^{\text {er }}$ trimestre. ISBN 2-7637-7413-X

BOLTANSKI, L., 1975. Los usos sociales del cuerpo. Buenos Aires. Ediciones Periferia.

BOURDIEU, P., 1985. ¿Qué significa hablar? Ediciones Akal, S. A. Madrid-España.

BUTLER, J., 2005. Cuerpos que importan: Sobre los límites materiales y discursivos del "sexo". Buenos Aires. Paidós.

CARDOSO DE OLIVEIRA, R., 1996. “O trabalho do antropólogo: Olhar, Ouvir, Escrever”. En Revista de Antropología, vol. 39, n¹. 
CAMPOS-NAVARRO, R., D. TORREZ y E. N. ARGANIS-JUAREZ, 2002. "Las representaciones del padecer en ancianos con enfermedades crónicas”. Cad. Saúde Pública, Rio de Janeiro, 18(5):1271-1279, set-out.

CHIRICO M. M., 1987. "El relato de vida como instrumento de investigación: Ramón, un trabajador del partido de La Matanza”. En Desarrollo Económico, Vol 27, n 107.

COMELlES J. M. y A. A. MARTINEZ, 1997. "Paradojas de la antropología médica europea". En Nueva Antropología 16 (52), pp. 187-214.

CSORDAS, T., 1990. "Embodiment as a Paradigm for Anthropology”. En Ethos, Vol. 18, $\mathrm{n}^{\circ} 1$, pp. 5-47. Disponible en http://www.jstor.org/pss/640395

CSORDAS, T., 1992a. "Introduction: the body as representation and being in the world". En Embodiment and Experience. The existential ground of culture and self. Cambridge, Cambridge University Press.

CSORDAS, T., 1992b. "Words from the Holy People: a case study in cultural phenomenology". En Embodiment and experience. The existential ground of culture and self. Cambridge, Cambridge University Press.

CSORDAS, T., 1994. The sacred self: A Cultural Phenomenology of Charismatic Healing. University of California Press.

DE CASTRO, A., G. GARCIA, e I. RODRÍGUEZ., 2006. “La dimensión corporal desde el enfoque fenomenológico-existencial”. En Psicol. Caribe. [on line]. Jun., n¹7 [consultado 29 enero 2008], pp. 122-148.

En http://ciruelo.uninorte.edu.co/pdf/psicologia_caribe/17/6_La dimension corporal.pdf

DEVILLARD, M. J., 2002. "De los discursos antropológicos sobre naturaleza, cuerpo y cultura". En Política y Sociedad. Dpto. de Antropología Social. Facultad de CC. Políticas y Sociología. UCM., Vol 39, n³, pp. 597-614. Madrid.

ELIADE, M., 1954. Tratado de Historia de las Religiones. Instituto de Estudios Políticos. Madrid.

EPELE, M. “Cuerpo, Consumo y Sujeción. Las Paradojas del Deseo en el Estudio del Género entre Usuarios de Drogas". Mabel Grimberg (ed.) Narrativas y Experiencias del Padecimiento. Coedición Fac. de Filosofía y Letras-UBA- Santiago Alvareza Ed. En prensa.

EPELE, M., 2001. "Violencia y Trauma. Políticas del Sufrimiento Social entre usuarias de drogas". En Cuadernos de Antropología Social. $\mathrm{N}^{\circ}$ 14: 117-137. Facultad Filosofía y Letras (UBA), Buenos Aires.

FERREIRA DA SILVA, L., 2004. Sócio-antropologia da saúde. Sociedade, cultura e saúde/doença. Universidade Aberta, Portugal. 
FITZPATRICK, R., 1990. “Conceptos comunes de enfermedad”. En La Enfermedad como Experiencia (R. Fitzpatrick, J. Hinton, N. Staton, G. Scambler \& J. Thompson, org.), México, DF: Fondo de Cultura Económica.

FOSTER, G. M., 1994. Hippocrates' Latin American Legacy: Humoral Medicine in the New World. Gordon and Breach Science Publishers S. A. University of California, Berkeley.

FREIDSON, E., 1978. La profesión médica. Península, Barcelona.

GARROTE, N., 1995. "El itinerario social del alimento". En Cultura, salud y enfermedad. Temas en Antropología médica. Comp.: Marcelo Alvarez y Victorio Barreda. Instituto Nacional de Antropología y Pensamiento Latinoamericano. Bs As. Pp.94-104.

GIMÉNEZ, G., 1997. "Materiales para una Teoría de las Identidades Sociales". Revista de la frontera norte. Vol. IX, $\mathrm{n}^{\circ} 18$, Julio-Diciembre. México.

GLASER, B., 2008. "Conceptualization: On Theory and Theorizing Using Grounded Theory”. International Journal of Qualitative Methods, Vol.1 (2).

Disponible en http://ejournals.library.ualberta.ca/index.php/IJQM/article/view/4605

GOOD, B. J., 1994a. “A body in pain. The making of a World of Chronic Pain.” En Pain as Human experience. An anthropological perspective. Berkeley, University of California Press.

GOOD, B. J., 1994b. "How medicine constructs its objects." En Medicine, rationality and experience. An anthropological perspective. Cambridge University Press.

GRIMBERG, M.,1991. “Tradición obrera y cultura somática. El Procesamiento colectivo de un saber sobre la relación trabajo-salud entre "los gráficos"'. En Cuadernos Médicos Sociales n57, Rosario.

GRIMBERG, M., 1992. "Proceso salud-enfermedad-atención y Hegemonía. Guía para la discusión." Doc de trabajo. ICA-UBA.

GRIMBERG, M., 1995. “Teorías, propuestas y prácticas sociales. Problemas teóricometodológicos en Antropología y Salud”, en Alvarez M. (comp.) Cultura, Salud y Medio Ambiente. Instituto Nacional de Antropología, Buenos Aires.

GRIMBERG, M., 1998. "VIH/SIDA y proceso salud-enfermedad-atención: construcción social y relaciones de hegemonía". Seminario-Taller de Capacitación de formadores. LUSIDA, Buenos Aires.

GRIMBERG, M., S. MARGULIES y S. WALLACE, 1992. “Construcción social y hegemonía: representaciones médicas sobre SIDA. Un abordaje antropológico.” Programa de Antropología y salud. I.C.A. Facultad de Filosofía y Letras. UBA. 
GUBER, R., 2001. La Etnografía. Método, campo y reflexividad. Bogotá, Grupo Editorial Norma.

GUBER, R., 2004. El Salvaje Metropolitano. Reconstrucción del conocimiento social en el trabajo de campo. Buenos Aires, Editorial Piados.

IDOYAGA MOLINA, A., 2001. "Lo sagrado en las terapias de las medicinas tradicionales del NOA y Cuyo". Scripta Ethnologica. Buenos Aires: CAEA - CONICET, vol. 23, pp.9-75.

IDOYAGA MOLINA, A., 2002. Culturas, Enfermedades y Medicinas. Reflexiones sobre la atención a la salud en contextos interculturales de Argentina. Area transdepartamental Folklore. IUNA.UDI (Unidad de Desarrollo Institucional). Buenos Aires.

IDOYAGA MOLINA, A., 2006. "El mal de ojo entre los Zapotecas (México) y las categorías conceptuales de Kearney: ¿Cosmovisión Paranoica u opresión étnica?” Perspectivas Latinoamericanas. Nagoya: Universidad de Nanzan, vol. 3, pp.82-113.

IDOYAGA MOLINA, A. y G. KORMAN, 2002. “Alcances y límites de la aplicación del Manual Diagnóstico y Estadístico de las Enfermedades Mentales (DSM-IV) en contextos interculturales del Gran Buenos Aires". Scripta Ethnologica. Buenos Aires: CAEA CONICET, vol. 24, pp.163-214.

JODELET, D., 2008. "El movimiento de retorno al sujeto y el enfoque de las representaciones sociales". Cultura y representaciones sociales, año $3, \mathrm{n}^{\circ} 5$. IIS, Instituto de Investigaciones Sociales, UNAM, Universidad Nacional Autonoma de Mexico: Mexico. Septiembre. Disponible en http://www.culturayrs.org.mx/revista/num5/Jodelet.pdf

KEARNEY, M., 1969. "Los conceptos de aire y susto: representaciones simbólicas del ambiente social y geográfico percibido". América Indígena, abril, vol. XXIX (2): 431-450.

KLEINMAN, A., 1977. "Depression, somatization and the new cross-cultural psychiatry". En Social Science and Medicine, 11(3):3-10.

KLEINMAN, A., 1994. "Pain and Resistance: The Deligitimation and Religitimation of Local Worlds". En Pain as Human Experience. An Anthropological Perspective. Berkeley, University of California Press, pp.169-198.

KLEINMAN, A y J. KLEINMAN, 1991. "Suffering and its professional transformation: toward an ethnography of interpersonal experience." Culture, Medicine and Psychiatry, 15: 275-302.

KLEINMAN, A y T. CSORDAS, 1996. "The therapeutic process". En Medical Anthropology. Contemporary Theory and Method. Sargent, C. and T. Johnson, eds. Wesport: Praeger Publishers. 
KORNBLIT A. y A. M. MENDES DIZ, 2000. La Salud y la Enfermedad: Aspectos biológicos y sociales. Grupo Editor Aique, 1ra Edición, Capital Federal.

KOSSMANN, I. y C. VICENTE, 1992. Salud y plantas medicinales. Nuestra capacidad de estar sanos por naturaleza. Editorial Planeta Tierra, Buenos Aires.

LÉVI-STRAUSS, C., 1968. Antropología estructural. Editorial Universitaria de Buenos Aires,

LE BRETON, D., 1995. Antropología del cuerpo y modernidad. Buenos Aires, Nueva Visión.

LOCK, M. y N. SCHEPER-HUGHES, 1996. "A critical interpretative approach in Medical Anthropology: Rituals and Routines of Discipline and Dissent." En Medical Anthropology. Contemporary Theory and Method. Sargent, C. and T. Johnson, eds. Wesport: Praeger Publishers.

MAFFIA, M., 2005. "Las viviendas de Azampay”. Sempé C., S. Salceda y M. Maffia (editoras) Azampay. Presente y pasado de un pueblito catamarqueño. Ediciones Al Margen, La Plata.

MAFFIA, M., L. PASTORINO, B. ZUBRZYCKI y M. DE LUCA, 1999. "La propiedad de la tierra y el agua en la localidad de Asampay, provincia de Catamarca. Una visión desde la Antropología Sociocultural y el Derecho”. Actas de las Primeras Jornadas de Estudios Agrarios y Agroindustriales, Buenos Aires.

MAFFIA, M., R. STORINO, M. URRUTIA, M. BASALDÚA, M. FORA, B. ZUBRZYCKI y A. VALERO, 2000. "Estudio inicial antropológico-epidemiológico sobre la enfermedad de Chagas en la localidad de Asampay, Departamento de Belén, Provincia de Catamarca." Actas del V Congreso Argentino de Antropología Social, Tomo 2. La Plata, Argentina.

MAFFIA, M., D. CARAMAGNA, M. APEZTEGUÍA, B. ZUBRZYCKI y R. GARCÍA MANCUSO, 2001. “Testeo y adecuación de un modelo socioecológico para las enfermedades gingivo-periodontales en una población rural del noroeste argentino". International Journal of Dental Anthropology 2: 1-8. Colombia.

MAFFIA, M. y B. ZUBRZYCKI, 2001. "Migraciones en Catamarca: el caso de la pequeña localidad de Asampay”. Estudios Migratorios Latinoamericanos 47: 149-179. Centro de Estudios Migratorios Latinoamericanos. Argentina.

MAFFIA, M. y B. ZUBRZYCKI, 2005. "La migración: principal estrategia de reproducción de la sociedad azampeña.” Sempé C., S. Salceda y M. Maffia (editoras) Azampay. Presente y pasado de un pueblito catamarqueño. Ediciones Al Margen, La Plata. 
MAFFIA, M., B. ZUBRZYCKI y S. BALLINA, 2005. "Estrategias metodológicas de abordaje en el estudio del parentesco y la familia". Sempé C., S. Salceda y M. Maffia (editoras) Azampay. presente y pasado de un pueblito catamarqueño. Ediciones Al Margen, La Plata.

MAGARIÑOS DE MORENTIN, J. A. y colaboradores, 1990. Esbozo semiótico para una metodología de base en ciencias sociales. Investigación 6. I.I.C.S., Universidad Nacional de La Plata.

MAGRASSI, G. E. y J. C. RADOVICH, 1982. "La medicina popular". La Vida de Nuestro Pueblo, $\mathrm{n}^{\circ} 8$, Centro Editor de América Latina.

MAKOWSKI MUCHNIK, S. 2000. "Historia oral y exclusión social: el encuentro con el Otro". V Seminario Internacional de Historia Oral, Guanajuato, noviembre, 2000.

MALLART GUIMERÀ, L., 2008. "Reflexiones sobre la etnografía por el estudio de los sistemas médicos africanos”. En Fernández Juárez, G., I. González González y P. García Ortiz (coord.) La diversidad ante el espejo: salud, interculturalidad y contexto migratorio. ISBN 978-9978-22-717-6, pp. 187-196.

MARCEL, G., 1953. El misterio del ser. Buenos Aires, Editorial Sudamericana.

MARTINEZ SALGADO, C., 1996. "Introducción al trabajo cualitativo en investigación”. En Szasz, I y S. Lerner (comps.) Para comprender la subjetividad. México: El colegio de México.

MARTÍNEZ, G. J. y A. M. PLANCHUELO, 2003. "La medicina tradicional de los criollos campesinos de Paravachasca y Calamuchita, Córdoba (Argentina)". Scripta Ethnologica. Buenos Aires: CAEA - CONICET, vol. 25, pp.83-116.

MAUSS, M., 1950. "Effet physique chez l'individu de l'idée de mort suggérée par la collectivité (Australie, Nouvelle-Zélande)". En Sociologie et Anthropologie, Presses universitaires de France.

MENÉNDEZ, E. L., 1985. “Aproximación crítica al desarrollo de la Antropología Médica en América Latina”, Nueva Antropología, VII (28).

MENÉNDEZ, E. L., 1990a. Informe: Sistemas locales de salud. Aproximación teórico-metodológica. Reunión: Evaluación del proceso de implantación de SILOS, Sao Paulo, Brasil, Documento no publicado.

MENÉNDEZ, E. L., 1990b. Antropología Médica. Orientaciones, desigualdades y transacciones. CIESAS, México.

MENÉNDEZ, E. L., 1992a. Morir de alcohol. Saber y hegemonía médica. México. Ciesas. 
MENÉNDEZ, E. L., 1992b. “Grupo doméstico y proceso salud/enfermedad/atención. Del 'teoricismo' al movimiento continuo". En Cuadernos médico sociales $\mathrm{n}^{\mathrm{o}}$ 59: 3-18 México.

MENÉNDEZ, E. L., 1994. "La enfermedad y la curación ¿Qué es medicina tradicional?" En Alteridades, 4 (7):71-83.

MENÉNDEZ, E. L., 1997a. "Holísticos y especializados: los usos futuros de la antropología social". En Nueva Antropología [en línea] XVI (agosto). Disponible en http://redalyc.uaemex.mx/redalyc/src/inicio/ArtPdfRed.jsp?iCve=15905302

MENÉNDEZ, E. L., 1997. "El punto de vista del actor. Homogeneidad, diferencia e historicidad”. En Relaciones vol XVII, nº 69:237-271. El colegio de Mochoacan, México.

MENÉNDEZ, E. L., 2004. "Modelos de atención de los padecimientos: de exclusiones teóricas y articulaciones prácticas". En: Salud Colectiva. H. Spinelli comp. Buenos Aires, Lugar Editorial.

MENÉNDEZ, E. L., 2005. "Intencionalidad, experiencia y función: la articulación de los saberes médicos”. Revista de Antropología Social, no 14:33-69.

MERLEAU-PONTY, M., 1984. Fenomenología de la Percepción. Buenos Aires, Planeta-Agostini.

MINAYO, M. C. S., 2004. El desafio del conocimiento. Investigación cualitativa en salud. Buenos Aires, Lugar Editorial.

MINAYO, M. C. S., S. F. DESLANDES, O. C. NETO y R. GOMES, 2002. Investigación social. Teoría, método y creatividad. Buenos Aires, Lugar Editorial.

MÓDENA, M. E., 1990. Madres, médicos y curanderos: diferencia cultural $e$ identidad ideológica. Ediciones de la casa chata.

MÓDENA, M. E., 2002. "Combinar recursos curativos: un pueblo mexicano en las últimas décadas del siglo XX”. En Diego Armus (ed) Entre médicos y curanderos. Cultura, historia y enfermedad en América Latina moderna. Vitral-Grupo ed. Norma.

MORA, M., 2002. "La teoría de las representaciones sociales de Serge Moscovici". Atenea Digital. Revista de Pensamiento e Investigación Social, $\mathrm{n}^{\circ} 2$.

Disponible en http://www.raco.cat/index.php/Athenea/article/viewFile/34106/33945

OCAMPO, M. C. y G. N. GRACIA, 1994. "Conversación única e irrepetible: lo singular de la historia oral". En Garay, G. (comp.) La historia con micrófono. Méjico: Instituto Mora. 
ORTALE, M. S. 2003. Prácticas y representaciones sobre desnutrición infantil de causa primaria en familias pobres urbanas del Gran La Plata. Tesis de Doctorado, FCNyM Universidad Nacional de La Plata. Agosto, 2003.

PADULA G., A. TOBISCH y S. A. SALCEDA, 2005. "Crecimiento y nutrición de la población infanto adolescente de Azampay (Catamarca)”. Revista Argentina de Antropología Biológica, vol 6 (1): 47-60.

PALMA, N. H., 1973. Estudio antropológico de la medicina popular de la Puna Argentina. Bs As, Ediciones Cabargón.

PALMA, N. H., 1978. La medicina popular en el Noroeste Argentino. Bs As, Ediciones Huemul.

PALMA, N. H., 2002. "De la medicina tradicional a la medicina científica y de la medicina científica a la medicina tradicional (Del Noroeste Argentino al Conurbano Bonaerense) Reflexiones acerca de la dialéctica entre el conocimiento popular y el conocimiento científico", Revista Kallawaya, Nueva Serie n 9, La Plata- Salta, agosto.

PELTO, P. y PELTO G., 1996. "Research designs in medical Antrhopology". En Medical Anthropology. Contemporary Theory and Method. Sargent, C. and T. Johnson, eds. Praeger Publishers, Wesport, U.S.

PÉREZ DE NUCCI, A. M., 1995. La medicina tradicional del Noroeste Argentino. Historia y presente. Bs As, Ediciones del Sol.

PORTELLI, A., 1992. "Narrar la historia y tiempo. Un ejemplo de Kentucky". En The Oral History Review, vol 20, $\mathrm{n}^{\circ} 1$ y 2.

PORTELLI, A., 1993. "El tiempo de mi vida: las funciones del tiempo en la historia oral”. En Aceves Lozano, J. (comp.) Historia oral. Méjico: Antologías Universitarias.

PRECE, G.; M. H. DI LISCIA, y L. PIÑERO, 1996. Mujeres populares. El mandato de cuidar y curar. Ed. Biblos.

PRESAS, M. A., 1971. "Interpretación existencial de la enfermedad en Karl Jaspers". En Quirón, enero-abril vol 2, n¹.

PRESAS, M. A., 1978. Situación de la filosofía de Karl Jaspers con especial consideración de su base Kantiana. Bs As, Ediciones Depalma.

PRINZ, J. J., 2010. “The Moral Emotions". En The Oxford Handbook of Philosophy of Emotion, ed. Peter Goldie, New York: Oxford University Press.

RICOEUR, P., 2001. La Metáfora viva. Madrid, Ediciones Cristiandad, S.A. Editorial Trotta, S.A. 
RABELO, M., P. ALVES y I. SOUZA, 1999. "Significacao e Metáforas na Experiencia da Enfermidade". En Experiencia de Doenca e Narrativa. Editora Fiocruz.

RUBEL, A. J. y M. R. HASS, 1996. “Ethnomedicine.” En Medical Anthropology. Contemporary Theory and Method. Sargent, C. and T. Johnson, eds. Wesport: Praeger Publishers.

SANMARTÍN ARCE, R, 2000. "La entrevista en el trabajo de campo". Revista de Antropología Social, n9: 105-126.

SARTRE, J. P., 2006. El ser y la nada. Bs As, Losada (eds vs.).

SCAMBLER G. y A. SCAMBLER, 1990. "La enfermedad iceberg y algunos aspectos de la conducta en el consultorio". En: La Enfermedad como Experiencia (R. Fitzpatrick, J. Hinton, N. Staton, G. Scambler \& J. Thompson, org.), México, DF: Fondo de Cultura Económica. Pp 42-64.

SCARPA, G. F., 2002. "Plantas empleadas contra trastornos digestivos en la medicina tradicional criolla del Chaco Noroccidental" Disponible en http://www.dominguezia.org.ar/volumen/articulos/184.pdf [consultado el 16 de noviembre de 2009]

SCHEPER-HUGHES, N., 1990. "Three propositions for a critically applied medical anthropology”, Social Science \& Medicine. Vol. 30, n²: 189-197.

SCHEPER HUGHES, N. y M. LOCK, 1987. "The Mindful body: a Prolegomenon to Future Work in Medical Anthropology." Medical Anthropology Quaterly. New Series, vol. 1, $\mathrm{n}^{\circ}$ 1: 6-41. Marzo.

SELLTIZ, C.; M. JAHODA, M. DEUTSCH y S. W. COOK, 1959 (1 ${ }^{\text {a }}$ ed.). Métodos de investigación en las relaciones sociales. $3^{\mathrm{a}}$ ed., Ediciones Rialp, S.A.

SEMPÉ C., S. SALCEDA y M. MAFFIA (editoras), 2005. Azampay. presente y pasado de un pueblito catamarqueño. Ediciones Al Margen, La Plata.

SIMMEL, G., 1950 [1918]. Intuición de la vida: cuatro capítulos de metafísica. Buenos Aires. Nova.

SINGER, M., 1990. "Reinventing medical anthropology: Toward a critical realignment”. Social Science \& Medicine. Vol. 30, n²: 179-187.

SONDERÉGUER, M., 2001. "Testimonios, memorias y justicia instaurativa en Argentina". En: V Encuentro de Historia Oral. Abril, 2001.

TAUSSIG, M., 1992. "La reificación y la conciencia del paciente”. En Un gigante en convulsiones. El mundo humano como sistema nervioso en emergencia permanente. España. Ed. Gedisa. 
TORRENT, S., 1998. "Práctica para la resolución de los problemas de salud, enfermedad, atención, en comunidades de los departamentos de Capayán y Belén. Provincia de Catamarca". En: Congreso de desarrollo Regional. Secretaría de Ciencia y Tecnología, Universidad Nacional de Catamarca. Octubre, 1998.

TURNER, B. S., 1989. El cuerpo y la sociedad. Exploraciones en teoría social. Fondo de Cultura Económica, México.

TURNER, B. S., 1991. "Recent Developments in the Theory of the Body." En The Body. Social Process and Cultural Theory. Featherstone, M. Hepworth, M. and B. S. Turner. London, Sage Publications.

TURNER, V., 1980. La selva de los símbolos. Aspectos del ritual Ndembu. Siglo XXI de España Editores SA.

VALLES, M., 1997. Técnicas cualitativas de investigación social. Reflexión metodológica y práctica profesional. Madrid: Síntesis.

VASILACHIS DE GIALDINO, I., 2008. "Los fundamentos epistemológicos de la metodología cualitativa". En Cohen, N. y J. I. Piovani (comps.) La metodología de la investigación en debate. Buenos Aires: EUDEBA, Edulp.

WACH, J., 1967. El estudio comparado de las religiones, Buenos Aires, Paidos.

WALDRAM, J. B., 2000. "The efficacy of traditional medicine: Current theoretical and methodological issues". En Medical Anthropology Quarterly. 14(4): 603-625.

ZUBRZYCKI, B., 2002. "Campos comuneros en el valle de Hualfín (Catamarca). Antecedentes, problemática y situación actual”. Andes. Antropología e Historia 13: 305-320. Universidad Nacional de Salta. Argentina.

ZUBRZYCKI, B., 2007. Campos comuneros en el distrito La Ciénaga (Belén, Catamarca). Tesis de Doctorado, FCNyM, Universidad Nacional de La Plata. 